volume 5

ISSUE 7

2017 settembre

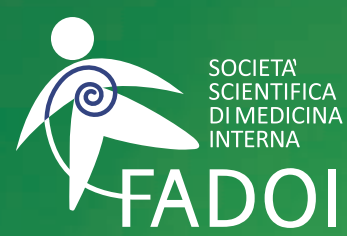

FEDERAZIONE

DELLE ASSOCIAZIONI

DEI DIRIGENTI

OSPEDALIERI

INTERNISTI

Editor in Chief

Roberto Nardi

The official journal of the Federation of Associations of Hospital Doctors on Internal Medicine (FADOI)

\title{
Le malattie infiammatorie immuno-mediate (IMIID) di interesse internistico: fisiopatologia, aspetti clinici e prospettive di terapia
}

Guest Editors: A. Fontanella, R. Nardi, M. Masina, G. Uomo 


\section{PRESIDENTE ELETTO}

Dario Manfellotto, Roma, Italy

\section{PAST PRESIDENT}

Mauro Campanini, Novara, Italy

\section{SEGRETARIO}

Micaela La Regina, La Spezia, Italy

\section{SEGRETARIO VICARIO}

Andrea Montagnani, Grosseto, Italy

\section{STAFF DI SEGRETERIA}

$\begin{array}{ll}\text { Comunicazione } & \text { Paola Gnerre, Savona, Italy } \\ \text { Ricerca } & \text { Roberta Re, Novara, Italy } \\ \text { Formazione } & \text { Maurizia Gambacorta, Todi }(P G), \text { Italy }\end{array}$

\section{TESORIERE}

David Terracina, Roma, Italy

\section{STAFF DI TESORERIA}

Francesco D’Amore, Roma, Italy

\section{PRESIDENTE FONDAZIONE FADOI}

Mauro Campanini, Novara, Italy

\section{COORDINATORE}

Giuseppe Augello, Canicatti ( $A G)$, Italy

\section{DIPARTIMENTO PER LA RICERCA CLINICA} "CENTRO STUDI FADOI"

\section{Direttore Giancarlo Agnelli, Perugia, Italy}

Direttore vicario $\quad$ Francesco Dentali, Varese, Italy

DIPARTIMENTO PER LA FORMAZIONE

E AGGIORNAMENTO

Direttore Mauro Silingardi, Guastalla (RE), Italy

COORDINAMENTO FORMAZIONE

AREA CENTRO-NORD

Francesco Orlandini, La Spezia, Italy

COORDINAMENTO FORMAZIONE

AREA CENTRO SUD

Generoso Uomo, Napoli, Italy

\section{COORDINATORE COMMISSIONE GIOVANI}

Flavio Tangianu, Oristano, Italy

MEMBRO FISM E RESPONSABILE PER L'INNOVAZIONE IN MEDICINA INTERNA

Antonino Mazzone, Legnano (MI), Italy

ITALIAN JOURNAL OF MEDICINE

Editor in Chief Giorgio Vescovo, Padova, Italy

RESPONSABILE DEI QUADERNI DELL'IJM E EDIZIONI ON LINE

Roberto Nardi, Bologna, Italy

DELEGATO FADOI ITALIAN STROKE ORGANIZATION E CONSULTA CARDIOVASCOLARE

Michele Stornello, Siracusa, Italy

\section{RAPPORTI CON EFIM}

Gualberto Gussoni, Milano, Italy

Ombretta Para, Firenze, Italy

Giorgio Vescovo, Padova, Italy

RESPONSABILE SITO NAZIONALE E COMUNICAZIONE

Salvatore Lenti, Arezzo, Italy

\section{RESPONSABILE SISTEMA GESTIONE QUALITÀ}

Franco Berti, Roma, Italy

\section{RESPONSABILE CLINICAL COMPETENCE}

Antonino Mazzone, Legnano (MI), Italy

\section{RESPONSABILE AREA ECOGRAFIA}

Francesco Cipollini, Ascoli Piceno, Italy

Marcello Romano, La Spezia, Italy

\section{RESPONSABILE MEDICINA DI GENERE}

Cecilia Politi, Isernia, Italy

\section{RESPONSABILE AREA NUTRIZIONE}

Roberto Risicato, Siracusa, Italy

Luciano Tramontano, Praia a Mare (CS), Italy

\section{RESPONSABILE AREA DI CLINICAL GOVERNANCE}

Giovanni Iosa, Cesenatico (FC), Italy

Stefano De Carli, Udine, Italy 


\section{Italian Journal of Medicine}

A Journal of Hospital and Internal Medicine

Fondazione FADOI - Organigramma

\section{PRESIDENTE FONDAZIONE}

Mauro Campanini, Novara, Italy

\section{COORDINATORE}

Giuseppe Augello, Canicatti ( $A G)$, Italy

\section{DIPARTIMENTO PER LA RICERCA CLINICA} CENTRO STUDI FADOI

\section{Direttore Giancarlo Agnelli, Perugia, Italy}

Direttore vicario $\quad$ Francesco Dentali, Varese, Italy

\section{SEGRETERIA}

Grazia Panigada, Pescia (PT), Italy

\section{RESPONSABILE AREA MALATTIE CARDIOVASCOLARI}

Paolo Verdecchia, Assisi (PG), Italy

\section{STAFF AREA MALATTIE CARDIOVASCOLARI}

Cecilia Becattini, Perugia, Italy

Pierpaolo Di Micco, Napoli, Italy

Fernando Gallucci, Napoli, Italy

Alessandro Squizzato, Varese, Italy

\section{RESPONSABILE AREA MALATTIE INFETTIVE}

Ercole Concia, Verona, Italy

\section{STAFF AREA MALATTIE INFETTIVE}

Anna Maria Azzini, Verona, Italy

Gianluca Giuri, Castelnovo ne' Monti (RE), Italy

Matteo Giorgi Pierfranceschi, Piacenza, Italy

Carlo Tascini, Pisa, Italy

\section{RESPONSABILE AREA MALATTIE RESPIRATORIE}

Leonardo Fabbri, Reggio Emilia, Italy

\section{STAFF AREA MALATTIE RESPIRATORIE}

Bianca Beghè, Reggio Emilia, Italy

Piera Boschetto, Ferrara, Italy

Gaetano Cabibbo, Modica (RG), Italy

Francesco Corradi, Firenze, Italy

Francesco Ventrella, Cerignola $(F G)$, Italy

RESPONSABILE AREA MALATTIE REUMATOLOGICHE

Carlo Salvarani, Reggio Emilia, Italy

\section{STAFF AREA MALATTIE REUMATOLOGICHE}

Laura Morbidoni, Senigallia (AN), Italy

Nicolò Pipitone, Reggio Emilia, Italy

Tito D'Errico, Napoli, Italy

RESPONSABILE AREA MALATTIE METABOLICHE

Roberto Vettor, Padova, Italy

\section{STAFF AREA MALATTIE METABOLICHE}

Tiziana Attardo, Agrigento, Italy

Giovanni Gulli, Savigliano (CN), Italy

Ada Maffettone, Napoli, Italy

Maurizio Nizzoli, Forli, Italy

RESPONSABILE AREA ORGANIZZATIVA

IN MEDICINA INTERNA

Antonio Greco, San Giovanni Rotondo (FG), Italy

\section{STAFF AREA ORGANIZZATIVA IN MEDICINA INTERNA}

Marco Candela, Jesi (AN), Italy

Giovanni Mathieu, Pinerolo (TO), Italy

Valentino Moretti, San Daniele del Friuli (UD), Italy

Filomena Pietrantonio, Brescia, Italy

Elisa Romano, La Spezia, Italy

\section{DIRETTORE DIPARTIMENTO PER LA FORMAZIONE} E AGGIORNAMENTO

Mauro Silingardi, Guastalla (RE), Italy

\section{COORDINAMENTO DI AREA FORMATIVA CENTRO-NORD}

Francesco Orlandini, La Spezia, Italy

\section{COORDINAMENTO DI AREA FORMATIVA CENTRO SUD}

Generoso Uomo, Napoli, Italy

STAFF DIPARTIMENTO PER LA FORMAZIONE

E AGGIORNAMENTO

Roberto Frediani, Domodossola (VB), Italy

Marco Grandi, Sassuolo (MO), Italy

\section{SEGRETERIA DIPARTIMENTO PER LA FORMAZIONE E} AGGIORNAMENTO

Luigi Magnani, Voghera (PV), Italy

\section{BOARD SCIENTIFICO}

Clelia Canale, Reggio Calabria, Italy

Fabrizio Colombo, Milano, Italy

Giuseppe De Matthaeis, Città Sant'Angelo (PE), Italy

Massimo Giusti, Torino, Italy

Luca Masotti, Cecina (LI), Italy

Nicola Mumoli, Livorno, Italy

Maurizio Ongari, Porretta Terme (BO), Italy

Ruggero Pastorelli, Colleferro (RM), Italy

Fulvio Pomero, Savigliano (CN), Italy

Roberto Risicato, Siracusa, Italy

Antonio Sacchetta, Conegliano (TV), Italy

Giancarlo Tintori, Pisa, Italy

\section{COMMISSIONE TECNICHE E METODICHE INNOVATIVE} DI FORMAZIONE E VERIFICA

Responsabile dell'Innovazione

in Medicina Interna Antonino Mazzone, Legnano (MI), Italy

STAFF

Francesco Dentali, Varese, Italy

Andrea Montagnani, Grosseto, Italy

Filippo Pieralli, Firenze, Italy

\section{DIRETTORE SCIENTIFICO FONDAZIONE FADOI}

Gualberto Gussoni, Grosseto, Italy

\section{REFERENTI SLOW MEDICINE}

Roberto Frediani, Domodossola (VB), Italy

Luigi Lusiani, Castelfranco Veneto (TV), Italy

\section{RESPONSABILE AREA DOLORE}

Domenico Panuccio, Bologna, Italy 


\title{
QUADERNI - Italian Journal of Medicine
}

\author{
LE MALATTIE INFIAMMATORIE IMMUNO-MEDIATE (IMID) \\ DI INTERESSE INTERNISTICO: FISIOPATOLOGIA, \\ ASPETTI CLINICI E PROSPETTIVE DI TERAPIA \\ Guest Editors: A. Fontanella, R. Nardi, M. Masina, G. Uomo
}

\section{RASSEGNE}

Le IMID: inquadramento introduttivo

A. Fontanella, G. Uomo

Infiammazione e IMID

T. d'Errico, M. Laccetti

Malattia IgG4-relata

C. Mastrobuoni, G. Uomo

IMID in ematologia .

F. Rezzonico, A. Mazzone

IMID in reumatologia

A. Parisi, R. Buono, R. Russo, G. Uomo

IMIDs in neurologia.

G.T. Maniscalco, C. Florio

IMID in diabetologia

R. Nicosia, C. Ricordi

IMIDs in endocrinologia

M.R. Poggiano, V. Nuzzo

Malattie infiammatorie intestinali

M. Salice, L. Calandrini, C. Praticò, M. Mazza, A. Calafiore, G. Carini,

C. Calabrese, A. Belluzzi, F. Rizzello, P. Gionchetti, M. Campieri

La malattia celiaca nel terzo millennio: nuove prospettive

su patogenesi, clinica, diagnosi e terapia

G. Caio, F. Giancola, R. De Giorgio, U. Volta

Malattie epato-biliari autoimmuni

M. Visconti, L. Fontanella, G. Marino Marsilia

Pancreatiti autoimmuni.

P.G. Rabitti, R. Boni

F. Gallucci

La sindrome infiammatoria da ricostruzione immune.

I. Ronga, G. Uomo

Le malattie autoinfiammatorie

M. Gattorno, A. Brucato

Il rischio cardio-vascolare nelle IMIDs 


\section{QUADERNI - Italian Journal of Medicine}

Quale ruolo degli inibitori delle PCSK9 in Medicina Interna nella prevenzione cardio-vascolare in alternativa alle terapie tradizionali?

P. Gnerre, P. Zuccheri, M. Campanini, G. Pinna, R. Nardi

Trombo-embolismo venoso e malattie autoimmuni sistemiche . . . . . 188

A. Fontanella, P. Gnerre, R. Nardi

IMID nell'anziano: cenni sul trattamento . M. Masina

Farmaci biosimilari e farmaci innovativi in reumatologia: quale futuro?

M. Todoerti, C. Montecucco 


\title{
Le IMIID: inquadramento introduttivo
}

\author{
Andrea Fontanella, ${ }^{1}$ Generoso Uomo ${ }^{2}$ \\ ${ }^{1}$ UOSC Medicina Interna, Ospedale Fatebenefratelli, Napoli; ${ }^{2}$ UOSC Medicina Interna 3, AORN Cardarelli, Napoli, Italia
}

\section{Introduzione}

Le malattie infiammatorie immunomediate (IMID) identificano un gruppo di condizioni patologiche apparentemente non collegate tra loro ma che condividono un comune meccanismo infiammatorio. ${ }^{1}$ Le IMID potrebbero in alternativa essere chiamate anche malattie da disregolazione citochinica in quanto, sebbene per molte di esse la eziologia sia sconosciuta, è lo sbilanciamento delle citochine infiammatorie a rivestire in sostanza un ruolo patogenetico primario. In condizioni patologiche ben distinte tra loro quali ad esempio la spondilite anchilosante, il diabete mellito di tipo 1 e la sclerosi multipla, la disregolazione del sistema immune può compromettere ogni organo e apparato incrementando morbidità e mortalità specifica. I meccanismi patogenetici che sottendono la inter-relazione infiammazione-risposta immune sono complessi e non del tutto completamente chiariti. Di recente è stato stressato il ruolo dei linfociti B-regolatori (LB-reg), cellule a funzione immunosoppressiva che sostengono la tolleranza immunitaria, in presenza di stati infiammatori. ${ }^{2}$ In condizioni fisiologiche queste cellule attraverso la produzione di interleuchina-10 (IL-10), IL-35 ed il TGF (Tumor Growth Factor) - $\beta$ bloccano l'espansione delle cellule $\mathrm{T}$ patogenetiche e di altri linfociti pro-infiammatori; in presenza di differenti ambienti infiammatori si realizza una induzione selettiva di varie e distinte popolazioni di LB-reg con diversi subsets possibili indotti dall'infiammazione, capaci a loro volta di indirizzare in differenti modi la risposta infiammatoria generale ed organo-specifica (Figura 1). Numerosi studi

Corrispondente: Generoso Uomo, Medicina Interna 3, Dipartimento Medico Polispecialistico, AORN Cardarelli, via Cardarelli 9, 80131 Napoli, Italia.

Tel.: +39.081.7472101 - Fax: +39.081.7472104.

E-mail: gene.uomo@virgilio.it

Articolo pubblicato secondo la Creative Commons Attribution NonCommercial 4.0 License (CC BY-NC 4.0).

CCopyright A. Fontanella e G. Uomo, 2017

Licensee PAGEPress, Italy

QUADERNI - Italian Journal of Medicine 2017; 5(7):1-3 nell'animale da esperimento e nell'uomo sostanzialmente attestano che un disordine/interruzione/deviazione di questi fini processi mediati dalle cellule $\mathrm{B}$ può portare potenzialmente ad una ampia varietà di malattie autoimmuni. Anche i linfociti $\mathrm{T}$ sono naturalmente coinvolti in queste complesse inter-relazioni, in particolare le $\gamma \delta$ T-cells. ${ }^{3}$ Si tratta di un sottotipo di linfociti T responsabili del mantenimento della omeostasi e della integrità dei tessuti epiteliali, attraverso la produzione di citochine a prevalente effetto paracrino capaci di modulare l'infiammazione (in alte concentrazioni portano ai fenomeni tissutali tipici dei processi infiammatori cronici). Allo stesso tempo queste particolari cellule $\mathrm{T}$ sono sensibili ai cambiamenti del milieu citochinico indotto dal coinvolgimento delle cellule immunocompetenti coinvolte nelle malattie infiammatorie croniche. Il grado di interessamento pluri-organo nell'infiammazione dipende poi da una miriade di fattori, comprendenti: a) tipo di stimolo iniziale o trigger (es. infezioni, danno cellulare, mimetismo molecolare, risposta inappropriata ad auto-antigeni); b) tipo di cellule, recettori e meccanismi di signaling implicati; c) sintesi e liberazione di citochine effettrici di vario tipo; d) definizione temporale della risposta (es. acuta $v s$ cronica, precoce vs tardiva); e) tipo di patologia risultante (es. sistemica $v s$ locale, distruzione $v s$ riparazione tissutale). ${ }^{4}$ L'insieme di questi fattori (inflammosoma) in specifici subsets patogenetici delinea il rapporto infiammazionerisposta immune in determinate patologie (Figura 2). ${ }^{4}$ In base a queste recenti conoscenze fisiopatologiche può essere identificato un nuovo inquadramento tassonomico di numerose affezioni accomunate da una stretta interdipendenza infiammazione-autoimmunità. Riconoscendo una prevalente patogenesi legata ad alterazioni dell'immunità innata o di quella acquisita, si possono classificare vari gruppi di malattie. In particolare, nella area immunità innata: gruppo inflammosoma-dominante: gotta, amiloidosi, asbestosi; TNF (Tumor Necrosis Factor)-dominante: malattie infiammatorie del colon, artrite psoriasica, arterite a cellule giganti; IFN (Interferone)-dominante: lupus eritematoso sistemico. Nell'area immunità adattiva rientrano: gruppo cellule (linfociti)B-centriche: tiroidite di Hashimoto, sindrome di Guillain-Barrè; Th-2 centriche: asma, allergia; Th-1 centriche: psoriasi, polimiosite; Th17 centriche: artrite reumatoide, psoriasi, sclerosi mul- 
tipla; gruppo immunità reversibile: SIRS (Systemic Inflammatory Response Syndrome) ed ALJ (Acute Lung Injury).

L'incidenza delle IMID nelle popolazioni occidentali è di circa il $5-7 \% \%^{1,5}$ con una frequente coesistenza nello stesso paziente di malattie multiple. ${ }^{6}$ Varie IMID possono manifestarsi nello stesso ambito familiare e molte di esse condividono identici fattori precipitanti quali infezioni o traumi. L'evidenza più convincente che accomuna la fisiopatologia e il trattamento di molte malattie autoimmuni è stata fornita dall'efficacia terapeutica dell'utilizzo nella pratica clinica degli inibitori del TNF- $\alpha$ ed in particolare dall'infliximab, il primo di essi introdotto in terapia. Risultati clinici soddisfacenti sono stati riscontrati in una serie di malattie apparentemente non-correlate tra loro, fra cui l'artrite reumatoide, la malattia di Crohn, la psoriasi. Tutto ciò, insieme all'osservazione che il trattamento di una condizione è capace di migliorare aspetti patologici in multipli organi ed apparati, ha rafforzato ancora di più il concetto che si tratti di malattie immunomediate favorendo il fiorire di nuovi studi su strategie di trattamento comuni e realizzando un perfetto paradigma di una vera ricerca traslazionale bench to bedside.

$\mathrm{Nel}$ presente volume verranno presentati in modo sintetico gli aspetti patogenetici e clinico-terapeutici delle IMID in vari ambiti patologici. Verranno discusse tematiche di ordine ematologico, reumatolo-

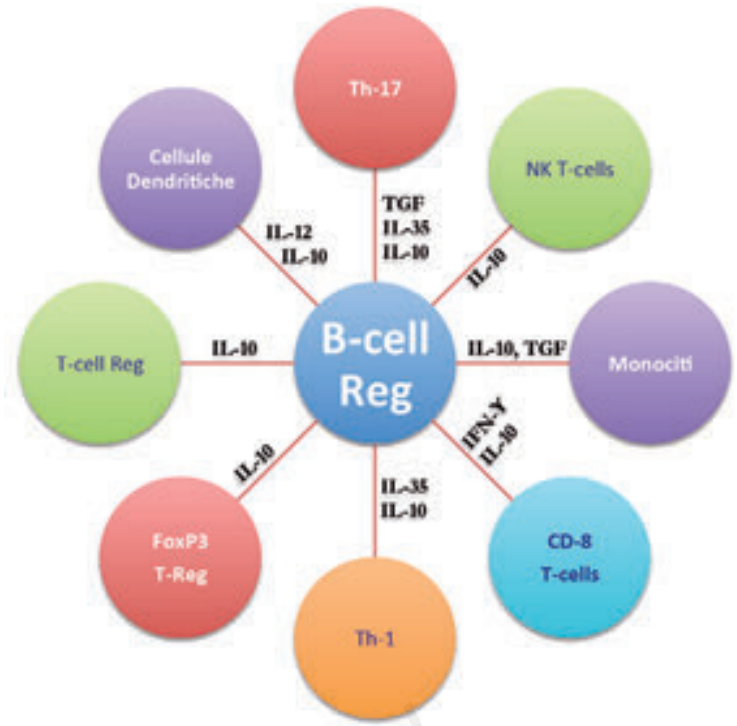

Figura 1. Ruolo centrale delle B-cell Reg nella regolazione della inter-relazione infiammazione-immunità. Attraverso la produzione di IL-10, TGF- $\beta$ e IL-35 le B-cell Reg possono sopprimere la differenziazione dei linfociti pro-infiammatori, quali i monociti che producono TNF- $\alpha$, le cellule dendritiche producenti IL-12, le cellule Th-17, Th1 e le cellule T-citotossiche CD8+; le B-cell Reg inducono inoltre la differenziazione dei linfociti $\mathrm{T}$ immunosoppressivi, T regolatori e NK. B-cell Reg: cellule (linfociti) B regolatori; TNF: tumor necrosis factor; IL: interleuchine; IFN: interferone; FoxP3 T-reg: linfociti T immunosoppressivi; NK T cells: linfociti T natural killer.

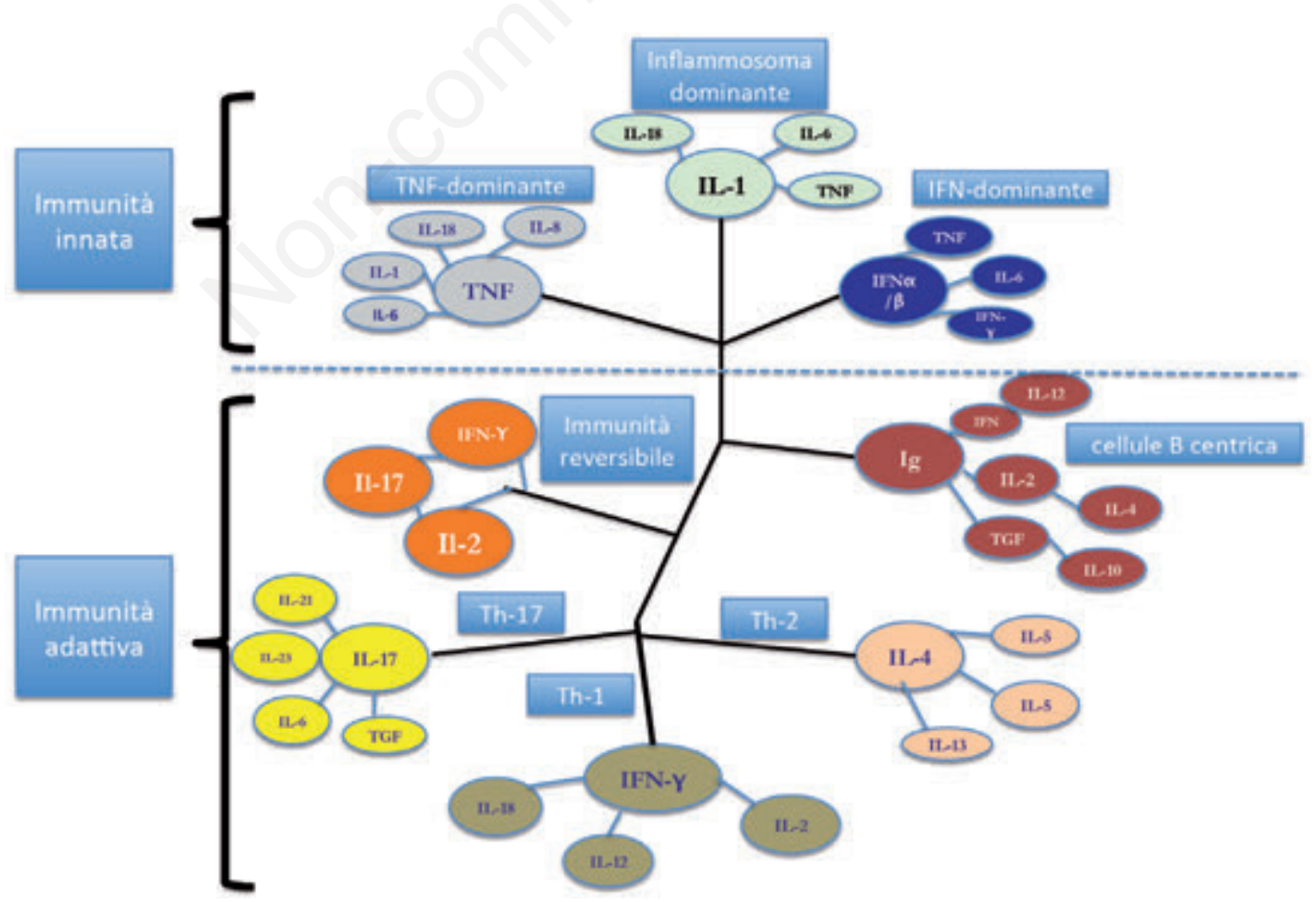

Figura 2. Relazione immunità innata/immunità adattiva e risposta infiammatoria in vari disordini (vedi testo). IL: interleuchine; Ig: immunoglobuline; TNF: tumor necrosis factor; IFN: interferone. 
gico, neurologico, diabetologico, endocrinologico, gastroenterologico, dermatologico, oncologico, geriatrico e cardiovascolare. Nella parte finale saranno presentate le più recenti acquisizioni in tema di trattamento, con focalizzazione particolare sui risultati ottenuti nella pratica clinica con la utilizzazione dei farmaci biotecnologici, capaci di realizzare: rapidi effetti sulla infiammazione, prevenzione della disabilità, miglioramento della qualità di vita $\mathrm{e}$, in determinati casi, raggiungimento dell'obiettivo della completa remissione di malattia.

\section{Bibliografia}

1. Kuek A, Hazlemann BL, Ostor AJK. Immune-mediated inflammatory diseases (IMIDs) andi biologic therapy: a medical revolution. Postgrad Med J 2007; 83: 251-60.

2. Rosser EC, Mauri C. Regulatory B-cells: origin, phenotype anf function. Immunity 2015; 42:607-12.

3. Fay NS, Larson EC, Jameson JM. Chronic inflammation and $\gamma \delta$ T-Cells. Frontiers Immunol 2016; 7:1-6.

4. Wrigth KT, Giardina C, Vella AT. Therapeutic targeting of the inflammome. Biochem Pharmacol 2014; 92: 184-91.

5. Davidson A, Diamond B. Autoimmune diseases. N Engl J Med 2001; 345: 340-50.

6. Brophy S, Pavy S, Lewis P. Inflammatory eye, skin, and bowel disease in spondyloarthritis: genetic, phenotypic and environmental factors. J Rheumatol 2001; 28: $2667-73$ 


\title{
Infiammazione e IMID
}

\author{
Tito d'Errico, ${ }^{1}$ Marco Laccetti ${ }^{2}$ \\ ${ }^{1}$ Medicina Interna, Ospedale degli Incurabili, ASL Napoli 1 Centro, Napoli; ${ }^{2}$ UOC Medicina Interna 1, UOS Immunologia e \\ malattie disreattive, AORN Cardarelli, Napoli, Italia
}

\section{Introduzione al tessuto connettivo}

Il connettivo è il tessuto più esteso e grande dell'intero organismo (rappresenta il $20 \%$ del peso corporeo) ed è costituito da una matrice intercellulare che costituisce l'ambiente, l'habitat dove sono immerse e vivono le cellule del nostro organismo: la cellula sta al connettivo come l'uomo sta all'aria che respira. A differenza degli altri tipi di tessuto il connettivo è caratterizzato dalla presenza di una sostanza extracellulare che conferisce ad esso alcune particolari proprietà. Grazie a queste particolarità, che si localizzano in una complessiva resistenza del tessuto alla trazione ed alla compressione, è possibile operare una prima classificazione del connettivo che verrà ampliata dalla classificazione di tipo funzionale, ovvero a cosa serve all'interno di un organismo. ${ }^{1-7}$

\section{Funzionalità del tessuto connettivo}

A seconda della composizione morfologica del tessuto connettivo, ovvero delle proprietà chimico fisiche, si distinguono tre tipi di connettivo: il tessuto connettivo propriamente detto, il tessuto connettivo strutturale o di sostegno e il tessuto connettivo trofico.

\section{Funzionalità associativa e di sostegno parziale}

Il tessuto connettivo propriamente detto, la cui classe è rappresentata da tessuti mucosi o da tessuti che costituiscono il lume o lo stroma di molti organi, si in-

Corrispondente: Tito d'Errico, via Pietro Nenni 1280011

Acerra (NA), Italia.

E-mail: titoderrico1963@libero.it

Marco Laccetti, Napoli, Italia.

E-mail: laccetti@libero.it

Articolo pubblicato secondo la Creative Commons Attribution NonCommercial 4.0 License (CC BY-NC 4.0).

CCopyright T. d'Errico e M. Laccetti, 2017

Licensee PAGEPress, Italy

QUADERNI - Italian Journal of Medicine 2017; 5(7):4-18 filtra tra gli spazi lasciati vuoti da altri tessuti e per questo motivo si definisce tessuto di sostegno parziale.

\section{Funzionalità meccanica e di sostegno}

Grazie alle proprie particolarità strutturali che conferiscono ad alcuni tessuti connettivali resistenza a stress fisici, come ad esempio trazioni e compressioni, alcuni tessuti connettivali servono in gran parte al sostegno e alla mobilità dell'organismo. Le ossa, ad esempio, sono dei tessuti connettivali altamente specializzati che grazie alla loro resistenza formano sia il telaio dell'animale sia una corazza naturale.

\section{Funzionalità trofica}

Oltre a riempire gli organi e servire da sostegno meccanico, i tessuti connettivali, hanno l'importante funzione di trasferire risorse energetiche o molecole di grande funzionalità lungo tutto il corpo dell'animale. Il sangue, ad esempio, è un tessuto connettivale che opera alla perfezione le azioni appena elencate in quanto è vettore di sostanze di nutrimento, serve ad incanalare le sostanze di rifiuto verso gli opportuni centri di smaltimento e, in ultima analisi, ha il compito di trasportare buona parte delle molecole che servono per la vita dell'animale come le piastrine o i complessi sistemi di difesa contro i patogeni. Secondo questa prospettiva il connettivo è l'organo più importante che esista (per organo, in medicina, si intende una struttura che svolge una o più funzioni): infatti esso svolge come detto svariate funzioni fondamentali per il nostro organismo, la difesa dei patogeni fa si che tutte le reazioni immunitarie avvengono nel connettivo (che, dunque, da questo punto di vista rappresenta e viene indicato come il campo di battaglia, la sede dove avvengono tutte le reazioni di difesa del nostro organismo).

\section{Fisiologia del connettivo}

Una delle funzioni del connettivo è, come già detto, quella di essere ricettacolo di tossine che ven- 
gono convogliate dal sangue ed immagazzinate nel connettivo stesso. Queste tossine provengono principalmente dall'interno del corpo, e in particolare dal metabolismo cellulare (tossine endogene), ma anche dall'esterno, per esempio i virus, i batteri, i farmaci, i metalli pesanti, varie sostanze chimiche. Sia le tossine endogene che quelle esogene ogni giorno devono essere smaltite e tale lavoro viene effettuato dal sistema linfatico che, proprio come un operatore ecologico, porta via giornalmente i rifiuti che si sono accumulati. Per consentire ciò il connettivo, nell'arco delle 24 ore, attraversa due fasi di circa 12 ore ciascuna: una fase di smaltimento di scorie metaboliche e sostanze estranee, ed una fase di ricostruzione della matrice connettivale e delle sostanze indispensabili alla vita delle cellule. . $^{8-10}$

\section{Struttura del connettivo}

Nella prima fase della giornata, che va dalle 3 alle 15 circa, esso appare come una gelatina sciolta, solubilizzata (stato di sol) ed in questa prima parte della giornata avviene la demolizione e lo smaltimento di scorie e proteine (fase di smaltimento). Nella seconda fase, che va dalle 15 alle 3 circa, il connettivo appare, invece, come una gelatina che si ricondensa (stato di gel) ed in questa seconda parte della giornata avviene la ricostituzione della matrice connettivale e delle proteine (fase di ricostruzione).

Questo equilibrio, però, può rompersi per una serie di ragioni: ad esempio, per un trauma, infezioni virali o batteriche, insufficienza funzionale del sistema linfatico, eccessiva produzione di tossine dovuta ad errata alimentazione o all'assunzione di sostanze chimiche. Tutti questi eventi portano ad un aumento di scorie nel connettivo. Quando l'organismo è particolarmente sovraccaricato da questo punto di vista, si mettono in moto meccanismi di detossicazione e drenaggio suppletivi, grazie alla produzione di alcuni enzimi (per es. la ialuronidasi) che producono uno stato continuativo di sol del connettivo (fase di smaltimento): questa fase, però, non dura più solo 12 ore, ma continua fino a quando non viene ottenuta una pulizia profonda e completa. ${ }^{11-14}$ Tale meccanismo suppletivo prende il nome di infiammazione. Quindi la gelatina disciolta (stato di sol) della matrice connettivale rigelificherà (stato di gel) solo quando sarà fatta completa pulizia del connettivo stesso. Solo allora, dopo aver svolto la sua funzione di drenaggio supplettivo, l'infiammazione finirà e verrà ripristinato il normale bioritmo giornaliero tra fase di sol e fase di gel del connettivo. Da questa prospettiva l'infiammazione e, ovviamente, la febbre che ne costituisce il sintomo più generale, rappresentano un meccanismo biologicamente opportuno e non una malattia da combattere come, invece, vengono normalmente considerate (Tabella 1).

Le ricerche scientifiche degli ultimi anni hanno dimostrato come il nostro sistema immunitario inizia a funzionare in maniera ottimale a partire da una temperatura di $38,4^{\circ} \mathrm{C}$. Inoltre, nei centri più all'avanguardia nella cura dei tumori viene usata l'ipertermia, cioè l'induzione di un'infiammazione molto alta prodotta artificialmente nella zona da trattare, proprio perché si produce un forte stimolo immunitario. In tutte le malattie infiammatorie, il primum movens della riposta immunitaria è rappresentato dalla migrazione dei globuli bianchi, chiamati anche leucociti, dai vasi sanguigni nei tessuti dove si sviluppa il processo patologico. Nel caso di malattie infiammatorie non dovute ad infezioni, il processo infiammatorio e la migrazione dei leucociti non hanno più un ruolo di difesa dell'organismo, ma un ruolo patologico critico provocando un importante danno tessutale. Infatti, le malattie autoimmuni sono dovute a un errore del sistema immunitario, il quale dirige le proprie potenzialità offensive contro tessuti propri dell'organismo anziché contro gli agenti infettivi. Ne derivano gravi danni tessutali con conseguente sviluppo di malattie diverse a seconda dell'organo e tessuto colpito. Queste comprendono malattie altamente invalidanti, come la sclerosi multipla, il lupus eritematoso sistemico, l'artrite reumatoide, la psoriasi, il diabete mellito insulinodipendente, ed altre ancora. Nella maggior parte dei casi le terapie a disposizione riescono solo a rallen-

Tabella 1. Tipi di infiammazione.

Infiammazione acuta (angioflogosi)

- di breve durata, da pochi minuti fino a pochi giorni

- prevalgono fenomeni vascolari con formazione di essudato composto da liquidi con proteine plasmatiche

- migrazione nel tessuto infiammato di leucociti, soprattutto granulociti neutrofili

Infiammazione cronica (istoflogosi)

- Durata più lunga, anche anni

- Prevalente componente cellulare con macrofagi, linfociti e fibroblasti

- Proliferazione di vasi sanguigni e fibrosi 
tare l'evoluzione della malattia senza riuscire a ottenere una guarigione. ${ }^{15,16}$

\section{Sequenza e meccanismi generali}

La risposta infiammatoria è scatenata dal danno prodotto da agenti fisici (calore, radiazioni), chimici (veleni, tossici, solventi) e biologici (batteri, virus, altri parassiti e loro prodotti). Il danno primario si manifesta con la necrosi o con alterazioni subletali delle cellule presenti nel sito di azione (sito infiammatorio): cellule dei tessuti, leucociti, piastrine e cellule endoteliali. Questo permette la genesi dei primi segnali responsabili della liberazione delle molecole attive (mediatori) le quali, a loro volta, generano la sequenza dei fenomeni clinici flogistici nell'area direttamente interessata dal danno. Per es., sulla superficie cutanea sottoposta all'azione di uno stimolo dannoso, la comparsa dei segni clinici della flogosi può essere descritta in questo modo: 1) fugace pallore, immediatamente associato al danno, dovuto a una vasocostrizione locale determinata da molecole liberate dalle cellule presenti nel tessuto danneggiato; 2) comparsa di rossore (rubor) e aumento della temperatura locale (calor), dovuti a vasodilatazione persistente e aumento del flusso sanguigno; 3 ) formazione di una vescicola o di una tumefazione (tumor) per l'accumulo locale di liquido nello spazio interstiziale; 4) estensione dell'area interessata con comparsa di dolore (dolor) e alterazione della funzionalità del tessuto e dell'organo (functio laesa). Questa sequenza è determinata dall'azione concertata dei mediatori liberati dalle cellule proinfiammatorie che sono coinvolte. L'evidenza clinica di questi sintomi è legata all'amplificazione della risposta, direttamente proporzionale all'intensità dello stimolo dannoso, al tempo per cui esso agisce e al numero delle cellule proinfiammmatorie che vengono reclutate e attivate. La rilevanza clinica è dovuta anche alla rapidità con cui la risposta infiammatoria ripristina l'omeostasi per mezzo della guarigione e della riparazione. L'innesco e l'amplificazione della risposta, il danno collaterale alle reazioni difensive e la sua guarigione o riparazione sono controllati dalle molteplici famiglie di mediatori ad azione pro-e antinfiammatoria. Alcuni di questi sono immediatamente pronti per l'uso (per es., istamina e serotonina), altri vengono mobilizzati più o meno rapidamente (per es., chinine vasoattive e complemento), altri ancora sono il prodotto di complesse attività biochimiche (per es., prostanoidi e leucotrieni) o geniche (per es., citochine ed enzimi chiave per la sintesi delle varie famiglie di mediatori). Sono stati comunque parzialmente chiariti due fenomeni importanti: 1) il tipo di risposta infiammatoria, acuta o cronica, viene determinato dall'iniziale interazione con alcune cellule infiammatorie e dalla successiva liberazione di citochine di tipo I (Th1) e di tipo II (Th2); 2) l'amplificazione della risposta infiammatoria, rilevante per l'evidenziazione della sintomatologia clinica e per la produzione del danno, è dovuta soprattutto all'attivazione di gruppi di geni, normalmente inattivi, nei leucociti e nelle altre cellule dei tessuti coinvolti. ${ }^{5}$

\section{Infiammazione acuta}

Il quadro di infiammazione acuta si manifesta quando viene riconosciuto dall'organismo lo stimolo dannoso. Hanno così inizio i fenomeni vascolari descritti e vengono reclutati e attivati i granulociti (basofili, neutrofili ed eosinofili). Il riconoscimento iniziale avviene da parte di cellule localmente presenti: cellule dendritiche, cellule NK (natural killer), linfociti e macrofagi. Il reclutamento di altre cellule nel sito è mediato da una sottofamiglia di citochine, dette chemiochine, liberate o prodotte dalle cellule che per prime hanno avvertito lo stimolo dannoso. Le chemiochine fanno affluire specificamente i vari leucociti, permettono una nuova liberazione di mediatori a pronta disponibilità e, successivamente, stimolano la produzione di altri mediatori. L'attivazione comprende una serie di segnali recettoriali che agiscono su alcune vie metaboliche favorendo la sintesi di altre molecole coinvolte nel meccanismo flogistico, quali prostanoidi, PAF (Platelet activating factor), leucotrieni; essi forniscono inoltre segnali per il nucleo e, quindi, per la trascrizione dei geni proinfiammatori. Le cellule attivate sono caratteristiche del sito infiammatorio (infiltrato) e della risposta flogistica sistemica (leucocitosi). La vasodilatazione (rubor e calor) è imputabile all'azione di mediatori come l'istamina, le chinine e le varie prostaglandine. Essi agiscono soprattutto sui recettori delle cellule endoteliali determinando l'attivazione di un enzima (NOS, ossido nitrico sintetasi) che genera l'ossido nitrico (NO) a partire dall'arginina. L'NO è un gas diffusibile che raggiunge facilmente le cellule muscolari dei vasi provocandone il rilassamento. Per questo motivo la vasodilatazione interessa attivamente le arteriole (dotate di muscolatura liscia) e solo passivamente per l'aumento del flusso, i capillari e le venule (privi di muscolatura liscia). Contemporaneamente alla vasodilatazione, si verifica l'alterazione della permeabilità della parete vasale, soprattutto in quei distretti dove è presente un endotelio continuo. Gli stessi mediatori (istamina, chinine e prostaglandine), con diversa efficacia, disorganizzano le giunzioni strette (impermeabili) tra le cellule endoteliali, permettendo il passaggio di proteine plasmatiche dal compartimento vascolare a quello interstiziale. Ciò altera il 
normale gradiente osmotico tra i due compartimenti, per cui acqua e ioni del plasma tendono a passare in eccesso nell'interstizio. Questo liquido, per molti versi simile al plasma, si accumula progressivamente nello spazio interstiziale, producendo le vescicole o il caratteristico turgore (tumor) dei tessuti infiammati. ${ }^{4,5}$ All'accumulo contribuisce, oltre all'insufficienza del richiamo oncotico del plasma a livello delle venule, anche l'inadeguatezza del drenaggio linfatico, il quale normalmente è in grado di eliminare soltanto una piccola parte del liquido in eccesso (circa $5 \mathrm{mmHg}$, in valore pressorio). Il liquido che si accumula nello spazio interstiziale del sito infiammato si chiama essudato e si distingue dal trasudato tanto per la composizione (presenza di proteine simili a quelle del plasma), quanto per la patogenesi: l'essudato è legato soprattutto all'alterazione della pressione oncotica, cioè in ultima analisi al passaggio di proteine dal plasma all'interstizio, mentre il trasudato è legato all'aumento della pressione idrostatica ematica a monte di un blocco o di un restringimento vasale.

Si possono distinguere vari tipi di essudato a seconda della loro composizione proteica e della presenza o meno di cellule ematiche: essudato sieroso, sierofibrinoso, fibrinoso, purulento (pus), emorragico. Il tipo di essudato è caratteristicamente associato alla natura e alla gravità dello stimolo dannoso. Gli essudati sieroso e fibrinoso dipendono essenzialmente dall'entità della disorganizzazione delle giunzioni strette tra gli endoteliociti e, quindi, dal grado di permeabilità che lascia passare molecole di maggiore peso (per es. il fibrinogeno). L'essudato purulento dipende soprattutto dall'intensità dello stimolo chemiotattico delle chemiochine e quindi dall'abbondanza di granulociti e macrofagi giunti nel sito infiammatorio. Per questo il pus è costituito non solo da componenti plasmatici ma anche da leucociti, batteri e detriti cellulari derivati dalle azioni difensive messe in atto localmente contro l'agente patogeno, sul tessuto circostante e sui leucociti stessi. L'essudato emorragico è associato a gravi lesioni della parete vasale, la quale lascia passare il sangue in toto. Esso risulta quindi ricco di piastrine, eritrociti e di tutte le proteine plasmatiche. La risposta infiammatoria progredisce e si amplifica perché in seguito al danno vengono coinvolte e attivate cellule sia del sangue sia dei tessuti interessati. Il meccanismo molecolare che determina la migrazione dei leucociti nel sito infiammatorio, la scelta del tipo di leucocita da reclutare e, infine, la loro attivazione (espressione di nuovi geni) è parzialmente conosciuto. A seconda del meccanismo con cui viene avvertito lo stimolo dannoso vengono prodotti due pool di citochine e di chemiochine che caratterizzeranno il tipo e l'attivazione delle cellule reclutate. Il tipo I comprende chemio- chine che richiamano soprattutto cellule NK, linfociti $\mathrm{T}$ (helper CD4 e citotossici CD8) e macrofagi, dando un quadro di infiammazione linfomonocitaria; altre citochine presiedono allo sviluppo di una risposta immune cellulomediata. Il tipo II comprende chemiochine e citochine attive su granulociti e linfociti $\mathrm{B}$; esse pertanto presiedono alla risposta acuta tipica della immunità mediata da anticorpi e delle allergie. La migrazione, diretta dalle chemiochine, avviene con una caratteristica sequenza di fasi. Dapprima i leucociti aderiscono alla parete endoteliale del vaso (marginazione), quindi, emettono pseudopodi lungo le cellule endoteliali, seguendo il gradiente chemiochinico e, attraverso le giunzioni strette precedentemente disorganizzate, passano al di là della parete (migrazione). Durante questo processo la cellula si deforma adattandosi allo stretto passaggio tra le cellule endoteliali. La membrana basale e, poi, la matrice extracellulare vengono localmente digerite da enzimi litici (metalloproteinasi come collagenasi, ialuronidasi, elastasi ecc.) liberati dagli stessi leucociti attivati, $i$ quali in questa maniera si fanno strada fino al sito infiammatorio che è il punto massimale del gradiente chemiochinico. Localmente i leucociti esplicano una sequenza di eventi difensivi che comprendono: la fagocitosi dell'agente patogeno, la sua uccisione (killing) e la sua digestione; il tutto legato a fini meccanismi molecolari di attivazione e di controllo. La fagocitosi è caratteristica dei fagociti professionali (neutrofili e macrofagi), ma può essere osservata anche in altre cellule. Essa è un evento dipendente da recettori presenti sulla membrana dei fagociti e dagli specifici ligandi presenti sulla particella da internalizzare (opsonine, quali anticorpi e frazioni del complemento) e avviene come interazione ordinata tra queste due molecole (meccanismo a chiusura lampo) che porta la membrana plasmatica del fagocito a circondare la particella, fino alla formazione di un vacuolo (fagosoma). Nel microambiente del fagosoma vengono sintetizzati dal complesso citocromico della NADPH-ossidasi vari metaboliti dell'ossigeno, i quali, essendo altamente reattivi, uccidono i batteri tramite perossidazione dei vari componenti. Nel frattempo, i lisosomi primari si fondono con il fagosoma (fagolisosoma) e permettono alle idrolasi lisosomiali di degradare il parassita ucciso. La progressione della risposta flogistica si manifesta attraverso il coinvolgimento di altri distretti dell'organismo, che possono essere anche lontani dal sito infiammatorio e spiega inoltre le manifestazioni sistemiche che si possono osservare in una risposta infiammatoria pienamente realizzata. Le principali manifestazioni sistemiche sono la febbre, le modificazioni ematiche e le reazioni vascolari e funzionali degli altri distretti dell'organismo. La febbre, cioè l'aumento della temperatura corporea al di sopra di 
$37,5^{\circ} \mathrm{C}$, è dovuta all'azione di molecole, dette pirogeni endogeni, per la maggior parte identificate come citochine, prostaglandine e altri mediatori. Questi agiscono su un gruppo di neuroni dei nuclei periventricolari dell'ipotalamo (organo subfornicale, organum vasculosum, eminenza mediana e altri forniti di endotelio fenestrato permeabile alle citochine, contrariamente al resto della barriera ematoencefalica) che hanno la funzione di termostato e sono, infatti, in grado di controllare la temperatura dell'organismo, mantenendola normalmente attorno ai $37^{\circ} \mathrm{C}$. $\mathrm{La}$ regolazione del termostato è associata all'attività metabolica di questi neuroni e all'intensità degli stimoli da essi generati. Quando le citochine e gli altri mediatori pirogenici si legano agli specifici recettori su questi neuroni, la loro attività aumenta, regolando verso l'alto il termostato. La maggiore attività equivale alla liberazione di segnali neurormonali che sui bersagli finali si traducono in una diminuzione della dispersione del calore corporeo (per es. vasocostrizione degli strati superficiali corporei) e, soprattutto, in un aumento della produzione di calore. Questo secondo effetto può essere raggiunto attraverso numerosi stimoli neurormonali che, tuttavia, si concludono nell'attivazione delle vie biochimiche che portano all'aumento del metabolismo basale (aumento del consumo di ossigeno) e all'aumento del consumo di ATP. Il sangue modifica la sua composizione sia in cellule (leucocitosi) sia nella parte plasmatica (comparsa delle proteine di fase acuta). La leucocitosi è uno dei segni clinici più caratteristici dell'infiammazione ed è dovuta in un primo momento al richiamo, mediato da chemiochine, dei leucociti dai compartimenti di riserva (midollo), successivamente anche alla proliferazione e maturazione, stimolate da altre citochine, di elementi staminali presenti soprattutto nel midollo. La leucocitosi dell'infiammazione acuta può essere neutrofila, se aumentano soprattutto i granulociti neutrofili; eosinofila, se aumentano soprattutto i granulociti eosinofili; oppure, infine, linfomonocitaria, nel caso di malattie virali acute. La leucocitosi dell'infiammazione cronica è soprattutto linfomonocitaria. Il richiamo prevalente di un tipo di leucocita dipende dalle citochine che vengono generate all' $\mathrm{i}$ nizio e nel corso della risposta infiammatoria. Le proteine di fase acuta, assenti in condizioni normali, compaiono dopo l'attivazione dei loro geni da parte delle citochine (per es. IL-6) negli epatociti. La proteina $\mathrm{C}$ reattiva (uno dei più affidabili marcatori per la valutazione di uno stato infiammatorio sistemico), insieme con alcune frazioni del sistema del complemento, è in grado di attivare la fagocitosi da parte di macrofagi e neutrofili. Fibrinogeno e antiproteasi sono coinvolti nel processo coagulativo finalizzato alla riparazione. La funzione della proteina amiloide A è sconosciuta, ma, per la ricchezza di $\beta$-foglietti nella sua molecola, è all'origine di una $\beta$-fibrillosi sistemica, l'amiloidosi a partenza epatica. La risposta infiammatoria pienamente sviluppata influenza la fisiologia di quasi tutti gli organi e tessuti: i muscoli (astenia, dolori, ecc.), il sistema cardiovascolare (aumento della frequenza, variazioni pressorie, ecc.), i reni (aumento della filtrazione glomerulare) e il sistema nervoso centrale (sindrome da stress e depressione) appaiono coinvolti in maniera più o meno profonda, grazie all'azione diretta o indiretta delle citochine e di altri mediatori. L'evoluzione della risposta infiammatoria dipende soprattutto dal tipo di citochine e di mediatori che prevale nel sito infiammatorio e, quindi, dall'effetto che questi hanno sulle cellule dell'organismo. Le citochine e i mediatori agiscono sui recettori presenti diffusamente sia sulle cellule infiammatorie sia su quelle dei vari tessuti dell'organismo. Questi recettori, una volta attivati, generano segnali che hanno effetti metabolici nel citosol (per es., attivazione di enzimi, proteine citoscheletriche, ecc.) e a livello nucleare con la trascrizione di nuovi geni, come molecole di adesione, nuove isoforme enzimatiche, recettori, componenti per il programma di apoptosi. ${ }^{7} \mathrm{La}$ trascrizione di nuovi geni modifica profondamente le proprietà biologiche, producendo uno stato di attivazione più adatto alle esigenze della risposta difensiva. La cascata di segnali che porta alla trascrizione inizia dai recettori di membrana, si svolge nel citosol con l'attivazione di varie famiglie di chinasi e proteine di trasduzione e arriva ad attivare pochi fattori di trascrizione i quali, da soli, coordinano l'espressione di un esteso numero di geni proinfiammatori. I meccanismi difensivi messi in atto dalla risposta infiammatoria tendono a eliminare lo stimolo dannoso e i detriti delle cellule danneggiate e a riparare il danno, ripristinando l'omeostasi funzionale e strutturale. Il primo passo è il controllo negativo della risposta che con l'annullamento dello stimolo dannoso e il diminuire dei mediatori tende a eliminare anche le cellule infiammatorie attivate. Per la maggior parte di esse si compie il programma di apoptosi attivato da stimoli citochinici. L'espressione sulla loro superficie dei recettori Fas e TNF (Tumor necrosi factor) - $\mathrm{R} 1$ e la disponibilità dei rispettivi ligandi Fas-L e TNF- $\alpha^{17-22}$ avvia la cascata di segnali che attiva le proteasi (caspasi) e l'endonucleasi che uccide la cellula secondo le tipiche modalità dell'apoptosi. Eliminato lo stimolo dannoso e fermata la risposta, viene riparato l'eventuale danno cellulare. Se il danno è modesto, un'opportuna proliferazione delle quote staminali dei vari tessuti danneggiati porta al completo ripristino della precedente architettura e funzione tessutale (restitutio ad integrum). Se invece si ha una perdita consistente di tessuto, allora la riparazione avviene con la formazione della 
cicatrice, in cui il macrofago svolge ancora un ruolo centrale. È importante notare che nell'infiammazione cronica, dove la produzione del danno è continua, anche il processo di riparazione è continuo ed è prevalente quello per cicatrizzazione. Per questo, il connettivo fibroso sostituisce progressivamente i vari parenchimi, portando alla fibrosi e alla insufficienza funzionale di organo o tessuto. La morte di un individuo a causa di un processo infiammatorio si verifica per due condizioni più frequenti: 1) le capacità difensive sono inadeguate a eliminare in tempo utile lo stimolo dannoso e a riparare il danno prodotto; 2 ) gli effettori difensivi (citochine, perforine, radicali liberi, mediatori) agiscono in maniera impropria e/o cronica sul tessuto sano circostante danneggiandolo e, inoltre, perpetuando o amplificando il meccanismo dannoso che supera le capacità omeostatiche dell'organismo, come avviene nello shock anafilattico o nello shock settico. ${ }^{21,23}$

\section{Infiammazione cronica}

La permanenza dello stimolo dannoso e la prevalenza delle citochine del tipo Th1 fanno evolvere la risposta infiammatoria acuta nel senso della cronicizzazione e, quindi, verso il quadro di istoflogosi. Le cellule responsabili dell'infiammazione cronica sono i macrofagi (soprattutto le loro forme attivate), i linfociti Th1, i linfociti citotossici CD8 e le cellule NK. L'infiammazione si presenta in tre forme cliniche: la leucocitosi linfomonocitaria, l'infiltrato tessutale linfomonocitario e i vari tipi di granuloma. La leucocitosi linfomonocitaria si manifesta nelle fasi attive della malattia con agente patogeno presente in abbondanza nell'organismo. Rappresenta la prima reazione difensiva evocata da citochine del tipo Th1. $\mathrm{Si}$ verifica caratteristicamente nelle malattie virali e nelle malattie batteriche o da parassiti intracellulari in fase attiva. L'infiltrato tessutale linfomonocitario è il corrispettivo tessutale della leucocitosi linfomonocitaria e riguarda i distretti dove fisicamente si trova l'agente dannoso. La sua diffusione appare proporzionale alla diffusione dell'agente patogeno, come si riscontra nei tessuti infettati da virus. Nel granuloma, l'infiltrato infiammatorio cronico si evolve e si organizza in una caratteristica struttura di strati cellulari concentrici. Al centro vi sono una o più cellule giganti polinucleate, contenenti l'agente patogeno. Attorno vi sono nell'ordine: macrofagi con morfologia di cellule epitelioidi e altri macrofagi tessutali tipicamente attivati; infine, vi possono essere linfociti e all'esterno uno strato di fibroblasti e tessuto cicatriziale. Nel granuloma non vi è segno di vascolarizzazione, per cui, quando esso raggiunge dimensioni tali da impedire la diffusione dei nutrienti, è possibile che le cellule centrali vadano in necrosi coagulativa (necrosi caseosa). Le citochine di tipo I, responsabili del reclutamento, vengono liberate dai linfociti Th1, dalle cellule NK, dai macrofagi, dalle cellule dendritiche e dai linfociti citotossici. Tra le citochine effettrici del danno vi sono il TNF- $\alpha$ e l'IL-1. Il TNF- $\alpha$ è il ligando per il TNF-R1 a cui è associata una cascata di segnali simile a quella del recettore Fas e che innesca il programma di apoptosi $;{ }^{23}$ per questo molte cellule del tessuto vanno in apoptosi, provocando un'amplificazione del primitivo danno. I linfociti il cui recettore per l'antigene presenta le catene $\gamma \delta$ appaiono più efficienti nella produzione di citochine effettrici e, inoltre, si ritrovano in numero maggiore nei granulomi e negli infiltrati cronici. La risposta mediata da linfociti e macrofagi e i danni prodotti dalle citochine e dagli effettori liberati da queste cellule sono frequenti in patologia umana, soprattutto se si considera il deterioramento funzionale di organi e tessuti dovuto alla sostituzione fibrotica. Questa si verifica più spesso per la formazioni di granulomi da corpi estranei o da materiali indigeribili, in infezioni da virus, batteri e altri parassiti con persistenza dell'agente nell'organismo, in seguito a processi che innescano risposta autoimmune e, infine, nel corso di intossicazione cronica da agenti chimici. L'alterato riconoscimento dei propri antigeni (autoimmunità), soprattutto di quelli legati a tessuti, viene considerato come il maggiore meccanismo di deterioramento dei vari organi e tessuti nell'età matura e avanzata. Un recente studio ${ }^{1}$ si è focalizzato su una classe di leucociti chiamati linfociti $\mathrm{T}$ che sono fondamentali nell'induzione di malattie infiammatorie croniche ed autoimmuni. La scoperta ha identificato la TIM-1 (Tcell immunoglobulin and mucin domain molecule), una nuova glicoproteina presente sulle cellule $\mathrm{T}$, in grado di mediare l'adesione dei linfociti alla parete dei vasi sanguigni e la successiva migrazione nei tessuti bersaglio. Il blocco della TIM-1 è stato in grado di impedire la formazione di focolai infiammatori e il conseguente danno tessutale in vari organi. In particolare, il nuovo meccanismo identificato dal gruppo veronese è fondamentale per le malattie infiammatorie del sistema nervoso centrale come, per esempio, la sclerosi multipla. I fattori scatenanti tale patologia non sono noti con certezza, ma numerose evidenze cliniche e sperimentali indicano che alla base vi è una reazione del sistema immunitario che individua quale bersaglio dei suoi linfociti il rivestimento dei neuroni, la mielina, compromettendone così la capacità di condurre gli impulsi elettrici da e per il cervello. All'infiltrazione dei linfociti nel tessuto cerebrale è correlata la comparsa dei segni clinici e patologici di disfunzione del sistema nervoso centrale tipici della sclerosi multipla. La migrazione dei linfociti all'interno del cervello studiata dal gruppo 
della professoressa Constantin rappresenta quindi un momento fondamentale per lo sviluppo della malattia e il suo blocco potrebbe costituire un approccio terapeutico molto potente in questa patologia così come in altre malattie autoimmuni. La scoperta scientifica dell'ateneo scaligero apporta dunque un contributo importante nella conoscenza del funzionamento delle cellule del sistema immunitario e identifica un nuovo potenziale bersaglio farmacologico nelle malattie infiammatorie croniche ed autoimmuni rappresentato della glicoproteina TIM-1. Come visto i meccanismi reattivi relativamente primitivi e non-specifici dei polimorfonucleati e dei macrofagi oltre ad essere una efficace forma di difesa dell'organismo sono anche in grado di produrre effetti dannosi, causati dalla loro attivazione massiva con produzione di mediatori chimici e liberazione del loro contenuto per cui come disse Lewis Thomas siamo in maggior pericolo a causa loro piuttosto che degli invasori esterni (Tabelle 2 e 3) (http://en.wikipedia.org/wiki/Lewis_Thomas).

È evidente quindi che quando il processo infiammatorio non venga spento, come capita sempre in corso di malattie autoimmuni, il perpetuarsi dei suoi effetti rappresenti il principale problema da cui il nostro organismo debba difendersi.

\section{Le citochine}

Le citochine sono un gruppo di glicoproteine a basso peso molecolare (fino a $25 \mathrm{kD}$ ), prodotte dalle cellule del sistema immunitario, durante la fase effettrice dell'immunità naturale, per modulare la risposta immunoflogistica e la fagocitosi. Le citochine con le chemochine e le molecole di adesione, svolgono importanti attività biologiche nell'immunità, nelle malattie infettive, nella cancerogenesi e nella riparazione dei tessuti. ${ }^{24}$ In relazione all'attività biologica, vengono prodotte differenti molecole attive nel sistema immunitario: interleuchine (IL), tumor necrosis factors (TNF), linfotossine (LT), interferoni (IFN), colony stimulating factors (CSF), chemochine $(\mathrm{CC}, \mathrm{CXC})$, citochine regolatrici. Le citochine sono caratterizzate da tre proprietà che rendono i loro effetti biologici complessi, più precisamente, pleiotropici, ridondanti e sinergici. Il pleiotropismo consiste nel fatto che le citochine svolgono differenti effetti su diversi tipi di cellule bersaglio; la ridondanza significa che più citochine mediano le stesse attività biologiche; il sinergismo indica che l'effetto combinato di più citochine può risultare maggiore della somma degli effetti biologici delle singole citochine. Le citochine per espletare le loro attività biologiche

Tabella 2. Danno tissutale per liberazione di sostanze dai neutrofili durante l'infiammazione.

\begin{tabular}{|c|c|}
\hline \multicolumn{2}{|l|}{ Enzimi lisosomiali presenti nei granuli } \\
\hline Metaboliti attivi dell'ossigeno & \\
\hline Prodotti del metabolismo dell'acido arachidonico & \\
\hline $\begin{array}{l}\text { Modalità, di rilascio del contenuto dei granuli: } \\
\text { - lisi cellulare } \\
\text { - difetto nel funzionamento della fagocitosi }\end{array}$ & \\
\hline 1) Degranulazione prematura (Rigurgito durante 1 & estione) \\
\hline 2) Fagocitosi fallita o ostacolata da materiale gran & piatto o fisso (es. immunocomplessi precipitati) \\
\hline 3) Sostanze dannose per la membrana (es cristalli & rato) con rilascio citotossico \\
\hline
\end{tabular}

Tabella 3. Danno tissutale determinato da cellule inflammatorie.

Specie reattive dell'ossigeno

- Sono utili alla degradazione dei microorganismi e possono quindi digerire componenti tissutali extracellulari

- L'attività delle proteasi è contrastata da antiproteasi plasmatiche (a1-anti-tripsina, a2-macroglobulina, etc.)

Enzimi lisosomali

- Sono utili alla degradazione dei microorganismi e possono quindi digerire componenti tissutali extracellulari

- L'attività delle proteasi è contrastata da antiproteasi plasmatiche (a1-anti-tripsina, a2-macroglobulina, etc.)

Aderenza delle cellule fagocitiche

- L'aderenza alla membrana basale o altre componenti della matrice extracellulare e ad altre cellule da parte dei fagociti aumenta il danno causato dalle specie reattive dell'ossigeno e dagli enzimi per mancato accesso degli inibitori plasmatici 
devono legarsi a specifici recettori presenti sulla membrana delle cellule bersaglio. La loro attività può essere distinta in autocrina, quando si legano a recettori presenti sulla membrana dello stesso tipo di cellula che le secerne; paracrina, quando si legano a recettori presenti su cellule-bersaglio situate in prossimità delle cellule che le producono; endocrina, quando i recettori specifici sui quali si legano sono espressi da cellule e tessuti fisicamente distanti ed appartenenti a sistemi biologici complessi, sia in condizioni fisiologiche sia patologiche. Il legame di una citochina alla sua cellula bersaglio può stimolare sia l'espressione di recettori per citochine, sia la produzione di altre citochine che a loro volta agiscono su altre cellule bersaglio (effetto a cascata). Le citochine regolano l'intensità e la durata della risposta immunitaria, sia di tipo cellulare che umorale, la proliferazione e il differenziamento di varie cellule, l'induzione della risposta infiammatoria, la regolazione dell'ematopoiesi, la fisiopatologia dell'endotelio vascolare e la riparazione dei tessuti. Il tipo e l'ampiezza della risposta immunitaria sono determinati e regolati, inizialmente, dal meccanismo di riconoscimento dell'antigene. A questo complesso fenomeno segue la modulazione della risposta stessa che è, per gran parte, determinata dalla produzione, dal rilascio nel mezzo-ambiente e dalla efficace attività biologica delle citochine. Questi fenomeni sono comuni sia alle risposte fisiologiche e controllate, sia a quelle immunitarie patologiche ed alterate nella loro regolazione. ${ }^{25}$ L'espressione delle citochine è regolata da segnali specifici sulla membrana delle cellule che le producono; questi segnali vengono trasdotti in modo da indurre neosintesi di RNA e proteine regolatrici, la promozione della crescita e della differenziazione cellulare (risposta cellulare lenta). Il network citochinico, nella fisiopatologia immunitaria, interviene nella neutralizzazione delle tossine batteriche solubili che richiede la sintesi di anticorpi (risposta umorale), nelle infezioni virali, quale parte integrante della citotossicità cellulo-mediata, nella persistenza dei microrganismi patogeni nell'organismo ospite, nelle risposte allergiche, nella patogenesi delle malattie autoimmunitarie e nella comparsa dell'ipersensibilità di tipo ritardato. È possibile distinguere due sottopopolazioni di cellule Th CD4+ (Th1, Th2) in base alle citochine secrete, capaci di svolgere funzioni biologiche diverse. Il sottogruppo Th1 è responsabile delle funzioni cellulo-mediate e della attivazione dei linfociti T-citotossici; mentre il sottogruppo Th2 è responsabile della regolazione dell'immunità umorale. ${ }^{26} \mathrm{Il}$ fenomeno della polarizzazione è alla base della risposta immunitaria ed in esso la predominanza di un tipo di citochine inibisce la proliferazione e la funzione di cellule capaci di produrre l'altro tipo di citochine (Th1/ Th2). Attual- mente è largamente condiviso il modello, proposto da Kourilsky e Truffa-Bianchi, ${ }^{27}$ in base al quale le cellule coinvolte in una specifica risposta immunitaria agiscono di concerto le une con le altre. Esso implica che, nonostante la loro differente attività funzionale, linfociti $\mathrm{T}$, cellule dendritiche, macrofagi, cellule NK ed NKT sono capaci di rispondere in maniera coordinata ad un dato stimolo antigenico. In effetti tutte queste cellule, ed anche quelle neuroendocrine, sono capaci di dare risposte polarizzate. Questo processo complesso e coordinato determina un field (ambiente) di citochine, caratterizzato dalla sintesi di gruppi di citochine e chemochine e dei loro specifici recettori e definibile come la concentrazione locale di più citochine presenti in un determinato sito dell'organismo. La regolazione coordinata dei geni che codificano per l'espressione delle citochine è fondamentale per ottenere una risposta sincrona ed uniforme. La regolazione genica è ottenuta tramite fattori trascrizionali (STAT 4, GATA 3), così come dalla presenza di fenomeni epigenetici (metilazione del DNA, rimodellamento cromatinico, acetilazione degli istoni). Attualmente sono descritti 4 field nei quali prevalgono rispettivamente Th0, Th1, Th2, Th17. Field citochinici polarizzati sono indotti, implementati e mantenuti da una combinazione di diversi tipi cellulari. Un determinato field citochinico confinato inizialmente nel sito di presentazione dell'antigene, può successivamente diffondere ad altri organi ed a tutto l'organismo. Alterazioni di questi meccanismi di controllo possono contribuire alla patogenesi di malattie autoimmunitarie. Un esempio è quello fornito dalla gravidanza che, normalmente, implica a livello fetoplacentare la prevalenza di un ambiente Th2, che in termini di reattività immunitaria dell'organismo tende a far aggravare malattie caratterizzate da una prevalente produzione di citochine Th2, quale il LES, oppure ad indurre la remissione dell'artrite reumatoide, malattie con prevalente profilo Th1. Attualmente gli studiosi hanno compreso molto circa i segnali innati che coordinano le risposte adattative. Accanto alle connessioni cellula-cellula, che forniscono segnali di attivazione, le cellule presentanti l'antigene comunicano con le cellule $\mathrm{T}$ attraverso la via di produzione delle citochine. Le cellule dendritiche presentanti l'antigene e i macrofagi, in conseguenza delle interazioni con diversi prodotti microbici, producono una varietà di questi fattori solubili che sono responsabili dell'espansione e differenziazione delle cellule T naive per generare le cellule Th1 e Th2. IL12 è considerata la citochina segnale prodotta dalle cellule del sistema innato che influenza l'immunità adattativa cellulo-mediata. Questa ha un ruolo centrale nel promuovere la differenziazione delle cellule $\mathrm{T}$ CD4+ naive in cellule effettrici Th1 e stimola le 
cellule NK e le cellule T CD8+ a produrre IFN $\gamma$. IL12 è richiesta per lo sviluppo di risposte adattative innate verso molti patogeni cellulari e data la sua importante funzione essa può risultare implicata nello sviluppo di varie condizioni autoimmuni. La scoperta delle IL-23 e IL-27, strettamente associate alla IL12 , ha modificato le prospettive sulle cause e la prevenzione delle malattie autoimmuni. In particolare, alcune di esse sono mediate da una nuova classe di cellule Th (Th17) associate ad alterati livelli di IL23 e IL-27. Ciò fornisce importanti implicazioni per lo sviluppo di nuove terapie per il trattamento di patologie autoimmuni organo specifiche. Poiché i livelli di IL-23 e IL-17 sono aumentati nelle malattie come: la sclerosi multipla, morbo di Crohn, psoriasi, fibrosi cistica, asma e le immunoartriti, ciò costituisce un target molto importante ai fini del trattamento di queste patologie. Studi sull'IL-27 hanno confermato che questa citochina ha attività peculiari sul sistema immunitario. Ci sono studi da quali emerge chiaramente una sua attività proinfiammatoria, però ci sono anche numerose evidenze, su modelli murini, che indicano un suo ruolo dominante nella soppressione dell'iperattività immunitaria. Queste conoscenze sono utili per nuove strategie terapeutiche atte a sopprimere risposte immunitarie inappropriate. ${ }^{28-30}$

\section{Il TNF- $\alpha$}

Il fattore di necrosi tumorale $\alpha(\mathrm{TNF} \alpha)$ è una citochina che induce e stimola la fase acuta della flogosi. I macrofagi sono i maggiori produttori di TNF $\alpha$ sebbene altre cellule possono produrre questa citochina (Linfociti T CD4+, cellule NK, neutrofili, mastociti, eosinofili e neuroni). È ormai riconosciuto al TNF un ruolo centrale nella regolazione dell'immunoflogosi; il TNF viene talvolta definito anche cachessina, cachectina o TNF- $\alpha$. Può indurre febbre, morte apoptotica delle cellule, cachessia, infiammazione; può inibire la carcinogenesi e la replicazione virale, in caso di sepsi induce la produzione cellulare di IL-1 e IL-6. Alterazioni della produzione di TNF$\alpha$ sono implicate nell'eziopatogenesi delle IMID. ${ }^{31,32}$ Il Tumor Necrosis Factor- $\alpha$ svolge un ruolo fondamentale nel sistema immunitario, inducendo la lisi delle cellule bersaglio e confinando il processo flogistico. La produzione del TNF- $\alpha$ ed il suo rilascio nella sede della flogosi comporta una attivazione localizzata dell'endotelio vascolare, il rilascio di NO con vasodilatazione e aumento della permeabilità vascolare; inoltre aumenta l'espressione delle molecole di adesione sulle cellule dell'endotelio vascolare e l'espressione delle molecole del tipo MHC II. Il risultato finale consiste nel reclutamento a livello della lesione di cellule infiammatorie, immunoglobuline e complemento. Il TNF- $\alpha$ agisce anche sulla adesività piastrinica, favorendo la formazione del trombo e l'occlusione dei vasi e, quindi, il contenimento dell'infezione e la necrosi tissutale (da ciò deriva la sua denominazione). L'attività biologica del TNF- $\alpha$ è mediata dal suo legame a due differenti tipi di recettore p55 e p75 presenti su cellule, quali neutrofili, cellule dell'endotelio vascolare e fibroblasti. La forma solubile dei due tipi di recettore, presente nel siero e nel fluido sinoviale, svolge un ruolo regolatore dell'attività biologica, che se rimane circoscritta alla sede della flogosi può essere benefica, ma che a livello sistemico può divenire disastrosa perché innesca manifestazioni cliniche quali, shock settico e CID. Il TNF è prodotto da un singolo gene localizzato sul cromosoma 6 all'interno del locus per l'MHC e viene sintetizzato come omotrimero successivamente clivato proteolicamente ed immesso in circolo, si lega al suo recettore (ce ne sono due) a bassa affinità, tuttavia il TNF viene sintetizzato in grandi quantità, quindi satura facilmente il suo recettore. Il TNF aumenta localmente l'espressione di molecole di adesione sulla superficie delle cellule endoteliali vascolari, facilita lo stravaso dei leucociti nel sito di infezione, attiva i leucociti travasati e stimola i fagociti mononucleati a produrre Chemochine, le quali contribuiscono al Reclutamento Linfocitario; inoltre il TNF induce la Co-stimolazione dei linfociti $\mathrm{T}$ e la produzione di immunoglobuline; stimola la sintesi di CSF; aumenta l'espressione di molecole MHC classe I; agisce come fattore angiogenetico per la neoformazione di capillari, e come fattore di crescita per i fibroblasti favorendo la deposizione di tessuto connettivo. Il TNF è un pirogeno endogeno, agisce sulle regioni regolatorie ipotalamiche inducendo la sintesi di prostaglandine e quindi ipertermia; stimola $\mathrm{i}$ fagociti mononucleati a produrre IL-1 e IL-6; stimola gli epatociti a produrre le Proteine di Fase Acuta; attiva la Coagulazione; inibisce la replicazione delle cellule staminali del midollo osseo (la somministrazione cronica di TNF può quindi indurre immunodeficienza). La somministrazione prolungata di TNF provoca soppressione dell'appetito, distruzione progressiva di adipociti e cellule muscolari (Cachessia), per questo motivo chiamato cachessina. Ad alte dosi riduce la perfusione tissutale in seguito a depressione della contrattilità miocardica, con riduzione della Pressione Arteriosa, rilascio del tono della muscolatura liscia vasale, stimolando la produzione da parte dell'endotelio di sostanze vasodilatatrici come l'ossido nitrico (NO). Dosi crescenti di TNF causano effetti progressivamente più pericolosi quali Trombosi intravascolare e CID, gravi disturbi metabolici e insulino-resistenza. Il TNF stimola vari mediatori: IL-1, IL-6, GM-CSF, PDGF, IFN, TGF- $\beta$, Prostaglandine, Leucotrieni, ACTH, Adrenalina, Noradre- 
nalina, Glucagone; inoltre può avere un ruolo nel processo apoptotico, in quanto va ad agire sui mitocondri, alterandone la permeabilità e l'omeostasi elettrochimica. ${ }^{31}$

\section{Interluechine}

\section{Interleuchina-1}

Prima citochina ad essere scoperta è prodotta dai Fagociti Mononucleati, Monociti/ Macrofagi in risposta a LPS, TNF, dai linfociti T CD4, e anche da cellule epiteliali ed endoteliali; sono prodotte due forme di IL-1, denominate IL-1 $\alpha$ e IL- $1 \beta$, rispettivamente da due geni diversi; hanno una omologia strutturale del $30 \%$, ma la loro attività biologica è praticamente identica. Entrambe sono sintetizzate come precursori di $33 \mathrm{kd}$, successivamente clivate proteoliticamente per ottenere la forma matura di 17 $\mathrm{Kd}$. Sia IL- $1 \alpha$ che IL- $1 \beta$ si legano agli stessi recettori di membrana. Sono descritti due diversi recettori di membrana: il P80, IL-1 RT 1 (recettore di tipo I) che ha un'affinità lievemente maggiore per IL-1 $\beta$ rispetto che per IL-1 $\alpha$, è espresso da linfociti T, fibroblasti, epatociti e cellule endoteliali e rappresenta il principale recettore per le risposte mediate da IL-1; il P68, IL-1 RT 2 (recettore di tipo 2) che ha un'affinità lievemente maggiore per IL-1 $\alpha$ ed è presente sulla membrana dei linfociti $\mathrm{B}$, monociti, macrofagi e neutrofili. L'attività biologica principale della citochina IL-1 è svolta da IL-1 $\beta$ che si lega appunto al recettore di tipo I, il quale è in grado di trasdurre il segnale. IL-1 $\beta$ può legarsi anche al recettore di tipo II che però non è in grado di trasdurre il segnale in quanto sottrae IL $1 \beta$ dal legame col recettore di tipo I. Vi è poi una terza molecola, prodotta dai $\mathrm{Fa}-$ gociti Mononucleati, strutturalmente omologa a IL1 (e quindi in grado di legarsi ai suoi stessi recettori), ma funzionalmente inattiva. Essa agisce quindi da inibitore competitivo di IL-1 e viene detta IL-1 RA (cioè IL-1 Receptor Antagonist). IL-1 a basse dosi favorisce l'infiammazione locale, agisce sulle cellule endoteliali favorendo la coagulazione, aumenta l'espressione di molecole di adesione, provoca il rilascio di chemochine che reclutano altri leucociti sul luogo dell'infiammazione, stimola la proliferazione dei CD 4+, stimola la crescita e il differenziamento dei linfociti B e la risposta di molte cellule effettrici. IL-1 ad alte dosi entra nel circolo ematico ed agisce quindi con un meccanismo di tipo endocrino, è un pirogeno endogeno, stimola la sintesi di proteine di fase acuta, induce cachessia. A differenza del TNF, IL-1 non provoca danno tissutale (sebbene sia secreta in risposta ad LPS), non è letale, non elimina le cellule tumorali, non aumenta l'espressione di molecole MHC I, potenzia, anziché sopprimere l'azione dei
CSF sul midollo, quindi stimola la replicazione delle cellule staminali midollari. È il più potente stimolo mitogeno per le cellule T. ${ }^{33}$

\section{Interleuchina-2}

In un primo tempo definita Fattore di Crescita dei linfociti $T$ ha una duplice funzione, agisce come fattore di crescita per i linfociti $\mathrm{T}$ ed agisce anche come fattore di trascrizione per se stessa, ovvero è capace di attivare la trascrizione dei geni che codificano per la produzione ulteriore di IL-2 e del suo recettore. Il linfocita $\mathrm{T}$ attivato comincia a produrre notevoli quantità di questa citochina e se ne auto-alimenta con un meccanismo di tipo autocrino. È prodotta da Linfociti $\mathrm{T}$ attivati ed è diretta a Linfociti $\mathrm{T}$, Linfociti B, Cellule NK, in risposta ad uno stimolo antigenico. Sono descritti due diversi recettori per IL-2, il p55: IL-2 R $\alpha$, che ha una affinità di 10-8 M ed il p70: IL-2 R $\beta$, che ha una affinità di 10-9 M. I linfociti T Resting, cioè quiescenti, esprimono sulla loro superficie il recettore IL-2R $\beta$ insieme ad un altro polipeptide denominato catena $\gamma$. Si forma quindi un complesso: IL-2R $\beta \gamma$ che ha però un'affinità piuttosto bassa per IL-2, cioè solo $10-9 \mathrm{M} .^{34}$ Sono dunque necessarie elevate quantità di citochina per poter stimolare il linfocita T quiescente. IL-2 svolge principalmente le seguenti azioni biologiche: è fattore di crescita autocrino per i linfociti $\mathrm{T}$, stimola la sintesi di altre citochine, quali INF $\gamma$ e LT (linfotossina), stimola la crescita delle cellule NK, potenziando la loro azione citotossica e generando le cosiddette LAK (Lymphokine Activated Killer), stimola la proliferazione delle cellule B e la produzione di anticorpi, promuove l'apoptosi delle cellule T. Può sembrare paradossale che l'IL-2 agisca sui linfociti T sia come Fattore di Crescita che come Fattore di Morte, ma va considerato che queste azioni si verficano a stadi diversi di attivazione della cellula e non contemporaneamente e che l'effetto pro-apoptotico di IL-2 avviene in combinazione con altri segnali quali il Fas.

\section{Interleuchina-4}

IL-4 è stata inizialmente definita $B$ cell growth factor (BCGF) o B cell differentiating factor (BCDF) per la sua attività stimolatoria e pro-differenziativa nei confronti dei linfociti $\mathrm{B}$. Essa è stata successivamente riconosciuta come una citochina pleiotropica in grado di modulare la risposta immune agendo su vari tipi cellulari, come linfociti $\mathrm{T}$, linfociti $\mathrm{B}$, macrofagi, cellule endoteliali ed altri. È prodotta dalle cellule T CD4 e CD8, dai timociti e dalle cellule non immunocompetenti quali granulociti basofili e timociti. IL-4 è una glicoproteina del peso molecolare di circa $20 \mathrm{kDa}$, è costituita oltre che da gruppi glicosi- 
dici da sei residui cisteinici, che formano legami disolfuro, la cui riduzione determina la perdita dell'attività biologica. Il recettore per IL-4 è espresso sulla superficie di molte cellule di derivazione emopoietica (cellule T, cellule B, mastociti) e su altri tipi cellulari, quali cellule epatiche, cellule muscolari. IL-4 svolte molte funzioni, tra le quali l'induzione della crescita e differenziazione delle cellule Th2, l'incremento dell'espressione degli antigeni MHC classe II sulle cellule B, l'induzione dello switch isotipico per la sintesi di $\operatorname{IgE}$ ed IgG 4 nei linfociti B, l'inibizione della produzione di IL-6, IL-1 TNF- $\alpha$ ed IL- $8 .^{30}$ Inoltre partecipa nel richiamo di cellule della flogosi attraverso la modulazione dell'espressione di molecole di adesione (V-CAM-1) sulle cellule endoteliali dei vasi.

\section{Interleuchina-6}

IL-6 è stata inizialmente descritta come fattore solubile con molteplici attività, in quanto si presentava come fattore stimolante gli epatociti, fattore di stimolazione dei linfociti B. IL-6 è prodotta da numerosi tipi cellulari quali i fagociti mononucleati, le cellule endoteliali, i linfociti T e B, gli astrociti, i fibroblasti, le cellule stromali midollari, i cheratinociti ed alcune cellule tumorali. La IL-6 presenta un peso molecolare variabile tra 22 e $29 \mathrm{kD}$ ed agisce attraverso un recettore specifico, il CD126, formato da una catena polipeptidica responsabile del legame alla molecola e da una seconda catena deputata alla trasduzione del segnale attivatorio all'interno della cellula. IL-6 rappresenta l'attivatore principale della differenziazione dei linfociti in plasmacellule e cellule produttrici di IgA, di indurre il ciclo cellulare nei progenitori emopoietici, ${ }^{35}$ megacariocitopoietici, mielopoietici e di stimolare gli epatociti a produrre proteine della fase acuta. Infatti, dato che elevati livelli di IL-6 sono spesso correlati con concentrazioni di Proteina C Reattiva (CRP) elevate si è ipotizzato che IL-6 fosse il principale stimolatore delle cellule epatiche per la sintesi di tale proteina. Elevati livelli di IL-6 possono sia essere predittivi di malattie cardiovascolari che essere elevati in pazienti con angina instabile. Per tale motivo IL-6 come CRP sono considerati marcatori di infiammazione. Tali marcatori sono utilizzati in clinica, non solo per stratificare il rischio ma anche per identificare i pazienti che possono trarre un beneficio da una terapia adeguata. IL6 è anche una delle interleuchine che si riscontrano nel processo di aterosclerosi. Infatti, determinati studi effettuati su topi hanno messo in evidenza che la presenza di IL-6 nelle placche sia utile nella progressione delle stesse. Il ruolo della IL-6 nell'aterosclerosi appare comunque bivalente. IL-6 è una citochina pro-infiammatoria ma nell'aterosclerosi può presentare anche capacità antiinfiammatorie in quanto induce la sintesi di IL1-RA e rilascia TNF R solubile riducendo così l'effetto delle citochine proinfiammatorie. ${ }^{36}$

\section{Interleuchina-7}

È una citochina prodotta da cellule stromali dalla quale dipende lo sviluppo dei linfociti B e T. È fattore di crescita ed antiapoptotico per i precursori dei linfociti B e T, essenziale per la differenziazione dei linfociti T con TCR $\gamma-\delta$. Funziona, inoltre, come cofattore durante la mielopoiesi ed è capace di attivare i monociti/macrofagi ed i linfociti NK. Il suo recettore è un eterodimero costituito da una catena $\alpha$, che lega IL-7 e da una catena gamma, componente comune al recettore di IL-2, IL-4, IL-9, IL-15. Dati sperimentali suggeriscono che, anche nell'uomo, IL-7 potrebbe agire come fattore stimolante la leucopoiesi, dato che riveste grande importanza nel trattamento dei pazienti trapiantati di midollo osseo.

\section{Interleuchina-8}

L'IL-8 o CXCL8 è una chemochina, prodotta dall'endotelio vascolare, appartenente alla famiglia CXC o $\alpha$-chemochine, ed in particolare alla sottofamiglia ELR caratterizzata dalla presenza di acido glutammico-leucina-arginina, in prossimità della porzione $\mathrm{N}$-terminale che esplica attività angiogenica. Essendo proteine basiche, la struttura delle chemochine è caratterizzata da quattro cisteine che danno origine a due ponti di solfuro. Questo motivo strutturale determina una struttura tridimensionale cruciale per l'interazione col recettore. IL-8 presenta una struttura dimerica essenziale per il legame funzionale col suo recettore e, inoltre, favorisce e stabilizza il legame con molecole complesse quali i glicosaminoglicani. L'attività biologica dell'IL-8 è dovuta all'attivazione di recettori di membrana di tipo rodopsinico caratterizzati da sette domini transmembrana, a loro volta associati a proteine $\mathrm{G}$ eterotrimeriche la cui attivazione causa l'aumento di concentrazione di calcio intracellulare. Attualmente sono stati riconosciuti cinque recettori per le chemochine appartenenti alla famiglia CXC, meglio identificati CXCR-1/CXCR-5. Oltre a richiamare i leucociti nella regione di flogosi, IL-8 induce degranulazione dei neutrofili e adesione dei polimorfonucleati all'endotelio. Recenti studi hanno evidenziato una corrispondenza diretta tra elevati livelli plasmatici di IL-8 ed aumentato rischio di malattie cardiovascolare in pazienti apparentemente sani. Attualmente sono stati riconosciuti cinque recettori per le chemochine appartenenti alla famiglia CXC, meglio identificati CXCR-1/CXCR-5. Oltre a richiamare i leucociti nella regione di flogosi, IL-8 induce degranulazione dei neutrofili e adesione dei polimorfonucleati all'endotelio. ${ }^{37}$ 


\section{Interleuchina-10}

È una citochina pleiotropica che regola varie funzioni nelle cellule emopoietiche. È stata identificata come prodotta dai linfociti Th2 in quanto capace di inibire la risposta Th1 ed in particolare la produzione di IFN- $\gamma$. La sua principale caratteristica è quella contenere ed inibire le reazioni infiammatorie, contribuendo a facilitare l'eliminazione del patogeno dall'organismo ospite che, quindi, subisce un danno minimo. IL-10 ha un ruolo importante anche nella tolleranza immunitaria, nello sviluppo dei linfociti $\mathrm{T}$ e nel differenziamento dei linfociti B. IL-10 ha dimostrato di poter essere utilizzata per scopi terapeutici, così come i suoi antagonisti biologici. Importanti caratteristiche biologiche della IL-10 devono essere ancora chiarite: differenti tipi di recettore possono spiegare i diversi effetti biologici sui monociti/macrofagi e CD4+ e sui linfociti B e T CD8+. I dati sperimentali raccolti da modelli in vivo di malattie autoimmunitarie, neoplasie, e trapianti di organo rivelano che IL-10 può produrre differenti risultati in relazione al tempo, al livello ed alla localizzazione della sua espressione. In alcune condizioni si osserva l'atteso effetto immunosoppressivo, in altri un ampliamento della risposta immunitaria ed infiammatoria. ${ }^{37}$ Infine, è tutta da valutare la potenziale efficacia terapeutica di IL-10 in aggiunta a farmaci immunomodulanti, in modo da ottenere efficacia terapeutica e minimi effetti collaterali.

\section{Interleuchina-15}

È un polipeptide di $15 \mathrm{kDa}$ appartenente alla famiglia delle citochine che possiedono 4 domini $\alpha$ elica. La sua espressione è controllata a livello trascrizionale, del trafficking intracellulare e posttrascrizionale da parte di differenti elementi segnale. IL-15 utilizza due differenti recettori che rispondono a due differenti vie di trasduzione del segnale: una parzialmente in comune con IL-2 presente nei linfociti $\mathrm{T}$ ed NK e l'altra specifica presente nei monociti-macrofagi. In questi tipi cellulari il segnale di IL-15 vie trasdotto preferibilmente tramite Jak2STAT5, mentre nelle cellule $\mathrm{T}$ attivate tramite Jak1/Jak3 e STAT5/STAT3. IL-15 svolge un ruolo essenziale nello sviluppo, e nelle attività biologiche delle cellule NK. ${ }^{38}$

\section{Interleuchina-18}

Èstrutturalmente omologa ad IL-1 ed il suo recettore appartiene alla superfamiglia dei recettori del tipo IL-1R Toll-like, ma è funzionalmente molto differente da IL-1. Il suo recettore è presente su molteplici istotipi, è strutturalmente costituito da due componenti (IL-18 R $\alpha$-binding chain, e IL-18 R $\beta$-signaling chain) entrambi appartenenti alla famiglia degli IL-1R. Sulle cellule NK la sintesi di IFN- $\gamma$ è stimolata da IL-18 e IL-12, il cui segnale di legame al recettore viene trasdotto attraverso la stessa via (IRAK-TRAF6). IL-18 ha molteplici effetti biologici: induce la produzione di IFN- $\gamma$ nelle cellule NK (attività antitumorale), B, CD8, macrofagi; è potente induttore di NO, mostrando attività antimicrobica nei confronti dei patogeni intracellulari. La somministrazione di LPS da $P$. acnes, stimola le cellule di Kupffer a produrre IL-18, che attraverso l'induzione di aptoptosi Fas-L dipendente, produce danno tissutale a livello epatico. Dal momento che IL-18 è capace di indurre la produzione di chemochine di tipo CC e CXC e IL- $1 \beta$ e TNF- $\alpha$, essa svolge un ruolo particolarmente efficace nell'infiammazione. IL-18 è prodotta da cellule del sistema immunitario e da cellule che di esso non fanno parte. È costituita da un singolo peptide di 193 aa., di PM 18.000. È sintetizzata da un gene che è localizzato sul cromosoma 11q22.2-22.3. IL-18 mRNA è presente in vari tipi cellulari: cellule di Kupffer, macrofagi, B e T linfociti, cellule dendritiche,osteoblasti, cheratinociti, astrociti, microglia. Da sola IL-18 è capace di stimolare la produzione di citochine di tipo Th2 (IL-4, IL13) e le reazioni allergiche. IL-18 regola l'attività citotossica delle cellule NK e dei linfociti T. Nei macrofagi IL-18 stimola la produzione di IFN- $\gamma$, così come nei linfociti T, B ed NK; in maniera coordinata con IL-12, IL-18 stimola la risposta immunitaria mediata da Th1, la eccessiva produzione di IL-12 ed IL18 induce flogosi e fa ritenere IL-18 una potente citochina proinfiammatoria. Questa citochina è prodotta da vari tipi cellulari che non appartengono solo al sistema immunitario, come i cheratinociti. IL-18 in forma attiva è prodotta per azione della caspasi-1 (ICE) o della caspasi-3 (PR3). ${ }^{39}$

\section{Interleuchina-17/23}

Riguardo la patogenesi delle malattie autoimmuni ultimamente l'attenzione e stata focalizzata su 2 nuove citochine, IL-17 e IL-23. IL-17 viene prodotta dai linfociti T-helper 17, una linea cellulare T diversa dai linfociti TF1 a TF2 prodotta da cellule T naive, l'IL-23 è prodotta dai linfociti $\mathrm{T}$ helper 17. È stato ipotizzato che agenti microbici, alterazioni del micro bioma intestinale e stress biomeccanico, possano portare ad una up-regolazione di IL-23 prodotta a sua volta dalle cellule dendritiche che svolgono un ruolo fondamentale nella differenziazione e nell'attivazione dei linfociti $\mathrm{T}$ helper 17. Tra le varie interleuchine, IL-6, IL-20, e TGF $\beta$ sono fondamentali per la differenziazione, IL-17, IL-21, IL-22, IL-10 e IL1 $\beta$ per l'amplificazione, e IL-23 per la stabilizzazione. IL-23 fa parte della famiglia dell'interleuchina 12 ed è una citochina eterodimerica formata dalla subunita p40 e dalla subunita $\mathrm{p} 19$. IL-23 è principalmente prodotta dalle cellule dendritiche e svolge un ruolo fon- 
damentale nella maturazione degli osteoclasti e nel mantenimento della massa ossea, anche se da sola non è sufficiente ad indurre l'osteoclastogenesi. Successivamente all'attivazione dei linfociti T helper 17, tali cellule sono in grado quindi di produrre interleuchine quali IL-17A, IL-17F, IL-22, IL-26, CCL20. La famiglia della IL-17 e caratterizzata da 6 membri ed in particolare sono state studiate IL-17A e IL-17F che sono prodotte non solo dai linfociti $\mathrm{T}$ helper 17 ma anche da altre cellule, in particolare dai neutrofili, mastociti, macrofagi, cellule natural killer e linfociti $\mathrm{T}$ citotossici. ${ }^{40} \mathrm{Il}$ suo recettore è localizzato in particolare su macrofagi, neutrofili, cheratinociti, cellule endoteliali, fibroblasti, osteoblasti, osteoclasti e condrociti, e quando attivato determina la secrezione di citochine pro-infiammatorie e chemochine e di conseguenza infiammazione, iperproliferazione dei cheratinociti, distruzione della matrice e danno cartilagineo. I linfociti T helper 17 producono anche l'IL-22, che fa parte della famiglia dell'IL-10 ed induce il rilascio di peptidi antimicrobici e metalloproteasi da parte dei fibroblasti, delle cellule endoteliali, epiteliali, degli osteoblasti, dei macrofagi e delle cellule dendritiche. A livello cutaneo IL-17, IL-22 e IL20 attivano la via del segnale STAT3 a livello dei cheratinociti, inducendone la loro iperproliferazione e l'espressione di citochine pro-infiammatorie, fattori di crescita, peptidi antimicrobici e metalloproteasi che causano infiammazione cutanea e psoriasi. A livello articolare, IL23, TNF $\alpha$ e IL17 attivano il pathway dell'NFk $\beta$, con conseguente aumento dell'espressione di RANKL, promuovendo pertanto l'osteoclastogenesi e l'assorbimento osseo e la conseguente comparsa di artrite. ${ }^{41}$ In un interessante studio condotto nel 2012 in vitro da Sherlock (Nat Med. 2012 Jul 1;18(7):1069-76. doi: 10.1038/nm.2817), si dimostra che l'IL-23 era un'interleuchina essenziale nell'entesite, in quanto promuoveva la produzione di altre citochine infiammatorie (in particolare IL-6, IL-17 e IL-22) con conseguente entesite e nuova formazione ossea anche in completa assenza di sinovite. Tale schema e stato poi riprodotto da McInnes in uno studio condotto su pazienti affetti da spondilite anchilosante (Nat Med. 2012 Jul 6;18(7):1018-9. doi: $10.1038 / \mathrm{nm} .2854)$, secondo cui un'up-regolazione dell'IL-23 porta ad attivazione e differenziazione dei linfociti $\mathrm{T}$ helper 17, con conseguente produzione di IL-17, implicata soprattutto nell'erosione ossea, e IL22, implicata nell'osteoproliferazione, due processi opposti che si ritrovano nelle spondiloartriti. L'asse IL-23/IL-17 svolge pertanto un ruolo fondamentale nei processi di infiammazione articolare, infiammazione cutanea ed entesite e questo è stato dimostrato da diversi studi genetici, studi condotti su animali, studi preclinici e clinici. Recenti studi di as- sociazione genomewide hanno dimostrato come alcuni geni implicati nella produzione di IL-17 siano suscettibili per le spondiloartriti. Studi invece su modelli animali hanno dimostrato come IL-17 determini infiammazione sinoviale e distruzione delle articolazioni, e come l'entesite sia specificamente dipendente dalla presenza di IL-17A e IL-22. Per quanto riguarda invece l'ileite, IL-17A ha mostrato un effetto patogenetico, mentre IL-22 un effetto protettivo. In uno studio effettuato su pazienti affetti da artrite psoriasica (Mol Cell Biochem. 2012 Jan;359(1-2):419-29. doi: 10.1007/s11010-011-1036-6), è stato dimostrato come aumentati livelli di IL-17A siano presenti sia in pazienti con artrite psoriasica che in pazienti con artrite reumatoide e che tale aumento mostra una differenza statisticamente significativa rispetto a pazienti con osteoartrite. ${ }^{42}$ È stato inoltre dimostrato che in pazienti con artrite psoriasica IL-17A promuove la produzione di IL-8, IL-6 e metalloproteasi. Lo scenario delle spondiloartriti e pertanto uno scenario citochinico complesso caratterizzato quindi da osteoproliferazione, distruzione della cartilagine, erosione ossea, entesite, sinovite ed anche lesioni cutanee, ed in tale scenario l'asse IL-17/23 è coinvolto in diversi processi, in particolare nella psoriasi, entesite, distruzione ossea e nuova formazione ossea.

\section{Conclusioni}

Le IMID (immunomediated inflammatory diseases) sono condizioni cliniche distinte per sintomatologia, agenti eziologici, organi o apparati interessati, ma con comune meccanismo patogenetico, l'immunoflogosi. Le IMID sono numerose e spaziano dalla patologia autoimmune alle immunodeficienze: le allergopatie, le vasculiti, la sarcoidosi, le immunoartriti, le gastroenteriti e tante altre; tutte però hanno un denominatore comune, la disregolazione del Sistema Immunitario. In queste malattie vi è sempre l'interazione tra fattori genetici e ambientali che attraverso la disregolazione del Sistema Immunitario, innescato da una causa spesso non nota, attiva il complesso meccanismo dell'immunoflogosi che realizzerà la sintomatologia clinica nelle diverse condizioni. La conoscenza avanzata, ma ancora parziale degli intimi meccanismi dell'immunoflogosi nelle IMID e la scoperta di numerose citochine, chemochine e molecole di adesione, che svolgono importanti attività biologiche, ha concretizzato la possibilità di realizzare molecole biotecnologiche dirette contro specifici mediatori dell'infiammazione disponendo quindi di una terapia per malattie che fino ad un recente passato risultavano orfane di un efficace trattamento. Il completo riconoscimento di tutti gli attori che regolano la immunoflogosi servirà in futuro ad aumentare le possibilità terapeutiche 
nelle IMID, consentendo al clinico di agire efficacemente e in sicurezza.

\section{Bibliografia}

1. Angiari S. Donnarumma t. et al TIM-1 glygoproyein binds the adhesion receptor P-selectin and mediates tcell. Immunity 2014 Apr 201417 (40)4 542 -53

2. J.C. Buckingham, R.J. Flower, Lipocortin 1: a second messenger of glucocorticoid action in the hypothalamopituitary-adrenocortical axis, "Molecular Medicine Today”, 1977, 3, pp. 296-302.

3. J. Di Donato et al., A cytokine-responsive IkB kinase that activates the transcription factor NF-kB, "Nature", 1997, 388, pp. 548-54.

4. J.C. Fantone, P.A. Ward, Inflammation, in Essential pathology, ed. E. Rubin, J.L. Farber, Philadelphia, Lippincott, 19952, pp. 32-66.

5. Inflammation. Basic principles and clinical correlates, ed. J.I. Gallin et al., New York, Raven Press, 1988.

6. A. Israel, IkB kinase all zipped up, "Nature", 1997, 388, pp. 519-21.

7. Zhang J, Wang CM, Zhang P, Wang X, Chen J, Yang J, Lu W, Zhou W, Yuan W, Feng Y. Expression of programmed death 1 ligand 1 on periodontal tissue cells as a possible protective feedback mechanism against periodontal tissue destruction. Mol Med Rep. 2016 Mar;13(3):242330. doi: 10.3892/mmr.2016.4824. Epub 2016 Jan 28.

8. Hubmacher D, Apte SS The biology of the extracellular matrix: novel insights. Curr Opin Rheumatol. 2013 Jan;25(1):65-70. doi: 10.1097/BOR.0b013e32835b137b.

9. Cromar GL, Xiong X, Chautard E, et al. Toward a systems level view of the ECM and related proteins: a framework for the systematic definition and analysis of biological systems. Proteins. 2012;80:1522-1544.

10. Doyle JJ, Gerber EE, Dietz HC. Matrix-dependent perturbation of TGFbeta signaling and disease. FEBS Lett. 2012;586:2003-2015.

11. Hattori N, Carrino DA, Lauer ME, et al. Pericellular versican regulates the fibroblast-myofibroblast transition: a role for ADAMTS5 protease-mediated proteolysis. J Biol Chem. 2011;286:34298-3431

12. Antipova O, Orgel JP. Nonenzymatic decomposition of collagen fibers by a biglycan antibody and a plausible mechanism for rheumatoid arthritis. PLoS One. 2012; 7:e32241

13. Trappmann B, Gautrot JE, Connelly JT, et al. Extracellular-matrix tethering regulates stem-cell fate. Nat Mater. 2012;11:642-649

14. Ihn H1 Pathogenesis of fibrosis: role of TGF-beta and CTGF. Curr Opin Rheumatol. 2002 Nov;14(6):681-5.

15. Chujo S, Shirasaki F, Kawara S, Inagaki Y, Kinbara T, Inaoki M, Takigawa M, Takehara K. Connective tissue growth factor causes persistent proalpha2(I) collagen gene expression induced by transforming growth factorbeta in a mouse fibrosis model. J Cell Physiol. 2005 May;203(2):447-56.

16. Leask A, Abraham DJ. The role of connective tissue growth factor, a multifunctional matricellular protein, in fibroblast biology. Biochem Cell Biol. 2003 Dec;81 (6):355-63.
17. Saldanha C Physiological role of erythrocyte nitric oxide. Clin Hemorheol Microcirc. Clin Hemorheol Microcirc. 2016 Oct 20. [Epub ahead of print]Pub MedEur Rev Med Pharmacol Sci. 2016 Oct;20(20):4277-4285.

18. Wu JJ, Zhu YT, Hu YM. Mechanism of feedback regulation of neutrophil inflammation in Henoch-Schönlein purpura. Eur Rev Med Pharmacol Sci. 2016 Oct;20(20): 4277-4285.

19. Kersul AL, Iglesias A, Ríos Á, Noguera A, Forteza A, Serra E, Agustí A, Cosío BG Molecular mechanisms of inflammation during exacerbations of chronic obstructive pulmonary diseaseArch Bronconeumol. 2011 Apr;47(4):176-83. doi: 10.1016/j.arbres.2010.12.003. Epub 2011 Mar 31.

20. Karadag F, Kirdar S, Karul AB, Ceylan E. The value of $\mathrm{C}$-reactive protein as a marker of systemic inflammation in stable chronic obstructive pulmonary disease. Eur J Intern Med. 2008 Mar;19(2):104-8. doi: 10.1016/j.ejim. 2007.04.026.

21. You-Sun Kim ,Michael J. Morgan, Swati Choksi,Zhenggang Liu Tumor necrosis factor signaling, in Cell Death and Differentiation, vol. 10, 2003, pp. 45-65, PMID 12655295

22. Chen G, Goeddel DVTNF-R1 signaling: A beautiful pathway, in Science, vol. 296, 2002, pp. 1634-5

23. Gaur U, Aggarwal BB.Regulation of proliferation, survival and apoptosis by members of the TNF superfamily, in Biochemical Pharmacology, vol. 66, 2003, pp. 1403-140

24. Kaushansky K. Hematopoietic Growth Factors, signaling and chronic myeloproliferative disorders. Cytokine Growth Factor Rev 2006; 17 (6) : 423-30

25. Aggarwal B.B., Puri R.K. Common and uncommon features of cytokines and cytokine receptors: an overview. pp. 3-24. In Human cytokines: their role in disease and therapy. Blackwell Sci., Cambridge Mass., 1995

26. Constant S.L., Bottomly K. Induction of TH1 and TH2 CD4+ T cell respons $\neg$ es: the alternative approaches. Annu. Rev. Immunol. 1997; 15:297-322

27. Kourilsky P, Truffa-Bianchi P. Cytokine fields and the polarization of the immune system. Trends Immunol. 2001; 22 :502-09

28. Kastelein RA, Hunter CA, Cua DJ. Discovery and biology of IL-23 and IL-27: related but functionally distinct regulators of inflammation. Annu Rev Immunol 2007, 25: $221-42$

29. Steinman L. A brief history of $\mathrm{T}(\mathrm{H}) 17$, the first major revision in the $\mathrm{T}(\mathrm{H}) 1 / \mathrm{T}(\mathrm{H}) 2$ hypotesis of $\mathrm{T}$ cell mediated tissue damage. Nat Med 2007; 13:139-45

30. Hooks J. Cytokines, Chemokines and Adhesion molecules. In Manual of Clinical Immunology, VI ed, pp. 319-375. Rose NR, Hamilton RG, Detrick B (eds), ASM, Washington DC, 2002

31. Locksley RM, Killeen N, Lenardo MJ, The TNF and TNF receptor superfamilies: integrating mammalian biology, in Cell, vol. 104, nº 4, 2001, pp. 487-501.

32. Blandizzi C, Gionchetti P, Armuzzi A, Caporali R, Chimenti S, Cimaz R, Cimino L, Lapadula G, Lionetti P, Marchesoni A,Marcellusi A, Mennini FS, Salvarani C. The role of tumour necrosis factor in the pathogenesis of immune-mediated diseases. Int J Immunopathol Pharmacol.2014 Jan-Mar;27(1 Suppl):1-10.

33. Smirnova MG, Kiselev SL, Gnuchev NV, Birchall JP, Pearson. "Role of the pro-inflammatory cytokines tumor 
necrosis factor-alpha, interleukin-1 beta, interleukin- 6 and interleukin-8 in the pathogenesis of the otitis media with effusion". Eur. Cytokine Netw. 200313 (2): 161-72

34. Gaffen S.L. and Liu K.D. "Overview of interleukin-2 function, production and clinical applications" Cytochine 28 (2004) 109-123

35. J. Wolf, S. Rose-John; C. Garbers, Interleukin-6 and its receptors: a highly regulated and dynamic system., in Cytokine, vol. 70, $\mathrm{n}^{\mathrm{o}}$ 1, novembre 2014, pp. 11-20

36. Jones SA, Directing transition from innate to acquired immunity: defining a role for IL-6, in J. Immunol., vol. $175, n^{\circ} 6,2005$, pp. 3463-8.

37. Bacon K, Baggiolini M, Broxmeyer H, Horuk R, Lindley I, Mantovani A, Maysushima K, Murphy P, Nomiyama H, Oppenheim J, Rot A, Schall T, Tsang M, Thorpe R, Van Damme J, Wadhwa M, Yoshie O, Zlotnik A, Zoon K, Chemokine/chemokine receptor nomenclature, in J. Interferon Cytokine Res., vol. 22, $\mathrm{n}^{\mathrm{o}}$ 10, ottobre 2002, pp. 1067-8
38. Budagian V. et al. IL-15/IL-15 receptor biology: A guided tour through an expanding universe. Cytokine \& Growth Factor Reviews, 17:259, 2006

39. Gerdes N, Sukhova GK, Libby P. et al. Expression of IL18 and functional IL-18R on human vascular endothelial cells, smooth muscle cells and macrophages: implication for atherogenesis. J Exp Med 2002; 195:245-57

40. Weaver CT, Hatton RD, Mangan PR, Harrington LE. IL17 family cytokines and the expanding diversity of effector T cell lineages. Annu Rev Immunol 2007; 25: 821-52

41. Raychaudhuri SP, Raychaudhuri IL-23/IL-17 axis in spondyloarthritis-bench to bedside. Clin Rheumatol 2016 Jun;35(6):1437-41

42. L Gossec, et al. European League Against Rheumatism (EULAR) recommendations for the management of psoriatic arthritis with pharmacological therapies: 2015 update. Ann Rheum Dis doi:10.1136/annrheumdis-2015208337 


\title{
Malattia IgG4-relata
}

\author{
Chiara Mastrobuoni, Generoso Uomo \\ UOSC Medicina Interna 3, Dipartimento Medico Polispecialistico, AORN Cardarelli, Napoli, Italia
}

\section{Introduzione}

La malattia IgG4-relata (IgG4-related disease, IgG4-RD) è un'entità morbosa di recente sistematizzazione nosologica caratterizzata da un infiltrato linfoplasmacitico denso ricco in plasmacellule IgG4 positive, fibrosi e, spesso ma non sempre, da elevati livelli di IgG4 nel siero. ${ }^{1}$ Le lesioni tipiche della IgG4$\mathrm{RD}$, che di fatto viene a costituire un disordine fibroinfiammatorio immuno-mediato, sono state riscontrate in quasi tutti gli organi ed apparati dell'organismo, dal pancreas alle vie biliari, ghiandole salivari, rene, polmoni, aorta, mammelle, tessuti periorbitari, prostata, pericardio, linfonodi, meningi, tiroide, cute. ${ }^{2,3}$ Per la stretta interdipendenza fra infiammazione ed autoimmunità verificata sul piano patogenetico, la IgG4-RD può rientrare a ragione nel più vasto gruppo delle IMID (Immune Mediated Inflammatory Disease) oggetto del presente volume.

\section{Aspetti patogenetici}

Multipli meccanismi immuno-mediati contribuiscono al processo fibro-infiammatorio che costituisce la base istopatologica della IgG4-RD. La Figura 1 riporta uno schema di insieme dei meccanismi implicati. Autoimmunità ed agenti infettivi costituiscono $\mathrm{i}$ potenziali triggers e in popolazioni orientali sono stati documentati specifici sierotipi HLA e particolari polimorfismi genetici associati ad un netto incremento della suscettibilità alla malattia. ${ }^{1,4}$ Negli studi iniziali su pazienti con pancreatite autoimmune è stata verifi-

Corrispondente: Generoso Uomo, UOSC Medicina Interna 3, Dipartimento Medico Polispecialistico, AORN Cardarelli, via Cardarelli 9, 80131 Napoli, Italia.

Tel.: +39.081.7472101 - Fax: +39.081.7472104.

E-mail: gene.uomo@virgilio.it

Articolo pubblicato secondo la Creative Commons Attribution NonCommercial 4.0 License (CC BY-NC 4.0).

CCopyright C. Mastrobuoni e G. Uomo, 2017

Licensee PAGEPress, Italy

QUADERNI - Italian Journal of Medicine 2017; 5(7):19-24 cata la presenza di anticorpi diretti contro antigeni proteici dell'Helicobacter pylori ed ipotizzato che essi possano agire da autoanticorpi in persone geneticamente predisposte (mimetismo molecolare). In alternativa, vi è la possibilità che anche altre specie batteriche, nel momento dell'interazione con le cellule mononucleate periferiche, possano indurre la produzione sia di IgG4 che interleuchina-10 attraverso la immunità innata. Nel soggetto sano le molecole di IgG4 sono rilasciate dai linfociti Th2-helper come anticorpi bivalenti simmetrici, costituiscono circa il 5\% delle IgG totali, sono omologhe per il $95 \%$ alle altre sub-classi di IgG, non attivano in modo efficace la via classica del complemento e, in linea generale, svolgono solo un ruolo limitato nei meccanismi immuni. ${ }^{5}$ Una caratteristica peculiare, però, delle IgG4 è la loro instabilità strutturale dovuta alla labilità dei ponti disolfuro che legano le catene pesanti della struttura anticorpale: in questo modo diviene possibile la ricombinazione random delle catene con formazione di anticorpi asimmetrici con differenti siti antigenici e perdita della capacità di formare immunocomplessi. Un trigger autoimmunitario costituisce lo stimolo iniziale per la risposta immune Th2-cellulare che si associa alla IgG4-RD e le IgG4 sieriche prodotte in eccesso si legano a vari antigeni dei tessuti bersaglio. Alcune interleuchine (Figura 1) vengono iper-espresse inizialmente dalle cellule Th2 e poi dai linfociti T-regolatori e a loro volta contribuiscono all'eosinofilia sierica e tissutale, all'aumento di $\operatorname{IgE}$ e IgG4 sieriche, all'infiltrazione di cellule IgG4 positive e alla progressione della fibrosi, tutte caratteristiche della malattia. Il risultato finale è la massiva infiltrazione di cellule infiammatorie con danno epiteliale, ingrandimento degli organi colpiti e disfunzione d'organo.,

\section{Aspetti nosologici}

Nel corso degli anni sono stati suggeriti diversi nomi e termini per identificare condizioni confinate a singoli organi rientranti nello spettro della IgG4-RD ${ }^{7}$ (Tabella 1). La malattia non era stata riconosciuta quale disordine sistemico fino al 2003, epoca della segnalazione di manifestazioni extrapancreatiche in pazienti affetti da pancreatite autoimmune, una malattia correlata alla presenza di elevati livelli sierici di IgG4 


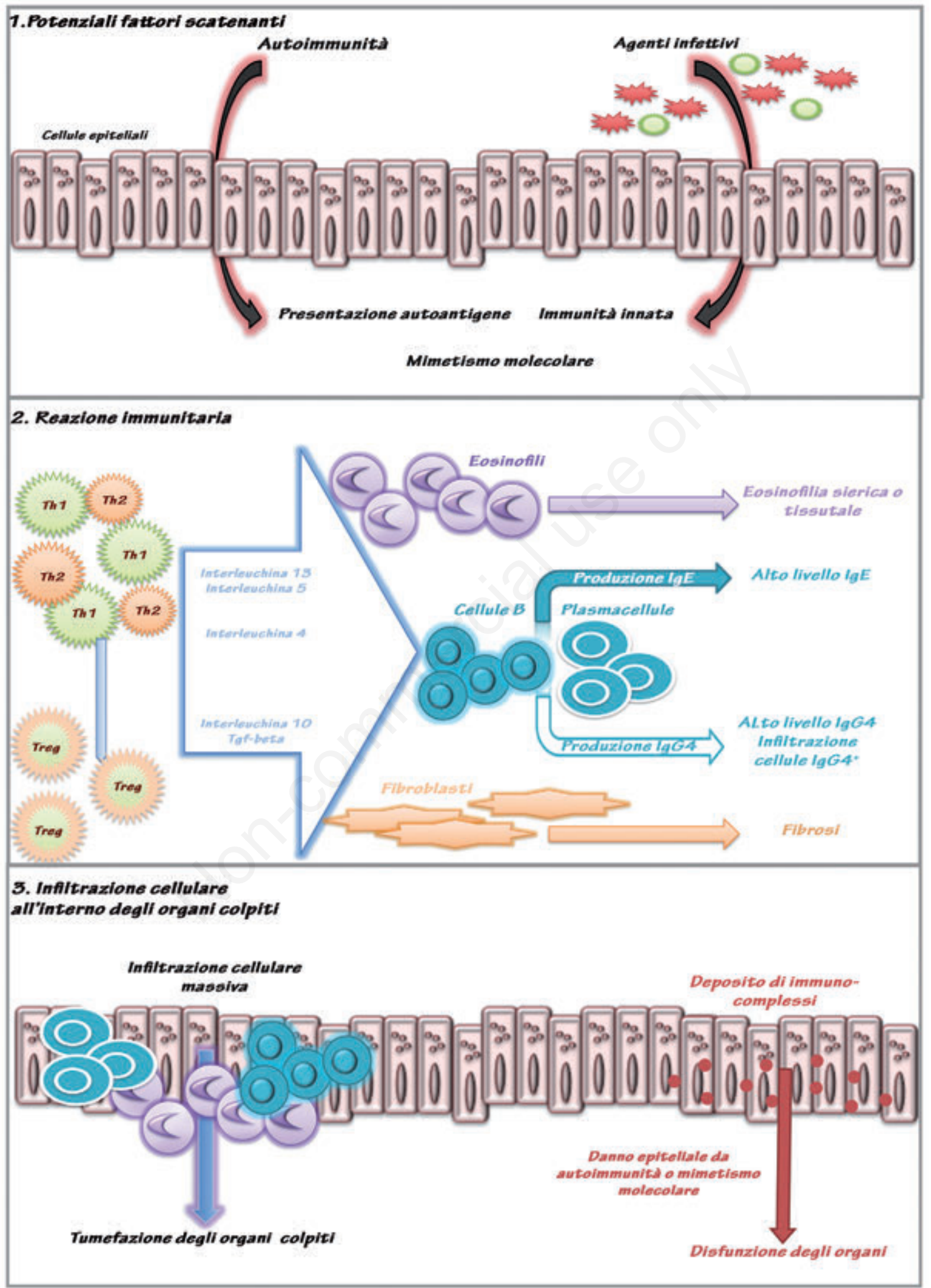

Figura 1. Meccanismi patogenetici della IgG4-Rd con relative implicazioni cliniche. 
e caratterizzata da infiltrati plasmacellulari IgG4 positivi. ${ }^{2}$ In poco meno di un decennio dal riconoscimento di espressioni patologiche extrapancreatiche è venuta a configurarsi una sindrome proteiforme con possibile interessamento di quasi tutti gli organi ed apparati. L'inquadramento nosologico nella definizione di IgG4-RD è del $2011^{3}$ ed è omnicomprensivo dell'ampio spettro della malattia (Figura 2).

\section{Aspetti clinico-diagnostici}

L'epidemiologia della malattia è poco indagata $\mathrm{e}$ quasi tutte le segnalazioni provengono da studi giapponesi incentrati sulla pancreatite autoimmune. La prevalenza stimata di questo disordine è poco meno di un caso per 100.000 abitanti, costituendo circa il $6 \%$ di tutti i casi di pancreatite cronica. ${ }^{7,8}$ La maggior parte dei pazienti sono uomini $(60-80 \%)$ con età superiore ai 50 anni e questa predominanza del sesso maschile contrasta fortemente con altre malattie autoimmuni che mimano la IgG4-RD quali la cirrosi biliare primitiva e la sindrome di Sjögren. ${ }^{6}$ La maggior parte dei pazienti abitualmente non presenta sintomi costituzionali quali febbricola, astenia, dimagramento e i dati aspecifici di laboratorio di flogosi (VES, PCR) sono nella norma. La malattia è di frequente una scoperta incidentale radiologica o istologica. ${ }^{9}$ Alcuni pazienti presentano una malattia confinata ad un unico organo per molti anni mentre altri, fin dall'esordio, presentano interessamento subclinico di molti organi accanto al coinvolgimento dell'organo principale. L'interessamento multiorgano può essere già evidente al momento della diagnosi con evoluzione peggiora- tiva diversificata nei singoli distretti interessati. Sono di frequente riscontro lesioni tumefattive (ingrandimento pseudotumorale soffice a carico di molti organi e apparati - Figura 2) e manifestazioni allergiche (atopia, eczema, asma, sinusite ed eosinofilia periferica). ${ }^{10}$ L'andamento della malattia, anche in caso di interessamento multiorgano, è in genere subacuto e lentamente progressivo, se non trattato, verso la insufficienza d'organo critica. È questo il caso della colangite IgG4-RD che porta all'insufficienza epatica globale nell'arco di diversi mesi e dell'aortite che può causare aneurismi e dissezione aortica fino al $50 \%$ dei casi. Sono descritte lesioni distruttive ossee che somigliano a quelle della poliangioite granulomatosa o a lesioni tumorali dei seni paranasali, orecchio medio, ossa craniche.

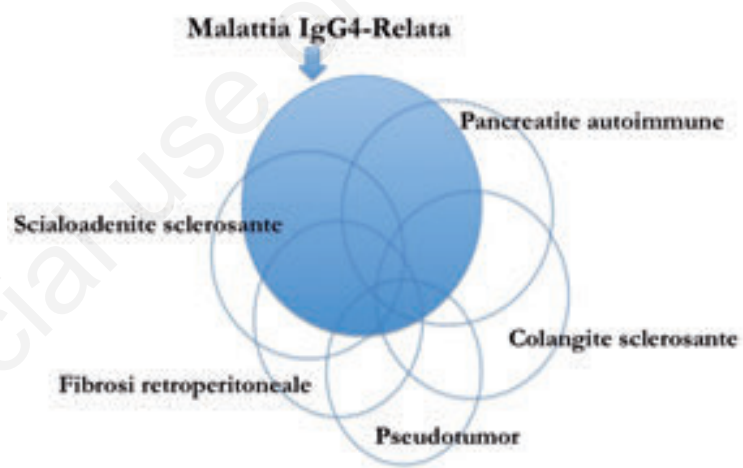

Figura 2. Schema di overlap dello spettro della IgG4-RD con le principali sindromi cliniche.

Tabella 1. Condizioni in passato considerate quali disordini individuali ed attualmente riconosciuti facenti parte della IgG4-RD.

Pancreatite autoimmune (pancreatite sclerosante linfoplasmacitica)

Fibrosi angiocentrica eosinofila (interessamento orbite e vie aeree superiori)

Mediastinite fibrosante

Pachimeningite ipertrofica

Nefrite idiopatica tubulo-interstiziale ipocomplementemica con estesi depositi tubulo-interstiziali

Pseudotumor infiammatorio (interessamento orbite, polmoni, rene e altri organi)

Tumore di Küttner (interessamento ghiandole sottomandibolari)

Sindrome di Miculicz (interessamento ghiandole lacrimali e salivari)

Fibrosclerosi multifocale (interessamento orbite, tiroide, retroperitoneo, mediastino e altri tessuti ed organi)

Periaortite e periarterite

Aneurisma aortico infiammatorio

Fibrosi reotroperitoneale (malattia di Ormond)

Tiroidite di Riedel

Mesenterite sclerosante 
La diagnostica per imaging è molto variabile con dati aspecifici e che di regola non consentono una distinzione sicura o affidabile tra lesioni neoplastiche e IgG4-RD. I dati più approfonditi sono quelli a livello pancreatico (vedi articolo Pancreatiti autoimmuni di Rabitti PG e Boni R in questo stesso volume) - Figura 3, osservazione personale. Le lesioni a carico dei grossi vasi arteriosi si caratterizzano alla tomografia computerizzata per un ispessimento di parete omogeneo ed enhancement tardivo dopo mezzo di contrasto e.v., legato alla infiammazione sclerosante che coinvolge la tunica avventizia vascolare (Figure 4 e 5, osservazione personale). La risonanza magnetica nucleare permette di valutare l'estensione del coinvolgimento fibrotico retroperitoneale e con tecniche dinamiche l'interessamento funzionale di tutto l'apparato escretorio renale.

La maggior parte dei pazienti affetti da IgG4-RD presentano concentrazioni sieriche di IgG4 elevate, con range molto ampi di incremento, ma va segnalato che nel 30\% circa dei casi si riscontrano livelli normali nonostante dati istopatologici ed immunoistochimici classici della malattia. Vi sono dati controversi circa l'utilità di misurazioni seriate dei livelli di IgG4 quali indicatori di attività di malattia. In corso di terapia steroidea le concentrazioni di $\mathrm{IgG} 4$ si riducono nella maggioranza dei pazienti con livelli elevati al baseline ma restano quasi sempre al di sopra dei valori normali senza correlarsi ad eventuali remissioni o recidive clinico-patologiche. ${ }^{11}$

Di recente, ${ }^{12-14}$ sono stati fatti vari tentativi di stan- dardizzare criteri diagnostici (certezza, probabilità elevata, probabilità bassa) ma che non hanno trovato ancora conferme su casistiche omogenee e

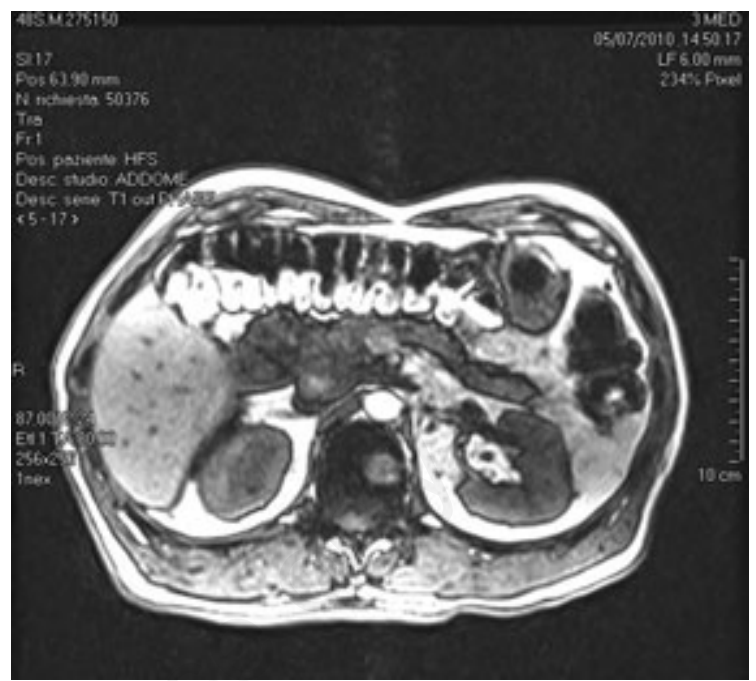

Figura 3. Risonanza Magnetica Nucleare addominale: evidenza di ingrandimento diffuso omogeneo del pancreas a profilo sostanzialmente conservato; osservazione personale: paziente di 42 anni affetto da IgG4-RD (conferma istologica) con espressione di pancreatite autoimmune, scialoadenite cronica, tiroidite di Riedel, sindrome di Miculicz.

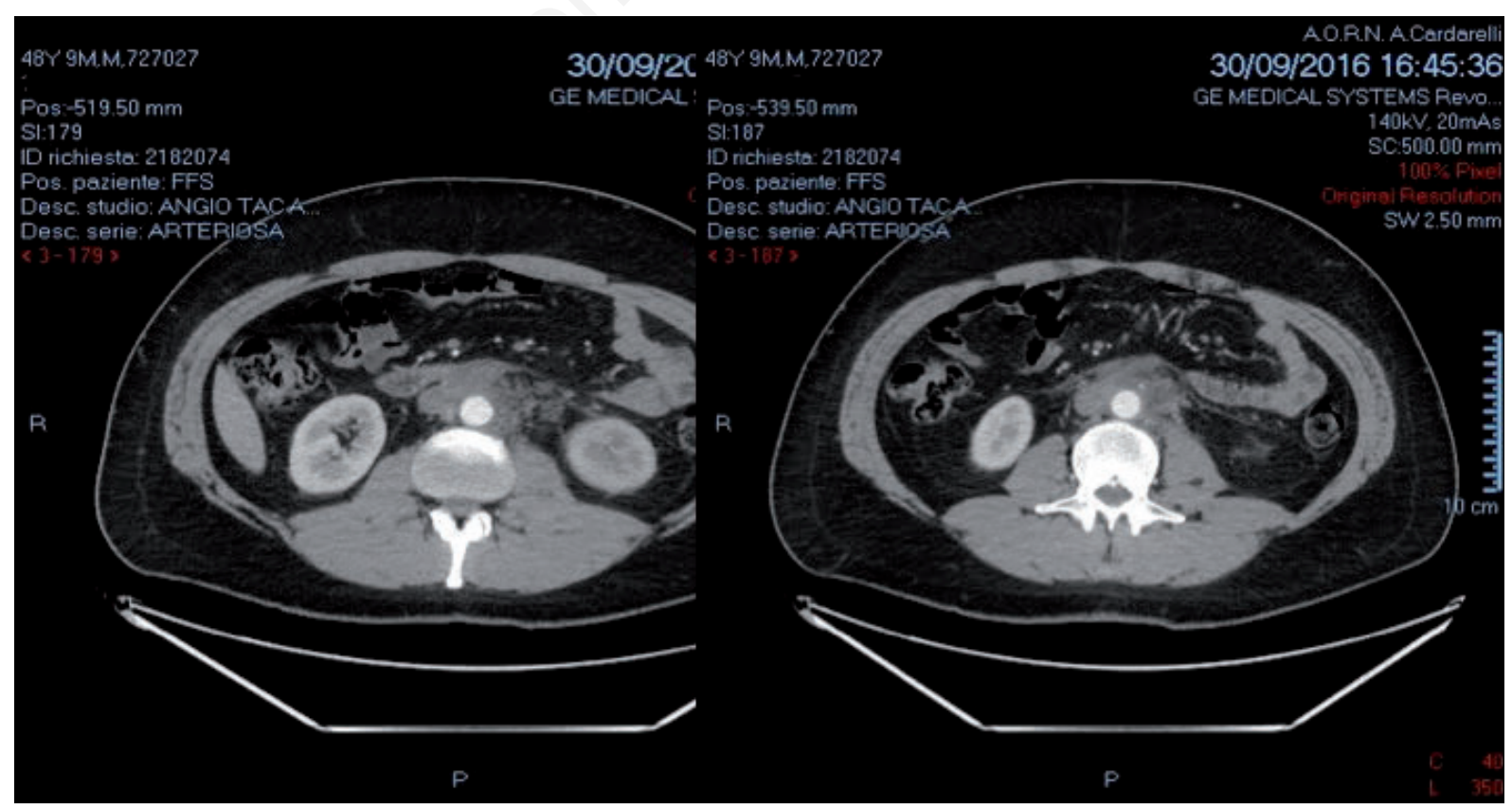

Figura 4. Tomografia assiale computerizzata con mdc: evidenza di ganga fibrotica periaortica con interessamento infiammatorio di parete; osservazione personale: paziente di 53 anni affetto da IgG4-RD con espressione di aortite e periaortite, fibrosi retroperitoneale con ostruzione ureterale, interstiziopatia polmonare, tiroidite autoimmune. 
numericamente adeguate. In sostanza i cardini diagnostici variamente combinati sono relativi all'interessa-

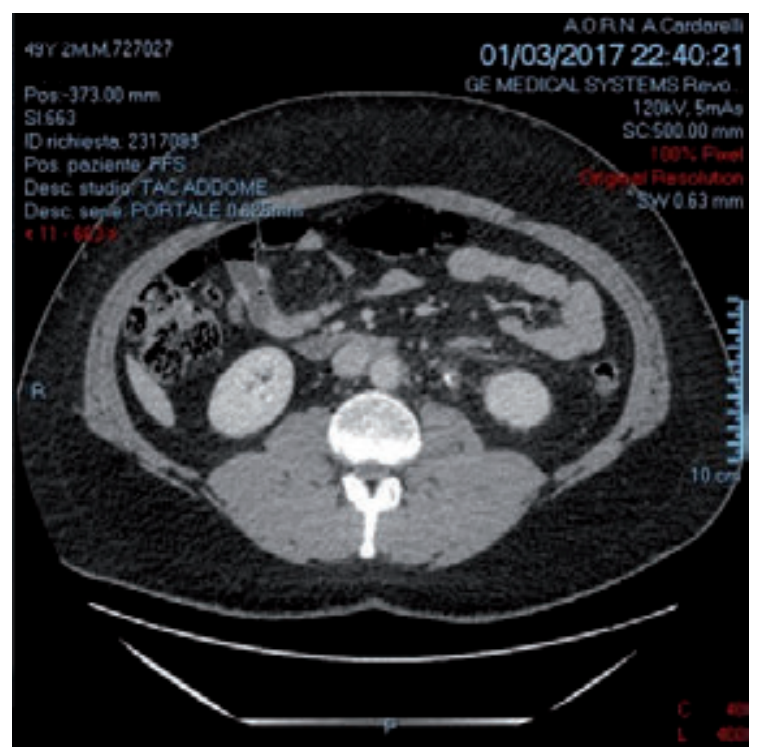

Figura 5. Tomografia assiale computerizzata con mdc dello stesso paziente della Figura 4 dopo sei mesi di trattamento steroideo (iniziale bolo e.v. di metilprednisolone $1 \mathrm{~g} / \mathrm{ev} \times$ tre giorni, poi $1 \mathrm{mg} / \mathrm{Kg}$ per due settimane e poi dosaggio a scalare con aggiunta al terzo mese di metotrexate $15 \mathrm{mg} / \mathrm{settimana):} \mathrm{netta} \mathrm{riduzione} \mathrm{della} \mathrm{ganga} \mathrm{fi-}$ brotica periaortica. mento multiorgano, alla presenza di dati istologici tipici e valori di IgG4 sierici elevati (>135 mg/dl). La diagnosi differenziale può risultare complessa chiamando in causa diverse patologie dei singoli organi interessati dal processo morboso (Tabella 2).

\section{Considerazioni terapeutiche}

Non abbiamo a disposizione al momento trials terapeutici randomizzati nella IgG4-RD. Ciò che sembra ormai accertato è che: a) quando si registra un interessamento di organi vitali è necessario un trattamento aggressivo in quanto la IgG4-RD può portare a disfunzione d'organo e deficit globale di funzione; b) non tutte le manifestazioni di malattia necessitano di un trattamento immediato (è il caso ad esempio della linfoadenopatia, quasi sempre asintomatica); c) il numero e l'estensione degli organi colpiti non correla con la necessità di dover per forza instituire un trattamento, al di fuori di uno stretto follow-up). ${ }^{1,3,7,15} \mathrm{~Pa}$ zienti con compromissione di vari organi possono non richiedere terapie sistemiche, laddove pazienti con singolo coinvolgimento d'organo (esempio tipico in caso di aortite) necessitano di trattamenti urgenti. I corticosteroidi costituiscono la prima linea di trattamento; una Consensus Statement giapponese sulla pancreatite autoimmune suggerisce di iniziare il trattamento con prednisone alla dose di $0,6 \mathrm{mg} / \mathrm{Kg}$ peso corporeo/die per un periodo di sei settimane per poi scendere pro-

Tabella 2. Diagnosi differenziale della IgG4-RD, organo per organo.

Orbite e tessuti perirobitari: linfoma, morbo di Graves, granulomatosi con poliangioite, sarcoidosi

Orecchio, naso e seni paranasali: malattie allergiche, sindrome di Churg-Strauss, granulomatosi con poliangioite, sarcoma, infezioni croniche

Ghiandole salivari: linfoma, sindrome di Sjögren, sarcoidosi, calcolosi

Meningi: pachimeningite ipertrofica idiopatica, tumore miofibroblastico infiammatorio, linfoma, granulomatosi con poliangioite, arterite a cellule giganti, istiocitosi a cellule di Langherans, sarcoidosi

Polmoni: neoplasie maligne, tumore miofibroblastico infiammatorio, sarcoidosi, granulomatosi con poliangioite, malattia di Castelman, granulomatosi linfomatoide, polmonite interstiziale idiopatica, malattia di Erdheim-Chester

Ipofisi: neoplasie, istiocitosi, ipofisite primaria e secondaria

Linfonodi: malattia di Castelman multicentrica, linfoma, sarcoidosi, lupus eritematoso sistemico

Tiroide: linfoma, carcinoma tiroideo differenziato (variante papillare), altre lesioni maligne

Aorta: arterite di Takayasu, sarcoidosi, malattia di Erdheim-Chester, istiocitosi, linfoma, aortite infettiva

Retroperitoneo: linfoma, sarcoma, fibrosi peritoneale indotta da metisergide, fibrosi retroperitoneale idiopatica

Rene: linfoma, carcinoma a cellule renali, nefrite tubulo-interstiziale da farmci, glomerulonefrite membranosa idiopatica, glomerulonefrite necrotizzante pauci-immune, sarcoidosi, sindrome di Sjögren, lupus eritematoso sistemico

Pancreas: neoplasie

Vie biliari: neoplasie, colangite sclerosante primitiva

Fegato: colangiocarcinoma, carcinoma epatocellulare, colangite sclerosante primitiva

Prostata: ipertrofia prostatica benigna

Cute: linfoma 
gressivamente la dose fino ad arrivare in $3 / 6$ mesi a 5 $\mathrm{mg} /$ die e poi continuare con $2,5 \mathrm{mg} /$ die fino a 3 anni. ${ }^{16}$ Gli steroidi sono abbastanza efficaci in tutte le manifestazioni d'organo della IgG4-RD, anche se sono possibili riaccensioni durante il dècalage della dose terapeutica. ${ }^{1}$ Mutuando quanto dimostratosi efficace in molte malattie autoimmuni, sono stati utilizzati farmaci quali azatiorpina, micofenolato-mofetil e soprattutto metrotrexate allo scopo di mantenere la remissione indotta dagli steroidi, ma mancano evidenze di trials clinici al riguardo. Per i pazienti con malattia refrattaria o recidivante, è stato utilizzato il rituximab, un anticorpo monoclonale capace di determinare delezione dei linfociti B. ${ }^{17}$ Diverse segnalazioni mostrano che i pazienti trattati si ottiene un rapido declino dei livelli sierici di IgG4 associato a buone risposte terapeutiche nell'arco di alcune settimane. Un fattore condizionante la risposta terapeutica è il grado di fibrosi nel contesto degli organi interessati dal processo patologico dal momento che gradi più rilevanti di infiammazione linfoplasmacitica e di fibrosi sembrano associarsi a minori riposte a steroidi e rituximab. ${ }^{6,18}$

\section{Conclusioni}

La IgG4-RD comprende ed unifica un corposo gruppo di disordini, in precedenza considerati pertinenza di un singolo organo o apparato, che in definitiva sono accomunati dagli stessi dati istopatologici. I meccanismi patogenetici e le inter-relazioni tra le espressioni istologiche, gli elevati livelli di IgG4 sieriche e di plasmacellule IgG4 secernenti a livello tissutale sono ancora in gran parte da chiarire. Vi è necessità di grande attenzione nella comunità medica verso questo disordine al fine di arrivare ad una diagnosi quanto più precoce possibile che possa prevenire gravi danni d'organo, fibrosi tissutale ingravescente e mortalità correlata. Migliori e più approfondite conoscenze del ruolo delle IgG4 in fisiologia e patologia, dei poliedrici aspetti dell'intero spettro della IgG4-RD e delle risposte ai trattamenti proposti, in particolare ai farmaci B-cell-depletori, porteranno nel prossimo futuro importanti delucidazioni non solo nella specifica malattia considerata nel presente articolo ma anche in generale nell'intero capitolo delle IMID.

\section{Bibliografia}

1. Stone JH, Zen Y, Deshpande V. IgG4-related disease. N Engl J Med 2012; 366: 539-51
2. Kamisawa T, Takuma K, Egawa N, Tsuruta K, Sasaki T. Autoimmune pancreatitis and IgG4-related sclerosing disease. Nat Rev Gastroenterol Hepatol 2010; 7: 401-9

3. Korosrohavi A, Stone JH. IgG4-related systemic disease: the age of discovery. Curr Opin Rheumatol 2011; 23: $72-3$

4. de Buy Wenniger LJM, Culver EL, Beuers U. Exposure to occupational antigens might predispose to IgG4-related disease. Hepatology 2014; 60: 1453-4

5. Carruthers MN, Khosroshahi A, Augustin T, Deshpande $\mathrm{V}$, Stone, JH. The diagnostic utility of serum IgG4 concentrations in IgG4-related disease. Ann Rheum Dis 2015; 74:14-8

6. Culver EL, Chapman RW. IgG4-related hepatobiliary disease: an overview. Nat Rev Gastroenterol Hepatol 2016; 13: 601-12

7. Kamisawa T, Zen Y, Pillai S, Stone JH. IgG4-related disease. The Lancet 2015; 385: 1460-71

8. Kanno A. Nationwide epidemiological survey of autoimmune pancreatitis in Japan in 2011. Pancreas 44, 535-539 (2015)

9. Della Torre E. Prevalence of atopy, eosinophilia, and IgE elevation in IgG4-related disease. Allergy 2014; 69, 269-72

10. Kamisawa T, Anjiki H, Kubota N. Allergic manifestations in autoimmune pancreatitis. Eur J Gastroenterol Hepatol 2009; 21: 1136-9

11. Culver EL. Elevated serum IgG4 levels in diagnosis, treatment response, organ involvement and relapse in a prospective IgG4-related disease UK cohort. Am J Gastroenterol 2016; 111:733-43

12. Okazaki K, Uchida K, Koyabu M, Miyoshi H, Takaoka M. Recent advances in the concept and diagnosis of autoimmune pancreatitis and IgG4-related disease. J Gastroenterol 2011; 46:277-88

13. Okazaki K, Uchida K, Miyoshi H, Ikeura T, Takaoka M, Nishio A. Recent concepts of autoimmune pancreatitis and IgG4-related disease. Clin Rev Allergy Immunol. 2011;41:126-38

14. Umehara H, Okazaki K, Masaki Y, Kawano M, Yamamoto M, Saeki T. A novel clinical entity, IgG4-related disease (IgG4RD): General concept and details. Mod Rheumatol. 2012;22:1-14

15. Joshi D, Webster GJM. Review article: Biliary and hepatic involvement in IgG4-related disease. Aliment Pharmacol Ther 2014; 40:1251-61

16. Kamisawa T, Okazaki K, Kawa S. Japanese consensus guidelines for management of autoimmune pancreatitis. III. Treatment and prognosis. J Gastroenterol 2010; 45:471-7

17. Khosroshahi A, Carruthers M, Deshpande V, Unizony S, Block DB, Stone JH. Rituximab for the treatment of IgG4-related disease: lessons from ten consecutive patients. Medicine (Baltimore) 2012; 91: 57-66

18. Lang D, Zwerina J, Pieringer H. IgG4-related disease: current challenge and future prospects. Ther Clin Risk Management 2016; 12:189-99. 


\title{
IMID in ematologia
}

\author{
Francesca Rezzonico, Antonino Mazzone
}

Dipartimento di Area Medica, ASST Ovest Milanese, Ospedale di Legnano (MI), Italia

\section{Introduzione}

Le malattie ematologiche immunomediate, sono frequenti in medicina interna, e spesso rappresentano una vera emergenza medica. Le principali che analizzeremo qui di seguito sono: Anemia emolitica autoimmune, neutropenia autoimmune, piastrinopenia autoimmune. Le anemie emolitiche autoimmuni (AEA) comprendono un gruppo eterogeneo di condizioni morbose caratterizzate dalla presenza di autoanticorpi diretti contro antigeni eritrocitari e da un quadro clinico di emolisi variabile nella sua gravità. L'incidenza nell'adulto è di $0,8-3$ casi x $10^{5} /$ anno con un tasso di mortalità dell' $11 \%$. La neutropenia è definita come riduzione del numero assoluto di neutrofili (ANC) nel sangue periferico $(<1500 / \mathrm{mmc})$. Va ricordato come la normale conta dei neutrofili vari in relazione all'età (valori sovrapponibili a quelli dell'età adulta vengono raggiunti in adolescenza) e all'etnia. La piastrinopenia immune, precedentemente denominata porpora trombocitopenica idiopatica o immune, identifica una entità nosografica caratterizzata da piastrinopenia isolata (conta piastrinica del sangue periferico $<100 \times 10^{9} / \mathrm{L}$ ) e assenza di ogni segno o sintomo clinico che non sia direttamente correlabile alla piastrinopenia. La stima di incidenza negli adulti risulta compresa fra 1,6 e 3,9 per 100.000 abitanti/anno. Il rischio di emorragie gravi è generalmente limitato (inferiore al $5 \%$ dei casi). La mortalità complessiva è inferiore all'1-2\%. I sintomi emorragici possono essere assenti o minimi fino al $50 \%$ dei casi. In tutte queste patologie oggi abbiamo utili innovazioni terapeutiche che ci permettono di risovere e gestire la

Corrispondente: Antonino Mazzone, Dipartimento di Area Medica, ASST Ovest Milanese, via Papa Giovanni Paolo II 1, 20025 Legnano (MI), Italia.

E-mail: antonino.mazzone@asst-ovestmi.it

Articolo pubblicato secondo la Creative Commons Attribution NonCommercial 4.0 License (CC BY-NC 4.0).

(C) Copyright F. Rezzonico e A. Mazzone, 2017

Licensee PAGEPress, Italy

QUADERNI - Italian Journal of Medicine 2017; 5(7):25-29 patologia nell' $80 \%$ dei casi. Le novità terapeutiche sono analizzati per ogni singola patologia.

\section{Anemia emolitica autoimmune}

Le anemie emolitiche autoimmuni (AEA) comprendono un gruppo eterogeneo di condizioni morbose caratterizzate dalla presenza di autoanticorpi diretti contro antigeni eritrocitari e da un quadro clinico di emolisi variabile nella sua gravità. L'incidenza nell'adulto è di $0,8-3$ casi x $10^{5} /$ anno con un tasso di mortalità dell' $11 \%$.

\section{Fisiopatologia e aspetti clinici}

Le AEA vengono distinte in base alle proprietà termiche dell'anticorpo, in forme da autoanticorpi caldi, che si legano agli eritrociti ad una temperatura intorno ai $37^{\circ} \mathrm{C}$, forme da anticorpi freddi (meno frequenti, circa il 20\% di tutte le AEA), che possiedono un optimum di reazione a $4^{\circ} \mathrm{C}$ e che comprendono la malattia da agglutinine fredde (CHD; cold hemagglutinin disease) e la emoglobinura parossistica a frigore, e forme miste. ${ }^{1}$ La distruzione degli eritrociti può avvenire attraverso lisi complemento mediata (prevalentemente intravascolare ed epatica) o mediante citotossicità cellulare mediata da anticorpi (prevalentemente splenica e negli organi linfoidi). Da un punto di vista clinico le AEA vengono distinte in forme primitive (idiopatiche, 50\%) e secondarie ad altre condizioni morbose: sindromi linfoproliferative $(20 \%)$, patologie autoimmuni (20\%), infezioni e neoplasie. La diagnosi è di solito semplice, basata sulla presenza di anemia emolitica e anticorpi anti eritrociti, evidenziata dalla positività del test dell'antiglobulina diretto (TAD) o test di Coombs, eseguito mediante agglutinazione con antisieri polispecifici e monospecifici (anti-IgG, IgM o IgA o anti-frazioni complementari). Oltre alla classica agglutinazione, relativamente poco sensibile, esistono altre metodiche per rivelare anticorpi antieritrocitari, quali il test di consumo del complemento, vari test immunoradiometrici, ELISA o citofluorometrici e il test all'antiglobulina in fase solida, generalmente più sensibili della classica agglutinazione. ${ }^{2}$ Nelle AEA da anticorpi caldi, il TAD è tipicamente positivo per l'antisiero $\operatorname{IgG}(\mathrm{e}$ anti $\mathrm{C} 3 \mathrm{~d}$ in 
alcuni casi). Le forme fredde sono generalmente causate da IgM, e il TAD è positivo per $\mathrm{C} 3 \mathrm{~d}$, poiché gli anticorpi sono spesso persi o presenti solo in piccola parte sulla superficie degli eritrociti a $37^{\circ} \mathrm{C}$. La maggioranza dei pazienti affetti da AEA presenta un TAD positivo, tuttavia, in una piccola percentuale di casi (circa il 10\%), nessuna delle metodiche tradizionali è in grado di dimostrare la presenza di anticorpi antieritrocitari. In questi ultimi casi viene posta diagnosi di AEA TAD-negativa dopo esclusione di altre cause di emolisi e in base alla risposta clinica alla terapia. Nelle AEA TAD negative può essere di aiuto l'uso del TAD dopo stimolazione mitogenica (Mitogen StimulatedDirect Antiglobulin Test, MS-DAT).

Il quadro clinico delle AEA è caratterizzato da una notevole variabilità in termini di esordio, manifestazioni cliniche e decorso, da insidioso a fulminante. Le AEA, indipendentemente dalle caratteristiche dell'autoanticorpo, presentano anemia tendenzialmente macrocitica di grado estremamente variabile: emoglobina $(\mathrm{Hb})$ da $3 \mathrm{~g} / \mathrm{dL}$ nelle forme più gravi fino a valori pressoché normali, reticolocitosi, moderata iperbilirubinemia prevalentemente di tipo indiretto, consumo di aptoglobina, possibile rialzo di $\mathrm{LDH}$ e, occasionalmente nelle forme iperacute e massive, emoglobinemia, emoglobinuria ed emosiderinuria. Il grado dell'anemia dipende anche dall'efficacia della risposta eritroblastica. I pazienti con reticolocitopenia ( $20 \%$ nell'adulto), rappresentano un'emergenza clinica e possono richiedere un supporto trasfusionale importante.

Le CHD sono caratterizzate da agglutinazione ed emolisi delle emazie nelle sedi corporee dove la temperatura raggiunge quella di reazione dell'anticorpo e quindi acrocianosi e fenomeni vasomotori nella microcircolazione superficiale (mani, piedi, orecchie, naso, etc.), scatenati per lo più dall'esposizione al freddo. L'anemizzazione è spesso più severa e il tasso di mortalità superiore alle altre forme di AEA (fino al 22\%).

L'emoglobinuria parossistica a frigore è stata classicamente descritta in passato in associazione alla sifilide. Attualmente si osserva frequentemente nei bambini a seguito di malattie infettive virali, ed è caratterizzata da un esordio acuto, saltuariamente grave e da anemia di grado severo con emoglobinuria. I sintomi clinici sono dominati dall'emolisi intravascolare determinata dall'emolisina bifasica di DonathLandsteiner, un anticorpo di classe IgG che si lega agli eritrociti a basse temperature $\left(4^{\circ} \mathrm{C}\right)$ e determina emolisi a $37^{\circ} \mathrm{C}$. Il quadro clinico è caratterizzato da malessere generale, brividi, febbre, crampi, dolori lombari e addominali, fenomeni vasomotori ed orticaria perlopiù a seguito di una esposizione a basse temperature.

La malattia da agglutinine fredde nella forma acuta può essere associata a polmonite atipica primaria, mentre nella forma cronica può essere secondaria a malattie linfoproliferative.

\section{Prospettive di terapia}

La definizione del tipo e delle caratteristiche termiche dell'autoanticorpo è di fondamentale importanza in quanto determina un diverso approccio terapeutico alla AEA. A prescindere dalle forme di AEA secondarie, in cui la terapia è quella della malattia di base, nelle forme idiopatiche da anticorpi caldi la terapia di prima scelta è rappresentata dai corticosteroidi (prednisone 1-1,5 mg/kg/die per 1-3 settimane fino a livello di $\mathrm{Hb}>10 \mathrm{~g} / \mathrm{dl}$ ). La risposta si verifica generalmente durante la seconda settimana di trattamento. Una volta ottenuta la stabilizzazione dei valori emoglobinici, la posologia dello steroide deve essere gradualmente e lentamente ridotta in 4-6 mesi (10-15 $\mathrm{mg} / \mathrm{settimana}$ fino alla dose giornaliera di $20-30 \mathrm{mg}$, quindi $5 \mathrm{mg}$ ogni 1-2 settimane fino alla dose di 15 $\mathrm{mg}$, quindi di 2,5 mg ogni due settimane fino a sospensione). I pazienti che proseguono il trattamento steroideo a bassa dose (prednisone $\leq 10 \mathrm{mg} / \mathrm{die}$ ) per più di 6 mesi hanno una incidenza più bassa di recidive e tempo di remissione più prolungato. I pazienti con quadri particolarmente severi possono richiedere la somministrazione di metilprednisolone alla dose di $100-200 \mathrm{mg} /$ die per $10-14$ giorni o $250-1000 \mathrm{mg} / \mathrm{die}$ per 1-3 giorni. La terapia di prima linea ha un tasso di risposta del $70-80 \%$ ma solo $1 / 3$ dei pazienti mantiene una remissione prolungata alla sospensione del farmaco. In assenza di risposta nella terza settimana, il trattamento è giudicato inefficace.

La splenectomia è la terapia dei pazienti che non rispondono o sono intolleranti allo steroide o che richiedono una terapia di mantenimento con prednisone $>10 \mathrm{mg} /$ die, di età inferiore ai 70 anni e con un buon performace status. La procedura consente di ottenere una risposta parziale o completa nei $2 / 3$ dei pazienti.

La terapia dei pazienti non candidabili a splenectomia o non responsivi alla procedura prevede la somministrazione di rituximab $(375 \mathrm{mg} / \mathrm{mq}$ la settimana per 4 settimane).

Altri trattamenti comprendono farmaci immunosoppressori (es. azatioprina 100-150 mg/die, ciclofosfamide $100 \mathrm{mg} / \mathrm{die})$. Nei pazienti plurirefrattari ulteriori trattamenti includono ciclofosfamide ad alta dose, alemtuzumab, plasma exchange e eritropoieina, in particolare in presenza di reticolocitopenia. ${ }^{3}$

Il supporto trasfusionale con emazie leucodeplete va riservato ai pazienti che presentano un quadro severo al fine di mantenere livelli clinicamente accettabili di emoglobina anche in relazione alle comorbidità e alla rapidità di insorgenza del quadro.

Nelle CHD i corticosteroidi e la splenectomia sono usualmente inefficaci e la misura terapeutica più utile nelle forme non gravi resta la protezione dal freddo.

Nei pazienti che necessitano trattamento, il rituximab è raccomandato come prima linea di terapia; a dosaggio standard è efficace in circa il $60 \%$ dei casi. 
Per i pazienti recidivati refrattari sono descritte associazione di rituximab e fludarabina, bortezomib e eculizumab, la cui conferma di efficacia richiede ulteriori studi. Promettenti sembrano inoltre i nuovi inibitori del complemento es., TNT003.

L'emoglobinura parossistica a frigore $(\mathrm{PCH})$ è usualmente autolimitantesi. In alcuni casi è richiesto il ricorso a trasfusioni e terapia steroidea, la cui efficacia è difficile da dimostrare, in relazione alla natura transitoria dell'emolisi.

\section{Neutropenia immune}

La neutropenia è definita come riduzione del numero assoluto di neutrofili (ANC) nel sangue periferico $(<1500 / \mathrm{mmc})$. Va ricordato come la normale conta dei neutrofili vari in relazione all'età (valori sovrapponibili a quelli dell'età adulta vengono raggiunti in adolescenza) e all'etnia.

La neutropenia può essere classificata in: congenita o acquisita (quest'ultima a sua volta suddivisa in base al meccanismo patogenetico o all'agente eziologico), primitiva o secondaria, o in base al meccanismo di induzione (da ridotta produzione, da sequestro endoteliale o tissutale, da aumentata distruzione) ${ }^{4}$

Il corrispettivo clinico della neutropenia è un incremento della diatesi infettiva, proporzionale al grado della stessa; si definisce lieve quando la conta assoluta è compresa tra 1500 e $1000 / \mathrm{mmc}$, moderata se ANC compresa tra 1000 e $500 / \mathrm{mmc}$, severa se ANC $<500 / \mathrm{mmc}$. Altri fattori che possono concorrere a determinare la severità della diatesi infettiva sono la durata della neutropenia, la riserva midollare, la conta assoluta dei monociti circolanti e lo stato funzionale dei fagociti.

\section{Fisiopatologia e aspetti clinici}

Nelle neutropenie immunomediate la bassa conta dei neutrofili deriva da un'aumentata distruzione periferica causata da anticorpi diretti contro antigeni di membrana. Comprendono forme mediate da alloanticorpi (incompatibilità materno fetale o reazioni trasfusionali) e forme mediate da autoanticorpi, che possono essere primitive (non associate ad altre patologie: neutropenia benigna dell'infanzia, neutropenia autoimmune cronica dell'adulto), o più frequentemente secondarie a patologie autoimmuni sistemiche (cirrosi biliare primitiva, sindrome di Sjögren, sclerosi sistemica, lupus eritematoso sistemico, artrite reumatoide/sindrome di Felty), infezioni (Helicobacter pylori, HIV, Parvovirus B19), neoplasie (leucemia a grandi linfociti granulari, tumore di Wilms, linfoma di Hodgkin), patologie neurologiche (sclerosi multipla), trapianto (cellule staminali, rene), farmaci (fludarabina, rituximab).
Dal punto di vista diagnostico, le varie tecniche impiegate per evidenziare la presenza di anticorpi anti neutrofili hanno diversi limiti per cui se ne suggerisce l'utilizzo di un minimo di due: il test di agglutinazione dei granulociti e il test in immunofluorescenza. A prescindere dalla metodica utilizzata, spesso risulta difficoltoso evidenziare la presenza degli autoanticorpi, poiché essi sono presenti a basso titolo con legami a bassa affinità.

La forme primitive hanno un'incidenza di 1/100.000 nuovi nati e sono di solito diagnosticate nei primi mesi di vita. Benché vi sia un significativo grado di neutropenia (ANC 500-1000/mmc), il decorso clinico è nella maggior parte dei casi benigno, caratterizzato da diatesi infettiva moderata con tendenza alla risoluzione spontanea entro i 2-3 anni nel 95\% dei casi. Gli anticorpi sono diretti contro antigeni HNA (human neutrophil antigen).

La neutropenia cronica idiopatica dell'adulto è caratterizzata tipicamente da insorgenza più tardiva, incidenza più alta nel sesso femminile $(70 \%)$, scarsa tendenza alla remissione spontanea (benché caratterizzata da un decorso clinicamente benigno), possibile associazione con anemia e piastrinopenia, positività per anticorpi anti neutrofili solo nel $35 \%$ dei casi.

Nelle forme secondarie la neutropenia, comunemente associata a piastrinopenia e/o anemia emolitica, è multifattoriale e la presenza di anticorpi anti neutrofili (il cui target è sconosciuto nella maggior parte dei casi), può essere associata a sequestro periferico, inibizione midollare, apoptosi.

\section{Prospettive di terapia}

Le forme primitive non richiedono generalmente terapia specifica. L'utilizzo di antibiotici è di solito sufficiente in caso di episodi infettivi. L'utilità di una profilassi antibiotica a medio lungo termine, usualmente con cotrimossazolo, va valutata caso per caso. In caso di infezioni gravi o interventi chirurgici è giustificato l'utilizzo di fattori di crescita (granulocyte colony stimulating factor, G-CSF).

Nelle forme secondarie il trattamento consiste nella terapia della malattia di base, con eventuale associazione di G-CSF in caso di complicanze infettive in casi selezionati (possibile flare della patologia reumatologica e/o sviluppo di vasculite leucocitoclastica in caso di sindrome di Felty o lupus eritematoso sistemico). ${ }^{5}$

\section{La piastrinopenia immune}

Precedentemente denominata porpora trombocitopenica idiopatica o immune, identifica una entità nosografica caratterizzata da piastrinopenia isolata (conta piastrinica del sangue periferico $<100 \times 10^{9} / \mathrm{L}$ ) e assenza di ogni segno o sintomo clinico che non sia 
direttamente correlabile alla piastrinopenia. La stima di incidenza negli adulti risulta compresa fra 1,6 e 3,9 per 100.000 abitanti/anno. Il rischio di emorragie gravi è generalmente limitato (inferiore al $5 \%$ dei casi). La mortalità complessiva è inferiore all'1-2\%. I sintomi emorragici possono essere assenti o minimi fino al $50 \%$ dei casi. ${ }^{6}$

\section{Fisiopatologia}

L'IWG (International Working Group, IWG) ha distinto le forme primitive (ITP primaria) da quelle secondarie (ITP secondaria). Pur essendo entrambe le forme di natura autoimmune, in quelle secondarie il disturbo dell'immunità è riconducibile alla presenza di una malattia sottostante rilevabile al momento della diagnosi (es. infezione da HCV, Helicobacter pylori, HIV, lupus eritematoso sistemico, sindrome da anticorpi antifosfolipidi, forme autoimmuni indotte da farmaci).

Gli autoanticorpi anti-piastrine rappresentano l'effettore finale del processo autoimmune, sono per lo più di tipo IgG, generalmente rivolti verso le glicoproteine (GP) IIb/IIIa o GP Ib/IX presenti sulle membrane piastriniche del paziente. Trattandosi di epitopi pubblici, gli autoanticorpi risultano attivi contro le piastrine eterologhe ottenute da donatori, spiegando così l'accorciata emivita delle piastrine trasfuse nel soggetto con ITP. Fatte salve le limitazioni tecniche nella dimostrazione della presenza di autoanticorpi specifici, nei soggetti con autoanticorpi non evidenziabili si ritengono operanti meccanismi patogenetici tuttora largamente sconosciuti. Gli autoanticorpi, oltre a distruggere le piastrine inibiscono la megacariocitopoiesi riducendo la produzione piastrinica. La piastrinopenia dell'ITP (primaria e secondaria) è pertanto dovuta a due fattori principali: distruzione delle piastrine circolanti e soppressione della produzione piastrinica. Di tale meccanismo patogenetico danno conto anche l'azione citotossica dei $\mathrm{T}$ linfociti sui megacariociti e i livelli relativamente ridotti di trombopoietina (TPO). ${ }^{7}$

Nella nuova terminologia sono inoltre incluse le definizioni di ITP severa (esordio con sintomi emorragici tali da richiedere un trattamento o comparsa di nuovi sintomi emorragici tali da richiedere terapia aggiuntiva) e ITP refrattaria (ITP severa e/o che richieda trattamento con assenza di risposta o ricaduta post splenectomia). Data la sempre maggior riluttanza di medici e pazienti a sottoporsi o a consigliare la splenectomia, anche per la disponibilità di nuovi agenti terapeutici, la definizione di refrattarietà così come adottata dall'IWG si sta rivelando poco applicabile.

L'IWG ha suggerito di adottare il termine ITP $d i$ nuova diagnosi per tutti quei casi che si presentino per la prima volta all'osservazione. Entro questa categoria vanno ricomprese anche le forme precedentemente denominate acute, tipiche dei bambini e molto spesso secondarie a dimostrate o presunte infezioni virali, nelle quali spesso si osserva una remissione spontanea. Il termine ITP persistente si riferisce a quei pazienti che nell'intervallo intercorrente fra i 3 e i 12 mesi dalla diagnosi non ottengono una remissione spontanea o non conservano la risposta alla terapia quando questa viene sospesa. Il termine "ITP cronica" viene attualmente riservato a quei pazienti in cui l'ITP persiste per un periodo superiore ai 12 mesi.

\section{Aspetti clinici}

Le manifestazioni emorragiche dell'ITP sono quelle tipiche dei difetti primari dell'emostasi, con prevalenza di petecchie ed ecchimosi cutanee e di sanguinamenti delle mucose. Pur con grande variabilità da soggetto a soggetto, i sintomi emorragici spontanei si manifestano generalmente a livelli piastrinici inferiori a $20-30 \times 10^{9} / \mathrm{L}$, mentre in caso di traumi anche minori, o in soggetti con concomitanti difetti dell'emostasi anche di tipo acquisito (quali quelli legati all'assunzione di aspirina e di altri agenti antipiastrinici o di terapia anticoagulante), essi si possono manifestare anche con livelli piastrinici più elevati $(>50-60$ x $10^{9} / \mathrm{L}$ ). I fattori predittivi di emorragia rimangono scarsamente individuabili. Tuttavia una grave piastrinopenia $\left(<10-20 \times 10^{9} / \mathrm{L}\right)$, precedenti manifestazioni emorragiche ed età avanzata sembrano indicare un aumentato rischio di emorragie maggiori.

La diagnosi di ITP viene fatta per esclusione. Secondo le raccomandazioni formulate da un gruppo internazionale l'iter diagnostico deve prevedere: anamnesi, esame obiettivo, esame emocromocitometrico e reticolocitemia, striscio sangue periferico, misurazione immunoglobuline, gruppo sanguigno, test diretto di Coombs, Helicobacter pylori, sierologia HIV e HCV, esame del midollo osseo in pazienti selezionati. La ricerca degli anticorpi antipiastrine non è utile ai fini diagnostici, perché nessun test di laboratorio si è dimostrato sufficientemente accurato. ${ }^{8}$

\section{Prospettive di terapia}

Premesso che la gran parte dei sanguinamenti maggiori si verifica in presenza di una conta piastrinica $<20 \times 10^{9} / \mathrm{L}$ e che l'inizio del trattamento deve essere individualizzato sulla base della tolleranza della terapia, dello stile di vita e della collaborazione del paziente, la terapia è indicata in tutti i pazienti con conta piastrinica $<<20-30 \times 10^{9} / \mathrm{L}$ e/o con manifestazioni emorragiche. Fanno eccezione i pazienti con patologie che aumentano il rischio emorragico e/o difetti congeniti o acquisti dell'emostasi (comprese terapie antitrombotiche), nei quali è raccomandabile mantenere una conta $>50 \times 10^{9} / \mathrm{L}$. Data la scarsità di studi prospettici, specialmente negli adulti, nei quali l'efficacia della terapia sia stata valutata in termini di riduzione della morbilità emorragica, il criterio di risposta co- 
munemente adottato consiste tuttora nell'incremento della conta piastrinica e nella sua durata nel tempo.

È consigliabile il ricovero ospedaliero dei pazienti con manifestazioni emorragiche anche non gravi ma con conta piastrinica $<20 \times 10^{9} / \mathrm{L}$.

Nei pazienti di nuova diagnosi, l'uso dei corticosteroidi per os (prednisone $1 \mathrm{mg} / \mathrm{kg} /$ die per 3-4 settimane, poi tapering) rappresenta l'approccio standard in assenza di serie controindicazioni.

Si osserva una risposta nel $50-90 \%$ dei casi ma solo il $10-30 \%$ dei pazienti mantiene la remissione alla sospensione o riduzione della terapia. L'uso delle immunoglobuline trova indicazione nei casi in cui sia clinicamente necessario un incremento delle piastrine nelle prime $24-48$ ore. In emergenza trova indicazione anche la trasfusione di una o più unità aferetiche di concentrati piastrinici, che risultano efficaci nonostante l'accorciata sopravvivenza in circolo.

Nelle forme secondarie, spesso la terapia deve essere integrata con il trattamento diretto verso la malattia di base.

Lo scopo della terapia nei casi che non rispondono alle terapie di prima linea o che ricadono dopo una risposta iniziale, consiste principalmente nel differire la splenectomia $o$ altri trattamenti più tossici oltre i primi 12 mesi dalla diagnosi (ITP cronica). In questa fase della malattia, infatti, le remissioni a lungo termine parziali o complete sono rare $(<10 \%)$. Non è dimostrato che il prolungamento della terapia corticosteroidea migliori la storia naturale dell'ITP. La splenectomia è storicamente l'opzione di scelta nell'ITP cronica; il ricorso a tale procedura si sta attualmente riducendo, benché l'argomento sia materia di dibattito: il 70\% circa dei pazienti ottiene una remissione ematologica e solo il $15-25 \%$ di questi va incontro a recidiva nell'arco di 10 anni, mentre la mortalità per l'intervento eseguito in laparoscopia si aggira intorno allo $0,2 \%$.

Negli ultimi anni si è consolidata l'esperienza clinica dell'uso degli agonisti dei recettori della trombopoietina. $^{8}$

Gli studi clinici hanno dimostrato come questi agenti siano in grado di indurre un incremento sostenuto della conta piastrinica portando alla riduzione delle terapie concomitanti per l'ITP e degli episodi emorragici e al miglioramento della qualità di vita. Se ne richiede tuttavia una somministrazione continua.

Romiplostim è un peptide che interagisce con il dominio extracellulare del TPO-R in modo identico alla trombopoietina. È somministrato settimanalmente per via sottocutanea ad un dosaggio variabile da 1 a $10 \mu \mathrm{g} / \mathrm{kg}$ di peso corporeo. Eltrombopag è un agonista orale non peptidico che si lega ad uno specifico dominio trans-membranario del TPO-R. I dosaggi variano da 25 a $75 \mathrm{mg}$.

L'EMA ha inizialmente ristretto il loro utilizzo a pazienti già sottoposti a splenectomia o per i quali vi fosse una controindicazione all'intervento chirurgico. Attualmente il loro uso può essere esteso ai pazienti non splenectomizzati, purché in fase cronica e non responsivi alle terapie di prima linea.

Romiplostim ed eltrombopag si legano a differenti siti del TPO-r sulla membrana dei megacariociti e perciò in caso di fallimento dell'uno, è giustificabile un tentativo con l'altro agente. ${ }^{9}$

I potenziali eventi avversi dei TPO-ra sono rappresentati da: piastrinopenia da sospensione, formazione di reticolina e rischio di fibrosi nel midollo osseo, aumentato rischio di tromboembolismo, sviluppo di neoplasie ematologiche maligne, tossicità epatica con eltrombopag. Si deve prendere in considerazione di effettuare aspirato e biopsia midollare nel corso della malattia e del trattamento, particolarmente in caso di comparsa di nuove anomalie morfologiche o peggioramento delle stesse, citopenia, o aumento delle cellule blastiche periferiche.

Ulteriori trattamenti di seconda linea comprendono anticorpi monoclonali anti-CD20 (Rituximab) e farmaci immunosoppressori (es. azatiorpina). Non sono a oggi disponibili studi comparativi. ${ }^{10}$

\section{Bibliografia}

1 Barcellini W., Anemia emolitica autoimmune: 1'esperienza SIE. Hematology Meeting Reports 2007; $1:(6)$

2 Zanella A., Barcellini W., Treatment of autoimmune hemolytic anemias. Haematologica 2014; Oct;99(10): 1547-54.

3 Barcellini W, Fattizzo B. Clinical Applications of Hemolytic Markers in the Differential Diagnosis and Management of Hemolytic Anemia. Dis Markers. 2015;2015:635670.

4 Capsoni F, Sarzi-Puttini P, Zanella A. Primary and secondary autoimmune neutropenia. Arthritis Res Ther. 2005;7(5):208-14.

5 Boxer LA.How to approach neutropenia Hematology Am Soc Hematol Educ Program. 2012;2012:174-82.

6 Arnold DM. Bleeding complications in immune thrombocytopenia. Hematology Am Soc Hematol Educ Program. 2015;2015:237-42.

7 Cooper N, Cooper N. State of the art - how I manage immune thrombocytopenia. Br J Haematol. 2017 Mar 10

8 Neunert C, Lim W, Crowther M, Cohen A, Solberg L, Jr., Crowther MA. The American Society of Hematology 2011 evidence-based practice guideline for immune thrombocytopenia. Blood. 2011;117(16):4190-207

9 Provan D, Stasi R, Newland AC, Blanchette VS, BoltonMaggs P, Bussel JB, et al. International consensus report on the investigation and management of primary immune thrombocytopenia. Blood. 2010 Jan 14;115(2):168-86.

10 Rodeghiero F, Stasi R, Gernsheimer T, Michel, et al. Standardization of terminology, definitions and outcome criteria in immune thrombocytopenic purpura of adults and children: report from an international working group. Blood 2009; 113: 2386-2393. 


\section{IMID in reumatologia}

Anna Parisi, Rosario Buono, Romualdo Russo, Generoso Uomo

UOSC Medicina Interna 3, AORN Cardarelli, Napoli, Italia

\section{Introduzione}

Le IMID (Immune Mediate Inflammatory Disease) sono ben rappresentate in campo reumatologico laddove costituiscono una frequente espressione sindromica di malattia. ${ }^{1}$ Per semplificazione verranno di seguito presi in considerazione i due prototipi di modello IMID calati in ambito reumatologico, la artrite reumatoide (AR) ed il lupus eritematoso sistemico (LES).

\section{Artrite reumatoide}

L'AR è la più comune forma di poliartrite infiammatoria a carattere autoimmune con una prevalenza nella popolazione caucasica adulta pari allo $0,5-1 \%$, sebbene siano state osservate considerevoli variazioni regionali che probabilmente riflettono l'importanza della predisposizione genetica nel favorire l'insorgenza della malattia. ${ }^{2}$ Numerosi studi eseguiti tra fratelli hanno mostrato come in questi casi la prevalenza della malattia superi il 2-4\%, mentre tra gemelli monozigoti può raggiungere anche il $15 \%$, a conferma del ruolo genetico nella patogenesi dell'AR. ${ }^{3}$ L'AR, come la maggior parte delle malattie infiammatorie croniche autoimmuni d'interesse reumatologico, predilige il sesso femminile, non soltanto per la maggiore frequenza (rapporto F:M = 2:1) ma anche per il decorso più aggressivo che ne condiziona la prognosi. ${ }^{4}$

La patogenesi dell'AR, ancora oggi non del tutto nota, è sicuramente multifattoriale e coinvolge soggetti geneticamente predisposti che vengono in con-

Corrispondente: Generoso Uomo, UOSC Medicina Interna 3, Dipartimento Medico Polispecialistico, AORN Cardarelli, via Cardarelli 9, 80131 Napoli, Italia.

Tel. +39.081.7472101 - Fax: +39.081.7472104

E-mail: gene.uomo@virgilio.it

Articolo pubblicato secondo la Creative Commons Attribution NonCommercial 4.0 License (CC BY-NC 4.0).

(C) Copyright A. Parisi et al., 2017

Licensee PAGEPress, Italy

QUADERNI - Italian Journal of Medicine 2017; 5(7):30-35 tatto con un evento scatenante (antigene sconosciuto) in grado di attivare il sistema immunitario, umorale e cellulare, con conseguente sviluppo di un processo infiammatorio inizialmente acuto che successivamente cronicizza. ${ }^{5}$ Per molti anni al fattore reumatoide (FR) è stato conferito un ruolo chiave nella patogenesi dell'AR. Il FR è un autoanticorpo in grado di riconosce il frammento Fc di un'immunoglobulina di isotipo $\mathrm{G}$ e formare immunocomplessi. ${ }^{6} \mathrm{Il} \mathrm{FR}$ è presente in un'alta percentuale di pazienti (circa $80 \%$ ) ma presenta un valore diagnostico limitato per la sua bassa specificità. Molto più specifici e sensibili sono gli anticorpi anti-proteine/peptidi citrullinati (ACPA) scoperti e validati nel corso degli ultimi anni. Tali anticorpi riconoscono proteine che hanno subito il processo di citrullinazione, cioè quel fenomeno fisiologico che interviene nella degradazione delle proteine intracellulari in corso di apoptosi e negli stati infiammatori e che in alcuni soggetti evoca una risposta autoreattiva. La citrullinazione è una modificazione post-traduzionale in seguito alla quale i residui di arginina vengono convertiti in citrullina in presenza di un enzima chiamato PAD (Peptidyl Arginine deaminase). ${ }^{7}$ Gli ACPA compaiono preferibilmente ma non esclusivamente nei pazienti che esprimono una o due copie degli alleli del cosiddetto Shared Epitope (SE), ${ }^{8}$ una sequenza aminoacidica altamente conservata condivisa da alcune molecole HLA-DRB1 a livello della terza regione ipervariabile della catena $\beta 1$ in posizione 70-74, ritenuta responsabile del legame di un ipotetico peptide immunogenico come i peptidi citrullinati. ${ }^{9} \mathrm{La}$ formazione degli ACPA può essere influenzata oltre che dalla presenza di SE anche dall'abitudine al fumo di sigaretta. Oggi si ritiene che il fumo di sigaretta possa favorire la citrullinazione delle proteine come dimostrato dalla presenza in alte concentrazioni di proteine citrullinate nel fluido di broncolavaggio alveolare dei fumatori. ${ }^{10}$ Questa interessante osservazione ha indotto a ipotizzare che il fumo possa provocare l'apoptosi delle cellule alveolari e la loro citrullinazione con successiva induzione di una risposta immunitaria specifica caratterizzata dalla presenza degli ACPA; rimane però ancora da chiarire come possano raggiungere le articolazioni diartrodiali e colpire il bersaglio sinoviale. Un altro fattore di rischio sembra essere rappresentato dalla presenza di periodontiti 
sostenute da un batterio, il Porphyromonas gingivalis. È stata dimostrata un'elevata prevalenza di periodontiti nell'AR e il trattamento della periodontite può migliorarne i sintomi. ${ }^{11}$

I progressi degli ultimi anni nelle metodiche di tipizzazione genetica hanno permesso di identificare numerose variazioni geniche oltre a SE associate all'AR. Ciò nonostante non è possibile a tutt'oggi codificare uno screening genetico dal momento che la presenza di tali geni nella popolazione generale è molto alta. Un singolo polimorfismo nucleotidico in posizione 1858 $(\mathrm{C} \rightarrow \mathrm{T})$ nella tirosin fosfatasi PTPN22, enzima implicato nell'inibizione del segnale recettoriale delle cellule $\mathrm{T}$ e $\mathrm{B}$, è stato dimostrato come fattore di rischio indipendente nei pazienti con AR. Si ritiene che tale mutazione riduca la soglia d'attivazione dei linfociti T e B facilitando lo sviluppo di cloni autoreattivi. Recenti studi hanno dimostrato l'associazione tra AR con positività per ACPA e diversi altri polimorfismi quali quelli nelle regioni che codificano per STAT4 (Signal Transducer and Activator of Transcription 4, fattore trascrizionale coinvolto nella differenziazione di Th-1 e Th-17), TNF-AIP3 (Tumor Necrosis Factor- $\alpha$ Induced Protein 3) e TRAF-1 (TNF-Receptor Associated Factor-1). Nei pazienti con AR e negatività per ACPA (circa il $30 \%$ ) il principale fattore di rischio genetico è rappresentato dall'espressione della molecola HLA-DR3, parte integrante di un aplotipo in cui sono comprese regioni che codificano per citochine proinfiammatorie come il TNF. ${ }^{12,13}$

Negli ultimi anni sta emergendo anche l'importanza di anomalie epigenetiche nella patogenesi dell'artrite reumatoide; in particolare, recentemente è stato dimostrato che pazienti affetti da AR presentano alterazioni nell'espressione di micro-RNA in cellule mononucleate del sangue periferico, nei linfociti $T$ e nei fibroblasti del plasma e dei fluidi sinoviali. ${ }^{14-18}$ I micro-RNA sono piccole molecole di RNA di circa 20-24 nucleotidi codificate da geni specifici nel genoma umano in grado di esercitare una funzione regolatrice negativa sull'espressione genica a livello post-trascrizionale. È stato verificato che i micro-RNA partecipano a processi cellulari fondamentali come proliferazione, differenziazione ed apoptosi ed ogni micro-RNA controlla a cascata l'espressione di diverse centinaia di altri micro-RNA. ${ }^{19} \mathrm{Al}$ momento non è del tutto chiaro il contributo del network dei micro-RNA nella patogenesi dell'AR ma recenti studi hanno evidenziato che differenti microRNA potenzialmente coinvolti nel controllo dei geni associati all'attivazione del pathway infiammatorio o immunologico, sono fortemente up-regolati nelle cellule mononucleate del sangue periferico e nelle cellule sinoviali dei pazienti affetti da AR se comparati con individui normali o affetti da osteoartrosi. ${ }^{17,18}$ Tali studi hanno rilevato una sovra- regolazione dei microRNA155 e -146 nei fibroblasti sinoviali in soggetti con AR rispetto a pazienti controllo affetti da osteoartrosi ed hanno dimostrato che l'espressione di miR-155 nei fibroblasti sinoviali potrebbe essere indotta da TNF- $\alpha$, interleuchina-1 $\beta$, lipopolisaccaridi, e lipoproteine batteriche ${ }^{17}$ Di recente altri Autori hanno sostenuto e dimostrato un significativo incremento di micro-RNA-146a, -155, -132, e -16 nelle cellule mononucleate del sangue periferico dei pazienti con AR rispetto ai controlli, suggerendo un coinvolgimento a più livelli dei micro-RNA nella patogenesi dell'AR. ${ }^{18,20}$

Il modello patogenetico dell'AR più ampiamente riconosciuto prevede 5 stadi successivi: ${ }^{21-25}$

Stadio 1: 1'Antigene viene presentato da parte delle APC (Antigen Presenting Cells, macrofagi e cellule dendritiche della membrana sinoviale) ai linfociti che cosi vengono attivati e innescano l'intero processo immuno-infiammatorio.

Tale fase è completamente priva di alterazioni istologiche, cliniche e radiologiche.

Stadio 2: i linfociti T e B proliferano all'interno della membrana sinoviale e si assiste alla produzione di anticorpi e FR che formano degli immunocomplessi che passano nel liquido sinoviale, precipitano sulla superficie della cartilagine articolare e attivano il sistema del complemento; vengono richiamati i PMN, che amplificano la flogosi esercitando una funzione attrattiva verso il panno sinoviale. In aggiunta, i linfociti T CD4 stimolano le cellule del sistema monocito-macrofagico, le quali promuovono, attraverso la produzione di particolari citochine, l'angiogenesi e la proliferazione dei sinoviociti; inizia quindi l'iperplasia della membrana sinoviale e si formano i villi sinoviali, la cui crescita è per il momento non polarizzata e senza invasione della cartilagine articolare; in tale fase già sono presenti la rigidità mattutina $\mathrm{e}$ una lieve tumefazione e dolorabilità a carico delle prime articolazioni coinvolte dalla malattia (mani, polsi, piedi); non vi sono invece alterazioni radiologiche.

Stadio 3: si distingue dallo stadio 2 per la severità dei fenomeni che lo caratterizzano e per la comparsa dei primi segni radiologici come l'ispessimento della capsula articolare.

Stadio 4: si caratterizza per la polarizzazione della sinovite e dallo sviluppo centripeto del panno sinoviale, tessuto di granulazione destruente che cresce nel cavo articolare e invade la cartilagine articolare, l'osso subcondrale e i tendini.; sul piano clinico ne deriva un'ulteriore accentuazione dei segni di flogosi e una maggiore limitazione funzionale delle articolazioni colpite; la radiologia mostra riduzione dello spazio articolare dovuta alla distruzione della cartilagine articolare ed osteoporosi periarticolare.

Stadio 5: Il tessuto di granulazione invade progressivamente la cartilagine e l'osso subcondrale, minando quindi il sostegno della cartilagine stessa e alterando l'integrità delle strutture periarticolari come i tendini 
e i legamenti; l'azione invasiva del panno è favorita dall'osteoporosi subcondrale prodotta a sua volta dall'azione di sostanze ad azione osteopenizzante che si liberano nel corso della sinovite reumatoide ed attivano gli osteoclasti; clinicamente tale stadio è caratterizzato dall'accentuazione dei sintomi dello stadio precedente e soprattutto da una notevole limitazione funzionale e dallo sviluppo di deformità; radiologicamente si caratterizza per presenza di notevole riduzione dello spazio articolare e comparsa di erosioni.

Il principale sito infiammatorio della malattia è quindi rappresentato dalla membrana sinoviale (Figura 1). La superficie rivolta verso la cavità articolare (definita lining), normalmente costituita da 1 o 2 strati cellulari privi di tight junctions in cui si riconoscono sinoviociti di tipo $\mathrm{A}$ (ad attività macrofagica) e di tipo $\mathrm{B}$ (ad attività fibroblastica), diviene ipertrofica e iperplastica (4-10 strati) o per accumulo di sinovociti di tipo A di provenienza ematogena o per ipertrofia dei sinoviociti di tipo B. ${ }^{26-28}$ Lo strato sottostante il lining, di fusione con la capsula articolare, in condizioni fisiologiche contiene vasi sanguigni e rari adipociti e fibroblasti, mentre in corso di AR viene infiltrato da numerose cellule, quali linfociti $\mathrm{T}$ e B, plasmacellule, macrofagi, mastcellule, cellule T natural-killer e cellule dendritiche. La sinovia assume quindi l'aspetto di un tessuto infiammatorio con carattere di aggressività e invasività, il cosiddetto panno sinoviale, che presenta fenomeni di neoangiogenesi ed erosioni cartilaginee e dell'osso subcondrale dell'articolazione colpita. ${ }^{27,28}$ Le cellule infiltranti si stimolano vicendevolmente nel microambiente sinoviale, producendo un complesso network di citochine proinfiammatorie quali TNF- $\alpha$, interferone (IFN)-gamma, interleuchina (IL)-1, IL-6, IL-8, IL-15, IL-17 che amplificano e auto-mantengono la risposta infiammatoria. ${ }^{29} \mathrm{Un}$ ruolo centrale nel network citochinico coinvolto nella sinovite reumatoide è svolto dal TNF in quanto, prodotto per lo più dai linfociti e dai macrofagi attivati, favorisce il rilascio di altre citochine proinfiammatorie (IL-1, IL-6, IL-17, IL-18), di chemochine (IL-8, RANTES, MCP-1) e l'espressione di molecole di adesione sulle cellule endoteliali; inoltre interviene nei processi di neoangiogenesi e danno tissutale. ${ }^{30}$ Anche le altre citochine pro-infiammatorie partecipano al danno articolare che caratterizza la malattia attraverso l'attivazione delle MAP-chinasi dei fibroblasti sinoviali, con conseguente derepressione selettiva dei geni che co-

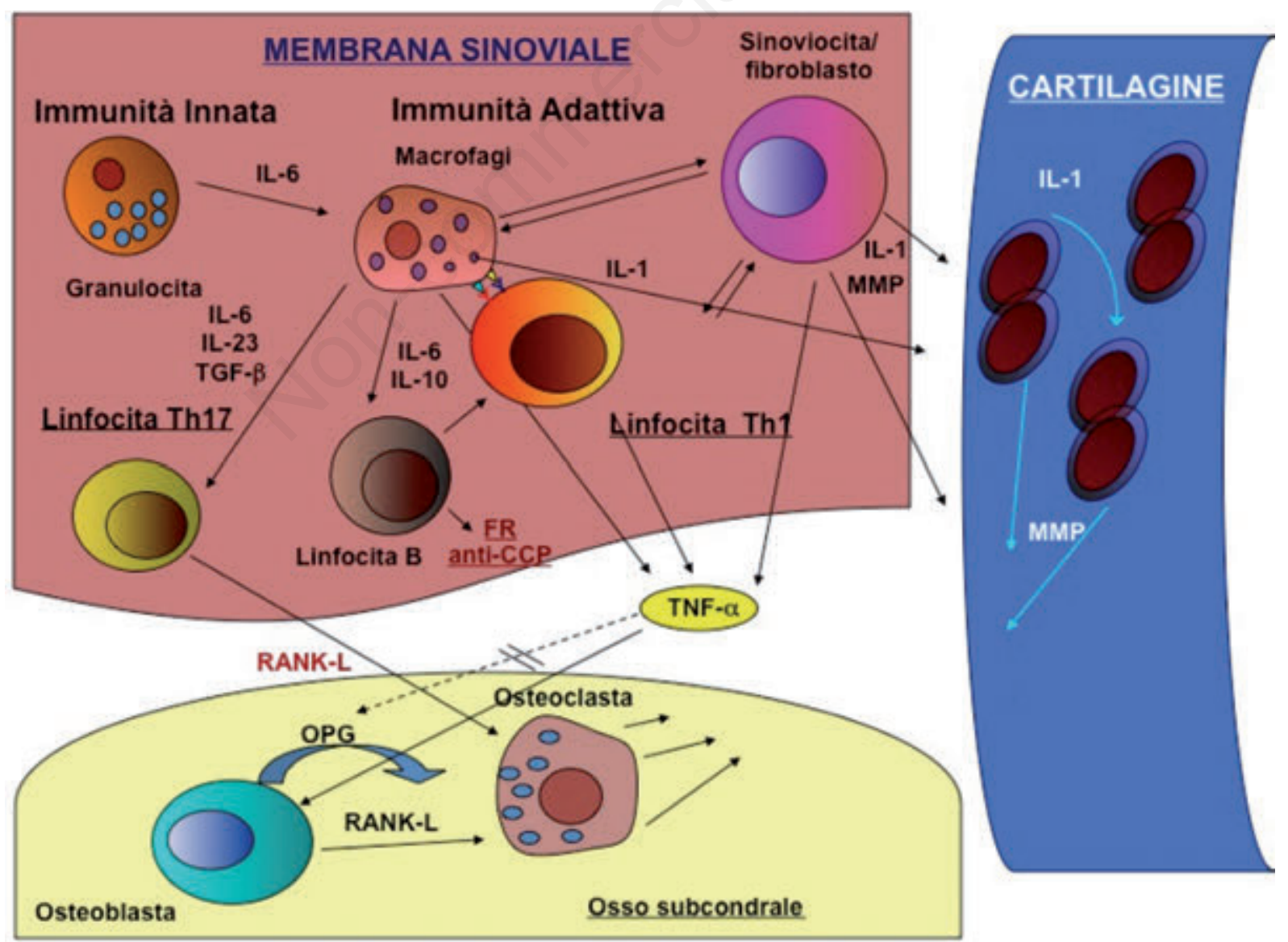

Figura 1. Inter-relazione infiammazione/immunità nelle genesi delle strutture articolari nelle AR (vedi testo). 
dificano per le metalloproteinasi, gli enzimi maggiormente responsabili della distruzione cartilaginea. ${ }^{31} \mathrm{Un}$ ulteriore meccanismo coinvolto nella distruzione ossea in corso di AR è quello del sistema RANK/RANK-Ligand (RANKL): RANK è espresso soprattutto dagli osteoclasti e dai loro precursori nei quali, in conseguenza del legame con RANKL (prodotto da linfociti $\mathrm{T}$ attivati e fibroblasti sinoviali), induce la differenziazione in osteoclasti maturi. ${ }^{32}$

\section{LES}

Il LES può essere considerato un esempio paradigmatico delle IMID per la documentata interazione di fenomeni infiammatori ed immunitari. La malattia ha genesi multifattoriale poichè sono implicati suscettibilità genetica, fattori ambientali e disturbi sia della immunità innata che adattiva ${ }^{33}$ (Figura 2). Sono stati descritti moltissimi loci genetici di suscettibilità e per una trentina di essi vi sono conferme stringenti del loro ruolo patogenetico, anche se poi i fini meccanismi molecolari attraverso cui si attivano i pathways infiammatori correlati non sono ancora completamente conosciuti. ${ }^{34,35}$ È noto e ben dimostrato come nel LES, indipendentemente dall'evento infiammatorio iniziale, vi sia un difetto dei meccanismi di allontanamento (clearance) dei residui apoptotici cellulari che svolgono un importante effetto patogeno. ${ }^{36}$ Le cellule deputate all'apoptosi esprimono proteine di segnale sulla membrana cellulare (eat-me e find-me proteins) che spingono le cellule immuni circolanti ad attaccarle/inglobarle e attraggono i macrofagi e le cellule dendritiche. ${ }^{37}$ Un deficit dei fagociti nel rimuovere in modo completo ed efficace il materiale apoptotico fa sì che frammenti di particelle nucleari siano catturate dalle cellule deputate alla presentazione degli antigeni e attraverso la interazione tra linfociti B e T si determini alla fine lo sviluppo degli anticorpi antinucleo che sono tipici della malattia. ${ }^{38}$ Sono descritte molecole di connessione tra le cellule apoptotiche ed i fagociti con concentrazioni sieriche più elevate nelle forme più gravi di LES giovanile e dell'adulto. ${ }^{39}$ Il coinvolgimento attivo dell'immunità cellulare è documentato dall'intensa attivazione delle cellule B-policlonali con presenza di forme immature e con difetti delle $C D 27$ neg/IgD neg B-memory-cells che diventano meno suscettibili alla immunosoppressione, correlandosi alla

\section{fattori}
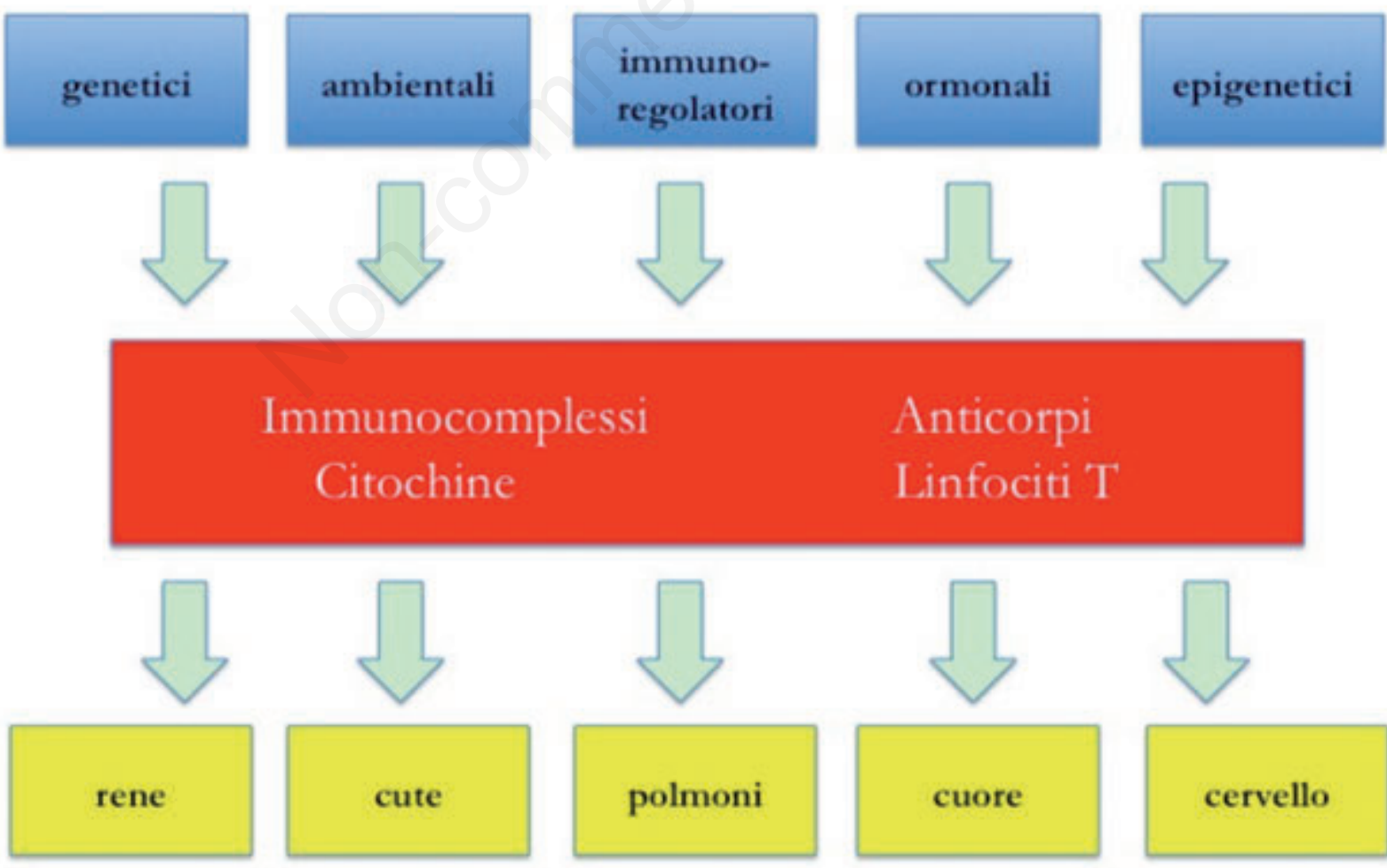

\section{danno d'organo}

Figura 2. Determinanti infiammatori ed immunitari nella patogenesi del danno d'organo in corso di LES (vedi testo). 
attività di malattia, in particolare al danno renale.$^{39} \mathrm{I}$ linfociti T-regolatori della risposta B-cellulare sono anch'essi attivati e si repertano in forma di infiltrati che danneggiano gli organi bersaglio. ${ }^{40} \mathrm{La}$ loro funzione di signaling e di stimolo risulta alterata con produzione non regolata di citochine varie (IL-6, 17, 18, IFN, TNF- $\alpha$ ) ed in particolare di BLys (B-Lymphocyte stimulator), attivamente coinvolte nel processo infiammatorio e nella genesi del danno tissutale nei pazienti con LES. ${ }^{41}$ Con la disponibilità di farmaci antagonisti specifici, la conoscenza del ruolo di questi mediatori ha offerto negli ultimi anni nuove ed efficaci opportunità terapeutiche. ${ }^{33}$

Fra i patogenetici ambientali capaci di innescare la malattia, la luce ultravioletta costituisce di certo il fattore ambientale meglio conosciuto e studiato. L'esposizione ai raggi ultravioletti A e B, soprattutto se associata all'uso di creme fotosensibilizzanti, può scatenare la malattia o esacerbarne le manifestazioni cutanee. ${ }^{42}$ La conseguente necessità di evitare l'esposizione alla luce solare può portare ad un defict di vitamina $\mathrm{D}$ che è inversamente correlato alla attività di malattia. ${ }^{43}$ I raggi ultravioletti agiscono sull'induzione dell'apoptosi in modalità dose-dipendente provocando il rilascio di autoantigeni e produzione di citochine. Minori evidenze scientifiche vi sono per altri fattori ambientali potenzialmente patogenetici quali fumo di sigaretta, infezioni, pesticidi, ftalati. ${ }^{41}$ Di recente, poi, nell'ambito del LES farmaco-indotto, accanto alle forme da idralazina e pennicillamina, sono state descritte correlazioni con l'assunzione di biologici inibitori del TNF- $\alpha .{ }^{44}$ Vi sono differenze nel pattern di laboratorio fra il classico LES farmaco-indotto e queste ultime forme correlate agli anti-TNF- $\alpha$ in quanto gli anticorpi anti-DNA a doppia elica ed ipocomplementemia sono più frequenti nel LES antiTNF- $\alpha$ correlato. ${ }^{33,44}$

Le conoscenze dei meccanismi patogenetici nel LES si sono accresciute nel corso degli ultimi anni con evidenze sempre più stringenti della fondamentale inter-relazione fra infiammazione ad immunità innata/adattiva. Ciò ha portato non solo a meglio comprendere l'importanza di un management globale della malattia ma anche all'applicazione clinica di nuovi farmaci a bersaglio molecolare sempre più attivi per la loro attività di interferire fino a bloccare e il complesso interplay infiammazione-autoimmunità.

\section{Bibliografia}

1. Kuek A, Hazleman BL, Ostor AJK. Immune-mediated inflammatory diseases (IMIDs) and biologic therapy: a medical revolution. Postgrad Med J 2007; 83: 251-60

2. Silman AJ, Pearson JE Epidemiology and genetics of rheumatoid arthritis. Arthritis Res 2002; 4 (Suppl 3): 265-72
3. Abdel-Nasser AM1, Rasker JJ, Valkenburg HA. Epidemiological and clinical aspects relating to the variability of rheumatoid arthritis. Semin Arthritis Rheum1997; 27:123-40

4. Kvalvik AG1, Jones MA, Symmons DP. Mortality in a cohort of Norwegian patients with rheumatoid arthritis followed from 1977 to 1992 . Scand J Rheumatol 2000;29:29-37

5. Gierut A1, Perlman H, Pope RM. Innate immunity and rheumatoid arthritis. Rheum Dis Clin North Am. 2010; 36: 271-96.

6. Weyand CM, Goronzy JJ. Pathomechanisms in rheumatoid arthritis-time for a string theory? J Clin Invest. 2006; 116: 869-71.

7. Schellekens GA, de Jong BA, van den Hoogen FH, van de Putte LB, van Venrooij WJ. Citrulline is an essential constituent of antigenic determinants recognized by rheumatoid arthritis-specific autoantibodies. J Clin Invest. 1998; 101: 273-81.

8. Gregersen PK, Silver J, Winchester RJ. The shared epitope hypothesis. An approach to understanding the molecular genetics of susceptibility to rheumatoid arthritis. Arthritis Rheum. 1987; 30: 1205-13

9. Huizinga TW, Amos CI, van der Helm-van Mil AH, Chen W, van Gaalen FA, Jawaheer D, Schreuder GM, Wener M, Breedveld FC, Ahmad N, Lum RF, de Vries RR, Gregersen PK, Toes RE, Criswell LA. Refining the complex rheumatoid arthritis phenotype based on specificity of the HLA-DRB1 shared epitope for antibodies to citrullinated proteins. Arthritis Rheum. 2005; 52: 3433-8

10. Klareskog L, Padyukov L, Lorentzen J, Alfredsson L. Nat Mechanisms of disease: genetic susceptibility and environmental triggers in the development of rheumatoid arthritis. Clin Pract Rheumatol. 2006; 2: 425-33

11. Panayi GS. Developments in the immunology of rheumatoid arthritis, a personal perspective. Rheumatology (Oxford). 2011; 50: 815-7.

12. van der Helm-van Mil AH, Verpoort KN, le Cessie S, Huizinga TW, de Vries RR, Toes RE. The HLA-DRB1 shared epitope alleles differ in the interaction with smoking and predisposition to antibodies to cyclic citrullinated peptide. Arthritis Rheum. 2007; 56:425-32

13. Feitsma AL, Toes RE, Begovich AB, Chokkalingam AP, de Vries RR, Huizinga TW, van der Helm-van Mil AH. Risk of progression from undifferentiated arthritis to rheumatoid arthritis: the effect of the PTPN22 1858Tallele in anti-citrullinated peptide antibody positive patients. Rheumatology (Oxford). 2007; 46: 1092-5

14. Korczowska I. Rheumatoid arthritis susceptibility genes: An overview. World J Orthop. 2014; 18; 5: 544-9

15. Kochi Y, Suzuki A, Yamamoto K. Genetic basis of rheumatoid arthritis: a current review. Biochem Biophys Res Commun. 2014; 19: 254-62

16. Verpoort KN, van Gaalen FA, van der Helm-van Mil AH, Schreuder GM, Breedveld FC, Huizinga TW, de Vries RR, Toes RE. Association of HLA-DR3 with anticyclic citrullinated peptide antibody-negative rheumatoid arthritis. Arthritis Rheum. 2005; 52: 3058-62

17. Stanczyk J, Pedrioli DM, Brentano F, Sanchez-Pernaute O, Kolling C, Gay RE, Detmar M, Gay S, Kyburz D. Altered expression of MicroRNA in synovial fibroblasts and synovial tissue in rheumatoid arthritis. Arthritis Rheum. 2008; 58: 1001-9 
18. Pauley KM, Cha S, Chan EK. MicroRNA in autoimmunity and autoimmune diseases. J Autoimmun. 2009; 32: 189-94.

19. Ong SG, Lee WH, Kodo K, Wu JC. MicroRNA-mediated regulation of differentiation and trans-differentiation in stem cells. Adv Drug Deliv Rev. 2015; 88: 3-15

20. Pauley KM, Satoh M, Chan AL, Bubb MR, Reeves WH, Chan EK. Upregulated miR-146a expression in peripheral blood mononuclear cells from rheumatoid arthritis patients. Arthritis Res Ther. 2008;10:101-10

21. McInnes IB, O'Dell JR. State-of-the-art: rheumatoid arthritis. Ann Rheum Dis. 2010; 69: 1898-906

22. Steiner G. Auto-antibodies and autoreactive T-cells in rheumatoid arthritis: pathogenetic players and diagnostic tools. Clin Rev Allergy Immunol. 2007; 32: 23-36

23. Smolen JS, Redlich K, Zwerina J, Aletaha D, Steiner G, Schett G. Pro-inflammatory cytokines in rheumatoid arthritis: pathogenetic and therapeutic aspects. Clin Rev Allergy Immunol. 2005; 28: 239-48

24. Geiler T, Lorenz HM, Kalden JR, Manger B. Pathogenesis of rheumatoid arthritis. Med Klin (Munich). 1997; 15; $92: 347-53$

25. Goronzy JJ, Weyand CM. T and B cell-dependent pathways in rheumatoid arthritis. Curr Opin Rheumatol 1995; 7: 214-21

26. Bartok B, Firestein GS. Fibroblast-like synoviocytes: key effector cells in rheumatoid arthritis. Immunol Rev. 2010; 233: 233-55

27. Schönfeld C, Pap T, Neumann E, Müller-Ladner U.Z Fibroblasts as pathogenic cells in rheumatic inflammation. Rheumatol. 2015; 74: 33-8

28. Choy EH, Panayi GS. Cytokine pathways and joint inflammation in rheumatoid arthritis. N Engl J Med. 2001 22; 344: 907-16

29. Tran CN, Lundy SK, White PT, Endres JL, Motyl CD, Gupta R, Wilke CM, Shelden EA, Chung KC, Urquhart AG, Fox DA. Molecular interactions between T cells and fibroblast-like synoviocytes: role of membrane tumor necrosis factor-alpha on cytokine-activated T cells. Am J Pathol. 2007; 171: 1588-98.

30. Taylor PC, Feldmann M. Anti-TNF biologic agents: still the therapy of choice for rheumatoid arthritis. Nat Rev Rheumatol. 2009; 5: 578-82

31. Young-Min S, Cawston T, Marshall N, Coady D, Chri- stgau S, Saxne T, Robins S, Griffiths I. Biomarkers predict radiographic progression in early rheumatoid arthritis and perform well compared with traditional markers. Arthritis Rheum. 2007; 56: 3236-47.

32. Wada T, Nakashima T, Hiroshi N, Penninger JM. RANKL-RANK signaling in osteoclastogenesis and bone disease. Trends Mol Med. 2006; 12: 17-25

33. Lisnevskaia L, Murphy G, Isenberg D. Systemic lupus erythematosus. Lancet 2014; 384: 1878-88

34. Wahren-Herlenius M, Dörner T. Immunopathogenic mechanisms of systemic autoimmune disease. Lancet 2013; 382: 819-31

35. Guerra SG, Vyse TJ, Cunninghame Graham DS. The genetics of lupus: a functional perspective. Arthritis Res Ther 2012; 14: 211-23

36. Shao WH, Cohen PL. Disturbances of apoptotic cell clearance in systemic lupus erythematosus. Arthritis Res Ther 2011; 13: 202-09

37. Yamaguchi H, Takagi J, Miyamae T, et al. Milk fat globule EGF factor 8 in the serum of human patients of systemic lupus erythematosus. J Leukoc Biol 2008; 83: 1300-07

38. Dörner T, Giesecke C, Lipsky PE. Mechanisms of B cell autoimmunity in SLE. Arthritis Res Ther 2011; 13: 243-54

39. Blair PA, Noreña LY, Flores-Borja F, et al. CD19(+)CD24(hi) CD38(hi) B cells exhibit regulatory capacity in healthy individuals but are functionally impaired in systemic lupus erythematosus patients. Immunity $2010 ; 32: 129-40$

40. Moulton VR, Tsokos GC. Abnormalities of T cell signaling in systemic lupus erythematosus. Arthritis Res Ther 2011; 13: 207-16

41. Zandman-Goddard G, Solomon M, Rosman Z, Peeva E, Shoenfeld Y. Environment and lupus-related diseases. Lupus 2012; 21: 241-50

42. Jacob N, Stohl W. Cytokine disturbances in systemic lupus erythematosus. Arthritis Res Ther 2011; 13: 228-38

43. Caricchio R, McPhie L, Cohen PL. Ultraviolet B radiation-induced cell death: critical role of ultraviolet dose in inflammation and lupus autoantigen redistribution. $\mathrm{J}$ Immunol 2003; 171: 5778-86

44. Williams EL, Gadola S, Edwards CJ. Anti-TNF-induced lupus. Rheumatology (Oxford) 2009; 48: 716-20. 


\title{
IMIIDs in neurologia
}

\author{
Giorgia Teresa Maniscalco, Ciro Florio \\ Clinica di Neurologia, Ospedale A. Cardarelli, Napoli, Italia
}

\section{Introduzione}

Il sistema nervoso (SN) è frequentemente interessato da processi patogenetici di tipo autoimmune sia diretti contro antigeni specifici per il SN (malattie organo-specifiche) che in corso di malattie autoimmuni di tipo sistemico (malattie sistemiche).

Le malattie autoimmnuni organo-specifiche del SN sono rappresentate da un gruppo estremamente eterogeneo di malattie, diverse per meccanismo etiopatogenetico e fenotipo clinico e che possono schematicamente essere classificate in patologie autoimmuni del sistema nervoso centrale, del sistema nervoso periferico, della giunzione neuromuscolare e del muscolo, a seconda della sede dell'antigene bersaglio. Alla base di tali malattie vi sono infatti dei meccanismi patogenetici alquanto diversi che vanno da una prevalente citotossicità T-mediata contro antigeni mielinici nel caso della sclerosi multipla (SM), ad una attività anticorpo-mediata contro antigeni della giunzione neuromuscolare con secondaria attivazione del complemento in caso di miastenia gravis, ad infiltrati linfocitari con successiva attivazione dei macrofagi presenti nelle polineuropatie periferiche e nelle miopatie infiammatorie. Il coinvolgimento neurologico in corso delle malattie autoimmunitarie sistemiche è una condizione di frequente riscontro che può essere responsabile talvolta anche di severo peggioramento della malattia di base fino alla morte del paziente se non si interviene fin dalle fasi precoci. Nella maggior parte dei casi le manifestazioni neurologiche possono essere attribuite a vari meccanismi che comprendono compromissione vascolare su base ischemica, vasculiti, infiammazione citochinomediata, citotossicità da cellule $\mathrm{T}$, autoimmunità specifica contro antigeni neurali e rottura della barriera ematoencefalica. Può essere riscontrato un interessamento combinato o più spesso focale del sistema nervoso centrale o di quello periferico. Il trattamento di entrambe le condizioni varia grandemente in base alla patologia (se primariamente neurologica) o alla malattia internistica sottostante. I trattamenti in uso comprendono immunosoppressori storici quali l'azatioprina, la ciclofosfamide, la ciclosporina, il metotrexate ed il mitoxantrone, ormai entrati nell'uso comune dei diversi specialisti, e di farmaci con nuovi meccanismi d'azione, primi tra tutti quelli biologici, spesso più efficaci ma che necessitano di più stretto monitoraggio perché a maggior rischio di seri eventi avversi. Di seguito, a titolo esemplificativo, verranno prese in esame solo alcune delle malattie infiammatorie disimmuni neurologiche, le più importanti per ciascun distretto neurologico interessato e alcune tra quelle secondarie a patologie autoimmuni sistemiche (Tabella 1).

\section{Tabella 1. IMIDs in neurologia.}

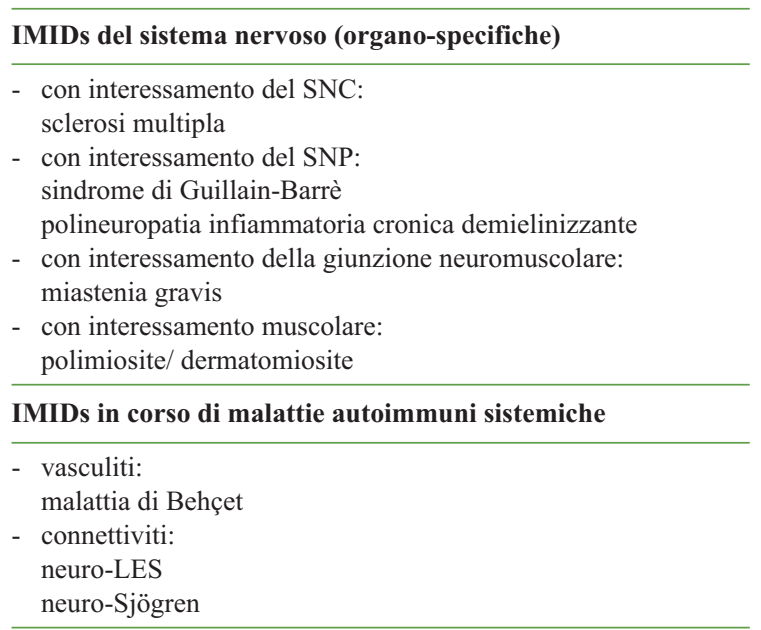

Corrispondente: Giorgia Teresa Maniscalco, Clinica di Neurologia, Ospedale A. Cardarelli, Napoli, Italia.

E-mail: gtmaniscalco@libero.it

Articolo pubblicato secondo la Creative Commons Attribution NonCommercial 4.0 License (CC BY-NC 4.0).

CC Copyright G.T. Maniscalco e C. Florio, 2017

Licensee PAGEPress, Italy

QUADERNI - Italian Journal of Medicine 2017; 5(7):36-56 


\section{Parte I: IMIDs neurologiche organo-specifiche}

\section{Parte I - A) Sclerosi multipla}

\section{Definizione}

La sclerosi multipla (SM) è una malattia cronica demielinizzante del sistema nervoso centrale ad eziologia autoimmunitaria caratterizzata da aree localizzate d'infiammazione, demielinizzazione, perdita assonale e gliosi nell'encefalo e nel midollo spinale. Colpisce prevalentemente giovani adulti ed è gravata da una disabilità di vario grado. Dal punto di vista epidemiologico, secondo la stima dell'Atlante mondiale della SM, la prevalenza nel nostro Paese è di 110 casi su 100.000 persone, mentre il tasso di incidenza medio è di oltre 3-4 casi per 100.000 abitanti per anno. ${ }^{1}$ I dati dell'Associazione Italiana Sclerosi Multipla (AISM) riportano circa 110.000 casi di SM in Italia. ${ }^{2}$

\section{Aspetti clinici}

La SM è una malattia particolarmente subdola perché può colpire qualsiasi zona del sistema nervoso centrale, midollo compreso, provocando sintomi che dipendono essenzialmente dalla localizzazione dei focolai di demielinizzazione e possono essere molto variabili da soggetto a soggetto. Sintomi comuni di esordio possono includere parestesie, o addormentamenti, deficit motori, disturbi visivi a carico in genere di un solo occhio, diplopia disturbi dell'andatura, incoordinazione motoria,vertigini, unitamente a fatica spasticità, atassia, nistagmo, dolore neuropatico, disturbi urinari con ritenzione urgenza o incontinenza, disfunzioni sessuali, deficit cognitivi, depressione del tono dell'umore o altri segni psichiatrici. Inoltre la frequenza con cui essi compaiono è diversa: alcuni sono decisamente frequenti (deficit visivi da neurite ottica retrobulbare, deficit della motilità oculare, nistagmo, deficit motori e sensitivi) altri sono rari o compaiono solo in fase avanzata di malattia (crisi epilettiche, dolore neuropatico, disturbi sfinterici e spasticità). Il decorso della SM è assai variabile: ${ }^{3}$ dopo il primo episodio vi può essere un intervallo libero più o meno prolungato in seguito al quale si può verificare una riattivazione di vecchi sintomi o di comparsa di sintomi inediti. Nelle forme recidivanti remittenti (RR) (circa 1'85\% degli esordi) si presentano episodi acuti della malattia (le cosiddette ricadute, che regrediscono completamente o parzialmente in un tempo variabile) alternati a periodi di benessere (definiti remissioni). Circa il 30-35\% di questi pazienti nel corso del tempo tende ad avere non più una remissione, più o meno completa, bensì un progressivo peggioramento dei sintomi: ciò può avvenire intorno ai 5-10 anni dall'esordio e caratterizza le forme secondarie-progressive
(SP). In circa il 10\% degli esordi della malattia non sono presenti ricadute, ma un progressivo peggioramento clinico che porta all'accumulo di disabilità: in questo caso parliamo di forme primarie progressive (PP). A questa classificazione vanno aggiunte le forme clinicamente isolate (CIS) caratterizzate dalla presenza di un singolo episodio clinico con quadro neuroradiologico altamente suggestivo per SM e le sindromi radiologicamente isolate (RIS) caratterizzate dal riscontro accidentale in risonanza magnetica di lesioni suggestive di SM in assenza di riscontro clinico.

\section{Diagnosi}

La diagnosi di SM è essenzialmente clinica, si basa sul riconoscimento di segni e sintomi a carico di più aree dell'encefalo e del midollo (la cosiddetta disseminazione nello spazio) che si presentano in tempi diversi (disseminazione temporale) con l'esclusione di altre condizioni che possono mimarla (no better explanation). La diagnosi di avvale della dimostrazione in risonanza magnetica (RM) di multiple areole demielinizzanti nella sostanza bianca ipertintense nelle sequenze T2-FLAIR, talora ipointense nelle sequenze T1 o captanti gadolinio, distribuite in sedi tipiche, quali la regione periventricolare, il corpo calloso e in regione sottotentoriale. Gli attuali criteri diagnostici sono stati revisionati nel 2011 (Tabella 1). ${ }^{4}$ L'iter diagnostico prevede inoltre l'esame del liquor per la ricerca di bande oligoclonali (a dimostrazione di sintesi intratecale di Ig), i potenziali evocati (PEV, BAEPs e SEP) e screening autoanticorpi (per escludere malattie autoimmuni sistemiche). Relativamente alla prognosi ad oggi non disponiamo ancora di criteri prognostici validi ma diversi studi hanno evidenziato che disturbi visivi o sensitivi all'esordio, un lungo intervallo tra la prima e la seconda ricaduta, un recupero neurologico completo, il sesso femminile e la giovane età di esordio sono associati ad una prognosi più favorevole. ${ }^{5} \mathrm{La}$ malattia generalmente progredisce provocando un accumulo di disabilità nel tempo con una media di circa 10 anni prima di presentare un deficit dell'andatura e di circa 15-20 anni prima di necessitare di un supporto per deambulare, corrispondente ad un punteggio di 6 alla scala di Kurtzke (EDSS). ${ }^{6}$ L'aspettativa di vita è sovrapponibile al normale al massimo ridotta di 7-10 anni e prevalentemente per complicazioni mediche simili a quelle della popolazione generale. ${ }^{7}$

La diagnosi differenziale comprende un'ampia gamma di patologie che specie all'esordio possono essere confondenti sia sul piano clinico sia sul piano dell'imaging e del laboratorio, come ad esempio: i) Vascolari: vasculiti cerebrali con lesioni multifocali cerebrali, fistole artero-venose spinali o che possono causare paraparesi, CADASIL; Neuro-Behçet; ii) Infettive: HTLV1, sifilide, neuroborreliosi; iii) Neoplastiche e paraneoplastiche: sindromi atassiche, encefalite limbica, 
sindrome opsoclono-mioclono; iv) Autoimmuni sistemiche: LES, sindrome da anticorpi antifosfolipidi, sindrome di Sjögren, sarcoidosi; v) Metaboliche: leucodistrofie dell'adulto, tipo adrenoleucodistrofia; vi) Malattie demielinizzanti idiopatiche: a decorso generalmente monobasico come ADEM, mielite traversa; Neuromieliteottica (NMO); CRION, malattie demielinizzanti post-infettive; vii) Nutrizionali: carenza di vitamina B12 e sindromi da malassorbimento; viii) Mitocondriali: Malattia di Leber.

\section{Terapia}

Il trattamento farmacologico della SM prevede tre campi di applicazione: il trattamento delle ricadute (basato su boli steroidei in vena,o nei casi più gravi non responsivi al cortisone, la plasmaferesi), quello sintomatico e quello modificante il decorso di malattia . I farmaci modificanti il decorso della malattia (DMT) hanno come principale obiettivo quello di ridurre la frequenza e la severità delle ricadute cliniche, rallentare la progressione della disabilità e migliorare la qualità di vita dei pazienti. Essi sono schematicamente distinti in immunomodulanti ed immunosoppressori, e, nei trials clinici registrativi, hanno mostrato diversi profili di efficacia e di sicurezza. ${ }^{8-26}$ Ad oggi si dispone di un ampio ventaglio di trattamenti che sono stati classificati dalle Autorità Regolatorie in farmaci di prima e seconda linea che si sono affiancati ad immunosoppressori storici quali mitoxantrone, ciclofosfamide ed aziatoprina. ${ }^{27-33}$ In casi selezionati, non responsivi ai comuni trattamenti, è indicato il trapianto di cellule mesenchimali autologhe. Gli attuali trattamenti DMT, sulla base delle indicazioni prescrittive dell'AIFA (nota 65), sono quindi classificati in:
- Farmaci di I linea: i) interferon (IFN): 1a e 1b; ii) glatiramer acetato (GA); iii) teriflunomide; iv) dimetil-fumarato (BG12).

- Farmaci di II linea: i) natalizumab (NTZ); ii) fingolimod (FTY); iii) alemtuzumab; iv) mitoxantrone (MTX).

I trattamenti DMT approvati come prima linea hanno dimostrato un'efficacia quasi sovrapponibile in termini di riduzione di ricadute, rallentamento della progressione di disabilità, riduzione del carico lesionale e dell'attività di malattia alla RM, ma il profilo di aderenza e tollerabilità e le vie di somministrazione sono differenti. ${ }^{8-20}$ Esistono delle evidenze sulla superiorità di efficacia della dose maggiore di interferone rispetto alle dosi minori, a scapito di maggiori effetti collaterali e maggiore immunogenicità (NAbs). I nuovi farmaci orali hanno dimostrato un'efficacia maggiore o comparabile agli iniettivi ma in assenza di dati di confronto diretto, a fronte di una minore conoscenza degli effetti a lungo termine e di effetti collaterali immediati. Tali dati rendono il ventaglio terapeutico con i farmaci di prima linea ampiamente adattabile alle diverse esigenze di trattamento dei singoli pazienti, tenendo conto tanto dell'attività di malattia, quanto dei i fattori prognostici e dello stile di vita/compliance dei pazienti. I farmaci di II linea si sono dimostrati più efficaci di quelli di prima linea nel controllare la malattia ${ }^{21-26}$ ma non esistono studi comparativi di efficacia tra essi. La scelta dell'utilizzo di tali farmaci deriva dal grado di aggressività della malattia e dall'attenta valutazione dei fattori di rischio relativi al paziente, dalla storia clinica del paziente (per es. pregresse i terapie immunosoppressive) e la presenza di patologie concomitanti. Tuttavia con l'utilizzo dei più recenti farmaci sono emerse nuove

Tabella 1. Revisione Criteri diagnostici McDonald 2010 per diagnosi SM.

\begin{tabular}{ll}
\hline Presentazione clinica & Dati aggiuntivi necessari \\
\hline$\geq 2$ episodi acuti e coinvolgimento & Nessuno \\
$\geq 2$ sistemi funzionali neurologici & \\
\hline$\geq 2$ episodi acuti e coinvolgimento & $\begin{array}{l}\text { Disseminazione spaziale dimostrata: } \geq 1 \text { lesione/i T2 in almeno } 2 \text { di } 4 \text { sedi tipiche oppure attendere un } \\
\text { ulteriore attacco in altra sede }\end{array}$ \\
\hline di 1 sistema funzionale neurologico & $\begin{array}{l}\text { Disseminazione temporale dimostrata: simultanea presenza di lesioni captanti e non gadolinio } \\
\text { asintomatiche, oppure una nuova lesione al follow up, oppure un secondo attacco }\end{array}$ \\
\hline 1 sistemi funzionali neurologici & $\begin{array}{l}\text { Disseminazione spaziale e temporale: } \geq 1 \text { lesione/i T2 in almeno } 2 \text { di } 4 \text { sedi tipiche oppure attendere } \\
\text { di } 1 \text { sistema funzionale neurologico }\end{array}$ \\
\hline oppure una nuova lesione al follow up, oppure un secondo attacco \\
progressiva suggestiva di SM & $\begin{array}{l}1 \text { anno di progressione di malattia con almeno } 2 \text { su } 3 \text { dei seguenti criteri: } \\
\text { DIS encefalica } \geq 1 \text { lesione/i T2 in sedi tipiche } \\
\text { DIS midollare } \geq 2 \text { lesioni T2 midollari } \\
\text { Liquor positivo } \text { (Bande oligoclonali e/o elevato IgG index) }\end{array}$ \\
\hline
\end{tabular}

Episodio acuto: comparsa di un disturbo neurologico della durata di almeno 24 ore, in assenza di febbre e/o infezioni, caratterizzato da deficit motori, visivi, sensitivi, di equilibrio, di coordinazione, sfinterici e cognitivi; tali eventi possono aver presentato una spontanea remissione, una risposta positiva ad un eventuale trattamento, ma possono altresì, in taluni casi, aver determinato degli esiti funzionali permanenti

Polman et al., 2011. ${ }^{4}$ 
problematiche derivanti dalla gestione degli stessi che giustifica una competenza elevata e una approfondita conoscenza dei molteplici effetti collaterali come cardiotossicità, teratogenicità e rischio infettivo, potenzialmente letale (come per es. la leucoencefalite progressiva multifocale PML).

\section{Bibliografia}

1. Howard J, Trevick S, Younger DS Epidemiology of Multiple Sclerosis. Neurol Clin. 2016 Nov; 34(4):919-939

2. Fonte AISM "Barometro della SM 2016 in sintesi" del $18 / 05 / 2016$

3. Jacques FH. Defining the clinical course of multiple sclerosis: the 2013 revision Neurology. 2015 Mar 3;84(9):963.

4. Polman $\mathrm{CH}$, et al. Diagnostic criteria for multiple sclerosis: 2010 revisions to the McDonald criteria. Ann Neurol. $2011 \mathrm{Feb} ; 69(2): 292-302$.

5. Confavreux C, Vukusic S. The clinical course of multiple sclerosis. Handb Clin Neurol. 2014;122:343-69

6. Kurtze JF Neurology. 1983 Nov;33(11):1444-52

7. Karamyan A, et al Causes of death in critically ill multiple sclerosis patients. Acta Neurol Scand. 2016 Dec 23

8. PRISMS (Prevention of Relapses and Disability by Interferon beta-1a Subcutaneously in Multiple Sclerosis) Study Group "Randomised double-blind placebo-controlled study of interferon beta-1a in relapsing/remitting multiple sclerosis"; Lancet 1998

9. The IFNB Multiple Sclerosis Study Group "Interferon beta- $1 \mathrm{~b}$ is effective in relapsing-remitting multiple sclerosis. Clinical results of a multicenter, randomized, double-blind, placebo-controlled trial”; Neurology 1993.

10. Johnson KP et al "Copolymer 1 reduces relapse rate and improves disability in relapsing-remitting multiple sclerosis: results of a phase III multicenter, double-blind placebo-controlled trial"; Neurology 1995

11. Jacobs LD et al. "Intramuscular interferon beta-1a for disease progression in relapsing multiple sclerosis. The Multiple Sclerosis Collaborative Research Group (MSCRG)" Ann Neurol 1996

12. Jacobs LD et al "Intramuscular interferon beta-1a therapy initiated during a first demyelinating event inmultiple sclerosis. CHAMPS Study Group." The New England Journal of Medicine 2000

13. Kappos L et al Group BS. "Long-term effect of early treatment with interferon beta-1b after a first clinical event suggestive of multiple sclerosis: 5 -year active treatment extension of the phase 3 BENEFIT trial". Lancet Neurology 2009

14. Filippi $\mathrm{M}$ et al "Interferon beta-1a for brain tissue loss in patients at presentation with syndromes suggestive of multiple sclerosis: a randomised,double-blind, placebocontrolled trial" Lancet. 2004.

15. Comi G et al "Effect of glatiramer acetate on conversion to clinically definite multiple sclerosis in patients with clinically isolated syndrome (PreCISe study): a randomised, double-blind, placebo-controlled trial" Lancet. 2009

16. Calabresi PA et al "Pegylated interferon $\beta$-1a for relapsingremitting multiple sclerosis (ADVANCE): a randomised, phase 3, double-blind study" Lancet Neurol 2014

17. P. O'Connor, et al. "Randomized trial of oral terifluno- mide for relapsing multiple sclerosis (TEMSO)" New Engl J Med 2011

18. Confavreux C "Oral teriflunomide for patients with relapsing multiple sclerosis (TOWER): a randomised, double-blind, placebo-controlled, phase 3 trial." Lancet Neurol. 2014

19. Gold R. "Placebo-controlled phase 3 study of oral BG12 for relapsing multiple sclerosis.(DEFINE STUDY)" N Engl J Med. 2012

20. Fox RJ "Placebo-controlled phase 3 study of oral BG12 or glatiramer in multiple sclerosis.(CONFIRM)". N Engl J Med. 2012

21. Rudick RA "Natalizumab plus interferon beta-1a for relapsing multiple sclerosis.” N Engl J Med. 2006

22. Polman $\mathrm{CH}$ "A randomized, placebo-controlled trial of natalizumab for relapsing multiple sclerosis". N Engl J Med. 2006

23. Plavina T, Subramanyam M, Bloomgren G, Richman S, Pace A, Lee S, Schlain B, Campagnolo D, Belachew S, Ticho B. "Anti-JC virus antibody levels in serum or plasma further define risk of natalizumab-associated progressive multifocal" Ann Neurol. 2014

24. Cohen JA et al Oral fingolimod or intramuscular interferon for relapsing multiple sclerosis. The New Engl J Med. 2010

25. Kappos L, et al . A placebo-controlled trial of oral fingolimod in relapsingmultiple sclerosis. The New England Journal of Medicine. 2010

26. Cohen JA, et al Alentuzumab versus interferon beta 1a as first-line treatment for patients with relapsing-remittingmultiple sclerosis: a randomized controlled phase 3 trial. Lancet. 2012;

27. Gonsette RE. Mitoxantrone in progressive multiple sclerosis: when and how to treat? Journal of the Neurological Sciences. 2003;

28. Neuhaus O, Kieseier BC, Hartung HP. Therapeutic role of mitoxantrone in multiple sclerosis.Pharmacology \& Therapeutics. 2006;

29. Et al Azathioprine versus beta interferons for relapsingremitting multiple sclerosis: a multicentre randomized non-inferiority trial. " Plos One 2014

30. Casetta I, Iuliano G, Filippini G. Azathioprine for multiple sclerosis. The Cochrane database of systematic reviews. 2007; (4): CD003982.

31. Zephir H, de Seze J, Duhamel A, Debouverie M, Hautecoeur P, Lebrun C, Malikova I, Pelletier J, SenechalO, Vermersch P. Treatment of progressive forms of multiple sclerosis by cyclophosphamide: a cohort study of 490 patients. Journal of the Neurological Sciences. 2004;

32. Hauser SL, Dawson DM, Lehrich JR, Beal MF, Kevy SV, Propper RD, Mills JA, Weiner HL. Intensive immunosuppression in progressive multiple sclerosis. A randomized, three-arm study of high-dose intravenous cyclophosphamide, plasma exchange, and ACTH. The New England Journal of Medicine.1983;

33. Hauser SL, Dawson DM, Lehrich JR, Beal MF, Kevy SV, Propper RD, Mills JA, Weiner HL. Intensive immunosuppression in progressive multiple sclerosis. A randomized, three-arm study of high-dose intravenous cyclophosphamide, plasma exchange, and ACTH. The New England Journal of Medicine.1983;

34. He D, Zhou H, Han W, Zhang S. Rituximab for relapsingremitting multiple sclerosis Cochrane Database Syst Rev. 


\section{Parte I - B) Neuropatie immunomediate}

Le neuropatie immunomediate comprendono la sindrome di Guillain-Barrè (GBS), la sindrome di MillerFisher, la neuropatia infiammatoria demielinizzante cronica (CIDP), le neuropatie motorie multifocali, le neuropatie associate a gammapatie monoclonali e le neuropatie sensitive sub-acute paraneoplastiche, tutte affezioni che si ritiene siano causate da una risposta autoimmunitaria nei riguardi di un antigene di pertinenza del nervo periferico. Il coinvolgimento del sistema immunitario è stato riconosciuto in maniera convincente nel 1980 con la pubblicazione del lavoro di Latov col quale si dimostrava il coinvolgimento incontrovertibile di anticorpi IgM che reagivano con una glicoproteina componente minore della mielina periferica in un paziente affetto da gammopatia monoclonale. ${ }^{1}$ Da allora sono state identificati numerosi altri anticorpi contro diversi antigeni del nervo periferico che hanno contribuito a chiarire oltre alla patogenesi l'identificazione e la diagnosi di nuove forme di malattie disimmuni del sistema nervoso periferico.

\section{Sindrome di Guillain-Barrè}

La sindrome di Guillain-Barrè (GBS) è la più frequente causa di paralisi acuta del nervo periferico, con progressione del deficit neurologico in pochi giorni o settimane e che per definizione dura al massimo 4 settimane, cui fa seguito una fase di stazionarietà e un successivo recupero. Il tasso di incidenza della sindrome Guillain-Barré in Europa e Nord America è di circa 0,81:100.000 e la malattia è leggermente più frequente nei maschi che nelle femmine. ${ }^{2}$ La GBS è caratterizzata da ipostenia progressiva degli arti che può essere sia distale che prossimale ma classicamente presenta andamento ascendente fino a coinvolgere i nervi cranici e nelle forme più gravi i muscoli respiratori. Si associa areflessia osteotendinea, anche se nelle forme pure assonali e motorie i riflessi possono essere presenti. Molto spesso i pazienti riferiscono parestesie diffuse o franco dolore mentre frequentemente è presente una compromissione del sistema nervoso autonomo che rappresenta l'eventualità più grave da tener sempre presente per il rischio di aritmie cardiache potenzialmente fatali. Si riconoscono numerose varianti diverse per interessamento regionale o funzionale tra le quali è bene tener presente la sindrome di Miller-Fisher caratterizzata da interessamento del nervi cranici con diplegia del faciale oftalmoplegia, atassia e areflessia osteotendinea, ${ }^{3}$ la forma paraparetica ${ }^{4}$ e la variante oculo-faringea-faciale. ${ }^{5} \mathrm{~L}$ 'aggressione immuno-mediata della GBS e delle varianti correlate è spesso scatenata da una precedente infezione delle prime vie aeree o batterica gastrointestinale: ${ }^{6}$ agenti patogeni interessati sono in genere il Campilobacter jejiuni, ${ }^{7}$ Mycoplasma pneumoniae, Haemophilus influenzae, virus dell'influenza A, citomegalovirus o virus di Epstein-Barr. ${ }^{8,9}$ Anche le vaccinazioni possono essere coinvolte sempre per un meccanismo di mimetismo molecolare con l'insorgenza di caratteristici cluster stagionali che si verificano periodicamente in concomitanza dell'utilizzo di nuovi ceppi di virus influenzali. ${ }^{10}$ La diagnosi è essenzialmente clinica. L'esame elettrofisiologico è lo strumento diagnostico più importante perché riesce a dimostrare l'origine miogena o neurogena della lesione, la compromissione della mielina o dell'assone, la localizzazione prossimale o distale del danno e la sua disseminazione. ${ }^{11}$ L'esame del liquor mediante rachicentesi prevalentemente serve ad escludere la presenza di cellularità che rimanda ad altre patologie mentre la concomitante presenza di aumento delle proteine (dissociazione albumino-citologica) diventa patognomonica. ${ }^{12}$ Per quanto riguarda il trattamento la terapia con gli steroidi non modifica il decorso della malattia, mentre si sono dimostrati efficaci sia la plasmaferesi che trattamento con immunoglobuline ad alte dosi. ${ }^{13,14}$ La plasmaferesi (PE) si è dimostrata efficace soprattutto se viene utilizzata precocemente, rendendo più rapido il recupero, determinando una minore utilizzazione della respirazione assistita; inoltre si è mostrata utile anche nelle forme di media gravità ove possono essere utilizzate due sedute soltanto a fronte delle 4-6 delle forme gravi. ${ }^{13} \mathrm{La}$ PE è controindicata nelle forme con severa compromissione delle funzioni autonomiche, con alterazioni dell'equilibrio elettrolitico, con le difficoltà dell'accesso venoso e per i pazienti ricoverati in unità intensive che non dispongono di apparati mobili per la PE. Tali motivi hanno portato all'utilizzo di terapie più facili da praticare in qualsiasi reparto come le immunoglobuline ev alla dose media di $0,4 \mathrm{~g} / \mathrm{kg} /$ die per 5 giorni consecutivi. ${ }^{15}$ Tale terapia sicuramente più maneggevole presenta minori controindicazioni, rappresentate dalla deficienza di Iga, insufficienza renale, scompenso cardiaco o rischio concreto di tromboembolismo.

Non è stato dimostrato che un secondo ciclo di IgGiv migliori la prognosi;nemmeno il trattamento sequenziale di $\mathrm{PE}$ e IgG si è dimostrato più attivo dei singoli trattamenti da soli, mentre è ovvio che effettuare la PE entro tre settimane dall'utilizzo delle IgGIV è assolutamente inutile in quanto rimuoverebbe le immunoglobuline somministrate dal circolo. Di fondamentale importanza rimane il trattamento di supporto con personale in grado di rispondere alle esigenze di questo tipo di pazienti oltre alla ventilazione assistita che riguarda circa il 30\% dei casi, il posizionamento del sondino naso-gastrico, la prevenzione di complicanze cardiocircolatorie e respiratorie, la profilassi della trombosi venosa profonda, il trattamento del dolore e soprattutto il supporto psicologico. È bene tener presente che nonostante un rapido e corretto trattamento un $20 \%$ di pazienti permane inabile a deambulare a 6 mesi, mentre resta ancora alta la mortalità che va da un 6 all' $11 \%{ }^{16}$ 


\section{Poliradiculonevrite demielinizzante infiammatoria cronica}

Fino a pochi anni fa tale affezione veniva considerata una variante cronica della GBS, nonostante raramente si presenti in maniera acuta come la Guillain-Barrè, mentre essa evolve in maniera subacuta oltre le tipiche 4 settimane $o$ in maniera lentamente progressiva nel corso di diversi mesi. La prevalenza è di circa $1,2-7,7$ casi su $100.000 .{ }^{17}$ Nei giovani la malattia può presentare un decorso a ricadute, avendo una prognosi favorevole a lungo termine in oltre il $50 \%$, mentre il $40 \%$ presenterà a 10 anni un grado variabile di disabilità ed il rimanente $10 \%$ rimarrà gravemente compromesso o morirà per le conseguenze dirette della malattia. ${ }^{18,19} \mathrm{La}$ CIDP è caratterizzata clinicamente dalla presenza di ipostenia quasi sempre simmetrica della muscolatura sia prossimale che distale, con frequente compromissione del versante sensitivo. Esistono diversi sottotipi che potrebbero riconoscere patogenesi antigeniche diverse, quali le forme motorie pure, le sensitive atassiche e le motorie e sensitive demielinizzanti. Le indagini diagnostiche sono simili a quella della GBS, con una maggiore presenza di segni di demielinizzazione, un variabile coinvolgimento assonale e un frequente riscontro di blocchi di conduzione all'esame elettrofisiologico,mentre alla biopsia del nervo si possono riscontrare segni di de-remielinizzazione cronica,infiltrati linfo-monocitari, edema e perdita di fibre.

Diversamente dalla GBS il trattamento steroideo si è dimostrato utile in oltre il $70 \%$ dei pz: ${ }^{20}$ tuttavia una quota dei pazienti appare refrattaria alla terapia per cui si rende necessario il ricorso alla plasmaferesi e alle immunoglobuline. ${ }^{21}$ Tra gli immunosoppressori nella pratica clinica vengono utilizzati l'azatioprina,la ciclosporina e la ciclofosfamide; più recentemente è stata dimostrata una significativa efficacia per il rituximab. ${ }^{22}$

\section{Bibliografia}

1. Latov $\mathrm{N}$ et al. Plasma-cell dyscrasia and peripheral neuropathy with a monoclonal antibody to peripheral-nerve myelin. N Engl J Med.; 1980

2. Sejvar JJ, Baughman AL, Wise M, Morgan OW. Population incidence of Guillain-Barré syndrome: a systematic review and meta-analysis. Neuroepidemiology 2011; 36: 123-33.

3. Lyu RK, Tang LM, Cheng SY, Hsu WC, Chen ST.Guillain-Barré syndrome in Taiwan: a clinical study of 167 patients. J Neurol Neurosurg Psychiatry 1997; 63: 494500 .

4. van den Berg B, Fokke C, Drenthen J, van Doorn PA, Jacobs BC. Paraparetic Guillain-Barré syndrome. Neurology 2014; 82: 1984-89.

5. Dosi R et al Acute multiple cranial neuropathy: An oculopharyngeal variant of Guillain-Barré Syndrome Australas Med J. 2014 Sep 30;7(9):376-8
6. Huang WC, Lu CL, Chen SC. A 15-year nationwide epidemiological analysis of Guillain-Barré syndrome in Taiwan. Neuroepidemiology 2015; 44: 249-54.

7. Jackson BR, Zegarra JA, López-Gatell H, et al, for the GBS Outbreak Investigation Team. Binational outbreak of Guillain-Barré syndrome associated with Campylobacter jejuni infection, Mexico and USA, 2011. Epidemiol Infect 2014; 142: 1089-99.

8. Jacobs BC, Rothbarth PH, van der Meché FG, et al. The spectrum of antecedent infections in GuillainBarré syndrome: a case-control study. Neurology 1998; 51: 1110-15.

9. Mori M, Kuwabara S, Miyake M, et al. Haemophilus infl uenzae infection and Guillain-Barré syndrome. Brain 2000; 123: 2171-78

10. Webb AJ, Brain SA, Wood R, Rinaldi S, Turner MR. Seasonal variation in Guillain-Barré syndrome: a systematic review, meta-analysis and Oxfordshire cohort study. J Neurol Neurosurg Psychiatry 2015; 86: 1196-201

11. Hadden RD, Cornblath DR, Hughes RA, et al, for the Plasma Exchange/Sandoglobulin Guillain-Barré Syndrome Trial Group. Electrophysiological classifi cation of Guillain-Barré syndrome: clinical associations and outcome. Ann Neurol 1998; 44: 780-88.

12. van den Berg B, Walgaard C, Drenthen J, Fokke C, Jacobs BC, van Doorn PA. Guillain-Barré syndrome: pathogenesis, diagnosis, treatment and prognosis. Nat Rev Neurol 2014; 10: 469-82.

13. Raphaël JC, Chevret S, Hughes RA, Annane D. Plasma exchange for Guillain-Barré syndrome. Cochrane Database Syst Rev 2012; 7: CD001798

14. Hughes RA, Swan AV, Raphael JC, Annane D, van Koningsveld R, van Doorn PA. Immunotherapy for Guillain-Barré syndrome: a systematic review. Brain 2007; 130: 2245-57.

15. Korinthenberg R, Schessl J, Kirschner J, Mönting JS. Intravenously administered immunoglobulin in the treatment of childhood Guillain-Barré syndrome: a randomized trial. Pediatrics 2005; 116: 8-14.

16. Islam Z, Jacobs BC, van Belkum A, et al. Axonal variant of Guillain-Barre syndrome associated with Campylobacter infection in Bangladesh. Neurology 2010; 74 : 581-87.

17. Dalakas MC: Clinical trials in CIDP and chronic autoimmune demyelinating polyneuropathies. J Peripher Nerv Syst 2012, 17(Suppl 2):34-39.

18. Koller H, Kieseier BC, Jander S, Hartung HP: Chronic inflammatory demyelinating polyneuropathy. $\mathrm{N}$ Engl $\mathrm{J}$ Med 2005, 352(13):1343-1356.

19. Said G: Chronic inflammatory demyelinating polyneuropathy. Neuromuscul Disord 2006, 16(5):293-303.

20. Czaplinski A, Steck AJ: Immune mediated neuropathies-an update on therapeutic strategies. J Neurol 2004, 251 (2):127-137.

21. van Schaik IN, Winer JB, de Haan R, Vermeulen M: Intravenous immunoglobulin for chronic inflammatory demyelinating polyradiculoneuropathy: a systematic review. Lancet Neurol 2002; 1 (8):491 -498.

22. Dalakas MC, Rakocevic G, Salajegheh M, Dambrosia JM, Hahn AF, Raju R,McElroy B: Placebo-controlled trial of rituximab in IgM anti-myelinassociated glycoprotein antibody demyelinating neuropathy. Ann Neurol 2009, 65(3):286-293. 


\section{Parte I - C) Miastenia gravis}

La miastenia gravis (MG) è un disordine immunomediato della giunzione neuromuscolare (NMJ), dovuto al legame di autoanticorpi a diverse componenti della giunzione stessa, più comunemente il recettore dell'acetilcolina (AChR). L'incidenza varia da 0,3 a 2,8 per $100.000,{ }^{1}$ colpisce tutte le razze e può verificarsi a qualsiasi età. Nei paesi occidentali, la MG mostra un picco di età di insorgenza nella terza decade di età soprattutto nelle donne e un maggior picco nella sesta e settima decade soprattutto negli uomini, mentre nei paesi asiatici vi è un'alta prevalenza di forme limitate della malattia con esordio nell'infanzia. ${ }^{2} \mathrm{La}$ MG è una malattia eterogenea con entità cliniche distinte. Essa è dovuta alla presenza di autoanticorpi (Abs) che, con meccanismi diversi, interferiscono con la trasmissione neuromuscolare (NMT) causando faticabilità e debolezza muscolare. La grande maggioranza dei pazienti presenta Abs sierici contro il recettore dell'acetilcolina (AChR). Tali Abs sono principalmente di isotipi IgG1 e IgG3 in grado di indurre gravi alterazioni della membrana postsinaptica attraverso l'attivazione del complemento e incremento dei processi di degradazione dell' $\mathrm{AChR}$, e, in minor misura, di interferire con il sito di legame del neurotrasmettitore. ${ }^{3} \mathrm{La} \mathrm{MG}$ con AChR Abs (AChR-MG) è spesso associata ad alterazioni del timo che si suppone possa svolgere un ruolo fondamentale nella patogenesi della malattia. L'iperplasia timica follicolare (TFH), che si riscontra di solito in pazienti di sesso femminile con esordio di MG precoce, è considerata il luogo in cui viene avviata la risposta autoimmune al recettore e successivamente sostenuta. Al contrario, difetti di selezione dei linfociti T sembrano essere responsabili dell'associazione MG con timoma, un tumore delle cellule epiteliali del timo, che è presente nel $10-15 \%$ dei pazienti con MG esordita nella quinta e sesta decade di vita. ${ }^{4} \mathrm{Nel} 5-8 \%$ della forme sieronegative vengono rilevati altri tipi di anticorpi sierici specifici rivolti contro il recettore tirosinchinasi muscolo-specifica (MuSK). MuSK è il core di un complesso multiproteico, che è fondamentale per l'aggregazione (clustering) e la configurazione post-sinaptica dell'AChR. ${ }^{5}$ Modelli sperimentali hanno dimostrato che i MuSKAbs interferiscono con la funzione del complesso proteico, ${ }^{6}$ tuttavia, pur essendo principalmente IgG4, non sono in grado di attivare il complemento e sono piuttosto inefficaci nel legare l'antigene. ${ }^{3}$ Recentemente è stato identificato come autoantigene per la MG un recettore lipoproteina a bassa densità correlata alla proteina 4 (Lrp4), detto recettore per l'agrina Lrp4 che media l'attivazione di MuSK. ${ }^{7}$ La frequenza di Lrp4 Abs nei pazienti negativi per AChR-e MuSK- Abs mostra marcata variabilità nei diversi studi; 8 gli effetti di tali anticorpi e i corrispettivi fenotipi clinici non sono completamente caratterizzati.
Esistono poi ancora alcuni pazienti affetti da MG senza Abs rilevabili. La frequenza di questi cosiddetti casi triplo negativo è sconosciuta. Nella MG all'eterogeneità della patogenesi si associa una marcata variabilità clinica, sia per distribuzione che per gravità della debolezza muscolare che può variare da sintomi puramente oculari ad una grave malattia generalizzata con potenziale pericolo di vita. Una diagnosi corretta è fondamentale al fine di offrire ai pazienti il trattamento più appropriato.

\section{Diagnosi}

La MG deve essere sospettata in pazienti con storia e segni di debolezza muscolare, fluttuante, che peggiora dopo sforzo e migliora a riposo. La conferma diagnostica viene poi raggiunta attraverso: a) individuazione di Abs sierici; b) studio elettromiografico (EMG) che dimostra un decremento del potenziale d'azione muscolare dopo stimolazione nervosa ripetitiva sovra massimale a bassa frequenza (RNS) o un aumento del jitter evidente con esame selettivo a singola fibra (SF EMG); c) la risposta clinica agli inibitori dell'acetilcolinesterasi (AChE-Is). I risultati positivi di b) e c) confermano un difetto post-sinaptico di NMT, mentre la rilevazione di specifici Abs stabilisce la diagnosi di MG. I test sierologici di routine comprendono dosaggi di AChR e MuSK Ab. Essi sono considerati specifici per MG e, in pratica, la loro individuazione in pazienti con sintomi coerenti conferma la diagnosi, senza reale necessità di ulteriori test. D'altra parte, quando i dosaggi degli Ab sono negativi, la conferma EMG è cruciale. Gli $A C h R A b s$ vengono rilevati nel $80-90 \%$ dei pazienti con MG generalizzata, in circa il $50 \%$ di quelli con sintomi esclusivamente oculari, e in quasi tutti i casi con $\mathrm{MG}$ associata a timoma. ${ }^{9,13}$ I pazienti AChR-negativi con malattia di recente insorgenza possono divenire positivi se ritestati dopo 6-12 mesi (sieroconversione). D'altra parte, il tasso di positività ai $\mathrm{AChR} \mathrm{Ab}$ è inferiore nelle forme ad esordio infantile ${ }^{14}$ e nelle forme più lievi della malattia. ${ }^{15} \mathrm{I} M u S K$ Abs vengono rilevati nel $30-40 \%$ dei pazienti AChR-negativi, con frequenza variabile tra le popolazioni. ${ }^{9}$ Questi Abs sono molto rari nella $\mathrm{MG}$ oculare e sono più comunemente associati ad una forma clinica con coinvolgimento della muscolatura cranica, del collo e dei muscoli respiratori. Un miglioramento significativo nella diagnosi sierologica della $\mathrm{MG}$ è stata la dimostrazione di cluster di AChR Abs sierici incapaci di legarsi al recettore quando sono in soluzione durante i comuni test laboratoristici, ma in grado di legarsi al recettore per l'aceticolina (AChRs) quando strettamente addensati tra loro, come avviene in vivo. ${ }^{16}$ Tali anticorpi sono IgG1 attivanti il complemento ${ }^{16}$ ed è stato dimostrato il loro ruolo patogenetico, ${ }^{17}$ sono presenti nel $38 \%$ dei pazienti MG sieronegativi, soprattutto in pazienti con 
età prepuberale di insorgenza e sintomi puramente oculari. ${ }^{18}$ Un miglioramento clinico significativo dopo la somministrazione di AChE-Is a breve durata d'azione, come il cloruro di edrofonio ev o la neostigmina im., depone per diagnosi di MG e una risposta positiva a questo test farmacologico è stata riportata in circa il $90 \%$ dei pazienti MG. ${ }^{11} \mathrm{Il}$ tasso di risposta è molto più basso (50-70\%) nella MuSK-MG. ${ }^{12}$ Tuttavia una reazione positiva al test con AChE-I non è specifica per $\mathrm{MG}$, in quanto può essere presente nelle sindromi di miastenia congenita, nella sindrome miastenica di Lambert-Eaton, nela sclerosi laterale amiotrofica (SLA), nella sindrome di Guillain-Barré, e, anche, in pazienti con tumori intracranici. ${ }^{2}$

\section{Aspetti clinici}

L'evoluzione della MG è imprevedibile, ma è generalmente caratterizzata dalla presenza di recidive, talvolta seguite da remissioni e una tendenza al peggioramento nei primi anni. Per 1' $85 \%$ di MG pazienti, la gravità massima viene raggiunta in meno di 3 anni. ${ }^{13}$ La gravità della MG varia notevolmente da un paziente all'altro e nello stesso paziente da un momento all'altro. Il coinvolgimento dei muscoli respiratori e i severi disturbi della deglutizione caratterizzano le forme gravi (20-30\% dei pazienti) e possono essere gestiti nelle unità di terapia intensiva permettendo una significativa riduzione della mortalità. Al contrario, la MG resta lieve nel 25\% dei pazienti. Tra questi due estremi, vi è la malattia intermedia: essa è debilitante a causa della marcata stanchezza muscolare, disturbi della deglutizione, ipofonia, claudicatio mandibolare e diplopia. Poiché le manifestazioni cliniche di MG variano secondo l'età di insorgenza, l'anticorpo implicato e la presenza di patologia timica, le forme di malattia sono generalmente divise in vari sottogruppi in base alla presenza di autoanticorpi ${ }^{10}$ (Tabella 1).

\section{Miastenia pura oculare}

Circa il 15\% dei pazienti MG presentano solo sintomi oculari. A causa della elevata percentuale di pazienti con manifestazioni oculari all'esordio è necessario attendere due anni in assenza di generalizzazione per classificare un paziente come avente forma oculare pura. La metà di questi pazienti sono antiAChR $\mathrm{Ab}$ negativi ma spesso sono rilevabili $\mathrm{AChR} \mathrm{Ab}$ in cluster. ${ }^{16}$

\section{Miastenia generalizzata con anticorpi anti-AChR}

Circa il 85\% della popolazione con MG mostra questa forma di la malattia. Non c'è una chiara correlazione tra il livello di anticorpi e la gravità della malattia, anche se tale correlazione è stata descritta a livello individuale. ${ }^{19}$ Anomalie del timo si trovano frequentemente in questi pazienti, e il più alto titoli di anticorpi sono visti in pazienti con iperplasia timica follicolare. ${ }^{20}$ Gli anticorpi anti-AChR appartengono al IgG1 e sottoclassi IgG3 che si legano al complemento. ${ }^{21}$ I pazienti possono essere suddivisi nei seguenti due sottogruppi.

MG ad esordio giovanile ( $<50$ anni): presenta una predominanza femminile (rapporto 3/1) e si associa prevalentemente a iperplasia follicolare timica. Spesso coesistono altre malattie autoimmuni-MG ad esordio tardivo (dopo 50 anni): questa forma tardiva è spesso associata alla presenza di timoma. ${ }^{4}$ La maggior parte dei pazienti si presentano sintomi generalizzati e gravi, il coinvolgimento bulbare. ${ }^{22,23}$

\section{Miastenia generalizzata senza classici anticorpi anti-AChR}

MG con anticorpi anti-MuSK: circa il 5\% della popolazione MG presenta questo tipo di anticorpi. I pazienti MuSK positivi sono tipicamente donne con una

Tabella 1. Classificazione della miastenia in relazione alla presenza di Abs.

\begin{tabular}{|c|c|c|c|c|}
\hline & AChR solubili & Musk & LRP4 & Cluster-AChR \\
\hline Popolazione target & $\begin{array}{l}\text { Esordio giovanile: } \mathrm{F}>\mathrm{M} \\
\text { Esordio tardivo: } \mathrm{F}=\mathrm{M}\end{array}$ & Giovani donne & Giovani donne & Come AChR \\
\hline Grado severità & Tutti i gradi di severità & Soprattutto forme severe & Generalmente forme moderate & Come AChR \\
\hline Patogenicità & In vitro e in vivo & In vitro e in vivo & In vitro & In vitro \\
\hline Isotipi & IgG1, IgG3 & IgG4 & IgG1 & $\operatorname{IgG1}$ \\
\hline Ruolo complemento & $\mathrm{Si}$ & No & Probabile & Probabile \\
\hline Patologia timica & $\begin{array}{l}\text { Esordio giovanile: iperplasia timica } \\
\text { Esordio tardivo: timoma }\end{array}$ & No & $?$ & Iperplasia timica \\
\hline $\begin{array}{l}\text { Correlazione titolo } \\
\mathrm{Ab} / \text { grado di disabilità }\end{array}$ & No & $\mathrm{Si}$ & $?$ & $?$ \\
\hline
\end{tabular}


forma grave di malattia, con frequente coinvolgimento del muscoli del distretto bulbare, facciale e respiratorio mentre i sintomi oculari e anomalie del timo sono rari. ${ }^{24} \mathrm{Vi}$ è una chiara correlazione tra la gravità della malattia e il titolo anticorpale. ${ }^{25}$

- MG con anticorpi anti-LRP4: dal 12 al 50\% delle forme sieronegative presentano anticorpi anti-LRP4 (22). Il fenotipo clinico dei pazienti che presentano anticorpi antiLRP4 non è ben definito.

- MG con AChR cluster: circa il 50\% dei pazienti sieronegativi presentano questi anticorpi. Il quadro clinico è simile alla MG con anticorpi anti-AChR e può associarsi iperplasia timica. ${ }^{16}$

\section{Miastenia neonatale}

Nel $10-20 \%$ dei casi, nei neonati da madri miasteniche può verificarsi una miastenia neonatale transitoria (TNM) che potrebbe durare da un paio di giorni a 3 mesi dovuta al trasferimento passivo degli anticorpi della madre, specialmente di anticorpi antiAChR. ${ }^{26}$ In caso di MuSK-MG, TNM è molto rara. ${ }^{27}$ Non vi è alcuna correlazione tra la gravità della malattia in della madre e l'insorgenza e la gravità della malattia nel bambino.

\section{Terapia}

La gestione clinica della MG si basa sull'utilizzo, di solito in combinazione, di diverse opzioni terapeutiche. L'intensità di cura è determinata dall'estensione e dalla gravità della debolezza muscolare, mentre la strategia di trattamento dovrebbe anche tener conto della fisiopatologia della malattia (sierologia e presenza di patologia timica) e dovrebbe essere adattata al singolo individuo.

\section{Terapia sintomatica}

Gli inibitori delle acetilcolinesterasi orali (oral AChE-Is), di cui la piridostigmina è l'agente più comunemente usato, rappresentano il trattamento di prima linea nella MG, pur non agendo sulla storia naturale di malattia. La maggior parte dei pazienti con AChR-MG sono responder alla piridostigmina, in genere ben tollerata. ${ }^{28}$ D'altra parte, i pazienti MuSKMG, per la maggior parte, non migliorano con i AChE-Is, e le dosi piridostigmina standard, spesso inducono effetti collaterali nicotinici (diarrea, scialorrea, ipersecrezione bronchiale, fascicolazioni, bradicardia) e può anche peggiorare la debolezza fino a una crisi colinergica. $^{24}$

\section{Immunomodulazione a lungo termine: timectomia}

La timectomia è indicata in tutti i pazienti con evidenza di timoma. In questi casi, la chirurgia è il cardine del trattamento oncologico (che include radio- e che- mioterapia per i tumori invasivi), mentre non sembra migliorare significativamente il decorso della MG. Nei pazienti senza timoma, la timectomia entro i tre anni dall'esordio è rivolta al trattamento della $\mathrm{MG}$ (timectomia terapeutica), e la sua efficacia è stata recentemente dimostrata in un trial clinico randomizzato. ${ }^{29}$ Attualmente, si raccomanda la timectomia, nei pazienti con MG generalizzata, in particolare nei soggetti con precoce insorgenza associata ad iperplasia follicare timica e AChR Abs. ${ }^{29}$ L'indicazione di timectomia dovrebbe essere estesa anche alle forme generalizzate con cluster-AChR Abs, in quanto è molto probabile che la patogenesi della malattia sia la stessa. ${ }^{16} \mathrm{D}$ 'altra parte, il ruolo della timectomia in pazienti con altri anticorpi è molto controversa. Nelle forme di MuSK-MG, l'iperplasia timica è rara e gli studi clinici non sono riusciti a dimostrare un beneficio definito dalla timectomia. Ciò vale anche per le forme di Lrp4-MG.

\section{Immunomodulazione a breve termine: immunoglobuline e plasmaferesi}

La plasmaferesi, che rimuove gli anticorpi dalla circolazione, e le immunoglobuline per via endovenosa (IVIg), che interferiscono con l'attività degli anticorpi, hanno un rapido ma breve effetto nella MG. Il protocollo standard per la plasmaferesi consiste in cinque scambi di un volume plasmatico a giorni alterni; le IVIg sono di solito somministrate ad un dosaggio di $2 \mathrm{~g} / \mathrm{kg}$ per 2-5 giorni. La loro indicazione principale è il trattamento delle esacerbazioni della malattia nei pazienti con sintomi gravi o crisi respiratorie. Altre indicazioni sono la preparazione alla timectomia o come trattamento periodico in casi selezionati che non rispondono alla terapia immunosoppressiva convenzionale..$^{30,31}$

\section{Terapia immunosoppressiva}

L'immunosoppressione è il trattamento cardine per la MG e l'approccio terapeutico è determinato dalla gravità della debolezza, dalla velocità di progressione e dalle caratteristiche del paziente (età, stile di vita e condizioni associate). I corticosteroidi sono in uso da molti anni, ed inconvenienti e complicanze (compreso il rischio di deterioramento MG all'inizio del trattamento) sono ben noti. ${ }^{32}$ Tuttavia, questi agenti rappresentano ancora la prima opzione terapeutica in considerazione della loro efficacia $(70-80 \%$ del tasso di risposta) e l'effetto a rapida insorgenza. Prednisone e prednisolone sono le preparazioni più comunemente utilizzati, iniziando con dosi elevate o con un regime progressivamente crescente, fino a $1 \mathrm{mg} / \mathrm{kg} / \mathrm{die}$ in pazienti con MG generalizzata; ${ }^{32}$ un programma a giorni alterni è generalmente preferito ad una somministrazione cronica ${ }^{30}$ Diverse classi di immunosoppressori, compresi i farmaci citostatici (azatioprina, micofenolato mofetil e metotrexato), la ciclofosfamide e gli ini- 
bitori della calcineurina (ciclosporina A e tacrolimus), sono anche utilizzati nel trattamento MG. Questi agenti possono essere utilizzati in monoterapia, ma per l'insorgenza ritardata dell'effetto, vengono spesso somministrati in associazione con prednisone (per ridurre il suo dosaggio e durata del trattamento) e possono sostituire gli steroidi nel trattamento a lungo termine. L'azatioprina (2-3 mg/kg/die come dose iniziale, $1 \mathrm{mg} / \mathrm{kg}$ come dose di mantenimento) è l'immunosoppressore di prima scelta nei pazienti MG. Il micofenolato mofetile (a una dose standard di 2-2,5 $\mathrm{g} / \mathrm{die}$ ) viene generalmente utilizzato come seconda scelta; ciclosporina A (a una dose iniziale di 4-6 mg/ $/ \mathrm{kg}$ e una dose di mantenimento $<3-4 \mathrm{mg} / \mathrm{kg} / \mathrm{die}$ ) e tacrolimus ( $3 \mathrm{mg} /$ die o $0,1 \mathrm{mg} / \mathrm{kg}$ b.w./day) sono considerati di terza scelta..$^{33}$ In alcuni casi la MG viene definita refrattaria al trattamento convenzionale, quando i pazienti presentano gravi ricadute di malattia, nonostante un adeguato trattamento immunosoppressivo, e/o richiedono alte dosi di steroidi o altri farmaci immunosoppressivi con rischio di gravi effetti collaterali. ${ }^{34} \mathrm{La}$ MG refrattaria può essere gestita con trattamenti di plasmaferesi ed IVIg intermittenti, in associazione con la terapia immunosoppressiva. ${ }^{35}$ Questa opzione fornisce benefici a breve termine, ha un impatto significativo sullo stile di vita del paziente, però è costosa $\mathrm{e}$ non è esente da effetti collaterali. La ciclofosfamide per via endovenosa, ha determinato un miglioramento significativo in tutte le forme di $\mathrm{MG}^{36}$ ma il suo impiego è limitato dalla rilevante tossicità. Recentemente è stata dimostrata una elevata efficacia dell'anticorpo monoclonale rituximab soprattutto nelle forme MuSK positive ${ }^{37}$ L'eculizumab, si è dimostrato efficace e ben tollerato in un piccolo RCT di fase II in pazienti AChR-MG. ${ }^{38}$

\section{Bibliografia}

1. Deenen JCW, Horlings CGC, Verschuuren JJGM, Verbeek ALM. The epidemiology of neuromuscular disorders: a comprehensive overview of the literature. J Neuromuscul Dis 2015;2:73-85.

2. Keesey JC. Clinical evaluation and management of myasthenia gravis. Muscle Nerve. 2004;29:484-505.

3. Gomez AM, Van Den Broeck J, Vrolix K, et al. Antibody effector mechanisms in myasthenia gravis pathogenesis at the neuromuscular junction. Autoimmunity. 2010;43:353-370

4. Marx A, Pfister F, Schalke B, et al. The different roles of the thymus in the pathogenesis of the various myasthenia gravis subtypes. Autoimmun Rev. 2013;12:875-884.

5. Burden SJ, Yumoto N, Zhang W. The role of MuSK in synapse formation and neuromuscular disease. Cold Spring Harb Perspect Biol. 2013;5:a009167

6. Huijbers MG, Zhang W, Klooster R, et al. MuSK IgG4 autoantibodies cause myasthenia gravis by inhibiting binding between MuSK and Lrp4. Proc Natl Acad Sci USA. 2013;110:20783-20788.
7. Zhang W, Coldefy AS, Hubbard SR, et al. Agrin binds to the N-terminal region of Lrp4 protein and stimulates association between Lrp4 and the first immunoglobulinlike domain in muscle-specific kinase (MuSK). J Biol Chem. 2011;286:40624-40630.

8. Zisimopoulou P, Evangelakou P, Tzartos J, et al. A comprehensive analysis of the epidemiology and clinical characteristics of anti-LRP4 in myasthenia gravis. J Autoimmun. 2014;52: 139-145.

9. Meriggioli MN, Sanders DB. Muscle autoantibodies in myasthenia gravis: beyond diagnosis?. Expert Rev Clin Immunol. 2012;8:427-438.

10. Berrih-Aknin S, Frenkian-Cuvelier M, Eymard B. Diagnostic and clinical classification of autoimmune myasthenia gravis. J Autoimmun. 2014;48-49:143-148.

11. Benatar M. A systematic review of diagnostic studies in myasthenia gravis. Neuromusc Disord. 2006;16:459-467.

12. Evoli A, Padua L. Diagnosis and therapy of myasthenia gravis with antibodies to muscle-specific kinase. Autoimmun Rev. 2013;12:931-935

13. Grob D, Brunner NG, Namba T. The natural course of myasthenia gravis and effect of therapeutic measures. Ann N Y Acad Sci 1981;377: 652e69.

14. Chiang LM, Darras BT, Kang PB. Juvenile myasthenia gravis. Muscle Nerve. 2009;39:423-431

15. Chan KH, Lachance DH, Harper CM, et al. Frequency of seronegativity in adult-acquired generalized myasthenia gravis. Muscle Nerve. 2007;36:651-658.

16. Leite MI, Jacob S, Viegas S, et al. IgG1 antibodies to acetylcholine receptors in 'seronegative' myasthenia gravis. Brain. 2008;131:1940-1952.

17. Jacob S, Viegas S, Leite MI, et al. Presence and pathogenic relevance of antibodies to clustered acetylcholine receptor in ocular and generalized myasthenia gravis. Arch Neurol. 2012;69:994-1001

18. Rodríguez Cruz PM, Al-Hajjar M, Huda S, et al. Clinical features and diagnostic usefulness of antibodies to clustered acetylcholine receptors in the diagnosis of seronegative myasthenia gravis. JAMA Neurol. 2015;72: 642-649.

19. Vincent A, Newsom-Davis J. Acetylcholine receptor antibody as a diagnostic test for myasthenia gravis: results in 153 validated cases and 2967 diagnostic assays. J Neurol Neurosurg Psychiatry 1985;48:1246e52.

20. Berrih S, Morel E, Gaud C, Raimond F, Le Brigand H, Bach JF. Anti-AChR antibodies, thymic histology, and $\mathrm{T}$ cell subsets in myasthenia gravis. Neurology 1984;34:66e71.

21. Verschuuren JJ, Huijbers MG, Plomp JJ, Niks EH, Molenaar PC, MartinezMartinez P, et al. Pathophysiology of myasthenia gravis with antibodies to the acetylcholine receptor, muscle-specific kinase and low-density lipoprotein receptor-related protein 4. Autoimmun Rev 2013;12:918e 23 .

22. Higuchi O, Hamuro J, Motomura M, Yamanashi Y. Autoantibodies to lowdensity lipoprotein receptor-related protein 4 in myasthenia gravis. Ann Neurol 2011;69: $418 \mathrm{e} 22$.

23. Klein R, Marx A, Strobel P, Schalke B, Nix W, Willcox $\mathrm{N}$. Autoimmune associations and autoantibody screening show focused recognition in patient subgroups with generalized myasthenia gravis. Hum Immunol 2013;74:1184e93 
24. Evoli A, Tonali PA, Padua L, Monaco ML, Scuderi F, Batocchi AP, et al. Clinical correlates with anti-MuSK antibodies in generalized seronegative myasthenia gravis. Brain 2003;126:2304e11.

25. Bartoccioni E, Scuderi F, Minicuci GM, Marino M, Ciaraffa F, Evoli A. AntiMuSK antibodies: correlation with myasthenia gravis severity. Neurology 2006;67:505e7.

26. Morel E, Eymard B, Vernetdergarabedian B, Pannier C, Dulac O, Bach JF. Neonatal myasthenia-gravis e a new clinical and immunological appraisal on 30 cases. Neurology 1988;38:138e42.

27. Behin A, Mayer M, Kassis-Makhoul B, Jugie M, EspilTaris C, Ferrer X, et al. Severe neonatal myasthenia due to maternal anti-MuSK antibodies. Neuromuscul Disord 2008;18:443e6.

28. Meriggioli MN, Sanders DB. Autoimmune myasthenia gravis: emerging clinical and biological heterogeneity. Lancet Neurol. 2009;8:475-490

29. Wolfe GI, Kaminski HJ, Aban IB, Minisman G, Kuo HC, Marx A, Ströbel P, Mazia C, Oger J, Cea JG, Heckmann JM, Evoli A, et al MGTX Study Group.. Randomized Trial of Thymectomy in Myasthenia Gravis. Engl J Med. 2016 Aug 11;375(6):511-22.

30. Mantegazza R, Bonanno S, Camera G, et al. Current and emerging therapies for the treatment of myasthenia gravis. Neuropsychiatr Dis Treat. 2011;7:151-160.
31. Sathasivam S. Current and emerging treatments for the management of myasthenia gravis. Ther Clin Risk Manag. 2011;7:313-323.

32. Jani-Acsadi A, Lisak RP. Myasthenia gravis. Curr Treat Options Neurol. 2010;12:231-243

33. Sanders DB, Wolfe GI, Benatar M, Evoli A et al.International consensus guidance for management of myasthenia gravis; Neurology. 2016 Jul 26;87(4):419-25.

34. Drachman DB, Adams RN, Hu R, et al. Rebooting the immune system with high-dose cyclophosphamide for treatment of refractory myasthenia gravis. Ann N Y Acad Sci. 2008;1132:305-314

35. Sathasivam S. Current and emerging treatments for the management of myasthenia gravis. Ther Clin Risk Manag. 2011;7:313-323.

36. Buzzard KA, Meyer NJ, Hardy TA, et al. Induction intravenous cyclophosphamide followed by maintenance oral immunosuppression in refractory myasthenia gravis. Muscle Nerve. 2015;52:204-210.

37. Iorio R, Damato V, Alboini PE, et al. Efficacy and safety of rituximab for myasthenia gravis: a systematic review and meta-analysis. J Neurol. 2015;262:1115-1119.

38. Howard JF Jr, Barohn RJ, Cutter GR, et al. A randomized, double-blind, placebo-controlled phase II study of eculizumab in patients with refractory generalized myasthenia gravis. Muscle Nerve. 2013;48:76-84 


\section{Parte I - D) Miopatie infiammatorie immunomediate}

Le miopatie infiammatorie idiopatiche (IIM), dette anche miositi, sono rare patologie croniche muscolari caratterizzate da debolezza muscolare, prevalentemente prossimale, incremento degli enzimi muscolari ed infiltrati infiammatori evidenti alla biopsia muscolare. Esse possono coinvolgere anche altri organi come la cute, il cuore, il tratto gastrointestinale, ed i polmoni. Sulla base delle differenze cliniche ed istopatologiche le IIM sono classificate tradizionalmente in polimiosite (PM), dermatomiosite (DM), e miosite da corpi inclusi (MCI) ${ }^{1,2} \mathrm{Di}$ recente sono state decritte due nuove entità cliniche: la miosite aspecifica e la miopatia necrotizzante (IMNM). ${ }^{3}$

\section{Caratteristiche cliniche}

La DM o la PM dovrebbero essere sospettate in tutti i pazienti che si presentano con progressiva debolezza muscolare, in particolare quando la debolezza è relativamente simmetrica, prevalentemente prossimale, non associata a perdita di sensibilità. Non si verifica ptosi palpebrale in quanto sono risparmiati i muscoli extraoculari. La PM e la DM tipicamente si presentano con vari gradi di debolezza muscolare degli arti prossimali e del tronco che si sviluppa nel corso di settimane o mesi. ${ }^{1}$ Una ipostenia distale può verificarsi tardivamente nella PM e $\mathrm{DM}$, o all'esordio nella miosite da corpi inclusi (MCI) con coinvolgimento dei flessori del polso e delle dita. ${ }^{1}$ Le mialgie sono rare nella PM e nella DM. ${ }^{4}$ I riflessi tendinei profondi sono normali, tranne nei muscoli gravemente indeboliti e non vi è coinvolgimento della sensibilità. La debolezza dei muscoli flessori del collo è una componente comune di miopatie infiammatorie ma raramente determinano la sindrome della testa cadente; il coinvolgimento del diaframma e dei muscoli accessori possono contribuire all'insufficienza respiratoria per la quale è necessario ventilazione assistita. ${ }^{5}$ La debolezza dei muscoli faringei può verificarsi in casi avanzati di IIM con conseguente disfagia, voce nasale, raucedine, ri- gurgito nasale e polmonite ab ingestis. ${ }^{6}$ Nella dermatomiosite le manifestazioni cutanee a volte concomitano, ma più spesso precedono da diversi mesi o anni il coinvolgimento muscolare. ${ }^{2}$ Le manifestazioni cutanee nella DM sono suddivise in patognomoniche, altamente caratteristiche e lesioni cutanee compatibili ${ }^{7}$ (Tabella 1).

Altre manifestazioni comuni extramuscolari includono varie anomalie cardiache, malattia polmonare interstiziale (ILD) e neoplasie. ${ }^{8}$ Manifestazioni cardiache includono aritmia, insufficienza cardiaca congestizia, la miocardite, pericardite, angina, e fibrosi. ${ }^{8}$ Nella DM l'insufficienza cardiaca cronica è stata attribuita agli effetti dell'ipertensione arteriosa legata all'uso di steroidi. ${ }^{8} \mathrm{La}$ ILD è una malattia polmonare ad eziologia sconosciuta, caratterizzata da infiltrati infiammatori e fibrosi interstiziale. La DM-ILD è clinicamente più grave e comporta una prognosi peggiore rispetto alla PM-ILD. ${ }^{9}$ Questo è probabilmente attribuibile alla presenza di anticorpi anti gene associato alla differenziazione anti-melanoma 5 (MDA5): tali anticorpi sono associati con un ILD rapidamente progressiva e vengono rilevati esclusivamente nella DM e nelle forme di DM senza coinvolgimento muscolare (dermatomiosite amiopatica ADM). ${ }^{10} \mathrm{La} \mathrm{DM}$ ha inoltre una forte associazione con neoplasie specifiche, tra cui cancro dell'ovaio, del polmone, del pancreas, dello stomaco e del colon-retto. Circa il 15\% dei pazienti adulti con DM, in particolare quelli di età superiore ai 40 anni, hanno o un tumore maligno pre-esistente o svilupperà una neoplasia. ${ }^{11}$ È interessante notare che i pazienti con IIM ILD hanno un minor rischio di sviluppare neoplasia. ${ }^{11}$

Una diagnosi di miosite richiede l'esclusione di una serie di condizioni simili, comprese le distrofie dei cingoli e quelle facioscapulomerali, le miopatie metaboliche, mitocondriale, endocrine ed indotte da farmaci.

\section{Diagnosi}

La diagnosi delle miositi infiammatorie necessita di diversi esami strumentali e laboratoristici. I livelli sierici di creatin-chinasi (CK) nei pazienti con DM attiva pos-

Tabella 1. Manifestazioni cutanee della dermatomiosite.

Lesioni cutanee patognomoniche

1. Papule di Gottron: papule di tonalità violacea in sede sovrafalangea

2. Segno di Gottron: eritema violaceo maculare simmetrico sulla porzione dorsale delle articolazioni interfalangee/metacarpo-falangea

Lesioni cutanee altamente caratteristiche

1. Eritema periorbitale violaceo (rash eliotropio) con o senza edema delle palpebre

2. Telangiectasia periungueale grossolanamente visibile con o senza cuticole distrofiche

3. Eritema violaceo simmetrico sulla parte dorsale delle mani e le dita (dove può monitorare le guaine dei tendini estensori)

Lesioni cutanee compatibili di DM

1. Poichilodermia atrofica vascolare: eritema violaceo con teleangectasie, ipopigmentazione, iperpigmentazione

2. Calcinosi cutenea 
sono essere normali, ma nella maggior parte dei casi appaiono aumentati fino a 50 volte il limite superiore della norma. ${ }^{1,2} \mathrm{Il} \mathrm{CK}$ sarà elevato di circa $5-50$ volte in pazienti con PM attiva, di circa 10 volte o più nella $\mathrm{IMNM}^{12}$ e normale o solo lievemente elevato nella a SIBM (meno di 10 volte). ${ }^{13}$ I livelli sierici di CK non correlano con l'attività della malattia, se confrontati nei diversi pazienti, ma possono riflettere i cambiamenti nell'attività della malattia all'interno di un singolo paziente. Le caratteristiche elettromiografiche (EMG) dei pazienti con miosite sono: a) aumento dell'attività inserzionale spontanea con potenziali di fibrillazione, $b$ ) potenziali d'azione motori polifasici (MAP) di breve durata e di bassa ampiezza, e c) il reclutamento precoce dei MAPs. ${ }^{1}$ La biopsia muscolare è in grado di fornire preziose informazioni diagnostiche nei pazienti con sospetta IIM. Il quadro morfologico presenta alterazioni istopatologiche (fibre in necrosi, fenomeni di fagocitosi, infiltrati cellulari, fibre in rigenerazione) che consentono non solo di confermare l'ipotesi di miopatia infiammatoria ma anche di definirne il tipo. Nella DM I fenomeni necrotici così come quelli rigenerativi interessano più fibre muscolari ed è frequente il riscontro di una atrofia perifascicolare. Gli infiltrati, rappresentati in alta percentuale da linfociti B, sono prevalentemente perivascolari e/o perimisiali. Nella PM e nella MCI le fibre in necrosi sono per lo più isolate o raccolte in piccolo gruppi, gli infiltrati (linfociti T), sono prevalentemente endomisiali. Nel caso della MCI inoltre si osserva la presenza di inclusioni eosinofile. ${ }^{2}$ I dosaggi di anticorpi sono utilizzati frequentemente per valutare i pazienti con IIM e possono essere classificati come autoanticorpi associati a miosite (MAA) o autoanticorpi-miosite specifici (MSA). Il termine MSA viene applicato ad autoanticorpi trovati prevalentemente nel siero di pazienti con miosite, tuttavia essi possono non avere specificità del $100 \% .{ }^{14}$ I MAA invece, sono riscontrabili principalmente in altre malattie del connettivo ed includono: anti-Ro, anti-La, anti-PM-Scl, anti-p (snRNPs) U1, U2, U4 / 6, U5, e U3, anti-Ku, anti-KJ, anti-Fer, anti-Mas, e anti-hPMS1. Ė stato riportato che il $60-80 \%$ dei pazienti adulti affetti da PM, DM, o IMNM hanno almeno un MSA. ${ }^{14}$

\section{Terapia}

Il trattamento delle miopatie infiammatorie è ancora generalmente empirico e legato all'esperienza del medico curante. Nonostante sia stato solo di recente valutato nel contesto di uno studio clinico controllato randomizzato, glucocorticoidi sono l'unico trattamento approvato. Tuttavia un numero considerevole di pazienti non risponde ai soli glucocorticoidi per cui immunosoppressori, immunomodulatori, e, più recentemente, farmaci biologici sono comunemente utilizzati nella pratica clinica. Quelli più comunemente usati includono l'azatioprina $(2-3 \mathrm{mg} / \mathrm{kg} / \mathrm{die})$, il methotrexate $(0,5-0,8 \mathrm{mg} / \mathrm{kg})$, la ciclosporina $(6-8$ $\mathrm{mg} / \mathrm{kg})$ e la ciclofosfamide $(1-2 \mathrm{mg} / \mathrm{kg})$. Rituximab è stato recentemente studiato in un ampio studio clinico multicentrico che ha mostrato determinare un netto miglioramento clinico in circa l' $83 \%$ dei pazienti. ${ }^{15}$

\section{Bilbiografia}

1. Dalakas M. Polymyositis, dermatomyositis and inclusion-body myositis. The New England journal of medicine 1991;325:1487-1498.

2. Dalakas M, Hohlfeld R. Polymyositis and dermatomyositis. Lancet 2003;362:971-982

3. Hoogendijk J, Amato A, Lecky B, Choy E, Lundberg I, Rose M, Vencovsky J, de Visser M, Hughes R. 119th ENMC international workshop: trial design in adult idiopathic inflammatory myopathies, with the exception of inclusion body myositis, 10-12 October 2003, Naarden, The Netherlands. Neuromuscular disorders : NMD 2004; $14: 337-345$

4. Greenberg S. Inflammatory myopathies: evaluation and management. Seminars in neurology 2008;28:241-249.

5. Marie I, Dominique S, Remy-Jardin M, Hatron P, Hachulla E. Interstitial lung diseases in polymyositis and dermatomyositis. La Revue de medecine interne / fondee par la Societe nationale francaise de medecine interne 2001;22:1083-1096.

6. Ebert E. Review article: the gastrointestinal complications of myositis. Alimentary pharmacology \& therapeutics 2010;31:359-365.

7. Euwer RL, Sontheimer RD. Dermatologic aspects of myositis. Curr Opin Rheumatol 1994;6:583e9.

8. Khan S, Christopher-Stine L. Polymyositis, dermatomyositis, and autoimmune necrotizing myopathy: clinical features. Rheumatic diseases clinics of North America 2011;37:143-158

9. Marie I, Dominique S, Remy-Jardin M, Hatron P, Hachulla E. [Interstitial lung diseases in polymyositis and dermatomyositis]. La Revue de medecine interne / fondee par la Societe nationale francaise de medecine interne 2001;22:1083-1096

10. Mimori T, Nakashima R, Hosono Y. Interstitial lung disease in myositis: clinical subsets, biomarkers, and treatment. Current rheumatology reports 2012;14:264-274

11. Marie I. Morbidity and mortality in adult polymyositis and dermatomyositis. Current rheumatology reports 2012;14:275-285.

12. Amato A, Barohn R. Evaluation and treatment of inflammatory myopathies. Journal of neurology, neurosurgery, and psychiatry 2009;80:1060-1068

13. Griggs R, Askanas V, DiMauro S, Engel A, Karpati G, Mendell J, Rowland L. Inclusion body myositis and myopathies. Annals of neurology 1995;38:705-713.

14. Targoff I. Myositis specific autoantibodies. Current rheumatology reports 2006;8:196-203.

15. Oddis C, Reed A, Aggarwal R, et al. Rituximab in Myositis Study G. Rituximab in the treatment of refractory adult and juvenile dermatomyositis and adult polymyositis: A randomized, placebo-phase trial. Arthritis and rheumatism 2012;65:314-324. 


\section{Parte II: IMIDs neurologiche in corso di malattie sistemiche}

\section{Parte II - A) Vasculiti}

\section{Neuro-Behcet's disease}

Il neuro-Behçet (NBD) è una delle manifestazioni più serie della malattia di Behçet $(\mathrm{BD})$, malattia infiammatoria dei vasi, multisistemica, recidivante ad etiologia sconosciuta. ${ }^{1}$ Pur essendo una malattia rara la BD presenta una caratteristica prevalenza lungo la Via della Seta ovvero in quei paesi che vanno dall'Estremo al Medio Oriente e nei paesi dell'Aera Mediterranea. $^{2} \mathrm{La} \mathrm{BD}$ è più frequente negli uomini nell'area del Mediterraneo orientale e nelle donne in Nord Europa paesi, e in genere colpisce giovani adulti di età compresa tra 20-40 anni. ${ }^{3}$ È stata inoltre segnalata una forte associazione con l'allele di istocompatibilità HLA B51 nelle aree ad alta prevalenza di malattia. ${ }^{4,5}$ La BD si presenta come una malattia multisistemica con coinvolgimento dermatologico, articolare, oculare, gastrointestinale, vascolare e del sistema nervoso (SN). La diagnosi BD può essere tardiva perché i sintomi possono recidivare e manifestarsi in diverse fasi di malattia: attualmente, i criteri diagnostici più utilizzati sono quelli approvati dal Gruppo Internazionale di Studio ${ }^{6}$ che prevedono l'utilizzo di un sistema di punteggio il cui valore maggiore o uguale a 4 è suggestivo di BD (Tabella 1).

\section{Caratteristiche cliniche}

Si definisce Neuro-Behçet (NBD) l'insieme delle manifestazioni neurologiche della malattia, presenti dal 4 al $49 \%$ dei pazienti con $\mathrm{BD}^{7-11}$ che possono svilupparsi anche dopo 10 anni dall'esordio. ${ }^{10,12}$ NDB generalmente coinvolge il sistema nervoso centrale (SNC) ma, meno frequentemente, può coinvolgere anche il sistema nervoso periferico (SNP) $)^{10,11}$ (Tabella 2). Esistono due principali sottotipi di NBD: parenchimale (una meningo-encefalite infiammatoria) e non-parenchimale (secondaria a coinvolgimento vascolare). La NBD parenchimale generalmente si presenta come sindrome troncoencefalica ad esordio subacuto (oftalmoparesi, neuropatia cranicale, disturbi cerebellari e/o piramidali), oppure come sindrome emisferica (emiparesi, emisindrome sensitiva, epilessia, disturbi cognitivi e raramente demenza) o midollare e può includere disturbi del comportamento, cefalea. La NBD non parenchimale si presenta generalmente con cefalea e disturbi visivi secondari ad ipertensione endocranica, generalmente dovuta a trombosi venosa cerebrale, oppure come stroke correlato a trombosi arteriosa, dissezione o aneurismi (meno comune). La NBD parenchimale presenta in genere un decorso recidivante-remittente o progressivo. La forma non parenchimale tende ad essere mo- nofasica ma talora può recidivare. Recentemente sono stati stabiliti i criteri diagnostici ${ }^{13}$ per la diagnosi di NBD riportati in Tabella 3.

\section{Diagnosi}

Oltre ai dati clinici gli esami strumentali rappresentano un'importante elemento per orientare la diagnosi. La risonanza magnetica $(\mathrm{RM})$ è estremamente utile, soprattutto per la diagnosi differenziale con le altre sindromi neurologiche. ${ }^{14-21}$ Nella forma parenchimale tipicamente le lesioni acute appaiono come ipo-intense $\mathrm{o}$ isointense nelle sequenze T1 pesate, captanti gadolinio, ipertintense nelle sequenze T2 e FLAIR, iperintense nelle sequenze in diffusione e mostrano un ridotto coefficiente di diffusione delle ADC (apparent diffusion coefficient). In fase cronica tali piccole lesioni appaiono non captanti gadolinio e possono risolversi completamente. La localizzazione è per lo più nel troncoencefa-

Tabella 1. Criteri internazionali per BD: un punteggio maggiore/uguale a 4 indica diagnosi di BD.

\begin{tabular}{lc}
\hline Segni/sintomi & Punti \\
\hline Lesioni oculari & 2 \\
\hline Afte genitali & 2 \\
\hline Afte orali & 2 \\
\hline Lesioni cutanee & 1 \\
\hline Manifestazioni neurologiche & 1 \\
\hline Manifestazioni vascolari & 1 \\
\hline Pathergy test positivo & $1 *$
\end{tabular}

*Il Pathergy test è opzionale. Tuttavia, quando si esegue il Pathergy test, un punto supplementare può essere assegnato per un risultato positivo.

Tabella 2. Classificazione del NDB.

SNC parenchimale

- Multifocale

- Troncoencefalo

- Midollare

- Cerebrale

- Asintomatica

- Neuropatia ottica

SNC non parenchimale

- Trombosi venosa cerebrale

- Aneurismi intracranici

- Aneurismi extracranci cervicali/dissezione

- Sindrome meningea acuta

SNP (relazione con BD incerta)

- Neuropatia periferiche e mononeuropatie multiple

- Miopatia e miosite

Malattia mista (parenchimale e non parenchimale) 
lico (ponte), gangli basali e diencefalo. Non è evidente una chiara disposizione periventricolare. Talora possono presentarsi come lesioni isolate emisferiche di diversa grandezza (forme pseudotumorali), talora come lesioni midollari. Può essere evidente atrofia del troncoencefalo. Nella forma non-parenchimale la RM con sequenze angiografiche può mostrare trombosi venosa dei seni cerebrali. Talora la presenza di enhancement meningeo si può evidenziare in caso di sindrome meningea acuta. Nelle forme associate ad ipertensione endocranica la RM può apparire normale. Il liquido cefalo-rachidiano (CSF) appare alterato nel 70-80\% dei casi. ${ }^{6,10,11,22} \mathrm{La}$ forma parenchimale è generalmente associata a modesta pleiocitosi (talora neutrofili, talora linfociti) e/o lieve aumento delle proteine liquorali. In genere le bande oligoclonali (BO) sono assenti. La normalità dell'analisi del liquor non esclude la diagnosi di NBD parenchimale. La forma non-parenchimale è associata ad elevati livelli di pressione liquorale. Sono stati dimostrati elevati livelli liquorali della IL-6 nelle forme parenchimali acute. ${ }^{23,24}$ La presenza di pleiocitosi, incremento delle proteine liquorali ed elevati livelli di IL-6 si sono dimostrati fattori prognostici sfavorevoli per successivi tre anni di malattia. ${ }^{23-29}$ Il Pathergy test (test patergico) rappresenta uno dei maggior criteri per la diagnosi di $\mathrm{BD}$. La reazione patergica consiste in una iperreattività aspecifica della cute ad un trauma come per esempio la puntura di un ago. Un test è definito positivo quando compare una papula o pustola $24-48$ ore dopo un'iniezione intradermica ed è altamente suggestivo ma non patognomonico di BD. Inoltre la sensibilità al test presenta delle variazioni geografiche significative: sono positivi al test il $60-70 \%$ dei pazienti in Turchia e Giappone mentre è estremamente raro nei pazienti del Nord Eurpa e del Nord America. ${ }^{30,31}$

\section{Diagnosi differenziale}

Nella diagnosi differenziale della NBD è necessario considerare la sclerosi multipla (SM), soprattutto quando si presenta con caratteristiche atipiche. Alcune sintomi neurologici come esordio con neurite ottica, oftalmoplegia internucleare, atassia e disartria cerebellare sono più comuni della SM mentre cefalea, disturbi co- gnitivi e comportamentali sono più comuni nel NBD. ${ }^{25}$ Il coinvolgimento del midollo spinale è meno comune nel NBD. ${ }^{26}$ La presenza di $\mathrm{BO}$ è più frequente nella SM che ne NBD. ${ }^{27}$ La pleiocitosi prevalentemente neutrofila è più tipica del NBD parenchimale mentre un lieve incremento dei linfociti predomina nella SM. ${ }^{28}$ Per quanto riguarda i reperti in RM nella SM le lesioni sono tipicamente periventricolari, con più raro coinvolgimento dei gangli basali e della capsula interna e ponte. ${ }^{29}$ La presenza di atrofia del troncoencefalo associata alla presenza di lesioni sottocorticali sono più suggestivi di NBD che di SM. ${ }^{29}$ Altra diagnosi differenziale è con il lupus eritematoso stistemico (LES) e le altre malattie infiammatorie sistemiche come la sindrome di Sjögren. In tal caso la diagnosi differenziale richiede l'utilizzo di markers sierologici e altri test paraclinici caratteristici per ciascuna malattia sistemica. Il coinvolgimento del SNP è più frequente nelle altre malattie infiammatorie piuttosto che nella NBD. La diagnosi differenziale include inoltre la sarcoidosi e, talora, il linfoma del SNC.

\section{Trattamento}

Non esistono ad oggi trattamenti con livelli di evidenza di tipo I in quanto non esistono trials comparativi. ${ }^{32}$ Per il trattamento delle riacutizzazioni della NBD parenchimale è raccomandato un ciclo di corticosteroidi, preferibilmente metilprednisolone iv per 3-10 giorni seguito da mantenimento con corticosteroidi per via orale per circa sei mesi. ${ }^{13}$ È raccomandato intraprendere un trattamento modificante il decorso di malattia (DMT) dopo una significativa recidiva di NBD parenchimale, in relazione alla severità dei sintomi, al grado di recupero neurologico, alla risposta agli steroidi, al numero di recidive precedenti e i sintomi sistemici associati. ${ }^{13}$ L'Azatioprina è considerata il DMT di prima linea; in alternativa è possibile utilizzare il micofenolato, il metotrexate e la ciclofosfamide. È raccomandato l'uso di agenti biologici quali i TNF- $\alpha$ bloccanti (infliximab, adlimumab, etanercept) o l'interferone $\alpha$ quando la terapia di prima linea risulta inefficace. ${ }^{13}$ In caso di NBD è raccomandata cautela nell'utilizzo della ciclosporina per la potenziale associazione di complicanza neurologiche. La ciclosporina

Tabella 3. International consensus recommendation criteria (ICR) per la NDB.

Malattia di neuro-Behçet definita presenza dei seguenti tre criteri:

1. Criteri ISG per BD soddisfatti

2. Sindrome neurologica (con segni obiettivi) riconosciuta come causata da BD e supportata dati strumentali caratteristici quali neuroimaging (RM) e liquorali (CSF)

3. No better explanation dei sintomi neurologici

Malattia di neuro-Behçet probabile uno dei seguenti criteri in assenza di una migliore spiegazione dei segni neurologici:

1. Sindrome neurologica come nella forma definita, con caratteristiche di BD sistemica ma che soddisfa i criteri ISG

2. Sindrome neurologica non caratteristica che occorre in un contesto di BD supportata dai criteri ISG

ISG, International Study Group Criteria 2014. 
è da evitare nel paziente con storia di NBD e deve essere interrotta in caso di coinvolgimento del SNC. ${ }^{13} \mathrm{Il}$ trattamento della trombosi venosa cerebrale prevede l'utilizzo dei corticosteroidi limitati al periodo della presentazione dei sintomi. Vi è controversia sull'utilizzo degli anticoagulanti, che rappresentano il gold standard del trattamento delle trombosi venose cerebrali di qualsiasi eziologia, ma non in quella da NBD in cui la trombosi è dovuta ad un processo infiammatorio. Se deve essere intrapreso un trattamento anticoagulante è necessario escludere la presenza di un aneurisma e la sua durata deve essere in genere di 3-6 mesi. ${ }^{13}$

\section{Bibliografia}

1. Hatemi G, Yazici Y, Yazici H (2013) Behc, et's syndrome. Rheum Dis Clin North Am 39:245-261

2. Khairallah M, Accorinti M, Muccioli C, Kahloun R, Kempen JH et al (2012) Epidemiology of Behc, et disease. Ocul Immunol Inflamm 20:324-33

3. Sakane T, Takeno M, Suzuki N, Inaba G. Behcet's disease. N Engl J Med.1999;341:1284

4. Yazici H, Akhan G, Yalçin B, Müftüolu A. The high prevalence of HLA-B5 in Behçet's disease. Clin Exp Immunol.1977;30:259-261.

5. Mizuki N, Inoko H, Ohno S. Molecular genetics (HLA) of Behçet's disease. Yonsei Med J. 1997;38:423-427

6. International Team for the revision of the International Criteria for Behcet's Disease (ITR-ICBD) F. Davatchi, S. Assaad-Khalil, K.T. Calamia,J.E. Crook, B. SadeghiAbdollahi, M. Schirmer, T. Tzellos,C.C. Zouboulis et al The International Criteria for Behçet's Disease (ICBD): a collaborative study of 27 countries on the sensitivity and specificity of the new criteria J Eur Acad Dermatol Venereol. 2014 Mar;28(3):338-47.

7. Serdaroglu P. Behçet's disease and the nervous system. J Neurol.1998;245:197-205.

8. Farah S, Al-Shubaili A, Montaser A. Behçet's syndrome: A report of 41 patients with emphasis on neurological manifestations. J Neurol Neurosurg Psychiatry.1998;64:382384.

9. Siva A, Saip S, Kantarci O, et al. Neuro-Behçet syndrome (NBS): Clinical and imaging correlates. J Neurol. 1997;244 Suppl 3:545.

10. Akman-Demir G, Serdaroglu P, Tasci B. Clinical patterns of neurological involvement in Behçet's disease: Evaluation of 200 patients. The Neuro-Behçet Study Group. Brain.1999;122:2171-2182.

11. Kidd D, Steuer A, Denman AM, Rudge P. Neurological complications in Behçet's syndrome. Brain.1999;122: 2183-2194.

12. Matsuo K, Yamada K, Nakajima K, Nakagawa M. Neuro-Behçet disease mimicking brain tumor. Am J Neuroradiol. 2005;26:650-653.

13. Seema Kalra • Alan Silman • Gulsen Akman-Demir • Saeed Bohlega et al Diagnosis and management of Neuro-Behcet's disease: international consensus recommendations; J Neurol 2014; 261:1662:1676

14. Al Kawi MZ, Bohlega S, Banna M (1997) MRI findings in neuroBehcet's disease. Neurology 41:405-408
15. Wechsler B, Dell'lsola B, Vidailhet M et al (1993) MRI in 31 patients with Behc, et's disease and neurological involvement: prospective study with clinical correlation. J Neurol Neurosurg Psychiatry 56:793-798.

16. Coban O, Bahar S, Akman-Demir G et al (1996) A controlled study of reliability and validity of MRI findings in neuro-Behc, et's disease. Neuroradiology 38:312-316

17. Koc, er N, Islak C, Siva A, Saip S, Akman C, Kantarci O, Hamuryudan V (1999) CNS involvement in neuroBehc,et syndrome: an MR study. Am J Neuroradiol 20:1015-1024

18. Lee SH, Yoon PH, Park SJ, Kim DI (2001) MRI findings in neuro-Behcet's disease. Clin Radiol 56:485-494

19. Akman-Demir G, Bahar S, Coban O, Tasci B, Serdaroglu P (2003) Cranial MRI in Behc, et's disease: 134 examinations of 98 patients. Neuroradiology 45:851-859

20. Borhani-Haghighi A, Sarhadi S, Farahangiz S (2011) MRI findings of neuro-Behc, et's disease. Clin Rheumatol 30:765-770

21. Albayram S, Saip S, Hasiloglu ZI et al (2011) Evaluation of parenchymal neuro-behc, et disease by using susceptibilityweighted imaging. Am J Neuroradiol 32:1050-1055

22. Al-Fahad S, Al-Araji A (1999) Neuro-Behcet's disease in Iraq: a study of 40 patients. J Neurol Sci 170:105-111

23. Hirohata S, Kikuchi H, Sawada T et al (2012) Clinical characteristics of neuro-Behcet's disease in Japan: a multicenter retrospective analysis. Mod Rheumatol 22:405-413

24. Akman-Demir G, Erdem Tuzun, Sema Icoz et al (2008) Interleukin-6 in neuro-Behcet's disease: association with disease subsets and long-term outcome. Cytokine 44:373-37

25. Motomura S, Tabira T, Kuriowa Y et al (1998) A clinical comparative study of multiple sclerosis and neuro-Behc, et syndrome. J Neurol Neurosurg Psychiatry 43:210-213

26. Yesilot N, Mutlu M, Gungor O, Baykal B, Serdaroglu P, AkmanDemir G (2007) Clinical characteristics and course of spinal cord involvement in Behc, et's disease. Eur J Neurol 14:729-737

27. Saruhan-Direskeneli G, Yentu "r SP, Mutlu M et al (2013) Intrathecal oligoclonal IgG bands are infrequently found in neuroBehc, et's disease. Clin Exp Rheumatol 31(3 Suppl 77):25-27

28. McLean BN, Miller D, Thompson EJ (1995) Oligoclonal banding of IgG in CSF, blood-brain barrier function, and MRI findings in patients with sarcoidosis, systemic lupus erythematosus, and Behc, et's disease involving the nervous system. J Neurol Neurosurg Psychiatry 58:548-55

29. Coban O, Bahar S, Akman-Demir G et al (1999) Masked assessment of MRI findings: is it possible to differentiate neuroBehc, et's disease from other central nervous system diseases? Neuroradiology 41:255-260

30. Hatemi I, Hatemi G, Celik AF et al (2008) Frequency of pathergy phenomenon and other features of Behc, et's syndrome among patients with inflammatory bowel disease. Clin Exp Rheumatol 26(4 Suppl 50):S91-S95

31. Yazici H, Chamberlain MA, Tuzun Y et al (1984) A comparative study of the pathergy among Turkish and British patients with Behcet's disease. Ann Rheumc Dis 43:74-75

32. Akman-Demir G, Saip S, Siva A (2011) Behçet's Disease. Curr Treat Options Neurol 13:290-310 


\section{Parte II - B) Neuro-LES}

Il lupus eritematoso sistemico (LES) è malattia autoimmune cronica che coinvolge più organi, caratterizzata dalla produzione di autoanticorpi e conseguente danno tissutale. L'eziologia del LES è parzialmente nota e coinvolge molteplici fattori genetici e ambientali. Il LES colpisce più spesso le donne di razza caucasica in età fertile. Circa il $50 \%$ dei pazienti con LES presentano un coinvolgimento neurologico, ${ }^{1}$ che rappresenta un fattore prognostico sfavorevole, determinando una maggior mortalità e morbilità e più in generale un peggioramento della qualità di vita. Ad oggi sono state identificate circa diciannove sindromi neuropsichiatriche associate con LES (NPLES), divise in manifestazioni centrali e periferiche ${ }^{2}$ (Tabella 1$)$. Sono stati individuati una varietà di meccanismi patogenetici implicati nel NPLES, compresi una vasculopatia ischemico-infiammatoria, un'infiammazione diffusa citochino-mediata, alterazioni della barriera emato-encefalica e presenza di cellule $\mathrm{T}$ sensibilizzate o auto-anticorpi nel sistema nervoso centrale e periferico (SNC e SNP).

Il NPSLE può essere la prima manifestazione della malattia e la sua prevalenza varia dal $21 \%$ al $95 \%{ }^{3,4}$ Il coinvolgimento del SNC è più frequente di quello periferico e può essere ulteriormente classificato in manifestazioni diffuse o focali. ${ }^{5}$ I pazienti possono presentare eventi neuropsichiatrici singoli o multipli che non sempre sono correlati all'attività della malattia sistemica. ${ }^{3}$ I fattori di rischio associati con NPLES includono: danni del sistema nervoso centrale o elevata attività del LES generalizzato; storia di precedenti eventi neuropsichiatrici o concomitanza di altre manifestazioni neuropsichiatriche; la presenza da moderata ad alti titoli di anticorpi antifosfolipidi (APL) ${ }^{5,6} \mathrm{I}$ principali quadri clinici nel NPLES sono:

\section{Cefalea}

Il mal di testa è un sintomo aspecifico comune per LES o altre malattie reumatiche. Nella maggioranza dei casi si tratta di una cefalea tensiva, talora di emicranica. ${ }^{7}$ La presenza di segni neurologici focali, febbre o infezioni concomitanti, la presenza di sindrome da anticorpi antifosfolipidi (APS), una condizione di immunosoppressione, l'uso di anticoagulanti, la presenza di alterazione dello stato mentale, meningismo e una elevata attività del LES generalizzato sono indicativi di cause secondarie e richiedono ulteriori indagini con RM cerebrale ed eventuale rachicentesi. ${ }^{8}$ I farmaci anti-infiammatori non steroidei ed i triptani possono essere utilizzati per alleviare il dolore. La terapia di prevenzione dell'emicrania prevede l'uso di $\beta$-bloccanti, anticonvulsivanti, come l'acido valproico e il topiramato, e antidepressivi. ${ }^{9}$

\section{Deterioramento cognitivo}

Si definisce disfunzione cognitiva (DC) un declino cognitivo rispetto ad un precedente livello di funzionamento mentale documentato da una valutazione neuropsicologica. ${ }^{4}$ I principali domini cognitivi compromessi nel LES sono l'attenzione, la velocità di elaborazione e la memoria: ${ }^{3}$ il deficit cognitivo è definito da punteggi che cadono di 2,0 deviazioni standard al di sotto della media. ${ }^{10} \mathrm{La}$ RM può evidenziare un certo grado di atrofia cerebrale, la presenza di lesioni della sostanza bianca o segni di ischemia cerebrale, generalmente correlati con la gravità del DC. ${ }^{8}$ La fisiopatologia del DC deve essere ancora pienamente compresa e può coinvolgere meccanismi di tipo vascolare, infiammatorio o da alterazione della BBB. Anche gli autoanticorpi potrebbero contribuire alla patogenesi del DC nel LES: ${ }^{5}$ pazienti affetti da lupus eritematoso sistemico con lupus anticoagulante hanno

Tabella 1. Sindromi neurologiche nel NPLES.

\begin{tabular}{ll}
\hline Sistema nervoso centrale & Sistema nervoso periferico \\
\hline Cefalea & Mononeuropatia \\
\hline Epilessia & Polineuropatia \\
\hline Malattia cerebrovascolare & Neuropatia cranicale \\
\hline Malattia demielinizzante & Plessopatia \\
\hline Mielopatia & Poliradicolonevrite acuta \\
\hline Disordini del movimento & Disordini disautonomici \\
\hline Meningite asettica & Miastenia gravis \\
\hline Disturbi del tono dell'umore & \\
\hline Disordini cognitivi & \\
\hline Disturbi d'ansia & \\
\hline Psicosi & \\
\hline
\end{tabular}


una probabilità tre volte maggiore di avere un deficit neuropsicologico. ${ }^{11} \mathrm{Il}$ trattamento per il CD rimane incerto. I pazienti possono rispondere al metilfenidato o al prednisone $(0,5 \mathrm{mg} / \mathrm{kg}) .{ }^{12} \mathrm{~L}$ 'aspirina è indicata solo per i pazienti con comorbidità cardiovascolare per migliorare le prestazioni cognitive; la riabilitazione cognitiva e la psicoeducazione sono trattamenti complementari che possono aiutare a migliorare le performance cognitive. ${ }^{8}$

\section{Epilessia}

L'epilessia si verifica nel $12 \%$ al $22 \%$ dei pazienti con LES ed è associata ad un aumento della morbidità e della mortalità. ${ }^{8}$ Le crisi tonico-cloniche generalizzate rappresentano il tipo più comune (dal 67\% all' $88 \%$ ), ma possono verificarsi anche crisi parziali e complesse. Anomalie all'EEG sono comuni (dal 60\% al $70 \%$ ) nel LES, e la presenza di elementi epilettiformi all'EEG sono suggestive di maggior rischio di recidiva epilettica. ${ }^{13}$ Anche nella patogenesi dell'epilessia sembrano coinvolti meccanismi di tipo infiammatorio. ${ }^{14}$ Può verificarsi anche una sindrome da encefalopatia posteriore reversibile (PRES), una sindrome clinico-radiologica caratterizzata da convulsioni, alterazione dello stato mentale, e deficit visivo. ${ }^{15}$ Si tratta di una condizione rara, con una buona prognosi, generalmente reversibile e raramente ricorrente. La risonanza magnetica mostra lesioni ipointense in $\mathrm{T} 1$, iperintense in $\mathrm{T} 2$ e nelle sequenze FLAIR nelle regioni parieto-temporo-occipitale bilaterali. Circa il $50 \%$ dei pazienti richiedono un trattamento sia con farmaci anticonvulsivanti e che antiipertensivi.

\section{Stato confusionale acuto}

È un disturbo della coscienza o della vigilanza con conseguente deficit attentivo associato alla presenza di anticorpi anti-NR2 e anticorpi anti-Sm nel liquor. ${ }^{16}$ Il meccanismo patogenetico alla base di questa manifestazione neuropsichiatrica diffusa sembra essere principalmente infiammatoria con un aumento della produzione di mediatori infiammatori, alterazione della BBB. Il Risperidone ( $2 \mathrm{mg} / \mathrm{die}$ ) può essere una opzione terapeutica ${ }^{17}$ tuttavia, corticosteroidi ed immunosoppressione dovrebbero essere considerati a seconda delle condizioni del paziente. ${ }^{8}$

\section{Psicosi, depressione e ansia}

Tali disturbi presentano una prevalenza dal $17 \%$ al $75 \%$ tra i pazienti con LES. ${ }^{18}$ I disturbi dell'umore sono associati con l'attività di malattia, ad alte dosi di prednisone ( $\geq 20 \mathrm{mg}$ ), malattia cutanea e presenza di mielite trasversa. ${ }^{19}$ Gli anticorpi anti-proteina $\mathrm{P}$ ribosomiale (anti-P) sono stati specificamente associati alla psicosi nei pazienti con lupus eritematoso sistemico. ${ }^{5,6}$ I glucocorticoidi e terapia immunosoppressiva sono indicati per la psicosi associata con SLE, specialmente in presenza di attività di malattia generalizzata. ${ }^{8}$

\section{Malattia cerebrovascolare}

Gli eventi cerebrovascolari rappresentano il 10\% e il $15 \%$ dei decessi nei pazienti con LES. ${ }^{20}$ L'ictus ischemico (IS) è la condizione più comune. I pazienti con LES hanno un duplice aumento del rischio di IS, un triplice aumento del rischio di ictus intracerebrale, e un aumento di quattro volte il rischio di emorragia subaracnoidea rispetto alla popolazione generale. ${ }^{20} \mathrm{Le}$ emorragie intracerebrali e subaracnoidea sono poco frequenti in pazienti con LES, e colpiscono per lo più giovani individui. Di solito si verificano nel primo anno dopo la diagnosi, e si traducono in alta mortalità e morbidità a lungo termine. ${ }^{21} \mathrm{I}$ fattori di rischio tradizionali non spiegano completamente l'alta prevalenza di IS in pazienti con LES: un'accelerato processo di aterosclerosi, mediatori infiammatori quali componenti del complemento, citochine e anticorpi aPL possono anche svolgere un ruolo nella genesi della malattia cerebrovascolare. La vasculite è una causa rara di ictus nel LES, pari al 7\% dei casi. I pazienti con SLE e ictus dovrebbero essere regolarmente studiati per la sindrome da anticorpi antifosfolipidi (APS), che si caratterizza per la presenza di anticorpi APL (arteriosi o venosi) e trombosi vascolare: una recente revisione sistematica ha indicato un aumento di cinque volte del rischio di IS o attacco ischemico transitorio nei pazienti con anticorpi aPL rispetto al controlli. ${ }^{22}$ È raccomandato l'uso di anticoagulanti orali lungo nei pazienti con APS e LES, per prevenire il ripetersi di trombosi arteriose e venose..$^{23}$

\section{Disordini del movimento}

I disordini del movimento sono rare manifestazioni neuropsichiatriche nel LES. Tuttavia sono stati descritti casi di parkinsonismo, mioclono e distonia su verosimile base a autoimmune o tromboembolica. ${ }^{24}$ La corea è la sindrome più descritta e può essere la prima manifestazione del LES nel 2\% dei pazienti, principalmente in donne. Può essere unilaterale o bilaterale e generalmente risolve spontaneamente. ${ }^{24} \mathrm{La}$ sindrome parkinsoniana correlata alla presenza di anticorpi antifosfolipidi è associata a vasculopatia ischemica, con scarsa risposta alla levodopa. I pazienti con APS possono presentarsi con tremore, tic, mioclono e sindrome corticobasale. ${ }^{24}$ Sono stati inoltre segnalati distonia focale compreso torcicollo e blefarospasmo.

\section{Meningite asettica}

L'incidenza di meningite asettica in pazienti affetti da LES è stata stimata intorno all' $1,4 \%-1,6 \%$. Essa può verificarsi in qualsiasi momento durante il corso della malattia, di solito durante attività di malattia. ${ }^{25}$ 
Poiché i pazienti sono spesso trattati con agenti immunosoppressori, è necessario escludere infezioni fungine batteriche, virali, fungine. Pur potendosi verificare una remissione spontanea, la maggior parte dei casi devono essere trattati con glucocorticoidi e terapia immunosoppressiva. ${ }^{8}$

\section{Mielite}

Nel LES la mielite si verifica nell' $1 \%-1,5 \%$ dei casi e si manifesta come mielite trasversa asimmetrico con emiparesi, tetraparesi, coinvolgimento della vescica, dolore neuropatico e la presenza di un livello sensoriale. I meccanismi fisiopatologici sottostanti non sono ancora noti: i rilievi istopatologici hanno rivelato sia meccanismi di tipo ischemico/trombotico (in particolare nei casi acuti) che di tipo infiammatorio. La mielite da LES si manifesta con due quadri clinici distinti: mielite della sostanza grigia e della sostanza bianca. I pazienti mielite della sostanza grigia hanno spesso una fase prodromica di febbre e ritenzione urinaria di esordio che evolve rapidamente in paraplegia. La risonanza magnetica rivela un'area midollare rigonfia ed attiva. ${ }^{26}$ Nella forma con coinvolgimento della sostanza bianca è associata con una presentazione meno grave, progressione lenta, maggiore spasticità ed ipereflessia. ${ }^{27} \mathrm{Nel}$ 91,7\% delle forme da sostanza grigia si possono evidenziare in RM lesioni midollari che coinvolgono più di tre segmenti vertebrali, ${ }^{27}$ poiché può verificarsi una co-occorrenza di LES con neuromielite ottica (NMO) tali pazienti devono essere testati per NMO-IgG anti-acquaporina 4 (AQP4). ${ }^{8}$ In presenza di mielite. La prevalenza di aPL varia dal $18 \%$ al $60 \%$ nei pazienti con LES con la mielite. Il trattamento prevede la terapia con steroidi ad alte dosi seguito da ciclofosfamide per via endovenosa. L'aggiunta di plasmaferesi ad un regime di ciclofosfamide endovenosa e steroidi ha portato ad una maggiore tasso di remissione. ${ }^{25}$ La recidiva di mielite trasversa acuta lupus-associata è comune (50-60\%) durante il tapering di steroidi. La gravità della compromissione neurologica (la forza muscolare $<3 / 5$ ) è la più importante variabile prognostica. Altre variabili prognostiche sono l'uso del catetere urinario al nadir neurologico e assenza di terapia con ciclofosfamide. Solo una piccola percentuale di pazienti recupera pienamente. Circa il $30 \%$ dei pazienti può avere il coinvolgimento del cervello, ed quindi è consigliabile eseguire una RM cerebrale. ${ }^{27}$

\section{Sistema nervoso periferico}

Alcuni pazienti con LES possono presentarsi con il coinvolgimento variabile di sistema nervoso periferico $(2-3 \%) .^{3}$ I sintomi clinici includono parestesia, dolore, disfunzione autonomica, atassia periferica, debolezza muscolare ed atrofia. Una polineuropatia pe- riferica distale simmetrica assonale sensoriale o sensomotoria è il sottotipo più comune di coinvolgimento periferico, mentre mononeuropatie multiple sono la seconda presentazione più comune. In una piccolissima percentuale di casi si possono manifestare anche sindromi poliradicolonevriti infiammatorie demielinizzanti acute o croniche.

\section{Bibliografia}

1. Kozora E, Erkan D, West SG, Filley CM, Zhang L, Ramon $\mathrm{G}$ et al. Site differences in mild cognitive dysfunction (MCD) among patients with systemic lupus erythematosus (SLE). Lupus. 2013;22(1):73-80.

2. Pamfil C, Fanouriakis A, Damian L, Rinzis M, Sidiropoulos P,Tsivgoulis G et al. EULAR recommendations for neuropsychiatricsystemic lupus erythematosus vs usual care: results from two European centres. Rheumatology (Oxford). 2015;54(7):1270-8.

3. Liang M, Corzillius M, Bae S, Lew RA, Fortin PR, Gordon C. The American College of Rheumatology nomenclature and case definitions for neuropsychiatric lupus syndromes. Arthritis Rheum. 1999;42(4):599-608

4. Hanly JG. Diagnosis and management of neuropsychiatric SLE. Nat Rev Rheumatol. 2014;10(6):338-347.

5. Sciascia S, Bertolaccini ML, Roccatello D, Khamashta MA, Sanna G. Autoantibodies involved in neuropsychiatric manifestations associated with systemic lupus erythematosus: a systematic review. J Neurol. 2014;261(9): 1706-14.

6. Bonfa E, Golombek SJ, Kaufman LD, Skelly S, Weissbach $\mathrm{H}$, Brot $\mathrm{N}$ et al. Association between lupus psychosis and antiribosomal P protein antibodies. N Engl J Med. 1987;317(5):265-71.

7. Hanly J, Urowitz MB, O'Keeffe AG, Gordon C, Bae SC, Sanchez-Guerrero J et al. Headache in systemic lupus erythematosus: Results from a prospective, international inception cohort study. Arthritis Rheum. 2013;65(11):2887-97.

8. Bertsias G, Ioannidis J, Aringer M, Bollen E, Bombardieri S,Bruce IN et al. EULAR recommendations for the managementof systemic lupus erythematosus with neuropsychiatricmanifestations: report of a task force of the EULARstanding committee for clinical affairs. Ann Rheum Dis. 2010;69(12):2074-82.

9. Diener HC, Charles A, Goadsby PJ, Holle D. New therapeutic approaches for the prevention and treatment of migraine. Lancet Neurol. 2015;14(10):1010-2.

10. Mikdashi J, Esdaile J, Alarcón GS, Crofford L, Fessler BJ, Shanberg L et al. Proposed response criteria for neurocognitive impairment in systemic lupus erythematosus clinical trials. Lupus. 2007;16(6):418-25. doi:10.1177/ 0961203307079044

11. Peretti CS, Peretti CR, Kozora E, Papathanassiou D, Chouinard VA, Chouinard G. Cognitive impairment in systemic lupus erythematosus women with elevated autoantibodies and normal single photon emission computerized tomography. Psychother Psychosom. 2012;81 (5):276-85.

12. Kozora E, Hanly J, Lapteva L, Filley C. Cognitive dysfunction in systemic lupus erythematosus: past, present, 
and future. Arthritis Rheum. 2008;58(11):3286-98.

13. Appenzeller S, Cendes F, Costallat LTL. Epileptic seizures in systemic lupus erythematosus. Neurology. 2004;63(10):1808-12.

14. Nabbout R. Autoimmune and inflammatory epilepsies. Epilepsia. 2012;53 Suppl 4:58-62.

15. Merayo-Chalico J, Apodaca E, Barrera-Vargas A, Alcocer-Varela A, Colunga-Pedraza I, González-Patiño A et al. Clinical outcomes and risk factors for posterior reversible encephalopathy syndrome in systemic lupus erythematosus: a multicentric case-control study. J Neurol Neurosurg Psychiatry. 2015;87(3):587-94.

16. Mikdashi J, Krumholz A, Handwerger B. Factors at diagnosis predict subsequent occurrence of seizures in systemic lupus erythematosus. Neurology. 2005;64(12): 2102-7.

17. Nishimura K, Omori M, Horikawa N, Tanaka E, Furuya T, Harigai M. Risperidone in the treatment of acute confusional state (delirium) due to neuropsychiatric lupus erythematosus: case report. Int J Psychiatry Med]. 2003;33(3):299-303.

18. Palagini L, Mosca M, Tani C, Gemignani A, Mauri M, Bombardieri S. Depression and systemic lupus erythematosus: a systematic review. Lupus. 2013;22(5):409-16.

19. Postal M, Lapa AT, Sinicato NA, Peliçari KO, Peres FA, Costallat LT, et al. Depressive symptoms are associated with tumor necrosis factor alpha in systemic lupus erythematosus. J Neuroinflammation. 2016
20. Holmqvist M, Simard JF, Asplund K, Arkema EV. Stroke in systemic lupus erythematosus: a meta-analysis of population-based cohort studies. RMD Open. 2015;1:e00168.

21. Panichpisal K, Rozner E, Levine SR. The management of stroke in antiphospholipid syndrome. Curr Rheumatol Rep. 2012;14(1):99-106.

22. Sciascia S, Sanna G, Khamashta MA, Cuadrado MJ, Erkan D, Andreoli L et al. The estimated frequency of antiphospholipid antibodies in young adults with cerebrovascular events: a systematic review. Ann Rheum Dis. 2015;74(11):2028-33.

23. Behrouz R. The risk of ischemic stroke in major rheumatic disorders. J Neuroimmunol. 2014;277(1-2):1-5.

24. Baizabal-Carvallo JF, Bonnet C, Jankovic J. Movement disorders in systemic lupus erythematosus and the antiphospholipid syndrome. J Neural Transm. 2013; 120(11):1579-89.

25. Kivity S, Agmon-Levin N, Zandman-Goddard G, Chapman J, Shoenfeld Y. Neuropsychiatric lupus: a mosaic of clinical presentations. BMC Med. 2015;13(1):43.

26. Schulz SW, Shenin M, Mehta A, Kebede A, Fluerant M, Derk CT. Initial presentation of acute transverse myelitis in systemic lupus erythematosus: demographics, diagnosis, management and comparison to idiopathic cases. Rheumatol Int 2012;32:2623-7.

27. Fangtham M, Petri M. 2013 update: hopkins lupus cohort. Curr Rheumatol Rep. 2013;15(9):360. 


\section{Parte II - C) - Neuro-Sjögren}

La sindrome di Sjögren primaria (PSS) è una malattia autoimmune caratterizzata da xeroftalmia, xerostomia, artralgia, mialgia e grave fatica. ${ }^{1}$ L'infiltrazione linfocitaria delle ghiandole lacrimali e salivari è il segno distintivo della malattia e si traduce in una distruzione parziale del parenchima ghiandolare. La diagnosi e la classificazione richiedono una positività alla biopsia delle ghiandole salivari o la presenza di anticorpi antisindrome di Sjögren A (anti-SSA). ${ }^{2}$ Il coinvolgimento del Sistema Nervoso raggiunge una prevalenza di circa il $20 \%$. Manifestazioni neurologiche possono essere i sintomi d'esordio della PSS in una proporzione non trascurabile di casi. Le manifestazioni a carico del SNC sono quelle meno frequenti (circa il 3,6\%) e comprendono: cefalea, ${ }^{3}$ deficit cognitivo frontale,,${ }^{4,5}$ malattia demielinizzante SM-like, ${ }^{6}$ mielite (neuromielite ottica NMO-like), ${ }^{7}$ meningoencefaliti, vasculiti, epilessia e stroke. ${ }^{8}$ Il coinvolgimento del SNP si verifica più frequentemente $(16,1 \%)$ e comprende : neuropatie craniali, polineuropatie sensitive, polineuropatie sensitive-motorie; rizopatie, mononeuriti multiple. ${ }^{8}$ Possibile è l'associazione con polimiosite o miastenia.

\section{Bibliografia}

1. Tincani A, Andreoli L, Cavazzana I, et al. Novel aspects of Sjögren's syndrome in 2012. BMC Med 2013;11:93.

2. Cornec D, Saraux A, Cochener B, et al. Level of agreement between 2002 American-European consensus group and 2012 American College of Rheumatology classification criteria for Sjögren's syndrome and reasons for discrepancies. Arthritis Res Ther 2014;16: R74.

3. Escudero D, Latorre P, Codina M, Coll-Canti J, Coll J (1995) Central nervous system disease in Sjögren's Sindrome. Ann de Medicine Interne 146 (4): 239- 242.

4. Malinow KL, Molina R, Gordon B (1985) Neuropsychiatric dysfunction in Primary Sjögren's Syndrome. Ann Med Intern 103: 344-9.

5. Lafitte C, Amoura Z, Cacoub P (2001) Neurological complications of Sjögren's Syndrome. J Neurol 248: 577-84

6. De Seze J, Devos D, Castelnovo G, Labauge P, Dubucquoi S, et al (2001) The prevalence of Sjögren's syndrome in patients with primary progressive multiple sclerosis. Neurology 57: 1359-63.

7. Rabadi MH, Kundi S, Brett D, Padmanabhan R (2010) Neurological Picture. Primary Sjögren syndrome presenting as neuromyelitis optica Neurol Neurosurg Psychiatry $81(2): 213-4$.

8. Guillermo Carvajal and Evolution in Sjögren's Syndrome (ASSESS) group Epidemiology of neurological manifestations in Sjögren's syndrome: data from the French ASSESS Cohort RMD Open 2016;2:e000179. 


\title{
IMIID in diabetologia
}

\author{
Riccardo Nicosia, ${ }^{1}$ Camillo Ricordi ${ }^{2}$ \\ ${ }^{1}$ University of Liverpool, Liverpool, United Kingdom; ${ }^{2}$ Diabetes Research Institute and Cell Transplant Center, University of \\ Miami, Miami, FL, USA
}

\section{Introduzione}

L'infiammazione è una risposta complessa,che integra più elementi, nei confronti di un agente biologico, chimico o fisico.Già descritta dagli egizi nel 3000 a.C., nel I secolo d.C. Celso elaborò i quattro segni caratteristici del processo infiammatorio: rubor, calor, tumor, dolor, ed infine Virchow, nel 1844, introdusse il quinto segno, la functio laesa.

L'infiammazione rappresenta un meccanismo di difesa, seguente all'azione dannosa di agenti fisici, chimici e biologici, il cui obiettivo finale è l'eliminazione della causa iniziale di danno cellulare o tessutale, nonché l'avvio del processo riparativo.

Vi sono due tipi d'infiammazione: i) acuta, come in seguito ad un urto; ii) cronica più silenziosa, difficilmente identificabile senza alcun esame, e pertanto più pericolosa.

Il secondo tipo d'infiammazione, definita infiammazione cronica, è la condizione che andremo ad analizzare. Verrà preso in studio il rischio di sviluppare una malattia cronica innescata dall'infiammazione, e sarà analizzato come il suo processo biologico si muove all'interno del diabete tipo $1 \mathrm{e}$ diabete tipo 2 .

Le malattie infiammatorie immunomediate (in inglese immune-mediated inflammatory diseases, IMID) raggruppano una serie di patologie apparentemente non correlate, ma che condividono uncomune processo infiammatorio ed una disregolazione del $\mathrm{Si}$ stema immunitario. Patologie molto differenti, quali

Corrispondente: Riccardo Nicosia, University of Liverpool, Liverpool, United Kingdom.

E-mail: riccardonicosia@hotmail.it

Camillo Ricordi, Diabetes Research Institute and Cell Transplant Center, University of Miami, Miami, FL, USA.

E-mail: cricordi@med.miami.edu

Articolo pubblicato secondo la Creative Commons Attribution NonCommercial 4.0 License (CC BY-NC 4.0).

C Copyright R. Nicosia e C. Ricordi, 2017

Licensee PAGEPress, Italy

QUADERNI - Italian Journal of Medicine 2017; 5(7):57-66 l'artrite reumatoide, il morbo di crohn ed il Diabete, possono essere considerate IMID.

È sempre più evidente che l'infiammazione gioca un ruolo fondametale nello sviluppo del diabete e nelle sue consequense metaboliche. ${ }^{1-7}$

Il diabete mellito di tipo 1 (DM1) è una malattia autoimmune multifattoriale, caratterizzata da una predisposizione genetica e da perdita progressiva di produzione di insulina da parte di cellule $\beta$ pancreatiche; il diabete di tipo 2 , invece, è una condizione cronica caratterizzata da iperglicemia e stress ossidativo. Molti studi sono stati portati avanti per dimostrare come l'infiammazione che guida lo sviluppo di queste condizioni può essere influenzata da una alimentazione anti-infiammatoria in modo da interagire con gli stessi targets molecolari di farmaci anti-infiammatori, senza però avere possibili effetti collaterali. Ad esempio i farmaci ad oggi disponibili per il diabete tipo 2 hanno una serie di controindicazioni come reazioni ematologiche e gastro-intestinali, coma e ipoglicemia, e disturbi nel metabolismo del fegato e dei reni, che con una dieta anti-infiammatoria potrebbero essere evitate. Acidi grassi Omega 3, Vitamina D e polifenoli sono i nutrienti fondamentali da introdurre in una dieta anti-infiammatoria. Studi recenti dimostrano che la combinazione di un alto dosagio di acidi grassi omega 3 e vitamina $\mathrm{D}$ può potenzialmente attenuare l'infiammazione in corso e preservare la massa delle cellule $\beta$ in pazienti diabetici, ed i polifenoli hanno provato di avere un effetto antinfiammatorio importante sui fattori di trascrizione del gene. Lo scopo di questo articolo è di spiegare il legame tra l'infiammazione cronica e diabete, analizzando le terapie ad oggi disponibili per la prevenzione e perchè una dieta anti-infiammatoria sia fondamentale per lagestione della malattia.

\section{Cos'è l'infiammazione?}

Durante una risposta immunitaria spesso una serie di processi portano alla formazione della cosiddetta infiammazione. Siconsidera l'infiammazione in termini di dolore associato alla distruzione cellulare, che risulta darisposte pro-infiammazione generate dal sistema immunitario congenito.Tuttavia, l'intero pro- 
cesso infiammatorio è un processo d'interazione di fasi sia pro che anti-infiammatorie. ${ }^{8,9}$

La fase pro infiammatoria induce dolore, gonfiore, rossore e calore; fattori che indicano distruzione cellulare in corso (infiammazione classica/acuta). La fase anti infiammatoria equivale alla risoluzione della risposta infiammatoria, permettendo così la riparazione cellulare e la rigenerazione. Solamente l'equilibrio tra queste due fasi consentirà alle cellule di riparare il micro tessuto danneggiato da eventi infiammatori.

Come premesso distinguiamo due tipi d'infiammazione; la prima è l'infiammazione che manifesta un dolore acuto, cioè l'infiammazione classica o infiammazione acuta. Essa inizia nell'arco di pochi minuti dopo la lesione al tessuto, ed il danno puo risultare puramente fisico o, in certi casi, puo coinvolgere l'attivazione di una risposta immunitaria. ${ }^{10-12}$

Un secondo tipo d'infiammazione è quella cellulare descritta come infiammazione cronica a bassa espressività, sotto la soglia del dolore. L'assenza di dolore associato a questo tipo d'infiammazione ne rende difficile l'identificazione, e cosi' può persistere per anni, se non decenni, causando irreversibili danni agli organi.

La mancata attivazione dei meccanismi volti alla risoluzione dell'infiammazione, necessari per i processi regenerativi, esiterà in danno ad organi, perdita di funzione ed esordio evidente di malattia cronica.

Per capire meglio il meccanismo infiammatiorio è necessario inoltrarsi nel sistema immunintario innato. La risposta infiammatoria immunitaria innata si divide in due complesse fasi: innesco e risoluzione della risposta infliammatoria.

L'innesco dell'infiammazione arriva con l'attivazione del fattore di trascrizione del gene nucleare fat-

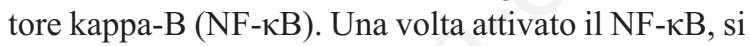
sposta nel DNA e causa la specifica trascrizione dell'enzima pro-infiammatorio quale il COX-2, che facilita la formazione di eicosanoidi pro-in fiammatori derivati da acido arachidonico (AA). Inoltre, il NF- $\kappa B$ induce anche la produzione di citochina pro-infiammatoria quali il IL-1, IL-6 e il TNF. La combinazione di eicosanoidi e citochina pro-infiammatorie avvierà la risposta infiammatoria; infiammazione cellulare a bassa espressività con una cascata di eventi che causa un accumulo di neutrofili nell'area bersaglio dell'infiammazione. Neutrofili che con una ampia varietà di meccanismi danno origine a danni cellulari collaterali significativi, sia per distruggere invasori microbiali che nel tentativo di riparare il danno cellulare causato da ferite fisiche (Figura 1).

Questa risposta infiammatoria iniziale non solo non si esaurisce sul nascere ma continuerà, ammenoché non ci sia una soluzione corrispondente che blocchi la migrazione di neutrofili nell'area bersaglio, potenzi l'eliminazione di detriti cellulari e avvii la ri- generazione del tessuto danneggiato. ${ }^{12}$ Questo processo risolutivo è mediato da un unico gruppo di ormoni: i resolvins. ${ }^{13}$

I resolvins sono derivati da acidi grassi omega 3 a catena lunga, come l'acido eicosapentaenoico (EPA) e acido docosaessaenoico (DHA). Senza adeguati livelli di EPA e DHA nel sangue o nel tessuto bersaglio l'infiammazione non si attenuerà. ${ }^{10,11}$

È fondamentale capire come la dieta sia il fattore numero uno da tenere in considerazione quando si parla d'infiammazione. Studi recenti hanno permesso una più completa comprensione del legame tra dieta $\mathrm{e}$ infiammazione del gene, mediate da fattori di trascrizione dei geni all'interno del sistema immunitario congenito. Il sistema immunitario congenito è la parte più primitiva nella nostra complessiva risposta immunologica ed è molto sensibile ai nutrienti. ${ }^{14}$

Il mediatore primario della risposta infiammatoria indotta dalla dieta è regolato dalla produzione di eicosanoidi pro-infiammatori derivanti dall'acido arachidonico (AA). L'acido arachidonico (AA) è un acido grasso omega 6 e i suoi livelli sono interamente controllati dalla dieta. L'obiettivo è quello di ridurre un eccesso di produzione di eicosanoidi pro-infiammatori, simile agli approcci dei farmaci anti-infiammatori, ma usando la dieta per raggiungere lo stesso obiettivo. ${ }^{15,16}$

Specifici marcatori ci consentono di misurare l'infiammazione cellulare: la proteina C-reattiva ad alta sensibilità (hs-CRP), anche se non è un marcatore molto selettivo poiché delle semplici infezioni possono aumentare i suoi livelli. ${ }^{17-19}$

Marcatore molto più selettivo per l'infiammazione cellulare è il rapporto di due acidi grassi chiave nel sangue. Il primo è l'acido grasso omega 6, l'acido arachidonico (AA), che è precursore di eicosanoidi proinfiammazione. L'altro acido grasso è l'omega 3 acido ecosapentaenoico (EPA), che genera eicosanoidi antiinfiammatori. Poiche' i livelli di DHA sono sempre maggiori di EPA a causa del metabolismo, il livello di EPA nel sangue diventa un buon marcatore sostituto dei livelli sia di EPA che di DHA. ${ }^{20}$

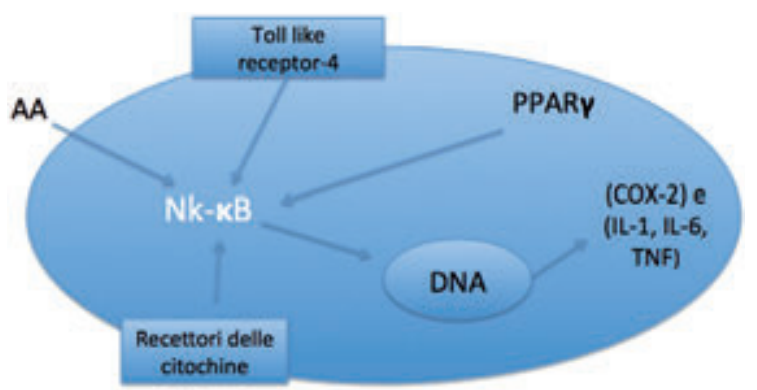

Figura 1. Versione semplificata dell'attivazione del NF$\kappa B$ indotta dalla dieta. 
Più alto è il rapporto AA/EPA nel sangue, maggiore è il livello d'infiammazione cellulare che verosimilmente si troverà in diversi organi ${ }^{10-12}$ (Figura 2).

Durante gli ultimi trent' anni l'infiammazione cellulare è aumentata a causa di quattro errori principali nella dieta: i) aumento nel consumo di oli vegetali raffinati ricchi di acido grasso omega 6; ii) aumento nel consumo di carboidrati raffinati; iii) diminuzione nel consumo di acidi grassi omega 3 a catena lunga; iv) diminuzione del consumo di polifenoli.

I primi due fattori aumentano la produzione di AA, aumentando in tal modo la risposta pro infiammatoria, mentre gli ultimi due fattori sono importanti per la produzione nelle risposte antinfiammatorie per la loro interazione con fattori di trascrizione dei geni.Alla base dei più comuni oli vegetali vi è l'acido linoleico. Esso è un acido grasso con omega 6 che prontamente si trasforma in AA (Figura 3). Visto che i carboidrati raffinati e gli oli vegetali raffinati sono fonti di calorie più economichenon è una sorpresa che la combinazione di queste due tendenze nutrizionali hanno aumentato anche una concentrazione di AA nei tessuti, portando così ad una infiammazione cellulare epidemica. ${ }^{21-23}$

Gli acidi grassi omega 3 EPA hanno un importante effetto inibitorio nella sintesi di AA e nel conseguente effetto di essi sull'infiammazione cellulare. ${ }^{24}$ In concentrazioni abbastanza alte, gli EPA possono parzialmente inibire l'attività dell'enzima desaturase delta-5, riducendo così la formazione di AA perché agisce da debole feed back inibitore, e perché entrambi gli acidi grassi usano lo stesso enzima (delta 5- desaturase) per la loro produzione.Non si conoscono farmaci che possono ridurre gli AA, soltanto la dieta. ${ }^{25,26}$ Una dieta ricca di acidi grassi omega 6 e carboidrati ad alto indice glicemico aumentà la produzione di AA. Pertanto, oltre a ridurre il consumo diretto di AA, bisogna ridurre simultaneamente il consumo gli acidi grassi omega 6, quali l'acido linoleico, e abbassare i livelli di insulina indotti dalla dieta. La riduzione di acido li-

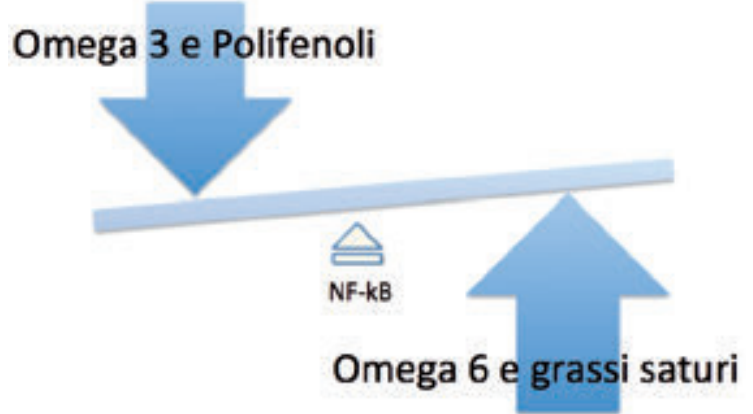

Figura 2. Controlli dietetici sul sistema immunitario innato. noleico nella dieta può essere acquisito usando grassi poveri di acidi grassi omega 6 , quali l'olio d'oliva o noci e usando fonti di proteine animali bassi di grassi saturi (come per esempio il pollo e il pesce magro) oppure ricchi in acidi grassi omega 3 (quali il pesce tipo tonno o salmone). La riduzione dei livelli d'insulina diminuirebbe il rapporto per cui qualsiasi acido linoleico nella dieta si trasformerebbe in AA. Si evince la necessità di ridurre il carico glicemico nella dieta, aumentando il consumo di frutta e verdure quali fonti primarie di carboidrati, e la simultanea riduzione di consumo di carboidrati ad alto livello glicemico, quali i grani e gli amidi. ${ }^{27,28}$ È stato recentemente dimostrato che gli acidi grassi omega 3 attivano il GPR-120, ricettore orfano collegante. A parte la capacità di legarsi agli acidi grassi omega 3, i GPR-120 attivati pare che riducano l'attività pro-infiammatoria di macrofagi nel tessuto adiposo. ${ }^{29,32}$

\section{Il ruolo dell'infiammazione il diabete di tipo uno}

Il diabete di tipo 1 (T1D) è una malattia autoimmune caratterizzata dalla perdita progressiva della massa di cellule $\beta$ pancreatiche, causando inevitabilmente iperglicemie e necessitando di terapia insulinica esogena. ${ }^{33}$ Come altre malattie autoimmuni, il diabete di tipo 1 è una patologia multifattoriale in cui, a un background di predisposizione genetica, si associa un evento scatenante in grado di superare la tolleranza periferica, con promozione di meccanismi autoimmunitari come l'attivazione di linfocitiautoreattivi. Nelle prime fasi, quest'attività autoimmunitaria è dimostrata dalla presenza di autoanticorpi diretti contro alcuni antigeni $\beta$-cellulari. Con il progredire della risposta autoimmune si determina la distruzione completa delle $\beta$-cellule e la comparsa dell'iperglicemia. ${ }^{34}$

La presenza in circolo di autoanticorpi diretti con-

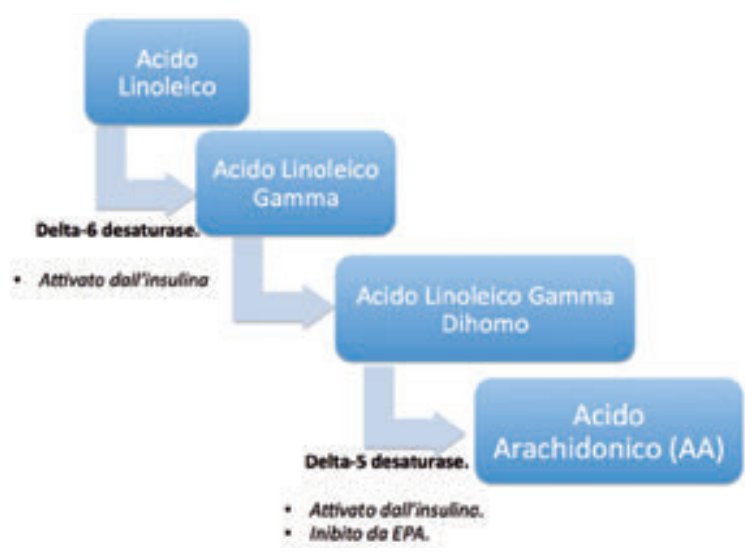

Figura 3. Metabolismo dei grassi acidi omega 6. 
tro il pancreas endocrino incrementa in modo significativo il rischio di sviluppare diabete di tipo $1 .^{35,36}$ L'importanza della tolleranza immunologica è nella capacità di riconoscere gli antigeni self da non-self nello sviluppo delle patologie autoimmuni. L'iperglicemia cronica è il risultato, nel diabete autoimmune, della distruzione selettiva delle $\beta$-cellule insulari pancreatiche, processo che ormai è noto essere mediato principalmente dai linfociti $\mathrm{T}$; la loro presenza è fondamentale affinché si sviluppi la malattia. La maggior parte delle complicanze collegate al diabete si verificano come risultato di non controllo dei livelli di glucosio nel sangue, livelli di zucchero particolarmente elevate per un lungo periodo di tempo. ${ }^{37}$

Molti studi hanno valutato il ruolo della infiammazione nel diabete di tipo 1 (T1D) e come una progressiva resistenza insulinica può favorire un peggioramento dell'infiammazione cronica. ${ }^{38-40}$ Com'è già stato descritto in precedenza, l'attivazione del fattore di trascrizione del gene NF- $\mathrm{KB}$ è comunemente sospetto in questo processo, poichè risulta un eccesso di produzione infiammatoria di citochine proinfiammatorie (quali IL-1, IL-6 e TNF). In particolare, risultaticonvincenti su esperimenti genetici ed epidemiologici hanno dimostrato un ruolo significativo di interleukin-6 (IL-6) nella patogenesi dell'infiammazione, nella resistenza insulinica nel diabete e le sue complicanze. ${ }^{41,42}$ Se NF- $\mathrm{kB}$ può essere considerato il fattore infiammatorio di trascrizione del gene, allora la famiglia deiPPAR (recettori attivati dai proliferatori dei perossisomi) può essere considerata il corrispettivo fattore anti-infiammatorio.

Il PPAR $\gamma$ (il recettore gamma attivato dai proliferatori dei perossisomi) è un fattore di trascrizione del gene antinfiammatorio. La sua attivazione crea lo stimolo per la produzione di nuove cellule grasse sane che aumentano la capacità del tessuto adiposo di isolare ancora grasso accumulato in altri tessuti, annullando in questo modo l'ipotossicità. I tiazolidindioni, un pilastro nel trattamento del diabete, sono esempi di farmaci che attivano il fattore di trascrizione del gene PPAR $\gamma .{ }^{43-45}$

Il PPAR $\gamma$ è stimolato dall'adiponectina (ormone proteico che regola il catabolismo degli acidi grassi),la cui funzionalità può essere migliorata incrementando il consumo di acidi grassi omega $3 .^{46-48}$

Inoltre, gli EPA e DHA possono attivare il PPAR $\gamma$ direttamente. ${ }^{49}$ Oltre ad un incremento nell'assunzione di acidi grassi omega 3 (EPA e DHA), è fondamentale la diminuzione di AA, per ridurre la generazione di eicosanoidi proinfiammatori, diminuire le citochine infiammatorie e aumentare la formazione di resolvins.I benefici di ridurre il rapporto AA/EPA sono stati confermati in studi svolti su topi Fat-1. I topi Fat-1 sono animali transgenici progettati per convertire gli acidi grassi omega 6 in acidi grassi omega 3 . Il risultato è che il loro rapporto AA/EPA è vicino a 1. Questi animali transgenici sono protetti dallo sviluppare il diabete rispetto a controlli di tipospontaneo quando esposti a iniezioni multiple di streptozotocin a basso dosaggio (SZT) che induce un effetto tossico diretto sulle cellule $\beta .^{50}$ Un altro cambiamento da attuare nella dieta è l'uso di polifenoli. In natura i polifenoli vengono prodotti dal metabolismo secondario delle piante dove ricoprono un ruolo sia di difesa che di support meccanico.In origine si pensava anche il loro ruolo primario era quello di antiossidante, ma adesso sappiamo che hanno un effetto anti-infiammatorio importante sui fattori di trascrizione del gene. Un alto dosaggio di polifenoli potrebbe attivare il chinasi AMP simile alla metformina (farmaco usato nel trattamento del diabete tipo 2) per ridurre la resistenza insulinica. ${ }^{51,52}$ Sia gli acidi grassi omega 3 che i polifenoli possono inibire l'attivazione di NF- $\kappa B^{53,54}$ Tuttavia, si richiede di assumere questi nutrient ad un livello terapeutico per avere un'inibizione significativa di NF$\kappa B$.Inoltre, è stato recentemente dimostrato anche che un alto dosaggio di vitamina $\mathrm{D}$ migliora la funzione soppressoria delle cellule regolatorie $\mathrm{T}$ presenti in diabetici di tipo 1 e la combinazione di olio di pesce e vitamina $\mathrm{D}$ ad alto dosaggio appaiono avere in modo sinergico proprietà anti-infiammatorie. . $^{55,56}$

Recentemente nel European Re-view for Medical and Pharmacological Sciences è stata pubblicata un'interessante ricerca sul caso di un ragazzo neo diagnosticato con T1D a cui era stata somministrata un'alta dose di acidi grassi omega 3 vitamina D. Il paziente preso in esame era un ragazzo di 14 anni, di professione sciatore, il quale venne ricoverato dopo aver accusato debolezza per tre giorni, polydipsia, polinuria e perdita di peso $(3 \mathrm{~kg})$. Gli esami del sangue segnalavano 660 di glucosio $\mathrm{mg} / \mathrm{dL}$ e $\mathrm{pH}$ di 7,2. Il ragazzo è stato ricoverato con la diagnosi di chetoacidosi diabetica e trattato con ignezioni multiple d'insulinagiornalmente, come da protocollo ospedaliero. Al momento del ricovero il ragazzo pensava $50 \mathrm{~kg}$ e misurava 5'7' (BMI 17.3). Ulteriori test mostrarono l'emoglobina glicosilata di (HbA1c) $12,8 \%$ (116 $\mathrm{mmol} / \mathrm{mol})$ e C-peptide $<0,1 \mathrm{nmol} / \mathrm{L}(<0,3 \mathrm{ng} / \mathrm{mL})$. Dopo sei giorni di ospedalizzazione, il peso era aumentato e aveva raggiunto $52,6 \mathrm{~kg}$. A nove giorni dalla diagnosi al ragazzo vennè iniziata la somministrare diun concentrato di omega 3 ultra raffinato EPA/DHEA con una dose di EPA di $800 \mathrm{mg}$ (2 capsule) tre volte al giorno per una dose totale di 2400 mg di EPA, mirando di raggiungere un obiettivo di un rapporto AA/EPA 1,0-2,0. A un mese alla diagnosi l'HbAlc era migliorata a 7,6\% $(60 \mathrm{mmol} / \mathrm{mol})$, il dosaggio giornaliero totale dell'insulina erano 11 unità $(0,2$ unità $/ \mathrm{kg} / \mathrm{di}), C$-peptide a digiuno era $0,26 \mathrm{nmol} / \mathrm{L}$ $(0,78 \mathrm{ng} / \mathrm{mL})$. A due mesi, il C-peptide a digiuno era $0,20 \mathrm{nmol} / \mathrm{L}(0,6 \mathrm{ng} / \mathrm{mL})$, il picco C-peptide 0,46 
$\mathrm{nmol} / \mathrm{L}(1,4 \mathrm{ng} / \mathrm{mL})$ e AUC C-peptide si è osservato per i sei mesi successivi e ne seguì un miglioramento dopo 9 mesi con valori a digiuno, picco e AUC che aumentavano rispettivamente a $63,6 \%, 9,6 \%$ e $15,4 \%$ (Tabella 1).

A 12 mesi, il picco C-peptide era aumentato a 0,55 $\mathrm{nmol} / \mathrm{L}(1,66 \mathrm{ng} / \mathrm{mL})$ corrispondente al $20 \%$ di incremento dalla basale e AUC C-peptide era leggermente più alto rispetto ai 9 mesi $(0,33$ vs $0,30 \mathrm{nmol} / \mathrm{L} / \mathrm{min})$ sebbene rimaneva leggermente più basso della basale (rispettvamente $78 \mathrm{mg} / \mathrm{dL}$ vs $119 \mathrm{mg} / \mathrm{dL}$ e $0.05 \mathrm{nmol} / \mathrm{L}$ $[0,16 \mathrm{ng} / \mathrm{mL}]$ vs $020 \mathrm{nmol} / \mathrm{L}[0,6 \mathrm{ng} / \mathrm{mL}])$. A $15 \mathrm{mesi}$ l'HbAl era di $6,7 \%$ ( $50 \mathrm{mmol} / \mathrm{mol})$, il peso corporeo era aumentato a $66 \mathrm{~kg}$ e l'altezza aveva raggiunto 5'9,3"'(BMI 21,3), e le unità di insulina TDD erano di $19(0,29$ unità $/ \mathrm{kg} / \mathrm{dì})$.

L'uso di una terapia combinata con acidi grassi omega 3 ed alte dosi di vitamin D è stato ben tollerato dal paziente ed ha avuto effetti positivi nella funzione delle cellule $\beta$. È possibile ipotizzare che questa terapia mirata a mantenere stretto il rapporto AA/EPA, e una dose alta di colecalciferolo all'esordio di T1D, può risultare in una significativa diminuzione della risposta infiammatoria della massa di cellule $\beta$ che porta alla preservazione delle stesse cellule $\beta$ ed all'inibizione delle risposte del sistema immunitario sia adattivo che cell-mediato. ${ }^{57-64}$ Le terapie anti-infiammatorie dovrebbero essere introdotte presto nel corso della malattia per potere avere un impatto sulla prevenzione della perdita di cellule $\beta^{83}$. In aggiunta, considerando che il T1D è una malattia autoimmune cronica e anti-infiammatoria, le strategie anti-infiammatorie potrebbero dover essere somministrate per un periodo di tempo lungo se si vogliono osservare benefici clinici evidenti. Prodotti naturali quali gli acidi grassi omega 3, vitamina D e potenzialmente polifenoli accoppiati a una dieta antinfiammatoria ${ }^{11}$ non potranno mai sostituire il bisogno insulinico nella gestione del diabete di tipo 1. Comunque, il loro uso appropriato a livello terapeutico può ridurre i livelli di insulina richiesti per gestire la malattia e potenzial-

Tabella 1. Variabili di C-peptide dopo 2 ore di MMTT.

\begin{tabular}{|c|c|c|c|}
\hline Mesi post diagnosi & \multicolumn{4}{c|}{ Varlabill di C-peptide dopo 2 ore MMTT } \\
\hline & $\begin{array}{c}\text { Digiunando } \\
\text { (nmol/L)* }\end{array}$ & $\begin{array}{c}90 \text { min } \\
\left(\mathrm{nmo} / \mathrm{L}^{*}\right.\end{array}$ & $\begin{array}{c}\text { AUC (nmol/ } \\
\text { L/min)* }\end{array}$ \\
\hline 2 & 0.20 & 0.43 & 0.39 \\
\hline 4 & 0.14 & 0.34 & 0.30 \\
\hline 6 & 0.11 & 0.30 & 0.26 \\
\hline 9 & 0.18 & 0.31 & 0.30 \\
\hline 12 & 0.05 & 0.55 & 0.33 \\
\hline
\end{tabular}

-dividi le unita in nmol/L di 0.333 per convertire in ne/mL

MMTr: Moxed-meal test tollerance. AUC: area under the curve mente aiutare la concentrazione della massa residua di cellule $\beta$.

\section{Diabete tipo 2 ed infiammazione}

Il diabete di tipo 2 è una malattia caratterizzata da iperglicemia cronica e stress ossidativo.Si ritiene possa avere causa genetica, eredo-familiare, e legata ad uno scorretto stile di vita, ; ciò non significa che se un genitore è affetto da diabete tipo 2 il figlio ne sarà colpito con certezza, ma che il figlio avrà grosse probabilità di svilupparlo nel corso della vita ${ }^{65}$

La caratteristica più comune del diabete di tipo 2 è la comparsa dell'insulino resistenza. IL corpo produce insulina a sufficienza per trasportare il glucosio nelle cellule, ma il corpo resiste ad essa. ${ }^{66}$

La gestione del diabete di tipo 2 dovrebbe essere incentrata inizialmente sul trattamento non farmacologico della malattia: dieta, esercizio fisico, controllo del peso, riduzione del consumo di alcol e severo controllo glicemico. Inoltre, essendo l'obesità una condizione strettamente legata al diabete di tipo 2, la perdità di peso è d'obbligo per il trattamento della malattia. ${ }^{67} \mathrm{Il}$ tessuto adiposo è l'unico organo del nostro corpo che può conservare i trigliceridi. Di consequenza, esso occupa la posizione centrale nel controllo dell'infiammazione cellulare, agendo da sistema di tamponamento del grasso (fat-buffering), soprattutto controllando i livelli di AA nel sangue. Le cellule sane di grasso sono in grado di estrarre le cellule grasse acide in eccesso (incluse AA) nel sangue e conservarlo come trigliceridi. ${ }^{68} \mathrm{C}^{\text {'è una }}$ consapevolezza crescente che il diabete di tipo 2, come l'obesità, siano condizioni infiammatorie. L'infiammazione che guida lo sviluppo di queste condizioni può essere influenzata da un'alimentazione anti-infiammatoria (come nel diabete di tipo 1) in modo da interagire con gli stessi targets molecolari di farmaci anti-infiammatori. ${ }^{37-73}$ Lo scopo di una dieta anti-infiammatoria è quello di comprendere come i nutrienti dietetici possano avere un impatto sui bersagli farmacologici d'infiammazione. Ciò comporterebbe una riduzione di quei componenti che attivano direttamente la risposta infiammatoria del sistema immunitario congenito, quali i fattori di trascrizione del gene NF- $\mathrm{kB}$. Questi nutrienti dietetici che inducono risposta infiammatoria potrebbero interrompere gli schemi di segnalazione ormonale tra i ricettori degli ormoni ed i loro bersagli interni, facendo aumentare la resistenza all'insulina e alla leptina (ormone che regola la sazietà).I nutrienti alimentari (gli AA, acidi grassi omega-6, e grassi saturi) che inducono questa risposta infiammatoria sono quelli che devono essere ridotti nella dieta. Gli AA possono attivare direttamente NF- $\mathrm{KB}$ oppure servire per la produzione di leucotine che attivano i NF- $\mathrm{KB} \cdot{ }^{32,33}$ L'approccio migliore per ridurre gli AA è quello di limitarne il consumo nella propria dieta. I grassi alimentari più comuni, con livelli 
bassi sia di omega- 6 che di grassi saturi, sono olio d'oliva e la maggior parte della frutta secca. Pertanto questi ingredienti alimentari dovrebbero costituire il volume del grasso alimentare in tutte le diete anti-infiammatorie. Successivamente bisogna tenere in questione il volume di proteine da consumare ad ogni pasto. L'apporto proteico ideale per un individuo di sesso femminile è di $20 \mathrm{~g}$ e per un individuo di sesso maschile è di $30 \mathrm{~g}$; le proteine devono essere presenti in ogni pasto in modo da garantire adeguati livelli di leucine che attivano la sintesi delle proteine per aumentare termogenesi. ${ }^{74} \mathrm{Il}$ contenuto di carboidrati dovrebbe essere in grado di mantenere il livello d'insulina stabile tra i pasti. Ciò potrà essere ottenuto con circa $40 \mathrm{~g}$ di carboidrati a basso contenuto glicemico per ogni pasto. Il grosso volume di carboidrati dovrebbe provenire da fonti ricchi di polifenoli e poveri di carboidrati, ciò significa che si consumeranno principalmente verdure colorate e senza amido, una moderata quantità di frutta, una quantità limitata di grani integrali e una riduzione radicale del consumo di carboidrati raffinati o di altri carboidrati ad alto indice glicemico (riso bianco, pane bianco, patate bianche). Inoltre si consiglia di ridurre il consumo di carne rossa, poichè negli Stati Uniti la maggior parte di essa proviene da allevamenti in cui gli animalisono nutriti con mangimi a base di grano, fornendo così sia acido linoleico che carboidrati ad alto indice glicemico. ${ }^{75}$ L'alimentazione anti-infiammatoria dovrebbe essere considerata una forma di tecnologia di silenziamento genetico, in particolar modo il silenziamento di quei geni coinvolti a generare l'infiammazione cellulare. Gli agenti farmacologici agiscono sulla flogosi già innescata, mentre la nutrizione anti-inffiammatoria ne previene l'innesco riducendo e/o inibendo l'attivazione del NF-кB.Una dieta ricca di carboidrati fortemente iperglicemizzanti aumenterà i livelli d'insulina postprandiale, diminuendo rapidamente i livelli di glucosio nel sangue e sollecitando il senso di fame. Ciò istituisce un incrementato consumo di calorie (principalmente carboidrati raffinati) interrompendo così il preciso equilibrio ormonale di segnalazione di sazietà e fame, ed aumentando l'appetito. ${ }^{76} \mathrm{Se}$ i livelli d'insulina rimangono elevati, il grasso immagazzinato nel tessuto adiposo rimarrà sequestrato a causa delle sua inibizione della lipase sensibile all'ormone che si trova nelle cellule grasse sane. Inoltre, l'insulina nel sangue puo anche agire come un ormone della fame a causa della sua capacità di abbassare i livelli di glucosio nel sangue. Ma, paradossalmente, l'insulina, se raggiunge l'ipotalamo, ha anche funzione di ormone della sazietà. ${ }^{77-79}$ In presenza di resistenza insulinica (indotta da infiammazione cellulare) i livelli alti di insulina nel sangue non riescono a trasmettere il loro messaggio alle cellule chiave nell'ipotalamo, ed i potenziali effetti di sazietà dati dall'insulina saranno mitigati. La leptina è un ormone rilasciato dalle cellule grasse ed è coinvolto anche nella sazietà e, come l'insulina, per potere esercitare la sua azione di sazietà deve raggiungere l'ipotalamo. L'iperinsulinemia potrebbe condurre alla riduzione di efficacia del percorso della lepticina. È stato ultimamente dimostrato che gli acidi grassi omega-3 attivano ilricettore orfano collegante, conosciuto come GPR-120. A parte la capacità di legare agli acidi grassi omega-3, pare che il GPR-120 riduca l'attività pro-infiammatoria dei macrofagi nel tessuto adiposo. Questo potrebbe essere il meccanismo primario per la riduzione precedentemente osservata nel livello di macrofagi nel tessuto adiposo in merito al supplemento di acidi grassi omega3. ${ }^{37,80-85}$ Uno studio è stato fatto con lo scopo di indagare sull'efficacia di una concentrazione di acidi grassi omega 3 su marcatori di livelli di trigliceridi e infiammazione, su pazienti con diabete mellito di tipo $2 \mathrm{e}$ ipertrigliceridemia.

Un totale di 30 pazienti (16 uomini e 14 donne) con diabete mellito di tipo 2 e ipertrigliceridemia sono stati presi in studio. L'età media era di $54 \pm 12$, con una durata di diabete mellito di 8 anni. Tutti i pazienti avevano un buon controllo del diabete. Lo studio consisteva nel trattare i pazienti per un periodo di 12 settimane preceduto da 9 settimane di consulenze nutrizionali, sia orali che scritte, da parte dei ricercatori che conducevano lo studio. Successivamente a questo periodo i pazienti ricevettero due capsule di eicosapentaenoico $465 \mathrm{mg}$ e docosahexanoico $375 \mathrm{mg}$ quotidianamente per 12 settimane. Il trattamento del diabete mellito fu mantenuto per tutto il periodo del protocollo. Tabella 2 mostra i cambiamenti dei parametri metabolici. ${ }^{69}$

Non sono stati registrati effetti indesiderati durante il trattamento e nessun paziente ha abbandonato l'esperimento. Si è notato che un intervento di omega-3 polinsaturi ha migliorato il profilo lipidico ed i marcatori infiammatori nei pazienti con diabete mellito di tipo 2 e con ipertrigliceridemia.In seguito a questo risultato e dai potenti effetti anti-infiammatori, si ipotizza che l'uso di acidi grassi Omega 3 potrebbe essere un nuovo primario approccio nel trattamento dell'ipertrigliceridemia e dello stato infiammatorio nei pazienti con diabete tipo 2. L'approccio alimentare fornisce una nuova strada per trattare non solo il diabete, ma anche molte altre malattie corniche essenzialmente causate da infiammazione cellulare. ${ }^{69}$

\section{Conclusioni}

Questo articolo spiega come l'infiammazione cronica, presente in pazienti affetti da diabete tipo 1 e diabete tipo 2 , può essere identificata e come può essere trattata usando una terapia non farmacologica. Attuando una dieta anti-infiammatoria, basata su una diminuzione di nutrienti che inducono una risporsta pro-infiammatoria (acidi grassi Omega 6, carboindrati raffinati e 
Tabella 2. Parametri metabolici.

Fattori

Iniziale

Dopo 3 mesi

\begin{tabular}{lll}
\hline Peso $(\mathrm{kg})$ & $81.4 \pm 10.7$ & $80.9 \pm 10.5$ \\
\hline BMI (kg/m^2) & $31.2 \pm 5.6$ & $30.8 \pm 5.2$ \\
\hline Glucosio Basale (mg/dl) & $148.3 \pm 67$ & $147.5 \pm 61.6$ \\
\hline Insullina (mU.l/) & $21.3 \pm 16.3$ & $18.9 \pm 7.1$ \\
\hline Colesterolo totale (mg/dl) & $218.3 \pm 61$ & $215.3 \pm 48.1$ \\
\hline Colesterolo-LDL (mg/dl) & $95.4 \pm 24$ & $102 \pm 20$ \\
\hline Colesterolo-HDL (mg/dl) & $39.6 \pm 10$ & $46.5 \pm 8.7$ \\
\hline Colesterolo-non-HDL (mg/dl) & $103.9 \pm 44$ & $89.6 \pm 14$ \\
\hline Trigliceridi (mg/dl) & $326.3 \pm 183$ & $216.4 \pm 48$ \\
\hline Pressione del sangue Sistolica $(\mathrm{mmHg})$ & $139 \pm 13$ & $137 \pm 14$ \\
\hline Pressione del sangue Diastolica $(\mathrm{mmHg})$ & $81 \pm 8.9$ & $81 \pm 7.2$ \\
\hline
\end{tabular}

-HDL: hich-density lipoprotein. LOL: low-density lipoprotein

grassi saturi) e su un aumento di nutrienti fondamentali per la produzione di risposte anti-infiammatorie (acidi grassi Omega 3, polifenoli), la sintesi di AA ed il consequente effetto di essi sull'infiammazione cellulare verrà inibita. Lo scopo di un'alimentazione anti-infiammatoria è quello di berasagliare gli stessi target molecolari di alcuni farmaci utilizzando specifici nutrienti/alimenti in concentrazioni terapeutiche in modo da avere gli stessi risultati, senza però avere nussuna controindicazione. Gli acidi grassi Omega 3 , usati ad alti dosi, hanno dimostrato di essere fondamentali nel trattamento. L'uso di Omega 3 incrementa la formazione di resolvins necessari a guidare la fase risolutive dell'infiammazione cellulare. Inoltre è stato studiato come la vitamina $\mathrm{D}$ può avere effetti anti-infiammatori, ed in particolare come in alte concentrazionimigliora la funzione soppressoria delle cellule regolatorie $\mathrm{T}$ presenti in diabetici di tipo 1 . In pazienti neo diabetici di tipo 1 una terapia basata su un alto dosaggio di acidi grassi Omega 3 e vitamina $\mathrm{D}_{3}$ ha dimostrato di essere di aiuto nella funzione e nella conservazione delle cellule- $\beta .^{64}$ Questo suggerisce come queste strategie anti-infiammatorie, combinate ad altre terapie, possano essere una buona strada per arrivare ad invertire l'autoimmunità della malattia.

\section{Bibliografia}

1. Vachharajani V, Granger DN. Adipose tissue: a motor for the inflammation associated with obesi- ty. IUBMB Life 2009; 61: 424-430.

2. Olefsky JM. IKKepsilon: a bridge between obesity and inflammation. Cell 2009; 138: 834-836.

3. Wellen KE, Hotamisligil GS. Obesity-induced in- flammatory changes in adipose tissue. J Clin In- vest 2003; 112: $1785-1788$
4. Coggins M, Rosenzweig A. The fire within: cardiac inflammatory signaling in health and disease. Circ Res 2012; 110: 116-125.

5. Kolb H, Mandrup-Poulsen T. The global diabetes epidemic as a consequence of lifestyle-induced low-grade inflammation. Diabetologia 2010; 53: 10-20.

6. Gonda TA, Tu S, Wang TC. Chronic inflammation, the tumor microenvironment and carcinogenesis. Cell Cycle 2009; 8: 2005-2013.

7. Glass CK, Saijo K, Winner B, Marchetto MC, Gage FH. Mechanisms underlying inflammation in neu- rodegeneration. Cell 2010; 140: 918-934.

8. Serhan CN, Brain SD, Buckley CD, Gilroy DW, Haslett C, O'neill LA, Perretti M, Rossi AG, Wal- Lace JL. Resolution of inflammation: state of the art, definitions and terms. FASEB J 2007; 21: 325-332.

9. Serhan CN. Resolution phase of inflammation: novel endogenous anti-inflammatory and pro-re- solving lipid mediators and pathways. Annu Rev Immunol 2007; 25: 101-137.

10. Sears b. Omegarx zone, Regan books. New York, NY, 2002.

11. Sears B. The Anti-inflammation Zone. Regan Books, New York, NY, 2005.

12. Sears B. Toxic Fat. Regan Books, New York, NY, 2008.

13. Spite M, Clària J, Serhan CN. Resolvins, specialized proresolving lipid mediators, and their potential roles in metabolic diseases. Cell Metab 2014; 19: 21-36.

14. Hotamisligil GS, Erbay E. Nutrient sensing and inflammation in metabolic diseases. Nat Rev Im- munol 2008; 8: 923-934.

15. Kopp E, Ghosh S. Inhibition of NF-kappaB by sodi- um salicylate and aspirin. Science 1994; 265: 956-959.

16. Holschermann H, Schuster D, Parviz B, Haberbosch W, Tillmanns H, Muth H. Statins prevent NF-kap- paB transactivation independently of the IKK- pathway in human endothelial cells. Atherosclero- sis 2006; 185: 240-245.

17. TALL AR. C-reactive protein reassessed. N Engl J Med 2004; 350: 1450-1452. 
18. Campbell B, Badrick T, Flatman R, Kanowshi D. Limited clinical utility of high-sensitivity plasma C-re- active protein assays. Ann Clin Biochem 2002; 39: 85-88.

19. Campbell B, Flatman R, Badrick T, Kanowshi D. Problems with high-sensitivity C-reactive protein. Clin Chem 2003; 49: 201.

20. Stark KD, Van Elswyk ME, Higgins MR, Weatherford CA, Salem N Jr. Global survey of the omega-3 fatty acids, docosahexaenoic acid and eicosapentaenoic acid in the blood stream of healthy adults. Prog Lipid Res 2016; 63: 132-152.

21. Drewnowski A, Specter SE. Poverty and obesity: the role of energy density and energy costs. Am J Clin Nutr 2004;79:6-16.

22. Darmon N, Darmon M, Maillot M, Drewnowski A. A nutrient density standard for vegetables and fruits: nutrients per calorie and nutrients per unit cost. J Am Diet Assoc 2005; 105: 1881-1887.

23. Drewnowski A, Darmon N, Briend A. Replacing fats and sweets with vegetables and fruits-a question of cost. Am J Public Health 2004; 94: 1555-1559.

24. Monsivais P, Drewnowski A. The rising cost of low- energydensity foods. J Am Diet Assoc 2007;107:2071-2076.

25. Sears B. The Zone. Regan Books, NY, 1995. Anti-inflammatory diets for obesity and diabetes. J Am College Nutr 2009; 28: 482S-491S.

26. Huber J, Loffler M, Bilban M, Reimers M, Kadl A, Todoric J, Zeyda M, Geyeregger R, Schreiner M, Weichhart T, Leitinger N, Waldhausl W, Stulnig TM. Prevention of high-fat diet-induced adipose tissue remodeling in obese diabetic mice by $n-3$ polyun- saturated fatty acids. Int J Obes 2007; 31: 1004- 1013.

27. Sears DD, Miles PD, Chapman J, Ofrecio JM, AlMazan F, Thapar D, Miller YI. 12/15-lipoxygenase is required for the early onset of high fat diet-induced adipose tissue inflammation and insulin re- sistance in mice. PloS One 2009; 4: e7250.

28. Chakrabarti Sk, Cole Bk, Wen Y, Keller Sr, Nadler JL. 12/15-lipoxygenase products induce inflamma- tion and impair insulin signaling in 3T3-L1 adipocytes. Obesity 2009; 17: 1657-1663.

29. Todoric J, Löffler M, Huber J, Bilban M, Reimers M, Kadl A, Zeyda M, Waldhäusl W, Stulnig TM. Adi- pose tissue inflammation induced by high-fat diet in obese diabetic mice is prevented by $n-3$ polyunsaturated fatty acids. Diabetologia 2006; 49: 2109-2119.

30. Huber J, Loffler M, Bilban M, Reimers M, Kadl A, Todoric J, Zeyda M, Geyeregger R, Schreiner M, Weichhart T, Leitinger N, Waldhausl W, Stulnig TM. Prevention of high-fatdiet-induced adipose tissue remodeling in obese diabetic mice by n-3 polyun- saturated fatty acids. Int J Obes 2007; 31: 1004- 1013.

31. Sears B. Commentary - High-dose omega-3 fatty acids and vitamin $\mathrm{D}$ for preservation of residual beta cell mass in type 1 diabetes. CellR4 2016; 4 (4): e2107

32. PEREZ-MARINEZ P, PEREZ-JIMENEZ F, LOPEZMIRANDA J. n- 3 PUFA and lipotoxicity. Biochim Biophys Acta 2010; 1801: 362-366.

33. EisEnbarth Gs. Type I diabetes mellitus. A chronic autoimmune disease. N Engl J Med 1986; 314: 1360-1368.

34. Eisenbath GS, Connelly J, Soeldner JS. The "natural" history of type I diabetes. Diabetes Metab Rev 1987;3:873-91.
35. Bingley PJ, Christie MR, Bonifacio E, Bonfanti R, Shattock M, Fonte MT et al. Combined analysis of autoantibodies improves prediction of IDDM in islet cell antibody-positive relatives. Diabe- tes 1994;43:1304-10.

36. Maclaren N, Lan M, Coutant R, Schatz D, Silverstein J, Muir A et al. Only multiple autoantibodies to islet cells (ICA), insulin, GAD65, IA-2 and IA-2 predict immunemediated (type 1) diabetes in relatives. J Autoimm 1999;12:279-87.

37. Krischer JP, Schatz D, Riley WJ, Spillar RP, Silverstein $\mathrm{JH}$, Schwartz $\mathrm{S}$ et al. Insulin and islet cell autoantibodies as time-dependent co- variates in the development of insulin-dependent diabetes: a pro- spective study in relatives. J Clin Endocrinol Metab 1993; 77:743-9.

38. Wenzlau JM, Juhl K, Yu L, Moua O, Sarkar SA, Gottlieb $\mathrm{P}$ et al. The cation efflux transporter ZnT8 (Slc30A8) is a major autoanti- gen in human type 1 diabetes. Proc Natl Acad Sci USA 2007; 104:17040-5.

39. L. Marigo, R. Cerreto, M. Giuliani, F. Somma, C. Lajolo, M. Cordaro. Diabetes mellitus: biochemical, histological and microbiological aspects in periodontal disease. European Review for Medical and Pharmacological Sciences . 2011; 15: 751-758

40. PietroPaolo M, barinas-Mitchell E, Kuller lh. The heterogeneity of diabetes: unraveling a dispute: is systemic in ammation related to islet autoim- munity? Diabetes 2007;56:1189-97.

41. Donath My, storlinG J, MaEDlEr k, ManDruP-PoulsEn t. In ammatory mediators and islet beta-cell fail- ure: a link between type 1 and type 2 diabetes. J Mol Med (Berl) 2003; 81: 455-470.

42. Chase HP, Cooper S, Osberg I, Stene LC, Barriga K, Norris J, Eisenbarth GS, Rewers M. Elevated C-re- active protein levels in the development of type 1 diabetes. Diabetes 2004; 53: 2569-2573.

43. Bastard JP, Maachi M, Lagathu C, Kim MJ, Caron M, Vidal H, Capeau J, Feve B. Recent advances in the relationship between obesity, inflammation, and insulin resistance. Eur Cytokine Netw 2006; 17: 4- 12.

44. Kristiansen OP, Mandrup-Poulsen T. Interleukin-6 and diabetes: the good, the bad, or the indiffer- ent? Diabetes 2005; 54: 114-124.

45. Savage DB. PPAR gamma as a metabolic regulator: insights from genomics and pharmacology. Expert Rev Mol Med 2005; 7: 1-16.

46. Fruchart JC, Duriez P. Mode of action of fibrates in the regulation of triglyceride and HDL-choles- terol metabolism. Drugs Today 2006; 42: 39-64.

47. Neschen S, Morino K, Rossbacher JC, Pongratz RL, Cline Gw, Sono S, Gillum M, Shulman GI. Fish oil regulates adiponectin secretion by a peroxisome proliferator-activated receptor-gam- ma-dependent mechanism in mice. Diabetes 2006; 55: 924-928.

48. Banga A, Unal R, Tripathi P, Pokrovskaya I, Owens RJ, Kern Pa, Ranganathan G. Adiponectin transla- tion is increased by the PPARgamma agonists pi- oglitazone and omega-3 fatty acids. Am J Physiol Endocrinol Metab 2009; 296: E480-489.

49. Itoh M, Suganami T, Satoh N, Tanimoto-Koyama K, Yuan X, Tanaka M, Kawano H, Yano T, Aoe S, Takeya M, Shimatsu A, Kuzuya H, Kamei Y, Ogawa Y. In- creased adiponectin secretion by highly purified eicosapentaenoic acid in rodent models of obesi- ty and human 
obese subjects. Arterioscler Thromb Vasc Biol 2007; 27: 1918-1925.

50. Li H, Ruan XZ, Powis SH, Fernando R, Mon WY, Wheeler DC, Moorhead JF, Varghese Z. EPA and DHA reduce LPS-induced inflammation responses in HK- 2 cells: evidence for a PPAR-gamma-dependent mechanism. Kidney Int 2005; 67: 867-874.

51. Bellenger J, Bellenger S, Bataille A, Massey KA, Nicolaou A, Rialland M, Tessier C, Kang JX, Narce M. High pancreatic n-3 fatty acids prevent STZ-induced diabetes in fat-1 mice: in ammatory pathway inhibition. Diabetes 2011; 60: 1090-1099.)

52. Khateeb J, Gantman A, Kreitenberg Aj, Aviram M, Fuhrman B. Paraoxonase 1 (PON1) expression in hepatocytes is upregulated by pomegranate polyphenols: a role for PPAR-gamma pathway. Atherosclerosis 2010; 208: 119-125.

53. Sears B, Ricordi C. Role of fatty acids and polyphenols in in ammatory gene transcription and their impact on obesity, metabolic syndrome and diabetes. Eur Rev Med Pharmacol Sci 2012; 16: 1137-1154.

54. Denys A, Hichami A, Khan NA. n-3 PUFAs modu- late T-cell activation via protein kinase $\mathrm{C}$-alpha and -epsilon and the NF-kappaB signaling path- way. J Lipid Res 2005; 46: 752-758.

55. Romier B, Van De Walle J, During A, Larondelle Y, Schneider YJ. Modulation of signaling nuclear fac- tor-kappaB activation pathway by polyphenols in human intestinal Caco-2 cells. Br J Nutr 2008; 100: 542-551.

56. Treiber G, Prietl B, Fröhlich-Reiterer E, Lechner E, Ribitsch A, Fritsch M, Rami-Merhar B, SteiglederSchweiger C, Graninger W, Borkenstein M, Pieber TR. Cholecalciferol supplementation improves suppressive capacity of regulatory T-cells in young patients with new- onset type 1 diabetes mellitus - A randomized clinical trial. Clin Immunol 2015; 161: 217-224.

57. Chen M, Yang ZD, Smith KM, Carter JD, Nadler JL. Activation of 12-lipoxygenase in proin ammatory cytokine mediated beta cell toxicity. Diabetologia 2005; 48: 486-495

58. Norris JM, Yin X, Lamb MM, Barriga K, Seifert J, Hoffman M, Orton HD, Barón AE, Clare-salzler M, chasE hP, szabo nJ, Erlich h, EisEnbarth Gs, rEWErs M. Omega-3 polyunsaturated fatty acid intake and islet autoimmunity in children at increased risk for type 1 diabetes. JAMA 2007; 298: 1420-1428.

59. Greenbaum CJ, Beam ca, boulWarE D, GitElMan sE, GottliEb Pa, hErolD kc, lachin JM, McGEE P, PalMEr JP, PEscovitz MD, krausE-stEinrauf h, skylEr Js, sosEnko JM; Type 1 Diabetes TrialNet Study Group. Fall in C-peptide during rst 2 years from diagnosis: evidence of at least two distinct phases from composite Type 1 Diabetes TrialNet data. Diabetes 2012; 61: 2066-2073.

60. Palmer JP. C-peptide in the natural history of type 1 diabetes. Diabetes Metab Res Rev 2009; 25: 325-328.

61. Keeren K, Huang D, sMyl c, fischEr a, rothE M, WEylanDt kh. Effect of different omega-6/omega-3 polyunsaturated fatty acid ratios on the formation of monohydroxylated fatty acids in thp- 1 derived macrophages. Biology (Basel) 2015; 4: 314-326.

62. Serhan CN, Chiang N, van DykE tE. Resolving in ammation: dual anti-inflammatory and pro-res- olution lipid mediators. Nat Rev Immunol 2008; 8: 349-361.
63. Sublette ME, Ellis SP, Geant al, Mann JJ. Meta-analysis of the effects of eicosapentaenoic acid (EPA) in clinical trials in depression. J Clin Psychiatry 2011; 72: 15771584.

64. Yokoyama M, Origasa H, Matsuzaki M, Matsuzawa Y, Saito Y, Ishikawa Y, Oikawa S, Sasaki J, Hishida H, Itakura h, Kita t, Kitabatake a, Nakaya n, Sakata t, Shimada k, Shirato k; Japan EPA lipid intervention study (JELIS) Investigators. Effects of eicosapen- taenoic acid on major coronary events in hyper- cholesterolaemic patients (JELIS): a randomised open-label, blinded endpoint analysis. Lancet 2007; 369: 1090-1098.

65. Bellenger J, Bellenger s, Bataille a, Massey ka, Nicolaou a, Rialland M, Tessier c, Kang JX, Narce M. High pancreatic n-3 fatty acids prevent STZ-in- duced diabetes in fat-1 mice: in ammatory path- way inhibition. Diabetes 2011; 60: 1090-1099.

66. Miller Mr, Yin X, Seifert J, Clare-salzler M, Eisenbarth GS, Rewers M, Norris JM. Erythrocyte membrane omega-3 fatty acid levels and omega-3 fatty acid intake are not associated with conversion to type 1 diabetes in children with islet autoimmunity: the Diabetes Autoimmunity Study in the Young (DAISY). Pediatr Diabetes 2011; 12: 669-675.

67. Landgrafleurs MM, Drummer C, Froschl H, SteinHuber R, Vonschacky C, Landgraf R. Pilot study on omega-3 fatty acids in type I diabetes mellitus. Diabetes 1990; 39: 369-375.

68. Luzi L, Codella R, Lauriola V, Messinger S, Alejan- Dro $\mathrm{R}$, Ricordi C. Immunomodulatory effects of ex- ercise in type 1 diabetes mellitus. Diabetes 2011; 60: A209-A210.

69. De Luis DA, Conde R, Aller R, Izaola O, González Sagrado M, Perez Castrillón JL, Dueñas A, Romero E.Effect of omega-3 fatty acids on cardiovascular risk factors in patients with type 2 diabetes mellitus and hypertriglyceridemia: an open study.Eur Rev Med Pharmacol Sci. 2009 Jan-Feb;13(1):51-5.

70. De Logegeril M, Salen P, Martin JL. Mediterranean diet, traditional risk factos, and the rate of cardio- vascular complications after myocardial infarc- tion: final report of the Lyon Diet Heart Study. Cir- culation 1999; 99: 779-785.

71. Virtue S, Vidal-Puig. Adipose tissue expandability, lipotoxicity and the Metabolic Syndrome-An allo- static perspective. Biochim Biophys Acta 2010; 1801: 338-349.

72. Todoric J, Löffler M, Huber J, Bilban M, Reimers M, Kadl A, Zeyda M, Waldhäusl W, Stulnig TM. Adi- pose tissue inflammation induced by high-fat diet in obese diabetic mice is prevented by n-3 polyunsaturated fatty acids. Diabetologia 2006; 49: 2109-2119.

73. Huber J, Loffler M, Bilban M, Reimers M, Kadl A, Todoric J, Zeyda M, Geyeregger R, Schreiner M, Weichhart T, Leitinger N, Waldhausl W, Stulnig TM. Prevention of high-fat diet-induced adipose tissue remodeling in obese diabetic mice by $n-3$ polyun- saturated fatty acids. Int J Obes 2007; 31: 1004- 1013.

74. Layman DK. Dietary guidelines should reflect new understandings about adult protein needs. Nutr Metab 2009; 6: 12 .

75. Pan A, Sun Q, Bernstein Am, Schulze Mb, Manson Je, Stampfer Mj, Willett Wc, Hu FB. Red meat consumption and mortality: results from 2 prospective cohort studies Arch Intern Med 2012; 172: 555-563. 
76. Zhang X, Zhang G, Zhang H, Karin M, Bai H, Cai D. Hypothalamic IKKbeta/NF-kappaB and ER stress link overnutrition to energy imbalance and obesity. Cell 2008; 135: 61-73.

77. Pliquett RU, Fuhrer D, Falk S, Zysset S, Von Cramon Dy, Stumvoll M. The effects of insulin on the central nervous system-focus on appetite regulation. Horm Metab Res 2006; 38: 442-446.

78. Davidowa H, Plagemann A. Insulin resistance of hypothalamic arcuate neurons in neonatally overfed rats. Neuroreport 2007; 18: 521-524.

79. Schwartz MW, Porte D. Diabetes, obesity, and the brain. Science 2005; 307: 375-379.

80. Todoric J, Löffler M, Huber J, Bilban M, Reimers M, Kadl A, Zeyda M, Waldhäusl W, Stulnig TM. Adipose tissue inflammation induced by high-fat diet in obese diabetic mice is prevented by $n-3$ polyunsaturated fatty acids. Diabetologia 2006; 49: 2109-2119.

81. Huber J, Loffler M, Bilban M, Reimers M, Kadl A, Todoric J, Zeyda M, Geyeregger R, Schreiner M, Weichhart T, Leitinger N, Waldhausl W, Stulnig TM.
Prevention of high-fat diet-induced adipose tissue remodeling in obese diabetic mice by $n-3$ polyunsaturated fatty acids. Int J Obes 2007; 31: 1004- 1013.

82. Sears B, Ricordi C. Role of fatty acids and polyphenols in inflammatory gene transcription and their impact on obesity, metabolic syndrome and diabetes. Eur Rev Med Pharmacol Sci. 2012 Sep;16(9):1137-54.

83. Baidal D.A, Ricordi C, Garcia-Contreras M, Sonnino A, Fabbri A. Combination high-dose omega-3 fatty acids and high-dose cholecalciferol in new onset type 1 diabetes: a potential role in preservation of beta-cell mass. European Review for Medical and Pharmacological Sciences. 2016; 20: 3313-3318

84. Sears B. Delaying adverse health consequences of aging: the role of omega 3 fatty acids on inflammation and resoleomics. CellR4 2016; 4 (4): e2111

85. Gomez-Meade C.A, Lopez-Mitnik G.V, Messiah S.E, M. Garcia-Contreras M, Sanchez J. Vitamin D status in children and adolescents with type 1 diabetes in a sunrich environment. CellR4 2016; 4 (5): e2140 


\title{
IMIIDs in endocrinologia
}

\author{
Maria Rita Poggiano, ${ }^{1}$ Vincenzo Nuzzo ${ }^{2}$ \\ ${ }^{1}$ Ospedale Buonconsiglio Fatebenefratelli, Napoli; ${ }^{2}$ Ospedale San Gennaro, Napoli, Italia
}

\section{Introduzione}

Negli ultimi anni le malattie autoimmuni sono progressivamente aumentate. La loro prevalenza complessiva risulta in incremento, potendo interessare nelle varie forme fino al $7 \%$ della popolazione generale e manifestandosi in forma clinica e subclinica (Tabella 1).

Esse hanno la tendenza ad aggregarsi tra di loro in uno stesso individuo o nell'ambito di più soggetti della stessa famiglia dando origine alle cosiddette sindromi poliendocrine autoimmuni (SPA), meglio definite come sindromi autoimmuni multiple in quanto possono essere coinvolti anche più organi o distretti non endocrini. ${ }^{1}$

\section{Le malattie autoimmuni della tiroide}

La tiroide è il bersaglio più frequentemente colpito di qualsiasi altro organo dalla risposta autoimmunitaria.

Le malattie autoimmuni della tiroide (AITD) con le due principali manifestazioni cliniche, la malattia di Basedow (BD) e la tiroidite di Hashimoto (HT), sono stimate come incidenza nel circa il 5\% della popolazione, ${ }^{1}$ mentre la prevalenza della patologia subclinica che si manifesta esclusivamente con la produzione di anticorpi anti-tiroide senza evidenza di malattia clinica, risulta essere più elevata. ${ }^{2-5}$

Queste due sindromi clinicamente distinte condividono meccanismi immunopatogenici comuni. Se infatti il segno distintivo della malattia d Basedow è la tireotossicosi, per la tiroidite di Hashimoto è l'ipotiroidismo. Entrambe sono caratterizzate dalla produzione di autoanticorpi tiroidei. ${ }^{6,7}$

Corrispondente: Maria Rita Poggiano, Ospedale Buonconsiglio Fatebenefratelli, via Francesco de mura 37, Napoli, Italia. Tel.: +39.081.5981426.

E-mail: marypoggiano@gmail.com

Articolo pubblicato secondo la Creative Commons Attribution NonCommercial 4.0 License (CC BY-NC 4.0).

CCopyright M.R. Poggiano e Vincenzo Nuzzo, 2017

Licensee PAGEPress, Italy

QUADERNI - Italian Journal of Medicine 2017; 5(7):67-74
Le AITD sono malattie autoimmuni organo specifiche i cui meccanismi scatenanti sono ancora poco chiari. I dati epidemiologici suggeriscono che i fattori chiave che portano alla rottura della tolleranza e allo sviluppo della malattia scaturiscono dall'interazione tra predisposizione genetica e fattori ambientali. ${ }^{8}$

Tra i fattori i ambientali i più importanti vi sono la dieta, lo iodio ed il fumo di sigaretta. ${ }^{9}$

Negli ultimi anni sono stati fatti notevoli progressi per l'individuazione dei fattori di rischio genetici nell'AITD. ${ }^{10}$ I geni di istocompatibilità (MHC) di classe II hanno dimostrato di predisporre all'AITD, mentre diversi geni non appartenenti al sistema MHC sono stati individuati come geni di suscettibilità contribuendo quindi alla genesi della patologia.

Le indagini epidemiologiche sui gemelli monozigoti hanno mostrato alti tassi di concordanza nell'incidenza di AITD confermando il contributo dei fattori genetici nell'eziologia della malattia. ${ }^{11}$

La malattia di Basedow è causata dalla produzione di anticorpi anti recettore del TSH (TSHR) che stimolando l'attivazione del recettore stesso, principale regolatore della sintesi degli ormoni tiroidei, determinano la consequenziale secrezione che genera la tireotossicosi clinica. ${ }^{12-14}$

Il gene della tireoglobulina $(\mathrm{Tg})$ è un candidato naturale per la genesi delle AITD dal momento che rappresenta circa il $80 \%$ del contenuto totale di proteine della tiroide. Inoltre, la $\mathrm{Tg}$, che è immagazzinata nella colloide viene immessa nella circolazione sanguigna dove è esposta al sistema immunitario. Recentemente la tireoglobulina è stata riconosciuta come uno dei fattori scatenanti la tiroidite autoimmune. ${ }^{15}$

Molti farmaci antitumorali (citochine, $\alpha$ interferone, e gli inibitori della tirosin-chinasi) e tossine ambientali possono indurre disfunzioni autoimmunitarie della tiroide. ${ }^{13,14}$ Anche il Clima è in grado di incidere sull'autoimmunità; ad esempio, donne che vivono in Siberia hanno mostrato un'alta prevalenza di anticorpi anti perossidasi tiroidea (TPO) probabilmente perchè il riscaldamento globale e i rapidi cambiamenti climatici potrebbero contribuire a slatentizzare predisposizioni autoimmuni. ${ }^{16}$

In ogni caso, la combinazione di fattori predisponenti genetici e fattori ambientali induce una disregolazione del sistema immunitario che risulta in 
un'aggressione immunitaria sulla tiroide. Istologicamente l'infiammazione ghiandolare è caratterizzata da fibrosi, infiltrazione linfoplasmacellulare, degenerazione delle cellule follicolari.

Numerose linee guida nella gestione e nel trattamento dell'ipo- e dell'ipertiroidismo sono state pubblicate negli ultimi anni. ${ }^{17-19}$

Nonostante ciò, il processo decisionale clinico rimane complesso soprattutto nelle forme subbcliniche.

La principale difficoltà sta nel determinare il punto di partenza ideale per la supplementazione degli ormoni tiroidei. Non tutti i soggetti con ipotiroidismo subclinico con livelli simili di TSH e T4 libero sviluppano una sintomatologia. Inoltre, la maggior parte dei dati epidemiologici e clinici dimostrano che la terapia ormonale tiroidea ha benefici in pazienti con patologie cardiovascolari, soprattutto nel gruppo di mezza età, ma sicuramente non è utile negli anziani dove la terapia deve essere posticipata il più possibile. ${ }^{18}$
In tale contesto l'intervallo di normalità del TSH andrebbe dunque tarato sull'età del paziente.

La malattia di Basedow è tradizionalmente trattata con tre opzioni usate ininterrottamente dal la metà del 1900, ovvero, farmaci antitiroidei, iodio radioattivo e la chirurgia. Anche in questa patologia la gestione delle forme subcliniche iperfunzionanti è un campo controverso.

Le linee guida esistenti per la gestione clinica dei pazienti con ipertiroidismo subclinico suggeriscono nella scelta terapeutica di effettuare un'attenta valutazione dei fattori di rischio clinici come la fibrillazione atriale, la disfunzione cardiaca, ed il metabolismo osseo. ${ }^{19}$

In conclusione l'AITD contiene un ampio spettro di disfunzioni, dagli sfumati segni ai marcati deterioramenti clinici pericolosi per la vita.

Ulteriori studi sui meccanismi fisiopatologici e sul background genetico aiuteranno in futuro a sviluppare nuove opzioni terapeutiche (Tabelle 2-4).

Tabella 1. incidenza e prevalenza delle principali endocrinopatie autoimmuni (casi $x$ milioni di abitanti).

\begin{tabular}{|c|c|c|c|c|}
\hline & Prevalenza stimata (casi/milione) & Incidenza nuovi casi/anno & Età media di comparsa & Femmine $\%$ \\
\hline Tiroidite cronica & 8000 & 218 & 59 & 95 \\
\hline Diabete mellito $<20$ aa & 2000 & 122 & 10 & 48 \\
\hline Diabete mellito $>20$ aa & 810 & n.d. & 45 & 35 \\
\hline Malattia Graves & 1510 & 139 & 48 & 88 \\
\hline Anemia perniciosa & 1509 & n.d. & 70 & 67 \\
\hline Morbo Addison & 144 & 6 & 35 & 93 \\
\hline Menopausa precoce & 100 & n.d. & $<40$ & 100 \\
\hline Adeno-ipofisiti & n.d & n.d. & 35 & 25 \\
\hline Neuro-ipofisiti & n.d. & n.d. & $40-50$ & 60 \\
\hline SPA-1 & $2-3$ & n.d. & 7 & 33 \\
\hline SPA-2 & 50 & n.d. & 35 & 20 \\
\hline SPA-3 & $\sqrt{x+3}$ & n.d. & 40 & 75 \\
\hline SPA-4 & 100 & n.d. & $25-35$ & 60 \\
\hline
\end{tabular}

Tabella 2. Fattori ambientali nelle AITD.

\begin{tabular}{lcc}
\hline Fattore & Induzione & Protezione \\
\hline Fumo & + & \\
\hline Alcool & & + \\
\hline Selenio & & + \\
\hline Vitamina D & & + \\
\hline Iodio & + & \\
\hline Stress & + & \\
\hline Infezioni & + & \\
\hline Farmaci & + & \\
\hline
\end{tabular}

Tabella 3. Dosaggio LT4 in soggetti ipotiroidei.

Dosaggio empirico basato su età e BMI

\begin{tabular}{lccc}
\hline LT4 $(\mathrm{mcg} / \mathrm{kg} /$ day $)$ & BMI $\leq 23$ & BMI $24-28$ & BMI $>28$ \\
\hline Age $\leq 40$ years & 1,8 & 1,7 & 1,6 \\
\hline Age $41-55$ years & 1,7 & 1,6 & 1,5 \\
\hline Age $>55$ years & 1,6 & 1,5 & 1,4 \\
\hline
\end{tabular}

Formula

LT4 $(\mathrm{mcg} / \mathrm{kg} / \mathrm{die})=-0,018 \times \mathrm{BMI}+2,13$ 


\section{L'insufficienza surrenalica autoimmune}

L'infiammazione della ghiandola surrenalica è causata da autoimmunopatie semplici o associate ad altre endocrinopatie che possono condurre all'insufficienza corticosurrenalica. ${ }^{20,21}$

L' adrenalite linfocitaria autoimmune, più comunemente nota come malattia di Addison, è la causa più frequente di insufficienza corticosurrenalica primitiva ma diviene clinicamente evidente solo quando oltre il $90 \%$ del tessuto ghiandolare è distrutto dal processo infiammatorio. ${ }^{22}$

Dal punto di vista anatomopatologico la forma autoimmune è caratterizzata da atrofia degenerativa della corteccia surrenalica con infiltrazione linfocitaria diffusa senza franche alterazioni della regione midollare.

I meccanismi immunitari cellulari ed umorali giocano un ruolo chiave nella patogenesi delle adrenaliti; triggers ambientali come infezioni virali, farmaci, fumo e stress possono innescare il processo infiammatorio in soggetti geneticamente predisposti.

A tale riguardo, sono state osservate associazioni con alleli HLA B8, D3 e D4 eccetto nei casi di adrenaliti autoimmuni associate ad altre endocrinopatie nelle quali non esiste a tutt'oggi una chiara evidenza di associazioni HLA. ${ }^{23}$

La caratteristica della malattia di Addison è la presenza di anticorpi rivolti contro enzimi coinvolti nella steroidogenesi, in particolare quelli contro la 21 idrossilasi (21 OH ab) ${ }^{24}$ Questi anticorpi, sono presenti soprattutto nel sesso femminile e sembrano predire nel $21 \%$ dei casi lo sviluppo di insufficienza surrenalica franca e nel $29 \%$ un iposurrenalismo subclinico.

Il ruolo degli anticorpi nella patogenesi della malattia di Addison non è tuttavia ancora definito.

Sembra infatti che la caratteristica anatomopatologica principale sia la distruzione del tessuto surrenalico mediato dai linfociti $\mathrm{T}$ e che la produzione degli $21 \mathrm{OH} \mathrm{Ab}$ sia secondaria al rilascio di peptidi durante questo processo. Dunque gli Ab avrebbero significato più come marcatori sierologici del processo autoimmune che non come causa della patologia stessa.

La sintomatologia dell'insufficienza corticosurrenalica primitiva varia a seconda dell'evoluzione di malattia.

Nell'insufficienza cronica il quadro clinico è subdolo e spesso non di facile identificazione per la scarsa specificità dei sintomi.

Il deficit di glucocorticoidi determina astenia, nausea, vomito, calo ponderale, mentre i disturbi più facilmente correlati al deficit mineralcorticoide sono l'ipotensione arteriosa e/o ortostatica, le lipotimie e il caratteristico craving (bramosia) per i cibi sapidi. ${ }^{21}$

Per la presenza di elevati valori di ACTH nell'insufficienza corticosurrenalica primitiva è presente ed è patognomonica l'iperpigmentazione della cute e delle mucose.

Tale iperpigmentazione o melanodermia si evidenzia particolarmente nelle aree cutanee più esposte $\mathrm{al}$ sole e in quelle sottoposte a maggiore pressione come i gomiti o le ginocchia. Ancor più frequente è l'iperpigmentazione delle pliche cutanee e della mucosa buccale e gengivale, più spesso evidenti quando la malattia è in stadio avanzato. Naturalmente la melanodermia non è presente nelle forme di insufficienza surrenalica ad insorgenza rapida.

La crisi surrenalica è una condizione di emergenza clinica caratterizzata da severa ipotensione non responsiva agli inotropi, nausea, dolori addominali ed è la manifestazione brusca in un paziente con insufficienza cronica nel quale si verifica un'improvvisa richiesta di ormoni surrenalici a causa di uno stress quale una malattia intercorrente, intervento chirurgico o nei casi di interferenza farmacologica. È bene a tal proposito ricordare che nei casi di concomitante ipotiroidismo la terapia sostitutiva con levotiroxina va introdotta solo dopo la correzione della funzione surrenalica per il rischio che l'aumentato metabolismo degli ormoni surrenalici indotto dagli ormoni tiroidei possa scatenare un' improvvisa carenza degli stessi determinando una crisi surrenalica acuta..$^{25,26}$

Tabella 4. TSH auspicabile nella terapia con LT4.

\begin{tabular}{ll}
\hline Age/Condition & Target Serum TSH, $\mathrm{mU} / \mathrm{L}$ \\
\hline Preconception & Lower quartile of the reference range, $<1.2$ \\
Pregnancy (1st trimester) & $<2-2.5$ \\
Children with $\mathrm{CoH}$ & $<5\left(\right.$ optimal values $(0.5-2.0)$ with a serum $\mathrm{FT}_{4}$ or total $\mathrm{T}_{4}$ in the upper limit \\
& $\quad$ of the normal range during the first year of life \\
Young patients & $1-2.5$ \\
Middle-aged patients & $1.5-3$ \\
Elderly patients & $>4.5$ \\
$\leq 65 \mathrm{y}$ & $>6.0$ \\
$60-70 y$ & $>7.0-8$ \\
$70-80 \mathrm{y}$ & Serum $\mathrm{FT}_{4}$ levels in the upper half of the normal range \\
$\mathrm{CH}$ & Risk-related TSH target \\
Thyroid cancer &
\end{tabular}


Per la diagnosi di adrenalite autoimmune innanzitutto è necessario documentare l'insufficienza ghiandolare; successivamente deve esserne confermata l'eziologia autoimmune. Tuttora purtroppo non esistono criteri diagnostici inequivocabili. Il principale obiettivo della diagnosi differenziale è l'esclusione delle principali patologie che possono determinare secondariamente insufficienza surrenalica primaria, quali la tubercolosi, HIV, farmaci o disordini genetici sottostanti. Una volta esclusi altri disordini, la diagnostica per immagini può aiutare nella diagnosi: la presenza di una ghiandola surrenalica di dimensioni aumentate rende l'ipotesi autoimmune francamente meno probabile; di contro, la presenza di anticorpi diretti contro enzimi della steroidogenesi aiuta a confermare la diagnosi.

La terapia è fondata sulla somministrazione a scopo sostitutivo di corticosteroidi. Nelle forme

ad insorgenza acuta si fonda sull'utilizzo di idrocortisone (100 mg ev seguiti da 50-100 mg ogni $6 \mathrm{~h}$ nella fase acuta) e sul ripristino del bilancio idroelettrolitico. ${ }^{25}$

Dopo la stabilizzazione del quadro emodinamico l'idrocortisone parenterale può essere sostituito dai corticosteroidi orali. La terapia cronica è basata sulla somministrazione di idrocortisone o cortisone acetato (25-37,5 mg/die in 2-3 somministrazioni) che è rapidamente assorbito e convertito in cortisolo a livello epatico. Negli ultimi anni la terapia cronica dell'insufficienza corticosurrenalica è stata implementata dall'introduzione in commercio di una nuova preparazione di idrocortisone somministrabile per via orale e caratterizzata da una farmacocinetica in grado di mimare più adeguatamente la naturale secrezione endogena del cortisolo migliorando la compliance del paziente e la tollerabilità della terapia. ${ }^{26-28}$

La somministrazione di mineralocorticoidi prevede l'impiego di 9- $\alpha$-fluoridrocortisone o fludrocortisone ad un dosaggio medio di $0,05-0,1 \mathrm{mg} / \mathrm{die}$ (Tabella 5).

Tabella 5. Farmacocinetica dei glucocorticoidi.

\begin{tabular}{lcc}
\hline Farmaco & $\begin{array}{c}\text { Dose equivalente } \\
\text { (mg) }\end{array}$ & $\begin{array}{c}\text { Emivita plasmatica } \\
\text { (ore) }\end{array}$ \\
\hline Idrocortisone & 20 & $8-12$ \\
\hline Cortisone & 25 & $8-12$ \\
\hline Prednisone & 5 & $12-36$ \\
\hline Prednisolone & 4 & $12-36$ \\
\hline Metilprednisolone & 4 & $12-36$ \\
\hline Triamcinolone & 4 & $12-36$ \\
\hline Betametasone & 0,6 & $36-72$ \\
\hline Desametasone & 0,75 & $36-72$ \\
\hline
\end{tabular}

\section{La menopausa precoce}

La menopausa precoce (premature ovarian failure, POF) è una sindrome caratterizzata da insufficienza ovarica e deplezione oocitaria prima dell'età della menopausa fisiologica. Pertanto, si definisce menopausa precoce un'amenorrea con anovulazione della durata di almeno 6 mesi con gonadotropine sieriche elevate (FSH $>40 \mathrm{UI} / \mathrm{L}$ in almeno due dosaggi) con ipoestrogenismo in donne di età inferiore ai 40 anni. ${ }^{29}$ Le cause di tale sindrome sono diverse (Tabella 2) ma nella gran parte dei casi resta ancora una patologia idiopatica anche se una certa percentuale di queste pazienti (13$66 \%$ presenta anticorpi anti-ovaio. Inoltre molto spesso la POF si associa a malattie autoimmuni e/o altre disendocrinopatie. ${ }^{30}$

Le manifestazioni cliniche sono eterogenee, infatti, in relazione all'epoca di sviluppo in cui si è completata la deplezione follicolare, alcune pazienti presentano una pubertà ritardata o mancato sviluppo puberale, altre sperimentano la menopausa dopo la pubertà o dopo una fisiologica storia riproduttiva caratterizzata da cicli mestruali regolari od oligomenorroici. ${ }^{31}$

Il pattern di crescita follicolare e l'assetto ormonale presentano le stesse caratteristiche riscontrabili nello stadio peri menopausale che, in un continuum, si conclude con la menopausa. ${ }^{32}$

Il riscontro di elevati valori basali (entro il $5^{\circ}$ giorno di un ciclo mestruale) di FSH (>10 UI/L) durante il periodo riproduttivo, in donne con cicli mestruali regolari ed ovulatori, costituisce la manifestazione più precoce del declino della funzionalità ovarica (ovarian ageing). I sintomi e i segni della menopausa precoce conseguenti all'ipoestrogenismo sono paragonabili a quelli osservabili nelle donne con menopausa fisiologica e consistono in: amenorrea primaria o secondaria, vampate di calore e sudorazioni da instabilità vasomotoria, dispareunia, ansietà, depressione, insonnia e labilità emotiva da instabilità psicologica, modificazione dell'immagine corporea. Le conseguenze a breve e lungo termine sono: atrofia dei tegumenti delle mucose e secchezza vaginale, incontinenza urinaria da instabilità vescicale, osteoporosi, alterazioni dell'assetto lipidico e un incremento del rischio cardiovascolare.

Una terapia in grado di ripristinare una corretta funzione ovarica non esiste. Sono state proposte terapie immunosoppressive corticosteroidee associate o meno a plasmaferesi (in caso di POF da causa autoimmune), ma i risultati sono sporadici e non confermati, tenendo anche conto dei possibili effetti collaterali di questi approcci terapeutici. ${ }^{33-35}$

La terapia deve essere dunque volta a correggere $\mathrm{i}$ sintomi, in particolare quelli legati all'ipoestrogenismo e alle sue conseguenze future (cardiopatia, osteoporosi) e comporta l'uso di estroprogestinici sotto 
forma di contraccettivi orali o la terapia ormonale sostitutiva classica, per via orale o transcutanea e secondo i tradizionali schemi di somministrazione, tenendo anche conto delle richieste e dei sintomi della paziente stessa.

L'atteggiamento comune è di proseguire la terapia fino ad una età compatibile con una menopausa fisio$\operatorname{logica}^{36}$ (Tabella 6).

\section{L'ipofisite autoimmune}

L'ipofisite linfocitaria autoimmune è una rarissima condizione patologica che coinvolge più spesso l' adenoipofisi e che va sospettata in pazienti con segni e/o sintomi di ipopituitarismo sosprattutto quando già affetti da altre endocrinopatie di origine autoimmunitaria (più frequentemente la tiroidite di Hashimoto).

Dal punto di vista istopatologico è caratterizzata da un infiltrato linfo-plasmacellulare che può coinvolgere la parte anteriore della ghiandola o estendersi all'infundibolo e alla neuroipofisi configurando in questi casi il quadro clinico della panipofisite. ${ }^{37}$

La maggiore incidenza della patologia interessa il sesso femminile e nel $60 \%$ circa dei casi circa insorge nell'immediato post partum entrando in diagnostica differenziale con la sindrome di Sheean.

Tuttavia, la reale prevalenza della malattia è ancora incerta e probabilmente sottostimata a causa della scarsa variabilità dei sintomi e del variabile decorso clinico. ${ }^{38}$

La storia naturale dell'ipofisite autoimmune può essere divisa in diverse tappe: una fase di infiammazione iniziale con ingrandimento della ghiandola che può determinare sintomi da effetto massa o deficit ormonali subclinici che si evidenziano solo con test dinamici.

Quando subentra la successive distruzione dei tessuti e atrofia può svilupparsi un ipopituitarismo permanente. ${ }^{39}$

La sintomatologia dell'ipofisite dipende dall'estensione e dalla localizzazione del processo infiammatorio consistendo in diversi gradi di disfunzione ipofisaria quali ipogonadismo, iposurrenalismo, ipotiroidismo, iperprolattinemia.

Tabella 6. Principali cause di POF.

Cause che determinano la comparsa di menopausa precoce

Genetica

Familiare

Autoimmune

Da alterazioni metaboliche o enzimatiche

Idiopatica

Iatrogena

Incidenza

$1 \%$ delle donne italiane
Inoltre, possono essere presenti sintomi da compressione sellare e para sellare quali cefalea, deficit del campo visivo o paralisi dei nervi cranici.

L'ipofisite autoimmune deve essere sospettata in pazienti con iperprolattinemia o segni di ipopituitarismo accompagnati da cefalea o alterazioni del campo visivo soprattutto in donne in stato di gravidanza o nell'immediato post partum.

In alcuni casi, il sospetto autoimmune è suffragato dalla buona risposta alla terapia immunosoppressiva e dalla comparsa di cicli di remissione e di recidiva frequentemente osservata lungo il decorso della malattia, così come descritto per altre malattie autoimmuni. ${ }^{40}$

Il gold standard per la diagnosi è comunque la biopsia ipofisaria per via transfenoidale seppur si tratti di una procedura invasiva e non di facile esecuzione.

Il rilevamento di anticorpi antipofisi può indirizzare la diagnosi ma al contempo, la negatività degli stessi non deve necessariamente escludere l'ipotesi autoimmune perché gli anticorpi possono negativizzarsi nel corso della malattia. ${ }^{41}$

La terapia è fondata sulla sostituzione ormonale in caso di deficit ipofisari e da decompressione chirurgica transfenoidale nei casi di allargamento parasellare dell'iposifisi (Tabella 7).

\section{Le sindromi poliendocrine autoimmuni}

Con tale termine vengono definite varie sindromi cliniche caratterizzate da insufficienze funzionali a carico di una o più ghiandole endocrine che possono essere associate anche a patologie autoimmuni non endocrine. Vengono classicamente divise in quattro tipi. ${ }^{42,43}$

\section{Sindromi poliendocrine autoimmuni di tipo I}

Conosciuta anche con il nome di sindrome di Witahcker o APECED (autoimmune polyendocrinopathy, candidiasis-ectodermal distrophy) si caratterizza per la presenza di micosi mucocutanea cronica, ipoparatiroidismo ed insufficienza corticosurrenalica. ${ }^{44,45}$ Solitamente tutte e tre le manifestazioni principali sono presenti anche se per la diagnosi clinica è sufficiente la presenza di almeno due dei tre quadri clinici. È una patologia a prevalenza molto bassa ad insorgenza precoce che può manifestarsi in maniera sporadica anche in età adulta. È una malattia monogenica con trasmissione di tipo autosomico recessivo, la cui causa è la presenza di mutazioni a carico del gene AIRE (autoimmune regulator) localizzato sul cromosoma $21 \mathrm{q} 22.3$ che si è dimostrato regolare l'attività di diversi geni implicati nella risposta immunitaria. Manifestazioni cliniche meno comuni comprendono il diabete mellito tipo 1, l'ipogonadismo ipergonadotropo, l'anemia perniciosa, l'epatite cronica attiva, la cheratocongiuntivite, la tiroidite autoimmune, la nefrite interstiziale, 
l'atrofia splenica, la vitiligo e l'alopecia. Talvolta sono presenti localizzazioni polmonari da candida.

L'ipoparatiroidismo ha un picco di incidenza tra $i$ 2 egli 11 anni e compare solitamente dopo la candidosi cronica mucocutanea e prima dell'Addison.

All'inizio può essere alterata soltanto la riserva funzionale delle paratiroidi e l'ipocalcemia manifestarsi solo nei periodi di stress. Il morbo di Addison rappresenta la manifestazione più tardiva riscontrabile nella SPA di tipo I mentre è la più frequente nella SPA di tipo II. Nei pazienti con M. di Addison possono essere riscontrati in circolo anticorpi anti corteccia surrenalica, anticorpi anti 17-idrossilasi e anticorpi anti 21-idrossilasi. La terapia resta per il momento sintomatica ed è mirata a trattare i sintomi della malattia.

\section{Sindromi poliendocrine autoimmuni di tipo II}

Conosciuta anche con il nome di sindrome di Schmidt, ${ }^{46,47} \mathrm{si}$ caratterizza per la presenza di Morbo di Addison in associazione a tiroidite autoimmune e/o diabete mellito di tipo I; colpisce soprattutto il sesso femminile (Rapporto M/F di 1/3) e la sua prima manifestazione compare generalmente in età adulta. L'eziologia della SPA di tipo II è ancora sconosciuta. La presenza di una patologia autoimmune tra gli ascendenti e discendenti dei pazienti affetti da SPA di tipo II può essere riscontrata in circa il cinquanta percento dei casi. Tale sindrome risulta associata a particolari aplotipi HLA, in particolare A1, B8, DR3 e DR4. Il quadro clinico spesso esordisce con i segni e sintomi dell'insufficienza surrenalica che risulta essere sempre presente. La tiroidite autoimmune si può associare nel $80 \%$ dei casi e un diabete tipo I è presente nel 30-50\% dei casi. La SPA di tipo II può inoltre associarsi anche se in percentuale net- tamente inferiore ad altre patologie autoimmuni quali la vitiligo, la gastrite cronica con anemia perniciosa, l'epatite cronica autoimmune e l'alopecia. La diagnosi si basa sul riscontro di una insufficienza funzionale delle ghiandole colpite e dalla presenza in circolo di anticorpi organo specifici. Il 50\% dei pazienti portatori d'insufficienza surrenalica autoimmune può essere affetto da una sindrome poliendocrina di tipo II, pertanto questi pazienti devono ripetere lo screening per patologia tiroidee e diabete ogni 5 anni. La terapia è sintomatica ed è mirata a correggere i deficit funzionali presenti nei singoli pazienti.

\section{Sindromi poliendocrine autoimmuni di tipo III}

Si caratterizza per la presenza di tiroidite autoimmune più altre manifestazioni autoimmuni in assenza di malattia di Addison. ${ }^{48,49}$ È la più frequente tra le sindromi poliendocrine autoimmuni. È nettamente più frequente nel sesso femminile manifestandosi spesso in età adulta. Ha una patogenesi autoimmune come indirettamente evidenziato dalla presenza di autoanticorpi circolanti. Frequentemente si riscontra in più membri della stessa famiglia. Cosìcome osservato nella SPA di tipo II risulta frequentemente associata a particolari aplotipi HLA. Il quadro clinico dipenderà dal tipo di ghiandola interessata. L'associazione più comune è tra tiroidite autoimmune e gastrite cronica con anemia perniciosa; in questo caso si parla anche di sindrome tireogastrica. La terapia è di tipo prevalentemente sintomatica.

\section{Sindromi poliendocrine autoimmuni di tipo IV}

Si caratterizza per la presenza di associazioni cliniche non incluse nelle precedenti. ${ }^{50}$

Tabella 7. Terapia dei pazienti con APS.

\begin{tabular}{ll}
\hline Patologia & Terapia \\
\hline Candidiasi cronica & Nistatina, fluconazolo, itraconazolo \\
\hline Ipoparatiroidismo & Calcitriolo, $\alpha$-calcidiolo, calcio citrato \\
\hline Morbo di Addison & Idrocortisone, cortone acetato \\
\hline Menopausa precoce & Estro-progestinici \\
\hline Tiroiditi autoimmuni & L-tiroxina \\
\hline Morbo Graves & Farmaci-anti-tiroidei \\
\hline DM-1 & Insulina \\
\hline Epatite autoimmune & Cortisone e azatiopirina \\
\hline Gastrite cronica/anemia perniciosa & Ferro per os - vitamina B12 i.m. \\
\hline Celiachia & Dieta priva di glutine \\
\hline Disfunzione gastrointestinale autoimmune & \\
\hline Deficit ipofisi & A seconda del deficit \\
\hline Cherato-congiuntivite & Lacrime artificiali, glucocorticoidi \\
\hline
\end{tabular}




\section{Bibliografia}

1. Jacobson DL, Gange SJ, Rose NR, Graham NM. Epidemiology and estimated population burden of selected autoimmune diseases in the United States. Clin Immunol Immunopathol. 1997; 84: 223-243.

2. Tunbridge WMG, Evered DC, Hall R, Appleton D, Brewis M, Clark F, et al. The spectrum of thyroid disease in a community: the Whickham survey. Clin Endocrinol Oxf. 1977; 7:481-493.

3. Vanderpump MPJ, Tunbridge WMG, French JM, Appleton D, Bates D, Clark F, et al. The incidence of thyroid disorders in the community: a twenty-year follow-up of the Whickham survey. Clin Endocrinol (Oxf) 1995; 43:55-68

4. Kabelitz M, Liesenkotter KP, Stach B, Willgerodt H, Stablein W, Singendonk W, et al. The prevalence of antithyroid peroxidase antibodies and autoimmune thyroiditis in children and adolescents in an iodine replete area. Eur J Endocrinol. 2003; 148 (3): 301-307

5. Pearce SH, Leech NJ. Toward precise forecasting of autoimmune endocrinopathy. J Clin Endocrinol Metab. 2004; 89 (2): 544-547.

6. Davies TF. Graves' Diseases: Pathogenesis. In: Braverman LE, Utiger RD, editors. Werner and Ingbar's The Thyroid: A fundamental and clinical text. eighth Lippincott Williams \&Wilkens; Philadelphia: 2000.; 518-530

7. Weetman AP. Chronic autoimmune thyroiditis. In: Braverman LE, Utiger RD, editors. Werner and Ingbar's .The thyroid. Lippincott Williams and Wilkins; Philadelphia: 2000; 721-732.

8. Huber A, Menconi F, Corathers S, Jacobson EM, Tomer Y. Joint genetic susceptibility to type 1 diabetes and autoimmune thyroiditis: from epidemiology to mechanisms. Endocr Rev. 2008; 29 (6): 697-725.

9. Tomer Y, Huber A. The etiology of autoimmune thyroid disease: a story of genes and environment. J Autoimmun. 2009; 32 (3-4): 231-239.

10. Tomer Y, Menconi F. Type 1 diabetes and autoimmune thyroiditis: the genetic connection. Thyroid. 2009; 19 (2): 99-102.

11. Villanueva R, Greenberg DA, Davies TF, Tomer Y. Sibling recurrence risk in autoimmune thyroid disease. Thyroid. 2003; 13: 761-764.

12. Tonacchera M, Pinchera A. Thyrotropin receptor polymorphisms and thyroid diseases. J Clin Endocrinol Metab. 2000; 85 (8): 2637-2639.

13. Dechairo BM, Zabaneh D, Collins J, Brand O, Dawson GJ, Green AP, et al. Association of the TSHR gene with Graves' disease: the first disease specific locus. Eur J Hum Genet. 2005; 13 (11):1223-1230.

14. Tomer Y, Hasham A, Davies TF, Stefan M, Concepcion E, Keddache M, et al. Fine mapping of loci linked to autoimmune thyroid disease identifies novel susceptibility genes. J Clin Endocrinol Metab. 2013;98 (1):E144-E152.

15. Chen CR, Hamidi S, Braley-Mullen H, Nagayama Y, Bresee C, Aliesky HA, et al. Antibodies to thyroid peroxidase arise spontaneously with age in NOD.H-2h4 mice and appear after thyroglobulin antibodies. Endocrinology. 2010; 151(9): 4583-4593

16. Graves PN, Tomer Y, Davies TF. Cloning and sequencing of a $1.3 \mathrm{~kb}$ variant of human thyrotropin receptor
mRNA lacking the transmembrane domain. Biochem Biophys Res Commun. 1992;187: 1135-1143

17. 2013 ETA Guideline: Management of Subclinical Hypothyroidism. Simon H.S. Pearce, Georg Brabant, Leonidas H. Duntas, Fabio Monzani, Robin P. Peeters, Salman Razvi, Jean-Louis Wemeau. Eur Thyroid J. 2013 Dec; 2 (4): 215-228

18. Guidelines for the Treatment of Hypothyroidism: Prepared by the American Thyroid Association Task Force on Thyroid Hormone Replacement. Jacqueline Jonklaas et al. Thyroid. 2014 Dec 1; 24(12): 1670-1751

19. American Thyroid Association Guidelines for Diagnosis and Management of Hyperthyroidism and other causes of Thyrotoxicosis. Ross, Burch, et al., Thyroid. Oct 2016, 26 (10): 1343-1421.

20. Ten S, New M, Maclaren N. Addison's disease. J Clin Endocrinol Metab 2001;86: 2909-22.

21. Nerup J. Addison's disease - a review of some clinical, pathological and immunological features. Dan Med Bull 1974; 21:201-17

22. Rodrigo Antonio Brandão Neto, Jozélio Freire de Carvalho Diagnosis and classification of Addison's disease (autoimmune adrenalitis). Autoimmunity Reviews 13 (2014) 408-411

23. Betterle C, Scalici C, Presotto F, et al. The natural history of adrenal function in autoimmune patients with antiadrenal autoantibodies. J Endocrinol 1998;117:467.

24. Winqvist O, Anders Karlsson F, Kämpe O. 21-Hydroxylase, a major autoantigen inidiopathic Addison's disease. Lancet 1992;339:1559-62.

25. R.L Rushworth, D Torpy,H Falhammar Adrenal crises: perspectives and research directions. Endocrine (2016)

26. Coursin DB, Wood KE. Corticosteroid supplementation for adrenal insufficiency. JAMA 2002;287:236

27. Johannsson G1, Nilsson AG, Bergthorsdottir R, Burman P, Dahlqvist P, Ekman B, Engström BE, Olsson T, Ragnarsson O, Ryberg M, Wahlberg J, Biller BM, Monson JP, Stewart PM, Lennernäs H, Skrtic S. Improved cortisol exposure-time profile and outcome in patients with adrenal insufficiency: a prospective randomized trial of a novel hydrocortisone dual-release formulation. J Clin Endocrinol Metab. 2012 Feb;97 (2):473

28. Nilsson AG1, Marelli C1, Fitts D1, Bergthorsdottir R1, Burman P1, Dahlqvist P1, Ekman B1, Engström BE1, Olsson T1, Ragnarsson O1, Ryberg M1, Wahlberg J1, Lennernäs H1, Skrtic S2, Johannsson G3. Prospective evaluation of long-term safety of dual-release hydrocortisone replacement administered once daily in patients with adrenal insufficiency. Eur J Endocrinol. 2014 Sep;171 (3):369-77.

29. Coulam CB, Adamson SC, Annagers JF. Incidence of premature ovarian failure. Obstet Gynecol 1986; 67:604-6. 2. Cohen I, Speroff L

30. Premature ovarian failure: Update; Ostetrical and Gynecological Surgery 1991;46:156-62.

31. Alper MM, Jolly EE, Garner PR. Pregnancies after premature ovarian failure. Obstet Gynecol 1985;67(suppl):59-62

32. Mc Donough PG. Diagnosis and therapy of primary amenorrhea. In: Gold JJ, Jasimovich JB. Gynecological Endocrinology. Harper \& Row Inc., Hagerstown, Maryland, 1980:278. Anasti JN

33. Premature ovarian failure: an update. Fertil Steril 1998; 70:1-15. 
34. V Kasteren YM and Schoemaker J Premature ovarian failure: a systematic review on therapetic interventions to restore ovarian function and achieve pregnancy. Hum Reprod Update 1999;5:483-92.

35. Armitage M, Nooney J and Evans S. Recent concerns surrounding HRT. Clin Endocrinol (Oxf) 2003;59:145-155.

36. Van Kasteren YM, Hoek A, Schoemaker J. Ovulation induction in premature ovarian failure: a placebo-controlled randomized trial combining pituitary suppression with gonadotropin stimulation. Fertil Steril 1995;64:273-8.

37. Gutenberg A, Buslei R, Fahlbusch R, Buchfelder M, Bruck W 2005 Immunopathology of Primary Hypophysitis: Implications for Pathogenesis. Am J Surg Pathol 29:329-338

38. Gutenberg A, Hans V, Puchner MJ, Kreutzer J, Bruck W, Caturegli P, Buchfelder M 2006 Primary hypophysitis: clinical-pathological correlations. Eur J Endocrinol 155:101- 107

39. Bellastella A, Bizzarro A, Coronella C, Bellastella G, Sinisi AA, De Bellis A. Lymphocytic hypophysitis: a rare or underestimated disease? Eur J Endocrinol. 2003 149: $363-376$

40. Goswami R, Kochupillai N, Crock PA, Jaleel A, Gupta N. Pituitary autoimmunity in patients with Sheehan's syndrome. J Clin Endocrinol Metab. 2002; 87: 41374141

41. De Bellis A, Bizzarro A, Bellastella A. Pituitary antibodies and lymphocytic hypophysitis. Best Pract Res Clin Endocrinol Metab. 2005;19:67-84

42. Neufeld M, Maclaren N, Blizzard R, 1980 Autoimmune polyglandular syndromes. Pediatr Ann 9: 154-162
43. Kahaly GJ, 2009 Polyglandular autoimmune syndromes. Eur J Endocrinol 161: 11-20

44. Proust-Lemoine E, Sangier-Veber L, Wémeau JL, 2012 Polyglandural autoimmune syndrome type 1 . Presse Med 41: e651-e662.

45. Proust-Lemoine E, Saugier-Véber P, Lefranc D, et al, 2010 Autoimmune polyendocrine syndrome type 1 in north-western France: AIRE gene mutation specificities and severe forms needing immunosuppressive therapies. Horm Res Paediatr 74: 275-284.

46. Carpenter CC, Solomon N, Silverberg SG, et al, 1964. Schmidt's syndrome (thyroid and adrenal insufficiency). A review of the literature and a report of fifteen new cases including ten instances of coexistent diabetes mellitus. Medicine (Baltimore) 43: 153-180

47. Robles DT, Fain PR, Gottlieb PA, Eisenbarth GS, 2002 The genetics of autoimmune polyendocrine syndrome type II. EndocrinolMetabClin North Am 31: 353-368.

48. Betterle C, Dal Pra C, Mantero F, Zanchetta R, 2002 Autoimmune adrenal insufficiency and autoimmune polyendocrine syndromes: autoantibodies, autoantigens, and their applicability in diagnosis and disease prediction. Endocr Rev 23: 327-364. Erratum in: Endocr Rev 23: 579

49. Horie I, Kawasaki E, Ando T, et al, 2012 Clinical and Genetic Characteristics of Autoimmune Poyglandular Syndrome Type 3 Variant in the Japanese Population. J Clin Endocrinol Metab 97: 1043-1045.

50. Dittmar M, Kahaly GJ, 2003 Polyglandular autoimmune syndromes: immunogenetics and long-term follow-up. J Clin Endocrinol Metab 88: 2983-2992 


\section{Malattie infiammatorie intestinali}

Marco Salice, Lucia Calandrini, Chiara Praticò, Marta Mazza, Andrea Calafiore, Giovanni Carini, Carlo Calabrese, Andrea Belluzzi, Fernando Rizzello, Paolo Gionchetti, Massimo Campieri

Centro delle Malattie Infiammatorie Croniche Intestinali, Policlinico Sant'Orsola-Malpighi, Università di Bologna, Italia

\section{Introduzione}

Nel corso degli ultimi due decenni abbiamo assistito a molti cambiamenti nella gestione delle malattie infiammatorie intestinali grazie ad una fervente attività di ricerca e all'introduzione di nuovi farmaci e di nuove tecniche diagnostiche.

Il nostro obiettivo è di fornire una breve guida adatta a tutti i professionisti coinvolti nella cura dei pazienti affetti da malattie infiammatorie intestinali.

Le malattie infiammatorie intestinali (IBD) comprendono la malattia di Crohn (CD), la colite ulcerosa (UC) e la malattia infiammatoria intestinale non classificata (IBDU).

Il nostro centro per la cura delle Malattia Infiammatorie Intestinali è stato fondato a Bologna quasi quaranta anni fa, seguendo l'ispirazione di due grandi maestri della gastroenterologia italiana Giuseppe Labò e Luigi Barbara. A quel tempo la comprensione della comunità medica della colite ulcerosa e della malattia di Crohn era ancora molto limitata, sia per l'inadeguatezza dei mezzi diagnostici esistenti che per una probabile minore incidenza.

\section{Cenni storici}

Il termine colite ulcerosa fu utilizzato per la prima volta da Samuel Wilks in un case report nel 1859; successivamente nel 1888 Sir William Hale White di Londra pubblicò una descrizione di casi di colite ulcerosa, patologia che si distingueva da altre cause note di colite, come la dissenteria, la tubercolosi e il tifo. $\mathrm{Nel}$

Corrispondente: Massimo Campieri, Dipartimento di Scienze Mediche e Chirurgiche, Università di Bologna, Italia.

E-mail: massimo.campieri@unibo.it

Articolo pubblicato secondo la Creative Commons Attribution NonCommercial 4.0 License (CC BY-NC 4.0).

(C) Copyright M. Salice et al., 2017

Licensee PAGEPress, Italy

QUADERNI - Italian Journal of Medicine 2017; 5(7):75-97
1909 la Royal Society of Medicine di Londra tenne un simposio sull'argomento, dal quale emersero numerose osservazioni: dai fattori di rischio, ai sintomi di presentazione più comuni ai tentativi di trattamento. Nei decenni successivi i più importanti successi furono il primo trial in cieco di Truelove nel 1955 che dimostrò una riduzione della mortalità nei pazienti trattati con corticosteroidi rispetto ai soggetti controllo e la scoperta di Svart dell'efficacia della sulfasalazina orale nella trattamento della UC. ${ }^{1}$ Un altro importante traguardo fu lo studio di Campieri che rivelò la migliore efficacia di clisteri di ritenzione contenenti acido 5-aminosalicilico (5-ASA), rispetto a clisteri di ritenzione con idrocortisone per il trattamento della colite ulcerosa lieve o moderata. ${ }^{2}$

Negli anni a seguire furono introdotti nuovi farmaci per il trattamento della UC come le tiopurine (6mercaptopurina e Azatioprina) e grazie all'applicazione della biologia molecolare, gli anticorpi monoclonali: gli anti-TNF $\alpha$, come Infliximab, Adalimumab e Golimumab e più recentemente, gli anti-Integrina come Vedolizumab.

La malattia di Crohn fu riconosciuta come un'entità separata dalla Colite ulcerosa solo nell'Ottobre del 1932, a seguito di una pubblicazione di Burril B. Crohn, Leon Ginzburg e Gordon Oppenheimer su Journal of American Medical Association in cui i tre medici descrivevano casi di enterite regionale.

Molti degli studi condotti sulla Malattia di Crohn durante la seconda metà del $\mathrm{XX}^{\circ}$ secolo coincisero con quelli sulla $\mathrm{UC}$, pertanto le due malattie furono trattate per molto tempo con gli stessi farmaci (5ASA, corticosteroidi, tiopurine e biologici). ${ }^{1}$ Negli ultimi anni, con l'aumento delle conoscenze, gli approcci terapeutici alle due malattie si sono progressivamente diversificati.

\section{Epidemiologia}

\section{Incidenza e prevalenza}

I tassi di incidenza e prevalenza annuali variano molto a seconda della regione geografica (Tabella 1).

L'incidenza e la prevalenza delle malattie infiammatorie intestinali sono più alte nei paesi con stile di 
vita occidentale, come il Canada, il Nord Europa e l'Australia. ${ }^{3}$ L'incidenza globalmente più elevata si registra nelle Isole Faroe (83/100.000 abitanti) ${ }^{4}$

Il tasso di incidenza annuale medio nei paesi dell'Europa occidentale è quasi il doppio di quello registrato nei centri dell'Europa dell'Est. Si osserva inoltre una stretta correlazione con il benessere di ciascun paese europeo. Le nazioni con PIL più elevato (Nord Europa e regione del Mediterraneo) hanno infatti un tasso di incidenza di IBD più elevato rispetto a quelle meno ricche (Europa orientale). ${ }^{5}$

Nei paesi in via di sviluppo, le malattia infiammatorie intestinali erano in passato un evento raro; tuttavia, negli ultimi anni, l'incidenza è progressivamente aumentata. Ciò può essere attribuito sia ai cambiamenti nello stile di vita (l'introduzione di una dieta occidentale, il miglioramento dei servizi igienico-sanitari, l'aumentato utilizzo di farmaci come antibiotici e antiinfiammatori e una maggiore esposizione all'inquinamento ambientale) che ad una migliore consapevolezza delle IBD da parte della popolazione e dei medici. ${ }^{6}$

L'incidenza delle malattie infiammatorie intestinali è in aumento in ogni regione del mondo e, poiché la mortalità è bassa e le malattie esordiscono più frequentemente nei giovani, la prevalenza globale continuerà ad aumentare in modo sostanziale. ${ }^{3}$

\section{Età}

L'età di insorgenza è di 20-30 anni per la CD e di 30-40 anni per la UC. Alcuni studi descrivono un secondo picco in entrambe le malattie a 60-70 anni, ma questa osservazione non è stata confermata. ${ }^{3}$ L'insorgenza delle IBD in età pediatrica costituisce il 7-20\% di tutti i casi. ${ }^{?}$

\section{Sesso}

La UC sembra verificarsi un po' più frequentemente negli uomini (60\%). La CD si riscontra invece il 20-30\% più frequentemente nelle donne, in particolare nelle aree ad alta incidenza, mentre sembra verificarsi maggiormente tra gli uomini in alcune zone a bassa incidenza. La distribuzione di CD e UC tra i pazienti pediatrici è opposta a quella di adulti: vi è una predominanza di $\mathrm{CD}$ tra i ragazzi e di UC tra le bambine.

\section{Etnia}

Vi è una maggiore prevalenza di IBD tra le popolazioni ebraiche, in particolare gli ashkenaziti.

Per lungo tempo è stata segnalata una minore incidenza tra le popolazioni non bianche, anche se recenti dati non sembrano confermare questa tendenza. ${ }^{3}$

\section{Mortalità}

La mortalità nella UC non è in generale differente da quella della popolazione generale, anche se è leggermente aumentata nei pazienti con malattia estesa. ${ }^{8}$

La CD è associata invece ad un piccolo, ma significativo aumento della mortalità rispetto alla popolazione generale. $^{9}$

\section{Fattori protettivi e fattori di rischio}

Nonostante anni di indagini, le cause delle malattie infiammatorie intestinali devono essere ancora identificate. I fattori associati ad un aumento o ad una riduzione dell'incidenza delle IBD sono l'anamnesi familiare per IBD, il fumo di sigaretta e l'appendicectomia. Altri fattori ambientali, come la dieta o l'uso di contraccettivi orali devono essere ulteriormente approfonditi (Tabella 2).

Tabella 1. Incidenza e prevalenza di UC vs CD secondo la regione geografica.

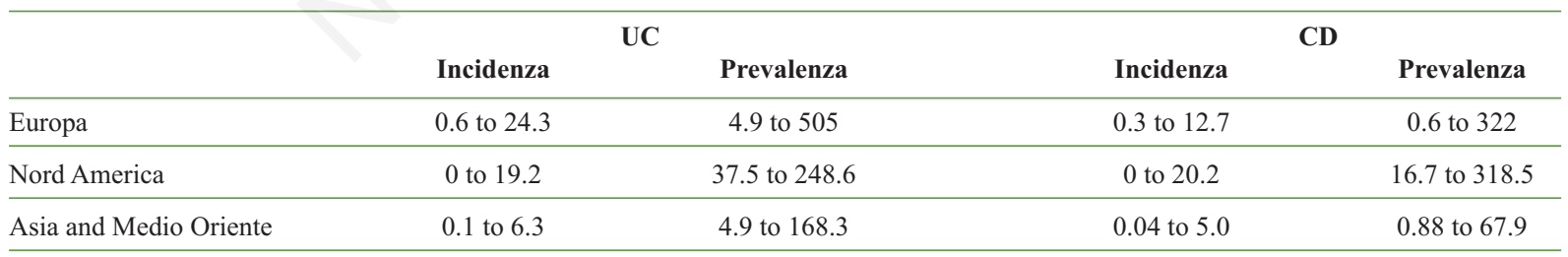

Tabella 2. Fattori protettivi e fattori di rischio di UC vs CD.

\begin{tabular}{lll}
\hline Fattori modificanti & UC & CD \\
\hline Fumo di sigaretta & Fattore protettivo & Fattore di rischio \\
\hline Appendicectomia & Fattore di rischio & Fattore protettivo \\
\hline Familiarità per IBD & Fattore di rischio & Fattore di rischio \\
\hline Dieta occidentale & Fattore di rischio (sospetto) & Fattore di rischio (sospetto) \\
\hline Contraccettivo orale & Fattore di rischio (sospetto) & Fattore di rischio (sospetto) \\
\hline
\end{tabular}




\section{Fumo di sigaretta}

Il fumo di sigaretta è un fattore protettivo per la UC (Tabella 3). Si osserva infatti un tasso di incidenza minore di UC nei fumatori attivi rispetto ai non fumatori. ${ }^{10} \grave{E}$ descritto un effetto protettivo del fumo di sigaretta anche per altre condizioni connesse alla UC come la colangite sclerosante primitiva e la pouchite, che porta a ipotizzare un effetto sistemico. ${ }^{11}$

Alcuni studi dimostrano infine che il fumo di sigaretta può influenzare il decorso della colite ulcerosa; tra i malati di UC i fumatori attivi sembrano infatti essere ricoverati in ospedale meno degli ex-fumatori. ${ }^{12}$

A differenza che nella $\mathrm{UC}$, il fumo di sigaretta è un fattore di rischio per la $\mathrm{CD}$. I fumatori hanno infatti una probabilità più che doppia di sviluppare la $\mathrm{CD} .{ }^{13}$

Il fumo influenza inoltre il decorso clinico della $\mathrm{CD}$. È noto, infatti, che i pazienti con $\mathrm{CD}$ che fumano presentano una malattia più aggressiva e complicata, hanno più probabilità di dover ricorrere a farmaci immunosoppressori e che il fumo di sigaretta aumenta il rischio di recidiva di malattia dopo resezione chirurgica. ${ }^{14}$

Alcuni studi descrivono infine un' associazione tra l'esposizione al fumo passivo in infanzia e lo sviluppo di CD. ${ }^{15}$ È necessario pertanto informare i pazienti sugli effetti negativi del fumo sul decorso della malattia.

\section{Appendicectomia}

L'appendicectomia sembra essere un fattore protettivo per lo sviluppo della UC (Tabella 3). ${ }^{16}$

L'impatto sul decorso clinico della UC non è chiaro e i risultati sono contrastanti. Recenti studi hanno dimostrato che l'appendicectomia, eseguita in qualsiasi momento in relazione alla diagnosi di UC, non è associata ad una riduzione della gravità della malattia. ${ }^{17,18}$

$\mathrm{Al}$ contrario, l'appendicectomia sembra essere associata ad un modesto rischio di sviluppare la $\mathrm{CD}$, che è aumentato nei primi anni dopo l'intervento chirurgico,ma si riduce a livelli normali dopo 5 anni. ${ }^{19}$

Inoltre si ritiene che i pazienti con $\mathrm{CD}$ e una pregressa appendicectomia abbiano un decorso di malattia peggiore. ${ }^{20} \mathrm{Il}$ meccanismo attraverso il quale appendicectomia protegge dalla $\mathrm{UC}$, ma aumenta il rischio di $\mathrm{CD}$ non è chiaro, un'ipotesi è che lo presenza di infiam- mazione appendicolare o di adenite mesenterica potrebbe proteggere dalla $\mathrm{UC}$ e/o predisporre alla $\mathrm{CD} .^{21}$

\section{Contraccettivi orali}

Alcuni studi descrivono un modesto aumento del rischio di sviluppare IBD nei pazienti che utilizzano contraccettivi orali, anche se il meccanismo rimane sconosciuto. $^{22}$

\section{Anamnesi familiare per IBD}

Il più importante fattore di rischio per lo sviluppo della $\mathrm{CD}$ o della UC è un'anamnesi familiare positiva per IBD. ${ }^{23}$

I parenti di primo grado, in particolare i fratelli, sono a più alto rischio, ma anche i familiari più lontani hanno una probabilità maggiore di sviluppare una IBD rispetto alla popolazione generale. Gli studi attribuiscono un rischio per i parenti di primo grado di un malato di CD del $4,5-5,2 \%$ per i non ebrei e $7,8 \%$ per gli ebrei; e un rischio per i familiari di primo grado di un malato di UC del 1,6\% per i non ebrei e del 5,2\% per gli ebrei. ${ }^{24}$

La storia familiare di IBD non sembra avere un impatto sul fenotipo clinico e sul decorso e della malattia. ${ }^{25}$

\section{Cenni di fisiopatologia}

Le IBD sembrano essere il risultato di una alterata risposta immunitaria ad una stimolazione antigenica microbica continua su uno sfondo di difetti genetici che riguardano la funzione di barriera della mucosa, la risposta immunitaria innata e/o acquisita. ${ }^{19}$ L'eziologia di queste malattie rimane ancora sconosciuta.

\section{La genetica delle IBD}

Gli studi sui gemelli e sui cluster familiari hanno messo in luce l'importanza dei fattori genetici nella patogenesi delle IBD, evidenziando un ruolo più rilevante nella $\mathrm{CD}$ che nella UC. ${ }^{26}$ Recenti studi sul genoma hanno identificato oltre 160 loci genetici di rischio per le IBD; la maggior parte dei quali contribuisce ad entrambi i fenotipi. ${ }^{27}$

Tabella 3. Fumo di sigaretta vs appendicectomia come fattori protettivi/di rischio per UC e CD.

\begin{tabular}{lll}
\hline Fumo di sigaretta & Sviluppo della malattia & Decorso clinico di malattia \\
\hline UC & & \\
CD & Fattore protettivo & Meno complicato \\
\hline Appendicectomia & Fattore di rischio & Più complicato \\
\hline UC & & \\
CD & & Risultati contrastanti \\
\hline
\end{tabular}


Il primo gene di suscettibilità scoperto per la CD fu il NOD $2^{28}$ che aprì poi la strada all'identificazione di altri loci coinvolti nella patogenesi delle IBD come IBD 5, IL23R e ATGIGL1. ${ }^{29}$

Le varianti genetiche scoperte fino ad oggi sembrano influenzare la funzione di barriera, l'immunità innata e l'immunità adattativa. È molto probabile che in un prossimo futuro il numero crescente di mutazioni genetiche ci aiuterà non solo a comprendere meglio la fisiopatologia della malattia, ma anche a definire sottopopolazioni di pazienti con IBD che possano essere trattate in modo altamente individualizzato. ${ }^{30}$

\section{Il ruolo della flora microbica nella patogenesi delle IBD}

L'equilibrio dinamico tra la flora commensale e la risposta difensiva dell'ospite a livello della mucosa ha un ruolo importante nella patogenesi delle IBD. I cambiamenti nella composizione della flora intestinale sono stati associati ad un maggiore rischio di sviluppare la UC o la CD. Ad esempio nella flora enterica dei pazienti con IBD sono stati trovati più comunemente rispetto a pazienti sani ceppi di Escherichia coli, in grado di aderire all'epitelio, ma che con bassa frequenza lo invadono. ${ }^{31}$

Non è ancora stato chiarito se la disbiosi intestinale riscontrata, sia la causa o la risposta alla gravità della malattia intestinale infiammatoria.

\section{L'influenza della dieta nella patogenesi delle IBD}

Negli ultimi decenni abbiamo osservato un crescente aumento delle IBD in aree, in precedenza a basso tasso di incidenza, che hanno acquisito un stile di vita più occidentale. Tra i cambiamenti adottati il più evidente è sicuramente la dieta, caratterizzata da un alto contenuto di grassi e proteine, ma un basso contenuto di frutta e verdura.

Molti studi hanno dimostrato inoltre che cambiamenti importanti nella dieta alterano significativamente la composizione del microbiota, che a sua volta interagirebbe con il sistema immunitario e con la successiva risposta infiammatoria. ${ }^{32,33}$

Questa ipotesi è stata avvalorata dal riscontro che un elevato consumo alimentare di acidi grassi polinsaturi, di acidi grassi omega-6, e di carne sono associati ad un aumentato rischio di CD e UC, che un'assunzione quotidiana di grosse quantità di cibi ricchi di fibre e frutta sono associati a un ridotto rischio di sviluppare $\mathrm{CD}$, e che un elevato quantitativo di verdure è stato associato ad una diminuzione del rischio di UC. ${ }^{34}$

\section{Il ruolo dei probiotici e dei prebiotici nelle IBD}

L'importante ruolo del microbiota nella patogenesi delle IBD è confermato dai buoni risultati ottenuti dal- l'utilizzo dei probiotici e dei prebiotici nel tentativo di regolare la disbiosi.

I probiotici sono microrganismi benefici che possono influenzare la composizione flora intestinale, l'attività metabolica e l'immuno-modulazione al fine di conferire beneficio all'organismo. ${ }^{35}$

Il loro ruolo è quello di alterare la diversità microbica attraverso l'inibizione competitiva di altri microbi, di aumentare la funzione di barriera della mucosa attraverso la produzione di acidi grassi a catena corta e di interagire con le cellule dendritiche intestinali per stimolare la risposta anti-infiammatoria. ${ }^{36}$ I probiotici più comuni utilizzati nel trattamento delle malattie infiammatorie dell'intestino sono il Lactobacillus sp, il Bifidobacterium sp, il Sacchrmomyces bouladrii, il E. coli Nissle 1917 e la combinazione VSL \# 3. In particolare quest'ultimo ha dimostrato una buona efficacia come terapia di mantenimento nei pazienti con IPAA. ${ }^{37}$

I prebiotici sono oligosaccaridi non digeribili che sono selettivamente fermentati nel colon in SCFAs e alterano la composizione e l'attività microbica al fine di conferire benefici per l'ospite. Alcuni esempi sono l'inulina, i fruttoligosaccaridi (FOS), i galattologosaccaridi e il lattulosio. ${ }^{38}$

\section{Difetti nella funzione di barriera}

Tra i difetti della funzioni di barriera della mucosa intestinale che predispongono al rischio di sviluppare IBD si annoverano le alterazioni nelle tight junctions e nel processo di autofagia e la distruzione della zona cuscinetto tra il contenuto luminale e l'epitelio. Quest'ultimo processo sembra essere correlato sia a mutazioni nel gene MUC2, che agli emulsionanti presenti nella dieta occidentale. ${ }^{39}$

\section{Difetti nella risposta immunitaria innata}

L'omeostasi intestinale richiede un buon equilibrio tra un'efficiente risposta immunitaria innata e il microbiota, che è riconosciuto attraverso recettori Tolllike e i recettori NOD-like presenti sulle cellule epiteliali e sulle cellule del sistema immunitario. ${ }^{40}$

L'alterazione del processo di riconoscimento antigenico è alla base dello sviluppo dello sviluppo dell'infiammazione. Non vi è alcuna chiara evidenza di specifici difetti del sistema immunitario innato nella UC, mentre le anomalie nella $\mathrm{CD}$ sono legate a varianti genetiche di NOD2, ATG16L1, IRGM, LRRK2 e XBP1, i cui prodotti mediano il riconoscimento microbico.

Inoltre, la produzione di citochine pro infiammatorie dell'immunità innata, come l'interleuchina $1 \beta$, l'interleuchina-6, il TNF $\alpha$ e il TRDL-1 è universalmente aumentata nei pazienti con IBD, ma non consente di discriminare tra la $\mathrm{UC}$ e la $\mathrm{CD} .{ }^{41} \mathrm{Il} \mathrm{TNF} \alpha$ è uno dei principali bersagli dei farmaci biologici esistenti. 


\section{Alterazioni nel sistema adattativo}

La riposta dell'immunità adattativa si differenzia tra le due malattie. Le sottopopolazioni linfocitarie tipiche della risposta nella CD sono di tipo Th1 e Th17, mentre la colite ulcerosa è caratterizzata da una risposta Th2 atipica, caratterizzata dalla presenza di Linfociti $\mathrm{T}$ natural killer atipici, che producono un abbondante quantità di IL13.

\section{Homing dei linfociti alla mucosa intestinale}

L'homing dei linfociti naive è il processo che permette la selettiva localizzazione di determinate popolazioni linfocitarie a livello dei linfonodi o di specifici tessuti. L'homing dei linfociti $\mathrm{T}$ naive nei tessuti linfoidi associati all'intestino si basa sulle interazioni delle cellule T naive con le HEV (venule ad alto endotelio), mediate da selectine, chemochine e integrine. Una caratteristica particolare dell'homing delle cellule $\mathrm{T}$ naive nei tessuti linfoidi associati all'intestino è il ruolo di una molecola della superfamiglia delle Ig chiamata MadCAM-1, espressa sulle HEV di questi siti e non in altre parti dell'organismo. Le cellule T naive esprimono due molecole che legano MadCAM1, la L-selectina e un'integrina chiamata $\alpha 4 \beta 7$.

Sebbene non siano descritti particolari difetti nell'homing linfocitario nei pazienti con IBD, Vedolizumab un antagonista $\alpha 4 \beta 7$ è stato recentemente approvato per il trattamento di pazienti con IBD.

\section{Colite ulcerosa}

\section{Definizione}

La colite ulcerosa (UC) è una malattia infiammatoria cronica intestinale limitata al colon.

L'infiammazione interessa il retto e può estendersi distalo-prossimalmente in modo continuo e circonferenziale. $^{42}$

\section{Presentazione clinica e decorso della malattia}

I sintomi della colite ulcerosa dipendono dall'estensione e dalla gravità della malattia. La diarrea ematica è il segno caratteristico della UC. Altri sintomi sono l'urgenza fecale, l'incontinenza, il dolore addominale e la defecazione notturna. I pazienti con proctite ulcerosa presentano di solito tenesmo, rettorragia e diarrea, anche se a volte possono riferire stitichezza. ${ }^{41}$

I sintomi e i segni sistemici (febbre, malessere generale e calo ponderale) sono caratteristici delle forme gravi di UC.

Le manifestazioni extra-intestinali possono essere presenti e a volte precedono la diagnosi di UC (vedi paragrafo Manifestazioni extra-intestinali nelle malattie infiammatorie intestinali).
Essendo una malattia cronica, la UC è caratterizzata da un alternanza di periodi di remissione e di riacutizzazione, che possono presentarsi spontaneamente o essere causati da fattori esacerbanti come una infezione intercorrente, una scarsa aderenza alla terapia o l'utilizzo di antibiotici. Gli obiettivi della terapia sono il raggiungimento e il mantenimento della remissione senza l'utilizzo di corticosteroidi. ${ }^{43}$

\section{Diagnosi}

La diagnosi di UC deve essere stabilita sulla base di una combinazione di elementi: anamnesi, valutazione clinica, caratteristiche endoscopiche e reperti istologici tipici. ${ }^{44}$

\section{Anamnesi}

Dovrebbe comprendere informazioni sull'esordio dei sintomi, in particolare il numero di scariche diarroiche miste a sangue, la presenza di urgenza fecale, tenesmo, dolore addominale, incontinenza fecale, episodi di diarrea notturna. Dovrebbero essere indagati anche i sintomi associati alle manifestazioni extra-intestinali (vedi paragrafo Manifestazioni extra-intestinali nelle malattie infiammatorie intestinali).

È importante valutare se il paziente sia un fumatore, abbia una familiarità per IBD o per neoplasia colo-rettale, abbia farmaco allergie, abbia preso farmaci (in particolare FANS e antibiotici) o se abbia particolari comorbidità. È utile inoltre indagare se il paziente abbia intolleranze alimentari, abbia fatto recentemente viaggi all'estero, se sia venuto a contatto con pazienti con malattie infettive e sia stato precedentemente sottoposto ad interventi chirurgici (in particolare l'appendicectomia).

\section{Valutazione clinica}

Nei pazienti con UC, la valutazione clinica dovrebbe comprendere la stima del benessere generale del paziente, i parametri vitali (la frequenza cardiaca, la temperatura corporea, la pressione arteriosa), il peso corporeo e l'altezza. L'esame obiettivo può essere completamente negativo nei pazienti con malattia lieve o moderata. L'obiettività addominale deve escludere segni di peritonismo o di distensione; è utile eseguire un'ispezione perianale, un'esplorazione rettale, una valutazione della mucosa orale, e verificare la presenza di alterazioni agli occhi, alla pelle e/o di un eventuale coinvolgimento articolare.

\section{Esami di laboratorio}

Le indagini di laboratorio iniziali dovrebbero comprendere l'emocromo completo, la funzionalità renale, gli elettroliti, gli enzimi epatici, l'assetto marziale e gli indici di infiammazione come la proteina $\mathrm{C}$ reattiva, la VES e la calprotectina fecale.

È utile inoltre escludere cause di diarrea infettiva 
attraverso la ricerca della tossina del Clostridium difficile, le copro colture con ricerca di Salmonella/Shigella/Campylobacter. In caso di anamnesi positiva per viaggi all'estero è consigliato eseguire la ricerca dei parassiti e degli elminti nelle feci, mentre in pazienti con sospetto di gastroenterite virale potrebbe essere adeguato richiedere la sierologia per Enterovirus, Adenovirus and Citomegalovirus e gli antigeni fecali per Rotavirus e Adenovirus.

Per escludere altre cause confondenti di diarrea potrebbe essere utile eseguire uno screening sierologico per malattia celiaca e valutare la funzionalità tiroidea.

\section{Endoscopia}

L'ileo-colonscopia con biopsie multiple è l'esame di scelta per stabilire la diagnosi di UC e per valutare l'estensione e la gravità della malattia.

Pur non esistendo caratteristiche endoscopiche tipiche della UC, si riscontra di solito un coinvolgimento del retto e una progressione di malattia distalo-prossimale con lesioni continue e confluenti ed una chiara delimitazione dell'infiammazione. ${ }^{44}$

\section{Istologia}

Le caratteristiche tipiche della UC sono una diffusa distorsione delle cripte e un infiltrato infiammatorio diffuso transmucosale con plasmociti, multipli aggregati linfoidi basali, neutrofili e macrofagi. I neutrofili invado l'epitelio delle cripte, provocando criptite e ascessi criptici. La deplezione di mucina è una caratteristica meno specifica. ${ }^{45}$

\section{Altri esami strumentali}

Anche se le tecniche di imaging non sono strettamente necessarie per la diagnosi di UC, la radiografia dell'addome dovrebbe essere eseguita in tutti i pazienti con una forma grave di UC per escludere dilatazioni coliche o la presenza di aria libera. ${ }^{46}$

L'ecografia addominale può essere utilizzata per valutare l'infiammazione del colon o del piccolo intestino. I vantaggi di questa tecnica sono il basso costo, la non invasività e la facilità nell'esecuzione, poiché non richiede preparazioni. I limiti sono invece la bassa specificità nel differenziare tra la UC e altre forme di infiammazione del colon e la stretta dipendenza dall'esperienza dell'operatore. ${ }^{47}$

\section{Classificazioni della UC}

\section{Classificazione sulla base dell'estensione}

È importante classificare la UC sulla base dell'estensione sia per il differente approccio terapeutico alla malattia e sia per decidere quando e con che frequenza eseguire la sorveglianza endoscopica per la neoplasia colo-rettale.
La classificazione di Montreal suddivide la malattia in proctite (limitata al retto), colite sinistra (estesa oltre il retto, ma non oltre la flessura splenica) e pancolite (estesa oltre la flessura splenica) (Figura 1).

Il più grande limite della classificazione basata sull'estensione è l'instabilità della malattia nel tempo, che tende ad estendersi distalo-prossimalmente. ${ }^{48}$

\section{Classificazione sulla base della gravità della UC}

È utile per scegliere la strategia terapeutica più adeguata. Nel corso degli anni sono stati proposti vari score per valutare la gravità della UC, anche se nessuno di essi è stato validato. ${ }^{49}$

Il Truelove and Witts Severity Index fu il primo punteggio elaborato a tale scopo; si basa su 6 variabili: il numero delle scariche, la presenza di sangue nelle feci, la frequenza cardiaca, la temperatura, l'emoglobina e la VES (Figura 2).

Anche se l'indice di gravità Truelove e Witts è utile per classificare i pazienti in modo generale, non è sufficientemente selettivo per misurare i cambiamenti nell'attività della malattia. ${ }^{50}$

Il Modified Mayo score (Figura 3) è frequentemente utilizzato negli studi clinici. Si compone di 4 caratteristiche: il numero delle evacuazioni, la presenza di sangue nelle feci, la valutazione endoscopica e la valutazione globale del medico.

Il paziente deve essere in grado di riferire il numero di evacuazioni in più rispetto alla norma, il sot-

\begin{tabular}{ll}
$\begin{array}{l}\text { Ulcerative } \\
\text { rectocolitis - URC }\end{array}$ & \multicolumn{1}{c}{ Classification of Montreal } \\
\hline $\begin{array}{l}\text { E } 1 \text { - Proctitis } \\
\text { E 2 - Left Sided Colitis }\end{array}$ & $\begin{array}{l}\text { Limited to rectum ( } 30 \%) \\
\text { Affects the rectum and left colon } \\
\text { (distal to the splenic flexure) (40\%) }\end{array}$ \\
E 3 - Pancolitis & $\begin{array}{l}\text { Affects the rectum and colon } \\
\text { proximal to the splenic angle (30\%) }\end{array}$
\end{tabular}

Figura 1. Classificazione di Montreal sull'estensione della UC.

\begin{tabular}{llll}
\hline & Mild & $\begin{array}{l}\text { Moderate 'in } \\
\text { between mild } \\
\text { and severe' }\end{array}$ & \\
\hline & & Severe \\
\hline $\begin{array}{l}\text { Bloody } \\
\text { stools/day }\end{array}$ & $<4$ & 4 or more if & $\geq 6$ and \\
Pulse & $<90 \mathrm{bpm}$ & $\leq 90 \mathrm{bpm}$ & $>90 \mathrm{bpm}$ or \\
Temperature & $<37.5^{\circ} \mathrm{C}$ & $\leq 37.8{ }^{\circ} \mathrm{C}$ & $>37.8{ }^{\circ} \mathrm{C}$ or \\
Haemoglobin & $>11.5 \mathrm{~g} / \mathrm{dL}$ & $\geq 10.5 \mathrm{~g} / \mathrm{dL}$ & $<10.5 \mathrm{~g} / \mathrm{dL}$ or \\
ESR & $<20 \mathrm{~mm} / \mathrm{h}$ & $\leq 30 \mathrm{~mm} / \mathrm{h}$ & $>30 \mathrm{~mm} / \mathrm{h}$ or \\
or CRP & Normal & $\leq 30 \mathrm{mg} / \mathrm{L}$ & $>30 \mathrm{mg} / \mathrm{L}$
\end{tabular}

Figura 2. Attività di malattia nei pazienti con UC, adattato da True love and Witts. 
topunteggio della rettorragia va calcolato basandosi sul peggior episodio di sanguinamento del giorno, la valutazione globale del paziente deve prendere in considerazione la presenza di dolore addominale e il benessere generale. Il punteggio va da 0 a 12 .

Un paziente viene definito in remissione se lo score totale è minore o uguale a 2 e nessuno dei quattro sottopunteggi è maggiore di uno. Uno score totale da 2 a 5 indica una malattia lieve, mentre da 6 a 12 identifica una forma moderato-grave..$^{51}$

La classificazione sulla risposta alla terapia è riassunta in Tabella 4.

\section{Marker molecolari}

Il progresso tecnologico e la ricerca hanno portato alla scoperta di marker molecolari e genetici che rappresentano un possibile strumento per predire il decorso e l'outcome della UC. L'obiettivo sarà di ottenere un profilo molecolare di ciascun paziente al momento della diagnosi, che ci permetterà di scegliere l'approccio più appropriato in termini di terapia e tipo di follow-up. ${ }^{52}$

\section{Gestione della UC}

Il trattamento della UC richiede un approccio individualizzato e multidisciplinare. I pazienti con malattia lieve-moderata di solito possono essere gestiti in regime ambulatoriale, mentre le forme gravi richiedono un ricovero ospedaliero.

\section{Gestione della proctite ulcerosa lieve-moderata}

La terapia di prima linea della proctite lieve o moderata è la mesalazina topica (5ASA) (Figura 4). La somministrazione di una supposta di $1 \mathrm{~g}$ al giorno è ugualmente efficace, ma più conveniente di dosi separate da $500 \mathrm{mg}$ al giorno. ${ }^{53-55}$ Le supposte risultano più efficaci dei clisteri, ${ }^{56}$ con $2 \mathrm{~g} /$ die di 5 ASA che costituiscono comunque un'alternativa.

Gli studi dimostrano che la mesalazina topica è più efficace dello steroide topico, che deve essere considerato come una terapia di seconda linea nei pazienti intolleranti alla 5ASA. ${ }^{57}$

La terapia topica con la mesalazina è più efficace della sola 5ASA orale. ${ }^{58}$ Infine nella nostra esperienza clinica, pur non essendoci molti studi sulla terapia combinata, consigliamo di associare sempre la Mesalazina MMX orale ad un dosaggio minimo di 2,4 g alla terapia topica soprattutto per prevenire l'estensione della malattia.

\section{Gestione della colite ulcerosa sinistra e della pancolite di grado lieve-moderata}

La colite ulcerosa sinistra e la pancolite ulcerosa di grado lieve-moderato devono essere trattate in prima linea con un clistere di mesalazina di almeno $1 \mathrm{~g} /$ die insieme alla mesalazina per os al dosaggio minimo di 2 g/die (Figura 5).

La sola terapia topica con steroidi o amino salicilati è meno efficace della combinazione con la terapia con mesalazina orale. ${ }^{59}$

\begin{tabular}{lllll}
\hline Mayo index & 0 & 1 & 2 & 3 \\
\hline Stool frequency & Normal & $1-2 /$ day $>$ normal & $3-4 /$ day $>$ normal & $5 /$ day $>$ normal \\
Rectal bleeding & None & Streaks & Obvious & Mostly blood \\
Mucosa & Normal & Mild friability & Moderate friability & Spontaneous bleeding \\
Physician's global assessment & Normal & Mild & Moderate & Severe \\
\hline
\end{tabular}

Figura 3. Modified Mayo score.

Tabella 4. Classificazione sulla risposta alla terapia.

\begin{tabular}{ll}
\hline Remissione nella UC & Completa risoluzione dei sintomi e guarigione mucosale all'endoscopia \\
\hline Risposta nella UC & Definita come un miglioramento clinico (riduzione del numero delle scariche ematiche) ed endoscopico \\
\hline Recidiva precoce & È definita come una recidiva entro i tre mesi dal raggiungimento della remissione. \\
\hline IBD steroido-refrattaria & $\begin{array}{l}\text { I pazienti che hanno malattia attiva nonostante un dosaggio di prednisolone fino a } 0,75 \mathrm{mg} / \mathrm{kg} / \mathrm{giorno} \mathrm{per} \\
\text { un periodo di } 4 \text { settimane }\end{array}$ \\
\hline IBD steriodo-dipendente & $\begin{array}{l}\text { Pazienti che: } \\
\text { 1. O sono incapaci di ridurre i corticosteroidi sotto ad un equivalente di } 10 \mathrm{mg} / \text { giorno di prednisolone entro } \\
\text { 2. Hanno una recidiva entro } 3 \text { mesi dalla sospensione degli steroidi }\end{array}$ \\
\hline IBD refrattarie alle tiopurine & $\begin{array}{l}\text { I pazienti che hanno una malattia attiva o una recidiva dopo aver raggiunto un dosaggio terapeutico di } \\
\text { tiopurine per almeno } 3 \text { mesi (cioè azatioprina 2-2,5 mg/kg/giorno o mercaptopurina } 1-1,5 \mathrm{mg} / \mathrm{kg} / \mathrm{die}) \mathrm{in} \\
\text { assenza di leucopenia }\end{array}$ \\
\hline
\end{tabular}


La monosomministrazione giornaliera di 5ASA è efficace come dosi separate. ${ }^{60} \mathrm{La}$ formulazione MMX della mesalazina orale è efficace e generalmente ben tollerato per indurre la remissione clinica ed endoscopica della colite ulcerosa lieve-moderata attiva. ${ }^{61}$

Nella nostra esperienza l'ottimizzazione della terapia topica con un clistere al giorno contenente $4 \mathrm{~g}$ die di mesalazina e a un flacone di $40 \mathrm{mg}$ di metil-prednisolone per almeno 45 giorni e poi a giorni alterni per ulteriori 45 giorni sembra essere efficace e può a volte evitare la necessità di introdurre gli steroidi orali.

\section{Gestione della UC lieve-moderata refrattaria a mesalazina topica e orale e cortisone topico}

In caso di refrattarietà alla mesalazina orale e topica e al cortisone topico il primo passo è la rivalutazione della malattia, l'esclusione di altre possibili cause, una valutazione dell'appropriatezza e dell'aderenza alle terapie convenzionali seguite fino a quel momento.

Prima di iniziare la terapia cortisonica sistemica devono essere presi in considerazione steroidi a bassa biodisponibilità sistemica ovvero la Budesonide MMX e il Beclometasone dipropionato.
Recentemente la Budesonide MMX è entrata in commercio in Italia. ${ }^{2} \mathrm{Si}$ consiglia un dosaggio di $9 \mathrm{mg}$ al giorno per i primi 30 giorni e di $9 \mathrm{mg}$ a giorni alterni per altre 4 settimane (Figura 6).

Il Beclometasone dipropionato orale è un'altra possibilità terapeutica in caso di colite sinistra o di pancolite. ${ }^{63} \mathrm{Si}$ consiglia un dosaggio di $10 \mathrm{mg} / \mathrm{die}$ il primo mese e di $5 \mathrm{mg} /$ die il secondo mese.

In caso di fallimento o di scarsa risposta, si consiglia di prendere in considerazione gli steroidi sistemici, ${ }^{64}$ iniziando con Prednisone $40 \mathrm{mg}$ al giorno per 1-2 settimane fino alla risposta clinica con un tapering di 5 o $10 \mathrm{mg}$ a settimana a seconda della gravità della malattia e della rapidità della risposta. Arrivati a un dosaggio di $20 \mathrm{mg}$ al giorno il decalage deve procedere con una riduzione di $2.5 \mathrm{mg}$ alla settimana. ${ }^{65}$

È indicato inoltre continuare la terapia con mesalazina topica e orale con l'obiettivo di mantenere a remissione dopo aver completato il tapering dello steroide. ${ }^{66}$

\section{Gestione della colite ulcerosa lieve-moderata di qualsiasi estensione refrattaria alla terapia steroidea}

In caso di mancata risposta ai corticosteroidi siste-

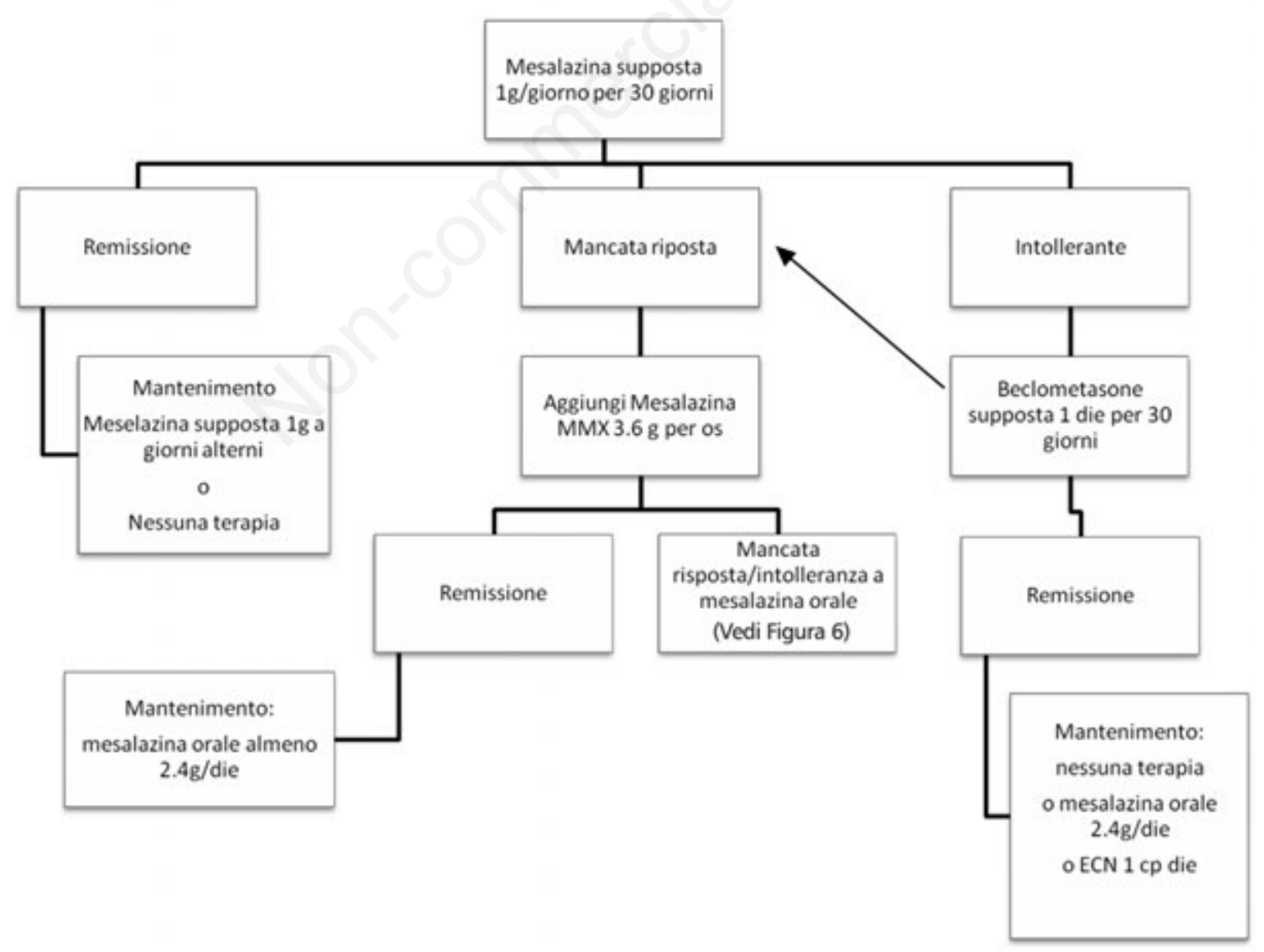

Figura 4. Proctite ulcerosa lieve-moderata. 


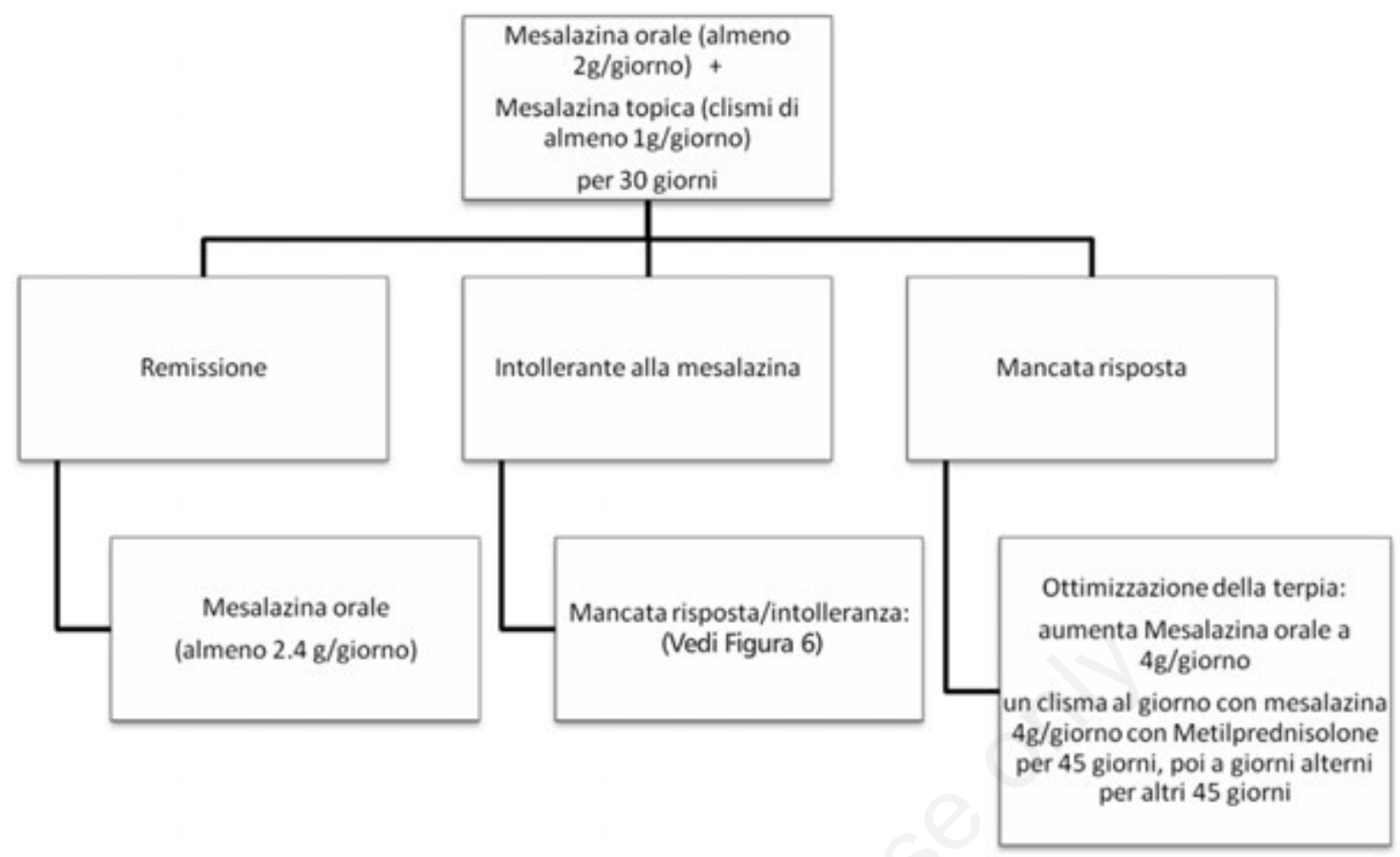

Figura 5. Colite sinistra lieve-moderata.

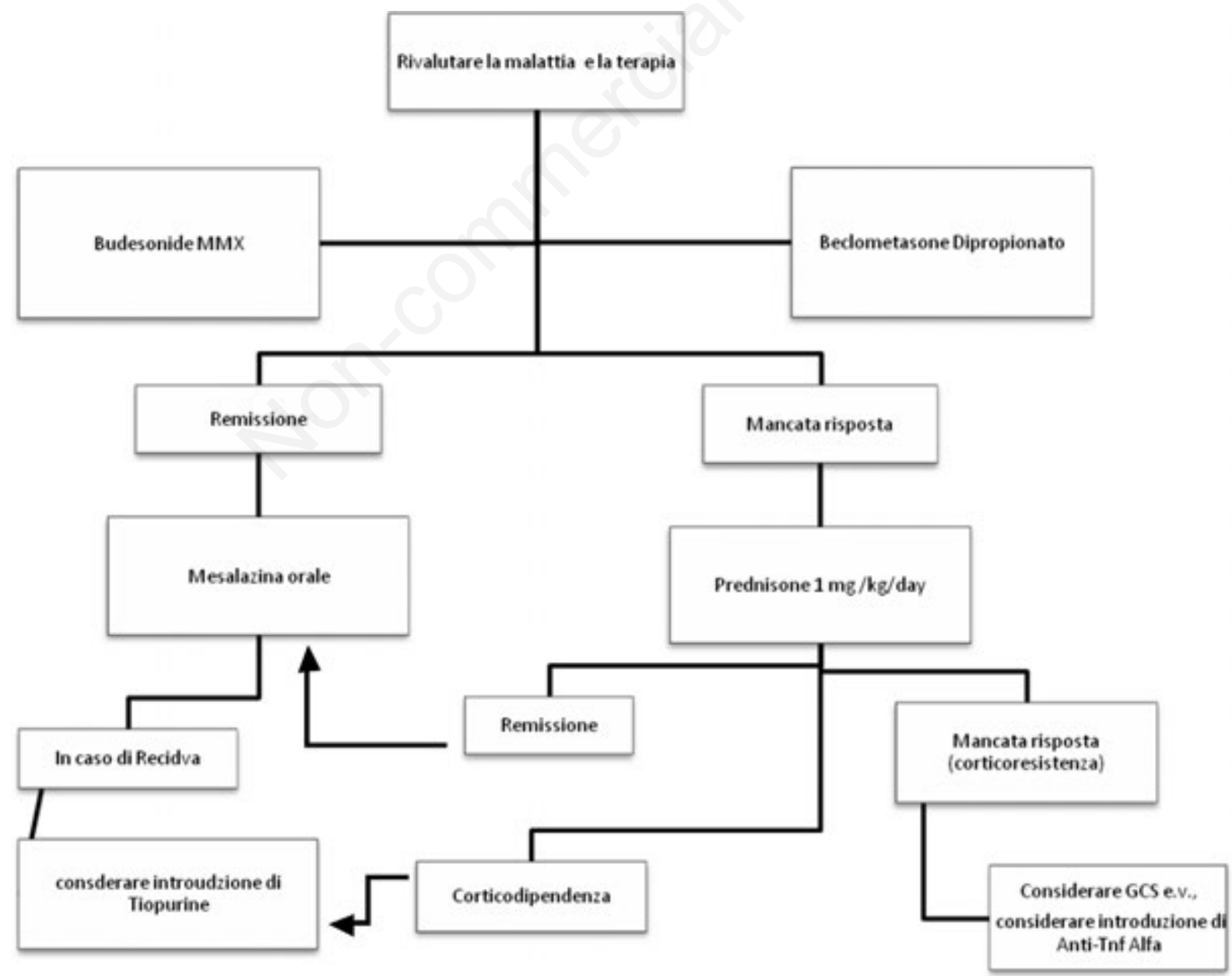

Figura 6. Gestione della UC lieve-moderata refrattaria alla mesalazina topica e orale e al cortisone topico. 
mici somministrati per via orale (malattia corticoresistente) potrebbe essere indicato il ricovero in ambito ospedaliero per la terapia steroidea per via endovenosa. La dose giornaliera raccomandata è di 40-60 mg ev di prednisone o di equivalente con un tapering da eseguire in circa 2 mesi.

Se il paziente non risponde al corticosteroide sistemico per via endovenosa, deve essere considerata la terapia con anti-TNF $\alpha$.

I farmaci anti-TNF $\alpha$ attualmente disponibili per la cura della UC sono Infliximab, Adalimumab e Golimumab.

La terapia con Infliximab è somministrata per via endovenosa e sembra essere efficace nell'indurre e mantenere una risposta anche nelle proctiti ulcerose. ${ }^{67}$

Il dosaggio di induzione è di $5 \mathrm{mg} / \mathrm{kg}$ ev alle settimane 0,2 e 6 , seguite da un dosaggio di mantenimento di $5-10 \mathrm{mg} / \mathrm{kg}$ ogni 8 settimane.

Adalimumab è un anticorpo monoclonale umanizzato contro il TNF- $\alpha$, che viene somministrato per via sottocutanea. Il dosaggio standard di induzione è di $160 \mathrm{mg}$ alla settimana 0 e di $80 \mathrm{mg}$ alla settimana 2 , seguito da un dosaggio di mantenimento dopo la quarta settimana dall'inizio di $40 \mathrm{mg}$ ogni 14 oppure ogni 7 giorni. ${ }^{68}$

Golimumab è un anticorpo monoclonale umanizzato contro il TNF, somministrato per via sottocutanea. Il dosaggio standard di induzione è di $200 \mathrm{mg}$ alla settimana 0 , di $100 \mathrm{mg}$ alla settimana 2 , seguito da un dosaggio di mantenimento di $50 \mathrm{mg}$ o $100 \mathrm{mg}$ (a seconda del peso del paziente) ogni 4 settimane, a partire dalla sesta settimana dall'inizio. ${ }^{69}$

Vedolizumab (antagonista dell'integrina $\alpha 4 \beta 7$ ) è da poco disponibile in Italia per il trattamento della colite ulcerosa refrattaria alla terapia convenzionale. Il dosaggio standard di induzione è di $300 \mathrm{mg}$ per via endovenosa alla settimana 0,2 e 6 seguito da un dosaggio di mantenimento di $300 \mathrm{mg}$ ogni 8 settimane, a partire dalla sesta settimana dall'inizio della terapia. ${ }^{70}$

In caso di fallimento della terapia medica è sempre opportuno valutare l'opzione chirurgica.

\section{Gestione della UC lieve-moderata steroido dipendente}

I pazienti con UC steroido-dipendente devono es- sere trattati con Azatioprina $(2,5 \mathrm{mg} / \mathrm{kg} / \mathrm{die})$ o Mercaptopurina $(1,5 \mathrm{mg} / \mathrm{kg} / \mathrm{die})$.

L'effetto terapeutico ottimale dell'Azatioprina e della 6MP si osserva dopo 2-3 mesi dall'inizio della terapia.

\section{Gestione della UC lieve-moderata refrattaria alle tiopurine}

I pazienti con UC refrattaria alle tiopurine dovrebbero essere trattati con anti-TNF $\alpha$, anche se è necessario prendere in considerazione l'intervento chirurgico.

\section{Terapia di mantenimento}

L'obiettivo della terapia è di mantenere la remissione clinica ed endoscopica senza steroidi. La scelta del trattamento di mantenimento deve essere basata sull'estensione della UC, sul decorso della malattia (frequenza delle riacutizzazioni), sulle terapie precedenti, sulla sicurezza del farmaco e sulla prevenzione del cancro (Tabella 5).

La raccomandazione generale è di continuare la mesalazina come trattamento di mantenimento a lungo termine, poiché può ridurre il rischio di cancro del colon-retto.

\section{Terapia di mantenimento con tiopurine e biologici}

L'azatioprina e/o mercaptopurina sono consigliate nei pazienti con attività di malattia lieve o moderata, ma con frequenti recidive durante il trattamento con 5-ASA a dosaggio ottimale o che sono intolleranti al 5-ASA. Le tiopurine sono inoltre indicate nella UC steroido-dipendente e nei pazienti che rispondono alla ciclosporina per l'induzione della remissione.

Nei soggetti che raggiungono la remissione con i farmaci anti-TNF, le possibilità per il mantenimento sono di continuare la terapia biologica o di passare alle tiopurine.

A causa di limitate evidenze, non può essere fornita ancora alcuna raccomandazione riguardo la durata del trattamento con azatioprina, con anti-TNF $\alpha$ o con Vedolizumab, anche se l'uso prolungato di questi farmaci può essere preso in considerazione, se necessario.

Tabella 5. Terapia di mantenimento in pazienti in remissione dopo terapia con mesalazina orale o topica.

\begin{tabular}{lll}
\hline & Proctite ulcerosa & Colite sinistra e pancolite \\
\hline Prima linea di mantenimento & $\begin{array}{l}\text { Mesalazina topica (minimo } 3 \mathrm{~g} / \text { settimana } \\
\text { in dosi separate) }\end{array}$ & Mesalazina orale (minimo 2,4 g/giorno) \\
\hline Seconda linea di mantenimento & $\begin{array}{l}\text { Mesalazina topica e Mesalazina orale } \\
\text { (minimo 2,4 g/giorno) }\end{array}$ & In caso di intolleranza a 5ASA valutare E. coli Nissle \\
\hline
\end{tabular}

*Al fine di prevenire l'estensione della proctite ulcerosa consigliamo di solito la mesalazina orale come terapia di mantenimento di prima linea. 


\section{Gestione della UC grave di qualsiasi estensione}

La colite ulcerosa grave è una condizione potenzialmente pericolosa per la vita.

È caratterizzata da un numero di evacuazioni di diarrea ematica superori a 6 e almeno uno tra i seguenti segni di tossicità sistemica (frequenza cardiaca sopra ai $90 \mathrm{bpm}$, temperatura sopra i $37,5^{\circ} \mathrm{C}$, Emoglobina al di sotto di $10,5 \mathrm{~g} / \mathrm{dL}$ o la VES superiore a 30 $\mathrm{mm} / \mathrm{h}$ ).

I pazienti che presentano queste caratteristiche devono essere ricoverati in ospedale.

La strategia diagnostica-terapeutica che proponiamo è indicata in Tabella $6 .{ }^{71,72}$

La terapia corticosteroidea è somministrata per via endovenosa in bolo ad un dosaggio consigliato dai 40 $\mathrm{mg} / \mathrm{die}$ a $1 \mathrm{mg} / \mathrm{kg} /$ die di Metilprednisolone. ${ }^{73}$

La terapia topica con clisteri di mesalazina e steroidi deve essere somministrata se il paziente è in grado di trattenerla. ${ }^{74}$

La terapia antibiotica con Metronidazolo è indicata solo in caso di sovrainfezione batterica, anche è spesso somministrata nella pratica clinica.

\section{Gestione della UC grave refrattaria alla terapia corti- costeroidea sistemica}

La risposta alla terapia corticosteroidea deve essere valutata al terzo giorno.

Le possibilità terapeutiche sono la chirurgia o la terapia di salvataggio con ciclosporina al dosaggio di
$2 \mathrm{mg} / \mathrm{kg} /$ die o Infliximab al dosaggio di $5-10 \mathrm{mg} / \mathrm{kg}$.

I pazienti dovrebbero essere rivalutati quotidianamente e in caso di mancato miglioramento clinico dopo 4-7 giorni dall'inizio della terapia di salvataggio, è indicata l'opzione chirurgica.

\section{Il ruolo della chirurgia nella UC}

Negli ultimi 20 anni il nuovo gold standard per la chirurgia della UC è diventata la proctocolectomia con confezionamento di anastomosi ileo- pouch-anale (IPAA), che garantisce ai pazienti un immagine del corpo invariato senza stomia. ${ }^{75}$

\section{Pouchite}

La pouchite è un'infiammazione aspecifica probabilmente causata da una risposta immunitaria al nuovo microbiota che si instaura nella pouch (disbiosi). Circa il $40 \%$ dei pazienti con IPAA hanno almeno un episodio di pouchite, anche se solo nel $10-20 \%$ dei casi diventa cronica.

La pouchite si manifesta con un aumento della numero delle evacuazioni, incontinenza e urgenza fecale e dolore addominale. Nei casi più gravi può essere presente la febbre. Il trattamento è la terapia antibiotica (metronidazolo e ciprofloxacina) e i probiotici (VSL \# 3).

Solo nel $8-10 \%$ dei casi è indicato l'abbattimento della pouch con confezionamento di un'ileostomia definitiva. ${ }^{76}$

Tabella 6. Strategia diagnostica-terapeutica nella gestione di colite ulcerosa grave.

\begin{tabular}{|c|c|}
\hline Obiettivi & Provvedimenti \\
\hline $\begin{array}{l}\text { 1. Valutare la gravità e la presenza delle complicanze della UC } \\
\text { (megacolon tossico, perforazione, anemia ed emorragia) }\end{array}$ & $\begin{array}{l}\text { a. Emocromo completo, VES e PCR } \\
\text { b. Valutazione clinica (in particolare temperatura, frequenza cardiaca, } \\
\text { numero delle evacuazioni, esame obiettivo dell'addome) } \\
\text { c. Rx dell'addome } \\
\text { d. Consulenza chirurgica }\end{array}$ \\
\hline 2. Escludere la presenza di infezioni enteriche & $\begin{array}{l}\text { a. Coprocolture (ECCO) } \\
\text { b. Ricerca della tossina del Clostridium (ECCO) } \\
\text { c. Ricerca dei parassiti ed elminti nelle feci } \\
\text { d. Antigeni fecali di Rotavirus e Adenovirus } \\
\text { e. Sierologia per Enterovirus }\end{array}$ \\
\hline 3. Confermare la diagnosi & $\begin{array}{l}\text { a. Rettosigmoidoscopia con biopsie per confermare la diagnosi ed } \\
\text { escludere sovra infezione da } \mathrm{CMV}^{46}\end{array}$ \\
\hline 4. Correggere e prevenire la disidratazione e gli squilibri elettrolitici & a. Digiuno, terapia reidratante per via endovenosa \\
\hline $\begin{array}{l}\text { 5. Profilassi tromboembolica in considerazione del fatto che i pazienti } \\
\text { con malattia infiammatoria attiva hanno un rischio trombo embolico } \\
\text { di } 1.5-3.5 \text { volte maggiore della popolazione generale }{ }^{71}\end{array}$ & a. Eparina sottocutanea a dosaggio profilattico \\
\hline $\begin{array}{l}\text { 6. Completare lo screening per la terapia di salvataggio con anti-tnf } \\
\alpha \text { o ciclosporina, dato che circa il } 40 \%-50 \% \text { dei pazienti } \\
\text { ospedalizzati non rispondo alla terapia corticosteroidea endovenosa }\end{array}$ & $\begin{array}{l}\text { a. Sierologia for CMV, EBV, HBV, HCV and HIV } \\
\text { b. Quantiferon test o Mantoux test } \\
\text { c. Coprocolture (ECCO) } \\
\text { d. Ricerca della tossina del Clostrium (ECCO) } \\
\text { e. Ricerca dei parassiti ed elminti nelle feci } \\
\text { f. Rx del torace } \\
\text { g. Colesterolemia e magnesio sierico }\end{array}$ \\
\hline
\end{tabular}




\section{Malattia di Crohn}

\section{Definizione}

La malattia di Crohn (CD) è una malattia infiammatoria cronica intestinale che può coinvolgere qualsiasi parte del tratto gastro-intestinale, anche se le sedi più colpite sono l'ileo terminale e il colon. L'infiammazione è segmentaria, asimmetrica e trans murale.

\section{Presentazione clinica}

La CD ha una presentazione clinica molto eterogenea e insidiosa, che dipende dalla localizzazione, dalla gravità e dal comportamento della malattia. Lo scenario più comune è un paziente giovane con dolore addominale in fossa iliaca destra, diarrea cronica, astenia, perdita di peso e febbricola. In caso di iperpiressia è necessario escludere la presenza di un ascesso addominale. Nei pazienti con coinvolgimento del colon è possibile riscontrare rettorragia e diarrea ematica. Circa un terzo dei pazienti presenta malattia perianale e il $50 \%$ manifestazioni extraintestinali, che a volte possono precedere la diagnosi di CD.

\section{Diagnosi}

La diagnosi di CD deve essere stabilita sulla base una combinazione di elementi: anamnesi, valutazione clinica, caratteristiche endoscopiche e reperti istologici tipici. ${ }^{77}$

\section{Anamnesi}

Dovrebbe comprendere informazioni sulla comparsa dei sintomi in particolare il dolore addominale, la diarrea, la febbre, l'astenia, il calo ponderale e la presenza di disturbi a livello perianale. Dovrebbero essere indagati anche i sintomi e i segni collegati alle manifestazioni extra-intestinali come artralgia, dolore agli occhi e comparsa di manifestazioni cutanee (vedi paragrafo Manifestazioni extra-intestinali nelle malattie infiammatorie intestinali).

È importante verificare se il paziente sia un fumatore, abbia una familiarità per IBD o per neoplasia colo-rettale, abbia farmaco allergie, abbia preso farmaci (in particolare FANS e antibiotici) o se abbia particolari comorbidità. È utile inoltre indagare se il paziente abbia intolleranze alimentari, abbia fatto recentemente viaggi all'estero, se sia venuto a contatto con malattie infettive enteriche, e sia stato precedentemente sottoposto ad interventi chirurgici (in particolare l'appendicectomia).

\section{Valutazione clinica}

Nei pazienti con $\mathrm{CD}$, la valutazione clinica deve comprendere la stima del benessere generale del paziente, i parametri vitali (la frequenza cardiaca, la tem- peratura corporea e la pressione arteriosa), il peso corporeo e l'altezza. L'obiettività addominale deve escludere segni di peritonismo, di distensione e masse addominali palpabili. È utile eseguire un'ispezione perianale, un'esplorazione rettale, una valutazione della mucosa orale, ed escludere la presenza di alterazioni agli occhi, alla pelle e un eventuale coinvolgimento articolare.

\section{Esami di laboratorio}

Le indagini di laboratorio iniziali dovrebbero comprendere: l'emocromo completo, la funzionalità renale, gli elettroliti, gli enzimi epatici, l'assetto marziale e gli indici di infiammazione come la proteina $\mathrm{C}$ reattiva, la VES e la calprotectina fecale.

È utile inoltre escludere cause di diarrea infettiva attraverso la ricerca della tossina del $C$. difficile, le copro colture con ricerca di Salmonella/Shigellal Campylobacter. In caso di anamnesi positiva per viaggi all'estero è consigliato eseguire la ricerca dei parassiti e degli elminti nelle feci, mentre in pazienti con sospetto di gastroenterite virale potrebbe essere adeguato richiedere la sierologia per Enterovirus, Adenovirus e Citomegalovirus e gli antigeni fecali per Rotavirus e Adenovirus.

Per escludere altre cause confondenti di diarrea potrebbe essere utile eseguire uno screening sierologico per malattia celiaca e valutare la funzionalità tiroidea.

\section{Endoscopia}

Il gold standard per la conferma della diagnosi di $\mathrm{CD}$ è l'ileo-colonscopia con biopsie multiple. Le caratteristiche endoscopiche tipiche sono l'infiammazione segmentaria e le ulcere serpiginose.

Poichè la guarigione mucosale è oggi un importante obiettivo terapeutico, la colonscopia ha assunto un ruolo importante anche nel monitoraggio della malattia.

\section{Istologia}

Le caratteristiche microscopiche tipiche della malattia di Crohn sono l'infiammazione focale cronica, la distorsione criptica focale e la presenza di granulomi. ${ }^{45}$

\section{Altri esami strumentali}

Le tecniche di Imaging sono complementari alla valutazione endoscopica.

La risonanza magnetica delle vie digestive, la TC e l'ecografia con lo studio delle anse intestinali hanno una elevata accuratezza nel diagnosticare le complicanze della CD come gli ascessi, le fistole e le stenosi del piccolo intestino permettendo di differenziarle tra infiammatorie e fibrotiche.

L'Ecografia (US) è una tecnica di imaging non invasiva, ben tollerata, priva di radiazioni che ha buona 
efficacia soprattutto nello studio dell'ileo terminale e del colon, mentre il digiuno, l'ileo prossimale e il retto sono difficilmente valutabili. La US può essere inoltre utilizzata per guidare le procedure interventistiche come il drenaggio di ascessi. Il limite della tecnica è la stretta dipendenza dall'esperienza dell'operatore.

La TC dell'addome e della pelvi per valutare l'intestino tenue e il colon richiede la distensione del lume, mediante la somministrazione di un mezzo di contrasto orale oltre che endovenoso. La tecnica è spesso utilizzata per guidare le procedure interventistiche. Il limite principale è l'esposizione alle radiazioni.

La risonanza magnetica delle vie digestive ha un'accuratezza diagnostica simile alla TC, ma ha il vantaggio di non esporre il paziente a radiazioni ionizzanti.

La RM della pelvi è la tecnica diagnostica di scelta per la valutazione della malattia perianale. Il limite della tecnica è la disponibilità e il costo più elevato.

La radiografia dell'addome è utile nei casi di emergenza come nel sospetto di perforazione o di sub occlusione intestinale. ${ }^{78}$

La VCE è da poco diventato uno strumento complementare per indagare il piccolo intestino nei pazienti con sospetta o accertata CD. È una tecnica minimamente invasiva e ben tollerata con una resa diagnostica elevata. ${ }^{79}$

\section{Classificazioni della CD}

$\mathrm{La} C \mathrm{C}$ è estremamente eterogenea, viene pertanto classificata pertanto sulla base del fenotipo, dell'attività della malattia e della risposta alla terapia.

\section{Classificazione sulla base del fenotipo}

La classificazione di Montreal suddivide la malattia in base all'età del paziente alla diagnosi, alla localizzazione e al comportamento della CD (Figura 7).

\section{Classificazione dell'attività di malattia}

L'attività di malattia è valutata sulla base della clinica, degli esami di laboratorio, dell'endoscopia e delle altre tecniche di imaging.

La remissione clinica è stata tradizionalmente utilizzata come target terapeutico, anche se i sintomi possono dipendere da altre cause e hanno una scarsa correlazione con l'attività endoscopica di malattia. ${ }^{80}$

Nelle linee guida ECCO l'attività di malattia è suddivisa arbitrariamente in lieve, moderata e grave sulla base del punteggio CDAI.

Un punteggio CDAI minore di 150 identifica la remissione clinica, mentre la risposta è definita come una riduzione del $\mathrm{CDAI} \geq 100$ punti.

L'endoscopia rimane il gold standard per la valutazione dell'attività della malattia; i limiti della tecnica sono l'invasività, la ridotta disponibilità e il costo. I punteggi endoscopici più utilizzati nei trial clinici sono il CDEIS e il SES-CD. ${ }^{81}$

Gli indici di infiammazione (la proteina $\mathrm{C}$ reattiva, la calprotectina fecale e la lattoferrina) sono uno strumento diagnostico utile per valutare l'attività di malattia. ${ }^{82}$

\section{Classificazioni sulla base della risposta alla terapia}

La CD può essere classificata sulla base della risposta alla terapia come steroido-dipendente steroido-refrattaria e refrattaria alla terapia immunomodulatrice (vedi paragrafo Classificazione sulla risposta alla terapia).

\section{Storia naturale e fattori predittivi}

$\mathrm{La} C \mathrm{C}$ è caratterizzata daun alternanza di periodi di remissione e di recidiva. La localizzazione tende ad essere stabile, ma il comportamento della malattia cambia nel tempo. Gli studi dimostrano che il rischio complessivo, a 20 anni dalla diagnosi, di sviluppare una complicanza stenosante o penetrante è di circa il $50 \%{ }^{83,84}$

È importante identificare i pazienti che rischiano di sviluppare una malattia grave o complicata per utilizzare un approccio terapeutico più aggressivo. Sono stati identificati semplici fattori predittivi di peggiore outcome, ma la loro capacità discriminatoria individuale rimane limitata. ${ }^{85-87}$

I fattori predittivi di un outcome peggiore nei pazienti con CD sono:

- Caratteristiche del paziente: i) giovane età alla diagnosi; ii) fumatore; iii) pregressa resezione intestinale per CD.

- Estensione di malattia: i) malattia estesa del piccolo intestino $(>100 \mathrm{~cm})$; ii) malattia grave del tratto gastrointestinale superiore; iii) coinvolgimento del retto; iv) malattia perianale.

- Comportamento della malattia: i) stenosante e fistolizzante all'esordio; ii) necessità di terapia steroidea all'esordio.

- Caratteristiche endoscopiche: ulcere profonde.

\begin{tabular}{|ll|}
\hline & \multicolumn{1}{c|}{ Montreal } \\
\hline Age at Diagnosis & A1: less than 16 years. \\
& A2: between 17 and 40 years. \\
& A3: over 40 years. \\
\hline Location & L1: ileal. \\
& L2: colonic. \\
& L3: ileocolonic. \\
& L4: isolated upper digestive \\
\hline Behavior & B1: non stricturing, non penetrating. \\
& B2: stricturing. \\
& B3: penetrating. \\
& P: perianal disease. \\
\hline
\end{tabular}

Figura 7. Classificazione di Montreal. 


\section{Gestione della CD}

Dopo la diagnosi di CD, l'approccio diagnosticoterapeutico dovrebbe prendere in considerazione l'attività, la localizzazione, il comportamento e i fattori predittivi di un peggiore outcome della malattia.

La scelta del farmaco più appropriato dipende da diversi fattori: l'equilibrio tra l'efficacia e i potenziali effetti collaterali, la precedente risposta al trattamento e la presenza di complicanze (ascessi e malattia perianale) o di manifestazioni extraintestinali.

Gli obiettivi sono i seguenti: i) valutare l'estensione della malattia (ileo-cecale localizzata, estesa del piccolo intestino, colica) (vedi paragrafo Endoscopia); ii) valutare il comportamento della malattia (infiammatoria, stenosante o fistolizzante) e escludere la presenza di un ascesso (vedi paragrafo Altri esami strumentali); iii) valutare la gravità della malattia (vedi paragrafo Classificazioni della $C D$ ); iv) valutare la presenza di malattia perianale (vedi paragrafo Profilassi); v) stratificare il rischio con i fattori predittivi di peggiore outcome (vedi paragrafo Storia naturale e fattori predittivi); vi) valutare la presenza di maniestazioni extraintestinali (vedi paragrafo Manifestazioni extra-intestinali nelle malattie infiammatorie intestinali); vii) precedente risposta al trattamento (vedi paragrafo Anamnesi).

\section{Approccio step up vs treat to target strategy nella CD}

Il management tradizionale della $\mathrm{CD}$ prevede una progressiva intensificazione del trattamento sulla base della risposta clinica. Esistono due problemi in questo approccio, in primo luogo la scarsa correlazione che esiste tra l'attività endoscopica di malattia e i sintomi. In secondo luogo c'è il rischio di ritardare inutilmente la terapia più appropriata in pazienti con un elevato rischio di malattia complicata.

Pertanto la remissione clinica è importante per il benessere del paziente, ma non può essere considerata il solo target terapeutico.

La valutazione endoscopica con riscontro di guarigione mucosale è infatti considerata il bersaglio terapeutico preferito. In alcuni casi le tecniche di imaging come l'entero-RM o l'ecografia con studio delle anse intestinali possono essere un'alternativa all'endoscopia. ${ }^{80}$

\section{Gestione della CD}

\section{Gestione della CD Ileo-cecale}

L'approccio terapeutico dovrebbe essere basato sull'attività clinica ed endoscopica di malattia prendendo in considerazione anche i fattori predittivi di malattia più aggressiva.

La terapia di prima linea della CD ileo-cecale lievemente attiva (CDAI 151-220) è la Budesonide $9 \mathrm{mg}$ al giorno per uno o due mesi con un decalage di $3 \mathrm{mg}$ ogni mese (Figura 8).
In pazienti con malattia moderatamente attiva (CDAI 220-450) e un rischio elevato di decorso aggressivo o con malattia gravemente attiva (CDAI maggiore di 450) la scelta dovrebbe ricadere sugli steroidi sistemici come prima scelta.

In caso di fallimento della terapia corticosteroidea sistemica è indicato iniziare gli anti-TNF $\alpha$. In pazienti che sono refrattari alle precedenti terapie, il vedolizumab è una possibile alternativa.

In caso di fallimento alla terapia convenzionale l'approccio chirurgico deve essere preso in considerazione.

In caso di malattia stenosante con segni di attività è indicato iniziare la terapia con tiopurine, mentre in caso contrario è utile una valutazione chirurgica

\section{Gestione della CD dell'intestino tenue estesa $(>100 \mathrm{~cm})$}

La CD dell'intestino tenue estesa dovrebbe essere trattata in prima battuta con i corticosteroidi sistemici (Figura 9). La terapia con anti-TNF $\alpha$ dovrebbe essere presa in considerazione precocemente in particolare in pazienti con fattori predittivi di malattia aggressiva.

In caso di malattia stenosante con segni di attività è indicato iniziare la terapia con tiopurine, mentre in caso contrario è utile una valutazione chirurgica.

\section{Gestione della CD del colon}

La terapia di prima linea della CD del colon sono i corticosteroidi sistemici. In pazienti refrattari, dovrebbe essere considerata la terapia con anti-TNF $\alpha$. In caso di fallimento della terapia biologica tradizionale, le opzioni terapeutiche attualmente disponibili sono il Vedolizumab e la chirurgia (Figura 10).

\section{Management della remissione indotta dalla terapia medica}

In tutti i pazienti deve essere consigliato di smettere di fumare, in considerazione dei noti effetti negativi del fumo di sigaretta sul decorso della CD.

La scelta dei farmaci per la prevenzione della recidiva deve tenere conto: i) del decorso della malattia (la presentazione iniziale, la frequenza e la gravità delle riacutizzazioni); ii) dei fattori predittivi di peggiore outcome; iii) dell'estensione di malattia; iv) dell'efficacia dei trattamenti in precedenza utilizzati per l'induzione e il mantenimento della remissione.

I pazienti in remissione clinica devono essere valutati routinariamente con: i) proteina $\mathrm{C}$ reattiva e/o calprotectina fecale; ii) endoscopia; iii) tecniche imaging (ecografia con studio delle anse e Rm delle vie digestive).

\section{Mantenimento della remissione dopo la prima presentazione di malattia}

Nei pazienti con malattia ileocecale localizzata in 
remissione dopo un ciclo di corticosteroidi sistemici, la terapia di mantenimento va calibrata secondo il rischio di recidiva. Le possibilità terapeutiche sono nessun trattamento e le tiopurine.

Non ci sono prove che la mesalazina sia utile per mantenere la remissione, in quanto i risultati delle meta-analisi sono incoerenti.

Nei pazienti con malattia estesa, le tiopurine sono raccomandate per il mantenimento della remissione.

Nei pazienti con malattia aggressiva e fattori prognostici negativi, dovrebbe essere presa in considerazione l'inizio di anti-TNF $\alpha$.

\section{Management della recidiva}

In caso di recidiva, è indicato un'escalation della terapia di mantenimento per prevenire la progressione di malattia.

\section{CD steroido dipendente}

I pazienti steroido-dipendenti dovrebbero essere trattati con le tiopurine o gli anti-TNF $\alpha$. Va discussa inoltre la possibilità di intervento chirurgico.

\section{CD refrattaria alle tiopurine}

Nei pazienti che a dosaggio terapeutico di tiopurine hanno una recidiva di malattia è indicato iniziare la terapia anti-TNF e va valutata anche l'opzione chirurgica.

\section{Terapia di mantenimento in pazienti in remissione con biologici o tiopurine}

Non esistono a oggi dati chiari riguardo la durata della terapia in pazienti che raggiungono la remissione clinica ed endoscopica con farmaci biologici o con tiopurine.

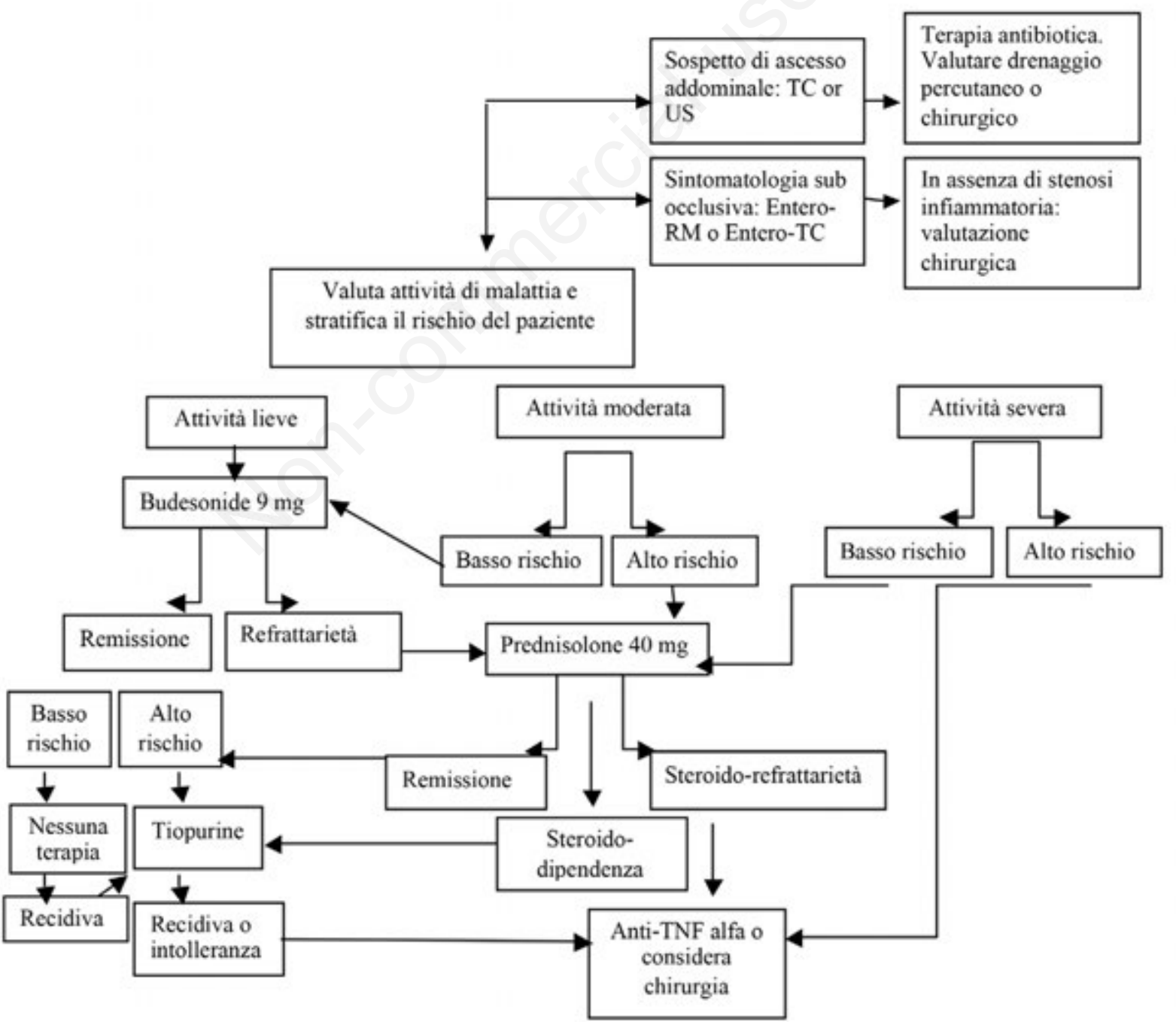

Figura 8. Gestione della CD Ileo-cecale. 
Se la remissione è stata raggiunta con l'utilizzo di biologici, le possibilità terapeutiche sono di passare gradualmente a tiopurine o continuare con anti-TNF $\alpha$ o Vedolizumab.

Nei pazienti in remissione con tiopurine, può essere indicata una sospensione dopo il raggiungimento di una deep remission per un numero soddisfacente di anni.

In caso di perdita di risposta ad un anti-TNF è utile eseguire un'ottimizzazione della terapia con un aumento della dose o un accorciamento dell'intervallo. Se l'ottimizzazione della terapia è inefficace, si raccomanda di passare a un altro anti-TNF, a Vedolizumab o considerare l'opzione chirurgica.

Quando è disponibile è consigliata la misurazione dei trough level dell'anti-TNF e degli anticorpi anti- farmaco per guidare l'ottimizzazione della terapia.

\section{Management della malattia perianale}

\section{Incidenza}

Circa un terzo dei pazienti con CD presenta malattia perianale. La presenza di malattia del colon e del retto rappresenta il maggiore fattore di rischio per lo sviluppo di fistole perianali. ${ }^{88-90}$

\section{Classificazione}

Le fistole perianali si classificano in: ${ }^{90}$

- Fistole semplici: sono basse, inter-sfincteriche o intrasfincteriche sotto la linea dentata con un singolo orifizio esterno.

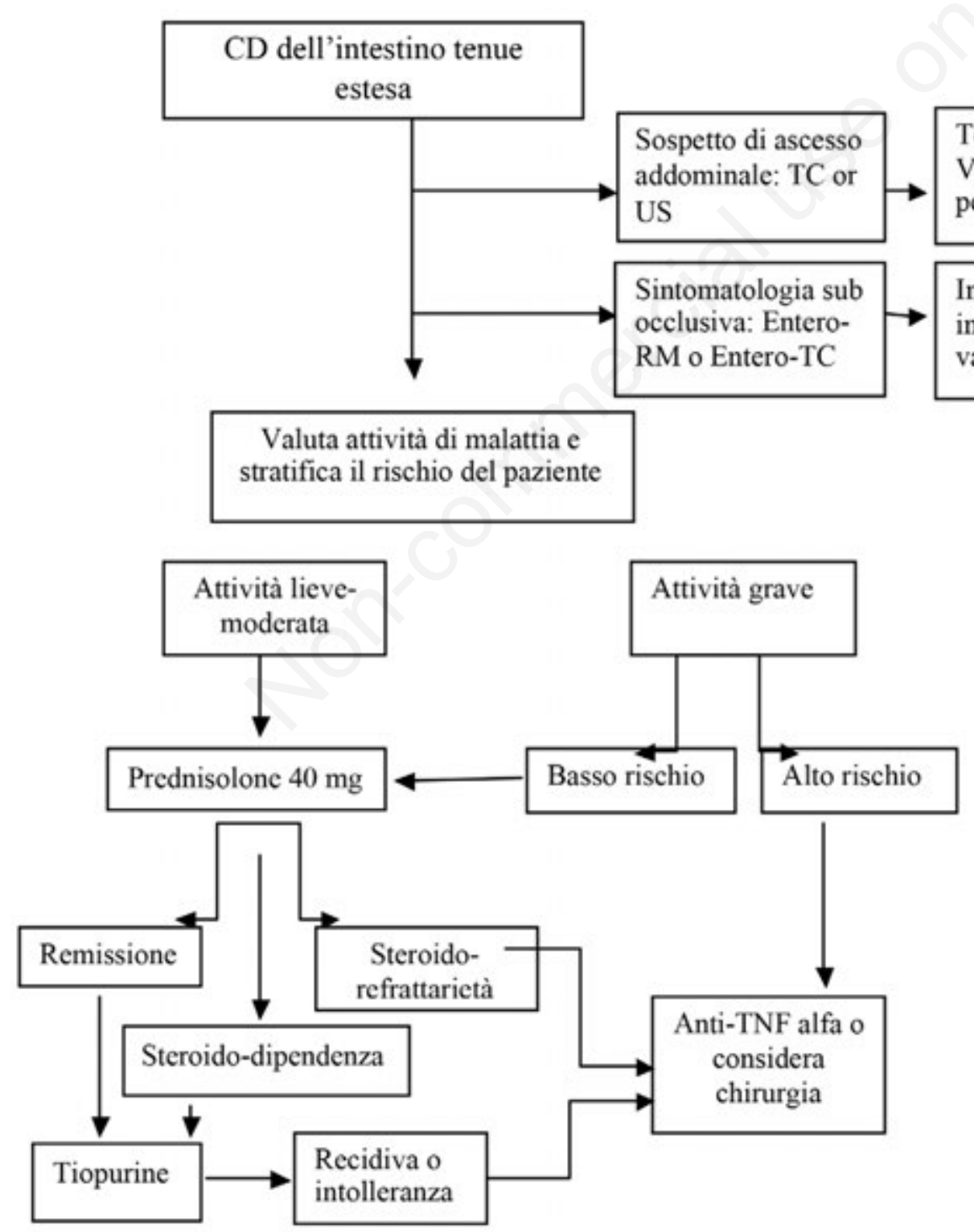

Figura 9. Gestione della CD dell'intestino tenue estesa.

Terapia antibiotica. Valutare drenaggio percutaneo o chirurgico

In assenza di stenosi infiammatoria: valutazione chirurgica 
- Fistole complesse: sono alte, sopra alla linea dentata (intersfinteriche, transfincteriche, extrasfincteriche, sovrasfincteriche), con molti orifizi esterni. Possono essere associate ad ascessi perianali, stenosi rettale, proctite e collegamento con la vescica o la vagina.

\section{Sintomi}

I sintomi principali sono il dolore perianale associato alla presenza di tumefazioni, la febbre (se sono presenti ascessi) e la fuoriuscita di pus, feci o sangue dagli orifizi fistolosi. Nei pazienti con malattia di lunga data può essere presente incontinenza fecale..$^{91}$

\section{Diagnosi}

La tecnica radiologica di riferimento per lo studio della malattia fistolizzante perianale è la RM della pelvi. In assenza di stenosi del retto l'Ecoendoscopia transanale può essere una buona alternativa. La specificità e la sensibilità di entrambe le modalità di imaging sono aumentata se combinate con l'examination under anesthesia (EUA), che è il gold standard per lo studio della malattia perianale fistolizzante.

Nei pazienti con malattia perianale è indicato eseguire una rettosigmoidoscopia, poichè la presenza di infiammazione del retto è importante dal punto di vista prognostico-terapeutico.

\section{Gestione della malattia perianale}

Gli aspetti principali da prendere in considerazione quando si pianifica una strategia per la gestione della malattia perianale fistolizzante sono: i) individuare l'origine della fistola e la sua anatomia; ii) identificare ed escludere la presenza di ascessi.
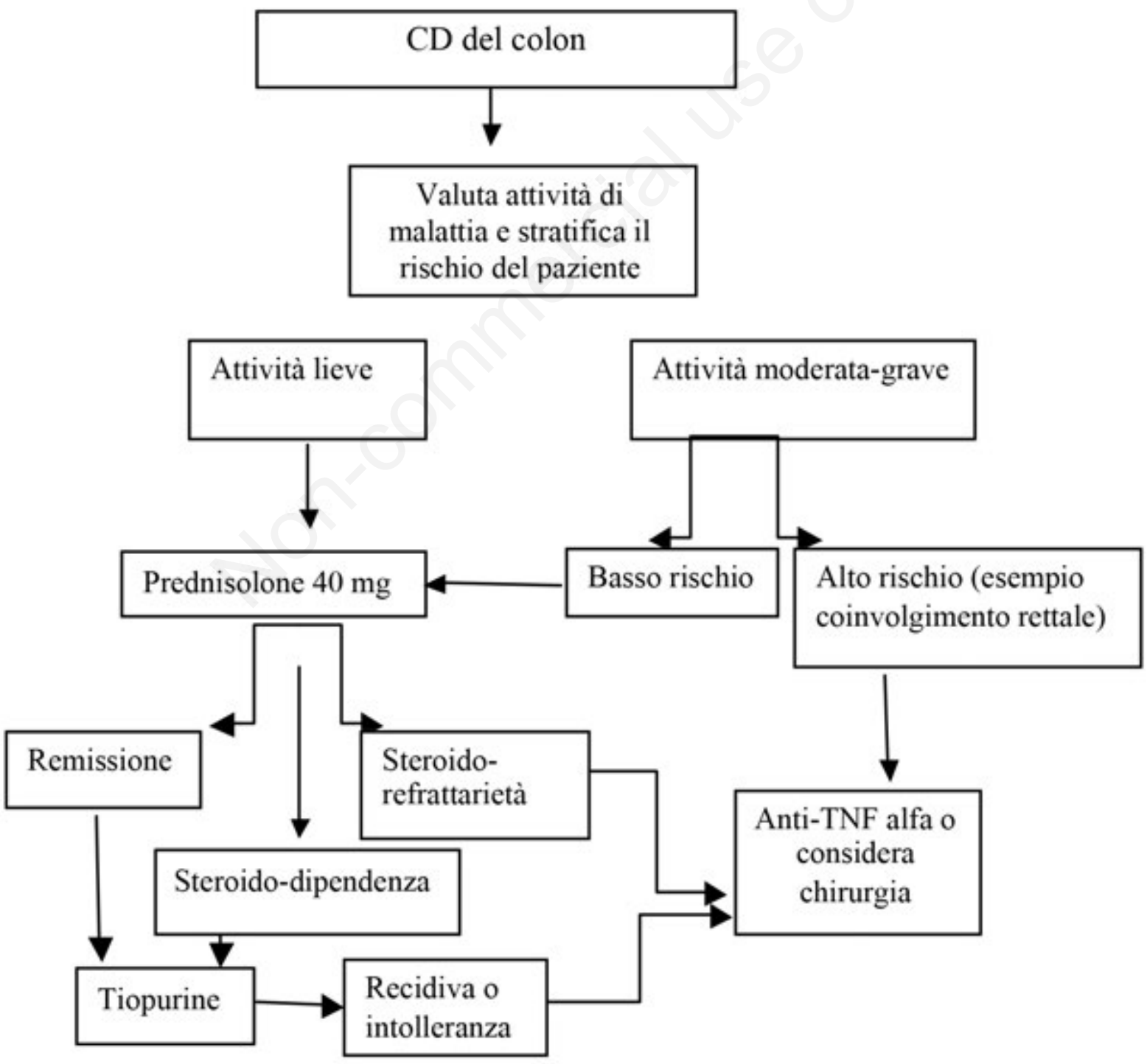

Figura 10. Gestione della colite di Crohn. 
- Fistola semplice: la fistola perianale semplice sintomatica deve essere inizialmente trattata con il posizionamento di un setone e con la terapia antibiotica (metronidazolo o ciprofloxacina). In caso di refrattarietà la terapia di seconda linea consigliata sono le tiopurine o gli anti-TNF.

- Malattia perianale complessa: dopo la bonifica chiruirgica della malattia perianale complessa e il posizionamento dei setoni la terapia di prima linea è il biologico (infliximab o adalimumab); l'associazione con la ciprofloxacina migliora l'outcome a breve termine.

In pazienti con malattia perianale refrattaria alla terapia medica, è indicato prendere in considerazione un approccio chirurgico con confezionamento di stomia ed eventuale proctectomia. ${ }^{92}$

Nuove prospettive terapeutiche per la malattia perianale

Negli ultimi anni vari studi stanno dimostrando l'efficacia delle cellule staminali mesenchimali, estratte dal tessuto adiposo sottocutaneo, nel trattamento della malattia perianale fistolizzante di Crohn. ${ }^{93}$

\section{La prevenzione della recidiva post-chirurgica}

La gestione della malattia di Crohn dopo l'intervento chirurgico richiede un approccio individualizzato che prenda in considerazione il rischio di recidiva e l'efficacia delle terapie attualmente disponibili.

Diagnosi: la recidiva postoperatoria è definita come la ricomparsa di lesioni endoscopiche, classificate con il punteggio di Rutgeerts, e/o dei sintomi, valutati sulla base del CDAI, dopo una resezione intestinale. ${ }^{94}$

Epidemiologia: circa il 70\% dei pazienti con malattia di Crohn vanno incontro nella loro vita ad una resezione intestinale. ${ }^{95,96}$

Il tasso di recidiva è strettamente legato all'endpoint utilizzato, infatti, la recidiva endoscopica si verifica più frequentemente di quella clinica.

Difatti entro 1 anno dall'intervento, la recidiva endoscopica si verifica nel $90 \%$ dei pazienti, quella clinica nel $30 \%$ e solo il 5\% dei pazienti sono sottoposti ad un ulteriore intervento chirurgico. ${ }^{97-99}$

Stratificazione del rischio: dopo una resezione chirurgica è importante stratificare il rischio di recidiva individuale, per poter pianificare un programma di sorveglianza e di attuare un eventuale trattamento di profilassi.

I fattori predittivi di recidiva post chirurgica precoce sono: i) fumo di sigaretta; ii) precedenti resezioni intestinali per $\mathrm{CD}$; iii) nessuna terapia di profilassi; iv) malattia fistolizzante al primo intervento chirurgico; v) localizzazione perianale; vi) presenza di granulomi e plessite mioenterica sul pezzo operatorio.

Profilassi: 1'alta incidenza della recidiva post-chirurgica nella $\mathrm{CD}$ richiede un rigoroso follow-up.
L'ileocolonscopia è il gold standard nella diagnosi della recidiva post-chirurgica ed è consiglia entro il primo anno dopo l'intervento chirurgico.

Altri strumenti meno invasivi per valutare l'attività di malattia sono la calprotectina fecale, la proteina $\mathrm{C}$ reattiva, l'ecografia con studio delle anse intestinali e l'entero-RM. ${ }^{100,101}$

In tutti i pazienti è necessario: i) consigliare di smettere di fumare; ii) stratificare il rischio di recidiva.

Basso rischio (non fumatore, prima resezione intestinale):

- Terapia: Mesalazina 4g/die, metronidazolo $1 \mathrm{~g} / \mathrm{die}$ 10 giorni/mese per 3 mesi

- Follow up: Laboratorio (calprotectina fecale, Ves e Pcr) ogni mese, valutazione clinica mensile con il punteggio CDAI, Ecografia con studio delle anse intestinali a 6 mesi e valutazione endoscopica ad un anno dall'intervento.

Rischio moderato (presenza di un fattore di rischio, ad esempio fumatore):

- Terapia: Mesalazina 4g die, metronidazolo $1 \mathrm{~g}$ die 10 giorni/mese per 6 mesi, se il paziente non riesce a smettere di fumare prendere in considerazione le tiopurine.

- Follow up: Laboratorio (calprotectina fecale, Ves e Pcr) ogni mese, valutazione clinica mensile con il punteggio CDAI, ecografia con studio delle anse intestinali a 3 mesi and endoscopia a 6 mesi.

Elevato rischio: (più di un fattore di rischio):

- Terapia: prendere in considerazione la terapia profilattica con le tiopurine o gli anti-tnf $\alpha$.

- Follow up: Laboratorio (calprotectina fecale, Ves e Pcr) ogni mese, Endoscopia a 6 mesi.

\section{Manifestazioni extra-intestinali nelle malattie infiammatorie intestinali}

Il $25-40 \%$ dei pazienti con IBD presentano manifestazioni extraintestinali, ${ }^{102}$ che coinvolgono più frequentemente l'apparato muscolo-scheletrico e la cute. Altre sedi interessate sono il sistema epatopancreatobiliare e l'occhio. ${ }^{103}$

\section{Manifestazioni muscolo-scheletrico}

\section{Spondiloartrtite}

L'artrite deve essere distinta dall'artralgia ed è caratterizzata classicamente da dolore, calore e tumefazione a livello di una o più articolazioni,che può causare una riduzione della mobilità

Le artriti enteropatiche rientrano all'interno del gruppo delle spondiloartriti sieronegative e sono distinte in forme assiali (spondilite anchilosante e sacroileite) e forme periferiche. Quest'ultime sono ulteriormente classificate in:

- Tipo I o pauciarticolare che interessa le grandi arti- 
colazioni (soprattutto il ginocchio) ed è correlata con l'attività di malattia della sottostante IBD.

- Tipo II o poliarticolare che interessa più frequentemente le articolazioni metacarpofalangee ed è indipendente dall'attività della malattia intestinale.

Le spondiloartrtiti si riscontrano nel $13 \%$ dei pazienti, le più frequenti sono le forme periferiche seguite dalla sacro ileite e infine dalla spondilite anchilosante.

La diagnosi si basa sulla presenza di dolore articolare di tipo infiammatorio e dal riscontro di alterazioni alle tecniche di imaging (Rm e Rx).

La gestione dei pazienti con IBD e spondiloartriti deve essere sempre concordata con il collega reumatologo. ${ }^{104}$

\section{Osteoporosi}

Ci sono molteplici fattori di rischio per l'osteroporosi nei pazienti con IBD, tra cui la prolungata terapia con corticosteroidi, la ridotta attività fisica, il riassorbimento osseo mediato dall'infiammazione, il malassorbimento di calcio e magnesio, la carenza di vitamina $\mathrm{D}$ e la riduzione dei livelli di albumina sierica. Il rischio di fratture nei pazienti con IBD è il $40 \%$ superiore a quello della popolazione generale e tende ad aumentare con l'età. ${ }^{105}$

L'esame di scelta è la DEXA che è indicata per qualsiasi paziente con IBD che abbia fatto un prolungato utilizzo di steroidi (definito come un trattamento consecutivo maggiore di 3 mesi o di più cicli) o nelle donne in menopausa o negli uomini sopra i 50 anni.

Nella prevenzione dell'osteoporosi è importante consigliare di smettere di fumare, di mantenere una adeguato apporto di calcio nella dieta $(1 \mathrm{~g} / \mathrm{die})$ e di fare attività fisica. Se è riscontrata osteopenia o osteoporosi deve essere presa in considerazione la supplementazione di vitamina D e i Bifosfonati. ${ }^{104}$

\section{Manifestazioni dermatologiche}

Le manifestazioni dermatologiche si riscontrano nel 2-34\% dei pazienti con IBD. Le forme più comuni sono l'Eritema nodoso e il Pioderma gangrenoso; ${ }^{106}$ meno frequenti sono la psoriasi, la stomatite aftosa orale, e la sindrome di Sweet.

Una valutazione dermatologica è obbligatoria in qualsiasi di questi disordini per aiutare a confermare la diagnosi e valutare una strategia terapeutica congiunta.

\section{Manifestazioni epato-pancreatobiliari}

Le manifestazioni epatopancreatobiliari delle IBD comprendono la colangite sclerosante primitiva, la litiasi biliare, la trombosi della vena porta e infine l'epatotossicità e la pancreatite indotte dai farmaci.

\section{Colangite sclerosante primitiva}

È una patologia cronica di origine sconosciuta ca- ratterizzata dalla presenza di infiammazione, stenosi e fibrosi delle vie biliari intra ed extra-epatiche di calibro medio-grande. ${ }^{107}$

La colangite sclerosante primitiva (PSC) ha uno stretto rapporto con le IBD; si calcola che il $75 \%$ dei pazienti con PSC ha la UC e il 5-10\% ha la CD. Al contrario solo il 5\% dei malati di UC (in misura maggiore se è interessato tutto il colon) e il $2 \%$ dei pazienti con CD sviluppa una colangite sclerosante primitiva.

La PSC è diagnosticata più frequentemente tra i 30 e i 59 anni con una prevalenza negli uomini (rapporto 2:1). L'esordio di malattia può essere insidioso, pertanto la patologia deve essere sospettata sempre nei pazienti con IBD che presentano ittero e un rialzo agli esami ematici di fosfatasi alcalina e gamma-GT con transaminasi nella norma. La sierologia può essere utile per la diagnosi, si calcola che il $33 \%$ dei pazienti ha una positività per ANA e l' $80 \%$ per ANCA. L'esame diagnostico di scelta è la Colangio-RM. Si ricorda infine che la PSC aumenta il rischio sia di colangocarcinoma che di cancro colo-rettale anche in pazienti senza una diagnosi di IBD. ${ }^{103}$

\section{Litiasi biliare}

La litiasi biliare è molto comune nei pazienti con IBD, in particolare nel CD con coinvolgimento ileale. La causa sembrerebbe essere un'interruzione del circolo entero-epatico con alterato riassorbimento dei sali biliari. ${ }^{108}$

\section{Manifestazioni oculari}

Le manifestazioni oculari accadono nel 0,3-5\% di tutti i pazienti con IBD. ${ }^{109} \mathrm{La}$ forma più frequente e è l'episclerite, meno comuni sono la sclerite e l'uveite. Nel sospetto di coinvolgimento oculare è necessaria una valutazione oftalmologica per la diagnosi e la gestione congiunta della patologia.

\section{Prevenzione del cancro nelle IBD}

I pazienti affetti da IBD sono ad aumentato rischio di sviluppare il cancro del colon-retto, che, nel caso della colite ulcerosa, varia con l'estensione e la durata della malattia, con la storia familiare di CRC, e con l'eventuale presenza di colangite sclerosante primitiva.

La sorveglianza endoscopica deve essere programmata in maniera individualizzata sulla base dei fattori di rischio del paziente.

La proctocolectomia elimina il rischio di CRC, ma non quella del cancro anale o il cancro sulla cuffia rettale o sulla pouch ileo-anale nei pazienti che sono stati sottoposti a IPAA.

Nei pazienti con CD, sono segnalati casi di adenocarcinoma sui tramiti fistolosi perianali o enterocutanei. I fattori di rischio principali sono il sesso 
femminile e la presenza di tramiti fistolosi cronici persistenti. È indicato pertanto un regolare follow-up nei pazienti con fistole perianali persistenti croniche, soprattutto quando la sintomatologia tende a cambiare, come ad esempio in caso di comparsa di dolore. ${ }^{110}$

\section{Bibliografia}

1. Daniel J. Mulder, Angela J. Noble, Christopher J. Justinich, Jacalyn M. Duffin; A tale of two diseases: The history of inflammatory bowel disease. J Crohns Colitis 2014; 8 (5): 341-348. doi: 10.1016/j.crohns.2013. 09.009

2. M. Campieri, G.A. Lanfranchi, G. Bazzocchi, G. Franzin, C. Brignola, A. Battocchia, F. Sarti, G. Labo, P.R. Dal Monte, Treatment Of Ulcerative Colitis With High-Dose 5-Aminosalicylic Acid Enemas, The Lancet, Volume 318, Issue 8241, 1981, Pages 270-271, ISSN 0140-6736, http://dx.doi.org/10.1016/S01406736(81)90523-7.

3. Natalie A. Molodecky, Ing Shian Soon, Doreen M. Rabi, William A. Ghali, Mollie Ferris, Greg Chernoff, Eric I. Benchimol, Remo Panaccione, Subrata Ghosh, Herman W. Barkema, Gilaad G. Kaplan, Increasing Incidence and Prevalence of the Inflammatory Bowel Diseases With Time, Based on Systematic Review, Gastroenterology, Volume 142, Issue 1, January 2012, Pages 46-54.e42, ISSN 0016-5085, http://dx.doi.org/10. 1053/j.gastro.2011.10.001

4. Hammer T, Nielsen KR, Munkholm P, Burisch J, Lynge E. The Faroese IBD Study: Incidence of Inflammatory Bowel Diseases Across 54 Years of Population-based Data. Journal of Crohn's \& Colitis. 2016;10(8):934942. doi:10.1093/ecco-jcc/jjw050.

5. J Burisch et al. East-West gradient in the incidence of inflammatory bowel disease in Europe: the ECCO-EpiCom inception cohort. Gut. 2014 Apr;63(4):588-97. doi: 10.1136/gutjnl-2013-304636.

6. Molodecky NA, Kaplan GG. Environmental Risk Factors for Inflammatory Bowel Disease. Gastroenterology \& Hepatology. 2010;6(5):339-346.

7. Jacques Cosnes, Corinne Gower-Rousseau, Philippe Seksik, Antoine Cortot, Epidemiology and Natural History of Inflammatory Bowel Diseases, Gastroenterology, Volume 140, Issue 6, May 2011, Pages 1785-1794.e4, ISSN 0016-5085, http://dx.doi.org/10. 1053/j.gastro.2011.01.055.

8. Jess T, Gamborg M, Munkholm P, Sorensen T. Overall and Cause-Specific Mortality in Ulcerative Colitis: Meta-analysis of Population-Based Inception Cohort Studies. Am J Gastroenterol. 2007;102(3):609-617

9. Canavan C, Abrams KR, Mayberry JF. Meta-analysis: mortality in Crohn's Disease. Aliment Pharmacol Ther. 2007 Apr 15;25(8):861-70

10. Harries AD, Baird A, Rhodes J. Non smoking: a feature of ulcerative colitis. BMJ. 1982;284(6317):706.

11. Mitchell SA, Thyssen M, Orchard TR, Jewell DP, Fleming KA, Chapman RW. Cigarette smoking, appendectomy, and tonsillectomy as risk factors for the development of primary sclerosing cholangitis: a case control study. Gut. 2002;51(4):567-573.
12. Loftus, EV Jr. Clinical epidemiology of inflammatory bowel disease: Incidence, prevalence, and environmental influences. Gastroenterology. 2004 May;126(6): 1504-17

13. Beaugerie L, Massot N, Carbonnel F, Cattan S, Gendre JP, Cosnes J. Impact of cessation of smoking on the course of ulcerative colitis. Am J Gastroenterology Jul;96(7):2113-6

14. To N,Gracie DJ, Ford AC. Systematic review with meta-analysis: the adverse effects of tobacco smoking on the natural history of Crohn's disease. Aliment Pharmacol Ther. 2016 Mar;43(5):549-61

15. Jones DT, Osterman MT, Bewtra M, Lewis JD. Passive Smoking and Inflammatory Bowel Disease: A Metaanalysis. The American journal of gastroenterology. 2008;103(9):2382-2393.

16. Rutgeerts P, D'Haens G, Hiele M, Geboes K, Vantrappen G. Appendectomy protects against ulcerative colitis. Gastroenterology. 1994 May;106(5):1251-3.

17. Parian A, Limketkai B, Koh J, Brant SR, Bitton A, Cho $\mathrm{JH}$, et al. Appendectomy does not decrease the risk of future colectomy in UC: results from a large cohort and metanalysis. Gut. 2016 Apr 13

18. Lee H-S, Park SH, Yang S-K, Kim S-O, Soh JS, Lee S, Bae JH, Lee HJ, Yang D-H, Kim KJ, Ye BD, Byeon JS, Myung S-J and Kim J-H. (2015), Appendectomy and the clinical course of ulcerative colitis: A retrospective cohort study and a nested case-control study from Korea. J Gastroenterol Hepatol, 30: 470-477,

19. Kaplan GG, Jackson T, Sands BE, Frisch M, Andersson RE, Korzenik J. The risk of developing Crohn's disease after an appendectomy: a meta-analysis. Am J Gastroenterol. 2008 Nov;103(11):2925-31.

20. Riegler G, Caserta L, Esposito I, De Filippo FR, Bossa F, Esposito P, Russo MI, Carratù Worse clinical course of disease in Crohn's patients with previous appendectomy. REur J Gastroenterol Hepatol. 2005 Jun;17(6): 623-7.

21. Koutroubakis IE, Vlachonikolis IG, Kouroumalis EA.The role of the appendix and appendectomy in the pathogenesis of ulcerative colitis: a critical review. Inflamm Bowel Dis 2002 Jul;8(4):277-86

22. Siew $\mathrm{C} \mathrm{Ng}$, Geographical variability and enviromental risk factors in inflamatory bowel disease Gut 2012;62:630-649

23. D.K Bonen, J.H Cho The genetics of inflammatory bowel disease Gastroenterology, 124 (2003), pp. 521536

24. H Yang, C McElree, M.P Roth, et al. Familial empirical risks for inflammatory bowel disease: differences between Jews and non-Jews Gut, 34 (1993), pp. 517-524

25. Roma et al, Inflamatory bowel disease in children: the role of a positive family history E J Gastro, 2010 Jun;22(6):710-5

26. Cho JH, Weaver CT The genetics of inflammatory bowel disease. Gastroenterology. 2007 Oct; 133(4): 1327-39

27. Jostins L, Ripke S, Weersma RK, et al. "Host-microbe interactions have shaped the genetic architecture of inflammatory bowel disease." Nature. 2012;491:119-124

28. Ogura, Y; Bonen, DK; Inohara, N; Nicolae, DL; Chen, FF; Ramos, R; Britton, H; Moran, T; Karaliuskas, R; Duerr, RH; Achkar, JP; Brant, SR; Bayless, TM; 
Kirschner, BS; Hanauer, SB; Nunez, G; Cho, JH. (2001) "A frameshift mutation in NOD2 associated with susceptibility to Crohn's disease." Nature 411 (6837): 603-606.

29. Xavier R;,Podolsky DK "Unravelling the pathogenesis of inflammatory bowel disease. "Nature 448, 427-434 (26 July 2007)

30. Kucharzik T, Maaser C, Lungering A et al. "Recent understanding of IBD pathogenesis: implications for future therapies." Inflamm Bowel Dis. 2006 Nov;12(11): 1068-83

31. Barnich N, Carvalho FA, Glasser A-L, et al. CEACAM6 acts as a receptor for adherent-invasive E. coli, supporting ileal mucosa colonization in Crohn disease .Journal of Clinical Investigation. 2007;117(6):15661574.

32. De Filippo C, Cavalieri D, Di Paola M, et al. . Impact of diet in shaping gut microbiota revealed by a comparative study in children from Europe and rural Africa. Proc Natl Acad Sci U S A. 2010;107:14691-14696

33. Maslowski KM, Vieira AT, Ng A, et al. . Regulation of inflammatory responses by gut microbiota and chemoattractant receptor GPR43. Nature. 2009;461: $1282-1286$

34. Hou JK, Abraham B, El-Serag H. Dietary intake and risk of developing inflammatory bowel disease: a systematic review of the literature. Am J Gastroenterol. 2011;106:563-573

35. Senguta R., Altermann E, Anderson RC, Mc Nabb WC... The role of cell surface architecture of lacobacilli in the host-microbe interactions in the gastrointestinal tract. Mediators Inflamm 2013;2013: 237921

36. Hardy H, Harris J, Lyon E, Beal J Probiotics, prebiotico and imunomodulation of the gut mucosal defences homeostasis and immunopathology. Nutrients 2013Jun; 5(6): 1869-1912

37. Gionchetti P, Rizzello F, Helwig U, Venturi A, Lammers KM, Brigidi P, Vitali B, Poggioli G, Miglioli M, Campieri M. Prophylaxis of pouchitis onset with prebiotico therapy: a double blind, placebo controller trial. Gastroenterology 2003

38. Hold GL, Smith M, Grange C, Watt ER, El-Omar EM, Mukhopadhya I. Role of the gut microbiota in inflammatory bowel disease pathogenesis: What have we learnt in the past 10 years? World Journal of Gastroenterology : WJG. 2014;20(5):1192-1210.

39. Torres, Joana, et al. "Crohn's disease." The Lancet (2016)

40. Abreu MT. Toll-like receptor signalling in the intestinal epithelium: how bacterial recognition shapes intestinal function. Nat Rev Immunol. 2010;10:131-144

41. Danese S, Fiocchi C. Ulcerative Colitis. New Engl J Med 2011Nov 3;365(18):1713-25

42. Kornbluth A, Sachar DB; Practice Parameters Committee of the ... Ulcerative colitis practice guidelines in adults: American College Of Gastroenterology, Practice Parameters Committee. Am J Gastroenterol. 2010 Mar;105(3):501-23; quiz 524

43. Marchioni Beery R, Kane S. Current approaches to the management of new-onset ulcerative colitis. Clinical and Experimental Gastroenterology. 2014;7:111-132.

44. Diagnass A. et al, Second European evidence-based consensus on the diagnosis and management of ulcerative colitis Part 1: Definitions and diagnosis, Journal of Crohn's and Colitis, Volume 6, Issue 10, December 2012, Pages 965-990

45. F. Magro et al; European consensus on the histopathology of inflammatory bowel disease. J Crohns Colitis 2013; 7 (10): 827-851.

46. Marchioni Beery, R., \& Kane, S. (2014). Current approaches to the management of new-onset ulcerative colitis. Clinical and Experimental Gastroenterology, 7, 111-132.

47. Parente F, Molteni M, Marino B, Colli A, Ardizzone S, Greco S, Sampietro G, Gallus S, Bowel Ultrasound and Mucosal Healing in Ulcerative Colitis. Dig Dis 2009;27:285-290

48. Satsangi J, Silverberg MS, Vermiere S, Colombel JF. The Montreal Classification of the inflamatory disease: controversies, consensus and implications. Gut 2006; 55:749-53

49. D'Haens G, Sandborn WJ, Feagan BG, Goebes K, Hanauer SB, Irvine EJ, et al. A review of activity indices and efficacy end points for clinical trials of medical therapy in adults with ulcerative colitis. Gastroenterology 2007; 132:763-86

50. Rice-Oxaley JM, Truelove SC. Ulcerative Colitis course and prognosis. Lancet 1950; 255:663-6

51. Rutgeerts P, Sandborn WJ, Feagan BG, et al. Infliximab for induction and maintenance therapy for ulcerative colitis. N Eng J Med. 2005;353(23):2462-2476

52. Vermiere S, Van Assche G, Rutgeerts P. Classification of inflamatory bowel disease: the old and the new. Curr Opinion Gastroenterol 2012 28:321-326

53. Andus T, Kocjan A, Muser M, Baranovsky A, Mikhailova TL, Zvyagintseva TD, et al. Clinical trial: a novel high-dose $1 \mathrm{~g}$ mesalamine suppository (Salofalk) once daily is as efficacious as a 500-mg suppository thrice daily in active ulcerative proctitis. Inflammatory Bowel Diseases. 2010;16(11):1947-1956.

54. Lamet M, Ptak T, Dallaire C, Shah U, Grace M, Spenard J, et al. Efficacy and safety of mesalamine $1 \mathrm{~g}$ HS versus $500 \mathrm{mg}$ BID suppositories in mild to moderate ulcerative proctitis: a multicenter randomized study. Inflammatory Bowel Diseases. 2005;11(7): 625-630.

55. Gionchetti P, Rizzello F, Venturi A et al Comparisons of mesalazine suppositories in proctitis and distal proctosigmoiditis Aliment Pharmacol Ther 1997;11: 1053-7

56. Van Bodegraven, A., Boer, R., Lourens, J., Tuynman, H. and Sindram, J. (1996), Distribution of mesalazine enemas in active and quiescent ulcerative colitis.. Aliment Pharmacol Ther, 10: 327-332.

57. Marshall JK, Irvine EJ. Rectal corticosteroids versus alternative treatments in ulcerative colitis: a metanalysis. Gut 1997;40:775-81

58. Gionchetti P, Rizzello F, Venturi A et al Comparison of oral with rectal meslazine in the treatment of ulcerative proctitis. Dis Colon Rectum 1998; 41: 93-7

59. Marteau P, Probert CS, Lindgren S, Gassul M, Combined oral and enema treatment with pentasa (mesalazine) is superior to oral therapy alone in patients with extensive mild/moderate active ulcerative colitis: a randomised, double blind, placebo controlled study. Gut 2005; 54:960-965 
60. Kamm MA, Sandborn WJ, Gassull M, Schreiber S, Jackowski L, Butler T,Lyne A, Stephenson D, Palmen M, Joseph RE. Once-daily, high-concentration MMX mesalamine in active ulcerative colitis. Gastroenterology 2007 Jan;132(1):66-75

61. Sandborn, W. J., Kamm, M. A., Lichtestein, G. R., Lyne, A., Butler, T,Joseph, R. E.. MMX Multi Matrix System ${ }^{\circledR}$ mesalazine for the induction of remission in patients with mild-to-moderate ulcerative colitis: a combined analysis of two randomized, double-blind, placebo-controlled trials. Alimentary Pharmacology \& Therapeutics, 26: 205-215.

62. Danese S, Siegel A Review article: integrating budesonide-MMX into treatment algorithms for mild-tomoderate ulcerative colitis Alimentary Pharmacology and Therapeutics. 2014; 39: 1095-1103

63. Campieri M, Adamo S, Valpiani D, D'arienzo A, D'albasio G, Pitzalis $\mathrm{M}$ et al Oral beclomethasone dipropionate in the treatment of extensive and left-sided active ulcerative colitis: a multicenter randomised study. Aliment Pharmacol Ther 2003;17:1471-80

64. Regueiro M, Loftus EV, Jr, Steinhart AH, Cohen RD. Clinical guidelines for the management of left-sided ulcerative colitis and ulcerative proctitis: summary statement. Inflamm Bowel Dis. 2006;12(10):972-978

65. Baron JH, Connell AM, Kanaghinis TG, Lennard-Jones JE, Jones AF. Out-patient treatment of ulcerative colitis. Comparison between three doses of oral prednisone. $\mathrm{Br}$ Med J.1962;2(5302):441-443)

66. Kornbluth A, Sachar DB. Ulcerative colitis practice guidelines in adults: American College of Gastroenterology, Practice Parameters Committee. Am J Gastroenterol. 2010;105(3):501-523)

67. Bougen G, Roblin X, Bourreille A, Feier L, Filippi J, Nancey S, Bretagne JF, Flouriè B, Hebuterne X et al Infliximab for refractory ulcerative proctitis. Aliment Pharmacol Ther. 2010 Jun;311178-85

68. Feagan BG, Sandborn WJ, Lazar A, et al. Adalimumab therapy is associated with reduced risk of hospitalization in patients with ulcerative colitis. Gastroenterology. 2014;146(1):110-118

69. Sandborn WJ, Feagan BG, Marano C, et al. Subcutaneous golimumab induces clinical response and remission in patients with moderate-to-severe ulcerative colitis. Gastroenterology. 2014;146(1):85-95

70. Khanna R, Zou G, Stitt L, Feagan BG, Sandborn WJ, Rutgeerts P, McDonald ... Lasch K. Effects of vedolizumab on health-related quality of life in patients withulcerative colitis: results from the randomised GEMINI 1 trial. Aliment Pharmacol Ther. 2017 Jan;45(2):264-275

71. Chande N. Prevention of venous thromboembolism in hospitalized patients with inflammatory bowel disease.Inflamm Bowl Dis. 2013;19(3):669-671

72. Marchioni Beery, Renée, and Sunanda Kane. "Current Approaches to the Management of New-Onset Ulcerative Colitis." Clinical and Experimental Gastroenterology 7 (2014): 111-132. PMC. Web. 18 Dec. 2016.

73. Turner D, Walsh CM, Steinhart AH, Griffiths AM. Response to corticosteroids in severe ulcerative colitis: a systematic review of the literature and a meta-regression. Clin Gastroenterol Hepatol.2007;5(1):103-110.

74. Kornbluth A, Sachar DB. Ulcerative colitis practice guidelines in adults: American College of Gastroenterology, Practice Parameters Committee. Am J Gastroenterol. 2010;105(3):501-523)

75. Berndtsson I, Oresland T., Quality of life before and after proctocolectomy and IPAA in patients with ulcerative proctocolitis-a prospective study. Colorectal Dis 2003;5:173-9

76. Wu H, Shen B. Pouchitis and pouch dysfunction. Gastroenterol Clin North Am 2009;38:651-68.) (Pardi DS, D'Haens, Shen B, Campbell S, Gionchetti P. Clinical guidelines for the management of pouchitis. Inflamm Bowel Dis 2009; 15:1424-31)

77. Gionchetti P et al 3rd European Evidence-based Consensus on the Diagnosis and Management of Crohn's Disease 2016: Part 2: Surgical Management and Special Situations. J Crohns Colitis 2016; 11 (2): 135-149. doi: 10.1093/ecco-jcc/jjw169

78. Panes J et al; Imaging techniques for assessment of inflammatory bowel disease: Joint ECCO and ESGAR evidence-based consensus guidelines. J Crohns Colitis 2013; 7 (7): 556-585

79. Collins PD. Video capsule endoscopy in inflammatory bowel disease. World Journal of Gastrointestinal Endoscopy. 2016;8(14):477-488. doi:10.4253/wjge.v8.i14.477.

80. Bouguen G, Levesque BG, et al. Treat to Target: A Proposed New Paradigm for the Management of Crohn's Disease, Clinical Gastroenterology and Hepatology, Volume 13, Issue 6, June 2015, Pages 1042-1050.e2, ISSN 1542-3565.

81. Khanna R, Nelson SA, Feagan BG,D'Haens G, Sandborn WJ, Zou GY, MacDonald JK,Parker CE, Jairath $\mathrm{V}$, Levesque BG.Endoscopic scoring indices for evaluation of disease activity in Crohn's disease. Cochrane Database of Systematic Reviews 2016

82. Mosli $\mathrm{MH}$ et al " $\mathrm{C}$ rective protein, fecal calprotectin and stool lactoferrin for detection of endoscopic activity in symptomatic inflammatory bowel disease patients: a systematic review and meta-analysis" am $\mathrm{j}$ gastroenterology 2015

83. Peyrin-Biroulet L, Loftus EV Jr, Colombel JF, Sandborn WJ; The natural history of adult Crohn's disease in population-based cohorts. Am J Gastroenterol. 2010 Feb; 105(3):289-97

84. Thia KT, Sandborn WJ, Harmsen WS, Zinsmeister AR, Loftus EV. Risk Factors Associated With Progression to Intestinal Complications of Crohn's Disease in a Population-Based Cohort. Gastroenterology. 2010;139 (4):1147-1155.

85. Zallot C, Peyrin-Biroulet L, Clinical Risk Factors for Complicated Disease: How Reliable Are They? Dig Dis 2012;30(suppl 3):67-72

86. Allez M, Lemann M, Bonnet J, Cattan P, Jian R, Modigliani R. Long term outcome of patients with active Crohn's disease exhibiting extensive and deep ulcerations at colonoscopy. Am J Gastroenterol. 2002 Apr; 97(4):947-53

87. Riss $\mathrm{S}$ et al. Repeat intestinal resections increase the risk of recurrence of Crohn's disease. Dis Colon Rectum. 2013 Jul;56(7):881-7.

88. Hellers G, Bergstrand O, Ewerth S, Holmstrom B. Occurrence and outcome after primary treatment of anal fistulae in Crohn's disease. Gut. 1980;21:525-527 
89. Schwartz DA, Loftus EV, Tremaine WJ, Pannaccione R, Hamsen WS, Zinsmeister AR, Sandborn WJ. The natual history of fistulizing Crohn's disease in Olmsted County, Minnesota. Gastroenterology. 2002;122:875-880

90. Sandborn WJ, Fazio VW, Feagan BG, Hanauer SB . AGA technical review on perianal Crohn's diseasGastroenterology. 2003 Nov; 125(5):1508-30.

91. Marzo M, Felice C, Pugliese D, et al. Management of perianal fistulas in Crohn's disease: An up-to-date review. World Journal of Gastroenterology: WJG. 2015;21(5):1394-1403

92. Gionchetti et al. 3rd European Evidence-based Consensus on the Diagnosis and Management of Crohn's Disease 2016: Part 2: Surgical Management and Special Situations. J Crohns Colitis (2016) 11 (2): 135-149

93. García-Olmo D, García-Arranz M, Herreros D, Pascual I, Peiro C, Rodríguez-Montes JA. A phase I clinical trial of the treatment of Crohn's fistula by adipose mesenchymal stem cell transplantation. Dis Colon Rectum.2005;48:1416-1423

94. Fornaro, Rosario et al. Post-operative recurrence in Crohn's disease. Critical analysis of potential risk factors. An update. The Surgeon, Volume 13 , Issue 6 , $330-347$

95. Bernell O, Lapidus A, Hellers G. Risk factors for surgery and postoperative recurrence in Crohn's disease. Ann Surg 231 (2000), pp 38-45

96. Binder V, Hendriksen C, Kreiner S. Prognosis in Crohn's disease - based on results from a regional patient group from the county of Copenhagen. Gut, 1985 , $26(2): 146-50$.

97. Olaison G, Smedh K, Sjödahl R. Natural course of Crohn's disease after ileocolic resection: endoscopically visualised ileal ulcers preceding symptoms. Gut. 1992;33(3):331-335.

98. Rutgeerts P, Geboes K, Vantrappen G, Kerremans R, Coenegrachts JL, Coremans G. Natural history of recurrent Crohn's disease at the ileocolonic anastomosis after curative surgery. Gut, 25(1984), pp. 665-672

99. Rutgeerts P, Geboes K, Vantrappen G, Beyls J, Kerremans R, Hiele M. Predictability of the postoperative course of Crohn's disease. Gastroenterology, 99 (1990), pp. 956-963

100. Onali S, Calabrese E, Petruzziello C, Lolli E, Ascolani M, Ruffa A, Sica G, Rossi A, Chiaramonte C, Pallone
F, Biancone L. Post-operative recurrence of Crohn's disease: A prospective study at 5 years. Dig Liver Dis. 2016 May;48(5):489-94.

101. Garcia-Planella E; Mañosa M; Cabré E; Marín L; Gordillo J; Zabana Y; Boix J; Sáinz S; Domènech E. Fecal Calprotectin Levels Are Closely Correlated with the Absence of Relevant Mucosal Lesions in Postoperative Crohn's Disease. Inflamm Bowel Dis. 2016; 22(12):2879-2885

102. Bernstein CN, Blanchard JF, Rawsthorne P, Yu N. The prevalence of extraintestinal diseases in inflammatory bowel disease: a population-based study. Am J Gastroenterol. 2001;96:1116-1122

103. Levine JS, Burakoff R. Extraintestinal Manifestations of Inflammatory Bowel Disease. Gastroenterology \& Hepatology. 2011;7(4):235-241.

104. Harbord M, Annese V, Vavricka SR et al. The First European Evidence-based Consensus on Extra-intestinal Manifestations in Inflammatory Bowel Disease. J Crohns Colitis 2015; 10 (3): 239-254.

105. American Gastroenterological Association medical position statement: Guidelines on osteoporosis in gastrointestinal diseases, This document presents the official recommendations of the American Gastroenterological Association (AGA) Committee on Osteoporosis in Gastrointestinal Disease. It was approved by the Clinical Practice Committee on September 21, 2002, and by the AGA Governing Board on November 1, 2002. Gastroenterology, Volume 124, Issue 3, 791 - 79

106. Tavarela Veloso F. Review article: skin complications associated with inflammatory bowel disease. Aliment Pharmacol Ter. 2004;20(suppl 4):50-53

107. Lee YM, Kaplan MM. Primary sclerosing cholangitis. N Engl J Med. 1995;332:924-933

108. Lapidus A, Bångstad M, Aström M, Muhrbeck O. The prevalence of gallstone disease in a defined cohort of patients with Crohn's disease. Am J Gastroenterol. 1999;94:1261-1266.

109. Petrelli EA, McKinley M, Troncale FJ. Ocular manifestations of inflammatory bowel disease. Ann Ophthalmol. 1982;14:356-360

110. Annese V et al. European Evidence-based Consensus: Inflammatory Bowel Disease and Malignancies. J Crohns Colitis 2015; 9 (11): 945-965. 


\title{
La malattia celiaca nel terzo millennio: nuove prospettive su patogenesi, clinica, diagnosi e terapia
}

\author{
Giacomo Caio, Fiorella Giancola, Roberto De Giorgio, Umberto Volta \\ Dipartimento di Scienze Mediche e Chirurgiche (DIMEC), Centro Unificato di Ricerca Biomedica Applicata (C.R.B.A.) e \\ Dipartimento dell'Apparato Digerente, Università di Bologna e Policlinico S. Orsola-Malpighi di Bologna, Italia
}

\section{Introduzione}

La malattia celiaca (MC) è una patologia autoimmune caratterizzata da un peculiare profilo genetico ed anticorpale, associato alla presenza di specifiche lesioni a livello dell'intestino tenue scatenate da un agente ambientale, il glutine, introdotto con la dieta. ${ }^{1}$ Il glutine è un insieme di proteine alcool-solubili presenti in diversi cereali, fra cui grano, segale, orzo, farro e kamut. ${ }^{1}$ Negli ultimi anni abbiamo assistito a profondi cambiamenti della diagnosi, patogenesi e storia naturale di questa condizione. ${ }^{2} \mathrm{La} \mathrm{MC}$ è andata incontro ad una vera e propria metamorfosi, imponendosi all'attenzione del mondo scientifico e mediatico per il costante incremento delle diagnosi, effettuate sempre più frequentemente anche in età adulta o addirittura geriatrica. ${ }^{2}$ Questa epidemia è stata imputata in parte alla maggiore disponibilità di test di screening sempre più sensibili e specifici ed in parte ad un effettivo aumento dei casi di MC. ${ }^{2} \mathrm{Le}$ cause di tale effettivo incremento della $\mathrm{MC}$ sono ancora oggetto di studio e dibattito. Alcune teorie ritengono che la globalizzazione associata alla diffusione ubiquitaria di una dieta mediterranea spuria ed estremizzata con un consumo di elevatissime quantità di glutine (fino a $20 \mathrm{~g} / \mathrm{die}$ ), abbia sicuramente contribuito all'incremento della patologia. ${ }^{3,4}$ Accanto all'aumento della quantità di glutine, sembra possa avere avuto un ruolo anche la qualità dello stesso glutine. Infatti, l'introduzione di nuove varianti di

Corrispondente: Umberto Volta, Dipartimento di Scienze Mediche e Chirurgiche, Policlinico S. Orsola-Malpighi, via Massarenti 9, 40138 Bologna, Italia.

Tel.: +39.051.214.3558 - Fax: +39.051.34.58.64.

E-mail: umberto.volta@aosp.bo.it

Articolo pubblicato secondo la Creative Commons Attribution NonCommercial 4.0 License (CC BY-NC 4.0).

CCopyright G. Caio et al., 2017

Licensee PAGEPress, Italy

QUADERNI - Italian Journal of Medicine 2017; 5(7):98-114 grano, modificate geneticamente più per motivi tecnologici che nutrizionali, potrebbe aver contribuito ad un vertiginoso incremento del numero delle diagnosi negli ultimi anni. ${ }^{4,5}$ In questo articolo, basato su un approccio pratico e orientato alla gestione internistica della MC, ripercorreremo gli aspetti epidemiologici, clinici e diagnostico-terapeutici di tale patologia unitamente ad alcune semplici informazioni sulla sua patogenesi.

\section{Epidemiologia}

L'epidemiologia della MC è stata completamente ridisegnata negli ultimi decenni. Grazie all'identificazione di nuovi marcatori sierologici è stato possibile effettuare studi di screening su campioni di popolazione generale che hanno chiarito che la $\mathrm{MC}$ è una patologia molto frequente, con una prevalenza maggiore di un caso ogni 100 individui (Tabella 1) $\cdot{ }^{6-12}$ A livello mondiale sono presenti alcune nicchie etniche, come la Finlandia, in cui la $\mathrm{MC}$ è ancora più frequente avendo una prevalenza del $2,5 \% .{ }^{10}$ Anche in quelle aree in cui fino a qualche tempo fa la MC era considerata rarissima (ad esempio l'estremo Oriente), studi di case-finding hanno dimostrato che questa condizione sta emergendo. ${ }^{12}$ Nonostante il notevole incremento diagnostico registrato negli ultimi tempi, la $\mathrm{MC}$ è ancora ampiamente sotto-diagnosticata. A tutt'oggi, in Italia, in base ai dati aggiornati a febbraio 2016 del Ministero della Salute, vi sono solo 183.000 pazienti diagnosticati a fronte dei circa 600.000 attesi.

\section{Punti chiave}

- Prevalenza attesa della celiachia $\geq 1 \%$ nella popolazione generale.

- Incremento delle diagnosi di celiachia anche in estremo Oriente, area a lungo ritenuta priva di celiachia.

- Meno di un terzo dei celiaci diagnosticati (in Italia 183.000 diagnosi su 600.000 attese).

- Incremento delle diagnosi in Italia di circa il 10\% all'anno negli ultimi 5 anni. 


\section{Patogenesi}

Studi in vitro ed ex vivo hanno dimostrato che il glutine (e le sue frazioni costituite da prolamine e glutenine ad alto peso molecolare) svolge di per sé un'azione tossica/pro-infiammatoria mediata dall'attivazione del sistema immunitario nei confronti della mucosa dell'intestino tenue. È bene ricordare che questo effetto occorre non solo nel paziente celiaco, ma anche nel soggetto sano e ciò fa riflettere sul potenziale lesivo esercitato dal glutine. ${ }^{5}$ Un ruolo patogenetico centrale nella $\mathrm{MC}$ è certamente svolto dalle gliadine, proteine costituite da singole catene polipeptidiche di peso molecolare compreso fra 30 e $90 \mathrm{kD}$. Le gliadine si dividono in quattro frazioni di diverso peso molecolare $(\omega, \gamma, \beta$ ed $\alpha$ ) che, dotate secondo questo ordine di tossicità crescente (a causa di peculiari sequenze amminoacidiche ricche in prolina e glutammina), non sono riconosciute come self dal sistema immunitario del paziente con MC. ${ }^{13-15}$ Anche se il glutine è l'agente scatenante della $\mathrm{MC}$, esso, da solo, non è in grado di evocare la malattia senza la già menzionata predisposizione genetica dettata dai geni per l'HLA DQ2 e/o DQ8 situati sul braccio corto del cromosoma $6 .{ }^{16,17}$ Inoltre, alcuni fattori ambientali possono svolgere un ruolo fondamentale nello scatenamento della $\mathrm{MC}$, a cominciare dalle infezioni virali, batteriche e parassitarie. ${ }^{18,19}$ Spesso la MC si manifesta dopo che il paziente ha contratto un'infezione intestinale oppure in seguito ad uno stress particolarmente intenso o, in alcune pazienti, nel periodo puerperale dopo gravidanze del tutto regolari. Altri fattori ambientali coinvolti nel possibile sviluppo della MC comprendono il mancato allattamento al seno, l'età di svezzamento con glutine (e la relativa quantità di glutine introdotta in tale periodo), il tipo di parto (cesareo o naturale), il microbiota intestinale e l'uso di antibiotici nella primissima infanzia. ${ }^{20-27}$ Due recenti studi su bambini nati da genitori celiaci hanno dimostrato che una diversa epoca d'introduzione del glutine (precoce o tardiva) nella dieta e l'allattamento al seno materno non sono in grado, contrariamente a quanto ritenuto in passato, di svolgere un'azione protettiva sullo sviluppo della MC. ${ }^{28,29}$

La transglutaminasi tissutale (tTG) è il principale autoantigene della MC che innesca i meccanismi immunologici che portano all'atrofia dei villi. La tTG è un enzima calcio-dipendente citoplasmatico presente non solo nell'intestino tenue (principale organo bersaglio), ma anche in numerosi altri organi ed apparati, quali cute, tiroide, pancreas, fegato, articolazioni, sistema nervoso e sistema riproduttivo. ${ }^{30}$ Ciò fa sì che il processo immunologico, una volta innescato, possa propagarsi al di fuori dell'intestino tenue, facendo assumere alla MC le caratteristiche di una malattia sistemica. Sia l'immunità innata (tTG-indipendente) che quella adattativa (tTG-dipendente) svolgono un ruolo di primo piano nel determinismo del danno intestinale. ${ }^{31,32}$ La risposta innata si basa su una tossicità diretta della gliadina, ed in particolare del peptide 31-43, in grado di stimolare la sintesi di IL-15, d'indurre l'espressione di molecole di stress sugli enterociti e di attivare i linfociti intraepiteliali nella mucosa intestinale. L'azione diretta del peptide di gliadina sugli enterociti può anche aumentare la permeabilità intestinale attraverso un eccessivo rilascio di zonulina, una particolare proteina che induce il disassemblamento delle giunzioni serrate (o tight junctions). ${ }^{33}$ L'altra via responsabile del danno di mucosa è quella dell'immunità adattativa che attraverso l'azione del

Tabella 1. Screening sierologico per malattia celiaca dell'adulto (confermata con biopsia duodenale) nella popolazione generale.

\begin{tabular}{|c|c|c|c|c|c|}
\hline & $\begin{array}{l}\text { Test anticorpale } \\
\text { di primo livello }\end{array}$ & $\mathbf{N}^{\circ}$ Casi & Età & Paese & $\begin{array}{c}\text { Prevalenza } \\
\text { malattia celiaca }\end{array}$ \\
\hline $\begin{array}{l}\text { Corazza GR, et al. } \\
\text { Scand J Gastroenterol } 1997 \text { (ref. 6) }\end{array}$ & EmA & 2237 & $20-87$ & Italia & $0,18 \%$ \\
\hline $\begin{array}{l}\text { Ivarsson A et al. } \\
\text { J Intern Med } 1999 \text { (ref. 7) }\end{array}$ & EmA & 1894 & $25-74$ & Svezia & $0,53 \%$ \\
\hline $\begin{array}{l}\text { Riestra S et al. } \\
\text { Scand J Gastroenterol } 2000 \text { (ref. 8) }\end{array}$ & EmA & 1170 & $14-89$ & Spagna & $0,26 \%$ \\
\hline $\begin{array}{l}\text { Volta U et al. } \\
\text { Dig Dis Sci } 2001 \text { (ref. 9) }\end{array}$ & EmA & 3483 & $14-65$ & Italia & $0,57 \%$ \\
\hline $\begin{array}{l}\text { Mustalahti et al. } \\
\text { Ann Med } 2010 \text { (ref. 10) }\end{array}$ & $\begin{array}{l}\text { Anti-tTG } \\
\text { EmA }\end{array}$ & 6403 & $30-93$ & Finlandia & $2,5 \%$ \\
\hline $\begin{array}{l}\text { Rubio-Tapia A et al. } \\
\text { Am J Gastroenterol } 2012 \text { (ref. 11) }\end{array}$ & $\begin{array}{l}\text { Anti-tTG } \\
\text { EmA }\end{array}$ & 7798 & $23-66$ & USA & $0,71 \%$ \\
\hline $\begin{array}{l}\text { Singh P et al. } 2016 \\
\text { J Gastroenterol Hepatol (ref. 12) }\end{array}$ & $\begin{array}{l}\text { Anti-tTG } \\
\text { EmA }\end{array}$ & 43.955 & Non specificata & Asia & $0,5 \%$ \\
\hline
\end{tabular}


peptide di gliadina denominato 33-mer porta all'attivazione T-linfocitaria mediata dalla tTG. Il peptide subisce il processo di deamidazione da parte della tTG (con trasformazione di una molecola di glutammina in acido glutammico). Il nuovo peptide riconosciuto come non-self viene presentato dalle cellule dendritiche/macrofagi DQ2 e/o DQ8 positive ai linfociti T CD4+ con l'attivazione di una cascata di citochine responsabile dell'atrofia dei villi. Parallelamente si ha una stimolazione dei linfociti B con conseguente sintesi di anticorpi specifici contro il complesso tTG-peptide di gliadina. ${ }^{13,31}$

\section{Punti chiave}

- Coinvolgimento sia dell'immunità innata che adattativa.

- Transglutaminasi tissutale: principale autoantigene della celiachia.

- Deamidazione dei peptidi di gliadina da parte della transglutaminasi tissutale.

- Peptidi di gliadina deamidati presentati dai macrofagi DQ2 e DQ8 positivi ai linfociti T CD4+ con conseguente sintesi di citochine ed atrofia dei villi.

\section{Genetica}

La suscettibilità genetica all'enteropatia da glutine è confermata dall'elevata familiarità della malattia presente nel $4-17 \%$ dei familiari di primo grado di celiaci e dalla stretta associazione con gli antigeni del sistema di istocompatibilità (HLA), ${ }^{34-37}$ presenti nel braccio corto del cromosoma $6 .{ }^{16}$ Oltre il $90 \%$ dei pazienti con celiachia sono HLA-DQ2 positivi o presentano positività per metà eterodimero del DQ2 (DQA $1 * 0501$, DQB $1 * 0201$ ), mentre quasi tutti i celiaci DQ2 negativi (circa il 10\%) sono HLA-DQ8 positivi. Il test genetico non può peraltro essere considerato un test diagnostico di celiachia, dal momento che anche il $30-40 \%$ della popolazione generale sana è DQ2-DQ8 positiva. ${ }^{17,38}$ È altresì possibile sfruttare il suo elevato valore predittivo negativo per escludere la diagnosi. ${ }^{39,40}$ Recentemente mediante i cosiddetti genome wide association studies (GWAS) sono stati identificati più di 40 geni non-HLA che potrebbero avere un ruolo nello sviluppo della MC. ${ }^{41}$

La determinazione dell'HLA trova indicazione in caso di dubbio diagnostico (ossia, discrepanza fra sierologia e biopsia) e nei familiari di $1^{\circ}$ grado degli affetti (genitori, figli e fratelli) per decidere, in questo secondo caso, se continuare il follow-up anticorpale in caso di sierologia negativa. ${ }^{42,43}$

\section{Punti chiave}

- Elevata familiarità della celiachia, presente nel 4$17 \%$ dei familiari di $1^{\circ}$ grado di celiaci.
- Stretta associazione con HLA-DQ2 e -DQ8, rispettivamente positivi nel $90 \%$ e $10 \%$ dei celiaci.

- Più di 40 geni non-HLA, identificati dai GWAS (genome wide association studies) come possibili cofattori della celiachia.

- Utilità del test genetico nei casi con discrepanza fra sierologia ed istologia e nei familiari di $1^{\circ}$ grado per verificare la predisposizione a celiachia.

\section{Presentazione clinica}

La MC colpisce più frequentemente il sesso femminile con un rapporto femmine/maschi di circa 2:1., ${ }^{1,2}$ Può esordire a qualsiasi età della vita, dalla prima infanzia all'età geriatrica, con due picchi d'insorgenza: poco dopo lo svezzamento con glutine entro i primi 2 anni di età e verso la seconda-terza decade di vita. La presentazione clinica della MC può essere ingannevole, dal momento che i sintomi variano notevolmente da paziente a paziente e ciò fa sì che la diagnosi rappresenti spesso una vera e propria sfida per i medici. $^{44,45}$

La classificazione di Oslo per le varie forme cliniche di MC individua le seguenti presentazioni cliniche: classica; non classica, subclinica, potenziale e refrattaria ${ }^{46}$ Nella forma classica è presente la tipica sindrome da malassorbimento con diarrea cronica, perdita di peso e marcata astenia. Sebbene questo esordio sia sempre meno frequente ai nostri giorni (presente in meno del $30 \%$ dei casi) grazie ad una diagnosi sempre più precoce, alcuni pazienti possono ancora giungere alla nostra osservazione con segni di severo malassorbimento come cachessia, atrofia muscolare, marcata ipoalbuminemia, turbe elettrolitiche e metaboliche. Nella forma non classica, invece, le manifestazioni gastrointestinali, se presenti, si caratterizzano per una stipsi (presente circa in un terzo dei celiaci all'esordio) o per un alvo alterno (del tutto simile alla sindrome dell'intestino irritabile) o per turbe dispeptiche con nausea e talvolta vomito.

Le manifestazioni extraintestinali, presenti sia nella forma classica che non classica, sono frequenti. Esse comprendono l'anemia microcitica sideropenica riscontrabile fino al $40 \%$ dei casi (per mancato assorbimento di ferro e per lo stato infiammatorio cronico $)^{47} \mathrm{o}$, più raramente, una anemia macrocitica per carenza di acido folico e/o di vitamina B12; alterazioni della densità minerale ossea (presenti in circa il 70\% dei pazienti alla diagnosi), sotto forma di osteopenia o di osteoporosi, per malassorbimento di calcio e vitamina D3. ${ }^{48}$ Accanto a queste manifestazioni si riscontrano anche iposomia (particolarmente importante nelle forme pediatriche), alterazioni dello smalto dentale, stomatite aftosa (presente fino al $20 \%$ dei celiaci a dieta libera), ${ }^{49}$ ipertransaminasemia (riscontrata nel $40-50 \%$ dei celiaci non trattati ed espressione della co- 
siddetta epatite celiaca legata in gran parte ad antigeni alimentari e batterici che giungono al fegato per l'aumentata permeabilità intestinale). ${ }^{50,51}$ È presente inoltre una vasta gamma di sintomi di pertinenza neurologica quali cefalea, parestesie, nevrassiti, ansia e depressione. Nel quadro clinico di presentazione possono essere incluse anche le alterazioni della sfera riproduttiva, caratterizzate da menarca tardivo, amenorrea, aborti ricorrenti, parti prematuri, menopausa precoce, alterazioni del numero e della motilità degli spermatozoi (tutte alterazioni reversibili con dieta aglutinata)..$^{2,52-56}$

La forma subclinica comprende pazienti che presentano sintomi o segni sotto la soglia d'identificazione clinica e spesso rilevabili solo a posteriori dopo l'inizio della dieta aglutinata. Esempio classico di questa forma sono i casi identificati in seguito a screening anticorpale nei familiari di celiaci e nell'ambito degli screening su popolazione generale. ${ }^{2,46}$ La prevalenza dei vari fenotipi clinici di MC osservata nella casistica del Centro di Riferimento per la Diagnosi della Malattia Celiaca del Policlinico S. Orsola-Malpighi di Bologna, è riportata nella Figura 1.

La MC può associarsi a diverse patologie autoimmuni ed idiopatiche, fra cui la dermatite erpetiforme (definita la celiachia della cute per la presenza di un costante interessamento della mucosa intestinale), il diabete mellito tipo 1, la tiroidite di Hashimoto, il deficit selettivo di IgA, l'alopecia areata, il morbo di Ad- dison, le malattie del connettivo (in particolar modo la sindrome di Sjögren), le malattie cromosomiche (sindrome di Down, di Turner, di Williams), le malattie neurologiche (neuropatia periferica, epilessia con o senza calcificazioni occipitali, atassia cerebellare), la patologia autoimmune epatica (colangite biliare primitiva, epatite autoimmune, colangite sclerosante primitiva) e la cardiomiopatia dilatativa idiopatica (Tabella 2)., ${ }^{2,53,57-67}$ L'importanza di diagnosticare una

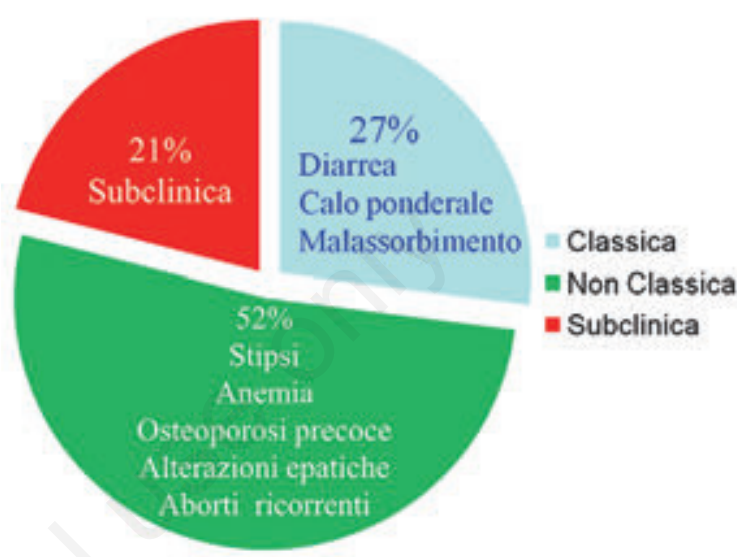

Figura 1. Prevalenza dei fenotipi clinici di malattia celiaca (MC) registrata presso il Centro di Riferimento per la Diagnosi della Malattia Celiaca del Policlinico S. Orsola-Malpighi di Bologna.

Tabella 2. Malattie associate alla celiachia.

\begin{tabular}{|c|c|c|}
\hline Autoimmuni & Idiopatiche & Cromosomiche \\
\hline Diabete mellito tipo 1 & Cardiomiopatia dilatativa & Sindrome di Down \\
\hline Tiroidite di Hashimoto & Epilessia con o senza calcificazioni occipitali & Sindrome di Turner \\
\hline Morbo di Graves & Atassia cerebellare & Sindrome di Williams \\
\hline Epatite autoimmune & Neuropatia periferica & \\
\hline Colangite biliare primitiva & Mioclonie multiple & \\
\hline Colangite sclerosante primitiva & Sclerosi multipla & \\
\hline Dermatite erpetiforme & Atrofia cerebrale & \\
\hline Vitiligine & Malattie infiammatorie croniche dell'intestino & \\
\hline Morbo di Addison & Sarcoidosi & \\
\hline Alopecia & Atopia & \\
\hline \multicolumn{3}{|l|}{ Psoriasi } \\
\hline \multicolumn{3}{|l|}{ Deficit di $\operatorname{Ig} A$} \\
\hline \multicolumn{3}{|l|}{ Gastrite atrofica autoimmune } \\
\hline \multicolumn{3}{|l|}{ Anemia emolitica autoimmune } \\
\hline \multicolumn{3}{|l|}{ Sindrome Sjogren } \\
\hline \multicolumn{3}{|l|}{ Sclerodermia } \\
\hline \multicolumn{3}{|l|}{$\underline{\text { Lupus eritematoso sistemico }}$} \\
\hline \multicolumn{3}{|l|}{ Polimiosite } \\
\hline \multicolumn{3}{|l|}{ Artrite reumatoide } \\
\hline \multicolumn{3}{|l|}{ Miastenia gravis } \\
\hline Nefropatia da IgA (m. di Bergèr) & & \\
\hline
\end{tabular}


MC associata a queste patologie concomitanti è duplice, dal momento che la dieta aglutinata è in grado non solo di risolvere le manifestazioni e prevenirne le complicanze, ma anche di migliorare i sintomi della patologia associata. $^{2}$

Per quanto concerne la forma potenziale di MC, questa si caratterizza per la positività dei marcatori sierologici e genetici in presenza di una mucosa intestinale normale o con segni minimi d'infiammazione (ossia, aumento dei linfociti intraepiteliali - LIE). ${ }^{46} \mathrm{La}$ forma potenziale può manifestarsi sia con sintomi classici e non classici o essere del tutto asintomatica. La comunità scientifica non è universalmente concorde circa l'opportunità di instaurare o meno una dieta aglutinata nei pazienti con MC potenziale.

Infine, la MC refrattaria è caratterizzata dalla persistenza di sintomi e di atrofia dei villi intestinali dopo almeno 12 mesi di dieta aglutinata stretta. La MC refrattaria può evolvere verso complicanze quali la digiunoileite ulcerativa, la sprue collagenosica e il linfoma intestinale. ${ }^{46}$

In questi ultimi anni abbiamo assistito ad un crescente incremento di altre forme di MC non incluse nella classificazione di Oslo, ${ }^{46}$ quali la celiachia sieronegativa e quella non-responsiva alla dieta aglutinata. La forma sieronegativa si caratterizza per la negatività dei marcatori anticorpali di MC con quadri clinici di severo malassorbimento e di marcata atrofia della mucosa intestinale.$^{68}$ Questa forma entra in diagnosi differenziale con altre patologie che causano atrofia dei villi intestinali. Con il termine di MC non-responsiva si indica quella forma clinica in cui si ha persistenza di sintomi prevalentemente gastrointestinali con normalizzazione della mucosa intestinale (i.e., ricrescita dei villi) ${ }^{69}$ Questa condizione raggruppa un'ampia gamma di varie cause responsabili del persistere della sintomatologia.

\section{Punti chiave}

- Maggior frequenza nel sesso femminile ( $\mathrm{F} / \mathrm{M}=2 / 1)$.

- Possibile insorgenza in ogni età della vita, inclusa l'età geriatrica.

- Principali forme cliniche: classica, non classica, subclinica, potenziale, sieronegativa, non responsiva (inclusa la refrattaria).
- Frequente associazione con altre patologie autoimmuni (diabete mellito tipo 1, tiroidite autoimmune, sindrome di Sjögren, colangite biliare primaria/epatite autoimmune, etc.).

\section{Diagnosi}

I due grandi pilastri su cui si basa la diagnosi di celiachia sono l'esame istologico della biopsia duodenale, che rimane il gold standard diagnostico, e gli anticorpi sierici che negli anni hanno acquisito una rilevanza sempre maggiore. Nonostante i grandissimi progressi compiuti dalla sierologia nessun test anticorpale al momento presenta una sensibilità ed una specificità del $100 \%$ (Tabella 3$)^{70}$ e ciò fa sì che la biopsia intestinale rimanga a tutt'oggi indispensabile per un corretto inquadramento diagnostico dell'enteropatia da glutine. ${ }^{71}$ Nella popolazione pediatrica è stato recentemente proposto dalle linee guida della Società Europea per la Gastroenterologia, Epatologia e Nutrizione Pediatrica (ESPGHAN) la possibilità di astenersi dall'effettuare la biopsia intestinale in bambini ed adolescenti con anticorpi anti-tTG oltre 10 volte il cut-off, presenza degli anticorpi anti-endomisio (EmA), HLA DQ2/DQ8 positivi e con segni/sintomi suggestivi di MC. ${ }^{72}$ Tale strategia diagnostica è tuttora oggetto di dibattito e negli USA non è stata applicata per la scarsa riproducibilità presentata dai vari kit commerciali per la ricerca degli anti-tTG.

Nel 2010 Fasano e Catassi ${ }^{73}$ hanno proposto un nuovo approccio alla diagnosi di MC che si fonda sul principio del four out of five rule, ossia si può formulare diagnosi di $\mathrm{MC}$ se sono presenti almeno quattro elementi dei seguenti cinque: i) segni e sintomi tipici di MC (diarrea e malassorbimento); ii) positività anticorpale degli anticorpi specifici; iii) HLA DQ2 e/o DQ8 positivo; iv) atrofia dei villi; v) risposta clinica alla dieta aglutinata. Partendo da tale regola è possibile comprendere come possano sussistere $\mathrm{i}$ vari sottotipi di MC quali la MC sieronegativa (assenza del punto ii), la MC potenziale (assenza del punto $i v$ ), la MC non classica (assenza punto $i$ ) e la MC non responsiva (assenza del punto $v$ ).

Tabella 3. Performance dei marker sierologici per la diagnosi di celiachia.

\begin{tabular}{lccccc}
\hline & $\begin{array}{c}\text { Sensibilità } \\
(\mathbf{\%})\end{array}$ & $\begin{array}{c}\text { Specificità } \\
(\mathbf{\%})\end{array}$ & $\begin{array}{c}\text { VPP } \\
(\mathbf{\%})\end{array}$ & $\begin{array}{c}\text { VPN } \\
(\mathbf{\%})\end{array}$ & \multicolumn{2}{c}{$\begin{array}{c}\text { Accuratezza diagnostica } \\
\text { (\%) }\end{array}$} \\
\hline Anti-tTG IgA & 97 & 91 & 91 & 97 & 98 \\
\hline EmA IgA & 94 & 100 & 100 & 94 & 97 \\
\hline DGP-AGA IgG & 84 & 99 & 98 & 87 & 92 \\
\hline
\end{tabular}

Anti-tTG, anticorpi antitransglutaminasi; EmA, anticorpi antiendomisio; DGP-AGA, anticorpi diretti contro i peptidi deamidati di gliadina; VPP, valore predittivo positivo; VPN, valore predittivo negativo. 


\section{Punti chiave}

- Anticorpi anti transglutaminasi (sensibilità 97\%) ed anti endomisio IgA (specificità 99-100\%), test sierologici con massima accuratezza diagnostica.

- Peptidi deamidati di gliadina IgG utili per la diagnosi nella prima infanzia e nel deficit selettivo di IgA.

- Gold standard diagnostico rimane l'atrofia dei villi intestinali documentata dalla biopsia duodenale in corso di esofagogastroduodenoscopia.

- Valutazione delle risposta sul piano clinico, anticorpale ed istologico alla dieta aglutinata per la conferma della diagnosi.

\section{Esami bioumorali}

Gli esami ematochimici di routine possono essere il primo indizio per sospettare l'esistenza di questa patologia. ${ }^{74}$ Bassi livelli sierici di emoglobina, albumina, calcio, potassio, magnesio e fosforo sono di più frequente riscontro nei celiaci con fenotipo classico rispetto a quello non-classico. L'anemia è nella maggior parte dei casi microcitica sideropenica con bassi valori di ferritinemia. Meno frequentemente l'anemia del paziente celiaco è macrocitica o dimorfica normocitica con aumentata variabilità dimensionale delle emazie per concomitante malassorbimento di folati e/o di vitamina B12 soprattutto nelle forme associate a gastrite atrofica autoimmune. ${ }^{47}$ Elevati livelli dell'isoenzima osseo della fosfatasi alcalina e un marcato deficit di vitamina $\mathrm{D} 3$ possono essere riscontrati nei pazienti con $\mathrm{MC}$ e osteopenia/osteoporosi. ${ }^{75} \mathrm{Un}$ rialzo delle transaminasi di origine criptogenetica è una possibile modalità di presentazione anche in assenza di altri sintomi. Le transaminasi si normalizzano dopo pochi mesi di dieta aglutinata..$^{50}$ In una discreta percentuale di celiaci adulti sono presenti, all'esame dello striscio ematico, alterazioni della membrana e del citoplasma dei globuli rossi (pitted red cells e corpi di HowellJolly) che sono espressione d'iposplenismo. ${ }^{76}$ Una possibile spia dell'iposplenismo, osservato esclusivamente nelle forme di $\mathrm{MC}$ dell'età adulta, è il riscontro di una marcata piastrinosi in associazione ad una milza di piccole dimensioni o addirittura assente all'esame ecografico. La presenza d'iposplenismo nei celiaci predispone non solo allo sviluppo di patologie infettive da batteri capsulati (Pneumococco, Meningococco), ma anche alla comparsa di patologia autoimmune e di complicanze quali la MC refrattaria, la digiunoileite ulcerativa ed il linfoma. ${ }^{77,78}$

\section{I test sierologici}

Negli ultimi 20 anni, l'impiego dei test sierologici su larga scala ha consentito di incrementare in maniera significativa il numero delle diagnosi di MC. Il ruolo degli autoanticorpi correlati alla celiachia non è quello di sostituirsi alla biopsia intestinale ma piuttosto quello di identificare i soggetti con sospetta celiachia da confermare con l'indagine istologica. ${ }^{71}$ Attualmente la diagnosi sierologica di $\mathrm{MC}$ si basa su test altamente predittivi ed ampiamente validati fra cui gli EmA, gli anti-tTG e gli anticorpi diretti verso i peptidi deamidati della gliadina (DGP). ${ }^{70}$

Gli anticorpi correlati alla celiachia appartengono alla classe IgA e IgG, ma solamente quelli di classe IgA possono essere considerati marker altamente sensibili e specifici per la MC. ${ }^{70}$ L'impiego dei marker di classe IgG (eccetto per DGP) è spesso fuorviante a causa dell'elevata percentuale di falsi positivi ed il loro uso dovrebbe essere limitato ai pazienti con deficit di IgA. ${ }^{79}$ Gli EmA sono il test anticorpale con la più elevata accuratezza diagnostica, in quanto hanno una specificità assoluta se eseguiti in laboratori di terzo livello e con operatori esperti. ${ }^{80}$ La sensibilità degli anti-tTG IgA è più elevata di quella degli EmA $\operatorname{IgA}(97 \%$ vs 94\%), mentre la specificità dei tTG IgA è sicuramente inferiore di quella degli EmA $(91 \%$ e $100 \%$, rispettivamente) (Tabella 3). ${ }^{80,81}$ I falsi positivi per gli anti-tTG di solito presentano bassi titoli di attività anticorpale (inferiori a 2 volte il cut-off). Una transitoria positività per anti-tTG $\operatorname{IgA}$, non associata a danno della mucosa duodenale, è stata osservata in pazienti con diabete tipo 1 all'esordio con successiva scomparsa degli anticorpi entro 6 mesi dalla loro identificazione. ${ }^{82}$ Recentemente la diagnostica sierologica della celiachia si è arricchita di un ulteriore marcatore, ossia i DGP. ${ }^{83}$ Dal punto di vista patogenetico, la deamidazione dei peptidi di gliadina da parte della tTG rende più immunogenici (ed in teoria più specifici) $i$ peptidi di gliadina così modificati rispetto ai peptidi nativi. Iniziali studi avevano dimostrato un'elevata sensibilità e specificità per la $\mathrm{MC}$, ma dati successivamente pubblicati hanno ridimensionato la loro accuratezza diagnostica ${ }^{84} \mathrm{I}$ dati della letteratura indicano che i DGP di classe IgG sono particolarmente utili per identificare la MC nella prima infanzia (età $<2$ anni). ${ }^{85}$ I DGP di classe IgA si sono dimostrati di scarsa utilità nella diagnosi della $\mathrm{MC}$ ed il loro impiego non è raccomandato. ${ }^{70}$ Secondo il protocollo pubblicato sulla Gazzetta Ufficiale del 19/08/2015, la diagnosi sierologica di MC dell'adulto si effettua determinando in prima battuta il dosaggio degli anti-tTG IgA unitamente alle IgA totali. Qualora positivi gli anti-tTG IgA ad alto titolo in presenza di IgA totali normali si può procedere direttamente alla biopsia duodenale. Nel caso di positività a basso titolo per gli anti-tTG IgA è utile effettuare la determinazione degli EmA IgA e, solo in caso di positività anche di questi, effettuare la biopsia duodenale per conferma definitiva.

Una stretta compliance alla dieta senza glutine nei pazienti celiaci porta alla scomparsa o al significativo calo degli anticorpi entro 12 mesi (18-24 mesi se il ti- 
tolo anticorpale è molto elevato) unitamente alla ricrescita dei villi intestinali. In tal senso gli anti-tTG di classe IgA devono essere considerati al momento come il test migliore per il follow-up della celiachia unitamente ai DGP IgG che possono essere maggiormente utili nella prima infanzia (al di sotto dei 2 anni di età).$^{70,85}$

\section{Biopsia duodenale}

Principale ed al momento insostituibile strumento diagnostico per la MC nell'adulto è la valutazione morfologica della biopsia duodenale che ancora oggi, nonostante tutti i tentativi di ridurne il ruolo, è da considerarsi il gold standard per la diagnosi. ${ }^{71}$ In questi ultimi anni sono cambiati radicalmente i criteri istologici sui quali si basava la diagnosi di MC con l'inclusione dell'atrofia lieve dei villi e delle lesioni minime, caratterizzate da un isolato aumento dei LIE. ${ }^{86,87}$ È raccomandata l'esecuzione di 4 biopsie a livello della seconda porzione duodenale e 2 biopsie a livello del bulbo. ${ }^{88}$ Presupposto fondamentale per una corretta valutazione morfologica è l'orientamento dei prelievi bioptici, utilizzando filtri millipore di acetato di cellulosa.${ }^{89,90}$ Le lesioni della mucosa intestinale compatibili con una diagnosi di MC vengono distinte in cinque stadi secondo la classificazione di Marsh, modificata da Oberhüber, che viene attualmente utilizzata in tutti i centri di riferimento per la diagnosi di MC. ${ }^{86}$ Le lesioni di tipo 1 e di tipo 2, caratterizzate da aumento dei LIE (senza o con iperplasia delle cripte) ma con villi normali, sono compatibili, ma non specifiche, per MC. In presenza di positività per anti-tTG ed EmA, le lesioni intestinali minime sono espressione di una MC potenziale. Nella maggior parte dei casi, le lesioni minime sono riconducibili ad altre cause, fra cui allergie alimentari (in particolare intolleranza alle proteine del latte vaccino), morbo di Crohn, colite linfocitica, infezioni intestinali di tipo batterico e parassitario, quale ad esempio la giardiasi, immunodeficienza comune variabile, patologie autoimmuni (tiroidite autoimmune, LES, diabete mellito autoim- mune), contaminazione batterica dell'intestino (SIBO), trattamento con anti-infiammatori non steroidei e infezione da Helicobacter pylori (Tabella 4). ${ }^{91-93}$ Negli ultimi anni si assiste al preoccupante fenomeno di un elevato numero di diagnosi di $\mathrm{MC}$ formulate in modo improprio sulla base di lesioni minime in assenza di marcatori genetici e sierologici. ${ }^{94}$ La lesione tipica della celiachia è rappresentata dall'atrofia dei villi con alterazione del rapporto villi/cripte $(<3: 1$ fino a raggiungere 1:1) ed incremento dei LIE. Questa lesione, definita come tipo 3 nella classificazione di Marsh-Oberhüber, viene a sua volta suddivisa a seconda della severità dell'atrofia in tre stadi: atrofia lieve (3a), parziale (3b) e subtotale (3c). ${ }^{86} \mathrm{Nel}$ tentativo di semplificare il lavoro degli anatomo-patologi e facilitare il rapporto tra patologi e clinici è stata proposta da Corazza e Villanacci una diversa versione della classificazione istologica che riduce il numero degli stadi da cinque a tre ${ }^{87}$ In particolare, le lesioni che caratterizzano la $\mathrm{MC}$ sono state divise in due categorie: non-atrofica (grado A) e atrofica (grado B); il grado $\mathrm{B}$ a sua volta è stato ulteriormente suddiviso in $\mathrm{B} 1$, in cui il rapporto villo/cripta è inferiore a $3: 1$, con villi ancora individuabili e $\mathrm{B} 2$, in cui i villi sono del tutto atrofici. La lesione di grado A, caratterizzata dall'incremento patologico del numero dei LIE, meglio riconosciuto dalla colorazione immunoistochimica per i CD3, comprende al suo interno la lesione tipo 1 e 2 secondo la classificazione di Marsh-Oberhüber, la lesione di grado B1 raggruppa al suo interno la lesione $3 \mathrm{a}$ e $3 \mathrm{~b}$, mentre il grado B2 in pratica corrisponde alla $3 \mathrm{c}$ (Tabella 5). ${ }^{87}$

\section{Le varianti nosologiche della celiachia}

\section{Celiachia potenziale}

Negli ultimi anni, un numero sempre maggiore di pazienti mostra una positività anticorpale per la sierologia (EmA ed anti-tTG IgA) della MC con HLA DQ2/DQ8 in assenza di atrofia dei villi. ${ }^{95,96}$ Per questa

Tabella 4. Cause di aumento del numero dei linfociti intraepiteliali nella mucosa intestinale con architettura dei villi normali.

Celiachia potenziale

Allergia alimentare (cereali, proteine del latte, derivati della soia, pesce, riso pollo)

Infezioni (enteriti virali, Giardiasi, Cryptosporidium, Helicobater pylori)

Contaminazione batterica del tenue

Farmaci (FANS)

Patologia del sistema immunitario (tiroidite di Hashimoto, artrite reumatoide, LES, diabete mellito tipo 1, enteropatia autoimmune)

Immunodeficienza comune variabile

Malattie infiammatori croniche intestinali (m. di Crohn, rettocolite ulcerosa)

Colite linfocitica 
categoria di pazienti, che costituisce circa il $10 \%$ dei soggetti con $\mathrm{MC}$, è stato coniato il termine di celiachia potenziale.$^{46} \mathrm{Nei}$ pazienti con MC potenziale la mucosa intestinale può presentarsi normale (Marsh 0 ) o lievemente infiammata con aumentato numero di LIE (Marsh 1) ${ }^{96}$ Nonostante l'assenza di lesioni severe della mucosa intestinale questi pazienti possono mostrare sintomi gastrointestinali e/o extraintestinali o essere totalmente asintomatici. ${ }^{2}{ }^{296}$ Sebbene i criteri per diagnosticare questa condizione siano chiari, la MC potenziale rimane un'area ancora poco studiata con molti punti interrogativi e risultati contrastanti nei pochi studi condotti sinora. ${ }^{96-102}$ Nei bambini più dell' $80 \%$ dei pazienti con celiachia potenziale sono asintomatici e il restante $20 \%$ mostra più frequentemente sintomi intestinali quali malassorbimento, diarrea cronica, dolore addominale ricorrente, rispetto alle manifestazioni extraintestinali, quali anemia sideropenica, ipertransaminasemia e bassa statura. ${ }^{98,99,102} \mathrm{Nel}-$ l'adulto invece alcuni lavori dimostrano come il fenotipo sintomatico nei soggetti con MC potenziale sia molto più frequente che nel bambino e sia caratterizzato principalmente da sintomi extraintestinali. $.6,97,100,101$ Un aspetto controverso è dato dalla necessità di trattare con una dieta aglutinata i soggetti con MC potenziale. Si ritiene utile suggerire la dieta aglutinata unicamente nei soggetti con MC potenziale sintomatica. Al contrario, i pazienti con $\mathrm{MC}$ potenziale asintomatica sono invece lasciati a dieta contenente glutine e seguiti con uno stretto follow-up clinico, sierologico ed istologico. ${ }^{96-102}$ Alcuni studi hanno segnalato la possibile fluttuazione o negativizzazione dei marker sierologici di celiachia, nella MC potenziale lasciata a dieta libera. Inoltre, solo una piccola percentuale di pazienti con MC potenziale che assume glutine nella dieta progredisce verso un'atrofia dei villi conclamata. ${ }^{96,98,99,101,103}$ Un importante contributo su questo punto è stato fornito dal nostro gruppo di ricerca che ha dimostrato come i soggetti adulti con MC potenziale asintomatica vadano lasciati a dieta libera. Infatti, solo il $6 \%$ di questi soggetti svilupperà un'atrofia dei villi in un follow-up medio di 3 anni, mentre i soggetti sintomatici andrebbero trattati con una dieta senza glutine in quanto grazie a questa si ottiene un netto miglioramento clinico della sintomatologia. ${ }^{96}$

\section{Punti chiave}

- Varietà di celiachia caratterizzata da sierologia e genetica positive con mucosa intestinale normale o lievemente infiammata.

- Incremento delle diagnosi di celiachia potenziale ( $>10 \%$ delle diagnosi totali di celiachia).

- Dieta aglutinata nella forma sintomatica e dieta con glutine in assenza di sintomi con successivo followup clinico, anticorpale e bioptico.

- Scarsa tendenza allo sviluppo di celiachia franca (atrofia dei villi) nelle forme asintomatiche lasciate a dieta con glutine con possibile negativizzazione della sierologia.

\section{Malattia celiaca sieronegativa}

Sebbene gli anticorpi specifici per la MC siano riscontrabili nella stragrande maggioranza dei pazienti, una piccola parte di celiaci (circa 2-3\%) può risultare negativa per i marcatori sierologici. In questi casi la diagnosi è strettamente legata al riscontro di atrofia dei villi all'istologia duodenale $\mathrm{e}^{68,104,105} \mathrm{e}$ risulterà fondamentale l'esecuzione del test genetico per celiachia, in quanto una sua negatività escluderebbe definitivamente la diagnosi, orientando il clinico verso altre cause di atrofia dei villi. La diagnosi definitiva di celiachia sieronegativa può essere confermata solo dopo un anno dall'inizio della dieta aglutinata. Tale tempo è necessario per dimostrare un miglioramento sia sintomatologico che istologico dopo dieta senza glutine. La complessità diagnostica di questa particolare variante della MC è dovuta alla diagnosi differenziale con altre condizioni di atrofia dei villi, quali infezioni parassitarie (Giardia lamblia), enteropatia autoimmune, contaminazione batterica del tenue, immunodeficienza comune variabile, gastroenterite eosinofila, enteropatia indotta da farmaci (sartani e FANS), linfoma intestinale, malattia di Crohn, sprue tropicale, enteropatia da HIV e malattia di Whipple (Figura 2) ${ }^{68,106,107}$ Di tutte le atrofie dei villi con assenza di anticorpi, il 28\%-45\% è costituito da celiachia sieronegativa ${ }^{68,108,109}$ I pazienti con MC sieronegativa mostrano un fenotipo clinico classico caratterizzato da diarrea e malassorbimento, con una netta prevalenza nel genere femminile $(6: 1){ }^{68}$ I soggetti con questa variante sembrerebbero essere più esposti a morbilità e mortalità

Tabella 5. Confronto fra le 2 classificazioni per la biopsia duodenale.

\begin{tabular}{ll}
\hline Classificazione istologica di Marsh-Oberhüber & Classificazione istologica di Corazza-Villanacci \\
\hline Lesione tipo 1 & Grado A \\
Lesione tipo 2 & Non atrofia \\
\hline Lesione tipo 3a & Grado B1 \\
Lesione tipo 3b & Atrofia parziale \\
\hline Lesione tipo 3c & Grado B2 \\
& Atrofia subtotale \\
\hline
\end{tabular}


rispetto ai soggetti con celiachia con positività anticorpale e per tale motivo devono essere sottoposti ad uno stretto follow-up. ${ }^{68,109}$ Inoltre, i pochi dati presenti in letteratura suggeriscono che la MC sieronegativa abbia una maggior predisposizione ad associarsi a malattie autoimmuni ed un maggior rischio di evoluzione verso una forma refrattaria. Questa aumentata morbilità potrebbe essere dovuta in parte alla diagnosi tardiva di questa condizione che mediamente è intorno ai 50 anni di età. ${ }^{68}$

\section{Punti chiave}

- Sierologia negativa nel 2-3\% dei pazienti con celiachia.

- Forma clinica caratterizzata da severo malassorbimento con diarrea e calo ponderale (fenotipo classico).

- Diagnosi differenziale con altre patologie caratterizzate da atrofia dei villi quali Giardiasi, enteropatia autoimmune, contaminazione batterica dell'intestino tenue, immunodeficienza comune variabile, enterite eosinofila, enteropatia da sartani e FANS, morbo di Whipple, enteropatia da HIV).

- Elevata frequenza di associazione con malattie autoimmuni e maggior rischio di evoluzione verso forma refrattaria.

\section{Malattia celiaca non responsiva}

La maggioranza dei pazienti con MC ha un'ottima risposta sintomatologica alla dieta aglutinata. Alcuni soggetti però, nonostante una presunta dieta aglutinata stretta, continuano ad accusare un'intensa sintomatologia intestinale ed extraintestinale. ${ }^{69,110} \mathrm{In}$ questo contesto, la mancata risposta sintomatologica alla dieta aglutinata viene definita celiachia non responsiva. La celiachia non responsiva può essere primaria se non vi è stata alcuna risposta dopo i primi 12 mesi di dieta senza glutine, o secondaria se, dopo un iniziale risposta sintomatologica, vi è una ricaduta. ${ }^{69} \mathrm{Il}$ periodo di almeno un anno di dieta è stato scelto per convenzione allo scopo di sottolineare il lungo periodo che può essere necessario per vedere gli effetti della dieta aglutinata sul miglioramento sintomatologico. Le principali cause di questa condizione includono una dieta aglutinata non stretta (che è la causa più frequente), un'errata diagnosi di $\mathrm{MC}$ e altri disturbi gastrointestinali che possono essere associati o coesistere con la MC, come la sindrome dell'intestino irritabile, la SIBO, la colite microscopica, l'intolleranza al lattosio, la malattia diverticolare, il morbo di Crohn, l'enteropatia autoimmune e farmaci) (Figura 3). ${ }^{69,110}$ In tali soggetti

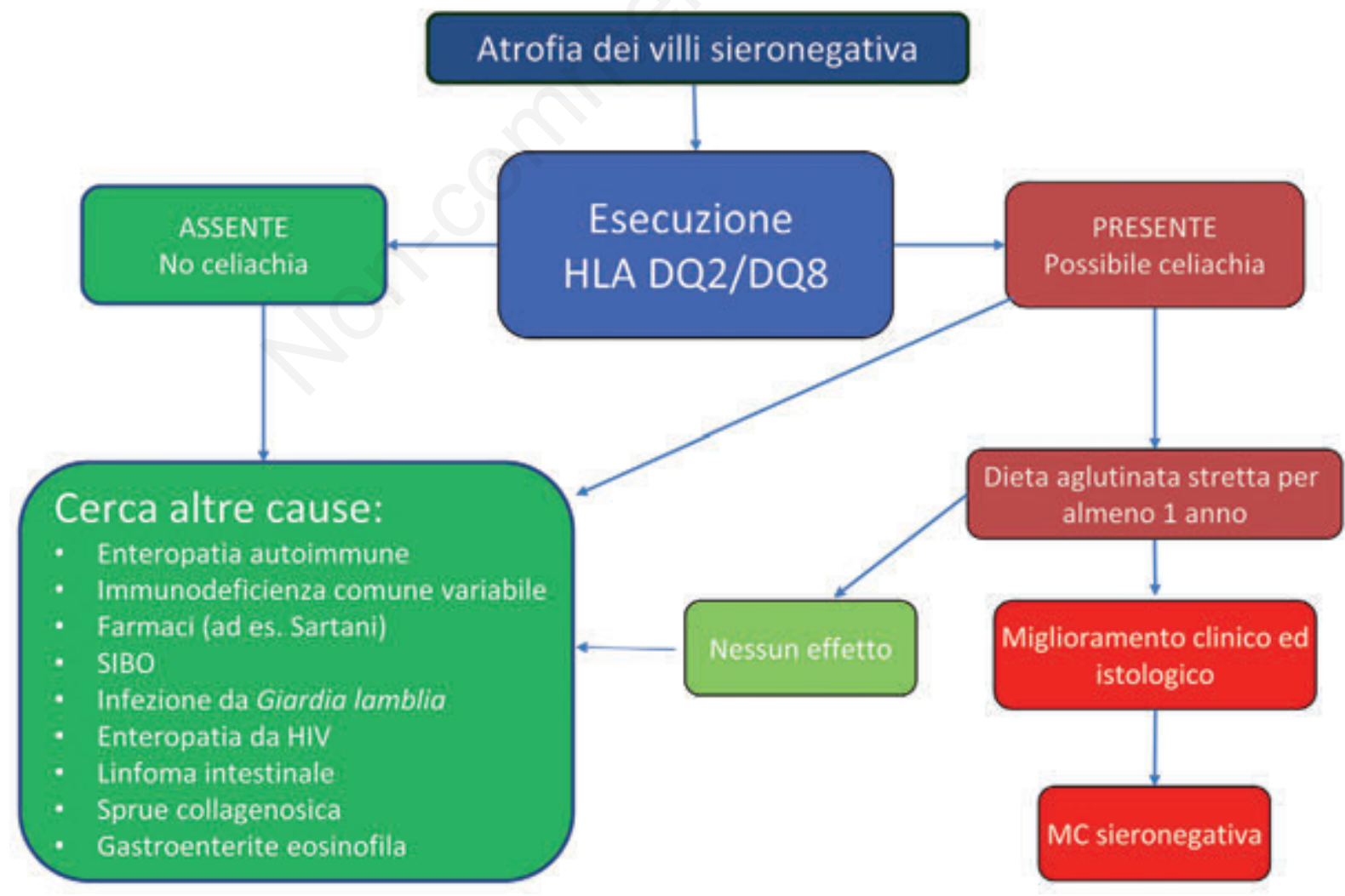

Figura 2. Algoritmo diagnostico dell'atrofia dei villi sieronegativa. SIBO, sindrome da contaminazione batterica dell'intestino tenue. 
sarà fondamentale la ripetizione della sierologia anticorpale e della biopsia duodenale per verificare la ricrescita dei villi intestinali. Con tali indagini si potrà escludere l'eventuale presenza di una $\mathrm{MC}$ refrattaria oppure orientarsi verso altre possibili cause dei disturbi gastrointestinali.

\section{Punti chiave}

- Varietà clinica con mancata risposta alla dieta aglutinata ab initio o dopo un periodo di miglioramento sul piano clinico.

- Varie cause responsabili fra cui le più frequenti sono la mancata compliance alla dieta aglutinata, la diagnosi errata di celiachia e l'associazione con patologie funzionali (reflusso gastro-esofageo e sindrome dell'intestino irritabile) ed altre intolleranze alimentari (intolleranza al lattosio e al fruttosio).

- Solo una piccola percentuale di pazienti con celiachia non responsiva ha una celiachia refrattaria $(<10 \%)$, caratterizzata da persistenza di atrofia della mucosa intestinale dopo almeno un anno di dieta aglutinata stretta.

\section{Complicanze della celiachia}

È stato ampiamente dimostrato che la MC diagnosticata tardivamente (dopo i 50 anni) e/o non accompagnata da una dieta aglutinata stretta, può avere una mortalità superiore rispetto a quella della popolazione generale. ${ }^{111}$ Sebbene rare (circa 1\% dei pazienti celiaci diagnosticati), ${ }^{112}$ le complicanze della MC comprendono l'iposplenismo, la celiachia refrattaria, il linfoma intestinale e l'adenocarcinoma del tenue, la colite collagenosica e la digiunoileite ulcerativa. Le complicanze vanno sempre sospettate ed escluse in tutti quei soggetti che, nonostante una dieta senza glutine corretta, lamentano un'ingiustificata persistenza o la ricomparsa di sintomi quali diarrea, subocclusione intestinale, dolore addominale, calo ponderale, febbre ed astenia severa. La possibile insorgenza di queste complicanze è da prendere in considerazione soprattutto nei casi in cui la diagnosi di celiachia è stata effettuata in età avanzata e/o in cui la dieta priva di glutine non sia stata seguita correttamente, particolarmente nei soggetti portatori di una omozigosi per il DQ2. ${ }^{113}$

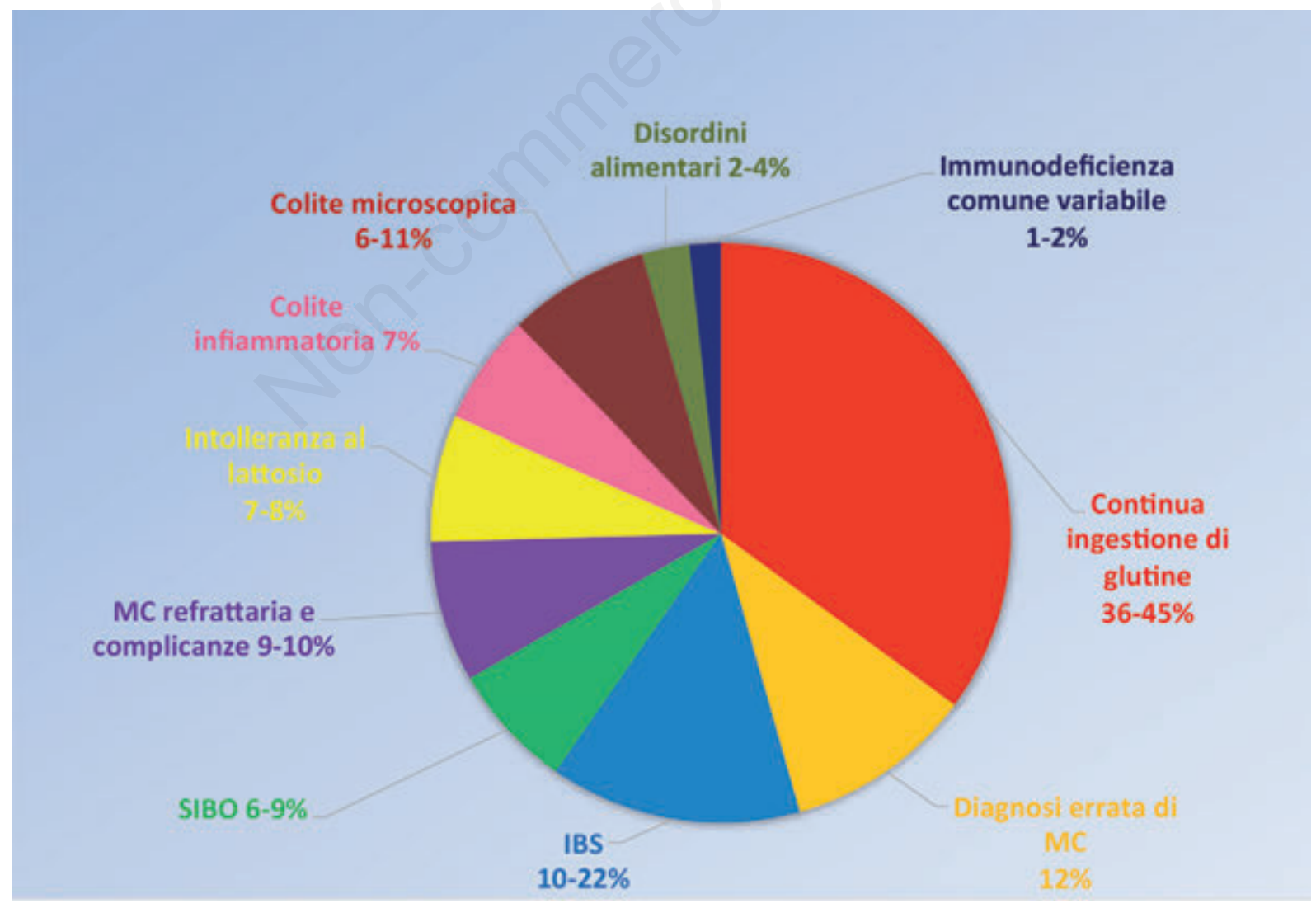

Figura 3. Cause di malattia celiaca (MC) non responsiva alla dieta aglutinata. SIBO, sindrome da contaminazione batterica dell'intestino tenue; IBS, sindrome dell'intestino irritabile. 


\section{Iposplenismo}

Una condizione di iposplenismo anatomico o funzionale è identificabile in circa il 30\% dei soggetti adulti affetti da celiachia e la prevalenza aumenta all' $80 \%$ dei soggetti con complicanze. ${ }^{77,114}$ I soggetti celiaci a cui si riscontrano ridotte dimensioni della milza all'ecografia addominale dovrebbero indurre il clinico ad eseguire alcuni accertamenti per confermare anche la presenza di un iposplenismo funzionale fra cui la ricerca dei corpi di Howell-Jolly su striscio di sangue periferico o la presenza di pitted red cells al microscopio a contrasto di fase. ${ }^{77,114}$ L'ipofunzione splenica è strettamente associata non solo allo sviluppo di complicanze e di altre malattie autoimmuni associate alla MC ma anche alle infezioni di batteri capsulati (Pneumococco, Hemophilus influenzae, Meningococco $){ }^{78}$ Proprio per il maggior rischio di sviluppare infezioni (in alcuni casi letali o con severi reliquati) da batteri capsulati è raccomandata una vaccinazione anti-pneumococcica ed anti-meningococcica in tale sottogruppo di pazienti. ${ }^{77,78,114}$

\section{Malattia celiaca refrattaria}

La MC refrattaria, che costituisce meno del 10\% dei casi di celiachia non responsiva ${ }^{110}$ e circa $1^{\prime} 1-1,5 \%$ dei casi totali di celiachia, ${ }^{115}$ è caratterizzata dalla presenza di sintomi quali malassorbimento, calo ponderale e diarrea associata alla persistenza di atrofia dei villi dopo almeno 1 anno di dieta aglutinata stretta, confermata dalla negativizzazione degli anticorpi specifici. ${ }^{46}$ Prima di porre tale diagnosi dovranno essere escluse altre cause più frequenti di celiachia non responsiva come descritto in precedenza. ${ }^{69,110}$ La celiachia refrattaria viene a sua volta suddivisa in due categorie, primaria e secondaria a seconda che i soggetti affetti non abbiano mai ottenuto una risposta sintomatologica fin dall'inizio della dieta nel primo caso, oppure abbiano avuto una ricaduta dei sintomi dopo un periodo più o meno lungo di miglioramento nel secondo caso. Inoltre, la celiachia refrattaria è caratterizzata da due sottotipi: nel tipo $1 \mathrm{i}$ LIE hanno un normale fenotipo $\mathrm{CD} 3+\mathrm{CD} 8+$, mentre nel tipo 2 è presente una popolazione clonale di LIE con perdita dell'espressione del CD8 e riarrangiamento monoclonale del T-cell receptor (TCR). ${ }^{115}$ Tale distinzione in due sottotipi è fondamentale per motivi di gestione terapeutica e di prognosi: infatti, il tipo 2 mostra una mortalità a 5 anni del $55 \%$, rispetto ad un $7 \%$ del tipo 1. ${ }^{116}$ La mortalità dei pazienti con celiachia refrattaria tipo 2 è soprattutto dovuta all'evoluzione del quadro in linfoma intestinale che sembra colpire più frequentemente il sesso maschile anche se la celiachia refrattaria è più frequente nel sesso femminile con un rapporto di 3:1. ${ }^{117}$ La diagnosi di celiachia refrattaria deve essere eseguita da centri di riferimento terziario sulla base del riscontro di persistenza di atrofia dei villi nonostante una dieta aglutinata stretta della durata non inferiore ad 1 anno con negativizzazione della sierologia anticorpale, esclusione di altre cause di persistenza di atrofia dei villi e fenotipizzazione della popolazione linfocitaria intestinale atta a confermare la presenza (tipo 2) o meno (tipo 1) di un riarrangiamento monoclonale del TCR. In tutti i casi di celiachia refrattaria tipo 2 sarà fondamentale eseguire alla diagnosi entero-TC e/o entero-RM seguite da PET, videocapsula ed enteroscopia per escludere la presenza o imminente evoluzione verso un linfoma intestinale. ${ }^{115,117}$ Proprio per questo rischio di evoluzione, nei soggetti con diagnosi di malattia celiaca refrattaria tipo 2 è stata suggerita l'esecuzione di esame con videocapsula una volta all'anno nel follow-up. ${ }^{118}$ Dal punto di vista terapeutico la gestione della malattia celiaca refrattaria tipo 1 si basa sulla terapia immunosoppressiva a base di steroidi, azatioprina, 6-mercaptopurina e methotrexate, mentre la terapia del tipo 2 si avvale di ulteriori strumenti fra cui la ciclosporina e chemioterapici quali la cladibrina e la fludarabina associati a terapia biologica con anticorpi monoclonali anti-CD52 (alemtuzumab). In alcuni casi è stato tentato un trapianto di cellule staminali autologhe con risultati promettenti. ${ }^{116-118}$

\section{Linfoma intestinale}

L'associazione fra $\mathrm{MC}$ e neoplasie maligne è nota da oltre 50 anni $^{119}$ e un ritardo nella diagnosi di MC espone ad un maggior rischio di sviluppare patologie neoplastiche. ${ }^{120}$ Negli ultimi anni un numero sempre maggiore di studi ha riportato un'aumentata incidenza da 6 a 9 volte superiore alla popolazione generale di linfoma intestinale non Hodgkin a cellule T e più raramente anche a cellule B. ${ }^{120}$ Lo sviluppo di un linfoma intestinale è preceduto nella maggior parte dei casi da una malattia celiaca refrattaria tipo 2 che evolve in malignità nel 33-52\% dei casi entro 5 anni dalla diagnosi, più rara è invece l'evoluzione dalla refrattaria tipo 1 che raggiunge un tasso di evoluzione del 14\% a 5 anni. ${ }^{121} \mathrm{Il}$ trattamento in questi casi si avvale della chemioterapia comprendente ifosfamide, epirubicina, etoposide methotrexate ad alto dosaggio seguito dal trapianto autologo di cellule staminali. Qualora il linfoma presenti un'elevata espressione di CD30 (>80\% della neoplasia) è possibile utilizzare terapia biologica con anti CD30 associato a monometil auristatin E (brentuximab vedotin) e regime chemioterapico a base di ciclofosfamidedoxorubicina-prednisone (CHP) seguito da trapianto di cellule staminali autologo. ${ }^{121}$

\section{Adenocarcinoma del tenue}

L'adenocarcinoma dell'intestino tenue è una neoplasia estremamente rara nella popolazione generale 
(5,7 casi/1.000.000 di persone all'anno), mentre diventa molto più frequente nei soggetti affetti da $\mathrm{MC}$ (odd ratio riportato in letteratura da 4,29 a 59,97). ${ }^{122}$ Seppur molto più raro rispetto alla patologia linfomatosa, l'adenocarcinoma del tenue è una complicanza che sta diventando sempre più frequente. Ancora oggi, purtroppo, la diagnosi di questa neoplasia avviene in concomitanza con quella di MC. A differenza del linfoma intestinale, l'adenocarcinoma del tenue non è preceduto da celiachia refrattaria ed è più frequente nel sesso femminile. ${ }^{12}$ La comparsa di un'improvvisa condizione di subocclusione intestinale e/o di anemizzazione, specie in un paziente diagnosticato tardivamente e a dieta aglutinata da poco tempo deve far indurre il sospetto nel clinico che dovrà escludere la presenza della neoplasia mediante l'esecuzione di entero-TC/RM, PET, videocapsula ed enteroscopia, in quanto nella maggior parte dei casi tale neoplasia nel celiaco è localizzata a livello digiunale. ${ }^{123}$

\section{Punti chiave}

- Le complicanze della celiachia comprendono l'iposplenismo, la celiachia refrattaria, il linfoma intestinale, l'adenocarcinoma del tenue, la digiunoileite ulcerativa e la sprue collagenosica.

- Solo 1\% delle diagnosi complessive di celiachia presenta una o più complicanze.

- La celiachia refrattaria di tipo 2, caratterizzata da una popolazione clonale di linfociti intraepiteliali con perdita dell'espressione del CD8 e riarrangiamento monoclonale del T-cell receptor, presenta una frequente evoluzione verso il linfoma intestinale con mortalità del 55\% a 5 anni dalla diagnosi.

- L'adenocarcinoma del tenue ha una più elevata frequenza nel sesso femminile (terza-quarta decade di vita) e viene spesso diagnosticato contestualmente al riscontro di malattia celiaca.

\section{Follow-up della MC dell'adulto}

Una prima visita di controllo entro 6 mesi dalla diagnosi e successivamente, ogni 12-24 mesi (eccetto l'insorgenza di complicanze in tal caso ogni 3-6 mesi) è sufficiente per verificare la compliance alla dieta senza glutine, escludere la comparsa di patologie autoimmuni ed alterazioni metaboliche, ma, soprattutto, diagnosticare precocemente la comparsa di eventuali complicanze. ${ }^{124}$

I pazienti devono essere sottoposti ad una visita con valutazione dietetica e controllo degli esami ematici fra cui: emocromo, dosaggio anti-tTG $\operatorname{IgA}$ (o IgG se vi è deficit delle $\operatorname{IgA}$ ), TSH, anti tireoperossidasi ed anti tireoglobulina, ferritina, folatemia e dosaggio vitamina D3, transaminasi ed assetto metabolico. ${ }^{124} \mathrm{Al}$ primo controllo è utile effettuare uno screening con anticorpi anti nucleo ed autoanticorpi non organo specifici per escludere la presenza di marker predittivi del possibile futuro sviluppo di malattie autoimmuni associate alla celiachia. Nell'adulto una densitometria ossea andrebbe eseguita dopo 12-18 mesi di dieta senza glutine e ripetuta periodicamente su indicazione del curante, solo se patologica o per altre indicazioni. I soggetti con osteopenia dovranno essere trattati con terapia a base di calcio e vitamina $\mathrm{D}$, mentre nei casi di osteoporosi dovrà essere presa in considerazione un'eventuale terapia con bifosfonati. Dal momento che in alcuni casi la dieta aglutinata può portare ad un improvviso ed eccessivo aumento ponderale, un'attenta valutazione metabolica dovrà essere messa in atto in questi casi. ${ }^{125}$ L'esecuzione di un'ecografia addominale durante il follow-up potrà escludere la presenza di atrofia splenica o l'insorgenza di una steatosi epatica durante la dieta aglutinata, che, se non eseguita correttamente, espone il paziente ad un eccessivo consumo di prodotti dietoterapeutici ricchi di grassi vegetali (olio di colza, olio di palma, olio di cocco). ${ }^{126}$

Va ricordato che i pazienti celiaci, nonostante l'esecuzione di una dieta aglutinata stretta possono comunque accusare sintomatologia intestinale che dovrà essere inquadrata clinicamente, ma che nel $30-50 \%$ dei casi è riconducibile ad una sindrome dell'intestino irritabile che dovrà essere trattata mediante consigli dietetici (riduzione apporto fibra insolubile, dei fruttooligo-saccaridi fermentabili e polioli - FODMAPs) e terapia farmacologica sintomatica. ${ }^{127}$

La dieta senza glutine, specie se fai da te e senza il supporto di uno specialista della nutrizione, può causare un deficit di vitamine ed oligoelementi che dovranno essere supportati in caso di necessità, in particolare quando il paziente riferisce la comparsa di astenia. ${ }^{128}$ Non è infrequente che i soggetti posti a dieta aglutinata sviluppino un alvo tendenzialmente stitico che in tal caso andrà corretto mediante l'utilizzo di terapia adeguata (ad esempio lassativi osmotici come il macrogol). ${ }^{129} \mathrm{Nel}$ caso vi sia il sospetto di una complicanza associata alla malattia celiaca il follow-up dovrà essere più ravvicinato nel tempo (3-6 mesi). ${ }^{118}$ Alla batteria di esami prescritta per il normale followup dovrà essere aggiunta la determinazione del protidogramma elettroforetico, LDH e $\beta$-2 microglobulina. Dovranno essere eseguiti esami endoscopici (EGDS con ripetizione di biopsia duodenale), ecografia addominale, fino all'esecuzione di esami di secondo e terzo livello quali entero-TC/RM, PET, videocapsula ed enteroscopia. ${ }^{116-118}$

Può essere considerata dal clinico (anche se non raccomandato dalle attuali linee guida) l'effettuazione di una biopsia duodenale di follow-up per verificare la ricrescita dei villi nei soggetti a dieta aglutinata, tenendo presente che alcuni studi hanno mostrato come il tempo medio dall'inizio della dieta alla restitutio ad 
integrum dei villi possa raggiungere i tre anni. Può essere quindi ragionevole effettuare la biopsia di followup almeno dopo 2 anni dall'inizio della dieta aglutinata stretta. ${ }^{104}$

\section{Punti chiave}

- Scopi del follow-up comprendono: verifica della compliance alla dieta, comparsa di patologie autoimmuni associate, possibile sviluppo di sindrome metabolica e insorgenza di complicanze.

- Valutazione dei parametri di assorbimento intestinale (ferritina, folatemia, vitamina D3, vitamina B12) e della sierologia come indice di buon compenso ed aderenza alla dieta.

- Importanza del controllo dello stato della mucosa duodenale dopo almeno 1 anno di dieta senza glutine nei pazienti che rimangono sintomatici e con deficit dei parametri di assorbimento.

- Metodiche strumentali rilevanti da effettuare in caso di sospetta complicanza: videocapsula, enteroRM, entero-TC, PET.

\section{Dieta e nuove terapie}

La dieta senza glutine è al momento l'unica ed efficace terapia disponibile per il paziente celiaco in quanto è in grado di indurre la scomparsa dei sintomi sia intestinali che extraintestinali, la negativizzazione degli anticorpi e la ricrescita dei villi intestinali. Inoltre la dieta ha un effetto protettivo sulle complicanze neoplastiche e non della celiachia. Accanto a questi estremi vantaggi sono però presenti alcuni svantaggi fra cui un impatto negativo sulla qualità della vita, problemi psicologici, paura delle contaminazioni con glutine involontarie, possibile deficit di minerali e vitamine, sindrome metabolica ed aumentato rischio cardiovascolare, stipsi ostinata. La maggior parte degli svantaggi descritti può essere superata mediante un'attenta educazione e supervisione del paziente da parte di un medico specialista affiancato da consigli nutrizionali da parte di dietisti con esperienza nella MC. Dal punto di vista psicologico il supporto di uno specialista psicologo può essere molto utile nell'accettare la nuova condizione. ${ }^{130}$ Lo svantaggio causato dal peggioramento della qualità di vita porta molti pazienti celiaci a ricercare terapie alternative alla dieta aglutinata in quanto più del $40 \%$ dei pazienti si dichiara poco soddisfatto della sua dieta. ${ }^{131}$

Negli ultimi anni i ricercatori hanno cercato di venire incontro alle richieste dei pazienti celiaci che richiedono terapie alternative alla dieta. ${ }^{132}$ Per questo motivo sono in corso numerosi trial clinici, ma solo due hanno recentemente raggiunto la fase 3 di sperimentazione: i trial clinici con la larazotide acetato e le glutenasi da coltura batterica (ALV003). ${ }^{133,134}$ La lara- zotide acetato è una molecola antagonista della zonulina che, come riportato nel capitolo della patogenesi, induce il disassemblamento delle tight junctions, causando un aumento della permeabilità intestinale e quindi un maggior passaggio di glutine attraverso la barriera intestinale. La larazotide acetato antagonizza la zonulina riducendo il passaggio di glutine attraverso la barriera intestinale. ${ }^{133}$ Sebbene questa molecola non sia in grado di consentire la reintroduzione del glutine nella dieta del celiaco, si è dimostrata però in grado di bloccare piccole quantità di glutine migliorando in maniera significativa i sintomi negli episodi di contaminazione involontaria. ${ }^{133}$ Analogo discorso vale per le glutenasi ALV003, enzimi in grado di degradare le molecole di glutine a livello dello stomaco, prima del loro passaggio in duodeno. ${ }^{134}$ Anche questa strategia sì è dimostrata in grado di digerire solo piccole quantità di glutine, per cui risulterebbe anch'essa efficace unicamente contro le contaminazioni, ma non sarebbe in grado di proteggere il paziente con $\mathrm{MC}$ da grandi quantità di glutine. ${ }^{134}$ Infine, è in corso uno studio per la messa a punto di un vaccino volto a desensibilizzare il paziente con $\mathrm{MC}$ nei confronti dei peptidi della gliadina. La sperimentazione ha superato la fase 1 con buona tollerabilità da parte dei pazienti trattati, ma i tempi per verificarne l'efficacia si preannunciano ancora molto lunghi. Qualora venisse comprovata l'efficacia, il vaccino rappresenterebbe una cura definitiva per la MC. ${ }^{135}$

\section{Punti chiave}

- La dieta aglutinata è l'unica terapia della celiachia.

- Tante luci (scomparsa dei sintomi, negativizzazione della sierologia, normalizzazione della mucosa duodenale) e poche ombre (alterazioni metaboliche, deficit vitaminici, lieve incremento del rischio di patologie cardiovascolari) correlate alla dieta.

- Terapie alternative alla dieta senza glutine in corso d'opera includono la messa a punto di una pillola con enzimi per digerire il glutine o con enzimi antagonisti della zonulina, la proteina che aumenta la permeabilità intestinale.

- È in fase di studio un vaccino per desensibilizzare i celiaci verso il glutine come possibile cura definitiva della celiachia, ma ancora non è possibile prevedere se tale ambizioso progetto avrà un esito positivo.

\section{Bibliografia}

1. Fasano A, Catassi C. Celiac disease. N Engl J Med 2012; 367:2419-26.

2. Volta U, Caio G, Stanghellini V, De Giorgio R. The changing clinical profile of celiac disease: a 15-year experience (1998-2012) in an Italian referral center. BMC Gastroenterol 2014; 14:194. 
3. Volta U, Caio G, Tovoli F, De Giorgio R. Non-celiac gluten sensitivity: questions still to be answered despite increasing awareness. Cell Mol Immunol 2013; 10:383-92.

4. de Lorgeril M, Salen P. Gluten and wheat intolerance today: are modern wheat strains involved? Int J Food Sci Nutr. 2014; 65:577-81.

5. van den Broeck HC, de Jong HC, Salentijn EM, et al. Presence of celiac disease epitopes in modern and old hexaploid wheat varieties: wheat breeding may have contributed to increased prevalence of celiac disease. Theor Appl Genet 2010; 121:1527-39.

6. Corazza GR, Andreani ML, Biagi F, et al. The smaller size of the 'coeliac iceberg' in adults. Scand J Gastroenterol 1997; 32:917-9.

7. Ivarsson A, Persson LA, Juto P, et al. High prevalence of undiagnosed coeliac disease in adults: a Swedish population-based study. J Intern Med 1999; 245:63-8.

8. Riestra S, Fernandez E, Rodrigo L, et al. Prevalence of coeliac disease in the general population of Northern Spain. Scand J Gastroenterol 2000; 35:398-402.

9. Volta U, Bellentani S, Bianchi FB, et al. High prevalence of celiac disease in Italian general population. Dig Dis Sci 2001; 46:1500-5.

10. Mustalahti K, Catassi C, Reunanen A, et al. The prevalence of celiac disease in Europe: results of a centralized, international mass screening project. Ann Med 2010; 42:587-95.

11. Rubio-Tapia A, Ludvigsson JF, Brantner TL, et al. The prevalence of celiac disease in the United States. Am J Gastroenterol 2012; 107:1538-44.

12. Singh P, Arora S, Singh A, et al. Prevalence of celiac disease in Asia: A systematic review and meta-analysis. J Gastroenterol Hepatol 2016; 3:1095-101.

13. Stamnaes J, Sollid LM. Celiac disease: Autoimmunity in response to food antigen. Sem Immunol 2015; 27:343-52.

14. De Ritis G, Auricchio S, Jones HW, et al. In vitro (organ culture) studies of the toxicity of specific A-gliadin peptides in celiac disease. Gastroenterology 1988; 94:41-9.

15. Qiao SW, Bergseng E, Molberg Ø, et al. Antigen presentation to celiac lesion-derived $\mathrm{T}$ cells of a 33-mer gliadin peptide naturally formed by gastrointestinal digestion. J Immunol 2004; 173:1757-62.

16. Sollid L, Thorsby E. HLA susceptibility genes in celiac disease: genetic mapping and role in pathogenesis. Gastroenterology 1993; 105:910-22.

17. Congia M, Cucca F, Frau F, et al. A gene dosage effect of the DQA1*0501/DQB1*0201 allelic combination influences the clinical heterogeneity of celiac disease. Hum Immunol 1994; 40:138-42.

18. Zanoni G, Navone R, Lunardi C, et al. In celiac disease a subset of autoantibodies against transglutaminase binds toll-like receptor 4 and induces activation of monocytes. PloS Med 2006; 3:e358.

19. Stene LC, Honeyman MC, Hoffenberg EJ, et al. Rotavirus infection frequency and risk of celiac disease autoimmunity in early childhood: a longitudinal study. Am J Gastroenterol 2006; 101:2333-40.

20. Akobeng AK, Ramanan AV, Buchan I, Heller RF. Effect of breast feeding on risk of coeliac disease: a systematic review and meta-analysis of observational studies. Arch Dis Child 2006; 9:39-43.
21. Myléus A, Ivarsson A, Webb C, et al. Celiac disease revealed in 3\% of Swedish 12-year-olds born during an epidemic. J Pediatr Gastroenterol Nutr 2009; 49:170-6.

22. Ludvigsson JF, Fasano A. Timing of introduction of gluten and celiac disease risk. Ann Nutr Metab 2012; 60:22-9.

23. Ivarsson A, Myléus A, Norström F, et al. Prevalence of childhood celiac disease and changes in infant feeding. Pediatrics 2013; 131:e687-94.

24. Szajewska H, Shamir R, Chmielewska A, et al. Systematic review with meta-analysis: early infant feeding and coeliac disease-update 2015. Aliment Pharmacol Ther 2015; 41:1038-54.

25. Szajewska H, Shamir R, Mearin L, et al. Gluten Introduction and the Risk of Coeliac Disease: A Position Paper by the European Society for Pediatric Gastroenterology, Hepatology, and Nutrition. J Pediatr Gastroenterol Nutr 2016; 62:507-13.

26. Andrén Aronsson C, Lee HS, Koletzko S, et al. Effects of Gluten Intake on Risk of Celiac Disease: A CaseControl Study on a Swedish Birth Cohort. Clin Gastroenterol Hepatol 2016; 14:403-9.

27. Leonard MM, Camhi S, Huedo-Medina TB, Fasano A. Celiac Disease Genomic, Environmental, Microbiome, and Metabolomic (CDGEMM) Study Design: Approach to the Future of Personalized Prevention of Celiac Disease. Nutrients 2015; 7:9325-36.

28. Lionetti E, Castellaneta S, Francavilla R, et al. Introduction of gluten, HLA status, and the risk of celiac disease in children. N Engl J Med 2014; 371:1295-303.

29. Vriezinga SL, Auricchio R, Bravi E, et al. Randomized feeding intervention in infants at high risk for celiac disease. N Engl J Med 2014; 371:1304-15.

30. Korponay-Szabò IR, Halttunen T, Szalai Z, et al. In vivo targeting of intestinal and extraintestinal transglutaminase 2 by coeliac autoantibodies. Gut 2004; 53:641-8.

31. Diosdado B., Wijmenga C. Molecular mechanisms of the adptive, innate and regulatory immune responses in the intestinal mucosa of celiac disease patients. Expert Rev Mol Diagn 2005; 5:681-700.

32. Jabri B, Kasarda DD, Green PH. Innate and adaptive immunity: the yin and yang of celiac disease. Immunol Rev 2005; 206:219-31.

33. Fasano A. Regulation of intercellular tight junctions by zonula occludens toxin and its eukariotic analogue zonulin. Ann NY Acad Sci 2000; 915:214-22.

34. Fasano A, Berti I, Gerarduzzi T, et al. Prevalence of celiac disease in at-risk and not-at-risk groups in the United States: a large multicenter study. Arch Intern Med 2003; 163:286-92.

35. Högberg L, Fälth-Magnusson K, Grodzinsky K, et al. Familial prevalence of coeliac disease: a twenty-year follow-up study. Scand J Gastroenterol 2003; 38:61-5.

36. Esteve M, Rosinach M, Fernández-Bañares F, et al. Spectrum of gluten-sensitive enteropathy in first-degree relatives of patients with coeliac disease: clinical relevance of lymphocytic enteritis. Gut 2006; 55:1739-45.

37. Biagi F, Campanella J, Bianchi PI, et al. The incidence of coeliac disease in adult first degree relatives. Dig Liver Dis 2008; 40:97-100.

38. Romanos J, Rosén A, Kumar V, et al. Improving coeliac disease risk prediction by testing non-HLA variants additional to HLA variants. Gut 2014; 63:415-22. 
39. Roy A, Pallai M, Lebwohl B, et al. Attitudes Toward Genetic Testing for Celiac Disease. J Genet Couns 2016; 25:270-8.

40. Karell K, Louka AS, Moodie SJ, et al. HLA type in celiac disease patients not carrying the DQA $1 * 05$ DQB1*02 (DQ2) heterodimer: results from the European Genetics Cluster on Celiac Disease. Hum Immunol 2003; 64:469-77.

41. Sharma A, Liu X, Hadley D, et al. Identification of NonHLA Genes Associated with Celiac Disease and Country-Specific Differences in a Large, International Pediatric Cohort. PLoS One 2016; 11:e0152476.

42. van Heel DA, Hunt K, Greco L, Wijmenga C. Genetics in coeliac disease. Best Pract Res Clin Gastroenterol 2005; 19:323-39.

43. Mazzilli MC, Calabrò A, Catassi C, et al. Linee guida per la standardizzazione del test HLA per la celiachia. Celiachia Notizie 2008;1:18-19.

44. Fasano A. Celiac disease: how to handle a clinical chamaleon. N Engl J Med 2003; 348:2568-70.

45. Woods W. Coeliac disease: the great imitator. Med J Aust 2004; $181: 371$

46. Ludvigsson JF, Leffler DA, Bai JC, et al. The Oslo definitions for coeliac disease and related terms. Gut 2013; 6:43-52.

47. Baydoun A, Maakaron JE, Halawi H, et al. Hematological manifestations of celiac disease. Scand J Gastroenterol 2012; 47:1401-11.

48. Kamycheva E, Goto T, Camargo CA Jr. Celiac disease is associated with reduced bone mineral density and increased FRAX scores in the US National Health and Nutrition Examination Survey. Osteoporos Int 2017; 28:781-90.

49. Krzywicka B, Herman K, Kowalczyk-Zając M, Pytrus T. Celiac disease and its impact on the oral health status - review of the literature. Adv Clin Exp Med. 2014; 23:675-81.

50. Volta U, De Franceschi L, Lari F, et al. Coeliac disease hidden by cryptogenic hypertransaminasaemia. Lancet 1998; 352:26-9.

51. Volta U, Granito A, De Franceschi L, et al. Anti-tissue transglutaminase antibodies as predictors of silent coeliac disease in patients with hypertransaminasaemia of unknown origin. Dig Liv Dis 2001; 33:420-5.

52. Volta U, Caio G, Tovoli F, De Giorgio R. Gut-liver axis: an immune link between celiac disease and primary biliary cirrhosis. Expert Rev Gastroenterol Hepatol. 2013; 7:253-61.

53. Volta U, Tovoli F, Caio G. Clinical and immunological features of celiac disease in patients with Type 1 diabetes mellitus. Expert Rev Gastroenterol Hepatol 2011; 5:479-87.

54. Caio G, De Giorgio R, Venturi A, et al. Clinical and immunological relevance of anti-neuronal antibodies in celiac disease with neurological manifestations. Gastroenterol Hepatol Bed Bench 2015; 8:146-52.

55. Saccone G, Berghella V, Sarno L, et al. Celiac disease and obstetric complications: a systematic review and metanalysis. Am J Obstet Gynecol 2016; 214:225-34.

56. Farthing MJG., Edwards CRW, Rees LH, Dawson AM. Male gonadal function in coeliac disease: sexual dysfunction, infertility and semen quality. Gut 1982; 23:608-614.

57. Leffler DA, Green PH, Fasano A. Extraintestinal mani- festations of coeliac disease. Nat Rev Gastroenterol Hepatol 2015; 12:561-71.

58. Gale L, Wimalaratna H, Brotodiharjo A, Duggan JM. Down's syndrome is strongly associated with coeliac disease. Gut 1997; 40:492-6.

59. Bonamico M, Pasquino AM, Mariani P, et al. Prevalence and clinical picture of celiac disease in Turner syndrome. J Clin Endocrinol Metab 2002; 87:5495-8.

60. Giannotti A, Tiberio G, Castro M, et al. Coeliac disease in Williams syndrome. J Med Genet 2001; 38:767-8.

61. Iltanen S, Collin P, Korpela M, et al. Celiac disease and markers of celiac latency in patients with primary Sjögren's syndrome. Am J Gastroenterol 1999; 94:1042-6.

62. Volta U, De Franceschi L, Molinaro N, et al. Frequency and significance of anti-gliadin and anti-endomysial antibodies in autoimmune hepatitis. Dig Dis Sci 1998; 43:2190-5

63. Volta U, Rodrigo L, Granito A, et al. Celiac disease in autoimmune cholestatic liver disorders. Am J Gastroenterol 2002; 97:2609-13.

64. Volta U, Bardazzi F, Zauli D, et al. Serological screening for coeliac disease in vitiligo and alopecia areata. $\mathrm{Br} \mathrm{J}$ Dermatol 1997; 136:801-2.

65. O' Leary C, Walsh CH, Wieneke P, et al. Coeliac disease and autoimmune Addison's disease: a clinical pitfall. QJM 2002; 95:79-82.

66. Cataldo F, Marino V, Ventura A, et al. Prevalence and clinical features of selective immunoglobulin A deficiency in coeliac disease: an Italian multicentre study. Gut 1998; 42:362-5.

67. Curione M, Barbato M, De Biase L, et al. Prevalence of coeliac disease in idiopathic dilated cardiomiopathy. Lancet 1999; 354:222-3.

68. Volta U, Caio G, Boschetti E, et al. Seronegative celiac disease: Shedding light on an obscure clinical entity. Dig Liver Dis 2016; 48:1018-22.

69. Mooney PD, Evans KE, Singh S, Sanders DS. Treatment failure in coeliac disease: a practical guide to investigation and treatment of non-responsive and refractory coeliac disease. J Gastrointest Liver Dis 2012; 21:197-203.

70. Volta U, Tovoli F, Piscaglia M, et al. Old and new serological test for celiac disease screening. Exp Rev Gatroenterol Hepatol 2010; 4:31-5.

71. Caio G, Volta U. Coeliac disease: changing diagnostic criteria? Gastroenterol Hepatol Bed Bench. 2012; 5:119-22.

72. Husby S, Koletzko S, Korponay-Szabó IR, et al. European Society for Pediatric Gastroenterology, Hepatology, and Nutrition guidelines for the diagnosis of coeliac disease. J Pediatr Gastroenterol Nutr 2012; 54:136-60.

73. Catassi C, Fasano A. Celiac Disease Diagnosis: Simple Rules Are Better Than Complicated Algorithms. Am J Med 2010; 123:691-3.

74. Kostopoulou O, Devereaux-Walsh C, Delaney BC. Missing celiac disease in family medicine: the importance of hypothesis generation. Med Decis Making 2009; 29:282-90.

75. Zanchetta MB, Longobardi V, Bai JC. Bone and Celiac Disease. Curr Osteoporos Rep. 2016; 14:43-8.

76. Corazza GR, Zoli G, Di Sabatino A, et al. A reassessment of splenic hypofunction in celiac disease. Am J Gastroenterol 1999; 94:391-7. 
77. Caraceni P, Benazzi B, Caio G, et al. Hyposplenism as a cause of pneumococcal meningoencephalitis in an adult patient with celiac disease. Ital J Med 2011; 5:124-7.

78. Di Sabatino A, Rosado MM, Cazzola P, et al. Splenic hypofunction and the spectrum of autoimmune and malignant complications in celiac disease. Clin Gastroenterol Hepatol 2006; 4:179-86.

79. Villalta D, Tonutti E, Prause C, et al. IgG antibodies against deamidated gliadin peptides for diagnosis of celiac disease in patients with IgA deficiency. Clin Chem 2010; 56:464-8.

80. Volta U, Molinaro N, De Franceschi L, et al. IgA antiendomysial antibodies on human umbilical cord tissue for celiac disease screening: save both money and monkeys. Dig Dis Sci 1995; 40:1902-5.

81. Stern M. Comparative evaluation of serologic tests for celiac disease: a European initiative toward standardization. J Pediatr. Gastroenterol Nutr 2000; 31:513-9.

82. Salardi S, Volta U, Zucchini S, et al. Prevalence of celiac disease in children with type 1 diabetes mellitus increased in the mid-1990 s: an 18-year longitudinal study based on anti-endomysial antibodies. J Pediatr Gastroenterol Nutr 2008; 46:612-4.

83. Volta U, Granito A, Fiorini E, et al. Usefulness of antibodies to deamidated gliadin peptides in celiac disease diagnosis and follow-up. Dig Dis Sci 2009; 853:1582-8.

84. Zucchini L, Giusti D, Gatouillat G, et al. Interpretation of serological tests in the diagnosis of celiac disease: Anti-deamidated gliadin peptide antibodies revisited. Autoimmunity 2016; 49:414-20.

85. Amarri S, Alvisi P, De Giorgio R, et al. Antibodies to deamidated gliadin peptides: an accurate predictor of coeliac disease in infancy. J Clin Immunol 2013; 33:1027-30

86. Oberhüber G, Granditsch G, Vogelsang H. The histopathology of celiac disease: time for a standardized report scheme for pathologists. Eur J Gastroenterol Hepatol 1999; 11:1185-94.

87. Corazza GR, Villanacci V. Coeliac Disease: some considerations on the histological diagnosis. J Clin Pathol 2005; 58: 573-4.

88. Oxentenko AS, Murray JA. Celiac Disease: Ten Things That Every Gastroenterologist Should Know. Clin Gastroenterol Hepatol 2015; 13:1396-404.

89. Villanacci V, Ceppa P, Tavani E, et al. Coeliac disease: the histology report. Dig Liver Dis 2011; 43:385-95.

90. Rostami-Nejad M, Villanacci V, Hogg-Kollars S, et al. Endoscopic and histological pitfalls in the diagnosis of celiac disease: A multicentre study assessing the current practice. Rev Esp Enferm Dig 2013; 105:326-33.

91. Brown I, Mino-Kenudson M, Deshpande V, Lauwers GY. Intraepithelial lymphocytosis in architecturally preserved proximal small intestinal mucosa. Arch Pathol Lab Med 2006; 130:1020-5.

92. Biagi F, Bianchi PI, Campanella J, et al.The prevalence and the causes of minimal intestinal lesions in patients complaining of symptoms suggestive of enteropathy. A follow-up study. J Clin Pathol 2008; 61:1116-8.

93. Kakar S, Nehra V, Murray JA, et al. Significance of intraepithelial lymphocytosis in small bowel biopsy samples with normal mucosa architecture. Am J Gastroenterol 2003; 98:2027-33.
94. Upton MP. "Give us this day our daily bread". Evolving concepts in celiac sprue. Arch Pathol Lab Med 2008; 132:1594-9.

95. Volta U, Villanacci V. Celiac disease: diagnostic criteria in progress. Cell Mol Immunol 2011; 8:96-102.

96. Volta U, Caio G, Giancola F, et al. Features and Progression of Potential Celiac Disease in Adults. Clin Gastroenterol Hepatol 2016; 14:686-93.

97. Kurppa K, Collin P, Viljamaa M, et al. Diagnosing mild enteropathy celiac disease: a randomized, controlled clinical study. Gastroenterology 2009; 136:816-23.

98. Tosco A, Salvati VM, Auricchio R, et al. Natural history of potential celiac disease in children. Clin Gastroenterol Hepatol 2011; 9:320-5.

99. Lionetti E, Castellaneta S, Pulvirenti A, et al. Prevalence and natural history of potential celiac disease in at-family-risk infants prospectively investigated from birth. J Pediatr 2012; 161:908-14.

100. Zanini B, Caselani F, Magni A, et al. Celiac disease with mild enteropathy is not mild disease. Clin Gastroenterol Hepatol 2013; 11:253-8.

101. Biagi F, Trotta L, Alfano C, et al. Prevalence and natural history of potential celiac disease in adult patients. Scand J Gastroenterol 2013; 48:537-42.

102. Auricchio R, Tosco A, Piccolo E, et al. Potential celiac children: 9-year follow-up on a gluten-containing diet. Am J Gastroenterol 2014; 109:913-21.

103. Kurppa K, Collin P, Lindfors K, et al. Spontaneous negative seroconversion of endomysial antibodies does not exclude subsequent celiac disease. J Pediatr Gastroenterol Nutr 2011; 53:576-9.

104. Rubio-Tapia A, Hill ID, Kelly CP, et al. ACG clinical guidelines: diagnosis and management of celiac disease. Am J Gastroenterol 2013; 108:656-76.

105. Rostami K, Kerckhaert J, Tiemessen R, et al. Sensitivity of antiendomysium and antigliadin antibodies in untreated celiac disease: disappointing in clinical practice. Am J Gastroenterol 1999; 94:888-94.

106. Shah VH, Rotterdam H, Kotler DP, et al. All that scallops is not celiac disease. Gastrointest Endosc 2000; 51:717-20.

107. Greenson JK. The biopsy pathology of non-coeliac enteropathy. Histopathology 2015; 66:29-36.

108. De Gaetani M, Tennyson CA, Lebwohl B, et al. Villous atrophy and negative celiac serology: a diagnostic and therapeutic dilemma. Am J Gastroenterol 2013; 108:647-53.

109. Aziz I, Peerally MF, Barnes JH, et al. The clinical and phenotypical assessment of seronegative villous atrophy; a prospective UK centre experience evaluating 200 adult cases over a 15 -year period (2000-2015). Gut 2016. [Epub ahead of print]

110. Dewar DH, Donnelly SC, McLaughlin SD, et al. Celiac disease: management of persistent symptoms in patients on a gluten-free diet. World J Gastroenterol 2012; 18:1348-56.

111. Rubio-Tapia A, Ludvigsson JF, Choung RS, et al. Increased mortality among men aged 50 years old or above with elevated IgA anti-transglutaminase antibodies: NHANES III. BMC Gastroenterol 2016; 16:136.

112. Biagi F, Gobbi P, Marchese A, et al. Low incidence but poor prognosis of complicated coeliac disease: a retrospective multicentre study. Dig Liver Dis 2014; 46:227-30. 
113. Al-Toma A, Goerres MS, Meijer JW, et al. Human leukocyte antigen-DQ2 homozygosity and the development of refractory celiac disease and enteropathy-associated T-cell lymphoma. Clin Gastroenterol Hepatol 2006; 4:315-9.

114. Di Sabatino A, Brunetti L, Carnevale Maffè G, et al. Is it worth investigating splenic function in patients with celiac disease? World J Gastroenterol 2013; 19:2313-8.

115. Roshan B, Leffler DA, Jamma S, et al. The incidence and clinical spectrum of refractory celiac disease in a north american referral center. Am J Gastroenterol 2011; 106:923-8.

116. Malamut G, Afchain P, Verkarre V, et al. Presentation and long-term follow-up of refractory celiac disease: comparison of type I with type II. Gastroenterology 2009; 136: 81-90.

117. Nasr I, Nasr I, Campling H, Ciclitira PJ. Approach to patients with refractory coeliac disease. F1000Res. $2016 ; 5$.

118. Nasr I, Nasr I, Beyers C, et al. Recognising and managing refractory coeliac disease: a tertiary centre experience. Nutrients 2015; 7: 9896-907.

119. Williams MJ, Sutherland DH, Clark CG. Lymphomsarcoma of the small intestine with a malabsorption syndrome and pneumatosis intestinalis. Report of a case with peroral jejunal biopsy. Gastroenterology 1963; 45:550e7.

120. Silano M, Volta U, Mecchia AM, et al. Delayed diagnosis of coeliac disease increases cancer risk. BMC Gastroenterology 2007; 7:8.

121. Malamut G, Cellier C. Complications of coeliac disease. Best Pract Res Clin Gastroenterol 2015; 29:451-8.

122. Ilus T, Kaukinen K, Virta LJ, et al. Incidence of malignancies in diagnosed celiac patients: a populationbased estimate. Am J Gastroenterol. 2014; 109:1471-7.

123. Aparicio T, Zaanan A, Svrcek M, et al. Small bowel adenocarcinoma: epidemiology, risk factors, diagnosis and treatment. Dig Liver Dis 2014; 46:97-104.

124. Catassi C, Copparoni R, Corazza GR, et al. Protocollo per la diagnosi ed il follow-up della malattia celiaca. Gazzetta Ufficiale della Repubblica Italiana, Serie Generale n.191 del 19/08/2015, pp. 148-158.

125. Tortora R, Capone P, De Stefano G, et al. Metabolic syndrome in patients with coeliac disease on a glutenfree diet. Aliment Pharmacol Ther 2015; 41:352-9.

126. Reilly NR, Lebwohl B, Hultcrantz R, et al. Increased risk of non-alcoholic fatty liver disease after diagnosis of celiac disease. J Hepatol 2015; 62:1405-11.

127. Laurikka P, Salmi T, Collin P, et al. Gastrointestinal Symptoms in Celiac Disease Patients on a Long-Term Gluten-Free Diet. Nutrients 2016; 14:8.

128. Thompson T. Folate, iron, and dietary fiber contents of the gluten-free diet. J Am Diet Assoc 2000; 100:1389-96.

129. Carroccio A, Ambrosiano G, Di Prima L, et al. Clinical symptoms in celiac patients on a gluten-free diet. Scand J Gastroenterol 2008; 43:1315-21.

130. Roos S, Kärner A, Hallert C. Psychological well-being of adult coeliac patients treated for 10 years. Dig Liver Dis 2006; 38:177-80.

131. Aziz I, Evans KE, Papageorgiou V, Sanders DS. Are patients with coeliac disease seeking alternative therapies to a gluten-free diet? J Gastrointestin Liver Dis 2011; 20:27-31.

132. McCarville JL, Caminero A, Verdu EF. Pharmacological approaches in celiac disease. Curr Opin Pharmacol 2015; 25:7-12.

133. Leffler DA, Kelly CP, Green PH, et al. Larazotide acetate for persistent symptoms of celiac disease despite a gluten-free diet: a randomized controlled trial. Gastroenterology 2015; 148:1311-9.

134. Lähdeaho ML, Kaukinen K, Laurila K, et al. Glutenase ALV003 attenuates gluten-induced mucosal injury in patients with celiac disease. Gastroenterology 2014; 146:1649-58.

135. Anderson RP, Jabri B. Vaccine against autoimmune disease: antigen-specific immunotherapy. Curr Opin Immunol. 2013; 25:410-7. 


\title{
Malattie epato-biliari autoimmuni
}

\author{
Mario Visconti, ${ }^{1}$ Luca Fontanella ${ }^{2}$, Giuseppina Marino Marsilia ${ }^{3}$ \\ ${ }^{1}$ Primario emerito di Medicina Interna, ASL Napoli $1 ;{ }^{2}$ Medico Dirigente Centro per le Malattie del Fegato, Ospedale del \\ Buon Consiglio Fatebenefratelli, Napoli, Italia; ${ }^{3}$ Medico Dirigente Anatomia Patologica, AORN A. Cardarelli, Napoli, Italia
}

\section{Introduzione}

Le malattie autoimmuni del fegato e delle vie biliari (autoimmune liver diseases $=$ AILD) sono malattie ad eziologia non ben definita e a patogenesi immunitaria, caratterizzate da lesioni infiammatorie che possono interessare il parenchima epatico, i piccoli dotti biliari intraepatici o tutto il sistema biliare.

Si distinguono nel loro ambito tre entità da lungo tempo definite sul piano nosografico: l'epatite cronica autoimmune (autoimmune hepatitis $=\mathrm{AIH}$ ), la cirrosi biliare primitiva o colangite biliare primitiva secondo una definizione nosologica più recente ( $p r i-$ mary biliary cholangitis $=$ PBC) e la colangite sclerosante primitiva (primary sclerosing cholangitis $=$ PSC). Esse si differenziano per aspetti epidemiologici, clinici, morfologici e sierologici, per potenzialità evolutive, per differenti associazioni con altre patologie immunitarie dell'apparato digerente (Tabellla 1$)^{1} \mathrm{o}$ di organi extradigestivi, per possibilità di trattamento terapeutico.

Di più recente individuazione sono invece le sindromi da overlap (overlapping syndrome $=\mathrm{OS}$ ), nelle quali si sovrappongono caratteri clinici,morfologici e sierologici che sono propri delle malattie su indicate.

In questo articolo ribadiamo in breve alcune conoscenze fondamentali delle epatobiliopatie autoimmuni, anche se da tempo ben note, e segnaliamo in modo più ampio gli aspetti innovativi individuati o definiti in questi ultimi anni, in particolare le conoscenze attuali sulle OS e su eventuali nuove possibilità e prospettive terapeutiche.

Corrispondente: Mario Visconti, Rampe S. Giovanni Maggiore 12, 80134 Napoli, Italia.

Tel.: +39.081.5515379

E-mail: mario.visconti1@tin.it

Articolo pubblicato secondo la Creative Commons Attribution NonCommercial 4.0 License (CC BY-NC 4.0).

CCopyright M. Visconti et al., 2017

Licensee PAGEPress, Italy

QUADERNI - Italian Journal of Medicine 2017; 5(7):115-137

\section{Epatite cronica autoimmune}

L'AIH si può definire come un'infiammazione epatocellulare automantenuta dalla perdita della tolleranza immunitaria degli epatociti per causa ignota e caratterizzata da specifiche alterazioni istologiche, ipergammaglobulinemia e presenza di autoanticorpi (AA) nel siero. È una malattia nella quale la terapia immunosoppressiva con i cortisonici ha una notevole efficacia, documentata da importanti studi clinici. Ciò nonostante sussistono ancora problemi diagnostici e terapeutici, dovuti a due cause principali: la relativa rarità e la marcata eterogeneità della malattia. ${ }^{2}$

\section{Epidemiologia}

L'AIH è una malattia poco frequente, ma non eccezionale. I dati più attendibili sulla sua frequenza in Europa sono quelli registrati nei Paesi scandinavi, laddove l'incidenza è di $1-2$ per 100.000 abitanti per anno e la prevalenza è di 11-17 per 100.000 abitanti. Ma vi è comunque una evidente difformità tra $i$ dati dichiarati in Norvegia nel 1998 e quelli ben inferiori dichiarati in Svezia nel 2010. ${ }^{3,4}$ In Danimarca invece è stato rilevato che dal 1994 al 2012 la prevalenza è raddoppiata sino a raggiungere un livello di 24 casi per 100.000 abitanti. ${ }^{5} \mathrm{Nel}$ Nord America, laddove sono meno frequenti le epatiti croniche virali, le AIH rappresentano 1'11-23\% delle patologie epatiche croniche. È interessante segnalare che dati di prevalenza relativamente più elevati sono descritti in aree abitate da una popolazione in maggior parte stabile: 42,5 casi e 24,5 casi per 100.000 abitanti sono stati riportati rispettivamente nei nativi dell'Alaska ${ }^{6} \mathrm{e}$ in Nuova Zelanda. ${ }^{7}$ Le casistiche descritte in Giappone ${ }^{8}$ e ancor più in Cina $^{9}$ farebbero ritenere che la malattia sia davvero rara nell'Estremo Oriente, ma segnalazioni più recenti, fondate su ricerche epidemiologiche più corrette, indicano un incremento dei casi di $\mathrm{AIH}$ in queste nazioni. ${ }^{10}$

Il sesso femminile è più colpito ( $70-80 \%$ dei casi), in particolar modo tra i 15 e i 40 anni di età; ma la malattia si può manifestare anche nei bambini e nei soggetti con più di 60 anni. ${ }^{11} \mathrm{Al}$ King's College Hospital di Londra, in un centro di cura terziario delle epatopatie croniche in età pediatrica, nell'ultima decade è 
stato riscontrato un aumento davvero significativo (7 volte) dell'incidenza delle AIH. ${ }^{12}$

\section{Istologia}

Il quadro istologico dell'AIH (Figure 1 e 2) è di tipo epatitico e varia in rapporto allo stadio della malattia.
L'esordio acuto è caratterizzato da infiltrato linfoplasmacellulare portale e periportale, epatite all'interfaccia, più o meno estesa, scarsa fibrosi e attività necroinfiammatoria nel lobulo.

L'attività infiammatoria, sebbene variabile, è di solito intensa e caratterizzata dalla presenza di plasmacellule nell'infiltrato infiammatorio portale $\mathrm{e}$ intralobulare. I linfociti presenti nello spazio portale

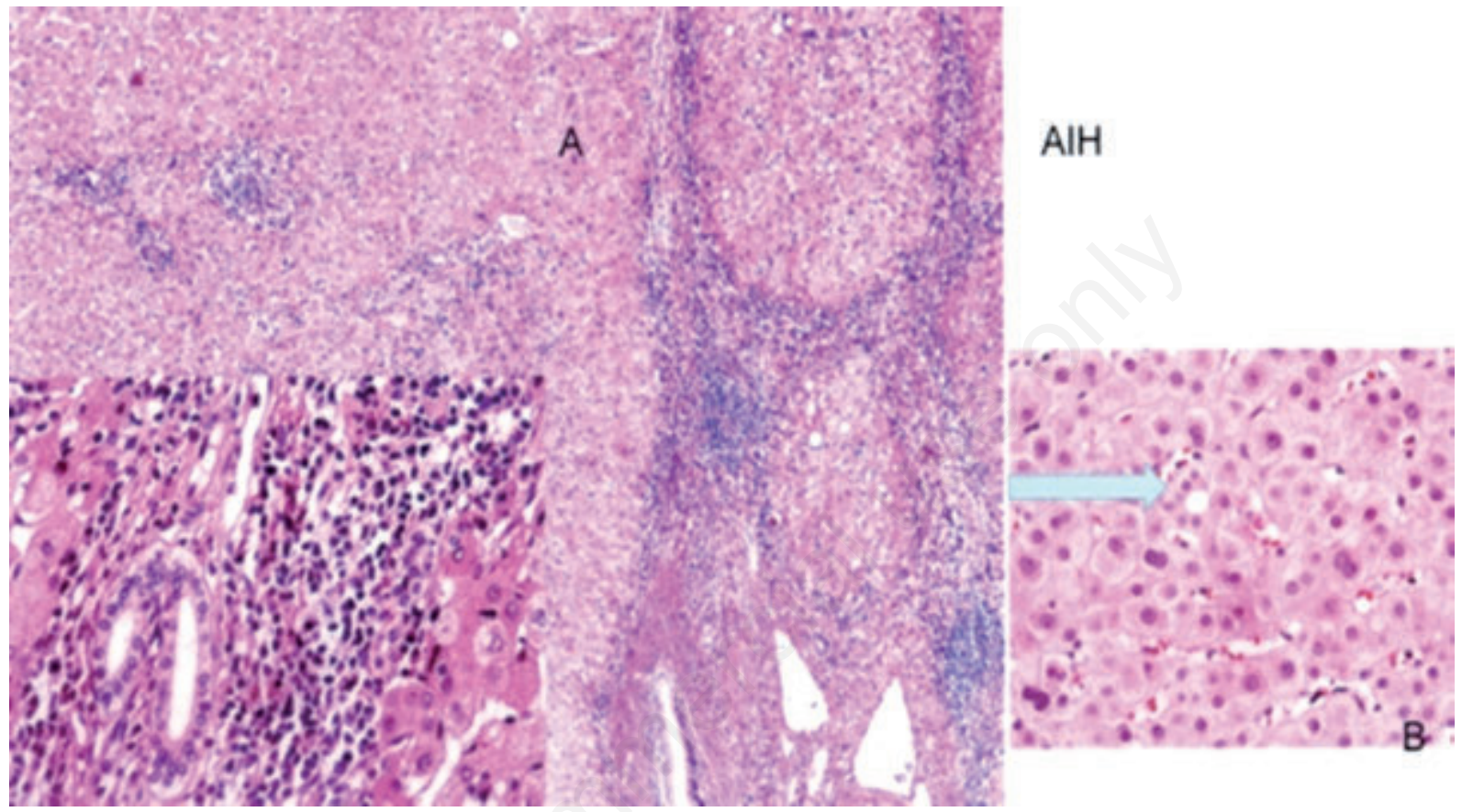

Figura 1. Alterazioni istologiche dell'AIH. A) A sinistra infiltrato linfocitario intralobulare. A destra l'infiltrato linfoplasmacellulare occupa lo spazio portale superando la lamina limitante e determinando epatite all'interfaccia. Nel riquadro, a maggiore ingrandimento uno spazio portale: si nota che il dotto è circondato, ma non danneggiato dall'infiltrato infiammatorio. B) La freccia indica una rosetta biliare. Si osserva, inoltre, rigenerazione epatocitaria caratterizzata da elementi di piccola taglia assemblati in lamine bicellulari.

Tabella 1. Possibili associazioni delle epatobiliopatie autoimmuni.

\begin{tabular}{lll}
\hline AIH & PBC & PSC \\
\hline Tiroidite autoimmune* & Tiroidite autoimmune* & Colite ulcerosa* \\
\hline Malattia di Graves & Artrite reumatoide* & Malattia di Crohn \\
\hline Colite ulcerosa* & Sindrome di Sjögren* & Cancro del colon/retto \\
\hline Anemia emolitica autoimmune & Scleroderma/sindrome CREST & Malattia celiaca* \\
\hline Trombocitopenia idiopatica & Malattia celiaca* & Colangiocarcinoma \\
\hline Lupus eritematoso sistemico & Connettivite mista & Artrite reumatoide* \\
\hline Sindrome di Sjögren* & Acidosi tubulare renale & Istiocitosi X \\
\hline Polimiosite & Fibrosi retroperitoneale & \\
\hline Connettivite mista & & \\
\hline
\end{tabular}

Malattia celiaca*

*Possibile associazione con numerose malattie autoimmuni epatobiliari. Modificata da Feld JJ, Heathcote EJ. ${ }^{1}$ 
sono prevalentemente $\mathrm{CD} 4+$, mentre quelli che determinano epatite all'interfaccia sono CD $8+{ }^{13}$

Circa un terzo delle biopsie di pazienti con AIH diagnosticata clinicamente, tuttavia, ha poche o nessuna plasmacellula nell'infiltrato; d'altra parte, la loro presenza nell'infiltrato infiammatorio di un'epatite a eziologia sconosciuta, deve sempre far prendere in considerazione quella autoimmune. ${ }^{14}$

L'attività necroinfiammatoria lobulare può essere di grado variabile, da minimo, con rari, piccoli aggregati di elementi infiammatori che circondano singoli epatociti in necrosi (corpi acidofili) a severo, con necrosi a ponte. Alla necrosi epatocitaria fa seguito la rigenerazione caratterizzata da elementi di piccola taglia disposti in lamine bicellulari e dalla formazione di rosette biliari.

I dotti biliari nella maggior parte dei casi presentano solo lievi alterazioni.

La presenza di granulomi o di steatosi macrovescicolare deve far sospettare un overlapping rispettivamente con una $\mathrm{PBC}$ o un'epatite $\mathrm{C}$.

Il progredire della malattia è caratterizzato dalla sostituzione delle aree necrotiche con la fibrosi e conseguente alterazione della struttura fino alla cirrosi.

Non esistono un grading e uno staging specifici per l'AIH; si utilizzano quelli delle epatiti croniche, Ludwig, ${ }^{15}$ METAVIR, ${ }^{16}$ Knodell, ${ }^{17}$ ecc.

Nei casi in cui viene sospesa la terapia immunosoppressiva, la biopsia può essere di ausilio per valutare la remissione o eventuale ripresa di malattia. La presenza di plasmacellule negli spazi portali è un segno del secondo evento. ${ }^{18}$

\section{Patogenesi}

La patogenesi delle AIH non è ancora del tutto chiara, ma appare assai probabile il concorso di almeno 5 fattori: i) predisposizione genetica correlata alla presenza di alcuni antigeni di istocompatibilità (HLA A1, B8, DR3, DR4); ii) esposizione sulla superficie della membrana cellulare degli epatociti di autoantigeni, come il citocromo P450 2D6 (CYP 450 2D6), bersaglio di anticorpi anti-LKM1, e il recettore delle asialoglicoproteine, bersaglio di specifici AA; iii) alterazione complessa della risposta immunitaria cellulare con intervento di varie citochine che provocano la differenziazione dei linfociti T CD4 helper (Th0) in cellule citotossiche Th17, Th1 e Th2, che con meccanismi diversi causano l'attivazione di cellule ad effetto citotossico diretto (linfociti T CD8 e natural killing); iv) l'evoluzione di linfociti B in plasmacellule con conseguente produzione di AA; ${ }^{19}$ v) l'azione di potenziali trigger, virali (HCV, HBV, citomegalovirus, HSV) e non virali (farmaci quali la minociclina, le statine, gli agenti anti-TNF), sul cui ruolo però i pareri sono discordi.

\section{Clinica}

L'AIH è ormai un'entità nosografica ben definita anche se può manifestarsi con quadri clinici differenti. Nel 25\% circa dei casi, soprattutto nei bambini, i primi sintomi della malattia sono quelli di un'epatite acuta similvirale. ${ }^{20}$

Nell'adulto un'epatite acuta può costituire realmente la prima espressione clinica della malattia o l'e-

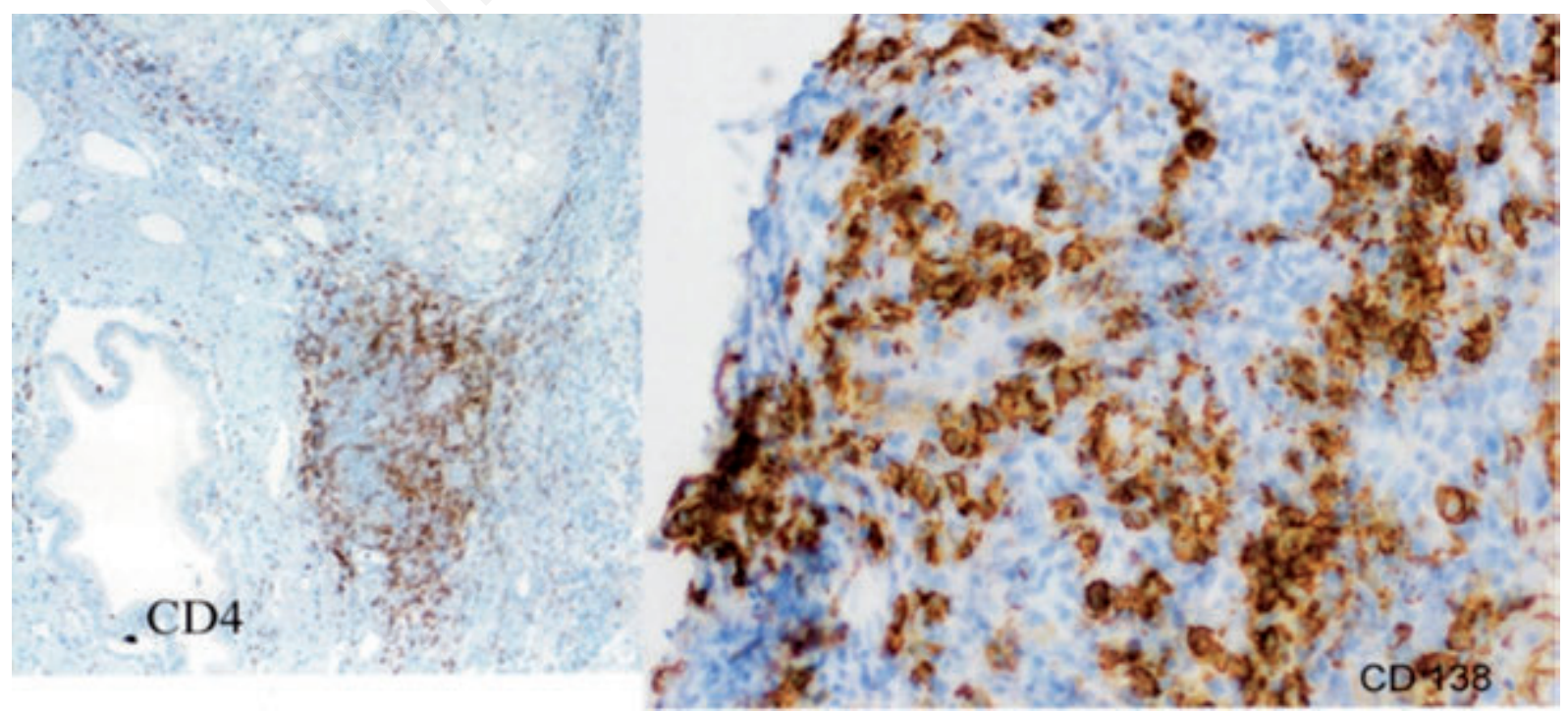

Figura 2. AIH. Aspetti citologici dell'infiltrato infiammatorio. A sinistra l'infiltrato linfocitario è costituito da linfociti T CD4+. A destra aggregati di plasmacellule CD 138+. 
sacerbazione di una patologia cronica già presente, ma non diagnosticata o erroneamente diagnosticata, anche già in fase evolutiva avanzata. ${ }^{20-23}$ Nelle forme a reale esordio acuto è possibile che non siano presenti le alterazioni sierologiche tipiche della malattia, ${ }^{24-25}$ per cui il sospetto diagnostico di AIH deve essere posto in tutti $i$ casi in cui non si riesca a individuare una diversa eziologia ed essere confermato con l'esame istologico. Infatti l'esatta diagnosi riveste grande importanza ai fini di un corretto indirizzo terapeutico e la tempestiva immunosoppressione può avere un effetto salvavita. ${ }^{26}$

Nell'adulto sono descritti anche casi asintomatici (sino al 25\%), svelati di solito da un moderato aumento dei valori delle aminotransferasi (AT), ma nella maggioranza dei casi la malattia sin dall'inizio ha caratteri di cronicità con sintomi aspecifici (astenia, malessere generale, nausea, anoressia, perdita di peso, dolore addominale alto, artromialgie., ma di entità diversa. Frequente è l'associazione con altre malattie, in particolare la tiroidite autoimmune, il diabete, le malattie infiammatorie intestinali, l'artrite reumatoide, l'amenorrea. Anche i casi asintomatici hanno abitualmente caratteri di progressiva evolutività e non raramente la diagnosi viene posta quando all'esame istologico sono già presenti una rilevante fibrosi o la cirrosi.

\section{Alterazioni di laboratorio}

Il profilo biuoumorale dell'AIH è caratterizzato da: i) un aumento delle AT seriche con un range di valori che, rispetto a quelli massimi normali (upper normal values $=\mathrm{UNV}$ ), possono essere lievemente o notevolmente superiori, talora anche sino a più di 50 volte; ii) un aumento della bilirubinemia con valori degli enzimi di colestasi, in particolare della fosfatasi alcalina (ALP), normali o di poco superiori alla norma; iii) un aumento dei valori delle immunoglobuline di classe $\operatorname{IgG}$ ( $85 \%$ dei casi), anche in assenza di cirrosi.

Non vi è una correlazione tra i livelli dell'incremento delle AT e la gravità degli aspetti istologici della malattia; le AT possono anche normalizzarsi spontaneamente nel decorso della malattia pur persistendo i segni istologici di un'attività infiammatoria, talora di notevole entità.

La normalità o la modesta alterazione degli enzimi di colestasi può costituire un importante dato per la diagnosi differenziale con le malattie immunitarie del fegato con prevalente impegno delle vie biliari (PBC, PSC).

L'incremento selettivo delle immunoglobuline di classe IgG (le immunoglobuline di classe IgA o IgM sono di solito nella norma o aumentate in misura lieve) può essere utile per la diagnosi differenziale con la steatoepatite alcolica e la PBC.

Naturalmente con il progredire della malattia verso la cirrosi possono comparire i segni di laboratorio tipici di questa malattia (ipoalbuminemia, leucopiastrinopenia, ecc.).

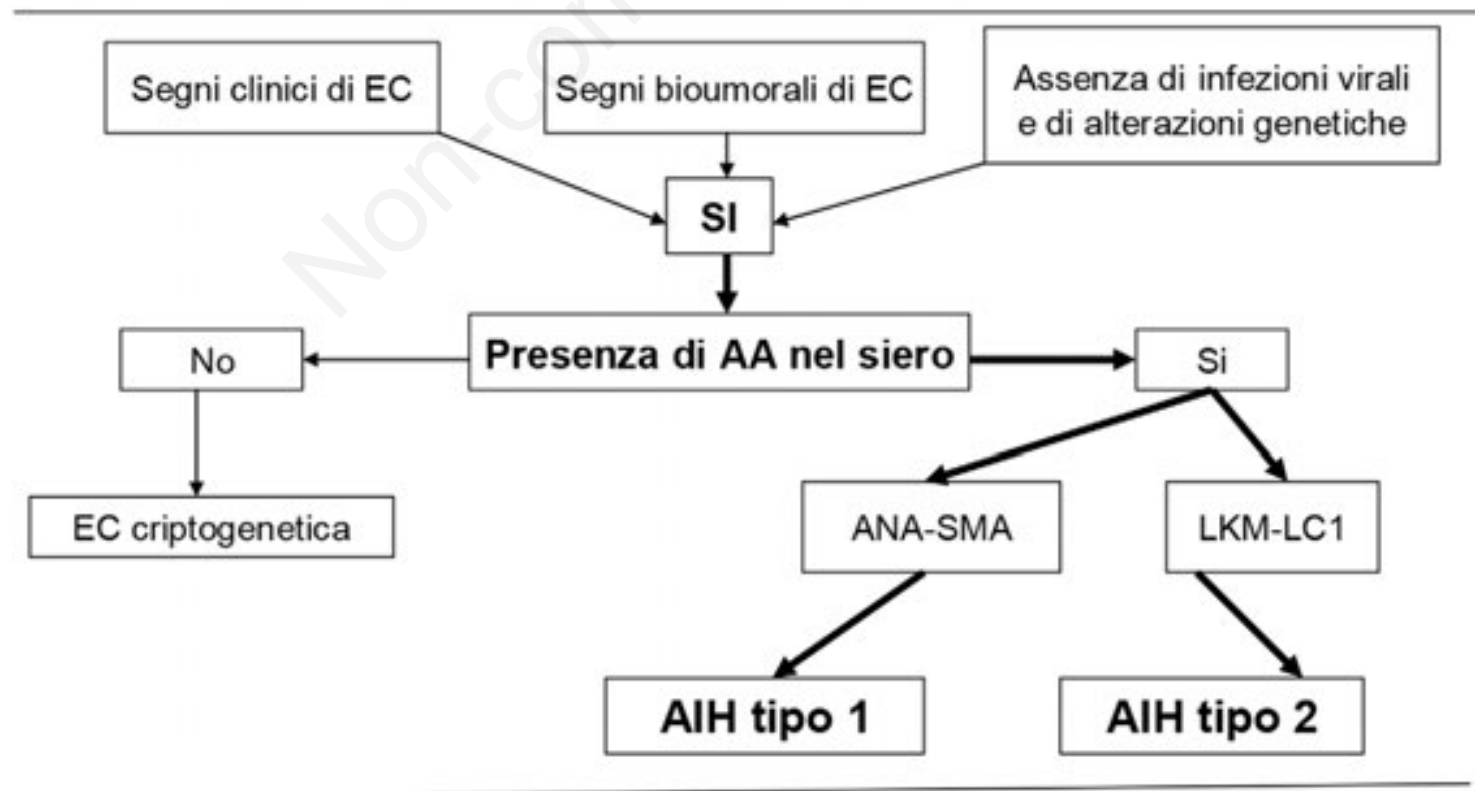

$\mathrm{AlH}=$ Epatite autoimmune; $\mathrm{EC}=$ Epatite cronica; $\mathrm{AA}=$ =Autoanticorpi; $\mathrm{ANA}=$ Anticorpi anti-nucleo; $S M A=A n t i c o r p i$ anti-muscolo liscio: $L K M=$ Anticorpi anti-microsomi epatici e renali di tipo 1; LC-1= Anticorpi anti-citosol epatico di tipo 1.

Figura 3. Algoritmo per la diagnosi e la classificazione delle AIH. Modificata da Bianchi F. et al., 2003. ${ }^{30}$ 


\section{Autoanticorpi}

Il principale criterio diagnostico di tutti i sistemi di scoring è costituito dalla presenza nel siero di AA anti-nucleo (ANA), anti-muscolo liscio (SMA) e antimicrosomi epatici e renali di tipo 1 (anti-LKM1) e anti-citosol epatico di tipo 1 (anti- LC1). ${ }^{27}$ In assenza di anti-KLM1 può essere rilevata la presenza (rara) di anti-LKM3. L'immunofluorescenza indiretta (IFL) è la tecnica di elezione per la ricerca degli AA: quando sono coesistenti alterazioni cliniche e di laboratorio sospette per AIH, nell'adulto titoli di $1 / 40$ possono indicare già un livello significativo e nel bambino possono avere valore anche livelli inferiori ( $1 / 20$ per ANA e SMA e 1/10 per anti-LKM1)., ${ }^{2,28}$ Se nelle ricerca di screening con l'IFL sono rilevabili anche anticorpi anti-mitocondrio (AMA) si deve porre il sospetto di una OS AIH-PBC.

In base agli AA si distinguono due tipi di AIH: il tipo 1, positivo per ANA e/o SMA, e il tipo 2, positivo per anti-LKM1 e anti-LC1. Nell'America del Nord il 96\% dei pazienti adulti risultano positivi per ANA o SMA o per entrambi i tipi di AA; solo il 4\% risulta positivo per anti-LKM1 e anti-LC1. Gli anti-LKM1 sono di più frequente riscontro nei pazienti europei e abitualmente non sono associati con gli ANA o i SMA (Figura 3). ${ }^{29}$

Le alterazioni cliniche, biochimiche e istologiche sono simili ma l'AIH di tipo 2 spesso esordisce in età pediatrica, ha caratteri di maggiore gravità nelle donne giovani ed è più frequentemente associata con altre malattie autoimmuni.

Viene da alcuni descritta anche un'AIH tipo 3, caratterizzata dalla presenza di AA per l'antigene solubile del fegato e l'antigene epato-pancreatico (antiSLA/LP), ma è più credibile che questi anticorpi siano un segno di un'AIH tipo 1 abitualmente associata a un decorso clinico più grave. ${ }^{30}$ È vero peraltro che gli antiSLA/LP in alcuni casi di AIH sono gli unici AA documentabili nel siero e assumono allora una notevole importanza diagnostica. ${ }^{31,32}$

Anche gli AA anticitoplasma dei neutrofili con pattern perinucleare (pANCA), descritti nell'AIH tipo 1, sono marker sierologici non specifici dell'AIH e la loro presenza potrebbe essere un segno di una OS AIH/PSC. Alcuni pANCA atipici reagiscono con componenti periferici della membrana nucleare e per tale motivo sono denominati pANNA. Sono rilevabili nell'AIH tipo 1 (non nell'AIH tipo 2) e possono essere considerati un ulteriore indicatore della diagnosi di AIH, soprattutto in assenza di altri anticorpi. ${ }^{19,30}$

Pur essendo molto importanti per la diagnosi e la classificazione delle $\mathrm{AIH}$, il ruolo patogenetico degli AA e il meccanismo con il quale possono contribuire al danno epatico non sono noti e debbono essere argomento di ulteriori ricerche.

\section{Condizioni fisiopatologiche particolari}

\section{AIH e gravidanza}

Raramente l'AIH viene diagnosticata in gravidanza; ma, come altre malattie autoimmuni, è relativamente frequente che si manifesti nel post-partum. Nelle donne che iniziano una gravidanza con la diagnosi già accertata di $\mathrm{AIH}$, è possibile che si verifichi un'attenuazione della malattia o anche una remissione, ma talora anche la sua riacutizzazione. Più frequente è la riacutizzazione nel post-partum. La terapia immunosoppressiva può essere continuata durante la gravidanza senza interferire con una sua favorevole evoluzione. ${ }^{2}$

\section{AIH IgG-4 correlate}

Le malattie IgG4-correlate sono malattie sistemiche immunomediate di recente individuazione caratterizzate da estesi infiltrati linfo-plasmocitari e processi fibrotici, a carico soprattutto delle ghiandole sottomandibolari, dei linfonodi, del pancreas, dei reni e dei polmoni. ${ }^{33}$ Sono stati descritti casi aneddotici di AIH potenzialmente IgG4 correlati, ${ }^{34,35}$ che pongono problemi di diagnosi differenziale con le PSC e non consentono di poter parlare con fondate motivazioni di una variante dell'AIH.

\section{Diagnosi}

Appare chiaro da quanto scritto in precedenza che la diagnosi di AIH è spesso difficile. L'International Autoimmune Hepatitis Group (IAIHG) ha stabilito nel $1993^{36}$ e rivisto nel $1999^{37} \mathrm{i}$ criteri diagnostici e un diagnostic scoring system per l'AIH, ma i criteri diagnostici erano davvero numerosi e complessi (dieci) e prevalentemente utili per finalità scientifiche. Uno studio successivo (2008) è stato eseguito dall'IAIHG con lo scopo di definire criteri diagnostici semplificati per la pratica clinica. ${ }^{38}$ Questo studio di coorte retrospettivo ha arruolato 359 pazienti con AIH e 393 controlli provenienti da 11 Centri di 10 nazioni del Nord e Sud America, dell'Europa e dell'Asia.

Tutti i Centri partecipanti erano specializzati nello studio delle malattie del fegato. I criteri diagnostici proposti sono stati, oltre il sesso e l'età, il titolo degli AA, il valore delle immunoglobuline seriche, l'assenza di epatite virale e il quadro istologico (Tabella 2). Lo score è stato validato da tre studi prospettici, che hanno dimostrato che esso ha un alto grado di sensibilità e di specificità per la diagnosi di $\mathrm{AIH} .{ }^{39-41}$

\section{Terapia}

Le AIH gravi possono essere causa di morte senza un adeguato intervento terapeutico; per tale motivo sono di fondamentale importanza una diagnosi tempestiva e la terapia immunosoppressiva. Nonostante 
una corretta terapia, è comunque possibile un'evoluzione sino alla cirrosi. Talora la cirrosi può essere già presente al momento della diagnosi; la terapia è in ogni caso utile perché può ridurre l'attività della malattia. ${ }^{30,42} \mathrm{La}$ terapia immunosoppressiva può essere ipotizzata anche nei pazienti adulti asintomatici con lievi manifestazioni bioumorali e istologiche, ma la decisione deve tener conto dei possibili effetti collaterali della terapia stessa. I pazienti con attività di malattia minima o assente possono non essere trattati, ma necessitano di controlli a brevi intervalli di tempo, ad es. ogni 3-6 mesi. ${ }^{11}$

L'efficacia della terapia immunosoppressiva è stata studiata in numerosi trial controllati fin dal 1960-70. ${ }^{2}$ È stato così documentato che, in confronto al placebo, sia la monoterapia con steroidi a dosi iniziali differenti (da $15 \mathrm{mg} /$ die di prednisolone a $60 \mathrm{mg} /$ die di prednisone) sia la terapia di combinazione con steroide+azatioprina riducono in modo significativo la mortalità. ${ }^{43-45}$ Controversi sono i risultati degli studi con l'impiego dell'azatioprina in monoterapia nella fase di induzione perché un risultato positivo (azatioprina $100 \mathrm{mg} / \mathrm{die})^{44}$ non è confermato da uno studio successivo che documenta una mortalità sensibilmente maggiore nel confronto con il prednisone ( $24 \%$ vs $5 \%){ }^{46}$

La valutazione complessiva dei dati forniti dagli studi clinici induce a ritenere che nell'AIH grave la terapia standard per indurre la remissione debba essere costituita dal prednisone con una dose iniziale di 30 $\mathrm{mg} /$ die e una riduzione di $10 \mathrm{mg}$ ogni 4 settimane. In alcuni casi è preferibile l'associazione con l'azatioprina $(50 \mathrm{mg} /$ die in USA o $1-2 \mathrm{mg} / \mathrm{kg} /$ die in Europa) sin dall'inizio o entro poche settimane successive alla risposta alla terapia steroidea.

La monoterapia con dosi maggiori di prednisone, iniziando con 40-60 mg/die e riducendo la posologia a $20 \mathrm{mg} /$ die entro 4 settimane, può essere preferita nei pazienti con controindicazioni all'azatioprina o con ri- sposta insoddisfacente alla terapia dopo 24 mesi di trattamento, anche se cirrotici.

La remissione clinica, bioumorale, immunologica e istologica si può ottenere nell' $80 \%$ circa dei pazienti. A tal punto il dosaggio del prednisone può essere progressivamente ridotto sino a $5 \mathrm{mg} /$ die e si può instaurare una terapia di mantenimento associando l'azatioprina (1-2 $\mathrm{mg} / \mathrm{kg} / \mathrm{die})$. La terapia di mantenimento può essere attuata con la sola azatioprina alla dose di $2 \mathrm{mg} / \mathrm{kg} / \mathrm{die},{ }^{19}$ non è dimostrato che la terapia di combinazione sia più efficace della terapia con la sola azatioprina; ${ }^{47}$ è vero peraltro che la remissione istologica è stata valutata in modo sistematico soltanto nei pazienti in follow-up con l'azatioprina in monoterapia.

La riduzione progressiva della posologia del prednisone viene abitualmente eseguita nella pratica clinica senza ripetere la biopsia epatica, sebbene quasi sempre, se la terapia immunosoppressiva viene interrotta in presenza di una residua epatite dell'interfaccia, si possano avere la recidiva e la progressione della malattia verso la fibrosi. ${ }^{48-50} \mathrm{La}$ contemporanea riduzione dei livelli serici delle IgG e delle AT è correlata con uno score istologico di flogosi più basso (Knodell index $<4)^{51}$ nel $90 \%$ circa dei casi, sebbene la completa remissione istologica si possa avere anche 3-6 mesi dopo la remissione biochimica

Il prosieguo della terapia sino al verificarsi della normalizzazione dei livelli serici delle AT, della bilirubina e delle $\gamma$-globuline e del quadro istologico epatico è un comportamento che appare utile per ridurre la frequenza delle recidive dall' $86 \%$ sino al $60 \%$ dopo la sospensione di ogni trattamento farmacologico.

Non vi è parere concorde sul tempo ideale di durata della terapia, ma per i pazienti con AIH di tipo 1 senza cirrosi la terapia con prednisone per 12-18 mesi e con azatioprina per 2-5 anni viene in genere considerata abbastanza ragionevole.

Le recidive sono molto frequenti, manifestandosi

Tabella 2. Criteri diagnostici semplificati per l'epatite autoimmune.

\begin{tabular}{|c|c|c|}
\hline Variabile & Cut off Punti & \\
\hline ANA or SMA & $>1: 40$ & 1 \\
\hline ANA or SMA & $>1: 80$ & $2 *$ \\
\hline LKM & $>1: 40$ & $2 *$ \\
\hline SLA & Positivi & $2 *$ \\
\hline \multirow[t]{2}{*}{ IgG } & $>$ limite superiore della norma & 1 \\
\hline & $>1,10$ volte limite superiore della norma & 2 \\
\hline \multirow[t]{2}{*}{ Istologia del fegato (evidenza di epatite se condizione necessaria) } & Compatibile con l'AIH & 1 \\
\hline & Tipica dell'AIH & 2 \\
\hline \multirow[t]{2}{*}{ Assenza di epatite virale } & 2 & \\
\hline & & $\begin{array}{l}>6: \text { AIH probabile } \\
>7: \text { AIH accertata }\end{array}$ \\
\hline
\end{tabular}

$\mathrm{ECA}=$ Epatite cronica autoimmune; ANA=AA anti-nucleo; SMA=AA anti-muscolo liscio; LKM=AA antimicrosomi epatici e renali; IgG=immunoglobuline G. *Soglia massima dell punteggio per tutti gli $\mathrm{AA}=2$ punti. Modificata da Hennes EM et al., $2008 .^{38}$ 
nell' $80 \%$ dei pazienti nell'arco di circa 3 anni dopo la sospensione della terapia. Esse sono associate con un maggior rischio di cirrosi e di insufficienza epatica; se sono frequenti vi è anche un rischio di un aumento del rischio di incidenza dell'epatocarcinoma e della mortalità per tutte le cause..$^{52,53}$

Il trapianto ortotopico di fegato è il trattamento di elezione nei casi di insufficienza epatica acuta o cronica non responsiva ad altri trattamenti. I risultati sono davvero soddisfacenti: una lunga sopravvivenza si ottiene in più dell' $85 \%$ dei casi.

\section{Terapie alternative}

Nei pazienti non responder alla terapia standard, con intolleranza o scarsa aderenza alla terapia steroidea è stato proposto l'impiego di altri farmaci immunosoppressivi, ma tutti necessitano di ulteriori studi per individuare il corretto rapporto tra risultati positivi ed effetti negativi. ${ }^{19}$

Il budenoside ha un'alta affinità per i recettori dei glucocorticoidi. Esso viene metabolizzato in misura $>90 \%$ durante il primo passaggio epatico; i suoi cataboliti non sono dotati di attività corticosteroidea, i cui effetti avversi sono pertanto limitati.

Negli studi iniziali condotti su piccole casistiche è dimostrato che gli effetti terapeutici del budenoside sono non inferiori a quelli del prednisolone e consentono di ottenere numerose remissioni complete (58$83 \%) .{ }^{54}$

Successivamente in uno studio multicentrico in doppio cieco 203 pazienti sono stati randomizzati per essere trattati con il budenoside o il prednisone, entrambi in combinazione con l'azatioprina: dopo 6 mesi un maggior numero di remissioni biochimiche è stato ottenuto nel braccio del bunedoside $(60 \%$ versus $38,8 \%)^{55}$ In una open-label extension dello studio pazienti trattati con il prednisone sono stati indirizzati alla terapia con il budenoside; il numero delle remissioni biochimiche è stato più elevato in confronto ai pazienti trattati sin dall'inizio con il budenoside (68,2\% versus $50,6 \%)$.

Questi promettenti risultati necessitano di conferma perchè la percentuale delle remissioni ottenute con il prednisone è sensibilmente inferiore a quella riferita nelle casistiche storiche e i dati istologici sono indispensabili per documentare una completa e attendibile remissione a lungo termine.

Nei pazienti con cirrosi e shunt porto-sistemici le proprietà metaboliche del budenoside ne aumentano la disponibilità sistemica e il rischio di effetti avversi indesiderati. Per tale motivo il budenoside non può essere utilizzato nei pazienti con cirrosi e in tutti i casi in cui vi sia una grave compromissione della funzione epatica. ${ }^{56}$ Inoltre si è rivelato inefficace come farmaco di salvataggio nei casi di AIH refrattari alla terapia steroidea o dipendenti dalla terapia stessa. ${ }^{57}$
Alcuni risultati incoraggianti sono stati descritti a seguito dell'uso daltri farmaci alternativi (micofenolato mofetile, tacrolimus, ciclosporina, rituximab, infliximab, ciclofosfamide, metotrexato), ma sono stati ottenuti con piccole casistiche o riferimenti aneddotici. ${ }^{19} \mathrm{Il}$ micofenolato mofetile sembra essere il farmaco alternativo più promettente, ma al momento frequenti casi di intolleranza agli effetti collaterali indesiderati fanno consigliare il suo impiego soltanto come terapia empirica di salvataggio. ${ }^{58}$

\section{Note sintetiche conclusive AIH}

1. L'AIH è una malattia infiammatoria del fegato ad eziologia non ben definita, immunomediata.

2. La lesione istologica fondamentale è l'epatite dell'interfaccia, con necrosi epatocellulare e infiltrazione linfoplasmocitaria portale e periportale.

3. La prevalenza dell'AIH non è ben precisabile (da 10 a 40 casi circa/100.000 abitanti), anche perché influenzata verosimilmente da fattori genetici e ambientali. Colpisce soprattutto il sesso femminile, in età compresa tra i 15 e i 40 anni, ma è possibile il riscontro anche nei bambini e negli anziani.

4. Il quadro clinico è molto variabile: sono descritti casi di epatite fulminante, soprattutto nei bambini e casi che decorrono in forma asintomatica per tempi anche molto lunghi.

5. Le alterazioni di laboratorio principali sono l'aumento dei valori delle AT seriche e la comparsa di autoanticorpi (ANA, SMA, anti-LKM1), che consentono di classificare varie forme di AIH.

6. La diagnosi di AIH è spesso difficile, per cui sono stati all'elaborati alcuni scoring diagnostici; tra essi il più recente elaborato dalla IAIHG è particolarmente utile nella pratica diagnostica.

7. La terapia con farmaci immunosoppressori (prednisone, azatioprina) attuata con accuratezza consente la remissione in un'alta percentuale di casi ( $80 \%$ circa) diagnosticati tempestivamente.

8. La sospensione della terapia di mantenimento è quasi sempre seguita da recidive, per lo più con aspetti di maggiore gravità rispetto all'episodio precedente.

9. La terapia alternativa di maggiore efficacia e sicurezza è costituita dal budenoside, peraltro non attuabile nei pazienti già in fase di cirrosi.

10. Il trapianto ortotopico di fegato in pazienti gravi, non responsivi alle terapie farmacologiche, ha un outcome particolarmente favorevole.

\section{Colangite biliare primitiva}

La PBC è una malattia colestatica cronica idiopatica, causata da un danno progressivo dei dotti biliari intraepatici, che con il successivo coinvolgimento del 
parenchima epatico può evolvere nel tempo sino alla cirrosi e al carcinoma epatocellulare.

\section{Epidemiologia}

La PBC presenta una grande variabilità di incidenza e prevalenza nei vari studi di popolazione ${ }^{59} \mathrm{La}$ prevalenza maggiore è riscontrata negli USA che risulta di 400 per milione di abitanti ${ }^{60}$ seguita dal Europa del nord con prevalenza di 200-250 per milione di abitanti e Africa, Asia e Australia con 20 per milione di abitanti. ${ }^{61,62}$

In tutte le popolazione la $\mathrm{PBC}$ è più diffusa tra le donne. Il motivo di questa distribuzione non è noto, ma alcuni recenti studi hanno evidenziato che la monosomia del cromosoma $\mathrm{X}$ è più frequente nelle donne affette da PBC. Tali dati fanno presupporre che l'immunodeficienza $X$ relata potrebbe indurre alla formazione del granuloma e dell'aumento dei livelli di IgM, caratteristiche presenti nella PBC. ${ }^{63}$ La malattia può colpire tutte le razze, in genere ricorre maggiormente tra la quarta e sesta decade di vita, è assente nei bambini e costituisce lo $0,5-2 \%$ delle morti per cirrosi epatica.

\section{Istologia}

Come già accennato nella definizione nosografica, la PBC è caratterizzata, morfologicamente (Figura 4), da infiammazione portale con danno dei dotti biliari intraepatici di piccolo calibro ed eventuale necrosi epatocitaria periportale e intralobulare. Successivamente compaiono neoduttulazione, colestasi e fibrosi; l'evento finale è rappresentato dalla cirrosi, che può essere complicata dal carcinoma epatocellulare.

- Il danno biliare interessa inizialmente i dotti di piccolo calibro (diametro 40-80 micron) ${ }^{64} \mathrm{e}$, successivamente, quelli settali. Esso è caratterizzato da rigonfiamento citoplasmatico, picnosi dei nuclei e irregolarità del bordo dei biliociti, interruzione della membrana basale (criterio di diagnosi differenziale con la PSC in cui la membrana basale appare ispessita), iperplasia e pluristratificazione dell'epitelio. L'infiltrato infiammatorio è costituito in prevalenza da linfociti $\mathrm{T}(\mathrm{CD} 4+\mathrm{e} \mathrm{CD} 8+) .{ }^{65}$ Nello stadio iniziale della malattia le componenti plasmacellulare ed eosinofilica possono essere cospicue, ma la caratteristica istologica della PBC è la presenza di granulomi epitelioidi che circondano il dotto biliare danneggiandolo fino alla distruzione e determinando quell'immagine istologica che è stata definita da Rubin ${ }^{66}$ come colangite cronica non suppurativa distruttiva, o colangite florida. I resti del dotto biliare, circondati dall'infiltrato flogistico, possono essere messi in evidenza con la Cheratina 7. La presenza di arteria non accompagnata dal dotto è interpretata come segno di duttopenia. ${ }^{67} \mathrm{I}$ dotti di medio e grosso calibro sono preservati dal processo o mostrano soltanto elementi della flogosi nella parete.

- Le alterazioni parenchimali sono rappresentate da infiammazione, necrosi e colestasi. La necrosi interessa singoli epatociti con la formazione di corpi acidofili; ad essa si associa attivazione delle cellule di Kupffer. L'infiltrato infiammatorio è costituito da linfociti e macrofagi ed è generalmente di lieve entità. Si possono osservare granulomi anche nel lobulo a ridosso dell'area portale. Un intenso infiltrato linfocitario, con estesa epatite all'interfaccia può essere osservato nelle forme da overlap PBC-AIH, ma non è patognomonico di questa forma. La presenza di plasmacellule IgM + negli spazi portali è un reperto tipico della $\mathrm{PBC}$; la prevalenza di plasmacellule $\mathrm{IgG}+$ invece favorisce la diagnosi di AIH. ${ }^{68}$

L'attività biliare all'interfaccia rappresenta l'aspetto istologico predominante con il progredire della malattia. Essa è legata alla tossicità degli acidi biliari e tende a scomparire nello stadio terminale cedendo il posto alla fibrosi. Non è raro osservare aree di iperplasia nodulare rigenerativa anche in assenza di cirrosi. ${ }^{69}$ Essa spiega la comparsa di ipertensione portale prima dell'insorgenza della cirrosi.

La fibrosi sostituisce le aree periportali distrutte dall'infiammazione e dalla necrosi con un orientamento porto-portale; la cirrosi è di tipo micronodulare.

Sebbene sia difficile distinguere questa cirrosi da altre di diversa etiologia, vi sono alcun stigmate che possono aiutare nell'orientamento diagnostico: tra queste la perdita dei dotti biliari di piccolo calibro, la colestasi con la presenza di corpi di Mallory, i depositi di rame negli epatociti.

In base al susseguirsi di questi eventi Scheuer ${ }^{70}$ ha diviso questa malattia in quattro stadi: I, lesioni duttali floride; II, proliferazione duttale; III, fibrosi; IV cirrosi (Figura 5).

\section{Patogenesi}

L'esatto meccanismo di danno epatico è sconosciuto, molte evidenze scientifiche sembrerebbero propendere per un danno di tipo autoimmune. I dati che supportano tali evidenze sono: anormalità nel sistema immune cellulare (aumento delle immunoglobuline sieriche, principalmente delle IgM), autoanticorpi circolanti, presenza di granulomatosi nel fegato e nelle regioni linfonodali, squilibrio nelle regolazione dei linfociti $\mathrm{B}$ e $\mathrm{T}$ e associazione, così come nella AIH e nella PSC, con diverse malattie autoimmuno-mediate. ${ }^{71}$

Diversi studi epidemiologici hanno confermato tre importanti aspetti distintivi che contribuiscono alla genesi di queste malattie croniche immunologiche indotte dalle malattie biliari. ${ }^{72}$ 
In primo luogo, la $\mathrm{PBC}$ ha un'importante componente genetica così come è dimostrato dall'aumentata prevalenza di $\mathrm{PBC}$ e altre AILD nei pazienti e nei loro familiari. È stata evidenziata un' associazione tra PBC e l'aplotipo HLA-DR8 e, solo in alcune popolazioni, con l'HLA-DPB1.

La seconda caratteristica è il ruolo dei fattori scatenanti come il fumo di sigaretta, le infezioni ricorrenti delle vie urinarie e la possibile esposizione a sostanze chimiche. ${ }^{73}$

Il terzo aspetto potrebbe essere l'anomala espres- sione degli antigeni mitocondriali E2 sulla superficie luminale dell'epitelio biliare.

In ogni caso l'origine del danno iniziale è l'attivazione dei linfociti $\mathrm{CD} 4+\mathrm{e} \mathrm{CD} 8+$ con una risposta predominante Th1 che induce un danno continuo dei dotti biliari interlobulari. Una volta distrutti, la rigenerazione dei dotti biliari è impossibile o inefficiente.

Come conseguenza della perdita dei dotti biliari intraepatici, vi è un'alterazione del normale flusso della bile con ritenzione e deposito di sostanze tossiche normalmente escrete dalla bile. La ritenzione delle
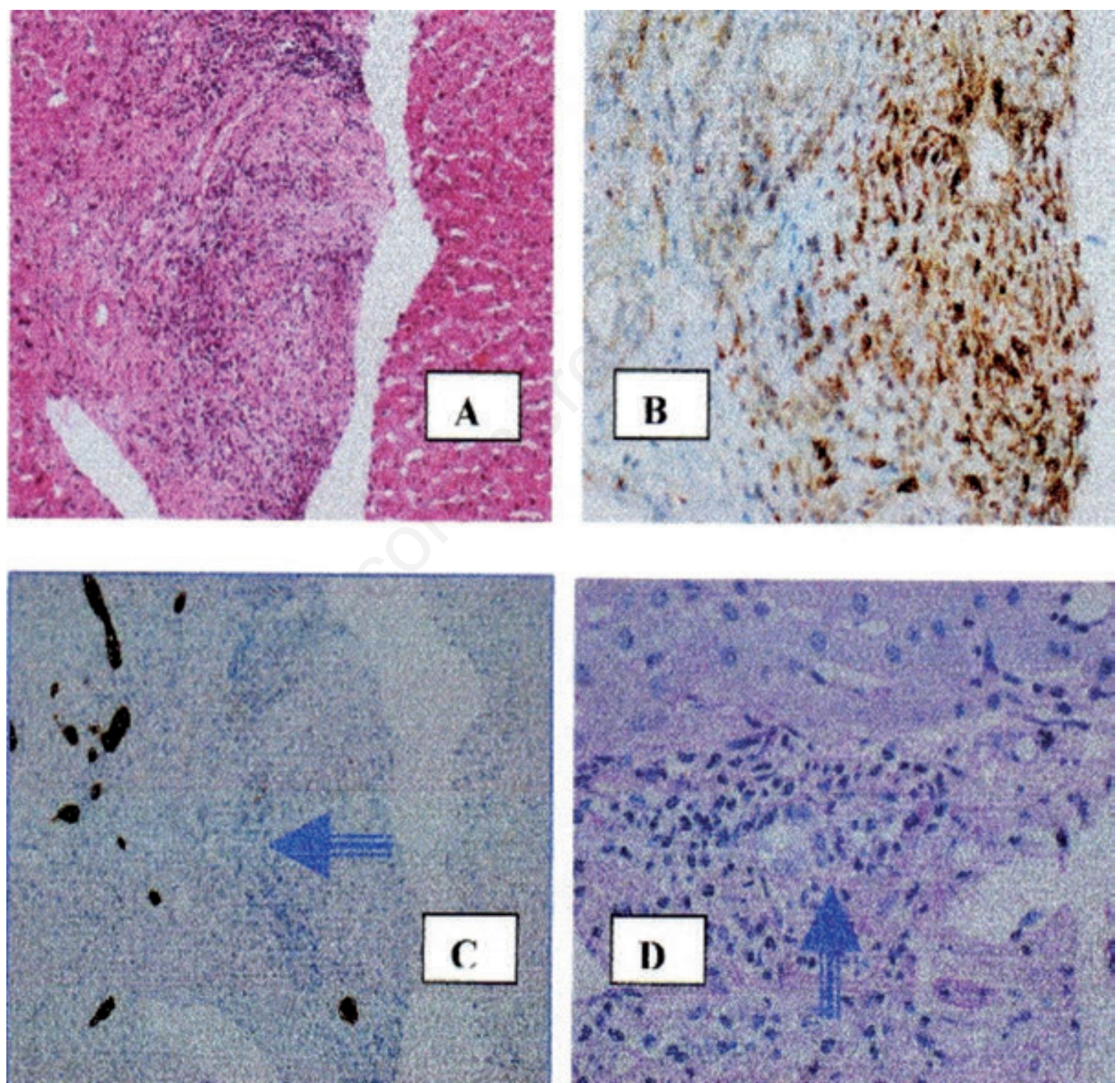

Figura 4. PBC. Aspetti istologici e citologici. A) Spazio portale occupato da un granuloma che ingloba il dotto biliare. B) CD68 evidenzia la componente istiocitaria del granuloma. C) La Cheratina 7 mette in evidenza la presenza di neoduttuli alla periferia dello spazio portale e residui dell'epitelio biliare (freccia). D) Colorazione PAS. Un dotto biliare circondato da infiltrato flogistico presenta alterazioni dell'epitelio e interruzione della membrana basale (freccia). 
sostanze tossiche, come bile e rame, può peggiorare il danno dei dotti biliari e degli epatociti. Inoltre, nel fegato, vi è un aumento nell'espressione degli antigeni HLA di classe II; pertanto gli epatociti e le cellule endoteliali dei dotti biliari sono più suscettibili all'attivazione del linfociti $\mathrm{T}$ e, in genere, la tossicità immunomediata è incrementata.

Uno studio controllo basato su interviste effettuate su 1032 pazienti, ha confermato molte delle argomentazioni sopradescritte. Nelle persone geneticamente predisposte alla $\mathrm{PBC}$ erano coinvolti molti fattori scatenanti quali fumo di sigarette e infezioni intercorrenti delle vie urinarie. Diversi studi svolti nel Regno Unito e negli USA hanno dimostrato un'associazione tra fumo di sigaretta e PBC..$^{71,74-77}$ Le sostanze chimiche inalate con il tabacco sembrerebbero alterare l'immunotolleranza.

La PBC è fortemente correlata alle infezioni ricorrenti del tratto urinario. In uno studio epidemiologico vi era una differenza significativa tra la ricorrenza delle infezioni del tratto urinario nel gruppo nei pazienti affetti da PBC (48\%) rispetto al gruppo di controlli (31\%). ${ }^{74}$ La contaminazione da Escherichia coli (E. coli) è la causa più frequente delle infezioni ricorrenti delle vie urinarie nelle donne. E. coli sembrerebbe innescare una risposta autoimmune che indurrebbe una risposta crociata tra le cellule $\mathrm{B}$ e $\mathrm{T}$ caratteristica dei pazienti affetti da $\mathrm{PBC} . .^{73-75,78}$

La PBC non sembrerebbe essere correlata con il consumo di alcol. ${ }^{75}$

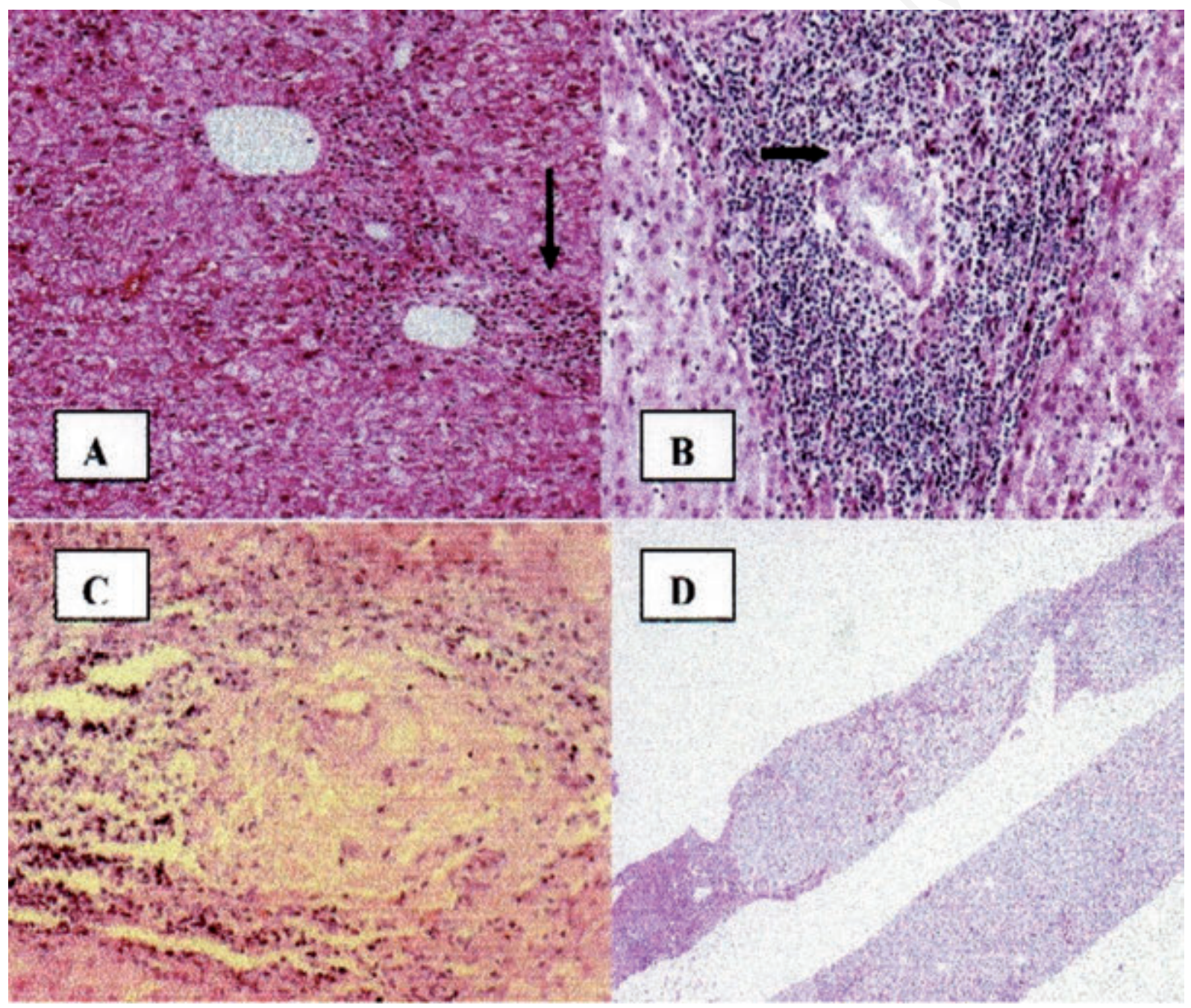

Figura 5. Aspetti istologici dei diversi stadi evolutivi della PBC. A) Un lieve infiltrato infiammatorio circonda un dotto biliare. Stadio I. B) Un aggregato linfocitario circonda un dotto biliare leso con epitelio iperplastico e distruzione della membrana basale (freccia). Stadio II. C) Duttopenia: dotto biliare sostituito da fibrosi; granuloma adiacente. Stadio IIIII. D) Setti fibrosi, a partenza da larghi spazi portali, delimitano noduli. L'infiltrato infiammatorio è ridotto di intensità rispetto agli stadi precedenti. Gli spazi portali sono svuotati dell'infiltrato infiammatorio, il dotto biliare non è visibile in tutti gli spazi. Stadio IV. 
Gli autori, inoltre, evidenziano che l'utilizzo degli estrogeni potrebbero contribuire allo sviluppo della malattia, e questa potrebbe anche essere una spiegazione al motivo per il quale la $\mathrm{PBC}$ è più diffusa tra le donne rispetto agli uomini. ${ }^{71,79}$

\section{Caratteristiche cliniche}

Circa il 25\% dei casi di PBC viene diagnosticato in una fase clinica del tutto asintomatica, durante l'esecuzione di esami ematochimici di controllo.

Nelle condizioni sintomatiche, in genere il primo sintomo riportato è la stanchezza (65\% dei casi). Anche il prurito (55\%) e la dolenzia del quadrante superiore destro (8-17\%) possono presentarsi come sintomi precoci. Nella fase avanzata della malattia possono evidenziarsi: epatomegalia (25\%), iperpigmentazione $(25 \%)$, splenomegalia (15\%), ittero (10\%) e xantelasmi. ${ }^{80}$

Negli ultimi stadi della malattia si riscontrano anche: sindrome sicca (50-75\%) con xeroftalmia e xerostomia. È possibile, anche se molto raro, l'evidenza di anelli di Kayser-Fischer.

Ovviamente l'ultimo stadio della malattia è caratterizzato da tutti i segni e sintomi tipici della cirrosi epatica.

\section{Diagnosi}

I criteri diagnostici della PBC sono elencati nella Tabella $3 .{ }^{81}$

I criteri maggiori per la diagnosi di tale patologia sono la presenza di anticorpi antimitocondrio (AMA) nel siero e il reperto istologico di colangite non suppurativa.

La presenza di AMA nel siero e in particolar modo della frazione anti-M2 (AMA positività IF> 1:40), rap- presentano il marker ematologico principale. La positività agli AMA può riscontrarsi nel $90-95 \%$ dei pazienti affetti da $\mathrm{PBC}$ con una specificità del $98 \%$. Si può riscontrare la presenza di altre frazioni di AMA e anche di altri AA (ANA e di SMA) senza uno specifico significato diagnostico. ${ }^{82,83}$

Alcuni pazienti possono presentare le caratteristiche cliniche, biochimiche e istologiche della PBC, senza però evidenziare una positività per AMA. Generalmente, in tali condizioni si pone la diagnosi di colangite autoimmune. In ogni caso, nonostante la migliore efficacia dei nuovi test biochimici, circa il 5\% di questi pazienti presenta negatività per AMA. ${ }^{84}$

Altri test di laboratorio possono risultare alterati nella PBC: i) aumento delle AT e della gammaglutamiltransferasi $(\gamma-G T)$; ii) aumento dei valori dei lipidi e del colesterolo, con un aumento della porzione frazionata delle lipoproteine ad alta densità; iii) un aumento della quota di sedimentazione degli eritrociti.

Aumento della bilirubina, aumento del tempo di protrombina e decremento dei valori di albumina, sono significativi di uno stadio avanzato della malattia ed espressione di cirrosi epatica. La presenza di trombocitopenia è il segno di ipertensione portale.

L'utilizzo di metodiche strumentali quali ecografia, TC addome e risonanza magnetica possono essere importanti per escludere la presenza di ostruzione delle vie biliari.

\section{Terapia}

La sopravvivenza media dei pazienti affetti da $\mathrm{PBC}$ che non pratichino terapia è approssimativamente di 9-10 anni dalla manifestazione dei sintomi, e circa il $26 \%$ dei pazienti sviluppa segni di scompenso epatico nell'arco di tale periodo. ${ }^{85}$ Dopo una

Tabella 3. Criteri per la diagnosi di PBC.

Criteri maggiori

Presenza di AMA con specificità per la frazione M2

Evidenza istologica di distruzione dei dotti biliari

Criteri minori

Prurito

Bilirubinemia totale $>2 \mathrm{mg} / \mathrm{dl}$

Incremento dei valori serici della fosfatasi alcalina

Incremento dei livelli di IgM

Sindrome di Sjögren

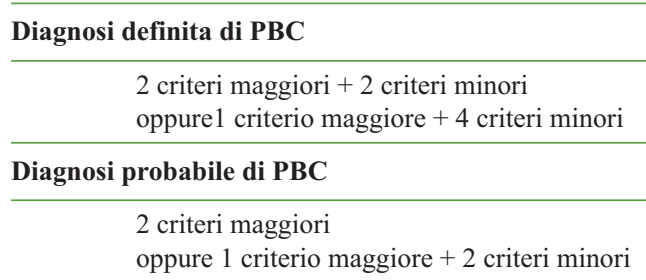

AMA, autoanticorpi antimitocondrio; IgM, immunoglobuline M; PBC, colangite biliare primitiva. Modificata da Ideo G ${ }^{8{ }^{8}}$ 
fase iniziale di relativa stabilità, generalmente la bilirubina può presentare un franco aumento nei mesi precedenti il decesso. Nei pazienti che presentano valori di bilirubina superiori ai $2 \mathrm{mg} / \mathrm{dl}$, la sopravvivenza media è di 4 anni; in quelli con valori superiori ai 6 $\mathrm{mg} / \mathrm{dl}$ la sopravvivenza media si riduce a 2 anni. ${ }^{86}$

L'utilizzo di acido ursodesossicolico (ursodeoxycholic acid = UDCA) ha dimostrato una chiara efficacia nel migliorare i valori biochimici di tali soggetti e i pazienti che praticano terapia con UDCA presentano una rallentamento nella progressione istologica. La distruzione dei dotti biliari interlobulari induce una ritenzione di acidi biliari idrofobici all'interno degli epatociti, probabilmente contribuendo all'ulteriore sviluppo di danno epatico. L'UDCA riduce la quota di acidi biliari idrofobici negli epatociti e potrebbe avere anche un effetto protettivo sulle membrane cellulari epatiche. Inoltre l'UDCA sembrerebbe anche limitare il danno immunomediato, in quanto ridurrebbe l'anomala espressione degli antigeni HLA I e HLA II sulla superficie luminale degli epatociti e delle cellule epiteliali biliari.

Diversi studi hanno dimostrato i benefici dell'UDCA nella PBC; come detto in precedenza in pazienti in trattamento evidenzierebbero una riduzione del danno istologico e della progressione a cirrosi. ${ }^{87,88}$

I pazienti in stadio I/II della PBC trattati con UDCA che ottengono una riduzione dei livelli di AST e di fosfatasi alcalina (ALP) di circa 1,5 volte al di sotto del limite di normalità (ULN) e anche una normalizzazione della bilirubina dopo circa 12 mesi dall'inizio della terapia, presentano un miglioramento della prognosi con riduzione degli eventi morte correlati al fegato, di rischio di trapianto epatico, di sviluppo di cirrosi e di episodi di scompenso. ${ }^{89}$

Un'analisi combinata di tre studi randomizzati, che hanno incluso complessivamente 548 pazienti affetti da PBC, ha mostrato un miglioramento della sopravvivenza e riduzione di trapianto epatico nei pazienti con PBC moderata/severa che assumevano 13-15 $\mathrm{mg} / \mathrm{Kg} /$ die di UDCA per più di 4 anni..$^{90}$

Il miglioramento dei valori biochimici in corso di UDCA rivela i pazienti che presentano una buona prognosi a lungo termine. ${ }^{91,92}$ I pazienti che mostrano ALP $<3$ ULN, AST $<2$ ULN e bilirubina di $1 \mathrm{mg} / \mathrm{dL}$ dopo un anno di UDCA, hanno un tasso di sopravvivenza liberi da trapianto epatico nei 10 anni del 90\% (95\% intervallo di confidenza, $81-95 \%$ ) rispetto al $51 \%$ (95\% intervallo di confidenza, 38-64\%) dei soggetti non trattati $(\mathrm{P}<0.001) .{ }^{93}$

Si può concludere che l'UDCA alla dose di 13-15 $\mathrm{mg} / \mathrm{kg} /$ die è attualmente considerata la terapia principe per i pazienti affetti da PBC e tutti i pazienti che presentino alterazione dei valori biochimici devono essere sottoposti a tale trattamento.

L'UDCA è ben tollerato alle dose sopraraccoman- date. Può presentarsi diarrea in circa il 2-9\% dei casi. Inoltre come eventi avversi riportati si segnalano: dolenzia nel quadrante addominale superiore, raramente scompenso epatico quando somministrato nei pazienti con malattia epatica avanzata. ${ }^{94}$

\section{Terapie alternative e adiuvanti}

Un gran numero di farmaci antinfiammatori, immunosoppressivi e anti-fibrotici sono stati sperimentati nei pazienti affetti da PBC.

I glucocorticoidi hanno dimostrato di aumentare $\mathrm{i}$ benefici dei pazienti trattati con UDCA. Una combinazione di glucocorticoidi (specificamente il budesonide) e UDCA ha evidenziato una migliore risposta biochimica e istologica in termini di infiammazione e fibrosi de novo. ${ }^{95,96} \mathrm{Il}$ budesonide non è comunque raccomandata nei pazienti cirrotici.

In uno studio sull'utilizzo del metotrexate (MTX) si è evidenziato che nessun paziente in uno stadio istologico di precirrosi ha presentato progressione a cirrosi se sottoposto a terapia con MTX; questo studio suggerisce che tale terapia potrebbe essere utile solo in un piccolo gruppo di soggetti. ${ }^{97}$

L'uso di colchicina ha mostrato un miglioramento dei test biochimici in tre diversi studi prospettici ed inoltre evidenziava un miglioramento nella sopravvivenza a 4 anni. La colchicina sembrerebbe rallentare la progressione della $\mathrm{PBC}$, ma non è in grado di arrestarla. ${ }^{98}$

L'utilizzo combinato di MTX/UDCA o di colchicina/UDCA sembrerebbe indurre una remissione clinica della malattia. La combinazione MTX/UDCA si è rilevata più efficace della combinazione UDCA/colchicina. ${ }^{99}$

Comunque vi sono altri studi che non sembrerebbero dimostrare l'efficacia dell'utilizzo del MTX da solo o in combinazione con l'UDCA. ${ }^{100,101}$

Uno studio randomizzato e controllato sulla ciclosporina in monoterapia ha mostrato un'efficacia nel migliorare le condizioni cliniche, biochimiche e di progressione istologica ${ }^{102}$ nonché un allungamento dei tempi di immissione in lista trapianto epatico, ${ }^{103}$ nonostante l'effetto nocivo della ciclosporina sul sistema di trasporto epato-biliare. ${ }^{104}$ Comunque, a causa del rilievo di numerosi effetti collaterali nei pazienti sottoposti a terapia con ciclosporina, non si è implementata ulteriormente la ricerca su questo farmaco anche in associazione con l'UDCA.

Circa un terzo dei pazienti non risponde alla terapia con UDCA e permane il rischio di progressione di malattia epatica; tali soggetti sono candidabili ad altri tipi di terapia.

Studi preliminari indicano che i pazienti che presentano una risposta subottimale all'UDCA possono beneficiare dell'associazione con glucocorticoidi (budesonide). ${ }^{105}$

Il metotrexate migliora i test biochimici se asso- 
ciato ad UDCA nei pazienti con mancata risposta a quest'ultimo. ${ }^{106}$

L'acido obeticolico, agonista del recettore farnesoide $\mathrm{X}$, che è presente nel nucleo delle cellule nel fegato ed è capace di inibire la produzione di acidi biliari, il cui accumulo può avere effetti tossici, è stato autorizzato di recente dalla FDA per il trattamento di pazienti non responder o intolleranti all'UDCA. Tenendo presente quanto si è detto sulla possibilità di impiegare in condizioni difficili altri farmaci già noti e che la decisione della FDA è avvenuta in base ad un unico studio clinico controllato con placebo e con un end point surrogato (la riduzione dei livelli di ALP nel siero), il suo impiego, in attesa di ulteriori studi condotti con una metodologia che dia risultati più affidabili, sembra possa essere utile solo in un numero davvero molto limitato di pazienti. ${ }^{107}$

\section{Trapianto epatico}

Il trapianto epatico rimane l'unica vera risorsa terapeutica per quei soggetti con malattia istologica evoluta e con insufficienza epatica o nei pazienti con severa distruzione dei dotti epatici. Il trapianto è indicato anche nei pazienti con bilirubina $>6 \mathrm{mg} / \mathrm{dl}$, prurito intrattabile, osteoporosi severa, qualità di vita insoddisfacente.

La PBC recidiva in circa il $20 \%$ dei pazienti a 5 anni.

\section{Terapia sintomatica}

Prurito: colestiramina ( $8-16 \mathrm{mg} / \mathrm{die})$ è la prima linea terapeutica. Altri tipi di terapia includono la rifampicina, glucocorticoidi, sertralina e oppiacei. Plasmaferesi, drenaggio biliare o dialisi extracorporea potrebbero essere utili nei pazienti con fallimento alle precedenti terapie.

Ipercolesterolemia: l'uso di UDCA riduce di circa $15-20 \%$ i valori del colesterolo LDL a un anno dalla terapia. Anche le statine risultano sicure ed efficaci nella PBC.

Osteopenia e osteoporosi: i trattamenti attuali includono: attività fisica, calcio e vitamina $\mathrm{D}$, bifosfonati ed estrogeni.

\section{Note sintetiche conclusive PBC}

1. La PBC è una malattia colestatica cronica idiopatica immunomediata, caratterizzata da una patologia flogistica progressiva dei dotti biliari intraepatici, con eventuale successivo coinvolgimento del parenchima epatico e possibile evoluzione sino alla cirrosi e al carcinoma epatocellulare.

2. L'evoluzione istologica dal danno esclusivo dei dotti biliari di piccolo e medio calibro sino alla cirrosi, secondo la classificazione di Scheuer, si realizza attraverso 4 stadi.
3. La malattia ha una prevalenza variabile nelle diverse aree geografiche. La maggiore prevalenza è stata descritta negli USA (40 casi circa/100.000 abitanti). Colpisce soprattutto il sesso femminile, in età compresa tra i 15 e i 60 anni.

4. La sintomatologia varia con il progredire degli stadi della malattia. Sintomi fondamentali sono il prurito, l'ittero e i segni biochimici della colestasi (iperbilirubinemia, ALP+, $\gamma$-GT+). Nel IV stadio sono presenti i segni clinici della cirrosi.

5. La presenza degli AMA, in particolare della frazione $\mathrm{M} 2$, è una caratteristica fondamentale della malattia (riscontro con titolo $\geq 1 / 40$ nel $90-95 \%$ dei pazienti con una specificità del $98 \%$ ). Sono stati descritti quadri clinici di PBC in assenza di AMA, per i quali si preferisce porre diagnosi di colangite autoimmune e impiegare anche una terapia immunosoppressiva.

6. Il farmaco efficace nel controllo dell'evoluzione della malattia è 1'UDCA, alla dose di 13-15 $\mathrm{mg} / \mathrm{kg} / \mathrm{die}$. Tutte le alternative terapeutiche (budenoside, colchicina, metotrexate, ecc.) hanno dato risultati meno validi e incostanti.

7. La terapia sintomatica prevede il trattamento del prurito (colestiramina), dell'ipercolesterolemia, dell'osteopenia e dell'osteoporosi.

8. Il trapianto epatico è l'unica vera risorsa terapeutica per quei soggetti con malattia istologica evoluta e grave insufficienza epatica o nei pazienti con severa distruzione dei dotti epatici o nei pazienti con bilirubina $>6 \mathrm{mg} / \mathrm{dl}$, prurito intrattabile, osteoporosi severa, qualità di vita insoddisfacente. La PBC recidiva in circa il $20 \%$ dei pazienti a 5 anni.

\section{Colangite sclerosante primitiva}

La PSC è una malattia colestatica a eziologia ignota caratterizzata da infiammazione e conseguente fibrosi dei dotti biliari extra- ed intraepatici. La PSC ha una progressione lenta sino a giungere all'ostruzione dei dotti biliari e conseguente cirrosi e scompenso epatico. Le lesioni dei dotti extra-epatici sono in genere prevalenti rispetto ai rami intraepatici, e in alcuni casi il danno è esclusivo dei dotti extraepatici. Il danno persistente dei piccoli dotti biliari non è compatibile con la PSC, ma recentemente sono stati descritti alcuni casi di danno dei dotti biliari in conseguenza a quello dei dotti extraepatici. ${ }^{108}$

\section{Epidemiologia}

La prevalenza e l'incidenza nel mondo della PSC sono molto variabili. In Nord America e in Europa la prevalenza varia da 6 a 16 casi/100.000 abitanti; l'incidenza è di circa 1 caso/100.000 abitanti/anno. ${ }^{109-111}$ Dati minori sono stati riportati in Asia ed Europa del sud. ${ }^{112,113}$ Generalmente colpisce più gli uomini (età 
media di 30-40 anni) con un rapporto maschi/femmine 2/1; nel sesso femminile colpisce in prevalenza una fascia di età leggermente più alta; in alcuni casi è presente anche in età pediatrica. ${ }^{114}$

\section{Patogenesi}

La PSC è una patologia complessa; la patogenesi non è stata del tutto definita, diversi fattori sembrerebbero determinare le caratteristiche anatomiche e cliniche di questa patologia.

La predisposizione genetica è sostenuta dalle seguenti considerazioni: i) rischio aumentato nei soggetti che hanno un primo grado di parentela con un paziente affetto da PSC; ${ }^{115}$ ii) associazione frequente con diversi aplotipi dell'HLA come HLA-DRB1*1501-DQB1* 0602, HLA-DRB $1 * 1301-D Q B 1 * 0603$ e HLA-A1-B8DRB1*0301-DQB1*0201; ${ }^{116-119}$ l'aplotipo HLA B8, Dr3 è di frequente riscontro anche nella $\mathrm{PBC}$ ed è associato anche a diverse altre malattie autoimmuni quali l'AIH, le tiroiditi, la celiachia e la miastenia gravis; iii) la PSC è spesso associata a malattie infiammatorie intestinali (inflammatory bowel disease $=\mathrm{IBD}$ ) in particolar modo alla colite ulcerativa (ulcerative colitis $=$ UC). Alcune evidenze dimostrano che vi sono 12 loci istocompatibili non-maggiori associati alla PSC. Molti di questi loci sono maggiormente correlati con la PSC che con la IBD, facendo ipotizzare la sovrapposizione di distinte strutture genetiche per queste due malattie. ${ }^{120}$

Nel caso in cui sia presente l'UC, sembrerebbe che le infezioni con infiltrazione della vena porta e dei vasi linfatici o l'invasione di endotossine a livello epatico possano favorire l'evoluzione della PSC. ${ }^{121}$ In ogni caso, diversi studi sull'uomo hanno dimostrato che l'infezione batterica della vena porta è rara nella UC. ${ }^{122}$ Il coinvolgimento eziologico dei virus, come reovirus o citomegalovirus, non è mai stato sufficientemente documentato. A differenza di tutte queste presunte cause eziologiche è generalmente accettata una patogenesi di natura autoimmune. Anticorpi anti-citoplasma dei neutrofili (pANCA) si trovano nel 26-85\% dei pazienti con PSC, ed è possibile frequentemente rilevare la presenza di diversi altri anticorpi nel siero come anticardiolipina, ANA e SMA, che però non hanno alcun carattere di specificità. Sono state descritte anche alterazioni delle cellule immunitarie come: riduzione dei livelli di cellule $\mathrm{T}$, aumento del rapporto $\mathrm{CD} 4 / \mathrm{CD} 8$ e aumento delle cellule $\mathrm{B}$. Un'alterazione della risposta immunitaria può essere indotta da una sovraespressione degli antigeni HLA classe II sulla membrana cellulare dei dotti biliari. ${ }^{123}$

\section{Caratteristiche cliniche}

La storia naturale della PSC è molto variabile rispetto ad altre patologie come la PBC e l'AIH. Al momento della diagnosi, la maggior parte dei pazienti
(30-50\%), sono uomini affetti da IBD con alterazioni ematochimiche della colestasi. Questi soggetti possono rimanere asintomatici per diversi anni e generalmente il periodo medio prima di giungere al trapianto è di 12 anni. ${ }^{124}$ Sebbene siano asintomatici, alcuni pazienti possono presentarsi con segni clinici, radiologici e istologici di malattia avanzata. I pazienti sintomatici possono presentare febbre, ittero, prurito e dolenzia del quadrante addominale superiore destro. In questi soggetti, la PSC ha una prognosi peggiore con una evoluzione a stadio 2 (danno periportale) in 5 anni nel $90 \%$ dei casi.

A causa della stenosi dei dotti biliari e della formazione di calcoli e fango biliare, generalmente la PSC è complicata da episodi ricorrenti di colangiti batteriche, le quali possono risolversi spontaneamente o necessitare di terapia antibiotica e dilatazione endoscopica.

Come detto in precedenza, frequentemente la PSC si associa a una IBD. I pazienti affetti da PSC dovrebbero essere sottoposti a colonscopia per rilevare la presenza di IBD anche in assenza di sintomi. La cronologia diagnostica si è modificata nel corso degli anni; in un recente studio su una coorte di pazienti, osservati dal 2003 al 2007, generalmente veniva posta diagnosi prima di PSC e successivamente di IBD; tale studio non concorda con dati precedenti che segnalavano di frequente prima la IBD e in seguito la PSC (coorte del 1993-1997). ${ }^{125}$

La UC è la manifestazione clinica più frequente della IBD associata alla PSC. Il grado di estensione, infiammazione e manifestazioni cliniche della UC possono essere molto variabili e di differente gravità nei pazienti affetti da PSC. ${ }^{126}$

I pazienti con PSC ed UC presentano un rischio cumulativo aumentato di sviluppo del cancro colonrettale (CRC) in confronto a quelli con solo UC. In alcuni casi la PSC potrebbe essere diagnosticata dopo una colectomia, così come la IBD potrebbe svilupparsi dopo un trapianto di fegato. ${ }^{127,128}$ Inoltre molti pazienti con PSC senza segni di IBD potrebbero in ogni caso sviluppare CRC nel corso degli anni. Questi dati suggeriscono di eseguire una colonscopia ogni 5 anni nei pazienti affetti da PSC per escludere la presenza di IBD e CRC. ${ }^{129}$

Lo sviluppo di colangiocarcinoma è una delle maggiori complicanze, rilevata nel $16 \%$ dei pazienti affetti da PSC. In alcuni studi si è evidenziata un'incidenza del 6-11\% di colangiocarcinoma nella storia naturale della PSC e del 7-36\% nei pazienti sottoposti a trapianto. ${ }^{123} \mathrm{Il}$ colangiocarcinoma è una complicanza precoce della PSC, infatti circa il 35\% delle diagnosi viene effettuata a soli 2 anni dall'evidenza di PSC, viceversa alcuni casi sono stati diagnosticati anche 25 anni dopo. ${ }^{123}$

La diagnosi di colangiocarcinoma rimane un im- 
portante problema diagnostico in molti casi; frequentemente questo tumore è difficilmente distinguibile tramite colangiogramma e un'accurata diagnosi tramite brushing delle via biliari può risultare estremamente difficoltosa. Un aumento del CA 19-9 potrebbe essere d'aiuto, ma non è particolarmente specifico in quanto un suo aumento può essere presente nella PSC isolata.

\section{Istologia epatica}

La biopsia epatica è richiesta nei pazienti con PSC soltanto quando vi è il sospetto di una OS AIH. Le lesioni istologiche della PSC sono spesso aspecifiche e variabili per le diverse possibilità di coinvolgimento dell'albero biliare. ${ }^{130}$ Purtroppo la classica descrizione di una fibrosi concentrica (onion spinning) che interessa i dotti biliari nell'area portale si osserva raramente nella pratica clinica. ${ }^{131}$ Metodi non invasivi sono utili per definire l'entità della fibrosi e consentire la diagnosi della cirrosi.

\section{Diagnosi}

La diagnosi di PSC è basata su criteri biochimici e strumentali (Figura 6). ${ }^{123}$

Un aumento dell'ALP e della $\gamma$-GT è uno degli aspetti biochimici più comuni. Sebbene i valori possano essere estremamente variabili è raro che siano del tutto normali durante il corso della malattia. ${ }^{132}$ Le AT sono generalmente normali o solo lievemente aumentate ( $\leq 2$ volte ULN); valori più alti di AT potrebbero essere il segnale di una sindrome da overlap. La bilirubinemia totale è in genere normale, mentre è fortemente aumentata solo nei pazienti con ostruzione significativa dei dotti biliari.

Altre alterazioni, come l'ipoalbuminemia, l'aumento del tempo di protrombina, la trombocitopenia, sono evidenti nei pazienti che hanno sviluppato cirrosi epatica.

Come precedentemente descritto, gli autoanticorpi (particolarmente i pANCA) possono essere presenti nei pazienti affetti da PSC. In alcuni casi, vi sono anche aumenti dei livelli di IgG-4, caratteristici della colangite autoimmune (CAI) e della pancreatite autoimmune (PAI) IgG-4 correlate.

Basandosi sui riscontri di studi retrospettivi, non è chiaro se i pazienti con PSC ed aumentati livelli di IgG-4 siano affetti da CAI/PAI o da un sottotipo di PSC caratterizzata da un decorso più sfavorevole. ${ }^{133,134}$ Un approfondimento diagnostico è necessario, poiché i pazienti affetti da CAI/PAI dovrebbero essere sottoposti a terapia steroidea. ${ }^{135}$

La colangio-RMN (CRMN) è la tecnica diagnostica di scelta per la diagnosi di PSC. I segni tipici includono: diffuso coinvolgimento dei dotti biliari extraepatici e/o intraepatici, con presenza di strutture anulari multifocali alternate a segmenti normali o lievemente dilatati. Comunque più del $25 \%$ dei pazienti presenta solo malattia intraepatica. ${ }^{136} \mathrm{La} \mathrm{CRMN}$ è una tecnica non invasiva, priva di radiazioni, di costo/efficacia migliore rispetto all'ERCP. ${ }^{137,138}$

Grazie alla ricostruzione tridimensionale, la CRMN è in grado di analizzare anche i dotti biliari di terzo e quarto ordine, migliorando l'accuratezza diagnostica nel caso in cui non vi fosse coinvolgimento delle vie extraepatiche. Come già accennato non appare accettabile una diagnosi di PSC con coinvolgimento esclusivo dei piccoli dotti biliari; una CRMN di alta qualità è dunque necessaria in tale condizione e l'integrità dei dotti biliari extraepatici deve essere associata, nei pazienti senza IBD, a un risultato negativo della ricerca della mutazione del gene $\mathrm{ABCB} 4$, che, oltre una colelitiasi plurisegmentaria, può causare anche lesioni istologiche dei piccoli dotti intraepatici apparentemente compatibili con una PSC. ${ }^{139}$

\section{Terapia}

Tutti gli studi randomizzati e controllati, atti a valutare l'efficacia dei farmaci nel prevenire la progressione della PSC, non hanno dato risultati positivi. L'UDCA è il farmaco più studiato; probabilmente è in grado di migliorare i valori biochimici e alcuni parametri istologici, ma non ha evidenziato un reale miglioramento della prognosi e del tempo di progressione a cirrosi. Una metanalisi effettuata su 8 studi conferma che l'UDCA non rallenta la progressione della PSC. ${ }^{140}$

Uno studio europeo nel quale è stato somministrato UDCA alla dose di $17-23 \mathrm{mg} / \mathrm{kg} / \mathrm{die}$ non ha mostrato un aumento della sopravvivenza del gruppo dei pazienti trattati rispetto a quelli che hanno assunto placebo. ${ }^{141}$

Un ulteriore studio effettuato in Nord America nel quale sono state somministrate dosi più alte di UDCA $(28-30 \mathrm{mg} / \mathrm{kg} / \mathrm{die} /)$ ha fatto rilevare che nei pazienti trattati il rischio di progressione era di circa 2 volte superiore rispetto al gruppo in placebo. L'end-point includeva: cirrosi, varici, colangiocarcinoma, trapianto epatico o morte. ${ }^{142}$

L'uso di alte dosi di UDCA sembrerebbe associato anche al rischio di sviluppo di CRC nei pazienti con UC. ${ }^{143}$

In definitiva alte dosi di UDCA non appaiono raccomandabili nella PSC per la loro tossicità e l'impiego di basse dosi necessita di maggiori dati sull'efficacia e la sicurezza.

Gli agenti immunosoppressori (ad es. corticosteroidi, ciclosporina, azatioprina, metotrexate) non hanno alcuna funzione nei pazienti affetti da PSC e per tale ragione il loro uso non è raccomandato. ${ }^{144}$

L'espansione endoscopica delle principali stenosi (definite come stenosi $\geq 1,5 \mathrm{~mm}$ nel dotto biliare comune $\mathrm{e} \geq 1 \mathrm{~mm}$ nel dotto epatico), sia grazie alla sola 
dilatazione o all'applicazione di uno stent, può migliore il drenaggio biliare a lungo termine, riducendo i sintomi e prevenendo le complicanze. ${ }^{145}$ Frequentemente è stata riscontrata la presenza di infezione nei pazienti con stenosi biliari; l'utilizzo di antibiotico per almeno 5 giorni dopo la dilatazione o l'applicazione di stent, può ridurre il rischio di colangiti.

Generalmente lo stent può essere rimosso dopo circa 6-8 settimane, evitando o riducendo di molto il rischio di complicanze. In ogni caso, molti pazienti necessitano della sostituzione dello stent circa ogni 612 mesi prima che si riesca ad ottenere una risoluzione delle stenosi.

Il trapianto epatico ha mostrato risultati davvero positivi nei pazienti affetti da PSC. I pazienti con cirrosi in classe A di Child-Pugh-Turcotte presentano una sopravvivenza del $90 \%$ a 5 anni dal trapianto. Per tale motivo il trapianto è indicato nei pazienti con cirrosi e con disfunzione non severa di fegato e in quei pazienti non cirrotici con episodi ripetuti e non trattabili di colangiti tali da indurre un grave peggioramento della qualità di vita (ad es. prurito incoercibile).

\section{Sindromi da overlap}

Con il termine sindromi da overlap si indicano forme varianti di AILD caratterizzate dalla coesistenza di una patologia epatitica e colestatica con concomitanti alterazioni proprie dell'AIH e della PBC (Figura 7) o dell' AIH e della PSC. ${ }^{146} \mathrm{La}$ coesistenza di PBC e PSC ${ }^{147}$ e di AIH o PBC e PSC ${ }^{148}$ è stata descritta in singoli casi, ma non vi è evidenza di una possibile OS PBC/PSC. ${ }^{149}$

L'incidenza e la prevalenza delle OS non è ancora definibile. In un ampio studio della Mayo Clinic sono stati valutati 162 patienti con AIH, 37 con PBC e 26 con PSC; aspetti propri di un'altra AILD sono stati ritrovati rispettivamente nel $12 \%, 19 \%$ e $54 \%$ dei casi. ${ }^{150}$ A Napoli, dove le AILD hanno un'incidenza minore rispetto alle epatiti di diversa natura, nell'Unità di Medicina interna dell'Ospedale S. Maria del Popolo degli Incurabili nel corso di 5 anni (1999-2003) abbiamo osservato segni bioumorali e istologici di OS più frequentemente rispetto ai segni di forme pure di immunopatologia epatica e biliare (9 casi: 5 OS, 4 forme pure). ${ }^{151}$

Anche definizioni standardizzate di OS non sono del tutto accettabili:

- non è chiaro se le OS sono autonome malattie autoimmuni del fegato o varianti dell'AIH o la coesistenza di 2 malattie nello stesso paziente;

- le alterazioni caratterizzanti l'AIH e la PBC o la PSC possono insorgere simultaneamente (vere OS), ma anche in modo sequenziale, ad es. all'inizio hanno gli aspetti di una sola malattia e successivamente si manifestano gli aspetti dell'altra malattia; ${ }^{152}$ la simultaneità dell'insorgenza è più frequente

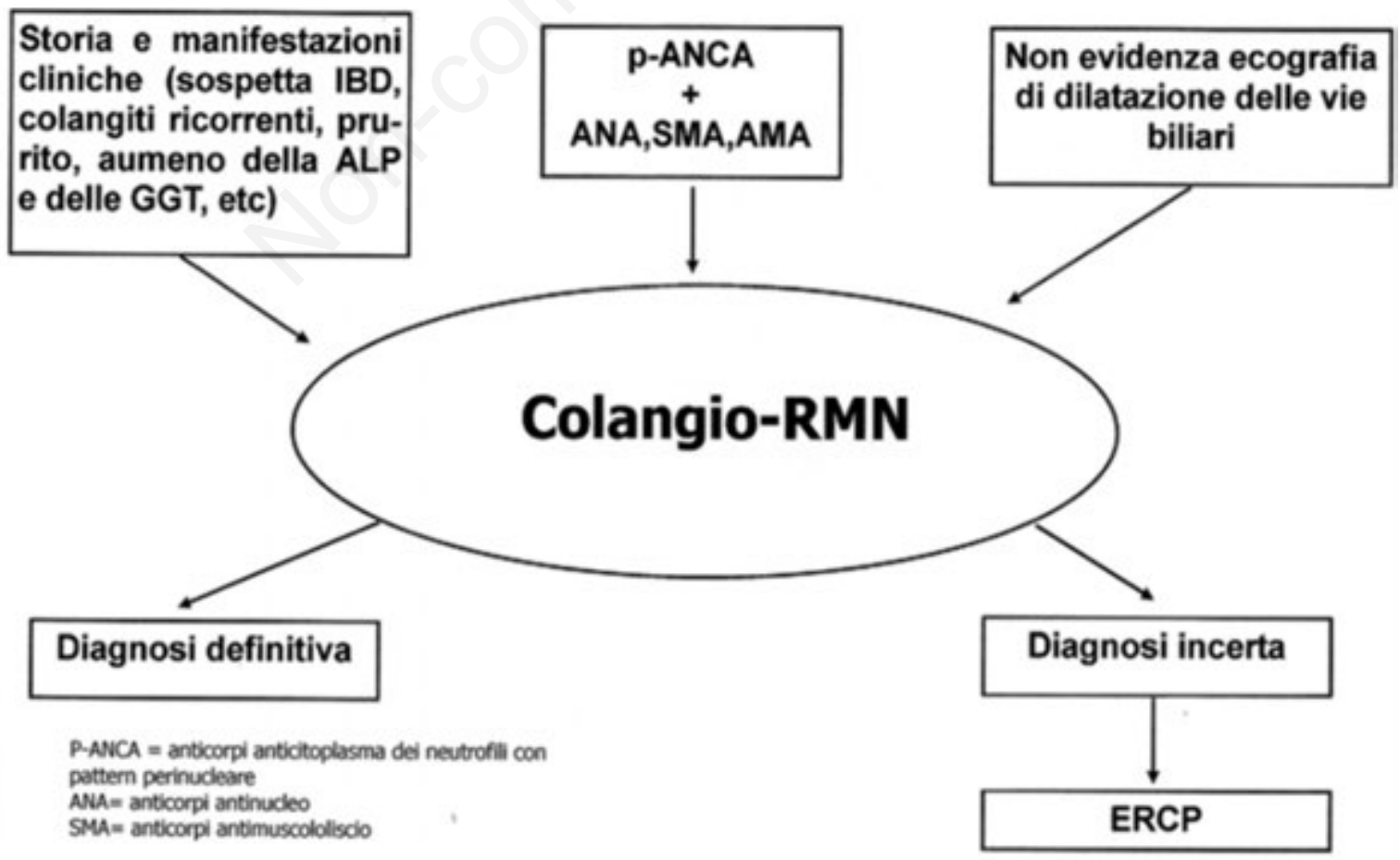

Figura 6. Flow-chart diagnostico della PSC. Modificata da Alvaro D e Attili AF. ${ }^{123}$ 
nella OS AIH-PSC, anche se talora la PSC può essere diagnosticata più tardivamente, anche molti anni dopo le prime espressioni dell' $\mathrm{AIH} ;{ }^{153}$

- vi è una notevole eterogeneità dei fenotipi clinici, anche in pazienti, cui è stata posta la diagnosi di una medesima OS: $:^{154}$ i) una overlap immunosierologica con titoli significativi di ANA/SMA e valori elevati di IgG e, contemporaneamente, una PBC AMA positiva; ii) una overlap biochimica: AST/ALT $>5 x \mathrm{xNV}$ in pazienti con PBC o PSC; o ALP $>3 x$ UNV in patienti con AIH (o $\gamma$-GT $>5 \times$ UNV nei bambini); iii) una overlap radiologica: aspetti clinici di AIH con alterazioni colangiografiche indicative di una colangiopatia infiammatoria; iv) una overlap istologica: infiltrati linfoplasmacitici ed epatite dell'interfaccia con lesioni dei dotti biliari indicative o di una $\mathrm{PBC}$ o di una PSC.

I criteri per la diagnosi di AIH-PBC sono stati proposti da Chazouillères et al. (criteri di Parigi, 1998). La diagnosi richiede almeno due dei seguenti 3 aspetti per ciascuna componente della OS. I criteri per la PBC sono: i) livelli serici di ALP almeno doppi rispetto agli UNV o di $\gamma$-GT almeno 5 volte $>$ UNV; ii) positività della ricerca degli AMA, iii) evidenza istologica di lesioni floride dei dotti biliari. I criteria per l'AIH sono: i) livelli serici di ALT almeno 5 volte $>$ UNV; ii) valori di IgG almeno doppi rispetto agli UNV o positività della ricerca degli SMA, iii) biopsia epatica con moderata o severa infiammazione periportale o periseptale. ${ }^{155}$ I criteri di Parigi sono stati confermati dalle linee guida della European Association for the Study of the Liver (EASL) per il trattamento delle malattie colestatiche del fegato pubblicate nel 2009; in ogni caso l'evidenza istologica dell' epatite dell' interfaccia è essenziale per la diagnosi di OS PBC-AIH. ${ }^{156}$

L'OS AIH-PSC è caratterizzata dalla sieropositi-

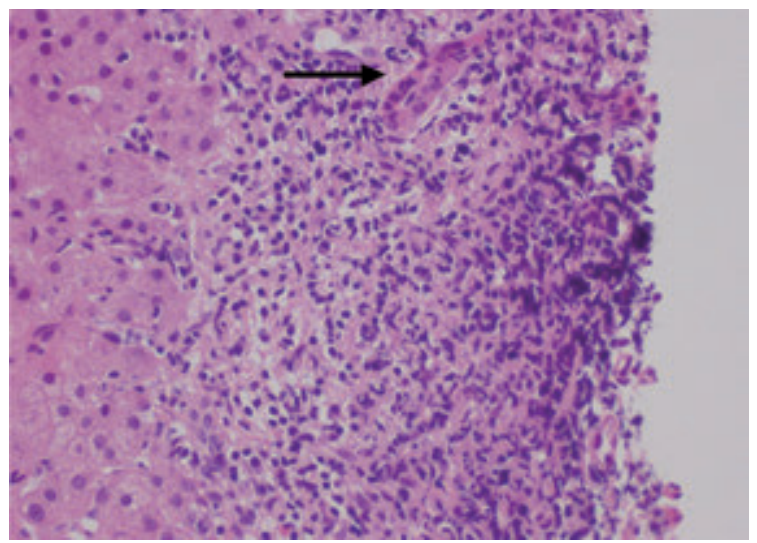

Figura 7. Overlap PBC AIH. Danno biliare (freccia in alto), infiltrato infiammatorio con cospicua quota di plasmacellule, estesa epatite all'interfaccia. vità per gli ANA e/o gli SMA, dall'ipergammaglobulinemia, dalla possibile sieropositività per i p-ANCA, dalla frequente concomitanza di una malattia infiammatoria intestinale, dall'epatite dell'interfaccia e dai tipici segni istologici di una classica AIH in associazione con le alterazioni bioumorali della colestasi e dalla evoluzione istologica verso la colangite fibrosaobliterativa, dalla duttopenia, dall'edema portale e dalla stasi biliare. La diagnosi è consolidata dalla CRMN con evidenza di segni colangiografici intraepatici o extraepatici di PSC. ${ }^{157-159}$

L'associazione tra PSC e AIH sembra essere la più frequente OS. In uno studio retrospettivo in un ampio numero di soggetti adulti con diagnosi iniziale di AIH tipo 1 fu rilevata con la CRMN una concomitante colangite sclerosante. ${ }^{160}$

La OS AIH-PSC è di riscontro particolarmente frequente nei bambini, come documentato da casistiche canadesi e inglesi: ${ }^{147}$ per questi pazienti è stato coniato il termine di colangite sclerosante autoimmune (autoimmune sclerosing cholangitis $=$ ASC). In uno studio prospettico della durata di oltre 16 anni tutti i bambini con positività della ricerca degli AA serici, alti livelli di IgG ed evidenza istologica di epatite dell'interfaccia sono stati sottoposti a colangiografia al momento delle prime manifestazioni cliniche. In circa la metà dei casi sono state rilevate alterazioni dei dotti biliari ed è stata formulata la diagnosi di ASC. In tutti i pazienti con ASC era positiva la ricerca degli ANA o dei SMA. L'ASC colpisce in percentuali uguali i bambini e le bambine. I piccoli pazienti con ASC frequentemente avevano una concomitante malattia infiammatoria intestinale e più spesso di quelli con AIH risultavano positivi alla ricerca dei pANNA. ${ }^{161}$

In alcuni articoli recenti è stata rivista la terapia delle OS. ${ }^{149,162}$

Nelle OS AIH-PBC il trattamento deve essere guidato dagli aspetti clinici e istologici della malattia.

L'UDCA in monoterapia (13-15 mg/kg/die) può essere efficace in alcuni pazienti con prevalenza delle lesioni della PBC; questi pazienti infatti possono ottenere una soddisfacente risposta bioumorale e una lenta progressione della fibrosi e dell'insufficienza epatica. ${ }^{163,164}$

Invece i pazienti con segni più evidenti di AIH (ad es. livelli elevati di AT e/o epatite dell'interfaccia) necessitano di associare all'UDCA la terapia immunosoppressiva (corticosteroidi in monoterapia o con l'azatioprina) per ottenere una risposta biochimica completa. ${ }^{165}$ In alternativa è possibile attendere i risultati e considerare successivamente l'opportunità dell'associazione con gli immunosoppressori. La terapia di combinazione è obbligatoria nei pazienti con $\mathrm{AIH}$ e valori molto elevati di ALP per ottenere la remissione clinica e ridurre lo sviluppo della cirrosi e il ri- 
schio del carcinoma epatocellulare o del colangiocarcinoma. ${ }^{154,165,166}$

Gli effetti favorevoli della terapia di combinazione sulle alterazioni bioumorali e/o sulla progressione della fibrosi nella OS AIH/PBC sono stati descritti anche da altri Autori in studi retrospettivi o prospettici, ${ }^{151,153,154}$ anche se la frequenza complessiva dei non responders e la possibilità di un'evoluzione negativa della malattia è maggiore rispetto a quella osservata nell' $\mathrm{AIH}$ isolata. ${ }^{164,166,167}$ È dunque non ancora chiara se l'evoluzione clinica della OS AIH/PBC sia differente da quella delle forme isolate di AIH o di PBC.

La prognosi delle OS AIH-PSC può essere migliore di quella dei pazienti con PSC, ma peggiore di quella dei pazienti con $\mathrm{AIH}{ }^{154}$

La remissione delle OS AIH-PSC con corticosteroidi e azatioprina, talvolta associati all'UDCA, si ottiene in una piccola percentuale di casi. La risposta del trattamento immunosoppressivo sembra essere più favorevole nei bambini che negli adulti, probabilmente perché la alterazioni epatitiche sono meno marcate di quelle dei tratti biliari. ${ }^{168,169}$

Il trattamento con alte dosi di UDCA (20-30 $\mathrm{mg} / \mathrm{kg} / \mathrm{die}$ ) ha dato risultati molto controversi. In alcuni studi queste dosi sono state capaci di incrementare $\mathrm{i}$ benefici clinici, ridurre la progressione istologica, produrre un effetto preventivo nei confronti del cancro del colon in caso di concomitante IBD; ${ }^{170,171}$ tuttavia i risultati di altri recenti studi documentano che l'UDCA non soltanto non sarebbe in grado di esercitare una favorevole influenza sulla progressione della malattia e sul rischio di sviluppo del colangiocarcinoma, ma potrebbe anche esercitare un effetto epatotossico diretto, ${ }^{140}$ anche la possibilità di prevenzione del cancro del colon nelle IBD appare dubbia. ${ }^{172}$

Abitualmente i pazienti con AIH/PSC hanno una minore sopravvivenza rispetto ai pazienti con AIH isolata; ${ }^{167}$ invece i pazienti con PSC isolata hanno una più lunga sopravvivenza. ${ }^{173}$

Non è sorprendente che i pazienti con OS AIH/PSC abbiano una peggiore evoluzione rispetto a quelli con AIH isolata e che la terapia immunosoppressiva sia spesso inefficace, ${ }^{174}$ perché una terapia davvero efficace per la PSC non è stata ancora identificata.

Il trapianto di fegato deve essere preso in considerazione nelle fasi avanzate sia della OS AIH-PBC sia della OS AIH-PSC.

\section{Bibliografia}

1. Feld JJ, Heathcote EJ. Epidemiology of autoimmune liver disease. J Gastroenterol Hepatol 2003;18:1118-28.

2. EASL Clinical Practice Guidelines: Autoimmune Hepatitis, J Hepatol 2015;63:971-1004.

3. Boberg KM, Aadland E, Jahnsen J, et al. Incidence and prevalence of primary biliary cirrhosis, primary sclerosing cholangitis, and autoimmune hepatitis in a Norwegian population. Scand J Gastroenterol 1998;33:99-103.

4. Werner M, Prytz H, Ohlsson B, et al. Epidemiology and the initial presentation of autoimmune hepatitis in Sweden: a nationwide study. Scand J Gastroenterol 2008;43:1232-40

5. Granbaek L, Vilstrup H, Jepsen P. Autoimmune hepatitis in Denmark: incidence, prevalence, prognosis and causes of death. A nation-wide registry-based cohorts. J Hepatol 2014;60:612-7.

6. Hurburt KJ, McMahon BJ, Deubner H, et al. Prevalence of autoimmune liver disease in Alaska Natives. Am J Gastroenterol 2002;97:2402-7.

7. Ngu JH, Bechlyk K, Chapman BA et al. Population based epidemiology study of autoimmune hepatitis: a disease of older women?. J Gastroenterol Hepatol 2010;25:1681-6.

8. Toda G, Zeniya M, Watanabe F, et al. Present status of autoimmune hepatitis in Japan correlating the characteristics with international criteria in an area with a high rate of HCV infection. Japanese National Study Group of Autoimmune Hepatitis. J Hepatol 1997;26: 1207-12.

9. Lam KC, Lai CL, Wu PC, Todd D. Etiological spectrum of liver cirrhosis in the Chinese. J Chronic Dis 1980;33:375-81.

10. Qiu D, Wang Q, Wang H, Xie Q, et al. Validation of the simplified criteria for diagnosis of autoimmune hepatitis in Chinese patients. J Hepatol 2011;54:340-7.

11. Manns MP, Czaja AJ, Gorham JD, et al. Diagnosis and management of autoimmune hepatitis. AASLD practice guidelines. Hepatology 2010;51: 2193-213.

12. Al-Chalabi T, Boccato S, Portmann BC, et al. Autoimmune hepatitis (AIH) in the elderly: a systematic retrospective analysis of a large group of consecutive patients with definite $\mathrm{AIH}$ followed at a tertiary referral centre. J Hepatol 2006;45:575-83.

13. De Biasio MB, Periolo, N,Avagnina A, et al. Liver infiltrating mononuclear cells in children whit type 1 autoimmune hepatitis. J Clin Pathol 2006; 59:417-23.

14. Abe M, Onji M, Kawai-Ninomiya K, et al. Clinicopathologic features of the severe form of acute type I hepatitis. Clin Gastroenterol Hepatol 2007; 5:255-8.

15. Scheuer PJ. Classification of cronic viral hepatitis: a need for reassessment. J Hepathol1991; 13:372-4

16. Group FMCS. Intraobserver and interobserver variationn liver biopsy interpretation in patients with chronic hepatitis C. The French METAVIR Cooperative Study Group. Hepathology 1994; 20:15-20.

17. Ishak K, Baptista A, Bianchi L, et al. Histological grading and staging of cronic hepatitis. J Hepathology 1995; 22:696-9.

18. Czaja AJ, Carpenter HA. Histological feature associated with relapse after corticosteroid withdrawal in type 1 autoimmune Hepatitis. Liver Int. 2003; 23:116-23.

19. Liberal R, Grant CR, Mieli-Vergani G, Vergani D. Autoimmune hepatitis. A comprehensive review. J Autoimmun 2013;41:126-39.

20. Takahashi $\mathrm{H}$ and Zeniya M. Acute presentation of autoimmune hepatitis. Does it exist? A published work review. Hepatol Res 2011;41:498-504.

21. Abe M, Mashiba T, Aeniya M, et al. Present status of 
autoimmune hepatitis in Japan: a nationwide survey. J Gastroenterol 2011;46:1136-41.

22. Stravitz RT, Lefkowitch JH, Fontana RJ, et al. Autoimmune acute liver failure: proposed clinical and histological criteria. Hepatology 2011;53:517-26.

23. Ferrari R, Pappas G, Agostinelli D et al. Type 1 autoimmune hepatitis: patterns of clinical presentation and differential diagnosis of the "acute" type. QJM 2004;97: 407-12.

24. Gleeson D and Heneghan MA. British Society of Gastroenterology (BSG) guidelines for management of autoimmune hepatitis. Gut 2011;60:1611-29.

25. Czaja AJ. Autoimmune hepatitis in special patient populations. Best Pract Res Clin Gastroenterology 2011;25: 679-200.

26. Karkhanis J, Verna EC, Chang MS, et al. Steroid use in acute liver failure. Hepatology 2014; 59:612-21.

27. Homberg JC, Abuaf N, Bernard O, et al. Chronic active hepatitis associated with anti liver/kidney microsome type 1: a second type of "autoimmune" hepatitis. Hepatology 1987;7:1333-39.

28. Mieli-Vergani G, Heller S, Jara P, et al. Autoimmune hepatitis. J Pediatr Gastroenterol Nutr 2009 ; 49:158-64.

29. Bianchi FB, Muratori P, Muratori L. Autoimmunity and autoreactivity in liver disease. In: Ascione A ed. Hepatology at bedside. Naples (Italy): Arte tipografica; 2003. pp141-9.

30. Liberal R, Grant Cr, Longhi MS, et al.. Diagnostic criteria of autoimmune hepatitis. Autoimmun Rev 2014;13:435-40.

31. Wies I, Brunner S, Henninger J, et al. Identification of target antigen for SLA/LP autoantibodies in autoimmune hepatitis. Lancet 2000;355:1510-5.

32. Baeres M, Herkel G, Czaja AJ, et al. Establishment of standardised SLA/LP immunossayes: specificity for autoimmune hepatitis, worldwide occurrence, and clinical characteristics. Gut 2002;51:259-64.

33. Kamisawa T, Funata N, Hayashi H, et al. A new clinicopathological entity of IgG-4 related autoimmune disease. J Gastroenterol 2003;38:982-4.

34. Chung H, Watanabe T, Kudo H, et al. Identification and characterization of immunoglobulin IgG-4 associated autoimmune hepatitis. Liver Int 2010;30:222-31.

35. Umemura T, Zen Y, Hamano H, et al. Clinical significance of immunoglobulin IgG-4 associated autoimmune hepatitis. J Gastroenterol 2011;46:48-55.

36. Johnson PJ, McFarlaine IG. Meeting report: International autoimmune hepatitis group. Hepatology 1993;18: 99817-1005.

37. Alvarez F, Berg PA, Bianchi FB, et al. International Autoimmune Hepatitis Group Report: review of criteria for diagnosis of autoimmune hepatitis. J Hepatol 1999;31:929-38.

38. Hennes EM, Zeniya M, Czaja AJ, et al., Simplified criteria for the diagnosis of autoimmune hepatitis. Hepatology 2008; 48:169-76

39. Czaja AJ. Performance parameters of the diagnostic scoring systems for autoimmune hepatitis. Hepatology 2008;48:1540-8.

40. Muratori P, Granito A, Pappas G, Muratori L. Validation of simplified diagnostic criteria for autoimmune hepatitis in Italian patients. Hepatology 2009;49:1782-3.

41. Yeoman AD, Westbrook RH, Al-Chalabi T, et al. Dia- gnostic value and utility of the simplified International Autoimmune Hepatitis Group (IAIHG) criteria in acute and chronic liver disease. Hepatology 2009;50:538-45.

42. Trivedi BJ, Hirschfield G. Treatment of Autoimmune Liver Disease. Current and Future Therapeutic Options. Ther Adv Chronic Dis 2013;4:119-41.

43. Cook GC, Mulligan R, Sherlock S. Controlled prospective trial of corticosteroid therapy in acute chronic hepatitis. Q J Med 1971;40;159-875.

44. Soloway RD, Summerskill WH, Baggenstos AH, et al. Clinical, biochemical, and histological remission of severe chronic active liver disease: a controlled study of treatment and early prognosis. Gastroenterology 1972;63:820-33.

45. Lamers MM, van Oijen MG, Pronk M, Drenth JP. Treatment options for autoimmune hepatitis; a systematic revue of randomized controlled trials. J Hepatol 2010;53:191-8.

46. Murray-Lyon M, Stern RB, Williams R. Controlled trial of prednisone and azathioprine in acute chronic hepatitis. Lancet 1973;1:735-7.

47. Johnson P, McFarlane I, Williams R. Azathioprine for long-term maintenance of remission in autoimmune hepatitis. N Engl J Med 1995;333:958-63.

48. Stellon AJ, Keating JJ, Johnson P, et al. Maintenance of remission in autoimmune chronic active hepatitis with azathioprine after corticosteroid withdrawal. Hepatology 1988;8:781-4.

49. Carpenter H, Czaja AJ. The role of histologic evaluation in the diagnosis and management of autoimmune hepatitis and its variants. Clin Liver Dis 2002;6: 685-705.

50. Czaja AJ, Carpenter H. Histological features associated with relapse after corticosteroid withdrawal in type 1 autoimmune hepatitis. Liver Int 2003; 23:116-23.

51. Lüth S, Herkel J, Kanzler S, et al. Serologic markers compared with liver biopsy for monitoring disease activity in autoimmune hepatitis. J Clin Gastroenterol 2008;42:926-30.

52. Montano-Loza A, Carpenter H, Czaja AJ. Consequences of treatment withdrawal in type 1 autoimmune hepatitis. Liver Int 2007; 27: 507-15.

53. Yoshizawa K, Matsumoto A, Ichijo T, et al. Long-term outcome of Japanese patients with type 1 autoimmune hepatitis. Hepatology 2012;56:668-76.

54. Danielsson A, Prytz H. Oral budesonide for treatment of autoimmune chronic active hepatitis. Aliment Pharmacol Ther 1994;8:585-90.

55. Manns M, Woynarowski M, Kreisel W, et al. Budesonide induces remission more effectively than prednisone in a controlled trial of patients with autoimmune hepatitis. Gastroenterology 2010;139:1198-1206.

56. Mederacke I, Helfritz F, Puls, F, et al. Budd-Chiari syndrome after treatment with budesonide in a cirrhotic patient with autoimmune hepatitis. Ann Hepatol 2012;11:143-4.

57. Czaja AJ, Lindor K. Failure of budesonide in a pilot study of treatment-dependent autoimmune hepatitis. Gastroenterology 2000;119:1312-16.

58. Hlivko J, Shiffman M, Stravitz R, et al. A single center review of the use of mycophenolate mofetil in the treatment of autoimmune hepatitis. Clin Gastroenterol Hepatol 2008;6:1036-40.

59. Schaffner F, Popper H. Clinical-pathologic relations in 
primary biliary cirrhosis. Prog Liver Dis 1982;7:529-54.

60. Griffiths L, Dyson JK, Jones DE. The new epidemiology of primary biliary cirrhosis. Semin Liver Dis 2014; 34 : 318-28.

61. Watson RG, Angus PW, Dewar M, et al. Low prevalence of primary biliary cirrhosis in Victoria, Australia. Melbourne Liver Group. Gut 1995; 36: 927-930.

62. Gershwin ME, Selmi C, Worman HJ, et al. Risk factors and comorbidities in primary biliary cirrhosis: a controlled interviewbased study of 1032 patients. Hepatology 2005; 42:1194-1202.

63. Invernizzi P, Selmi C, Ranftler C, et al. Antinuclear antibodies in primary biliary cirrhosis. Semin Liver Dis. 2005: 25:298-310.

64. Yamada S., Howe S., Sheuer PJ. Three-dimensional recostruction of biliary pathways in primary biliary cirrhosis: a computer-assisted study. J Pathol 1987; 152:317-23.

65. Kamihira T., Shimoda S, Harada K, et al. Distinct costimulation dependent and indipendent autoreactive $\mathrm{T}$ cell clones in primary biliary cirrhosis. Gastroenterology 2003; 125:1379-87.

66. Rubin E, Schaffner F, Popper H. Primary biliary cirrhosis. Chronic non suppurative destructive cholangitis. Am J Pathol 1965; 46:387-407

67. Nakanuma Y, Ohta G,. Histometric and serial section observations of the intrahepatic bile ducts in primary biliary cirrhosis. Gastroenterology 1979; 76:1326-32.

68. Daniels JA, Torbenson M, Anders RA, Boitnott JK. Immunostaining of plasma cell in primary biliary cirrhosis. Am J Clin Pathol 2009; 131:243-9.

69. Colina F, Pinedo F,Solis JA, et al. Nodular regenerative hyperplasia of the liver in early histologic stages of primary biliary cirrhosis. Gastroenterology 1992; 102: 1319-24.

70. Scheuer PJ. Primary biliary cirrhosis. Proc Roy Soc Med 1967; 60:1257-60.

71. Solis Herruzo JA, Solis Munoz P, Munoz Yague T. The pathogenesis of primary biliary cirrhosis. Rev Esp Enferm Dig 2009;101:413-23.

72. Hirschfield GM, Gershwin MR. Primary biliary cirrhosis: one disease with many faces. IMAJ 2011;13:55-9

73. Gershwin ME, Selmi C, Worman HJ, et al. Risk factors and comorbidities in primary biliary cirrhosis: a controlled interview-based study of 1032 patients. Hepatology 2005; 42:1194-202.

74. Corpechot C, Chrétien Y, Chazouillères O, Poupon R. Demographic, lifestyle, medical and familial factors associated with primary biliary cirrhosis. J Hepatol 2010;53:162-9.

75. Prince MI, Ducker SJ, James OF. Case-control studies of risk factors for primary biliary cirrhosis in two United Kingdom populations. Gut 2010;59:508-12.

76. Howel D, Fischbacher CM, Bhopal RS, et al. An exploratory population-based case-control study of primary biliary cirrhosis. Hepatology 2000;31:1055-60.

77. Parikh-Patel A, Gold EB, Worman H,et al. Risk factors for primary biliary cirrhosis in a cohort of patients from the United States. Hepatology 2001; 33: 16-21.

78. Smyk DS, Rigopoulou EI, Bogdanos DP. Potential roles for infectious agents in the pathophysiology of primary biliary cirrhosis: What's new? Curr Infect Dis Rep 2013;15:14-24
79. McNally RJ, Ducker S, James OF. Are transient environmental agents involved in the cause of primary biliary cirrhosis? Evidence from space-time clustering analysis. Hepatology. 2009;50:1169-74.

80. Leuschner U. Primary biliary cirrhosis - presentation and diagnosis. Clin Liver Dis 2003; 7: 741-58.

81. Ideo G. Le epatopatie autoimmuni e colestatiche. In: Ideo $\mathrm{G}$ ed. Compendio di Epatologia. Milano (Italia): Fondazione Amici Epatologia; 2005. pp98-110.

82. EASL Clinical Practice Guidelines: management of cholestatic liver diseases. J Hepatol 2009; 51:237-67.

83. Lindor KD, Gershwin ME, Poupon R, et al. Primary biliary cirrhosis. Hepatology 2009;50:291-308.

84. Oertelt S, Rieger R, Selmi C, et al. A sensitive bead assay for antimitochondrial antibodies: chipping away at AMA-negative primary biliary cirrhosis. Hepatology 2007; 45: 659-65.

85 . Leuschner U. Primary biliary cirrhosis-presentation and diagnosis. Clin Liver Dis 2003;7:741-758.

86. Shapiro JM, Smith H, Shaffner F. Serum bilirubin: a prognostic factor in primary biliary cirrhosis. Gut 1979;20: $137-40$

87. Poupon R. Primary biliary cirrhosis: A 2010 update. J Hepatol 2010;52:745-58.

88. Trivedi PJ, Hirschfield G. Treatment of Autoimmune Liver Disease. Current and Future Therapeutic Options. Ther Adv Chronic Dis. 2013;4:119-41.

89. Corpechot C, Chazouillères O, Poupon R. Early primary biliary cirrhosis: Biochemical response to treatment and prediction of long-term outcome. J Hepatol 2011;55: 1361-7.

90. Poupon RE, Lindor KD, Cauch-Dudek, K et al. Combined analysis of randomized controlled trials of ursodeoxycolic acid in primary biliary cirrhosis. Gastroenterology 1997;113:884-90.

91. Pares A, Caballeria L, Rodes J. Excellent long-term survival in patients with primary biliary cirrhosis and biochemical response to ursodeoxycholic acid. Gastroenterology 2006;130:715-20.

92. Kuiper EM, Hansen BE, de Vries RA, et al. Improved prognosis of patients with primary biliary cirrhosis that have a biochemical response to ursodeoxycholic acid. Gastroenterology 2009;136: 1281-7.

93. Corpechot C, Abenavoli L, Rabahi N, et al. Biochemical response to ursodeoxycholic acid and long-term prognosis in primary biliary cirrhosis. Hepatology 2008;48:871-7.

94. Hempfling W, Dilger K, Beuers U. Systematic review: ursodeoxycholic acid-adverse effects and drug interactions. Aliment Pharmacol Ther 2003; 18: 963-72.

95. Leuschner M, Maier KP, Schlichting J, et al. Oral budesonide and ursodeoxycholic acid for treatment of primary biliary cirrhosis: results of a prospective double-blind trial. Gastroenterology 1999;117: 918-25.

96. Rautiainen H, Karkkainen P, Karvonen AL, et al. Budesonide combined with UDCA to improve liverhistology in primary biliary cirrhosis: a three-year randomized trial. Hepatology 2005;41:747-52.

97. Kaplan MM, Cheng S, Price LL, Bonis PA. A randomized controlled trial of colchicine plus ursodiol versus methotrexate plus ursodiol in primary biliary cirrhosis: ten-year results. Hepatology 2004;39:915-23 
98. Kaplan MM. The use of methotrexate, colchicine, and other immunomodulatory drugs in the treatment of primary biliary cirrhosis. Sem Liver Dis 1997;17:129-36.

99. Leung J, Bonis PA, Kaplan MM. Colchicine or methotrexate, with ursodiol, are effective after 20 years in a subset of patients with primary biliary cirrhosis. Clin Gastroenterol Hepatol. 2011;9:776-80.

100. Gonzalez-Koch A, BrahmJ, Antezana C, et al. The combination of ursodeoxycholic acid and methotrexate for primary biliary cirrhosis is not better than ursodeoxycholic acid alone. J Hepatol 1997;27:143-9.

101. Combes B, Emerson SS, Flye NL, et al. Methotrexate (MTX) plus ursodeoxycholic acid (UDCA) in the treatment of primary biliary cirrhosis. Hepatology 2005;42:1184-93

102. Wiesner RH, Ludwig J, Lindor KD, et al. A controlled trial of cyclosporine in the treatment of primary biliary cirrhosis. N Engl J Med 1990;322:1419-24.

103. Lombard M, Portmann B, Neuberger J, et al. Cyclosporin treatment in primary biliary cirrhosis: results of a longterm placebo controlled trial. Gastroenterology 1993;104:519-26.

104. Mita S, Suzuki H, Akita H, et al. Inhibition of bile acid transport across $\mathrm{Na}+$ /taurocholate cotransporting polypeptide (SLC10A1) and bile salt export pump (ABCB 11)-coexpressing LLC-PK1 cells by cholestasis-inducing drugs. Drug Metab Dispos 2006; 34: 1575-181

105. Poupon R. Primary biliary cirrhosis: A 2010 update. J Hepatol 2010; 52;745-58

106. Babatin MA, Sanai FM, Swain MG. Methotrexate therapy for the symptomatic treatment of primary biliary cirrhosis patients, who are biochemical incomplete responders to ursodeoxycholic acid therapy. AlimentPharmacol Ther 2006;24:813-20.

107. Hirschfield GM, Mason A, Luketic V, et al. Efficacy of obeticholic acid in patients with primary biliary cirrhosis and inadequate response to ursodeoxycholic acid. Gastroenterology 2015;148:751-61.

108. Eaton JE, Talwalkar JA, Lazaridis KN,et al. Pathogenesis of primary sclerosing cholangitis and advances in diagnosis and management. Gastroenterology 2013;145:521-36.

109. Lindkvist B, Benito de Valle M, Gullberg B, et al. Incidence and prevalence of primary sclerosing cholangitis in a defined adult population in Sweden. Hepatology 2010;52:571-77.

110. Bambha K, Kim WR, Talwalkar JA, et al. Incidence, clinical spectrum, and outcomes of primary sclerosing cholangitis in a United States community. Gastroenterology 2003;125:1364-69.

111. Molodecky NA, Kareemi H, Parab R, et al. Incidence of primary sclerosing cholangitis: a systematic review and meta-analysis. Hepatology 2011;53:1590-99.

112. Ang TL, Fock KM, Ng TM, et al. Clinical profile of primary sclerosing cholangitis in Singapore. J Gastroenterol Hepatol 2002;17:908-13.

113. Escorsell A, Pares A, Rodes J, et al. Epidemiology of primary sclerosing cholangitis in Spain. Spanish Association for the Study of the Liver. J Hepatol 1994;21:787-791.

114. Kaplan GG, Laupland KB, Butzner D, et al. The burden of large and small duct primary sclerosing cholangitis in adults and children: a population-based analysis. Am J Gastroenterol 2007;102:1042-49.

115. Bergquist A, Lindberg G, Saarinen S, et al. Increased prevalence of primary sclerosing cholangitis among first-degree relatives. J Hepatol 2005;42:252-6.

116. Spurkland A, Saarinen S, Boberg KM, et al. HLA class II haplotypes in primary sclerosing cholangitis patients from five European populations. Tissue Antigens 1999;53:459-69.

117. Farrant JM, Doherty DG, Donaldson PT, et al. Amino acid substitutions at position 38 of the DR beta polypeptide confer susceptibility to and protection from primary sclerosing cholangitis. Hepatology 1992;16: 390-5.

118. Mehal WZ, Lo YM, Wordsworth BP, et al. HLA DR4 is a marker for rapid disease progression in primary sclerosing cholangitis. Gastroenterology 1994;106: $160-7$.

119. Olerup O, Olsson R, Hultcrantz R, et al. HLA-DR and HLA-DQ are not markers for rapid disease progression in primary sclerosing cholangitis. Gastroenterology 1995;108:870-878.

120. Liu JZ, Hov JR, Folseraas T, et al. Dense genotyping of immunerelated disease regions identifies nine new risk loci for primary sclerosing cholangitis. Nat Genet 2013;45:670-5.

121. O'Mahony CA, Vierling GM. Etiopathogenesis of primary sclerosing cholangitis. Semin Liver Dis 2006;26:3-21.

122. Palmer KR, Duerden BI, Holdsworth CD. Bacteriological and endotoxin studies in cases of ulcerative colitis submitted to surgery. Gut 1980;21:851-4.

123. Alvaro D, Attili AF. Biliary diseases: the cholangiopathies. In: Ascione A ed. Hepatology at bedside. Naples (Italy): Arte tipografica; 2003. pp 327-346.

124. Joo M, Abreu-e-Lima P, Farraye F, et al. Pathologic features of ulcerative colitis in patients with primary sclerosing cholangitis: a case-control study. Am J Surg Pathol 2009;33:854-862.

125. Sinakos E, Samuel S, Enders F, et al. inflammatory bowel disease in primary sclerosing cholangitis: a robust yet changing relationship. Inflamm Bowel Dis 2013;19:1004-1009.

126. Jorgensen KK, Grzyb K, Lundin KE, et al. Inflammatory bowel disease in patients with primary sclerosing cholangitis: clinical characterization in liver transplanted and nontransplanted patients. Inflamm Bowel Dis 2012;18:536-45.

127. Verdonk RC, Dijkstra G, Haagsma EB, et al. Inflammatory bowel disease after liver transplantation: risk factors for recurrence and de novo disease. Am J Transplant 2006;6:1422-29.

128. Chapman RW, Arborgh BA, Rhodes JM, et al. Primary sclerosing cholangitis: a review of its clinical features, cholangiography, and hepatic histology. Gut 1980;21:870-7.

129. Fevery J, Henckaerts L, Van Oirbeek R, et al. Malignancies and mortality in 200 patients with primary sclerosing cholangitis: a long-term single-centre study. Liver Int 2012;32:214-22.

130. Scheuer PJ. Ludwig Symposium on biliary disorders. Pathologic features and evolution of primary biliary cirrosis and primary sclerosing cholangitis. Mayo Clinic Proc 1998;73:179-83. 
131. Burak KW, Angulo P, Lindor KD. Is there a role for liver biopsy in primary sclerosing cholangitis? Amer J Gastroenterol 2003;98:1155-8.

132. Stanich PP, Bjornsson E, Gossard AA, et al. Alkaline phosphatase normalization is associated with better prognosis in primary sclerosing cholangitis. Dig Liver Dis 2011;43:309-33.

133. Bjornsson E, Chari S, Silveira M, et al. Primary sclerosing cholangitis associated with elevated immunoglobulin G4: clinical characteristics and response to therapy. Am J Ther 2011;18:198-205.

134. Mendes FD, Jorgensen R, Keach J, et al. Elevated serum IgG4 concentration in patients with primary sclerosing cholangitis. Am J Gastroenterol 2006;101:2070-75.

135. Oseini AM, Chaiteerakij R, Shire AM, et al. Utility of serum immunoglobulin G4 in distinguishing immunoglobulin G4-associated cholangitis from cholangiocarcinoma. Hepatology 2011;54:940-8.

136. McCarty RL, LoRusso NF, Wiesner RH, et al. Primary sclerosing cholangitis: findings on cholangiography and pancreatography. Radiology 1983; 149:39-44.

137. Kaltenthaler E, Vergel YB, Chilcott J, et al. A systematic review and economic evaluation of magnetic resonance cholangiopancreatography compared with diagnostic endoscopic retrograde cholangiopancreatography. Health Technol Assess 2004;8:81-9.

138. Talwalkar JA, Angulo P, Johnson CD, et al. Cost-minimization analysis of MRC versus ERCP for the diagnosis of primary sclerosing cholangitis. Hepatology 2004;40:39-45.

139. Gotthardt D, Runz H, Keitel V, at al. A mutation in the canalicular phospholipid transplanter gene, ABCB4, is associated with cholestasis, ductopenia, and cirrhosis in adults. Hepatology 2008;48:1157-66.

140. Triantos CK, Koukias NM, Nikolopoulou VN, et al. Meta-analysis: ursodeoxycholic acid for primary sclerosing cholangitis. Aliment Pharmacol Ther 2011;54: 901-10.

141. Olsson R, Boberg KM, de Muckadell OS, et al. Highdose ursodeoxycholic acid in primary sclerosing cholangitis: a 5-year multicenter, randomized, controlled study. Gastroenterology 2005; 129:1464-72.

142. Lindor KD, Kowdley KV, Luketic VA, et al. High-dose ursodeoxycholic acid for the treatment of primary sclerosing cholangitis. Hepatology 2009;50:808-14.

143. Eaton JE, Silveira MG, Pardi DS, et al. High-dose ursodeoxycholicacid is associated with the development of colorectal neoplasia in patients with ulcerative colitis and primary sclerosing cholangitis. Am J Gastroenterol 2011;106:1638-45.

144. Chapman R, Fevery J, Kalloo A, et al. Diagnosis and management of primary sclerosing cholangitis. Hepatology 2010;51:660-78.

145. Kaya M, Petersen BT, Angulo P, et al. Balloon dilation compared to stenting of dominant strictures in primary sclerosing cholangitis. Am J Gastroenterol 2001;96: 1059-66.

146. Washington MK. Autoimmune liver disease: overlap and outliers. Mod Path 2007;20:S15-S30.

147. Burak KW, Urbanski SJ, Swain MG. A case of coexisting primary biliary cirrhosis and primary sclerosing cholangitis: a new overlap of autoimmune liver diseases. Dig Dis Sci. 2001;46:2043-47.
148. Kingham JG, Abbasi A. Co-existence of primary biliary cirrhosis and primary sclerosing cholangitis: a rare overlap syndrome put in perspective. Eur J Gastroenterol Hepatol 2005;17:1077-80.

149. Durazzo M, Premoli A, Paschetta E, et al. Overlap syndrome of autoimmune hepatitis: An Open Question. Dig Dis Sci 2013;58:344-8

150. Czaja AJ. Frequency and nature of the variant forms of autoimmune liver disease. Hepatology 1998;28: 360-5.

151. Salvio A, d'Errico T, Varriale M, et al. Overlap syndromes: more frequent forms between autoimmune liver diseases? IX National Meeting of the Federation of Associations of Hospital Doctors on Internal Medicine (FADOI), Rome, 2004

152. Abdo AA, Bain VG, Kichian K, Lee SS. Evolution of autoimmune hepatitis in primary sclerosing cholangitis: a sequential syndrome. Hepatology 2002; 36. 1393-9

153. Rust C, Beuers U. Overlap syndromes among autoimmune liver diseases. World J Gastroenterol 2008;14: 3368-73.

154. Woodward J, Neuberger J. Autoimmune overlap syndromes. Hepatology 2001;33:994-1002.

155. Chazouilleres O, Wendum D, Serfaty I, et al. Primary biliary cirrhosis-autoimmune hepatitis overlap syndrome: clinical features and response to therapy. Hepatology 1998; 28:296-301

156. EASL Clinical Practice Guidelines: management of cholestatic liver diseases. J Hepato 2009; 51:237-67

157. Floreani A, Rizzotto ER, Ferrara F, et al. Clinical course and outcome of autoimmune hepatitis/primary sclerosing cholangitis overlap syndrome.Am J Gastroenterol 2005;100:1516-22

158. Kaya M, Angulo P, Lindor KP. Overlap of autoimmune hepatitis and primary sclerosing cholangitis: an evaluation of a modified scoring system. J Hepatol 2000;33:537-42.

159. Abdalian R, Dhar P, Jhaveri K,et al. Prevalence of sclerosing cholangitis in adults with autoimmune hepatitis: evaluating the role of routine magnetic resonance imaging. Hepatology 2008;47:949-57.

160. Wilshanski M, Chait P, Wade JA et al. Primary sclerosing cholangitis in 32 children: clinical, laboratory and radiographic features with survival analyses. Hepatology 1995;22:1415-22.

161. Gregorio GV, Portmann B, Karani J et al. Autoimmune hepatitis/sclerosing cholangitis overlap syndrome in childhood: a 16-year prospective study. Hepatology 2001;33:544-53.

162. Trivedi PJ, Hirschfield GM. Review article: overlap syndromes and autoimmune liver disease. Aliment Pharmacol Ther 2012;36:517-33

163. Miyake Y, Iwasaki Y, Kobashi H, et al. Efficacy of ursodeoxycholic acid for Japanese patients with autoimmune hepatitis. Hepatol Int. 2009;3:556-62.

164. Joshi S, Cauch-Dudek K, Wanless IR, et al. Primary biliary cirrhosis with additional features of autoimmune hepatitis: response to therapy with ursodeoxycholic acid. Hepatology. 2002;35:409-13

165. Boberg KM, Chapman RW, Hirschfield GM, et al. Overlap syndromes: the international autoimmune hepatitis group (IAIHG) position statement on a contro- 
versial issue. J Hepatol. 2011; 54:374-85.

166. Chazouilleres O, Wendum D, Serfaty L, et al. Long term outcome and response to therapy of primary biliary cirrhosis-autoimmune hepatitis overlap syndrome. J Hepatol. 2006;44:400-6.

167. Al-Chalabi T, Portmann BC, Bernal W, et al. Autoimmune hepatitis overlap syndromes: an evaluation of treatment response, long-term outcome and survival. Aliment Pharmacol Ther 2008; 28:209-20.

168. Mieli-Vergani G, Heller S, Jara P, et al. Autoimmune hepatitis. J Pediatr Gastroenterol Nutr 2009;49: 158-14

169. Feldstein AE, Perrault J, El-Youssif M, et al. Primary sclerosing cholangitis in children: a long-term followup study. Hepatology. 2003;38:210-7.

170. Saich R, Chapman R. Primary sclerosing cholangitis, autoimmune hepatitis and overlap syndromes in in- flammatory bowel disease. World J Gastroenterol. 2008;14:331-7.

171. Mitchell SA, Bansi DS, Hunt N, et al. A preliminary trial of high dose ursodeoxycholic acid in primary sclerosing cholangitis. Gastroenterology. 2001;121:900-7.

172. Lindstrom L, Boberg KM, Wikman O, et al. High dose ursodeoxycholic acid in primary sclerosing cholangitis does not prevent colorectal neoplasia.Aliment Pharmacol Ther2012;35:451-7.

173. Lüth S, Kanzler S, Frenzel C, et al. Characteristics and long-term prognosis of the autoimmune hepatitis/primary sclerosing cholangitis overlap syndrome. J Clin Gastroenterol 2009;43:75-80.

174. Perdigoto R, Carpenter HA, Czaja AJ. Frequency and significance of chronic ulcerative colitis in severe corticosteroid-treated autoimmune hepatitis. J Hepatol 1992; 14: 325-31. 


\title{
Pancreatiti autoimmuni
}

\author{
Pier Giorgio Rabitti, ${ }^{1}$ Roberto Boni ${ }^{2}$ \\ ${ }^{1}$ Dipartimento Medico Polispecialistico, Ospedale A. Cardarelli, Napoli; ${ }^{2}$ UOS Trattamento delle Patologie Croniche Multisi- \\ stemiche, Medicina Interna 1, Ospedale A. Cardarelli, Napoli, Italia
}

\section{Introduzione/storia}

Nel 1961 Sarles et al. ${ }^{1}$ descrivevano casi di pancreatite cronica caratterizzati da sclerosi infiammatoria, steatorrea e ipergammaglobulinemia, con pari distribuzione tra maschi e femmina e con esordio intorno alla sesta decade di età. Questa forma appariva differente dalle più comuni forme croniche etiliche sia per il quadro clinico sia per la genesi pertanto si ipotizzò un possibile meccanismo autoimmune e fu definita sclerosi infiammatoria primitiva del pancreas.

Nel 1991 Kawaguchi et al. ${ }^{2}$ pubblicavano, in due maschi anziani, una variante della colangite sclerosante primitiva associata ad una sclerosi linfoplamocitaria pancreatica che mimava un carcinoma del pancreas. Il reperto istologico mostrava fibrosi interstiziale, atrofia acinare e tromboflebiti. Si evidenziava la possibilità che una forma autoimmune di pancreatite potesse associarsi ad altra malattia anch'essa a genesi autoimmune.

Nel 1995 Yoshida et al. ${ }^{3}$ riportarono un tipo di pancreatite cronica con particolari caratteristiche istologiche (flogosi lifoplasmocitaria) con elevati tassi ematici di $\operatorname{IgG}$, presenza di autoanticorpi e risposta alla terapia cortisonica. Si definiva, nella etiologia, istologia e risposta terapentica ai corticosteroidi, la pancreatite cronica autoimmune (AIP: autoimmune pancreatitis).

Nel 1999 la scuola pancreatologica di Verona in una lettera all'editore di $G u t^{4}$ richiamava l'attenzione su una forma non alcolica di pancreatite cronica, definita come pancreatite cronica primitiva, caratterizzata da un processo infiammatorio legato ai T linfociti

Corrispondente: Pier Giorgio Rabitti, Dipartimento Medico Polispecialistico, Ospedale A. Cardarelli, Napoli, Italia. E-mail: piergiorgio.rabitti@gmail.com

Articolo pubblicato secondo la Creative Commons Attribution NonCommercial 4.0 License (CC BY-NC 4.0).

CCopyright P.G. Rabitti e R. Boni, 2017

Licensee PAGEPress, Italy

QUADERNI - Italian Journal of Medicine 2017; 5(7):138-144 e associata a malattie autoimmuni quali colangite sclerosante primitiva, colite ulcerativa, $m$. di Crohn e sindrome di Sjögren. Veniva ribadito il concetto di associazione tra malattie a genesi immunitaria.

Nel 2001 Hamano et al. ${ }^{5}$ ponevano l'accento sulla presenza costante di valori elevati delle IgG4 in questa forma di pancreatite così che nel 2003 Kamisawa et al. ${ }^{6}$ introducevano il concetto di malattia sistemica $d a$ IgG4 in cui oltre al pancreas potevano essere coinvolti, nel processo di sclerosi infiammatoria, dotti biliari, colecisti, area portale del fegato, mucosa gastrica e colica, ghiandole salivari, linfonodi, midollo osseo.

Da quanto sopra esposto c'era il bisogno di unificare in un unico capitolo questo tipo di pancreatite cronica e la necessità di utilizzare dei criteri clinici, istologici, di laboratorio, di imaging e terapeutici indispensabili a formulare una corretta diagnosi di AIP. La difficoltà di avere dei parametri condivisibili nasceva tuttavia dalla differente distribuzione nella popolazione mondiale delle due forme di AIP, come vedremo più avanti, e dal diverso iter diagnostico utilizzato nei diversi gruppi di studio.

\section{Epidemiologia}

La presenza di due forme di pancreatiti auto immuni distribuite in modo differente nelle popolazioni mondiali comporta la difficoltà di avere dati sull'incidenza e prevalenza della malattia; tuttavia, sulla base di due ampi studi, uno italiano ${ }^{7} \mathrm{e}$ l'altro coreano, ${ }^{8}$ possiamo affermare che l'AIP rappresenta il 4-6\% di tutte le forme croniche di pancreatiti. Dallo studio italiano PanCroInfAISP, ${ }^{7}$ su 893 pazienti, si evince che, in Italia, la malattia colpisce gli ultra cinquantenni (range 30-70 aa) con un rapporto maschio/femmina 2:1 e si associa con malattie autoimmuni specialmente del tratto gastroenterico; nel 30\% dei pazienti osservati era presente una colite ulcerativa. Da uno studio recente multicentrico internazionale ${ }^{9}$ progettato al fine di capire l'andamento della malattia, in un lungo periodo di osservazione, sono emersi però nuovi dati epidemiologi, su 1064 paziente con AIP: 978 (92\%) presentavano il tipo 1 di malattia e $86(8 \%)$ il tipo $2 . \mathrm{Nel}$ tipo $1 \mathrm{i}$ maschi erano presenti nel $77 \%$ dei casi, nel tipo 2 nel 55\%. L'età media nel tipol era di 61,4 anni mentre nel tipo 2 era di 39,9 anni. Appare dunque che il tipo uno 
sia più frequente e colpisca maggiormente il sesso maschile in età più avanza rispetto al tipo 2 che colpisce quasi in egual misura maschi e femmine. Il dilemma se l'AIP faccia parte di un'entità nosologica sistemica IgG4 correlata, in cui rientrerebbero anche le altre manifestazioni autoimmuni, attualmente ad essa associata, sarà discusso, più avanti, assieme alle caratteristiche dei due tipi di pancreatiti autoimmuni.

\section{Quadro clinico}

La malattia si può presentare ( $70-80 \%$ dei casi) con ittero in assenza di dolore; tale condizione è dovuta alla compressione delle vie biliari, nella forma focale a localizzazione cefalica (pseudotumor), o al coinvolgimento delle vie biliare nel processo autoimmunitario (colangite sclerosante autoimmune). La forma focale si presenta nel 40-63\% di casi di AIP. ${ }^{10}$ Il dolore addominale con irradiazione al dorso può essere presente $\mathrm{e}$ in alcuni casi l'esordio avviene con il quadro della pancreatite acuta, raramente severa. Vi può essere un'insufficienza endocrina, evidenziata dall'insorgenza del diabete e un'insufficienza esopancreatica caratterizzata dalla steatorrea e dimagramento. ${ }^{10,7}$ Diabete e steatorrea migliorano con la terapia steroidea. Nelle forme diffuse vi è, più frequentemente, l'associazione, in sincronia o tardivamente, con altre malattie autoimmuni che coinvolgono il tubo digerente (rettocolite ulcerativa, $\mathrm{m}$. di Crohn), le vie biliari (colangiti sclerosanti con stenosi ilare e intraepatiche), le ghiandole salivari e lacrimali (m. di Mikulicz), i polmoni (pneumoniti interstiziali, pseutotumor), i reni (nefrite interstiziale e idronefrosi da fibrosi retroperitoneale), tiroide (tiroiditi), linfoadenopatie (mediastiniche, ecc.). La risposta alla terapia steroidea accomuna le due forme anche se la forma diffusa tende più facilmente a recidivare, ${ }^{10,11}$ in letteratura, tuttavia, sono state osservate remissioni spontanee della malattia. Bisogna porre attenzione a non considerare come pancreatite autoimmune una pancreatite acuta (PA) in corso di malattie autoimmuni, come il LES, in questo caso la genesi della PA è dovuta alla vasculite 0 ai farmaci usati per trattare la malattia di base. ${ }^{12}$ L'AIP negli stadi avanzati si presenta con un pancreas atrofico, raramente calcifico, ma con dismorfismi duttali: stenosi e dilatazioni; deficit funzionali, assenza o lieve sintomatologia dolorosa, rari o molto rari episodi di pancreatite acuta.

\section{Eziopatogenesi e dati di laboratorio}

Come accennato nei paragrafi precedenti vi sono due forme di AIP: in una, denominata tipol vi è un incremento delle IgG4 sieriche e, nella maggioranza dei casi, un coinvolgimento diffuso del pancreas con malattie autoimmuni extrapancreatiche che colpiscono diversi organi. Sicuramente questa forma mostra chiare impronte di malattia autoimmune; nell'altra, denominata tipo 2 , le IgG4 sieriche mantengono un valore nell'intervallo di normalità e le malattie di accompagnamento, ad impronta autoimmune, sono a carico del digerente: la rettocolite ulcerativa (RCU) presente nel $20-30 \%$ dei casi e il morbo di Crohn in una percentuale di casi più bassa; ${ }^{13}$ questa forma, quasi del tutto assente nelle popolazioni asiatiche, si presenta più di frequente come forma pseudotumorale ${ }^{10}$ e con minori stigmate di malattia autoimmune. Alle differenze tra le due forme di AIP si associano però delle similitudini quali il corredo genetico HLA DRB $1 * 0405-\mathrm{DQB} 1 * 0401^{14} \mathrm{e}$ la risposta alla terapia steroidea. L'incremento sierico delle IgG4, nel tipo1, con valori $\geq$ a $280 \mathrm{mg} / \mathrm{dL}$ rappresenta il cut-off che permette di ottenere una specificità del $99 \%$, un valore predittivo positivo (PPV) del $75 \%$ ma una sensibilità bassa del $53 \% ;{ }^{15}$ gli anticorpi anti nucleo fanno parte dei reperti di laboratorio del tipo 1 ma sono meno specifici delle IgG4. In uno studio italiano ${ }^{16}$ è stato identificato un peptide nelle AIP, che ha omologia sia con la sequenza aminoacidica della proteina che lega il plasminogeno (PBP: plasminogen-binding protein) nell'Helicobacter pylori sia con un enzima fortemente espresso nella cellula acinare pancreatica; nello studio citato gli anticorpi contro il peptide PBP erano presenti nel $94 \%$ dei pazienti con pancreatite autoimmune e solo nel 5\% dei pazienti con cancro del pancreas; questi anticorpi non erano espressi nella popolazione sana di controllo o in pazienti con malattie autoimmuni non correlate con la AIP, manca tuttavia un approfondimento sulla validità del test nei pazienti con AIP e malattie autoimmuni correlate. Altri autoanticorpi quali quelli contro l'anidrasi carbonica II, la lattoferrina e il fattore reumatoidi sono presenti nei pazienti con AIP ma sono poco specifici per definire la malattia pertanto sono poco utile alla diagnosi. ${ }^{11}$

\section{Istologia}

Nel tipo 1 osserviamo un infiltrato linfoplasmacellulare pericanalicolare, con istochimica positiva per $\mathrm{IgG4}$, una fibrosi estesa con immagini a raggiera (LPSP: lymphoplasma-cytic sclerosing pancreatitis, acronimo del tipo 1) (Figura 1); si riscontrano anche processi infiammatori con obliterazione del lume a carico delle piccole vene. I linfociti sono del tipo CD4+ e CD8+, meno frequentemente quelli di tipo B..$^{11,13}$

Nel tipo 2 definito anche come IDCP (idiopathic duct-centric chronic pancreatitis) osserviamo un infiltrato linfoplamacellulare con istochimica negativa per IgG4 e abbondante presenza di neutrofili con distruzione dell'epitelio canalare (GEL: granulocyte epithelial lesion) e fenomeni di obliterazione intraduttale con possibili immagini di microascessi intraepiteliali. ${ }^{11,13}$ 
Nelle popolazioni orientali predomina il tipo 1 mentre in quelle occidentali accanto al tipo 1 si trova il tipo 2 nel $13 \%$ dei casi. ${ }^{9}$

\section{Diagnostica strumentale}

\section{Ecotomografia}

L'ecotomografia evidenzia un pancreas ingrossato ed ipoecogeno, nella forma diffusa, senza dilatazione del dotto pancreatico principale (DPP). Nella forma circoscritta troviamo delle aree ipoecogene (pseudotumor: Figure 2 e 3) con possibile dilatazione del Wirsung a monte della lesione. ${ }^{17}$ Usando il contrasto per gli ultrasuoni (CEUS: contrast-enhanced ultrasonography) nelle forme focali si ha un enhancement sia in fase precoce che in quella tardiva con lento washout. ${ }^{18}$ Gli ultrasuoni risultano molto utili nel follow up per evidenziare la risposta alla terapia cortisonica specialmente nelle forme localizzate nelle quali si vede regredire la massa pseudotumorale e se vi era una dilatazione del DPP, si osserva una riduzione della stessa.

\section{Tomografia computerizzata}

La tomografia computerizzata (TC) evidenzia un pancreas ingrossato e dismorfico (pancreas a salsiccia); nella fase precoce di contrasto si evidenza un orletto ipodenso attorno al pancreas, che persiste anche in fase tardiva, causato da un'edema perighiandolare (Figura 4). Si riscontra anche un enhancement della parete dei dotti biliari. ${ }^{11}$ Nelle forme diffuse è difficile evidenziare il DPP, perché compresso dal tessuto infiammatorio. Nelle forme localizzate lo studio dinamico perfusionale della lesione mostra zone ipo-isodense a contorni sfumati. Nelle AIP di lunga durata si può invece evidenziare una riduzione volumetrica della ghiandola per l'atrofia indotta dal pro-

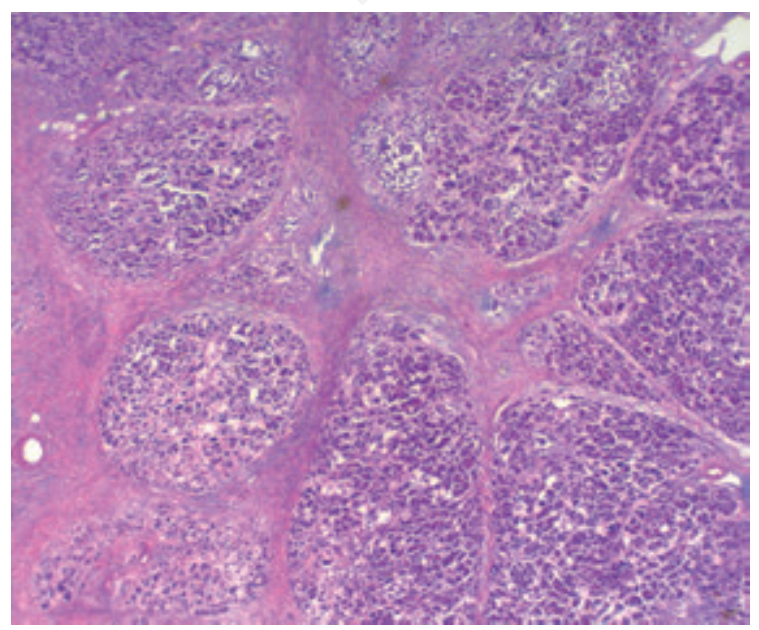

Figura 1. Fibrosi a raggiera (Cortesia Dr. G. Uomo). cesso autoimmune nonché calcificazioni, più tipiche, però, delle forme croniche alcoliche. Dilatazione del Wirsung si possono avere a monte delle masse pseudotumorali nelle forme localizzate ma non assumono mai l'aspetto di interruzione netta come nel cancro.

\section{Risonanza magnetica nucleare}

La risonanza magnetica nucleare (RMN) mostra le stesse anomalie (Figura 5) descritte nella TC con un pancreas ipointenso in $\mathrm{T} 1 \mathrm{e}$ tenuamente iperintenso in T2 e l'orletto ipertineso in T2 a dimostrazione dell'edema perighiandolare. Il DPP appare evanescente con stenosi segmentarie senza dilatazione del dotto a monte della stenosi come invece succede nel carcinoma. La colangiopancreatografia-RM (CPRM) con

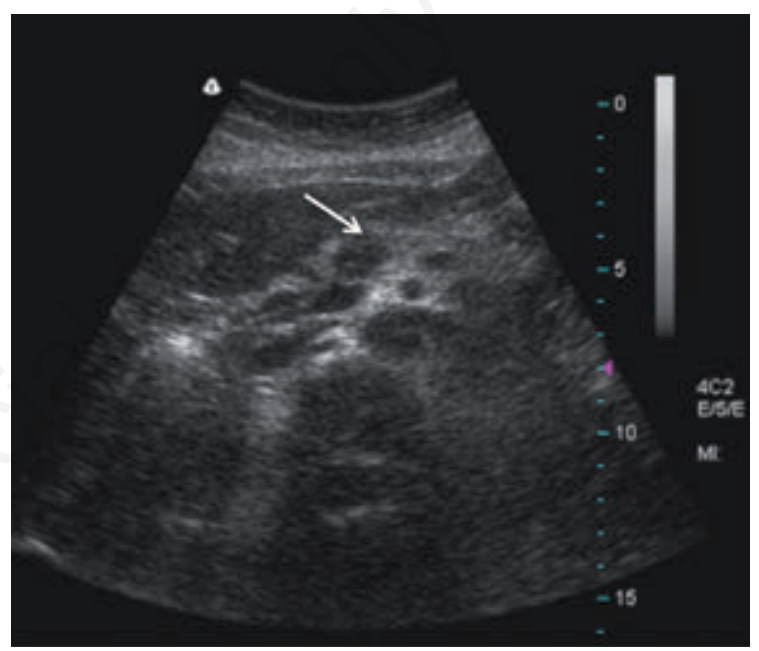

Figura 2. Lesione istmica di $\mathbf{1 8} \mathbf{~ m m}$ circa (Osservazione personale).

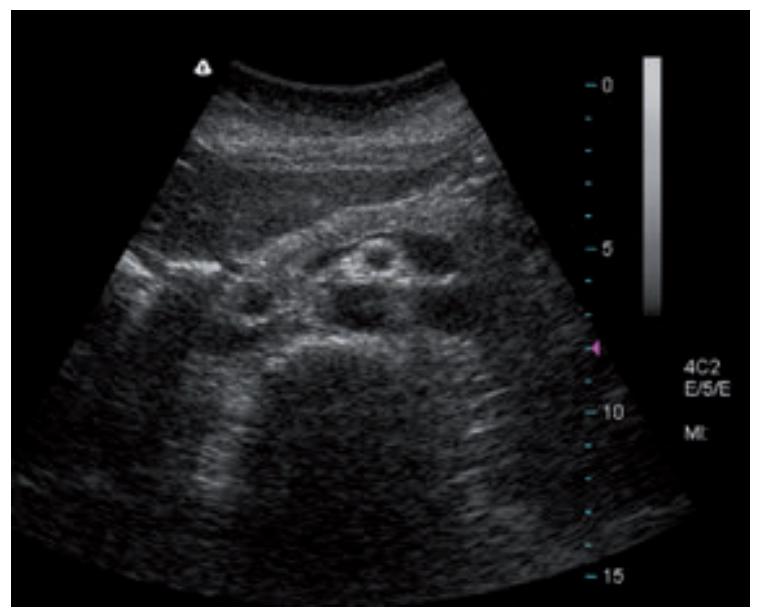

Figura 3. Scomparsa della lesione istmica dopo $50 \mathrm{gg}$ di terapia cortisonica (Osservazione personale; terapia 1 $\mathrm{mg} / \mathrm{kg} /$ die per 2 mesi poi a scalare con interruzione dopo 4 mesi). 
secretina riesce a dimostrare, nelle forme focali, l'integrità del DPP anche nei casi di stenosi serrate contrariamente a quanto accade nel carcinoma pancreatico, evidenzia anche delle irregolarità dell'albero biliare intra ed extraepatico con stenosi segmentarie $^{19,20}$ tanto da mimare un colangiocarcinoma. Anche la RMN come l'ecotomografia risulta utile nel monitoraggio della malattia in corso di terapia.

\section{Tomografia ad emissione di positroni}

La tomografia ad emissione di positroni (PET) associata alla TC con l'utilizzo del radioisotopo 18-fluorodesossiglucosio non è molto utile per discriminare una AIP focale da un tumore ma può monitorare la risposta alla terapia steroidea sia a livello pancreatico che nelle sede extrapancreatiche in caso di sincronia con le malattie autoimmuni associate alla AIP. ${ }^{21,22}$

\section{Colangiopancreatografia retrograda per via endoscopica}

La colangiopancreatografia retrograda per via endoscopica (ERCP, endoscopic retrograde cholangiopancreatography) evidenzia alterazioni del DPP che presenta restringimenti e alterazioni dello spessore della parete; stenosi del coledoco vengono evidenziate nel tratto intrapancreatico mentre le vie biliari intraepatiche presentano stenosi segmentali che mimano una colangite sclerosante primaria; tutte queste alterazioni duttali sono caratteristiche della AIP. Questa tecnica, inoltre, permette di posizionare stent in caso di ostruzione grave delle vie biliari in attesa dell'effetto terapeutico corticosteroideo risolutivo della la stenosi serrata.

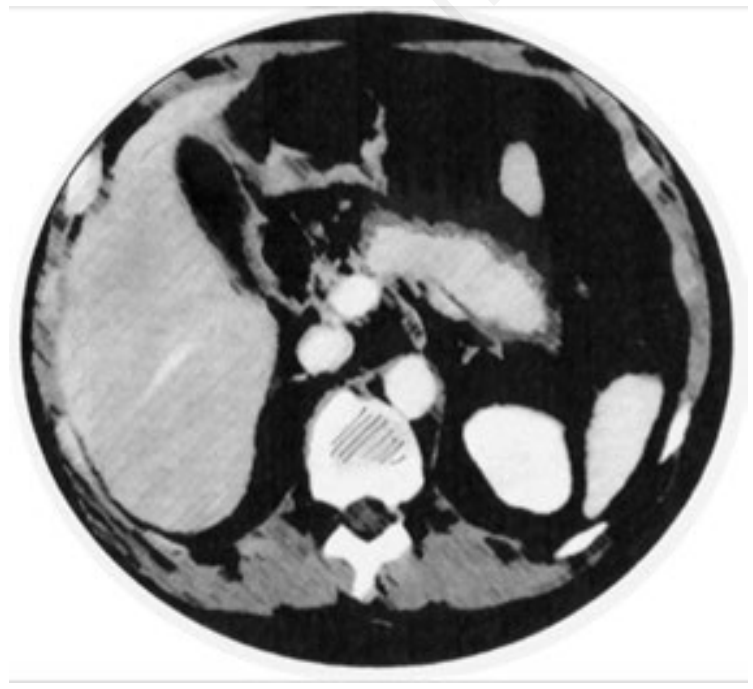

Figura 4. Immagine TC con contrasto: pancreas aumentato di volume, configurazione a salsiccia, con orletto ipodenso.

\section{Ecoendoscopia}

L'ecoendoscopia (EUS, endoscopic ultrasonography) è risultata essere una tecnica di grande ausilio nello studio delle patologie pancreatiche sia per evidenziare anomalie duttali sia per le alterazioni parenchimali ma soprattutto per la caratterizzazione delle lesioni pancreatiche circoscritte, permettendo di ottenere, mediante biopsia con ago sottile, preziose informazioni citologiche. In corso di AIP l'indagine permette di ottenere notizie sulle anomalie duttali (dilatazione e aumento di spessore della parete) e nel dubbio di colangicarcinoma, usando un mezzo di contrasto vediamo che l'enhancement precoce della parete ispessita si osserva solo nell'AIP. La citologia con ago sottile non è sempre dirimente in caso di massa pseudotumorale, pertanto, in mani esperte, è possibile utilizzare un tru-cut di 19 gauge $^{23}$ per ottenere un campione di materiale più idoneo. Ingrossamenti linfoghiandolari, di accompagnamento alla malattia, possono essere studiati bene con la EUS e seguirne l'evoluzione nel tempo.

\section{Ecoendoscopia-elastografia}

La tecnica, nata per lo studio delle modificazioni elastiche del tessuto di organi superficiali, quali prostata e mammella, in preda a neoplasie, è stata usata anche per organi profondi quali il fegato e ultimamente, per via endoscopica, per lo studio dei carcinomi pancreatici. Di fronte a lesioni focali, sospette per essere maligne, la EUS elastografia non da mai falsi negativi, evitando di sottodiagnosticare un cancro, tuttavia vi è un $20 \%$ di falsi positivi. ${ }^{24}$ L'errore possibile quindi, laddove la FNA non fosse dirimente, è di operare uno pseudotumor, ritenuto essere una neoplasia.

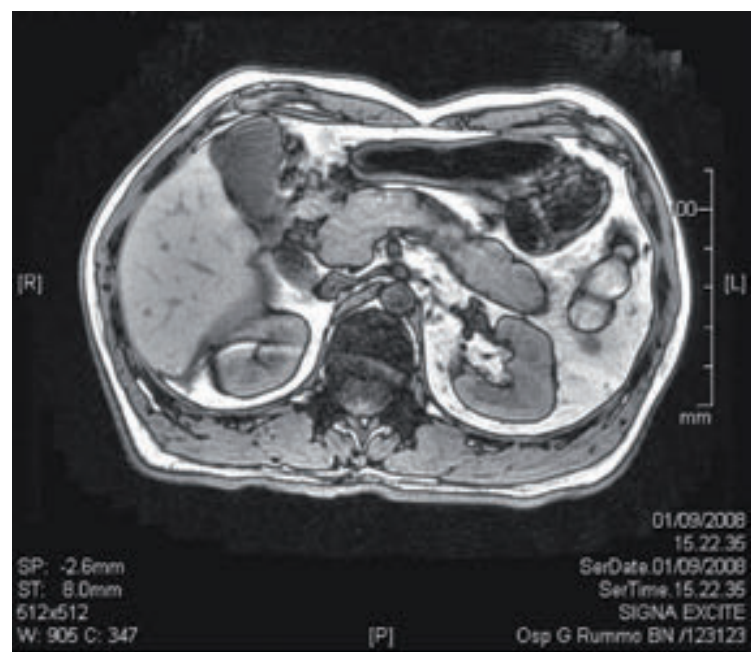

Figura 5. Immagine di pancreas a salsiccia alla RMN (Cortesia Dr. G. Uomo). 


\section{Criteri per la diagnosi}

Abbiamo visto che la distribuzione delle due forme di malattie differisce a secondo del tipo di popolazione preso in esame (tipo 1 nelle popolazioni asiatiche, tipo 1 e 2 nelle popolazioni occidentali) di conseguenza non esistono criteri univoci per la diagnosi dell'AIP. I criteri utilizzati in Asia sono in prevalenza radiologici e di laboratorio, negli USA istologici mentre in Italia, se la biopsia non è diagnostica, la risposta alla terapia steroidea diventa un marker di malattia quando vengano però, contemporaneamente, soddisfatti i parametri clinici, di laboratorio e di imaging che orientino per l'AIP, escludendo, con un buon margine di sicurezza, la presenza di un adenocarcinoma. ${ }^{10}$ Riportiamo nelle Tabelle 1-3 i criteri della Mayo Clinic, asiatici e italiani.

Nel 2006 ST Chari et al. ${ }^{25}$ della Mayo Clinic, pub- blicarono una tabella denominata The HISORt Criteria che è un acronimo per Histology, Pancreatic Imaging, Serology, Other organ involment, Response to steroid therapy con i parametri da loro ritenuti più utili per porre diagnosi di AIP, avendo analizzato principalmente pazienti con la malattia di tipo 1 (Tabella 1).

Negli studi Italiani, condotti principalmente dalla scuola pancreatologica di Verona, ${ }^{26}$ si evidenziavano quattro criteri necessari alla diagnosi di AIP: i) istologia o citologia che escluda un cancro del pancreas e che evidenzi la presenza di GEL (granulocyte epithelial lesion); ii) reperti di imaging suggestivi per l'AIP; iii) associazione con altre malattie autoimmuni extrapancreatiche; iv) risposta alla terapia steroidea; v) nei pazienti non operati sono sufficienti 3 dei 4 criteri; nei pazienti operati il reperto anatomopatologico.

Nel 2008 a seguito di una consensus conference

Tabella 1. The HISORt Criteria.

\begin{tabular}{|c|c|}
\hline Istologia: almeno uno dei seguenti reperti & $\begin{array}{l}\text { 1. Infiltrato linfoplasmacellulare periduttale con flebiti obliteranti e fibrosi con morfologia a vortice } \\
\text { o raggiera } \\
\text { 2. Infiltrato linfoplasmacellulare con fibrosi e presenza abbondante di cellule immunocompetenti } \\
\text { IgG4 positive } \geq 10 \text { per campo ad elevato ingrandimento }\end{array}$ \\
\hline Imaging pancreatico & $\begin{array}{l}\text { 1. Aumento omogeneo del pancreas con cercine ipodenso; dotto pancreatico irregolare e ridotto } \\
\text { di volume } \\
\text { 2. Massa pseudotumorale } \\
\text { 3. Restringimenti focali del Wirsung } \\
\text { 4. Atrofia pancreatica } \\
\text { 5. Calcificazioni pancreatiche } \\
\text { 6. Immagini d pancreatite focale }\end{array}$ \\
\hline Sierologia & 1. Livelli ematici elevati delle IgG4 (vn $8-140 \mathrm{mg} / \mathrm{dL}$ ) \\
\hline Coinvolgimento di altri organi & $\begin{array}{l}\text { 1. Restringimento delle vie biliari intraepatiche e all'ilo } \\
\text { 2. Persistente restringimento delle vie biliari extraepatiche } \\
\text { 3. Coinvolgimento delle ghiandole parotidi e lacrimali } \\
\text { 4. Linfoadenopatia mediastinica } \\
\text { 5. Fibrosi retroperitoneale }\end{array}$ \\
\hline
\end{tabular}
Modificata da Chari et al., $2006 .^{25}$

Tabella 2. Risultati della consensus conference nippo-coreana.

\begin{tabular}{ll}
\hline I. Imaging & $\begin{array}{l}\text { 1. Parenchima pancreatico: ingrossamento diffuso, segmentale o focale; occasionalmente presenza } \\
\text { di massa e/o orletto ipoecogeno/ipointenso/ipodenso peripancreatico. }\end{array}$ \\
& $\begin{array}{l}\text { 2. Dotti biliopancreatici: restringimento diffuso, segmentale o focale del dotto pancreatico prin- } \\
\text { cipale accompagnato spesso da stenosi del dotto biliare. } \\
\text { Entrambe le alterazioni devono coesistere }\end{array}$ \\
\hline II. Sierologia & $\begin{array}{l}\text { 1. Livelli elevati di IgG o IgG4 } \\
\text { E. Presenza di autoanticorpi }\end{array}$ \\
\hline III. Istologia & $\begin{array}{l}\text { 1. Infiltrazione linfoplasmacellulare e fibrosi con presenza di abbondante quantità di cellule im- } \\
\text { munocompetenti IgG4 positive }\end{array}$ \\
\hline Diagnosi & $\begin{array}{l}\text { La diagnosi viene formulata quando sono soddisfatti i criteri I e almeno uno dei criteri II e III } \\
\text { oppure quando si riscontra il quadro di pancreatite sclerosante linfoplasmacellullare nel pancreas } \\
\text { resecato. La diagnosi può essere formulata anche in pazienti coi soli criteri I che rispondono alla } \\
\text { terapia steroidea e nei quali sia stata esclusa, da esperti pancreatologi, la diagnosi di palatologia } \\
\text { neoplastica biliopancreatica. }\end{array}$
\end{tabular}

Modificata da Otsuki et al., 2008.27 
nippo-coreana ${ }^{27}$ veniva elaborato quanto riportato in Tabella 2.

\section{Terapia}

La terapia corticosteroidea non solo spegne la malattia ma diventa criterio di diagnosi nei casi dubbi di cancro e pseudotumor. Nel lavoro di Moon et al. ${ }^{28}$ dopo due settimane di terapia steroidea, alla dose di 0,5 $\mathrm{mg} /$ die di prednisolone per os, si aveva un miglioramento della cenestesi, dei dati di laboratorio e dell'imaging pancreatico, anche se, per la risoluzione completa della malattia, era richiesto un trattamento anche di mesi/anni con dosi scalari di cortisone fino al mantenimento con 2,5-5 mg/die. ${ }^{29} \mathrm{~A}$ tutt'oggi non vi è un accordo sulle dosi di cortisone da usare, variando da un minimo di $0,5 \mathrm{mg}$ ad un massimo di $1 \mathrm{mg}$ per $\mathrm{kg} / \mathrm{die}$ e iniziando a scalare la dose di $5 \mathrm{mg} /$ die dopo la $2^{\mathrm{a}}-3^{\mathrm{a}}$ settimana di terapia. Le ricadute sono presenti in entrambi i tipi di malattie con una percentuale variabile dal $6 \%$ al $54 \%,{ }^{10}$ il tipo $1^{9,10,30}$ sembra avere più di frequente una recidiva così come le forme focali rispetto alle forme diffuse. ${ }^{27}$ La recidiva può manfestarsi con un'alterazione dei parametri di laboratorio (incremento delle IgG4, indici di colestasi elevati, ecc.) oppure con una ripresa dei sintomi di esordio della malattia sia a livello pancreatico sia a carico degli altri organi colpiti da malattie autoimmuni associate alla PAI.

\section{AIP entità autonoma o espressione di una malattia sistemica IgG4 correlata?}

Nel 2003 Kamisawa T et al., ${ }^{31}$ analizzando i dati della letteratura e alcuni casi personali, formulavano l'ipotesi che l'AIP fosse parte di una malattia sistemica IgG4 correlata (IgG4-RD: IgG4 related disease). Il pancreas come le vie biliari o le ghiandole lacrimali o il tessuto retroperitoneali potevano essere espressioni di un unico capitolo di malattie autoimmune correlate alla infiltrazione tissutale di plasmacellule produttrici di IgG4, di linfociti T CD4 o CD8.
Quale sia il ruolo delle IgG4 nella patogenesi delle malattie è a tutt'oggi sconosciuto, tuttavia, creando una deplezione dei linfociti B col rituximab, ${ }^{32}$ si ha un rapido miglioramento clinico e dei reperti citoistologici. Tutti gli organi colpiti sono in preda ad un processo fibro-infiammatorio e tendono spesso a formare delle lesioni pseudotumorali. Escludendo dall'elenco la AIP tipo 1, le altre malattie IgG4 correlate vengono riportate nella Tabella 3 , modificata ed estratta dal lavoro multicentrico internazionale di Stone et al..$^{33}$ per la nuova nomenclatura delle malattie $\mathrm{IgG} 4$ correlate.

Qual è l'incidenza di queste malattie? Da uno studio giapponese, ${ }^{34}$ condotto per sette anni (2003-2009) si evince che l'incidenza di queste malattie IgG4 correlate, nella popolazione nipponica, varia da 0,28 a 1,08 per 100.000 abitanti. Non abbiamo dati così precisi per le popolazioni occidentali.

\section{Conclusioni}

La pancreatite cronica autoimmune esordisce col quadro clinico di un ittero ostruttivo con o senza una massa pancreatica, è caratterizzata, istologicamente, da infiltrato linfoplasmacellullare e fibrosi e presenta una drammatica risposta alla terapia cortisonica. La difficoltà nel formulare tale diagnosi consiste nel escludere con sicurezza una forma tumorale tenendo presente che anche un carcinoma del pancreas può presentare un miglioramento con la terapia cortisonica e che non sempre il reperto negativo di una FNA esclude la presenza della neoplasia. Bisogna inoltre monitorare la malattia per lungo tempo per cogliere i primi segni di una recidiva il chè comporta la necessità di una terapia cortisonica prolungata nel tempo con dosi a scalare e un mantenimento per mesi o anni a dosi di 2,5-5 mg/die. Dobbiamo ricordare che il tipo 1 è prerogativa assoluta delle popolazioni asiatiche mentre il tipo 2 lo si può trovare nelle popolazioni occidentali in pazienti con età inferiore di circa 10 anni (50 anni) rispetto al tipo 1 (60-70- anni).

Tabella 3. Nuova nomenclatura delle malattie IgG4 correlate.

\begin{tabular}{ll}
\hline M. Mikulicz & Periaotite/periarterite \\
\hline Tumore di Küttner (sialoadenite sclerosante) & Fibrosi retroperitoneale (malattia di Ormond) \\
\hline Tiroidite di Riedel & Aneurisma infiammatorio aortico \\
\hline Fibrosi eosinofilica angiocentrica & Pseudolinfoma cutaneo \\
\hline Fibrosclerosi multifocale & Pachimeningite ipertrofica idiopatica \\
\hline Pseudotumore infiammatorio & Nefrite tubulointerstiziale idiopatica \\
\hline Mediastinite fibrosante & Nefrite tubulointerstiziale ipocomplementemica idiopatica con depositi tubulointerstiziali \\
\hline Mesenterite sclerosante & Fibrosi cervicale idiopatica \\
\hline
\end{tabular}

Modificata da Stone et al., 2012.33 


\section{Bibliografia}

1. Sarles H, Sarles JC, Muratore R, Guien C. Chronic inflammatory sclerosis of the pancreas - an autonomous pancreatic disease? Am. J. Dig. Dis. 6,688-698 (1961).

2. Kawaguchi K., Koike M., Tsuruta K., Okamoto A., Tabata I., Fujita N. Lymphoplasmacytic sclerosing pancreatitis with cholangitis: a variant of primary sclerosing cholangitis extensively involving pancreas Hum Pathol $1991 ; 22$ (4) : 387-395

3. Yoshida K, Toki F, Takeuchi T, Watanabe S, Shiratori K, Hayashi N. Chronic pancreatitis caused by an autoimmune abnormality: proposal of the concept of autoimmune pancreatitis. Dig Dis Sci 1995; 40:1561-68.

4. L Frulloni P Bovo V Di Francesco G Cavallini, G Zamboni "Non-alcoholic duct destructive chronic pancreatitis" or "primary chronic pancreatitis"? Gut 1999; 44:579 doi:10.1136/gut.44.4.579

5. Hamano H., Kawa S., Horiuchi A., Unno H., Furuya N., Akamatsu T., and al. High serum IgG4 concentrations in patients with sclerosing pancreatitis N Engl J Med $2001 ; 344(10): 732-738$

6. Kamisawa T, Funata N, Hayashi Y, Eishi Y, Koike M, Tsuruta K, Okamoto A, Egawa N, Nakajima H. A new clinicopathological entity of IgG4-related autoimmune disease .J Gastroenterol. 2003;38(10):982-4.

7. Frulloni L, Gabbrielli A, Pezzilli R, et al. Chronic pancreatitis: report from a multicenter Italian survey (PanCroInfAISP) on 893 patients. Dig Liv Dis 2009;41: 311-7.

8. Kim KP, Kim MH, Song MH, et al. Autoimmune chronic pancreatitis. Am J Gas- troenterol 2004;99:1605-16.

9. Hart PA, Kamisawa T, Brugge WR, et al. Long-term outcomes of autoimmune pancreatitis: a multicentre, international analysis Gut 2013;62: 1771-1776.

10. Buscarini E, Frulloni L, De Lisi S et al. Autoimmune pancreatitis: A challenging diagnostic puzzle for clinicians .Digestive and Liver Disease 42 (2010) 92-98.

11. Rebours V., Lévy P. Les deux formes de la pancréatite auto-immune La Presse Médicale 2012;41: 580-592

12. Kyu-Pyo Kim, Myung-Hwan Kim, Jong Cheol Kim et al. Diagnostic criteria for autoimmune chronic pancreatitis revisited World J Gastroenterol 2006 April 28; 12(16):2487-2496

13. Zamboni G., Luttges J., Capelli P., Frulloni L., Cavallini G., Pederzoli P., and al. Histopathological features of diagnostic and clinical relevance in autoimmune pancreatitis: a study on 53 resection specimens and 9 biopsy specimens Virchows Arch 2004 ; 445 (6) : 552-56

14. Kawa S, Ota M, Yoshizawa K, et al. HLA DRB10405DQB10401 haplotype is associated with autoimmune pancreatitis in the Japanese population. Gas- troenterology 2002;122:1264-9.

15. Ghazale A, Chari ST, Smyrk TC, et al. Value of serum $\mathrm{IgG} 4$ in the diagnosis of autoimmune pancreatitis and in distinguishing it from pancreatic cancer. Am J Gastroenterol 2007;102:1646-53.

16. Frulloni L., Lunardi C., Simone R., Dolcino M., Scattolini C., Falconi M., and al. Identification of a novel antibody associated with autoimmune pancreatitis N Engl J Med 2009 ; 361 (22) : 2135-2142

17. Koyama R, Imamura T, Okuda C, et al. Ultrasono- graphic imaging of bile duct lesions in autoimmune pancreatitis. Pancreas 2008;37:259-64.

18. Numata K, Ozawa Y, Kobayashi N, et al. Contrastenhanced sonography of autoimmune pancreatitis: comparison with pathologic findings. J Ultrasound Med 2004;23:199-206

19. Carbognin G., Girardi V., Biasiutti C., Camera L., Manfredi R., Frulloni L., et al. Autoimmune pancreatitis: imaging findings on contrast-enhanced $\mathrm{MR}, \mathrm{MRCP}$ and dynamic secretin-enhanced MRCP Radiol Med 2009 ; $114(8): 1214-1231$

20. Sahani DV, Kalva SP, Farrell J, et al. Autoimmune pancreatitis: imaging features. Radiology 2004;233:345-52.

21. Vien X Nguyen, Giovanni De Petris, Ba D Nguyen. Usefulness of PET/CT Imaging in Systemic IgG4-related Sclerosing Disease. A Report of Three Cases JOP. J Pancreas (Online) 2011 May 6; 12(3):297-305.

22. Nakajo M, Jinnouchi S, Noguchi M, et al. FDG PET and PET/CT monitoring of autoimmune pancreatitis associated with extrapancreatic autoimmune dis- ease. Clin Nucl Med 2007;32:282-5.

23. Levy MJ, Reddy RP, Wiersema MJ, et al. EUS-guided trucut biopsy in establish- ing autoimmune pancreatitis as the cause of obstructive jaundice. Gastrointest Endosc 2005;61:467-72.

24. T H Lee et al. EUS Elastography: Advances in Diagnostic EUS of the Pancreas . Korean J Radiol.2012 JanFeb; 13(Suppl 1): S12-S16.

25. Chari S.T., Smyrk T.C., Levy M.J., Topazian M.D., Takahashi N., Zhang L., and al. Diagnosis of autoimmune pancreatitis: the Mayo Clinic experience Clin Gastroenterol Hepatol 2006 ; 4 (8) : 1010-1016

26. Frulloni L, Scattolini C, Falconi M, et al. Autoimmune pancreatitis: differ- ences between the focal and diffuse forms in 87 patients. Am J Gastroenterol 2009;104:2288-94.

27. Otsuki M, Chung JB, Okazaki K, et al. Asian diagnostic criteria for autoimmune pancreatitis: consensus of the Japan-Korea symposium on autoimmune pan- creatitis. J Gastroenterol 2008;43:403-8.

28. Moon SH, Kim MH, Park DH, et al. Is a 2-week steroid trial after initial negative investigation for malignancy useful in differentiating autoimmune pancreatitis from pancreatic cancer? A prospective outcome study.Gut. 2008 Dec;57(12):1704-12

29. Tabata T, Kamisawa T, Takuma K, Hara S, Kuruma S, Inaba Y. Differences between diffuse and focal autoimmune pancreatitis. World J Gastroenterol 2012

30. Raghuwansh P Sah et al. Differences in Clinical Profile and Relapse Rate of Type 1 Versus Type 2 Autoimmune Pancreatitis Gastroenterology 2010;139:140-148

31. Kamisawa $\mathrm{T}$ et al. A new clinicopathological entity of IgG4-related autoimmune disease. J Gastroenterol 2003; 38:982-984

32. Mahajan VS et al . IgG4- related disease. Annu Rev Pathol. 2014;9:315-47

33. Stone JH et al Recommendations for the Nomenclature of IgG4-Related Disease and Its Individual Organ System Manifestations. Arthritis \& Rheumatism Vol. 64, No. 10, October 2012, pp 3061-3067

34. Kazushige Uchida et al . Prevalence of IgG4-Related Disease in Japan Based on Nationwide Survey in 2009. International Journal of Rheumatology Volume 2012.Article ID 358371, 5 pages. 


\title{
IMID e tumori
}

\author{
Fernando Gallucci
}

UOSC Medicina Interna 3, AORN A. Cardarelli, Napoli, Italia

\section{Introduzione}

Le malattie infiammatorie immuno-mediate (IMID) comprendono un gruppo di patologie croniche caratterizzate tutte da meccanismi patogenetici di natura immunitaria. Infatti, sebbene si manifestino con quadri sintomatologici eterogenei, tra loro apparentemente non correlati, numerose evidenze scientifiche hanno dimostrato che le IMID dipendono da meccanismi patogenetici comuni; dati epidemiologici e genetici indicano che i pazienti affetti da IMID condividono fattori di suscettibilità genetica e che due o più IMID si possono manifestare negli stessi soggetti. Gli agenti eziologici specifici responsabili delle IMID non sono stati ad oggi identificati, tuttavia è stato accertato che queste patologie dipendono da un'alterazione dei meccanismi regolatori del sistema immunitario che, a sua volta, determina una iperespressione ed iperattivazione di citochine pro-infiammatorie, molecole di adesione, chemochine, etc., con conseguente mantenimento di uno stato infiammatorio cronico, che promuove una progressiva distruzione e conseguente rimodellamento patologico dei tessuti colpiti. ${ }^{1}$

La relazione tra infiammazione e sviluppo del cancro è stata studiata per diversi anni e tutte le fasi implicate nella carcinogenesi (iniziazione, promozione e progressione) potrebbero essere influenzate dal processo infiammatorio. ${ }^{2}$

Le ipotesi circa il possibile meccanismo alla base di questa relazione si fonda sull'assioma per il quale l'infiammazione cronica produce un alternarsi di danno cellulare ripetuto e successiva riparazione. Come conseguenza diretta, l'insulto cellulare determina un danno del DNA con mutazioni di proto-on-

Corrispondente: Fernando Gallucci, UOSC Medicina Interna 3, AORN A. Cardarelli, Napoli, Italia.

E-mail: fernandogallucci@libero.it

Articolo pubblicato secondo la Creative Commons Attribution NonCommercial 4.0 License (CC BY-NC 4.0).

CCopyright F. Gallucci, 2017

Licensee PAGEPress, Italy

QUADERNI - Italian Journal of Medicine 2017; 5(7):145-154 cogeni e/o geni soppressori tumorali mentre il processo di guarigione regolato dal rilascio di fattori di crescita potrebbe condurre alla proliferazione di cellule trasformate ${ }^{3,4}$ (Figura 1).

Diversamente da quanto si verifica durante il processo fisiologico alla base della riparazione tessutale, le cellule la cui crescita è sostenuta dal danno del DNA e/o dallo stimolo mutageno continuano a proliferare nel microambiente ricco di cellule infiammatorie e di fattori di crescita e di sopravvivenza che ne stimolano ulteriormente la crescita. Si può affermare che lo sviluppo della neoplasia rappresenti il risultato di ferite che falliscono nel loro processo di guarigione. ${ }^{5}$

Come succede per molti grandi temi della medicina moderna, l'argomento non è recentissimo e si fanno risalire a Virckow, nella seconda metà dell' 800 , la prima osservazione di cellule infiammatorie all'interno di tessuti neoplastici e la prima ipotesi di link fra infiammazione e cancro. ${ }^{6,7}$

Una decina di anni dopo, Sigismond Jaccoud nel trattato di Patologia Interna al capitolo VI sull'infiammazione preconizza concetti che costituiranno la base di tutta la ricerca degli ultimi 50-60 anni: l'infiammazione intera veniva considerata come un disordine nutritivo locale (qui è facile identificare idealmente i futuri mediatori infiammatori: citochine, fattori di crescita, etc.) che quando persistente può esitare in neoplasia. ${ }^{8}$

Oggi è possibile affermare che il link tra infiammazione e sviluppo di cancro è, almeno sul piano teorico, solido. ${ }^{9}$

In Oncologia clinica vi sono validi esempi di questa connessione: è il caso della relazione asbestosi mesotelioma pleurico, ${ }^{10}$ di quella tra l'infezione da virus del Papilloma umano e lo sviluppo di cancro della cervice uterina. ${ }^{11}$ Un altro esempio stringente è quello della infezione cronica da Schistosoma haematobium e lo sviluppo di neoplasie vescicali, ${ }^{12}$ oppure il ben noto rapporto tra Herpes virus tipo B ed il sarcoma di Kaposi. ${ }^{13}$

In ambito gastro-enterologico, vi sono varie condizioni mediche, infettive e non, con componente infiammatoria ben riconosciuta correlate ad un aumentato rischio di neoplasia; il riferimento è relativo ad Helicobacter e sviluppo di cancro gastrico, ${ }^{14}$ esofago di Barrett e cancro esofageo. ${ }^{15}$ Oppure il ben noto rapporto tra malattie infiammatorie croniche in- 
testinali (MICI) e cancro del colon, ${ }^{16}$ infezione cronica da $\mathrm{HCV} / \mathrm{HBV}$ e sviluppo di carcinoma epatocellu$\operatorname{lare}^{17,18}$ (Tabella 1).

Pazienti con pancreatite ereditaria, una rara forma di pancreatite cronica (PC) provocata da una mutazione del gene sul cromosoma 7 che codifica per il tripsinogeno presentano un rischio molto elevato di sviluppo di neoplasia pancreatica. Questa forma particolare di pancreatite è caratterizzata da un processo infiammatorio cronico progressivo e grave che interessa l'intera ghiandola e, nel lungo tempo, si osserva un rischio molto elevato (circa 53 volte maggiore) di sviluppare la neoplasia. ${ }^{19,20}$ Esistono evidenze epidemiologiche riferite all'incremento del rischio di cancro

Tabella 1. Malattie infiammatorie croniche e neoplasie correlate.

\begin{tabular}{ll}
\hline Malattie infiammatorie corniche intestinali & Cancro colorettale \\
\hline Epatite virale cronica & Epatocarcinoma \\
\hline Tiroidite di Hashimoto & Linfoma-cancro papillifero della tiroide \\
\hline Esofagite cronica & Adenocarcinoma dell'esofago \\
\hline Infezione da Helicobacter pylori & Cancro dello stomaco \\
\hline Pancreatite cronica & Cancro del pancreas \\
\hline Malattie infiammatorie della pelvi & Cancro dell'ovaio \\
\hline Infezioni epatiche da parassiti & Colangiocarcinoma \\
\hline Asbestosi & Mesotelioma \\
\hline Infezione dal HPV & Cancro della cervice uterina \\
\hline Infezione da Schistosoma & Cancro della vescica \\
\hline Lupus eritematoso discoide & Carcinoma cutaneo a cellule squamose \\
\hline Lupus eritematoso sistemico & Linfoma diffuso a grandi cellule B \\
\hline Colangite sclerosante primitiva & Colangiocarcinoma, cancro della colecisti \\
\hline Artrite reumatoide & Linfoma, cancro del polmone, cancro della pelle, in particolare non-melanoma \\
\hline Infezione da herpes virus tipo B & Sarcoma di Kaposi \\
\hline
\end{tabular}

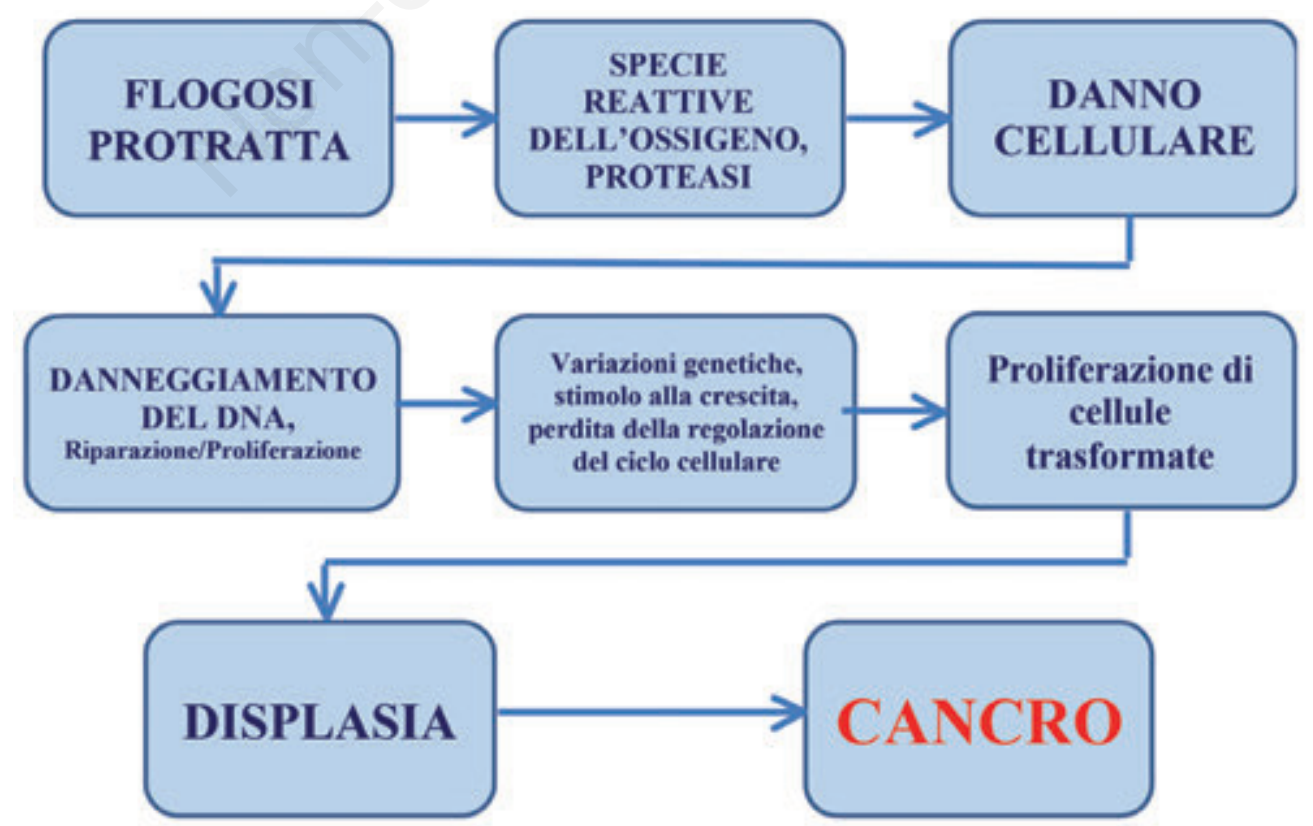

Figura 1. Infiammazione e cancro. 
anche nelle forme non-genetiche di PC (fino a 17 volte maggiore). ${ }^{21}$ Tale rischio sembra correlato alla durata della $\mathrm{PC}$ e, quindi, al tempo di esposizione al processo infiammatorio.

Nella PC, si verifica un danno cellulare ricorrente con attacchi ripetuti di infiammazione che realizzano una persistente infiltrazione di cellule infiammatorie insieme ad un processo fibrotico che conduce ad una progressiva atrofia. ${ }^{22}$ La combinazione di infiammazione cronica e proliferazione cellulare rappresenterebbe un pabulum ideale per lo sviluppo della neoplasia.

La sequenza di persistente infiammazione - displasia pancreatica - neoplasia intraepiteliale - cancro del pancreas è stata documentata e correlata alla perdita dei geni soppressori del tumore ed alla mutazione dei proto-oncogeni. ${ }^{23}$ Nella maggioranza dei pazienti con cancro del pancreas si riscontra la mutazione $\mathrm{K}-\operatorname{ras}^{24}$ ed, inoltre, la perdita addizionale delle funzioni p53 e DPC4/SMAD risulta strettamente correlata alla carcinogenesi. ${ }^{25,26}$

Numerosi mediatori dell'infiammazione, come le citochine, sono associati al cancro del pancreas, probabilmente per un'azione di stimolo dei pathways oncogenetici con effetto favorente la crescita tumorale e la diffusione delle metastasi.

Molte citochine (come TNF- $\alpha$, Interleuchina-1, Interleuchina-6) e fattori di crescita (come i Trasforming Growth Factors- $\alpha$ e - $\beta 1$, il Fibroblast Growth Factor2 ed il Platelet-derived Growth factor) sono implicate nella patogenesi della PC con meccanismi differenti, compresa l'attivazione delle cellule stellate pancreatiche ${ }^{27,28}$ e differenti tipi di cancro over-esprimono citochine che direttamente stimolano la crescita della cellula tumorale, come i Growth Factors.

\section{Artrite reumatoide}

Per quanto riguarda IMDs specifiche, sappiamo ad esempio, che i pazienti affetti da artrite reumatoide (AR) pur presentando un rischio simile alla popolazione generale di sviluppare la maggior parte dei tumori maligni, possiedono, tuttavia, un rischio aumentato relativamente ad alcune neoplasie, come il linfoma, il cancro del polmone e della pelle, specificamente quello non-melanoma. ${ }^{29-34}$

Gli studi epidemiologici condotti su ampie popolazioni dimostrano, infatti, che nei pazienti con AR il rischio di sviluppo del tumore maligno del polmone è aumentato di circa il $20-80 \%,{ }^{29,35,36}$ quello per il linfoma di circa due volte, ${ }^{35,37,38}$ mentre quello per il tumore cutaneo non melanoma è incrementato addirittura del 60$90 \%{ }^{36}$, rispetto alla popolazione generale.

Possiamo, quindi, ritenere che l'infiammazione sistemica nell'AR sia associata ad un aumento del rischio di sviluppo di neoplasie ${ }^{39}$ per effetto di mediatori come l'interleuchina-6 (IL-6), una citochina infiam- matoria coinvolta nella patogenesi delle manifestazioni locali e sistemiche della $\mathrm{AR}^{40}$ che risulta implicata anche nella mutazione e nella crescita del mieloma multiplo e dei tumori dell'ovaio, del polmone, della vescica, della mammella, del colon e della prostata. ${ }^{41}$

È stato osservato lo sviluppo di plasmocitomi monoclonali trapiantabili simili al mieloma multiplo dell'uomo in topi transgenici per IL- $6^{42}$ e che IL-6 è coinvolta nella crescita del mieloma umano e di cellule di carcinoma renale umano in vitro. ${ }^{43,44}$

\section{Lupus eritematoso discoide}

Il lupus eritematoso discoide (LED) è una malattia autoimmune che colpisce comunemente zone della pelle esposte al sole. I soggetti affetti da tale patologia hanno livelli elevati di cellule dendritiche plasmocitoidi secernenti interferone- $\alpha$ responsabile della perdita della tolleranza immunitaria ad autoantigeni con conseguente marcato stato infiammatorio in grado di sostenere la proliferazione e la differenziazione di cellule B iperattive. In alcuni casi, il LED delle labbra, del cuoio capelluto, delle orecchie o del naso può evolvere in carcinoma a cellule squamose (CCS) ${ }^{45} \mathrm{La}$ fotosensibilità e la infiammazione cronica immuno-mediata di lunga durata insieme alla guarigione disreattiva caratterizzata da atrofia, ipopigmentazione o cicatrici caratteristiche del LED rappresentano fattori di rischio per la progressione verso CCS. In rari casi, i cheratinociti delle lesioni del LED possono subire una trasformazione carcinomatosa dando luogo a CCS con prevalente interessamento del labbro inferiore. Il CCS correlato al LED mostra una maggiore aggressività rispetto a quello isolato. L'intervallo medio di tempo tra l'esordio del LED e lo sviluppo dell'eventuale CCS è solitamente di circa 20 anni, anche se può essere molto più breve. In un caso, è stato riportato lo sviluppo di CCS dopo appena pochi mesi dalla diagnosi di LED. ${ }^{46}$

I meccanismi responsabili della progressione del LED verso il CCS non sono ben definiti ma è stato suggerito che l'infiammazione cronica, il processo di guarigione disreattiva, la cicatrizzazione, l'atrofia e la depigmentazione con conseguenti danni indotti dai raggi UV possano indurre la trasformazione precancerosa iniziale dei cheratinociti. Inizialmente, i geni interessati nel processo di riparazione tessutale, alcuni fattori di trascrizione ed i percorsi cellulari sono comuni alla guarigione fisiologica delle ferite, alla proliferazione cellulare anomala ed all'apoptosi.

Nel LED, il complesso processo multifattoriale di guarigione della ferita è disregolato, con la conseguente formazione di cicatrici ipertrofiche, di cheloidi e di ulcere croniche.

Normalmente, la guarigione della ferita è un processo di riparazione auto-limitante strettamente rego- 
lato, mentre nei siti di infiammazione cronica o dei processi aberranti di guarigione vi è un aumento del rischio di cancro. ${ }^{47}$

Le cicatrici correlate al LED, le ulcerazioni e l'infiammazione cronica possono, quindi, svolgere un ruolo nella trasformazione maligna dei cheratinociti in questa malattia. ${ }^{45}$

Inoltre, la cicatrizzazione cronica, particolarmente nelle persone nere e soprattutto in presenza di cheratinociti già disregolati nel LED rappresentano un fattore di rischio per CCS della cute: ${ }^{45-47}$ cheratinociti trasformati che mostrano anche altre alterazioni citogenetiche possono diventare cancerosi. ${ }^{48}$

\section{Colangite sclerosante primitiva}

La colangite sclerosante primitiva (CSP), altra malattia infiammatoria cronica, ad eziologia sconosciuta, interessa il fegato colpendo prevalentemente i colangiociti in qualsiasi parte dell'albero biliare. Rappresenta il classico modello di malattia con effetti oncogeni secondari all'infiammazione cronica, in grado di far progredire un danno epiteliale persistente verso una trasformazione maligna. Tuttavia, la comprensione dei meccanismi specifici che regolano questa sequenza patogenetica è ancora limitata. Una sua peculiarità è rappresentata dalla stretta associazione (in circa il 70-80\%) con una MICI, con una certa variabilità tra aree geografiche..$^{49}$ Questa associazione è più evidente per la colite ulcerosa $(\mathrm{CU})(8 \%$ dei soggetti con CU sono affetti anche da CSP) che per la malattia di Crohn (MC) (1-3\%). ${ }^{50,51}$

Al pari di quanto avviene in altre malattie infiammatorie croniche, lo sviluppo del cancro può complicare anche la CSP, rendendosi responsabile di più del $40 \%$ dei decessi. Il colangiocarcinoma (CCA), il carcinoma della colecisti (CC) ed il carcinoma colon-rettale (CCR) sono stati variamente associati alla CSP, con una prevalenza fino al $13-14 \%$ e proprio il rischio di sviluppo del cancro costituisce uno dei problemi più difficili nella gestione della CSP. ${ }^{52}$ È stato dimostrato che i pazienti con CU e CSP presentano un aumento del rischio 4 volte maggiore per la displasia ed il CCR rispetto ai pazienti con sola $\mathrm{CU}$ e 10 volte più alto rispetto alla popolazione generale. ${ }^{53}$

Sebbene la CSP possa classicamente essere considerata come una malattia paradigmatica della sequenza di eventi che portano da un processo infiammatorio cronico con danno epiteliale ad una trasformazione neoplastica, i meccanismi che regolano tale evoluzione restano ancora indefiniti. Per cercare di comprendere i meccanismi di trasformazione maligna in corso di tale patologia, bisogna prendere in considerazione le interazioni epitelio-mesenchimali.

La lesione istologica patognomonica della CSP è caratterizzata da un denso accumulo di fibroblasti con progressivo deposito di matrice strettamente attorno al dotto biliare, suggerendo che le interazioni cellulari tra l'epitelio ed i compartimenti mesenchimali siano fortemente coinvolti in tali meccanismi. La produzione locale di citochine pro-infiammatorie, soprattutto di IL-6, di ossido nitrico (NO) e di specie reattive dell'azoto e dell'ossigeno con la conseguente stimolazione della proliferazione e danneggiamento del DNA costituisce probabilmente il principale evento patogenetico che porta alla trasformazione dei colangiociti. ${ }^{54}$

La ossidonitrico sintetasi inducibile (iNOS o NOS2) è significativamente up-regolata nell'epitelio biliare dei pazienti con CSP, quale risultato dell'azione delle citochine pro-infiammatorie, come il TNF- $\alpha$, rilasciate nel microambiente alterato dal processo infiammatorio. ${ }^{55}$

Una volta trasformati, i colangiociti neoplastici acquisiscono a loro volta la possibilità di rilasciare una serie di mediatori solubili (fattori di crescita, citochine e chemochine), che inducono una reazione stromale che favorisce le funzioni fondamentali pro-invasive del CCA.

Dati relativamente recenti hanno individuato il fattore di crescita PDGF-D derivato dalle piastrine quale mediatore fondamentale delle interazioni tumorestroma nel CCA. Il PDGF-D secreto dai colangiociti tumorali stimola, poi, il reclutamento di fibroblasti associati al cancro, ${ }^{56}$ dotandoli di una serie di funzioni secretorie, tra cui la produzione del fattore-C di crescita endoteliale vascolare, in grado di promuovere la linfoangiogenesi, un percorso cardine della invasività del CCA. ${ }^{57}$

Vi è anche la dimostrazione che donatori di NO stimolino la secrezione di PDGF-D da parte dei colangiociti umani in coltura (osservazioni non pubblicate di Luca Fabris e Mario Strazzabosco).

Nel complesso, questi dati suggeriscono un ruolo centrale del PDGF-D quale link tra gli effetti del NO e la trasformazione maligna con la creazione di una reazione stromale in grado di favorire la diffusione linfatica.

Per quanto riguarda la possibilità della CSP di poter estendere i propri effetti pro-oncogeni al colon quando associata a MICI, gli acidi biliari potrebbero giocare un ruolo importante nella patogenesi del CCR in corso di CSP associata alla $\mathrm{CU}$, in considerazione dei loro effetti stimolanti la proliferazione delle cellule epiteliali intestinali; gli effetti protettivi sullo sviluppo del CCR esercitate dall'acido ursodesossicolico, come mostrato da alcuni studi, possono essere una conseguenza dei suoi effetti sulla riserva di acidi biliari. ${ }^{58}$

Uno studio recente ha proposto il gene p53 soppressore tumorale, spesso mutato nel CCA, come responsabile della maggiore suscettibilità a sviluppare CRC nei pazienti con CSP associata a CU. ${ }^{59}$

In questo studio, p53 è risultato sovra-espresso nella mucosa intestinale di pazienti con CSP e CU ri- 
spetto ai pazienti affetti solo da $\mathrm{CU}$, anche in assenza di displasia, suggerendo che CSP potrebbe svolgere un ruolo diretto nella carcinogenesi colorettale associata alla CU, indipendentemente dall'attività infiammatoria della mucosa. Queste osservazioni rappresentano un esempio di come l'identificazione di pro-oncogeni possa essere utile nella selezione dei pazienti esposti ad un più alto rischio di malignità, candidati quindi a ricevere $\mathrm{i}$ benefici di un più stretto follow-up endoscopico o di approcci più radicali (cioè trapianto di fegato o procto-colectomia).

Studi recenti hanno suggerito che diversi fattori molecolari come l'instabilità genetica, un'alterazione epigenetica, il grado di risposta immunitaria, lo stress ossidativo ed il microbiota contribuiscano alla patogenesi del CCR in pazienti con CU. ${ }^{60}$ Quindi particolari alterazioni molecolari come le mutazioni genetiche, l'instabilità microsatellitare, la metilazione del DNA e la perdita di eterozigosi di p53, svolgerebbero un ruolo importante nella patogenesi della CRC in pazienti con CU. ${ }^{16,61}$ Per diagnosticare il CCR in fase iniziale, pertanto, dovrebbero essere valutate tali alterazioni molecolari nei campioni bioptici prelevati dalla mucosa del colon, con una tecnica di biopsia mirata.

Non vi è ancora consenso, tuttavia, per quanto riguarda la rilevazione del CCR in una fase iniziale nella gestione clinica dei pazienti con una $\mathrm{CU}$ di lunga durata. Clinicamente, è utile la valutazione dell'espressione di Ki67 e p53 nel tessuto del colon per rilevare il CCR e la displasia nei pazienti con CU. ${ }^{62,63}$ Inoltre, i dati recenti suggeriscono che un'alterazione dell'inibitore p16 della chinasi ciclina-dipendente sia un importante marcatore molecolare della progressione cancerogena precoce in pazienti con $\mathrm{CU} .{ }^{63}$

Pertanto, l'associazione della colonscopia e del monitoraggio dei marcatori molecolari, quali p53 e p16, dell'instabilità microsatellitare e dell'alterazione delle proteine mismatch repair in campioni di biopsia dovrebbe essere considerata quale programma di sorveglianza per la diagnosi precoce di CCR e displasia in pazienti con $\mathrm{CU}$, pur essendo necessari ulteriori studi per validare tale sorveglianza. La soppressione dell'infiammazione della mucosa con antinfiammatori come i corticosteroidi potrebbe essere utile per prevenire lo sviluppo del CCR nei pazienti con CU, perché è ormai chiaro che l'infiammazione cronica contribuisce allo sviluppo del CCR.

Uno studio retrospettivo ${ }^{64}$ relativo alla coorte di pazienti di Kyoto-Shiga con CU ha evidenziato che il sesso maschile, l'estensione della colite, la lunga durata di malattia ed una storia familiare di CCR ma non una concomitante CSP rappresentano un importante fattore predittivo per lo sviluppo di CCR nei pazienti con $\mathrm{CU}$ anche nella popolazione Giapponese, al pari dei paesi Occidentali.

I pazienti con $\mathrm{MC}$ e $\mathrm{CU}$ presentano un rischio au- mentato di sviluppare sia tumori intestinali che extraintestinali. La differenza di rischio tra $\mathrm{MC}$ e $\mathrm{CU}$ può riflettere lo stato sottostante di malattia, e/o fattori legati allo stile di vita. Il rischio di malignità gastrointestinali sembra essere in diminuzione negli ultimi anni senza un sostanziale aumento complessivo del rischio di tumori maligni, il che suggerisce che i benefici derivanti dai protocolli attuali di gestione delle due patologie superano i rischi correlati al cancro.

In uno studio relativamente recente, ${ }^{65}$ è stato evidenziato che i pazienti con $\mathrm{MC}$ e $\mathrm{CU}$ hanno un rischio a lungo termine più elevato di cancro invasivo, rispettivamente, del $30 \%$ e del $10 \%$ rispetto alla popolazione generale. L'eccesso di rischio nei pazienti con $\mathrm{MC}$ è in gran parte dovuto a tumori extraintestinali, in particolare neoplasie ematologiche e melanoma, entrambi potenzialmente correlati alla soppressione immunitaria, e tumori legati al fumo. Per quanto riguarda i tumori maligni gastrointestinali, la MC è stata associata ad un maggiore rischio di cancro dell'intestino tenue mentre sia la $\mathrm{MC}$ che la $\mathrm{CU}$ sono state associate ad un rischio aumentato di neoplasie epatobiliari, in particolare nei pazienti con associata colangite. Il rischio assoluto di tumore maligno invasivo era lievemente più elevato nella coorte di pazienti con $\mathrm{CU}$, rispetto alla coorte con $\mathrm{MC}$, probabilmente in relazione all'età avanzata: $6,3 \%$ vs 5,6\%, durante il decennio a partire dal primo anno dopo la diagnosi di MICI. Il rischio assoluto di neoplasie ematologiche è risultato quasi doppio nei pazienti con $\mathrm{MC}$ rispetto a quelli con $\mathrm{CU}$, ma tale rischio è stato inferiore a quello dei tumori gastrointestinali (Figura 2).

È noto, inoltre, che le MICI sono associate anche ad un rischio incrementato di sviluppo di neoplasie extra-intestinali. Un studio pubblicato di recente ${ }^{66}$ ha analizzato il database National Inpatients Sample, confrontando i pazienti con $\mathrm{MC}$ e CU con un gruppo di controllo costituito da pazienti affetti da diverticolite per valutare $i$ fattori di rischio associati allo sviluppo del cancro della tiroide. I risultati hanno mostrato che la $\mathrm{MC}$ ma non la $\mathrm{CU}$, è associata ad un rischio incrementato di cancro della tiroide, raccomandando che i pazienti con MC siano assiduamente sottoposti a monitoraggio per le patologie tiroidee.

\section{Tiroidite di Hashimoto}

La tiroidite di Hashimoto è caratterizzata da infiammazione, necrosi e processo di rigenerazione del tessuto tiroideo ed è stata associata allo sviluppo di linfoma e carcinoma papillifero della tiroide. ${ }^{67} \mathrm{La}$ frequenza di questa neoplasia nei pazienti con tiroidite di Hashimoto si ritiene che sia tra il 3 ed il $9 \%$. 68,69 Due classi di anticorpi stimolanti la crescita sono stati identificati in questa forma di tiroidite ${ }^{70}$ che potrebbero promuovere lo sviluppo di tumori mediante la trasformazione cellulare. 


\section{Sclerosi sistemica}

La sclerosi sistemica rappresenta un fattore di rischio particolarmente per lo sviluppo di tumori associati al fumo ed all'alcol, con preferenza per gli uomini rispetto alle donne, per cui nei pazienti con sclerosi sistemica sono necessarie misure preventive antitumorali sia primarie che secondarie. ${ }^{71}$

Per cercare, poi, di dare una risposta all'ipotesi di una possibile correlazione tra alcune terapie adoperate nella cura delle malattie infiammatorie croniche immunomediate e l'insorgenza di neoplasie, nello studio Safety Assessment of Biological Therapeutics ${ }^{72}$ che ha utilizzato dati provenienti da quattro fonti, tra cui i database Medicaid e Medicare, Tennessee Medicaid, e Kaiser Permanente Northern California, sono stati confrontati i tassi relativi di cancro nei soggetti trattati con gli inibitori del TNF- $\alpha$ con quelli dei pazienti trattati con altre terapie. L'incidenza di qualsiasi tipo di cancro solido non è risultata più elevata nella $\mathrm{AR}$ (hazard ratio, $\mathrm{HR}=0,80)$, nelle $\mathrm{MICI}(\mathrm{HR}=1,42)$, nella psoriasi $(\mathrm{HR}=0,58)$ o nella artrite psoriasica (AP) $(\mathrm{HR}=0,74)$ durante la terapia con inibitori del TNF- $\alpha$, rispetto alla terapia alternativa malattia-specifica. Tra i pazienti con AR, l'incidenza di uno dei 10 tumori più comuni negli Stati Uniti e del cancro della pelle non-melanoma non è aumentata con la terapia a base di inibitori del TNF- $\alpha$ rispetto al trattamento con i farmaci di confronto. In conclusione, in questo studio il rischio di cancro a breve termine non è stato più elevato tra $i$ pazienti trattati con inibitori del TNF- $\alpha$, ri- spetto alle terapie comunemente usate per le IMIDs.

Un recentissimo studio condotto allo scopo di definire l'incidenza di neoplasia nei pazienti con AP in corso di terapia convenzionale (322 pts) e biologica (296 pts trattati con anti-TNF- $\alpha$ ) ha confermato che la terapia biologica non determina un incremento del rischio di sviluppo di neoplasia quando correttamente somministrata e seguita con opportuno follow-up. ${ }^{73}$

Tocilizumab, un anticorpo monoclonale umanizzato che si lega al recettore di membrana ed a quello solubile $\alpha$ per IL-6, inibendo così il segnale proinfiammatorio IL-6-mediato, si è dimostrato efficace e sicuro sia in combinazione con DMARDs che in monoterapia in trials randomizzati controllati di fase 3 e $4 .{ }^{74,75}$ Sono stati valutati i tumori maligni nei bracci attivi ed in quelli di controllo in doppio cieco, controllati con placebo. I tassi sono stati confrontati con quelli della popolazione generale con tassi di incidenza standardizzati (SIR) sulla base di dati provenienti da registri tumori regionali. Il tasso complessivo di tumori maligni è rimasto stabile con la esposizione prolungata a tocilizumab durante l'estensione a lungo termine dei trials di fase 3 .

Inoltre, il rischio di sviluppare neoplasie, comprese quelle ematologiche sembra potenzialmente maggiore nei pazienti con AR che usano farmaci immunosoppressori. Case report descrivono l'insorgenza di linfoma in pazienti con AR trattati con metotrexate. Anche se l'ipotesi corrente è che la stessa $A R$ o, più specificamente, l'attività infiammatoria associata con

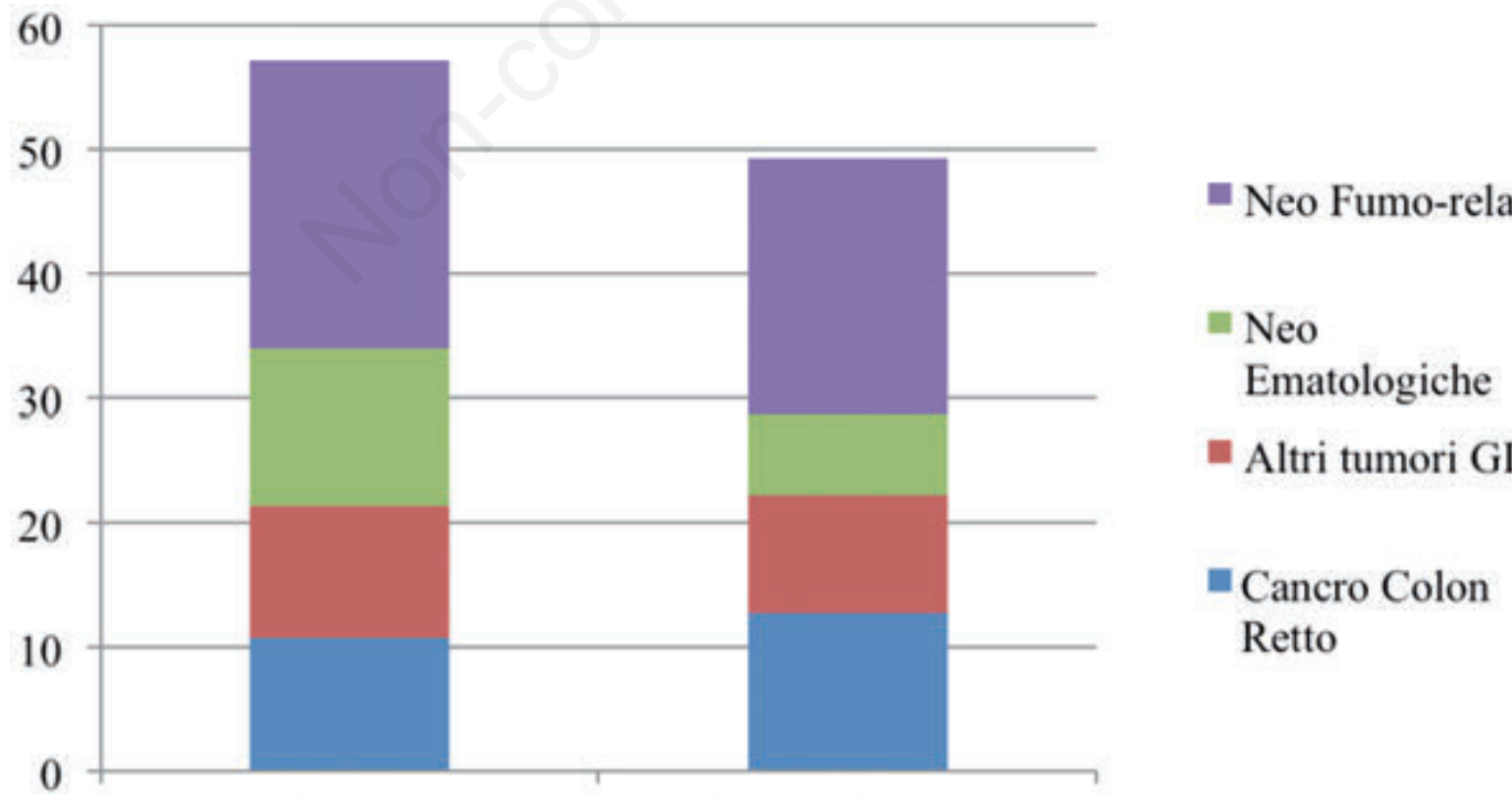

M. Crohn

Colite ulcerosa

Figura 2. Rischio assoluto di sviluppo di neoplasia maligna nel follow-up 1-11 anni dalla diagnosi di MICI. Dati da The Danish National Patient Register (DNPR) (1978-2010). 
i meccanismi patogenetici alla base della malattia sia responsabile dell'aumento del rischio di sviluppare il linfoma, alcune evidenze suggeriscono che i pazienti con AR trattati con farmaci biologici siano maggiormente a rischio di neoplasia maligna, in particolare tumori cutanei non-melanoma, rispetto ala popolazione generale. Alcuni studi hanno dimostrato un aumento del rischio complessivo di sviluppo di tumori maligni (inclusi il linfoma, la leucemia, il cancro del polmone e cancro della pelle non-melanoma) in corso di trattamento con l'anti-TNF, ${ }^{76-78}$ in contrasto con i dati di altri studi osservazionali e clinici che non confermano tale aumento. ${ }^{79-84} \mathrm{~L}$ 'incidenza di neoplasia non è risultata incrementata con il trattamento a lungo termine con tocilizumab e la tipologia dei tumori maligni è coerente con quella attesa nei pazienti con AR. ${ }^{85}$

In conclusione, è possibile riportare le considerazioni di una recentissima review ${ }^{86}$ sull'argomento che ha valutato la tendenza temporale dell'incidenza del cancro nei pazienti con MICI, mediante l'analisi dei dati della letteratura, effettuando meta-analisi di studi esistenti ed esaminando un database nazionale per individuare la tendenza dei ricoveri per cancro nei pazienti con MICI. Risulta che il rischio complessivo di CCR nei pazienti con CU si è ridotto negli ultimi tre decenni mentre non vi è stata alcuna variazione del rischio di cancro del piccolo intestino, significativamente elevato in questa categoria di pazienti. Il rischio complessivo di sviluppo di Linfoma non-Hodgkin è aumentato negli ultimi 16 anni ed i pazienti affetti da MICI in trattamento con tiopurine ed anti TNF- $\alpha$ presentano un aumentato rischio di questa neoplasia ematologica. È dimostrato un incremento di melanoma nei pazienti con MICI che resta, però, fondamentalmente stabile nel tempo. Anche il rischio di cancro della pelle non melanoma, maggiore nei pazienti in trattamento con tiopurine, risulta stabile nel tempo. Quindi, ci sarebbe evidenza di una diminuzione dell'incidenza del CCR nei pazienti con $\mathrm{CU}$, ma un aumento dell'incidenza di malattie linfoproliferative e tumori cutanei non melanoma, con l'uso di farmaci immunosoppressori nei pazienti con MICI.

\section{Punti chiave}

- Le malattie infiammatorie croniche immuno-mediate hanno alla base meccanismi patogenetici comuni che vedono coinvolto il sistema immunitario.

- Tali processi patogenetici, che si estrinsecano con un'alterazione dei meccanismi regolatori del sistema immunitario e con una iperespressione ed iperattivazione di mediatori flogistici, determinano uno stato infiammatorio cronico responsabile di un danno persistente a carico dei tessuti colpiti con conseguente loro rimodellamento.

- La cronica attivazione di tali meccanismi, con il perpetuarsi della flogosi, espone i pazienti affetti da una malattia infiammatoria cronica immunomediata ad un aumentato rischio neoplastico.

- Ancora dibattuta è l'eventuale influenza nel determinismo di tale rischio da parte di varie classi di farmaci adoperati nella terapia di queste malattie.

- La presenza di una malattia infiammatoria cronica immunomediata deve indurre ad una attenta sorveglianza volta ad individuare precocemente l'eventuale sviluppo di una neoplasia correlata.

\section{Bibliografia}

1. Rahman P, Inman RD, El-Gabalawy H and Krause DO. Pathophysiology and pathogenesis of immune-mediated inflammatory diseases: commonalities and differences. J Rheumatol Suppl. 2010;85:11-26.

2. Coussens LM, Werb Z. Inflammation and cancer. Nature 2002;420:860-7.

3. Rous P, Kidd J. Conditional neoplasms and subthreshold neoplastic states: a study of the tar tumors of rabbits. J Exp Med 1941;73:365-389.

4. Mackenzie IC, Rous P. The experimental disclosure of latent neoplastic changes in tarred skin. J ExpMed 1941;73:391-415.

5. Dvorak HF. Tumors: wounds that do not heal. Similarities between tumor stroma generation and wound healing. N Engl J Med 1986;315:1650-1659.

6. Virchow R (1863-1865). Die Krankhaften Geschwulste, edn 1 (3 vols) Berlin: August Hirschwald.

7. Balkwill F, Mantovani A. Inflammation and cancer: back to Virchow? Lancet 2001;357:539-545.

8. Jaccoud S. Trattato di Patologia Interna. Capitolo VI. Giuseppe Marghieri editore. Napoli 1872.

9. Beyaert R, Beaugerie L, Van Assche G et al. Cancer risk in immune-mediated inflammatory diseases (IMID). Mol cancer. 2013;12(1):98.

10. Markowitz S. Asbests-related lung cancer and malignant mesothelioma of the pleura: selected current issues. Semin Respir Crit Care Med. 2016;37(1):143-4.

11. Carozzi FM, Tornesello ML and Burroni E. Prevalence of human Papillomavirus Types in High-Grade Cervical Intraepithelial Neoplasia and Cancer in Italy. Cancer Epidemiol Biomarkers Prev 2010;19(9): 2389-2400.

12. Mostafa MH, Sheweita SA. and O'Connor PJ. Relatonship between Schistosomiasis and bladder cancer. Clinical Microbiology Reviews.1999, p.97-111.

13. Dedicoat M., Newton R. Review of the distribution of Kaposi's sarcoma-associated herpesvirus (KSHV) in Africa in relation to the incidence of Kaposi's sarcoma. British Journal of Cancer 2003;88:1-3.

14. Berger H, Marques MS, Zietlow R et al. Gastric cancer pathogenesis. Helicobacter 2016;21 Suppl 1:34-8.

15. Chaves P, Cruz C and Dias Pereira A. Gastric and intestinal differentiation in Barrett's metaplasia and associated adenocarcinoma. Dis Esophagus. 2005;18(6): 383-7.

16. Triantafillidis JK, Nasioulas G, Kosmidis PA. Colorectal cancer and inflammatory bowel disease: epidemiology, risk factors, mechanisms of carcinogenesis and prevention strategies. Anticancer Res 2009;29:2727-37. 
17. Huang YT, Yang HI, Liu J et al. Mediation Analysis of Hepatitis B and C in relation to Hepatocellular Carcinoma Risk. Epidemiology 2016;27(1):14-20.

18. Bréchot C. Pathogenesis of hepatitis B virus-related hepatocellular carcinoma: old and new paradigms. Gastroenterology. 2004;127(5 Suppl 1):S56-61.

19. Withcomb DC, Applebaum S and Martin SP. Hereditary pancreatitis and pancreatic carcinoma. Annals of the New York Academy of Sciences 1999;880:201-9.

20. Lowenfels AB, Maisonneuve P, Di Magno EP et al. Hereditary pancreatitis and the risk of pancreatic cancer. International Hereditary Pancreatitis Study Group. Journal of National Cancer Institute 1997;89(6):442-6.

21. Lowenfels AB, Maisonneuve P and Cavallini G. Pancreatitis and the risk of pancreatic cancer. International Pancreatitis Study Group. North England Journal of Medicine 1993;328(20):1433-7.

22. Whitcomb DC. Inflammation and Cancer V. Chronic pancreatitis and pancreatic cancer. Am J Phisiol Gastrointest Liver Physiol 2004; 287:G315-G319.

23. Rozenblum E, Schutte M and Goggins M. Tumor-suppressive pathways in pancreatic carcinoma. Cancer Research 1997;57(9):1731-4.

24. Hruban RH, van Mansfeld AD and Offerhaus GJ. K-ras oncogene activation in adenocarcinoma of the human pancreas. A study of 82 carcinomas using a combination of mutant-enriched polymerase chain reaction analysis and allele-specific oligonucleotide hybridization. Am J Path 1993;143(2):545-54.

25. Di Giuseppe JA, Hruban RH, and Goodman SN. Overexpression of $\mathrm{p} 53$ protein in adenocarcinoma of the pancreas. Am J Clin Path 1994;101(6):684-8.

26. Hahn SA, Schutte M and Hoque AT. DPC4, a candidate tumor suppressor gene at human chromosome 18q21.1. Science 1996;271(5247):350-3.

27. Friess H, Guo XZ et Nan BC. Growth factors and cytokines in pancreatic carcinogenesis. Ann N Y Acad Sci 1999;880:110-21.

28. Le X, Shi Q and Wang B. Molecular regulation of constitutive expression of interleukin-8 in human pancreatic adenocarcinoma. J Interferon Cytochine Res 2000;20 (11):935-46.

29. Wolfe F, Michaud K. Biologic treatment of rheumatoid arthritis and the risk of malignancy: analyses from a large US observational study. Arthritis Rheum 2007;56: 2886-95.

30. Smitten AL, Simon TA, Hochberg MC, et al. A metaanalysis of the incidence of malignancy in adult patients with rheumatoid arthritis. Arthritis Res Ther 2008;10:R45.

31. Askling J, Fored CM, Brandt L, et al. Risks of solid cancers in patients with rheumatoid arthritis and after treatment with tumour necrosis factor antagonists. Ann Rheum Dis 2005;64:1421-6.

32. Saliba L, Moulis G, Aboutaam M, et al. The risk of cancer with tumor necrosis factor inhibitors in patients concomitantly exposed to non-biological immunosuppressants differs according to the indication [abstract]. Arthritis Rheumatol 2014;66:S373

33. Raaschou P, Simard JF, Asker Hagelberg C, et al. Rheumatoid arthritis, anti-tumour necrosis factor treatment, and risk of squamous cell and basal cell skin cancer: cohort study based on nationwide prospectively recorded data from Sweden. BMJ 2016;352:i262.
34. Simon TA, Thompson A, Gandhi KK, et al. Incidence of malignancy in adult patients with rheumatoid arthritis: a meta-analysis. Arthritis Res Ther 2015;17:212.1-6.

35. Setoguchi S, Solomon DH, Weinblatt ME, et al. Tumor necrosis factor alpha antagonist use and cancer in patients with rheumatoid arthritis. Arthritis Rheum 2006;54:2757-64.

36. Hemminki K, Li X, Sundquist K, et al. Cancer risk in hospitalized rheumatoid arthritis patients. Rheumatology (Oxford) 2008;47:698-701.

37. Wolfe F, Michaud K. The effect of methotrexate and anti-tumor necrosis factor therapy on the risk of lymphoma in rheumatoid arthritis in 19,562 patients during 89,710 person-years of observation. Arthritis Rheum 2007;56:1433-9.

38. Askling J, Fored CM, Baecklund E, et al. Haematopoietic malignancies in rheumatoid arthritis: lymphoma risk and characteristics after exposure to tumour necrosis factor antagonists. Ann Rheum Dis 2005;64:1414-20.

39. Llorca J, Lopez-Diaz MJ, Gonzalez-Juanatey C, et al. Persistent chronic inflammation contributes to the development of cancer in patients with rheumatoid arthritis from a defined population of northwestern Spain. Semin Arthritis Rheum 2007;37:31-8.

40. Assier E, Boissier MC, Dayer JM. Interleukin-6: from identification of the cytokine to development of targeted treatments. Joint Bone Spine 2010;77:532-6.

41. Guo Y, Xu F, Lu T, et al. Interleukin-6 signaling pathway in targeted therapy for cancer. Cancer Treat Rev 2012;38:904-10.

42. Suematsu S, Matsusaka T, Matsuda T, et al. Generation of plasmacytomas with the chromosomal translocation $\mathrm{t}(12 ; 15)$ in interleukin 6 transgenic mice. Proc Natl Acad Sci USA 1992;89:232-5.

43. Kawano M, Hirano T, Matsuda T, et al. Autocrine generation and requirement of BSF-2/IL- 6 for human multiple myelomas. Nature 1988;332:83-5.

44. Miki S, Iwano M, Miki Y, et al. Interleukin-6 (IL-6) functions as an in vitro autocrine growth factor in renal cell carcinomas. FEBS Lett 1989;250:607-10.

45. Motswaledi MH, Khammissa RA, Wood NH, et al. Discoid lupus erythematosus as it relates to cutaneous squamous cell carcinoma and to photosensitivity. SADJ 2011;66:340-3.

46. Feller LL, Khammissa RR, Kramer BB, and Lemmer JJ. Oral squamous cell carcinoma in relation to field precancerisation: Pathobiology. Cancer Cell Int 2013;13:31.

47. Feller L, Altini M, Lemmer J. Inflammation in the context of oral cancer. Oral Oncol 2013;49:887-92.

48. Tao J, Zhang X, Guo N, et al. Squamous cell carcinoma complicating discoid lupus erythematosus in Chinese patients: Review of the literature, 1964-2010. J Am Acad Dermatol 2012;66:695-6.

49. Boonstra K, Beuers U, Ponsioen CY. Epidemiology of primary sclerosing cholangitis and primary biliary cirrhosis: a systematic review. J Hepatol. 2012;56:1181-1188.

50. Rasmussen HH, Fallingborg JF, Mortensen PB, et al. Hepatobiliary dysfunction and primary sclerosing cholangitis in patients with Crohn's disease. Scand J Gastroenterol 1997; 32:604-610.

51. Fausa O, Schrumpf E, Elgjo K. Relationship of inflammatory bowel disease and primary sclerosing cholangitis. Semin Liver Dis. 1991; 11:31-39. 
52. Giulia Bonato, Laura Cristoferi, and Mario Strazzabosco. Malignancies in Primary Sclerosing Cholangitis - A Continuing Threat. Dig Dis. 2015 ; 33(Suppl 2): 140-148.

53. Soetikno RM, Lin OS, Heidenreich PA, et al. Increased risk of colorectal neoplasia in patients with primary sclerosing cholangitis and ulcerative colitis: a meta-analysis. Gastrointest Endosc. 2002; 56:48-54.

54. Rizvi S, Borad MJ, Patel T, Gores GJ. Cholangiocarcinoma: molecular pathways and therapeutic opportunities. Semin Liver Dis. 2014; 34:456-464.

55. Spirlì C, Fabris L, Duner E, et al. Cytokine-stimulated nitric oxide production inhibits adenylyl cyclase and cAMP-dependent secretion in cholangiocytes. Gastroenterology. 2003; 124:737-753.

56. Cadamuro M, Nardo G, Indraccolo S, et al. Platelet-derived growth factor-D and Rho GTPases regulate recruitment of cancer-associated fibroblasts in cholangiocarcinoma. Hepatology. 2013; 58:1042-1053.

57. Cadamuro M, Vismara M, Brivio S, et al. JNK signaling activated by platelet-derived growth factor-D (PDGFD) stimulates secretion of vascular endothelial growth factor-C (VEGF-C) by cancer-associated fibroblasts to promote lymphangiogenesis and early metastasization in cholangiocarcinoma. J Hepatol. 2015;62:S389.

58. Ochsenkühn T, Bayerdörffer E, Meining A, et al. Colonic mucosal proliferation is related to serum deoxycholic acid levels. Cancer. 1999; 85:1664-1669.

59. Wohl P, Hucl T, Drastich P, et al. Epithelial markers of colorectal carcinogenesis in ulcerative colitis and primary sclerosing cholangitis. World J Gastroenterol. 2013; 19:2234-2241.

60. Yashiro M. Molecular alterations of colorectal cancer with inflammatory bowel disease. Dig Dis Sci 2015;60: 2251-63.

61. Itzkowitz S. Colon carcinogenesis in inflammatory bowel disease: applying molecular genetics to clinical practice. J Clin Gastroenterol 2003;36(5 Suppl):S70-4.

62. Li P, Xiao ZT and Braciak TA. Association between Ki67 Index and Clinicopathological Features in Colorectal Cancer. Oncol Res Treat. 2016;39(11):696702. Epub 2016 Oct 13.

63. Hsieh CJ, Klump B, Holzmann K, et al. Hypermethylation of the p16INK4a promoter in colectomy specimens of patients with long-standing and extensive ulcerative colitis. Cancer Res 1998;58:3942-5.

64. Yoshino T, Nakase H, Takagi T, et al. Risk factors for developing colorectal cancer in Japanese patients with ulcerative colitis: a retrospective observational studyCAPITAL (Cohort and Practice for IBD total management in Kyoto-Shiga Links) study I. BMJ Open Gastro 2016;3:e000122. doi:10.1136/bmjgast-2016-000122.

65. Kappelman MD, Farkas DK and Long MD. Risk of Cancer in Patients with Inflammatory Bowel Diseases: a Nationwide Population-Based Cohort Study with 30 Years of Follow Up Clin Gastroenterol Hepatol. 2014; 12(2): 265-73.e1. doi:10.1016/j.cgh.2013.03.034.

66. Wadhwa V, Lopez R, and Shen B. Crohn's Disease is associated with the risk for thyroid cancer. Inflamm Bowel Dis. 2016 Dec;22(12):2902-2906.

67. Mauras N, Zimmerman D and Goeliner JR. Hashimoto thyroiditis associated with thyroid cancer in adolescent patients. Journal of Pediatrics 1985;106(6):895-8.

68. Schlike CP, Hill JE, Schultz GF. Carcinoma in chronic thyroiditis. Surgery, Gyencology and Obstetrics 1960;111:552.

69. Crile GJ, Hazard JB. Incidence of cancer in struma Lympomatosa. Surgery, Gyencology and Obstetrics 1962;115:101

70. Valente WA, Vitti P, Rotella CM. Antibodies that promote thyroid growth. A distinct population of thyroidstimulating autoantibodies. North England Journal of Medicine 1983; 309(17):1028-34.

71. Olesen AB1, Svaerke C, Farkas DK, Sørensen HT. Systemic sclerosis and the risk of cancer: a nationwide population-based cohort study. $\mathrm{Br}$ J Dermatol. 2010 Oct;163(4):800-6

72. Haynes K, Beukelman T, Curtis JR and Newcomb C; SABER Collaboration. Tumor necrosis factor $\alpha$ inhibitor therapy and cancer risk in chronic immune-mediated diseases. Arthritis Rheum 2013; 65: 48-58.

73. Costa L, Caso F, and Del Puente A. Incidence of Malignancies in a Cohort of Psoriatic Arthritis Patients Taking Traditional Disease Modifying Antirheumatic Drug and Tumor Necrosis Factor Inhibitor Therapy: An Observational Study. J Rheumatol. 2016;43(12):2149-2154. Epub 2016 Sep 15.

74. Smolen JS, Beaulieu A and Rubbert-Roth A. Effect of interleukin-6 receptor inhibition with tocilizumab in patients with rheumatoid arthritis (OPTION study): a double-blind, placebo-controlled, randomised trial. Lancet 2008;371:987-997.

75. Gabay C, Emery P and van Vollenhoven R. Tocilizumab monotherapy versus adalimumab monotherapy for treatment of rheumatoid arthritis (ADACTA): a randomised, double-blind, controlled phase 4 trial. Lancet 2013;381:1541-1550.

76. Bongartz T, Sutton AJ, Sweeting MJ, et al. Anti-TNF antibody therapy in rheumatoid arthritis and the risk of serious infections and malignancies: systematic review and meta-analysis of rare harmful effects in randomized controlled trials. JAMA 2006;295:2275-85.

77. Askling J, Fahrbach K, Nordstrom B, et al. Cancer risk with tumor necrosis factor alpha (TNF) inhibitors: metaanalysis of randomized controlled trials of adalimumab, etanercept, and infliximab using patient level data. Pharmacoepidemiol Drug Saf 2011;20:119-30.

78. Mariette X, Matucci-Cerinic M, Pavelka K, et al. Malignancies associated with tumour necrosis factor inhibitors in registries and prospective observational studies: a systematic review and meta-analysis. Ann Rheum Dis 2011;70:1895-904.

79. Amari W, Zeringue AL, McDonald JR, et al. Risk of non-melanoma skin cancer in a national cohort of veterans with rheumatoid arthritis. Rheumatology (Oxford) 2011;50:1431-9.

80. Strangfeld A, Hierse F, Rau R, et al. Risk of incident or recurrent malignancies among patients with rheumatoid arthritis exposed to biologic therapy in the German biologics register RABBIT. Arthritis Res Ther 2010;12:R5

81. Lopez-Olivo MA, Tayar JH, Martinez-Lopez JA, et al. Risk of malignancies in patients with rheumatoid arthritis treated with biologic therapy: a meta-analysis. JAMA 2012;308:898-908.

82. Thompson AE, Rieder SW, Pope JE. Tumor necrosis factor therapy and the risk of serious infection and malignancy in patients with early rheumatoid arthritis: a 
meta-analysis of randomized controlled trials. Arthritis Rheum 2011;63:1479-85.

83. Moulis G, Sommet A, Béné J, et al. Cancer risk of antiTNF- $\alpha$ at recommended doses in adult rheumatoid arthritis: a meta-analysis with intention to treat and per protocol analyses. PLoS ONE 2012;7: e48991.

84. LE Blay P, Mouterde G, Barnetche T, et al. Short-term risk of total malignancy and nonmelanoma skin cancers with certolizumab and golimumab in patients with rheumatoid arthritis: metaanalysis of randomized controlled trials. J Rheumatol 2012;39:712-15.

85. Rubbert-Roth A, Sebba A, Brockwell L,et al. Malignancy rates in patients with rheumatoid arthritis treated with tocilizumab. RMD Open 2016;2:e000213.

86. Garg SK1, Loftus EV Jr. Risk of cancer in inflammatory bowel disease: going up, going down, or still the same? Curr Opin Gastroenterol. 2016;32(4):274-81. 


\title{
La sindrome infiammatoria da ricostruzione immune
}

\author{
Ilaria Ronga, Generoso Uomo \\ UOSC Medicina Interna 3, Dipartimento Medico Polispecialistico, AORN Cardarelli, Napoli, Italia
}

\section{Introduzione}

La sindrome infiammatoria da ricostruzione immune (IRIS, acronimo dell'inglese Immune Reconstitution Inflammatory Syndrome) è stata inizialmente riconosciuta e descritta in una percentuale variabile dal 10 al $40 \%$ di pazienti HIV-positivi che vanno incontro ad un deterioramento clinico paradosso concomitante e secondario al ripristino della funzione del loro sistema immunitario in corso di trattamento con schema politerapico HAART (Highly Active Antiretroviral Theraphy). ${ }^{1-3}$ Una volta migliorato l'assetto linfocitario con il ripristino dei livelli di CD4, in una parte di questi pazienti, quantificabile intorno al $25 \%$, si possono osservare non solo riaccensioni devastanti di infezioni subcliniche o quiescenti ma anche fenomeni infiammatori interstiziali a carico del parenchima polmonare, renale ed epatico. ${ }^{4,5}$ La sindrome nella sua variante più aggressiva è comune nei pazienti con livelli iniziali di CD4 più bassi e le infezioni più frequenti sono sostenute da micobatteri tipici ed atipici ma anche da criptococchi e histoplasma.$^{6}$ In epoca più recente sono stati segnalati casi di IRIS anche in pazienti sottoposti a trapianto d'organo e successiva terapia antirigetto una volta che la terapia immunosoppressiva veniva ridotta o sospesa, in pazienti neutropenici (per regimi chemio e/o neoplasie) al ripristino della conta bianchi e in pazienti gravide nel periodo post-partum. ${ }^{7,8}$ Del tutto recentemente poi vi sono state isolate segnalazioni di IRIS in pazienti con malattie autoimmuni sistemiche croniche una volta sospeso il trattamento con agenti anti-TNF (Tumor-Necrosis Factor)- $\alpha .{ }^{9-11}$

Corrispondente: Generoso Uomo, Medicina Interna 3, Dipartimento Medico Polispecialistico, AORN Cardarelli, via Cardarelli 9, 80131 Napoli, Italia.

Tel.: +39.081.7472101 - Fax: +081.7472104.

E-mail: gene.uomo@virgilio.it

Articolo pubblicato secondo la Creative Commons Attribution NonCommercial 4.0 License (CC BY-NC 4.0).

CCopyright I. Ronga e G. Uomo, 2017

Licensee PAGEPress, Italy

QUADERNI - Italian Journal of Medicine 2017; 5(7):155-160

\section{Patogenesi}

In estrema sintesi, IRIS si realizza in pazienti immunodepressi allorquando, in risposta a trattamenti efficaci, si viene a ripristinare la risposta immunitaria che diviene disregolata ed eccessiva, esitando in un danno dell'ospite ed associandosi ad elevata mortalità. La suscettibilità genetica svolge verosimilmente un ruolo predominante nel realizzare una risposta immunitaria esuberante allo stimolo antigenico infettivo o non infettivo con iperproduzione di citochine pro-infiammatorie e/o mancata immuno-regolazione di altre citochine. Sono stati segnalati specifici profili HLA (Human Leukocyte Antigen) e polimorfismi genici di interleuchina- 6 e TNF- $\alpha .{ }^{6}$ In condizioni fisiologiche si realizza un equilibrio fra alcune sottoclassi di linfociti T, tutti derivati dai Th0 CD4+: da un lato i Th-1 e Th-17 che attraverso la produzione e liberazione di interferone-gamma e interleuchina 17 e 22 svolgono azione pro-infiammatoria e sono implicati nei meccanismi del rigetto dei trapianti, dall'altro i linfociti Th2 e T-Regs che svolgono azione anti-infiammatoria, immunosoppressiva e sono coinvolti nella tolleranza del graft (Figura 1). Nella IRIS questo equilibrio vede la predominanza delle funzioni Th-1 e Th-17 rispetto a quelle Th-2 e T-Regs mediate. ${ }^{12}$ La conseguenza è l'innesco di un'infiammazione atipica altamente istolesiva con espressioni cliniche diretta conseguenza dell'attivazione del sistema immunitario contro numerose strutture dell'organismo, in primis dell'apparato respiratorio.

La patogenesi dei casi di IRIS nel post-partum rientra in questo schema. In gravidanza si determina uno stato di immunosoppressione relativa che consente di portare a termine la gravidanza senza che il sistema immune materno attacchi l'embrione o il feto. Nel periodo post-partum la risposta Th1 cellulare si ripristina rapidamente e questo può scatenare una condizione di IRIS. ${ }^{8}$

Il TNF- $\alpha$ svolge un ruolo chiave nel promuovere infiammazione ed iniziare la risposta dell'ospite alle infezioni. Farmaci antagonisti del TNF (adalimumab, etanercept, infliximab) ampiamente utilizzati nelle malattie autoimmuni si associano a maggior rischio di infezioni e poiché gli antagonisti del TNF si stoppano quando interviene una infezione e si inizia il tratta- 
mento antibiotico/antivirale, i livelli di questa citochina non più bloccata risalgono e si possono innescare i meccanismi che portano alla IRIS .

Fra i fattori di rischio segnalati per lo sviluppo di IRIS si annoverano: a) la presenza di infezioni opportunistiche all'inizio della HAART nei pazienti con patologia HIV-relata e di infezioni disseminate (tubercolotiche o da Cryptococcus) prima della terapia; b) livelli di linfociti CD4+ al di sotto di 50 cellule/ $/$ l. $^{13}$ L'intervallo di tempo tra il trattamento delle infezioni opportunistiche e l'inizio della HAART sembra essere importante per lo sviluppo di IRIS, particolarmente in caso di infezione tubercolare, in quanto un intervallo più breve si associa ad un rischio più elevato. ${ }^{14}$

\section{Considerazioni diagnostiche}

Per la mancanza di test diagnostici specifici la diagnosi di IRIS è posta fondamentalmente per esclusione e questo complica di molto il management di pazienti con quadri sindromici complessi nel contesto di stati di grave immuno-depressione. Le manifesta- zioni cliniche sono varie ma riconducibili sostanzialmente a due scenari principali: IRIS mascherata e IRIS paradossa. ${ }^{9,15}$

Nella prima forma, l'infezione è di nuova identificazione dopo l'inizio dei trattamenti immunosoppressivi e di regola l'agente patogeno è vitale. Nella IRIS paradossa, invece, la infezione è già presente e in terapia ma peggiora dopo il trattamento della malattia di base ed il patogeno responsabile può essere vitale o meno. Ai segni clinici dell'infezione si associano quelli di una risposta infiammatoria esagerata per perdita dei meccanismi che normalmente limitano l'infiammazione stessa. La compromissione multiorgano è frequente con grave coinvolgimento in primis polmonare poi epatico e renale.

Criteri clinici utili per porre il sospetto diagnostico sono l'associazione temporale tra il rapido ripristino del valore dei neutrofili e deterioramento clinico-radiologico pluriorgano e l'esclusione di altre cause quali eventi avversi o interazione da farmaci, inefficace trattamento delle infezioni opportunistiche, comparsa di infezioni opportunistiche alternative. Nella

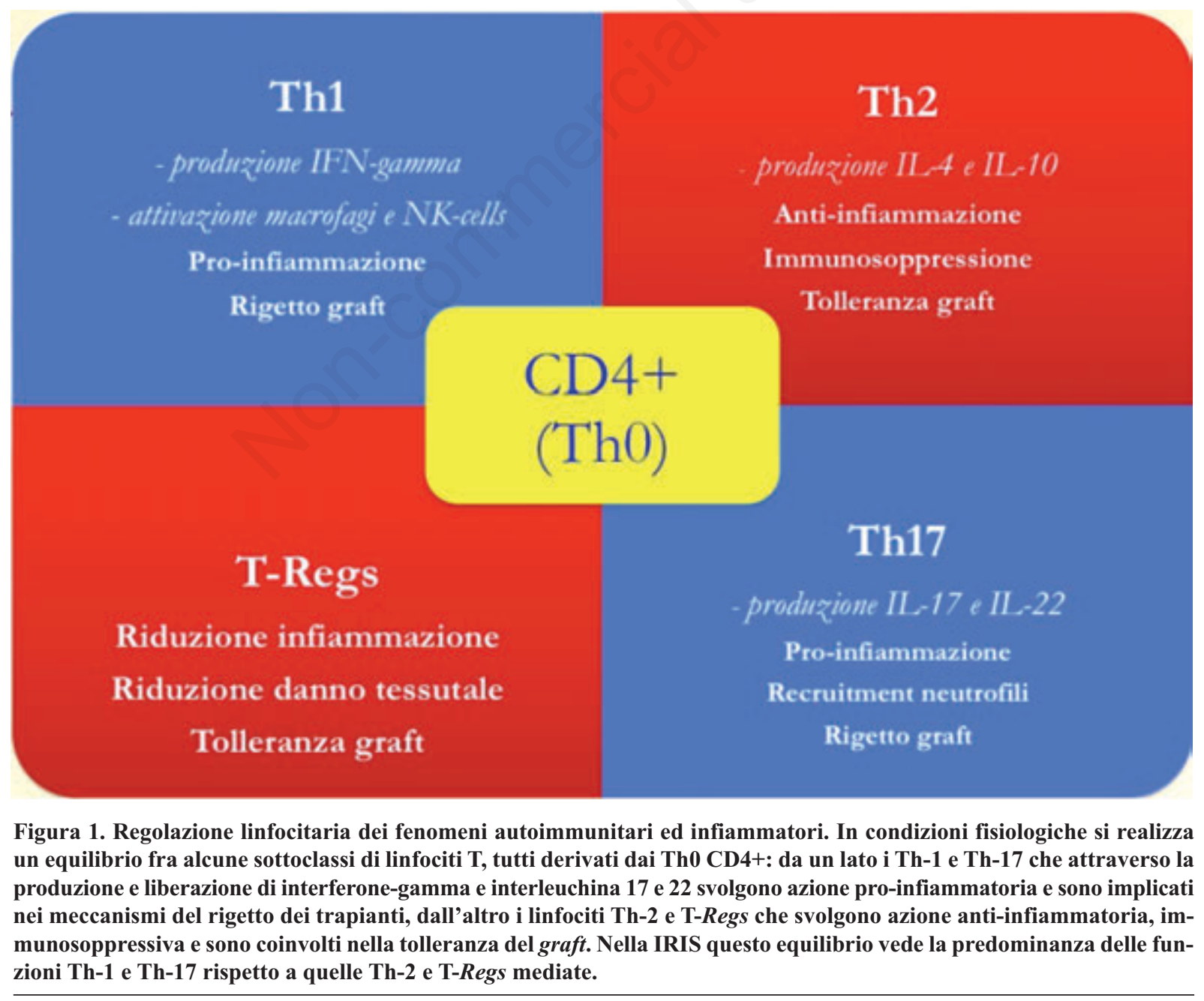


Tabella 1 sono indicati i criteri diagnostici proposti da French ${ }^{1}$ e Robertson. ${ }^{16}$

Per quanto attiene ai dati di laboratorio aspecifici, nella IRIS è stato segnalato un incremento marcato dei valori plasmatici del D-dimero e della PCR. ${ }^{17}$ Per una diagnostica più specifica andrebbero valutati i livelli sierici di chemochine e citochine quali l'interferonegamma, il TNF- $\alpha$, le interleuchine 2, 6, 7, 12, 13, 17 e 18 ma il loro dosaggio è assai complesso, sicuramente non alla portata di tutti i Laboratori e quindi al momento improponibile nella pratica clinica. ${ }^{18,19}$

\section{Trattamento}

La strategia terapeutica da adottare in corso di sindrome IRIS mira essenzialmente al trattamento dell'infezione riattivata e quindi antitubercolari nel caso di infezioni da Mycobacterium tubercolosis e Mycobacterium Avium Complex, antivirali in caso di infezioni da Cytomegalovirus e Herpes Zoster Virus, antifungini nel caso di criptococcosi. ${ }^{20-22} \mathrm{Se}$ si riscontrano quadri di epatocitonecrosi di grado marcato per riattivazione di infezioni virali viene indicata la sospensione della eventuale terapia antiretrovirale in atto. Nel caso di grave patologia infettiva in un paziente naive alla terapia anti-HIV e senza grave deficit dell'immunità cellulare, si può trattare con priorità la manifestazione infettiva acuta e in fase successiva, alla risoluzione del quadro clinico, iniziare una terapia an- tiretrovirale efficace. ${ }^{23}$ Mancando vere e proprie linee guida, il trattamento dell'IRIS è quindi sostanzialmente empirico, e si basa su osservazioni cliniche ed opinioni di esperti.

Considerando che l'IRIS si associa a marcata espansione dei linfociti $T$, iperproduzione di citochine pro-infiammatorie e deficit della funzione immunoregolatoria, diviene chiaro che le terapie più utili sia per il trattamento che la prevenzione dell'IRIS si basano sull'utilizzo di immunosoppressori ed immunomodulatori. ${ }^{24-27}$ Le diverse strategie farmacologiche utilizzate per il trattamento comprendono i corticosteroidi per via orale, gli antiinfiammatori non steroidei (FANS), la talidomide e gli antagonisti recettoriali dei leucotrieni. I FANS sono raccomandati nei casi lievi e/o moderati di IRIS, mentre i corticosteroidi sono utilizzati nei casi più gravi ed in tutte quelle condizioni che mettono a rischio la vita del paziente. C'è da tener presente però che $\mathrm{i}$ corticosteroidi possono riattivare infezioni da Herpes Virus e Sarcoma di Kaposi in pazienti HIV-positivi con una bassa conta di cellule $\mathrm{CD} 4+$ ma non i quelli con la conta di cellule CD4+ in aumento dopo la terapia antiretrovirale. ${ }^{23}$ Le dosi esatte dei corticosteroidi, così come la durata del trattamento non sono state ancora definite con precisione. Meintjes e collaboratori ${ }^{28}$ in uno studio randomizzato e controllato hanno dimostrato l'utilità del prednisone in pazienti con IRIS e infezione tubercolare, riscontrando una riduzione della necessità di ospedalizza-

Tabella 1. Definizioni di IRIS.

Definizione generale di IRIS proposta da French et al., 2004

La diagnosi richiede la presenza di due criteri maggiori $(\mathrm{A}+\mathrm{B})$ oppure un criterio maggiore $(\mathrm{A})$ più uno minore:

Criteri maggiori

A. presentazione atipica di infezioni opportunistiche o di tumori in pazienti che rispondono alla terapia antiretrovirale, che si manifesta con qualsiasi delle sottostanti modalità

- malattia localizzata

- reazione infiammatoria esagerata

- risposta infiammatoria atipica nei tessuti interessati

- progressione della disfunzione d'organo oppure ampliamento delle preesistenti lesioni a seguito del miglioramento clinico con la terapia patogeno-specifica prima della terapia antiretrovirale ed esclusione di tossicità da trattamento e nuove diagnosi

B. riduzione del livello plasmatico di HIV RNA $>\log 10$ copie/ml

Criteri minori

- aumento della conta delle CD4 dopo terapia antiretrovirale

- aumento della risposta immunitaria contro uno specifico patogeno

- spontanea risoluzionedell'infezione con la continuazione della terapia antiretrovirale

Definizione generale di IRIS proposta da Robertson et al., 2006 ${ }^{16}$

Criteri maggiori

- peggioramento dei sintomi di infiammazione/infezione

- relazione temporale con l'inizio della terapia antiretrovirale

- sintomi non spiegati dalla insorgenza di una nuova infezione acquisita o dalla malattia stessa o dalla progressione di una infezione acquisita preesistente

- calo della carica virale HIV $>\log _{10}$

Criteri minori

- aumento della conta delle CD4+ $\geq 25$ cellule $/ \mu 1$

- dimostrazione bioptica di infiammazione granulomatosa oppure di risposta infiammatoria eccessiva 
zioni e procedure terapeutiche, un miglioramento dei sintomi, performance e qualità della vita. Tuttavia, sono solo pochi i casi clinici descritti di utilizzo dei corticosteroidi in caso di IRIS associata a tubercolosi con manifestazioni a carico del sistema nervoso centrale, compressione tracheale da linfoadenomegalie e sindrome da distress ventilatorio dell'adulto..$^{29-31}$

Per quanto riguarda altri agenti immunomodulatori, gli inibitori del TNF- $\alpha$ si sono dimostrati utili nei casi refrattari agli steroidi. Vi è un caso segnalato ${ }^{32}$ di un paziente affetto da tubercolosi miliare trattato efficacemente con antimicrobici, che ha in seguito sviluppato lesioni paradosse a linfonodi ed encefalo, refrattarie sia a corticosteroidi ad alte dosi che alla ciclofosfamide, ma che hanno poi risposto ad infliximab. ${ }^{32}$

In virtù delle loro attività immuno-modulatoria e anti-infiammatoria per azione sulle cellule Th1, Th2, Th17 e Tregs, di recente è stato suggerito l'utilizzo potenziale delle statine nel trattamento della IRIS ma non sono segnalate ancora esperienze cliniche al riguardo. ${ }^{33,34}$

Considerando che mancano linee guida standardizzate per il management terapeutico della IRIS, la prevenzione gioca un ruolo fondamentale. Gli interventi preventivi dovrebbero essere indirizzati sia a ridurre il rischio di sviluppare la sindrome che ad attenuarne la gravità. È opportuno quindi: a) iniziare la terapia antiretrovirale in una fase molto precoce della malattia da HIV, quando la conta delle cellule $\mathrm{CD} 4+$ è superiore a 200 cellule $/ \mu \mathrm{l} ; \mathrm{b}$ ) eseguire uno screening pre-HAART per la presenza di infezioni opportunistiche; c) trattare in modo ottimale eventuali infezioni con tempi, dosi e modalità efficaci prima di iniziare la terapia antiretrovirale; d) tener conto che terapie immunosoppressive e/o immunomodulatorie possono scatenare una IRIS quando la malattia di base sembra rispondere bene. ${ }^{9,25-27,35}$

\section{Esperienza personale}

L'osservazione è relativa ad una paziente di 36 anni giunta alla nostra osservazione nel 2015 per oliguria ed edemi declivi. In anamnesi vi era una diagnosi (20 anni prima circa) di crioglobulinemnia policlonale HCV correlata. Nel 2005 comparsa di sindrome nefrosica associata ad ipertensione arteriosa e vasculite cutanea; in quella epoca erano già evidenti anche segni bioumorali di epatopatia cronica evolutiva. La paziente veniva quindi sottoposta a trattamento con steroidi, ribavirina ed interferone ma con risposta solo parziale sul piano clinico-laboratoristico. In epoca successiva, venivano effettuati vari tentativi con altri farmaci quali ciclosporina ed azatioprina a scopo dose-sparing degli steroidi senza mai riuscire però a scendere mai al di sotto di $20-25 \mathrm{mg}$ di prednisone/die. Al momento della nostra osservazione la pa- ziente si presentava in condizioni generali scadute e lamentava dispnea da sforzo, astenia marcata, associate a pallore di cute e mucose, edemi declivi, versamento pleuro-pericardico, ipertensione arteriosa, porpora palpabile arti inferiori ed epatomegalia. Gli esami ematochimici rilevavano proteinuria di grado marcato, anemia normocromica, insufficienza renale progressiva ed un criocrito $>5 \%$.

Veniva instaurata terapia di supporto generale associata a dosi adeguate di diuretici e steroidi $(75 \mathrm{mg}$ prednisone) senza risposte di rilievo. A questo punto, considerando la grave epatopatia che controindicava l'utilizzo della ciclofosfamide, si decideva di sottoporre la paziente ad un ciclo di trattamento con steroidi ad alte dosi (metilprednisolone $500 \mathrm{mg}$ e.v. per $3 \mathrm{gg}$ ), senza riuscire ad elicitare però alcuna risposta significativa. Si assisteva nel tempo ad un progressivo peggioramento clinico e dei dati di laboratorio; veniva pertanto somministrato rituximab alla dose di $100 \mathrm{mg}$, e.v. come prima dose in uno schema che prevedeva una seconda somministrazione a 6 mesi. Nei giorni successivi si assisteva ad un progressivo miglioramento dei parametri di laboratorio e della sintomatologia clinica. La paziente veniva quindi dimessa in quarta settimana ed avviata al follow up ambulatoriale. A tre mesi dalla dimissione comparsa di febbre alta continua, dispnea ingravescente, compromissione dello stato generale e grave astenia con anemizzazione normocromica. La paziente veniva di nuovo ricoverata; all'ingresso si presentava in scadute condizioni generali con insufficienza renale ingravescente. Veniva eseguita TC ad alta risoluzione del torace che mostrava un interessamento diffuso dell'interstizio polmonare con grave sindrome disventilatoria ipossiemica-ipercapnica secondaria (Figure 2 e 3). La paziente veniva sottoposta ad una politerapia complessa comprendente antibiotici ed antifungini, un nuovo ciclo di steroidi ad alte dosi e plasmaferesi, senza al-

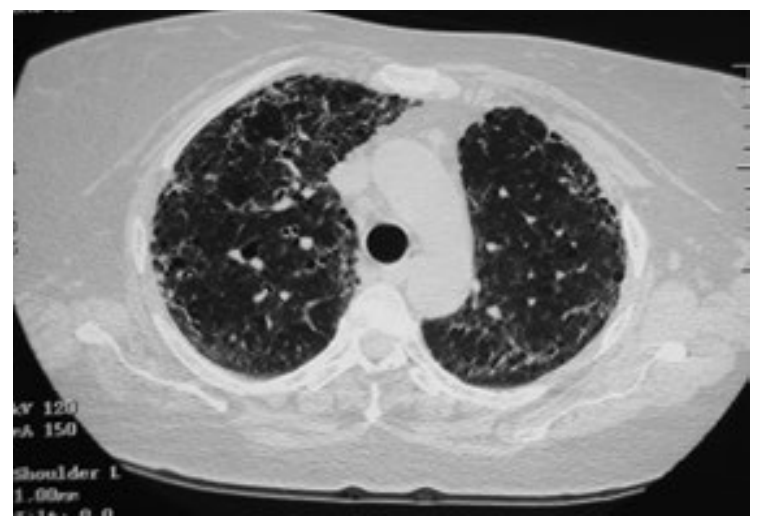

Figura 2. Diffuso interessamento dell'interstizio polmonare bilaterale. 


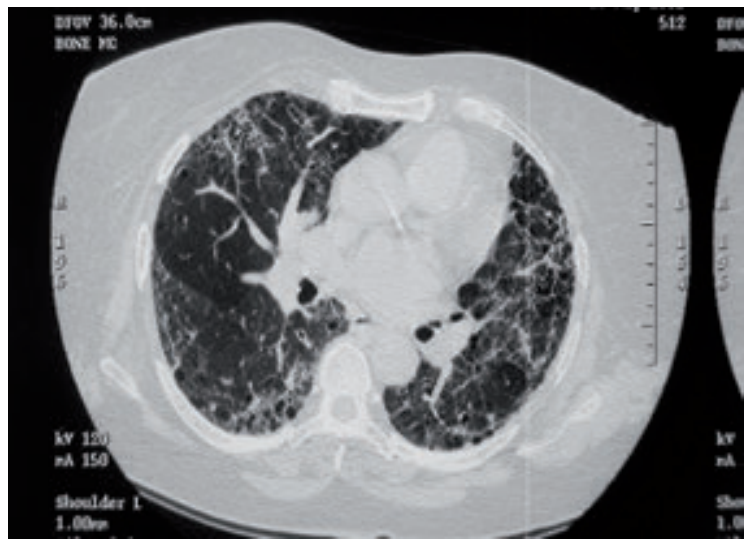

Figura 3. Scansione più bassa mostrante un diffuso ispessimento dell'interstizio polmonare con aspetto a nido d'ape (honeycombing).

cuna risposta positiva. Per l'aggravamento progressivo delle condizioni cliniche, la paziente veniva poi trasferita durante un turno notturno in area rianimativa dove veniva sottoposta ad intubazione oro-tracheale; nelle ore successive si assisteva ad un ulteriore peggioramento con decesso in quindicesima giornata di ricovero per multi-organ-failure.

In Letteratura (principali banche-dati della produzione scientifica occidentale) vi è un solo caso simile segnalato al dicembre 2016 in un paziente in cui il rituximab era stato utilizzato per trattare un linfoma refrattario. ${ }^{36}$

\section{Bibliografia}

1. French MA, Price P, Stone SF. Immune restoration disease after antiretroviral therapy. AIDS 2004; 18:1615-25

2. Shelburne SA, Visnegarwala F, Darcourt J, Graviss EA, Giordano TP, et al. Incidence and risk factors for immune reconstitution inflammatory syndrome during highly active antiretroviral therapy. AIDS 2005; 19 : 399-406

3. Breton G, Duval X, Estellat C, Poaletti X, Bonnet D, et al. Determinants of immune reconstitution inflammatory syndrome in HIV type-1infected patients with tuberculosis after initiation of antiretroviral therapy. Clin Infect Dis 2004 ; 39:1709-12

4. Ratnam I, Chiu C, Kandala NB, Easterbrook PJ. Incidence and risk factors for immune reconstitution inflammatory syndrome in an ethnically diverse HIV type 1-infected cohort. Clin Infect Dis 2006; 42:418-427

5. Shelburne SA 3rd, Hamill RJ, Rodriguez-Barradas MC. Immune reconstitution inflammatory syndrome: emergence of a unique syndrome during highly active antiretroviral therapy. Medicine (Baltimore) 2002; 81:213-227

6. Price P, Keane NM, Stone SF, Cheong KY, French MA. MHC haplotypes affect the expression of opportunistic infections in HIV patients. Hum Immunol 2001; 62:157-164
7. Sun HY, Singh N. Immune reconstitution inflammatory syndrome in non-HIV immunocompromised patients. Curr Opin Infect Dis 2009; 22: 394-402

8. van Lier DP, Janssen NA, Snoeren MM, VerweiJ PE, Blijlevens NM, van der Veledn WJ. Severe inflammation during recovery from neutropenia: the immune reconstitution inflammatory syndrome following chemotherapy. Ned Tijdschr Geneeskd 2015; 159: 89-98

9. French MA, King Ms, Tschampa JM. Immune Reconstitution Inflammatory Syndrome: A reappraisal. Clin Inf Dis 2009; 48:101-7

10. Gupta M, Jafri K, Sharim R, Silverman S, Sindher SB, Shahane A, Kwan M. Immune reconstitution inflammatory syndrome associated with biologic therapy. Curr Allergy Asthma Rep 2015; 15: 499-505

11. Tanaka T, Sekine A, Tsunoda Y, Takoi H, Lin SY, Hayasihara K, Saito T. Central nervous system manifestations of tuberculosis-associated immune reconstruction inflammatory syndrome during adalimumab therapy: a case report and review of the literature. Intern Med 2015; 54:847-51

12. Seddiki N, Sasson SC, Santer B, et al. Proliferations of weakly suppressive regulatory CD4+ T cells is associated with over-active CD4+ T cell responses in HIV-positive patients with mycobacterial immune restoration disease. Eur J Immunol 2009; 39:391-403

13. Haddow LJ, Dibben O, Moosa MY, Borrow P, Easterbrook PJ. Circulating inflammatory biomarkers can predict and characterize tuberculosis-associated immune reconstitution inflammatory syndrome. AIDS 2011; 25:1163-74

14. Meintjes G, Lawn SD, Scano F, Maartens G, French MA, Worodria W et al. International Network for the study of HIV-associated IRIS. Tuberculosis-associated immune reconstitution inflammatory syndrome: case definitions for use in resource-limiting settings. Lancet Infect Dis 2008; 8:516-23

15. Lai RP, Meintjes G, Wilkinson RJ. HIV-1 tuberculosisassociated immune reconstitution inflammatory syndrome. Semin Immunopathol 2016; 38:185-98

16. Robertson J, Meier M, Wall J, Ying J, Fichtenbaum CJ. Immune reconstitution syndrome in HIV: validating a case definition and identifying clinical predictors in persons initiating antiretroviral therapy. Clin Infect Dis 2006; 42:1639-46

17. Porter BO, Ouedraogo GL, Hodge JN. d-Dimer and CRP levels are elevated prior to antiretroviral treatment in patients who develop IRIS. Clin Immunol 2010; $136: 42-50$

18. Boulware DR, Meya DB, Bergemann TL, Wiesner DL, Rhein J, Musubire A, et al. Clinical features and serum biomarkers in HIV immune reconstitution inflammatory syndrome after cryptococcal meningitis: a prospective cohort study. PLoS Med 2010;7: e1000384

19. Tadokera R, Meintjes G, Skolimowska KH, Wilkinson KA, Matthews K, Seldon R, et al. Hypercytokinaemia accompanies HIV-tuberculosis immune reconstitution inflammatory syndrome. Eur Respir J. 2011;37:1248-59.

20. Garcia Vidal C, Rodriguez Fernandez S, Martinez Lacasa J, et al. Paradoxical response to antituberculous therapy in infliximab-treated patients with disseminated tuberculosis. Clin Infect Dis 2005; 40:756-759.

21. Lortholary O, Fontanet A, Mémain N, Martin A, Sitbon 
K, Dromer F; French Cryptococcosis Study Group. Incidence and risk factors of immune reconstitution inflammatory syndrome complicating HIV-associated cryptococcosis in France. AIDS. 2005; 19: 1043-9

22. Lawn SD, Myer L, Bekker LG, Wood R. Tuberculosisassociated immune reconstitution disease: incidence, risk factors and impact in an antiretroviral treatment service in South Africa. AIDS 2007; 21:335-41

23. Shelburne SA, Visnegarwala F, Darcourt J, Graviss EA, Giordano TP, White AC, Jr, et al. Incidence and risk factors for immune reconstitution inflammatory syndrome during highly active antiretroviral therapy. AIDS 2005; 19:399-406

24. Marais S, Wilkinson RJ, Pepper DJ, Meintjes G. Management of patients with the immune reconstitution inflammatory syndrome. Curr HIV/AIDS Rep 2009; 6:162-171

25. Knysz B, Gladysz A. Immune reconstitution disease: is it possible to establish recommendations? Postepy Hig Med Dosw 2007; 61:220-5.

26. Meintjes G, Lynen L. Prevention and treatment of the immune reconstitution inflammatory syndrome. Curr Opin HIV AIDS 2008; 3: 468476

27. Klotz SA, Woldemicheal MG, Mitku MW, Handrich M. Immune Reconstitution Inflammatory Syndrome in a resource-poor setting. J Int Assoc Phys AIDS Care 2009;8:122-7.

28. Meintjes G, Wilkinson RJ, Morroni C, Pepper DJ, Rebe K, Rangaka MX, Oni T, Maartens G. Randomized placebo-controlled trial of prednisone for paradoxical tuberculosis-associated immune reconstitution inflammatory syndrome AIDS $2010 ; 24: 2381-90$

29. Goldsack NR, Allen S, Lipman MC. Adult respiratory distress syndrome as a severe immune reconstitution di- sease following the commencement of highly active antiretroviral therapy. Sex Transm Infect 2003; $79: 337-8$.

30. Buckingham SJ, Haddow LJ, Shaw PJ, Miller RF. Immune reconstitution inflammatory syndrome in HIV-infected patients with mycobacterial infections starting highly active anti-retroviral therapy. Clin Radiol 2004; 59: 505-13

31. Crump JA, Tyrer MJ, Lloyd-Owen SJ, Han LY, Lipman MC, Johnson MA. Military tuberculosis with paradoxical expansion of intracranial tuberculomas complicating human immunodeficiency virus infection in a patient receiving highly active antiretroviral therapy. Clin Infect Dis. 1998 Apr; 26(4):1008-9.

32. Blackmore TK, Manning L, Taylor WJ, Wallis RS. Therapeutic use of infliximab in tuberculosis to control severe paradoxical reaction of the brain and lymph nodes. Clin Infect Dis 2008; 47 :e83-85

33. Falagas ME, Makris GC, Matthaiou DK, Rafailidis PI. Statins for infection and sepsis: a systematic review of the clinical evidence. J Antimicrob Chemother 2008; 61:774-785

34. Maher BM, Dhonnchu TN, Burke JP, Soo A, Wood AE, Watson RW. Statins alter neutrophil migration by modulating cellular Rho activity--a potential mechanism for statins-mediated pleotropic effects? J Leukoc Biol 2009; 85:186-193

35. Johnson T, Nath A. Neurological complications of immune reconstitution in HIV-infected populations. Ann N Y Acad Sci 2010; 1184: 106-20

36. Canaani J, Amit S, Ben-Era J, Pour MC, Sarid N, Lerman $\mathrm{H}$, Perry $\mathrm{C}$ et al. Paradoxical immuno reconstitution inflammatory syndrome associated with rituximab-containing regimen in a patient with lymphoma. J Clin Oncol 2013; 10: 31 (e178-80). 


\title{
Le malattie autoinfiammatorie
}

\author{
Marco Gattorno, ${ }^{1}$ Antonio Brucato ${ }^{2}$ \\ ${ }^{1}$ UO Pediatria II, Istituto G. Gaslini, Genova; ${ }^{2}$ Medicina Interna, Ospedale Papa Giovanni XXIII, Bergamo, Italia
}

\section{Introduzione}

Le malattie autoinfiammatorie sono un gruppo di patologie su base ereditaria, secondarie a mutazioni di geni che codificano per proteine coinvolte nella immunità innata $\mathrm{e}$ che regolano la risposta infiammatoria (1). Lo studio dei meccanismi eziopatogenetici legati alle mutazioni delle diverse proteine coinvolte nella risposta infiammatoria ha permesso una classificazione funzionale di queste malattie (Tabella 1)(2). Oltre a classico quadro delle febbri ricorrenti o periodiche, inizialmente identificate con il concetto di malattie autoinfiammatorie, lo spettro dei quadri clinici di presentazione di queste malattie si è notevolmente ampliato nel corso degli ultimi anni; forme che possono essere incontrate anche negli adulti possono essere per es. febbre mediterranea familiare, TRAPS, e la sindrome di Muckle-Wells.

\section{Le febbri periodiche}

\section{La febbre mediterranea familiare}

La febbre mediterranea familiare (FMF) è la prima malattia autoinfiammatoria ad essere stata identificata dal punto di vista molecolare, tramite l'identificazione del gene MEFV $(3,4)$. È caratterizzata clinicamente da brevi episodi ricorrenti di febbre e sierosite (pleurite, peritonite o pericardica) e monoartriti. È ampiamente diffusa nelle popolazioni Mediterranee con una prevalenza di mutazioni del gene MEFV, tra 1/200 e 1/1000 individui. È particolarmente elevata nella popolazione ebrea non ashkenazita, turca, armena e

Corrispondente: Antonio Brucato, Medicina Interna, Ospedale Papa Giovanni XXIII, Piazza OMS 1, 24127 Bergamo, Italia. Tel.: +39.0352673456.

E-mail: albrucato@asst-pg23.it

Articolo pubblicato secondo la Creative Commons Attribution NonCommercial 4.0 License (CC BY-NC 4.0).

(C) Copyright M. Gattorno e A. Brucato, 2017

Licensee PAGEPress, Italy

QUADERNI - Italian Journal of Medicine 2017; 5(7):161-171 araba ed è tuttavia sempre più spesso riconosciuta anche in Italia, Grecia e Spagna (5).

L'esordio è generalmente precoce, nelle prime 2 decadi di vita. Il fenotipo I, il più caratteristico, si manifesta con attacchi generalmente mensili o bimensili di febbre e sierosite, che durano 1-4 giorni e si risolvono spontaneamente. Possibili fattori scatenanti possono essere lo stress, l'esposizione al freddo, i pasti ricchi in grassi, le infezioni, alcuni farmaci e il ciclo mestruale. Gli attacchi, talora preceduti da sintomi prodromici (mialgia, cefalea, nausea, dispnea, artralgia, lombalgia, astenia e ansia) di durata variabile e si manifestano con febbre elevata $\left(38-40^{\circ}\right.$, della durata di 12-17 ore) refrattaria agli antibiotici, dolore addominale diffuso o localizzato (spesso simile all'addome acuto), costipazione (qualche volta diarrea nei bambini), artralgia (grandi articolazioni), artrite (articolazioni degli arti superiori/inferiori) e dolore toracico tipo pleuritico e/o pericarditico. Alcuni pazienti possono presentare un eritema erisipeloide agli arti inferiori.

L'amiloidosi tipo AA, con interessamento renale, è la più grave complicanza e si manifesta dopo un lungo periodo di malattia non trattata. Il cosidetto fenotipo 2, estremamente raro, si presenta con amiloidosi, quale primo e unico sintomo.

Il gene $M E F V$ codifica per la proteina pirina/marenostrina. La trasmissione della malattia è autosomica recessiva. La mutazione M694V in omozigosi si associa alla forma clinica più severa con maggiore predisposizione a sviluppare l'amiloidosi $(5,6)$. Il ruolo fisiologico della Pirina è tuttora oggetto di studio. Sicuramente la proteina è in grado di interagire con una serie di proteine intracitoplasmatiche (ASC, caspasi1) che illustreremo nel paragrafo delle Criopirinopatie, che regolano l'attivazione della risposta infiammatoria, a iniziare da una delle più potente citochina prodotta dai monociti e macrofagi, l'interleuchina (IL)-1. Il difetto molecolare legato alla presenza di mutazioni del gene MEFV induce una risposta pro-infiammatoria diretta attivando la secrezione di IL-1 (Tabella 1)(7,8).

Circa il 25\% dei pazienti presenta un genotipo incompleto con una sola mutazione in eterozigosi. Esiste inoltre un gruppo di $5-10 \%$ di pazienti con caratteristiche cliniche compatibili per FMF, ma negativi per mutazioni del gene MEFV. In base ai criteri di Tel-Ha- 
shomer, la diagnosi clinica è fondata su 2 dei criteri maggiori :1) febbre con sierosite, 2) amiloidosi AA, 3) efficacia della colchicina) oppure su 1 maggiore e 2 minori (i. attacchi ricorrenti di febbre, ii. eritema erisipela-like, iii. familiarità per FMF). Recentemente sono stati sviluppati nuovi criteri clinici per l'FMF e per le altre forme di febbre periodica basati sull'evidenza dei casi raccolti su un vasto registro Internazionale, denominato Eurofever (9).

Il farmaco comunemente utilizzato per la prevenzione degli attacchi è la colchicina che riduce o elimina gli attacchi e previene l'amiloidosi tipo A; la dose varia da $0,5 \mathrm{mg}$ in età pediatrica fino ad arrivare a $2 \mathrm{mg}$ negli adulti, soprattutto nei soggetti con mutazioni più severe. Ė considerato rischioso negli adulti superare la dose massime di $3 \mathrm{mg} / \mathrm{die}$. Il farmaco deve essere assunto regolarmente a vita: la colchicina migliora decisamente la qualità della vita dei pazienti. Per il controllo sintomatico di un attacco, può essere somministrato un antinfiammatorio non steroideo. La colchicina può ridurre l'assorbimento della vitamina B12 e non deve essere assunta insieme ai macrolidi, al diltiazem, al pompelmo, melograno e ciclosporina, perché in tal caso, può causare grave tossicità che si manifesta con rabdomiolisi, alopecia e soppressione del midollo osseo. La colchicina non è teratogena ed è compatibile con la gravidanza e l'allattamento Una percentuale tra il $30-40 \%$ dei pazienti con FMF pre- senta una risposta parziale alla Colchicna. In questi pazienti ha dato ottimi risultati il trattamento con gli inibitori di IL1 $\beta$, come l'Anakinra, o il Canakinumab (10).

Nei pazienti con amiloidosi renale, ormai sempre più rari dopo l'avvento della colchicina, possono rendersi necessari la dialisi e il trapianto renale.

\section{TRAPS: Sindrome Autoinfiammatoria Associata al recettore del TNF}

La sindrome TRAPS (Tumor necrosis factor Receptor Associated Periodic Syndrome) è una malattia autosomica dominante legata a mutazioni del gene TNFRSF1A, che codifica per il recettore 1A del Tumor Necrosis Factor (TNF) (11).

La TRAPS inizialmente fu denominata Febbre Familiare Iberniana, poiché identificata originariamente in famiglie di origine irlandese e scozzese. In realtà, le mutazioni del gene TNFRSF1A sono state riscontrate in molte altre popolazioni, inclusa quella italiana, con ascendenza mediterranee (12).

Finora sono state registrate circa 150 varianti di sequenza del gene TRAPS, il 60\%delle quali sicuramente associate con un fenotipo TRAPS tipico. Per la maggior parte si tratta di mutazioni missenso, che derivano da sostituzioni di un singolo amminoacido nei domini ricchi di cisteina (CRD), CRD1, CRD2, or

Tabella 1. Classificazioni delle malattie autoinfiammatorie ereditarie sulla base dei meccanismi patogenetici.

\begin{tabular}{|c|c|c|c|}
\hline 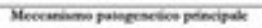 & Shatetis & 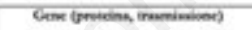 & 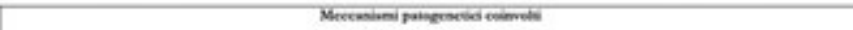 \\
\hline \multirow[t]{5}{*}{ Ieflummanemepatie } & an & 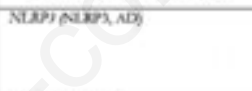 & 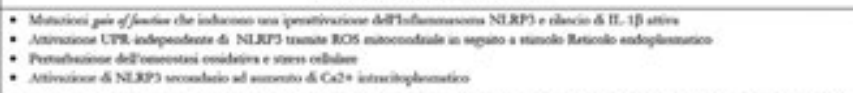 \\
\hline & hat & 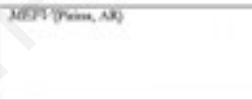 & 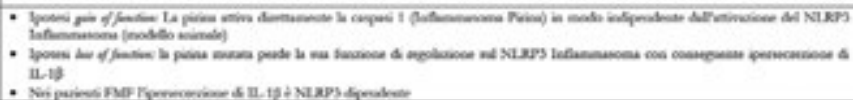 \\
\hline & P.WA & 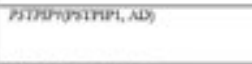 & 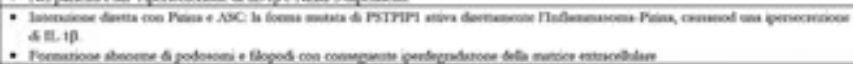 \\
\hline & F्C: & 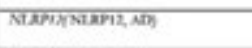 & 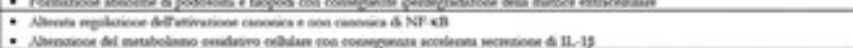 \\
\hline & Nacisus & 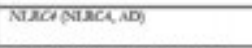 & 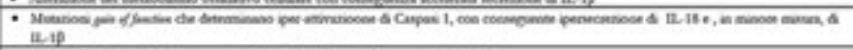 \\
\hline \multirow[t]{2}{*}{ 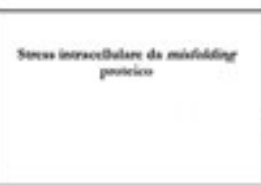 } & news & 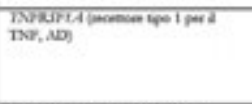 & 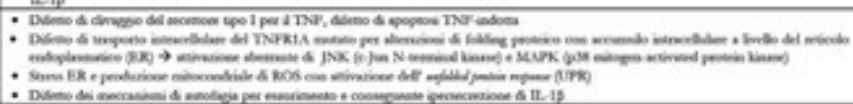 \\
\hline & $\operatorname{ligh}_{\log }$ & 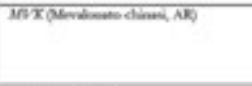 & 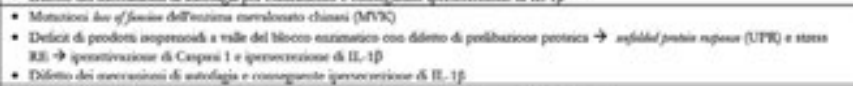 \\
\hline \multirow{4}{*}{ 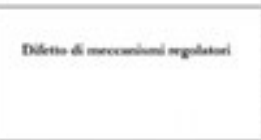 } & Deber 6 Maned & DWNanN2,ak & 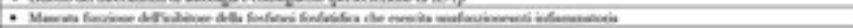 \\
\hline & Daks & 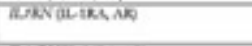 & 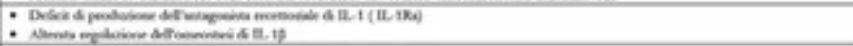 \\
\hline & DemL & 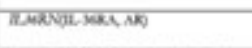 & 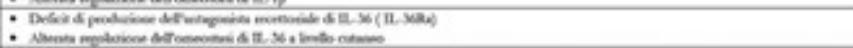 \\
\hline & MDa a & 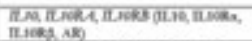 & 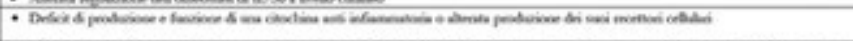 \\
\hline \multirow[b]{2}{*}{ 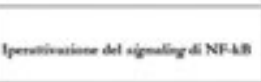 } & $\rightarrow=6 \mathrm{ken}$ & 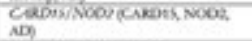 & 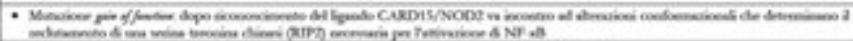 \\
\hline & CANes & 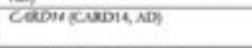 & 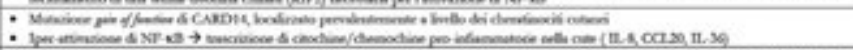 \\
\hline \multirow[t]{3}{*}{ letelknompoutit } & sestencasots & 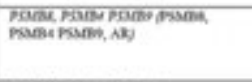 & 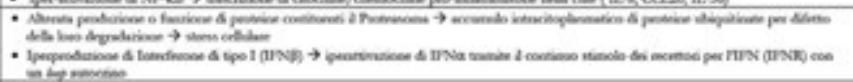 \\
\hline & Mn & 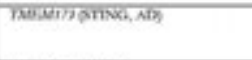 & 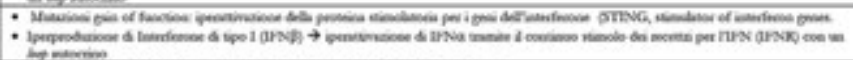 \\
\hline & 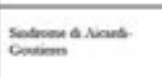 & 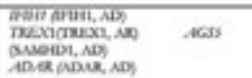 & 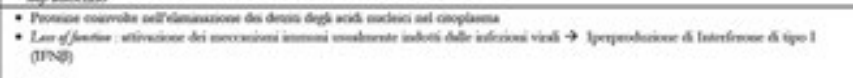 \\
\hline 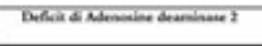 & Dewa & 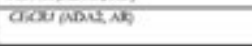 & 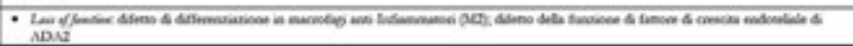 \\
\hline
\end{tabular}


CRD3 del dominio extracellulare del recettore di tipo I del TNF (TNFR1 op55TNFR). Questi CRD sono coinvolti nella formazione del legame disolfuro (fondamentali per la struttura tridimensionale del TNFRSF1A) e nel ripiegamento della porzione extracellulare della proteina (13). Il recettore I del TNF rappresenta uno dei 2 recettori cellulari del TNF, che insieme all'IL-1 $\beta$ rappresenta la citochina infiammatoria più potente dell'immunità innata. Oltre che a indurre la trascrizione di geni per proteine pro-infiammatorie tramite l'attivazione del fattore di trascrizione NF-kB, il recettore tipo I è anche cruciale per l'induzione della morte cellulare (apoptosi) delle cellule infiammatorie. La liberazione dei 2 recettori dalla membrana cellulare rappresenta un importante meccanismo di modulazione dell'azione pro-infiammatoria del TNF in quanto i recettori solubili sono in grado di legare il TNF in circolo impedendone il legame con i recettori di membrana. Attualmente vi sono almeno tre meccanismi implicati nella patogenesi della TRAPS: 1) difetto di clivaggio (shedding) dalla superficie cellulare, e quindi di capacità di inibizione del TNF (11), 2) difetto di apoptosi cellulare indotta da TNF $(14,15), 3)$ difetto di traffico intra-cellulare dei recettori mutati con accumulo nel reticolo endoplasmatico e induzione di stress cellulare riconducibile ai meccanismi di unfolded protein response (16) (2). Tale condizione stimola l'attivazione e la secrezione di citochine pro-infiammatorie, tra cui quella maggiormente espressa è l'IL-1 $\beta$.

Le mutazioni che coinvolgono i residui di cisteina hanno una più elevata penetranza e sono associate ad un fenotipo più aggressivo rispetto alle mutazioni che non coinvolgono le $\mathrm{CRD}$. Al contrario altre mutazioni a bassa penetranza, come la R92Q e la P46L sono associate generalmente ad un quadro clinico più lieve (13). In particolare, il significato patogenetico delle varianti R92Q e P46L, non è ancora stato completamente definito. La R92Q si comporta come un polimorfismo funzionale, essendo presente nell' $1,2-4 \%$ della popolazione normale. La maggior parte dei pazienti con mutazione R92Q mostra un decorso più mite, con un elevato tasso di risoluzione spontanea o un miglioramento clinico e una prevalenza nettamente inferiore di amiloidosi secondaria. Queste osservazioni supportano l'idea che tale variante rivesta un ruolo patogenetico limitato: grande prudenza dovrebbe essere esercitata nell'interpretazione di un'analisi molecolare positiva per queste varianti in pazienti con forme infiammatorie indefinite che non abbiano i caratteri tipici di una TRAPS (17).

Gli attacchi della TRAPS sono caratterizzati da episodi febbrili di lunga durata (7-20 giorni). La febbre è ondulante e con una frequenza ridotta (solitamente 2-4 episodi all'anno). Vi sono manifestazioni cutanee eterogenee: la lesione distintiva è una placca eritematosa, tumefatta, calda di varie dimensioni con bordi sfumati. Tende a coinvolgere gli arti superiori e inferiori ma anche la regione pettorale. Ha un decorso migrante dalla radice all'estremità degli arti. Altri sintomi associati all'attacco febbrile sono il dolore addominale (secondario a sierosite), le mialgie molto dolorose, che rappresentano l'altra manifestazione tipica della TRAPS e sono spesso associate ad un un franco quadro di fascite monocitaria. Infine possono essere presenti sintomi oculari, come edema periorbitario e congiuntivite, dolore toracico e scrotale. Anche la TRAPS, come la FMF, si associa ad amiloidosi renale, come complicanza tardiva, nei soggetti portatori di mutazioni ad alta penetranza a carico del gene TNFRSF1A, con malattia non riconosciuta o non trattata per lungo tempo (12).

Cicli di steroide per os attenuano la durata e la severità degli episodi quando somministrati al loro inizio dell'attacco. Nelle forme più gravi della malattia, $i$ segni clinici e bioumorali di infiammazione tendono a cronicizzarsi richiedendo l'uso giornaliero di steroidi. La Colchicina non è utile a prevenire la ricorrenza degli attacchi di TRAPS, anche se si è rivelata talvolta efficace nei soggetti portatori di mutazioni R92Q e P46L. I FANS trovano ampio impiego per gli attacchi lievi. Tra i farmaci biologici sono stati per primi utilizzati gli inibitori del TNF: in particolare l'Etanercept. Tuttavia, la maggior parte dei pazienti con TRAPS presenta una risposta parziale all' Etanercept (18). Al contrario, la terapia con inibitori di IL-1 è invece stata descritta come efficace nel controllare gli attacchi febbrili e la flogosi cronica in diversi studi $(10,19,20)$.

\section{Deficit di Mevalonato-chinasi associato a febbre periodica}

La febbre periodica associata al deficit di mevalonato-chinasi (ancora denominata Sindrome da IperIgD) è una malattia a trasmissione autosomica recessiva secondaria alla mutazione del gene $M V K$ che codifica per l'enzima mevalonato-chinasi $(21,22)$. Si tratta del secondo enzima nella via di sintesi degli isoprenoidi e del colesterolo. Il deficit completo di questo enzima causa una grave sindrome metabolica, la mevalonico aciduria (MA), caratterizzata da ritardo psicomotorio, difetto di crescita, progressiva atassia cerebellare, dimorfismi, progressiva disabilità visiva e ad un severo quadro infiammatorio cronico. Il deficit parziale della funzione enzimatica determina solo un quadro febbrile ricorrente ed è associato ad uno sviluppo psico-motorio normale e all'assenza di dimorfismi. È stato dimostrato che la riduzione dei metaboliti a valle del blocco enzimatico è in grado di indurre una ipersecrezione di IL-1 $\beta$ da parte dei monociti (23).

L'esordio della malattia è invariabilmente in età 
pediatrica, nei primissimi anni di vita. Gli episodi febbrili hanno una durata di circa 4-6 giorni e sono accompagnati da un diffuso malessere, dolore addominale associato a vomito e/o diarrea, linfadenopatia generalizzata, splenomegalia. Può essere presente anche rash cutaneo che può manifestarsi come lesioni maculo-papulari o eritematose diffuse. L'elevazione dei livelli plasmatici di $\operatorname{IgD}$ che è stato per lungo tempo considerato il marker diagnostico di questa malattia, ha tuttavia una bassa sensibilità e specificità. Raramente l'amiloidosi renale può rappresentare una possibile complicanza a lungo termine della malattia (24). Gli attacchi febbrili rispondono generalmente alla somministrazione di brevi cicli di steroide. Tuttavia a causa del perpetuarsi degli episodi febbrili alcuni pazienti possono richiedere un trattamento di fondo con farmaci biologici anti-TNF e anti-IL1 (25).

\section{Le criopirinopatie}

Le Criopirinopatie, o sindromi periodiche associate alla criopirina (cryopyrin associated periodic syndrome, CAPS) sono un gruppo di malattie infiammatorie ereditarie, trasmesse con carattere autosomico dominante, costituito dalla sindrome autoinfiammatoria familiare da freddo (FCAS, familial cold-induced autoinflammatory syndrome), dalla sindrome di Muckle-Wells (MWS) e dalla sindrome CINCA (chronic infantile neurological cutaneous articular). Il gene responsabile è il NLRP3 che codifica per una proteina denominata criopirina (26). NLRP3 unitamente ad altre proteine citoplasmatiche (ASC e Caspasi 1) forma il complesso intracitoplasmatico denominato Inflammasoma, che svolge un ruolo cruciale nel clivaggio della forma inattivata di IL-1 $\beta$ (proIL1 $\beta$ ) e nella secrezione della forma attiva di questa potente proteina pro-infiammatoria (27) (Figura 1). Le mutazioni di NLRP3 determinano una gain of function (guadagno di funzione) che induce una iperattivazione del sistema dell'Inflammasoma, con conseguente ipersecrezione di IL-1 $\beta$ in circolo (Figura 1) (28). Le mutazioni a carico del gene NLRP3 sono trasmesse con modalità autosomica dominante (anche se in un'elevata percentuale di pazienti si tratta di mutazioni de novo, insorte nella cellula germinale). Recentemente sono infine stati evidenziati dei pazienti CAPS negativi per mutazioni germinali di $N L R P 3$, ma portatori di mosaicismi somatici (29). Il fenotipo clinico legato alle mutazioni di NLRP3 è molto vasto (30). La FCAS è caratterizzata da episodi ricorrenti e di breve durata di febbre e rash orticariode, scatenati dall'esposizione al freddo, che tendono ad autolimitarsi nel giro di 2448 ore. Un quadro analogo è stato anche associato a mutazioni di un altro gene appartenetene alla famiglia NLRP, 1'NLRP12.
La sindrome di Muckle-Wells è invece caratterizzata da un quadro infiammatorio sub-cronico associato a rash orticarioide diffuso (Figura 2), artralgie, congiuntivite ed elevazione degli indici di flogosi. I pazienti, nel tempo, possono sviluppare sordità neurosensoriale e amiloidosi ranale.

La sindrome CINCA rappresenta la forma più severa ed è caratterizzata dalla presenza sin dalla nascita un quadro infiammatorio sistemico severo associato a rush cutaneo orticarioide, artrite, displasia scheletrica, severo interessamento del SNC (meningite cronica, ritardo mentale e sordità neurosensoriale) e caratteristici dimorfismi facciali (bozze frontali prominenti, ipoplasia del mento).

L'uso di inibitori di IL-1 come l'antagonista recettoriale di IL-1 (IL1Ra, Anakinra) o l'anticorpo monoclonale (Canakinumab) determinano un rapido e completo controllo delle manifestazioni infiammatorie, migliorando in modo evidente la qualità di vita dei pazienti. La diagnosi precoce e l'avvio tempestivo sono pertanto fondamentale per prevenire nei pazienti le complicanze a lungo termine della malattia.

\section{Malattie piogeniche}

\section{Sindrome PAPA}

La sindrome PAPA (pyogenic sterile arthritis, pyoderma gangrenosum and acne) è una malattia ad ereditarietà autosomica dominante ed esordio precoce, caratterizzata da intensi fenomeni flogistici a livello di cute e articolazioni. È secondaria a mutazioni del gene PSTPIP1, che codifica per la proteina omonima, anche nota come CD2BP1 (CD2-binding protein 1) (31). La proteina PSTPIP1 ha diverse possibili interazioni con altre proteine intra-citoplasmatica (tra cui FASL, CD2). È stato dimostrato che PSTPIP1 può formare un complesso tri-molecolare con Pirina e ASC, in grado di attivare caspasi 1 e pertanto indurre la secrezione di IL-1, che risulta aumentata nei pazienti PAPA in fase attiva di malattia (32). La manifestazione di esordio della malattia è generalmente una artrite piogenica sterile e si caratterizza per ricorrenti episodi infiammatori che mimano un artrite settica infettiva, che risulta peraltro costantemente sterile. L'artrite risponde bene agli steroidi e ai FANS. Più difficile il trattamento delle manifestazioni cutanee più severe, come il pioderma gangrenoso o la acne severa, che compaiono generalmente della seconda decade di vita. Tali manifestazioni sembrano rispondere a terapie biologiche con anti-TNF e anti-IL-1 $(10,32)$.

\section{Sindrome da deficit dell'antagonista del recettore di IL-1 (DIRA)}

La malattia associata al deficit dell'antagonista del recettore di IL-1 (deficency of IL-1 receptor antago- 
nist, DIRA) è una forma ad ereditarietà autosomica recessivasecondaria a mutazioni deleterie del gene $I L 1 R N$, che codifica per l'antagonista del recettore dell'IL-1 (IL-1Ra)(33). L'IL-1Ra antagonizza l'azione pro-infiammatoria dell'IL-1 a livello recettoriale. La sua mancata produzione determina un quadro di flogosi cronica legato ad difetto di omeostasi di IL-1 $\beta$ che in assenza del suo antagonista recettoriale continua a stimolare la cellula tramite il proprio recettore di membrana specifico.

I bambini affetti da sindrome DIRA presentano i primi segni di malattia sin dalla nascita o entro le prime 3 settimane di vita. Il quadro clinico è caratterizzato da una pustolosi cutanea con carattere desquamativo, associata a persistente elevazione degli indici di flogosi e lesioni infiammatorie sterili dell'apparato scheletrico a tipo osteomielite multifocale. Le lesioni ossee sono lesioni osteolitiche circondate da una rima sclerotica; spesso si associa slargamento delle metafisi distali delle ossa lunghe e la presenza di nuclei eterotopici di ossificazione. Vista la patogenesi della malattia, la terapia con l'inibitore ricombinante dell'IL-1 (Anakinra) si è dimostrata efficace nel determinare un rapido miglioramento del quadro clinico, rappresentando di fatto un vero e proprio intervento salva-vita (33).

\section{La sindrome DITRA \\ (deficiency of the IL-36-Receptor Antagonist)}

Una sindrome analoga alla DIRA è stata per la prima volta identificata in un gruppo di famiglie tunisine affette da una forma familiare di psoriasi pustolosa generalizzata. I pazienti erano portatori di mutazioni del gene $I L-36 R N$ che codifica per l'antagonista recettoriale di IL-36 (IL-36Ra), con modalità autosomica recessiva (34). Le mutazioni del gene causano un deficit di produzione e di attività dell'IL36Ra, con la conseguente perdita del ruolo

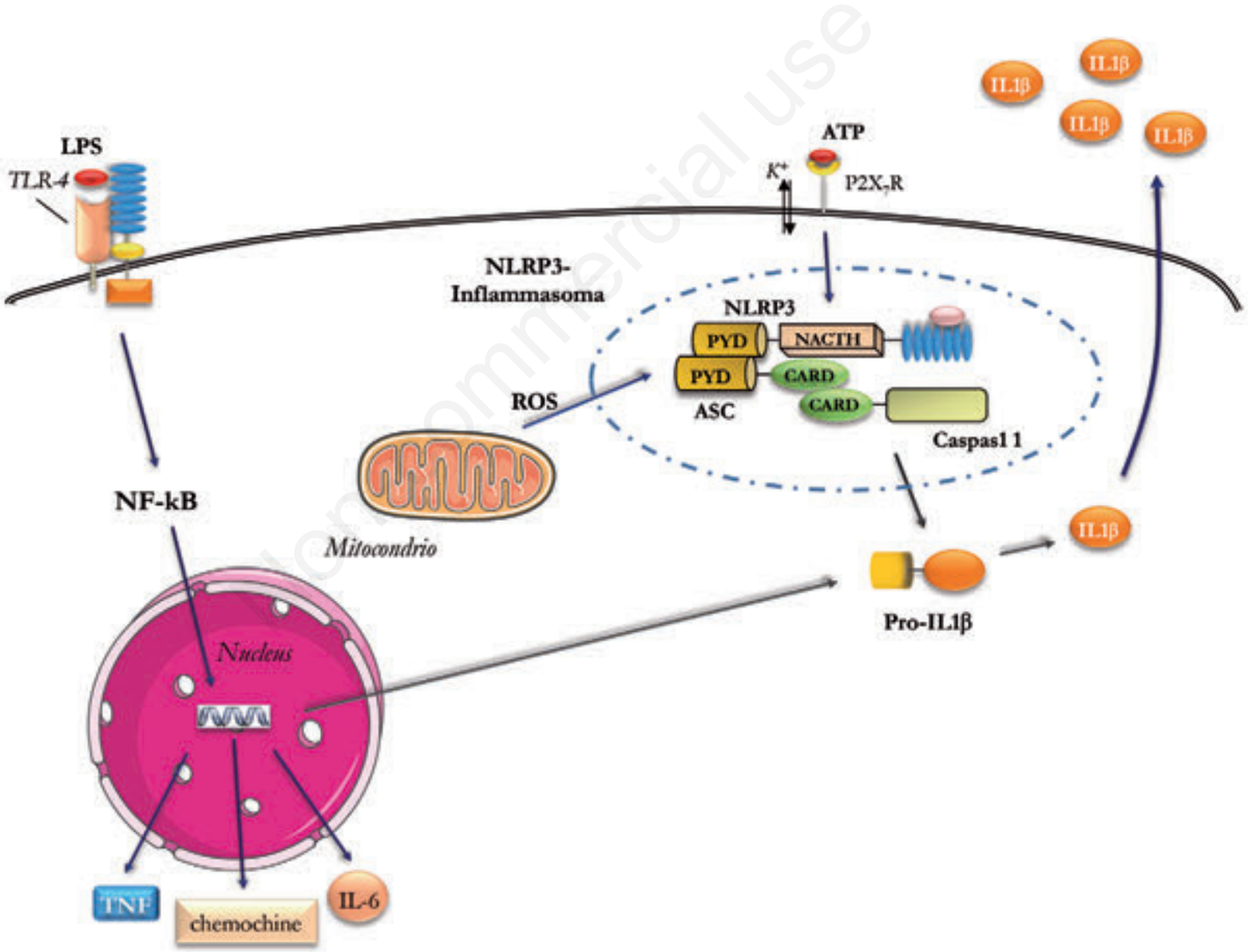

Figura 1. Meccanismi di attivazione del NLRP3-Inflammasoma. Le cellule dell'Immunità innata vengono attivate da uno stimolo esogeno come il lipopolisaccardie (LPS) tramite i Toll-like receptors (TLR) di membrana. Questo stimolo induce

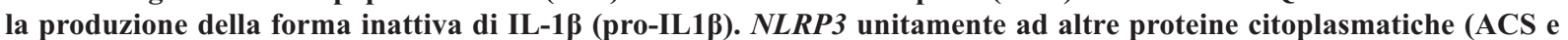
Caspasi 1) forma il complesso intracitoplasmatico denominato Inflammasoma, che svolge un ruolo cruciale nel clivaggio di pro-IL-1 nella forma attiva di $17 \mathrm{kD}$ e della conseguente secrezione nell'ambiente extracellulare. Il NLRP3-Inflammasoma è a sua volta attivato da un secondo segnale, costituito dall'ATP extracellulare (che induce una deplezione di potassio intracellulare) o da ROS (reactive oxyigen species) di origine mitocondriale responsabili dello stress ossidativo cellulare. 
anti-infiammatorio di tale antagonista a livello dei cheratinociti. Tale situazione determina una iperattivazione dell'IL-36 con un meccanismo del tutto analogo a quanto osservabile nel deficit di IL-1Ra causa della DIRA. L'IL-36 appartiene infatti alla famiglia di citochine dell'IL-1 ed il suo antagonista recettoriale ha una evidente omologia di sequenza con l'IL-1Ra.

I pazienti con DITRA presentano episodi ricorrenti di eruzione eritemato-pustolosa a carattere desquamativo associata a febbre elevata ed elevazione degli indici di flogosi. Nel corso degli episodi i pazienti possono andare incontro ad ipovolemia e possibili infezioni intercorrenti, potenzialmente letali (34). Al momento non è purtroppo disponibile un trattamento elettivo per tale condizione. I pazienti rispondo ad alte dosi di steroide per os o per via parenterale e necessitano di un attento sostegno del quadro cardiocircolatorio e copertura antibiotica nel corso delle recidive cutanee. L'uso degli immunosopressori (ciclosporina e metotrexate) e di farmaci biologici (anti-TNF) è del tutto aneddotico (34). Più recentemente è stato descritta in alcuni casi l'efficacia dell'antagonista recettoriale di IL-1 (anakinra) ad alte dosi (35) o dell'anticorpo monoclonale anti IL12/IL-23, Ustekinumab (36).

\section{Sindrome di Majeed}

Rappresenta il disturbo piogenico di gran lunga più raro e descritto al momento esclusivamente in pazienti di origine araba (Giordania e Siria) o Turca. Anche in questo caso la malattia è caratterizzata da una osteomielite multifocale ricorrente che però è tipicamente associata ad una anemia diseritropoietica e ad una dermatite infiammatoria $(37,38)$.

Il quadro osseo è caratterizzato dal lesioni osteolitiche ad esordio precoce, che colpiscono generalmente le metafisi delle ossa lunghe. Tali lesioni sono frequenti e generalmente durature, presentando rare remissioni. L'anemia diseritropoietica è caratterizzata da macrocitosi midollare e periferica; talvolta i valori plasmatici di emoglobina sono tanto bassi da richiedere periodiche trasfusioni. Il quadro cutaneo va dalla sindrome di Sweet (dermatite neutrofilia con lesioni a placche) alla pustolosi cronica.

Un'analisi di linkage ha permesso di identificare la mutazione del gene LPIN2 in due famiglie con tale quadro clinico. Una ottima risposta agli inibitori di IL1 (anakinra o l'anticorpo monoclonale anti-IL1, canakinumab) è stata recentemente segnalata (39).

\section{Malattie granulomatose}

\section{Sindrome di Blau}

La sindrome di Blau o granulomatosi sistemica familiare giovanile è una malattia autosomica dominante secondaria a multazioni del gene CARD15/NOD2, ca- ratterizzata da infiammazione granulomatosa a carico di articolazioni, cute e occhio $(40,41)$. CARD15 è, un membro della famiglia dei Nod-like receptor (NLR) ed è in grado di legare direttamente una struttura comune a diversi batteri, il muramyl dipeptide (MDP), inducendo l'attivazione di NF-kB ed alla conseguente ipersecrezione di citochine pro infiammatorie. L' interessamento articolare si caratterizza per una poliartrite delle piccole articolazioni delle mani, associate a tenosinovite proliferativa che danno alle articolazioni un aspetto particolarmente iperplastico. L'esame istologico mostra tipiche lesioni infiammatorie granulomatose associate alla presenza di cellule giganti multinucleate. L'interessamento cutaneo è caratterizzato da un rash brunastro papulonodulare diffuso o da placche rilevate evidenziabili alla palpazione. L'interessamento oculare rappresenta l'aspetto più severo della malattia, tende a manifestarsi sotto forma di una pan-uveite spesso bilaterale. Diversi pazienti sono stati trattati con steroidi ed immunosoppressori come il Methotrexate e Ciclosporina A con risultati variabili. Segnalazioni aneddotiche suggeriscono un effetto benefico del trattamento con anti-IL1, ma soprattutto degli anticorpi monoclonali anti-TNF (infliximab e adalimumab)(42).

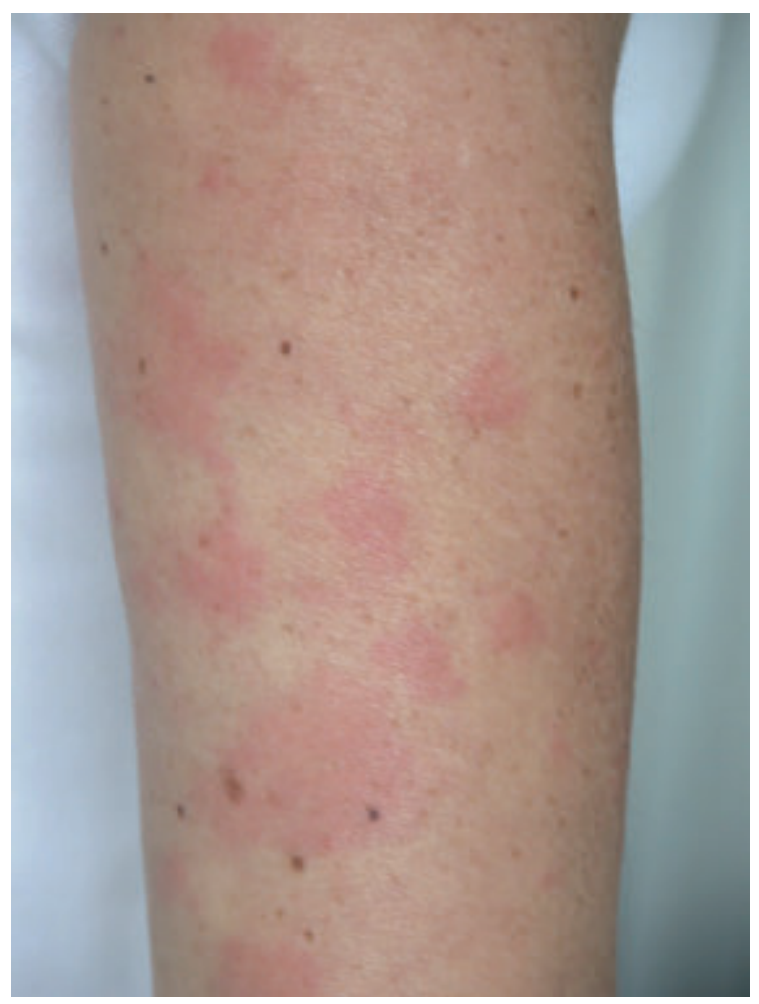

Figura 2. Rash orticaroide in una paziente adulta con sindrome di Muckle-Wells. 
La sindrome DADA2

(Deficit di adenosine deaminasi 2)

Si tratta di una malattia autosomica recessiva scoperta nel 2014 da due studi paralleli che descrivevano alcuni casi sporadici e familiari di diversa etnia (ebrei georgiani, turchi, europei) con un quadro clinico caratterizzato da episodi febbrili ricorrenti ad esordio precoce associati a livedo reticularis ed elevazione degli indici di flogosi $(43,44)$. Alcuni pazienti sviluppavano in età molto precoce degli infarti cerebrali ischemici o emorragici sotto-corticali di dimensioni variabili. In altri casi veniva descritto un quadro di vasculopatia infiammatoria a tipo vasculite, del tutto compatibile con una poliartrite nodosa (PAN) ANCA-negativa, anch'essa ad esordio precoce e a carattere familiare. La malattia è risultata essere secondaria a ad alcune mutazioni deleterie nel gene CECR1, codificante per l'enzima adenosine deaminasi (ADA) 2. ADA2 è una proteina omodimerica altamente glicosilata e secreta nell'ambiente extra-cellulare. La sua funzione è quella di catalizzare la conversione dell'adenosina e della 2deossiadenosina in inosina e 2-deossiinosina. ADA2 ha una omologia con ADA1, un enzima prevalentemente intracitoplasmatico che ha maggiore affinità per adenosina e le cui mutazioni sono associate ad una immunodeficienza severa combinata (SCID). ADA2 è espressa prevalentemente dalle cellule mieloidi, monociti, cellule NK, e linfociti T e B e oltre alla sua attività enzimatica, svolge anche una funzione di fattore di crescita per cellule endoteliali, linfociti e macrofagi (45).

L'assenza di ADA2 è stata associata ad uno sbilanciamento della differenziazione dei macrofagi in senso M1 (macrofagi pro-infiammatori) con un difetto di maturazione dei macrofagi $\mathrm{M} 2$, che hanno invece una funzione anti-infiammatoria (43). Tale condizione proinfiammatorie, unitamente al ruolo di fattore di crescita per le cellule endoteliale potrebbe spiegare l'elettivo trofismo per il danno endoteliale osservato in questa malattia.

I pazienti con deficit di DADA2 possono anche presentare una ipogammaglobulinemia con un deficit delle cellule B memoria, anche se raramente si evidenziano delle infezioni severe o frequenti.

I pazienti rispondono allo steroide ad alte dosi e spesso ne risultano dipendenti. I comuni immunosopressori non hanno evidente beneficio, mentre appare efficace il trattamento con farmaci anti-TNF (44). In alcuni casi è stato tentato con successo il trapianto di cellule staminali ematopoietiche (46).

\section{Le interferonopatie}

Recentemente sono state identificate una serie di malattie infiammatorie ereditarie associate ad alterazione dei meccanismi deputati all'attivazione o alla regolazione della risposta dell'IFN di tipo I, le cosiddette Interferonopatie $(47,48)$. Gli Interferoni di tipo I (IFN $\alpha$ e IFN $\beta$ ) sono citochine cruciali nella risposta nei confronti delle infezioni virali. Sono prodotte prevalentemente dalle cellule dell'immunità innata dopo l'attivazione di recettori intracellulari deputati al riconoscimento di segnali di danno come gli acidi nucleici di origine virale. L'attivazione della via di signaling dell'IFN di tipo I induce una risposta infiammatoria mirata alla limitazione della propagazione dell'infezione virale e alla eliminazione delle cellule infette. Generalmente un numero di meccanismi regolatori impediscono alle cellule dell'immunità innata di sviluppare una attivazione immunologica inappropriata in risposta agli acidi nucleici del self.

Mutazioni di alcuni nucleasi responsabili della rimozione e della degradazione del materiale nucleare intracellulare, come la DNAse1 o la DNAse1L3, sono state associate a casi di LES familiare (49). È molto interessante notare come l'iperattivazione di una risposta IFN di tipo I e la conseguenza risposta pro-infiammatoria è proprio quanto si verifica in occasione della rottura della tolleranza immunologica e della conseguenza risposta autoimmune in corso di Lupus eritematoso sistemico (LES)(50,51).

Tali dati configurano l'esistenza di una nuova classe di malattie infiammatorie che riconosce meccanismi patogenetici completamente diversi da quelli illustrati per le malattie auto infiammatorie fino ad ora descritte, in cui le mutazioni delle cellule dell'immunità innata non portano alla attivazione delle citochine più comunemente utilizzate nel corso della risposta verso i patogeni extra cellulari di origine batterica (IL1, TNF, IL-6), ma coinvolgono le vie di attivazione comunemente sfruttate dall'immunità innata nella risposta verso le infezioni virali, tramite l'attivazione dell'IFN di tipo I (48). L'esempio di tali malattie è fornito da 2 due condizioni distinte di recente identificazione, la sindrome CANDLE e la sindrome SAVI.

\section{La sindrome CANDLE (chronic atypical neutrophilic dermatosis with lipodystrophy and elevated temperature)}

Tale sindrome, nota anche come sindrome di Nakajo-Nishimura o Proteasome-Associated Autoinflammatory Syndrome (PRAAS), è caratterizzata un quadro infiammatorio cronico o ricorrente ad esordio precoce, associato a manifestazioni cutanee a tipo panniculite, con evoluzione in lipodistrofia, artropatia infiammatoria e miosite $(51,52)$. I pazienti mostrano una persistente elevazione degli indici di flogosi, anemia, elevazione degli enzimi epatici. Possono essere presenti anticorpi anti-nucleo (ANA) a basso titolo. La malattia è legata a mutazioni autosomiche recessive del gene RING10 gene, che codifica per la proteina PSMB8 (subunità $\beta 5 i$ ), un componente di un impor- 
tante complesso intracitoplasmatico, il Proteosoma. Il proteosoma è responsabile per la degradazione citoplasmatiche delle proteine cellulari ed è cruciale per il mantenimento della omeostasi cellulare, perché deputato ad degradare le proteine danneggiate o misfolded $\mathrm{o}$ comunque non più necessarie per il ciclo vitale della cellula. Recentemente è stato dimostrato che altre sub-unità del Proteosoma (PSMA3, PSMB4, PMSB10) possono essere mutate nella sindrome CANDLE, con una trasmissione che può essere digenica (53).

Un'alterazione dell'attività del proteasoma induce ad una eccessivo accumulo di aggregati proteici all'interno del reticolo endoplasmatico, inducendo uno stato di stress cellulare che attiva la cellula in senso pro-infiammatorio. I monociti dei pazienti con sindrome di CANDLE presentano uno stato di iperfosforilazione di STAT1 che porta ad una ipersecrezione di IFN di tipo I.

L'IFN di tipo I si lega ai suoi specifici recettori di membrana (IFNR) inducendo la fosforilazione di janus chinasi (JAK1 e JAK2) che a loro volta attivano i fattori di trascrizione STAT1 e STAT2.

Tale condizione determina una continua stimolazione autocrina di IFN di tipo I che è responsabile del severo quadro infiammatorio cronico riscontrato nella malattia.

I pazienti rispondono alla somministrazione di steroidi ad alte dosi. I comuni immunosoppressori hanno una scarsa efficacia, così come i farmaci biologici antiTNF, anti-IL1 e anti-IL6. Recentemente è stato proposto il trattamento con inibitori delle JAK chinasi, il cui razionale è quello di interrompere il loop autocrino legato alla continua produzione di IFN di tipo I inibendo la risposta a valle del recettore di membrana (48).

\section{La sindrome SAVI}

\section{(STING-associated vasculitis of infancy)}

La sindrome SAVI è caratterizzata da una vascolopatia infiammatoria associata a febbre, lesioni cutanee necrotizzanti (rash malare, ulcerazioni croniche delle estremità) e scarso accrescimento staturo-ponderale. Abbastanza precocemente si sviluppa una pneumopatia interstiziale infiammatoria che può portare a fibrosi polmonare e successivamente ad una ipertensione polmonare che può essere fatale precocemente, spesso nella seconda decade di vita (54).

La malattia è associata a mutazioni dominanti del gene TMEM173, che codifica per la proteina STING (stimulator of interferon genes). STING è una proteina di membrana situata nel reticolo endoplasmatico, fortemente espressa a livello delle cellule endoteliali. STING agisce come sensore del DNA a doppia elica citoplasmatico. Dopo la sua attivazioneinduce l'attivazione del fattore di trascrizione IRF3 (interferon regulatory factor 3) responsabile per la produzione di
IFN $\beta$. I pazienti SAVI hanno una mutazione gain-of function di STING che induce una attivazione costitutiva del promotore dell'IFN $\beta$ (54). Come i pazienti CANDLE, nel sangue dei pazienti SAVI è stata dimostrata una caratteristica segnatura genetica interferonica che contraddistingue tutte le Interferonopatie e può costituire un ottimo strumento di screening per la diagnosi di queste malattie (47).

\section{Conclusioni}

Le malattie autoinfiammatorie rappresentano pertanto un capitolo nuovo e molto rilevante, non solo in pediatria, nel vasto campo delle malattie infiammatorie. L'individuazione dei meccanismi molecolari responsabili delle malattie autoinfiammatorie ereditarie ha aperto nuove frontiere nella comprensione dei meccanismi di controllo dell'infiammazione. In particolare, lo studio di queste malattie ci sta aiutando a comprendere i meccanismi con i quali fattori esogeni ed endogeni di danno cellulare sono in grado di attivare il processo infiammatorio nelle cellule dell'immunità innata, sicuramente coinvolte in una serie di malattie infiammatorie multifattoriali (come la gotta, l'artrite idiopatica giovanile sistemica, la malattia di Still dell'adulto, le pericarditi ricorrenti (Tabella 2 e Figura 3) (55-64), le poliarteriti ANCA-negative, etc.) che riconoscono meccanismi di attivazione e mantenimento del quadro infiammatorio del tutto analoghi a quelli delle forme monogeniche $(1,2)$.

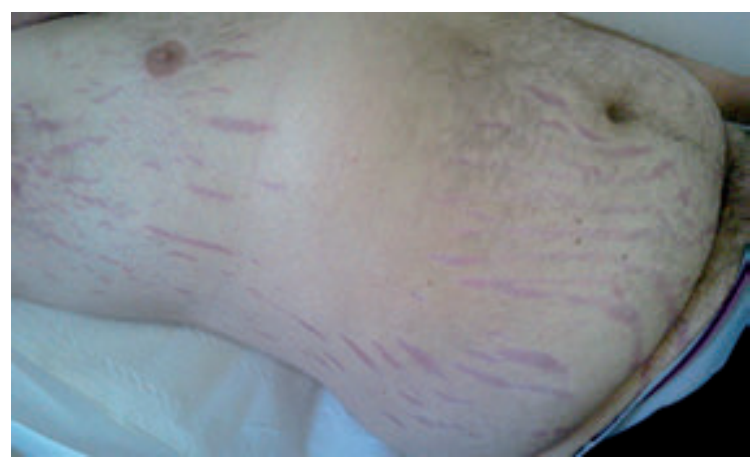

Figura 3. Strie rubre in un ex ragazzo, ora diventato adulto, trattato con cortisone ad alte dosi con tipici cicli: rapide riduzioni, recidiva, ripresa di dosi alte, rapida riduzione, recidiva, e così via, per pericardite recidivante in età pediatrica. 
Tabella 2. La pericardite ricorrente. Un prototipo di malattia autoinfiammatoria multifattoriale.

La malattie autoinfiammatorie hanno un fenotipo caratteristico, con violenti episodi infiammatori caratterizzati da febbre, drammatica elevazione dei tests di flogosi e manifestazioni cliniche varie, spesso con polisierositi e artralgie. Gli attacchi sono poi seguiti da intervalli liberi da sintomi con completo benessere e normalizzazione dei tests di flogosi. In molti di tali casi la IL1 gioca un ruolo centrale nella patogenesi. La pericardite recidivante ricorda in modo sorprendente questo fenotipo, soprattutto nelle sue forme più infiammatorie e in età pediatriche.

La pericardite è una malattia abbastanza frequente, che si ritiene nella maggiora parte dei casi essere causata da infezioni virali, almeno in Europa e negli USA. La diagnosi si basa sulla presenza di almeno due sei seguenti criteri: 1. dolore toracico tipico, modificato dal decubito e dal respiro profondo; 2. alterazioni ECG del tratto ST, del tratto PQ, della onda T, presenti nel $50-60 \%$ dei casi; 3. presenza di un versamento pericardico $(60 \%$ dei casi) spesso lieve $(<10 \mathrm{~mm})$; 4 . sfregamento pericardico (circa $30 \%$ dei casi) $(55)$. Spesso è una malattia benigna, ma nel $15-30 \%$ dei casi si complica. L'esordio può anche essere violento, con febbre alta, proteina C reattiva (PCR) elevatissima, sintomi sistemici importanti, e soprattutto interessamento pleuropolmonare (36\% degli adulti, $55 \%$ dei bambini) (56), tanto che la diagnosi di presentazione non è tanto quella di pericardite quanto spesso quella di pleuropolmonite. Aumento della transaminasi è presente nell' $8 \%$ dei casi, interessamento peritoneale nel 5\% dei casi (57), e una grave anemia (da infiammazione più o meno cronica) in una percentuale di casi non nota. Familiarità è stata osservata nel 10\% dei casi (58). Spontaneamente o a seguito delle terapie il malato guarisce completamente, e si ha un intervallo libero di lunghezza variabile, con benessere e normalizzazione completa degli indici di flogosi. Nel 15-30\% dei casi però il quadro si ripresenta, con caratteristiche del tutto simili (55). È chiaro che un quadro clinico di questo tipo, con attacchi violenti apparentemente non indotti da alcuno stimolo, che si ripetono periodicamente, fanno pensare alle malattie auto infiammatorie e alla possibile attivazione dell'inflammosoma con rilascio di IL1 (59). Le mutazioni genetiche associate alla FMF sono rarissime nella pericardite idiopatica recidivante (60). Le mutazioni associate alla TRAPS sono state osservate invece nel $6 \%$ di questi pazienti, associandosi ai seguenti elementi: familiarità, recidive che si estendono per più di un anno dall'attacco iniziale, scarsa risposta alla colchicina, necessità di impiego di immunosoppressori (61); la ricerca delle possibili mutazioni associate continua.

La terapia si basa sull'impiego di FANS ad alti dosaggi: ibuprofene 1200-2400 mg/die; indometacina 75-150 mg/die; naprossene 500-1500 $\mathrm{mg}$ /die (55), e preferibilmente endovena nei malati ospedalizzati (ottima es. la indometacina endovena, 2 fiale da $50 \mathrm{mg}$ in infusione continua nelle 24 ore). Nei casi importanti o recidivanti va sempre aggiunta la colchicina, a basse dosi e senza dose carico, per migliorare la tollerabilità, dato che può dare diarrea nel 7\% dei casi. Si può iniziare con mezza cp da $1 \mathrm{mg}$ al giorno e poi se bene tollerata dopo qualche giorno salire a mezza cp 2 volte al giorno oppure $1 \mathrm{cp}$ in singola dose, a seconda della tollerabilità e della compliance; di solito $0,5 \mathrm{mg}$ se il peso è $<70 \mathrm{~kg}$ e 1 $\mathrm{mg}$ se il peso è $>70 \mathrm{~kg}$ (55). L'uso dei cortisonici va limitato il più possibile (55), e se proprio si ritiene di non poterne fare a meno, nonostante per es. l'impiego della indometacina endovena, vanno utilizzate dosi basse, anche solo prednisone 5-10 mg, aggiunto a FANS e colchicina. L'impiego del cortisone infatti si associa a una spiccata tendenza successiva alla recidiva, che diventa quasi inevitabile se si utilizzano dosi alte ridotte poi troppo rapidamente $(55,59)$. Il continuo ciclo di cortisone ad alte dosi rapidamente sospeso e poi ripreso causa poi effetti collaterali importanti, soprattutto in età pediatrica, dove può causare arresto della crescita e strie rubre invalidanti (Figura 3). Il tapering dei farmaci e in particolare del cortisone deve essere molto lento e non automatico; ogni riduzione di terapia va fatta solo in assenza di sintomi e se la PCR è normalizzata, pena un alto rischio di rapida recidiva $(55,59)$.

La parentela delle pericarditi recidivanti con le malattie infiammatorie è stata recentemente sottolineata dalla risposta spettacolare alla anakinra osservata in casi fortemente infiammatori e resistenti o intolleranti alla colchicina e cortico-dipendenti $(62,63)$ come abbiamo recentemente dimostrato in un trial randomizzato controllato in doppio cieco (64); il farmaco è stata rapidamente efficace in tutti i malati, permettendo un rapidissimo tapering di tutte le terapie associate. Ottenuta una rapida remissione della malattia il problema diventa poi lo svezzamento dal farmaco stesso, dato che recidive sono possibili alla sospensione della anakinra. Tale fase richiede certamente un tapering lentissimo dell'anakinra (mesi), l'impiego concomitante della colchicina, se tollerata, e l'eventuale utilizzo di FANS a cicli. Ė importante però che tutti i malati hanno sospeso definitivamente il cortisone.

Nel complesso quindi l'andamento clinico tipico e la risposta spettacolare alla inibizione della ILl fa pensare che la pericardite recidivante cosiddetta idiopatica sia una forma frusta di malattia auto infiammatoria, soprattutto nei casi con caratteristiche infiammatorie più marcate e PCR elevatissima; il termine di pericardite recidivante idiopatica andrebbe forse abbandonato.

\section{Bibliografia}

1. Gattorno M, Martini A. Beyond the NLRP3 inflammasome: autoinflammatory diseases reach adolescence. Arthritis Rheum 2013 May;65(5):1137-47.

2. Masters SL, Simon A, Aksentijevich I, Kastner DL. Horror autoinflammaticus: the molecular pathophysiology of autoinflammatory disease $(*)$. Annu Rev Immunol 2009;27:621-68.

3.The French FMF Consortium. A candidate gene for familial Mediterranean fever. Nature Genetics 1997 Sep;17(1):25-31.

4.The International FMF Consortium. Ancient missense mutations in a new member of the RoRet gene family are likely to cause familial Mediterranean fever. Cell 1997 Aug 22;90(4):797-807.

5. Ozen S, Demirkaya E, Amaryan G, Kone-Paut I, Polat A, Woo P, et al. Results from a multicentre international registry of familial Mediterranean fever: impact of en- vironment on the expression of a monogenic disease in children. Ann Rheum Dis 2013 Mar 5.

6. Touitou I, Sarkisian T, Medlej-Hashim M, Tunca M, Livneh A, Cattan D, et al. Country as the primary risk factor for renal amyloidosis in familial Mediterranean fever. Arthritis Rheum 2007 May;56(5):1706-12.

7. Chae JJ, Cho YH, Lee GS, Cheng J, Liu PP, Feigenbaum $\mathrm{L}$, et al. Gain-of-function Pyrin mutations induce NLRP3 protein-independent interleukin-1beta activation and severe autoinflammation in mice. Immunity 2011 May 27;34(5):755-68.

8. Omenetti A, Carta S, Delfino L, Martini A, Gattorno M, Rubartelli A. Increased NLRP3-dependent interleukin 1beta secretion in patients with familial Mediterranean fever: correlation with MEFV genotype. Ann Rheum Dis 2014 Feb;73(2):462-9.

9. Federici S, Sormani MP, Ozen S, Lachmann HJ, Amaryan G, Woo P, et al. Evidence-based provisional clinical classification criteria for autoinflammatory pe- 
riodic fevers. Ann Rheum Dis 2015 May;74(5):799-805.

10. Ter HN, Lachmann H, Ozen S, Woo P, Uziel Y, Modesto $\mathrm{C}$, et al. Treatment of autoinflammatory diseases: results from the Eurofever Registry and a literature review. Ann Rheum Dis 2013 May;72(5):678-85.

11. McDermott MF, Aksentijevich I, Galon J, McDermott EM, Ogunkolade BW, Centola M, et al. Germline mutations in the extracellular domains of the $55 \mathrm{kDa}$ TNF receptor, TNFR1, define a family of dominantly inherited autoinflammatory syndromes. Cell 1999 Apr 2;97(1):133-44.

12. Lachmann HJ, Papa R, Gerhold K, Obici L, Touitou I, Cantarini L, et al. The phenotype of TNF receptor-associated autoinflammatory syndrome (TRAPS) at presentation: a series of 158 cases from the Eurofever/ EUROTRAPS international registry. Ann Rheum Dis 2013 Aug 21.

13. Aksentijevich I, Galon J, Soares M, Mansfield E, Hull $\mathrm{K}$, Oh HH, et al. The tumor-necrosis-factor receptor-associated periodic syndrome: new mutations in TNFRSF1A, ancestral origins, genotype-phenotype studies, and evidence for further genetic heterogeneity of periodic fevers. Am J Hum Genet 2001 Aug;69(2):301-14.

14. Micheau O, Tschopp J. Induction of TNF receptor I-mediated apoptosis via two sequential signaling complexes. Cell 2003 Jul 25;114(2):181-90.

15. Muppidi JR, Tschopp J, Siegel RM. Life and death decisions: secondary complexes and lipid rafts in TNF receptor family signal transduction. Immunity 2004 Oct;21(4):461-5.

16. Lobito AA, Kimberley FC, Muppidi JR, Komarow H, Jackson AJ, Hull KM, et al. Abnormal disulfide-linked oligomerization results in ER retention and altered signaling by TNFR1 mutants in TNFR1-associated periodic fever syndrome (TRAPS). Blood 2006 Aug 15;108(4):1320-7.

17. Shinar Y, Obici L, Aksentijevich I, Bennetts B, Austrup F, Ceccherini I, et al. Guidelines for the genetic diagnosis of hereditary recurrent fevers. Ann Rheum Dis 2012 Oct;71(10):1599-605.

18. Bulua AC, Mogul DB, Aksentijevich I, Singh H, He D, Muenz L, et al. Efficacy of etanercept in the tumor necrosis factor receptor-associated periodic syndrome (TRAPS). Arthritis Rheum 2011 Oct 17.

19. Gattorno M, Pelagatti MA, Meini A, Obici L, Barcellona $\mathrm{R}$, Federici $\mathrm{S}$, et al. Persistent efficacy of anakinra in patients with tumor necrosis factor receptor-associated periodic syndrome. Arthritis Rheum 2008 May;58(5): 1516-20

20. Gattorno M, Obici L, Cattalini M, Tormey V, Abrams $\mathrm{K}$, Davis N, et al. Canakinumab treatment for patients with active recurrent or chronic TNF receptor-associated periodic syndrome (TRAPS): an open-label, phase II study. Ann Rheum Dis 2017 Jan;76(1):173-8.

21. Houten SM, Romeijn GJ, Koster J, Gray RGF, Darbyshire P, Smit GPA, et al. Identification and characterization of three novel missense mutations in mevalonate kinase cDNA causing mevalonic aciduria, a disorder of isoprene biosynthesis. Human Molecular Genetics 1999 Aug;8(8):1523-8.

22. Houten SM, Kuis W, Duran M, De Koning TJ, van Royen-Kerkhof A, Romeijn GJ, et al. Mutations in MVK, encoding mevalonate kinase, cause hyperim- munoglobulinaemia $\mathrm{D}$ and periodic fever syndrome. Nature Genetics 1999 Jun;22(2):175-7.

23. van der Burgh R, Pervolaraki K, Turkenburg M, Waterham HR, Frenkel J, Boes M. Unprenylated RhoA contributes to IL-1beta hypersecretion in mevalonate kinase deficiency model through stimulation of Rac1 activity. J Biol Chem 2014 Oct 3;289(40):27757-65.

24. Ter Haar NM, Jeyaratnam J, Lachmann HJ, Simon A, Brogan PA, Doglio M, et al. The Phenotype and Genotype of Mevalonate Kinase Deficiency: A Series of 114 Cases From the Eurofever Registry. Arthritis Rheumatol 2016 Nov;68(11):2795-805.

25. Ter HN, Lachmann H, Ozen S, Woo P, Uziel Y, Modesto $\mathrm{C}$, et al. Treatment of autoinflammatory diseases: results from the Eurofever Registry and a literature review. Ann Rheum Dis 2013 May;72(5):678-85.

26. Hoffman HM, Wanderer AA, Broide DH. Familial cold autoinflammatory syndrome: phenotype and genotype of an autosomal dominant periodic fever. J Allergy Clin Immunol 2001 Oct;108(4):615-20.

27. Hoffman HM, Mueller JL, Broide DH, Wanderer AA, Kolodner RD. Mutation of a new gene encoding a putative pyrin-like protein causes familial cold autoinflammatory syndrome and Muckle-Wells syndrome. Nat Genet 2001 Nov;29(3):301-5.

28. Rubartelli A, Gattorno M, Netea MG, Dinarello CA. Interplay between redox status and inflammasome activation. Trends Immunol 2011 Dec;32(12):559-66.

29. Tanaka N, Izawa K, Saito MK, Sakuma M, Oshima K, Ohara O, et al. High incidence of NLRP3 somatic mosaicism in patients with chronic infantile neurologic, cutaneous, articular syndrome: results of an International Multicenter Collaborative Study. Arthritis Rheum 2011 Nov;63(11):3625-32.

30. Levy R, Gerard L, Kuemmerle-Deschner J, Lachmann HJ, Kone-Paut I, Cantarini L, et al. Phenotypic and genotypic characteristics of cryopyrin-associated periodic syndrome: a series of 136 patients from the Eurofever Registry. Ann Rheum Dis 2015 Nov;74(11):2043-9.

31. Wise CA, Gillum JD, Seidman CE, Lindor NM, Veile $\mathrm{R}$, Bashiardes S, et al. Mutations in CD2BP1 disrupt binding to PTP PEST and are responsible for PAPA syndrome, an autoinflammatory disorder. Hum Mol Genet 2002 Apr 15;11(8):961-9.

32. Omenetti A, Carta S, Caorsi R, Finetti M, Marotto D, Lattanzi B, et al. Disease activity accounts for long-term efficacy of IL-1 blockers in pyogenic sterile arthritis pyoderma gangrenosum and severe acne syndrome. Rheumatology (Oxford) 2016 Mar 17.

33. Aksentijevich I, Masters SL, Ferguson PJ, Dancey P, Frenkel J, van Royen-Kerkhoff A, et al. An autoinflammatory disease with deficiency of the interleukin-1-receptor antagonist. N Engl J Med 2009 Jun 4;360(23): 2426-37.

34. Marrakchi S, Guigue P, Renshaw BR, Puel A, Pei XY, Fraitag $\mathrm{S}$, et al. Interleukin-36-receptor antagonist deficiency and generalized pustular psoriasis. N Engl J Med 2011 Aug 18;365(7):620-8

35. Rossi-Semerano L, Piram M, Chiaverini C, De RD, Smahi A, Kone-Paut I. First clinical description of an infant with interleukin-36-receptor antagonist deficiency successfully treated with anakinra. Pediatrics 2013 Oct;132(4):e1043-e1047. 
36. Cordoro KM, Ucmak D, Hitraya-Low M, Rosenblum MD, Liao W. Response to Interleukin (IL)-17 Inhibition in an Adolescent With Severe Manifestations of IL-36 Receptor Antagonist Deficiency (DITRA). JAMA Dermatol 2017 Jan 1;153(1):106-8.

37. Ferguson PJ, Chen S, Tayeh MK, Ochoa L, Leal SM, Pelet A, et al. Homozygous mutations in LPIN2 are responsible for the syndrome of chronic recurrent multifocal osteomyelitis and congenital dyserythropoietic anaemia (Majeed syndrome). J Med Genet 2005 Jul;42(7):551-7.

38. Majeed HA, Kalaawi M, Mohanty D, Teebi AS, Tunjekar MF, al-Gharbawy F, et al. Congenital dyserythropoietic anemia and chronic recurrent multifocal osteomyelitis in three related children and the association with Sweet syndrome in two siblings. J Pediatr 1989 Nov;115(5 Pt 1):730-4.

39. Herlin T, Fiirgaard B, Bjerre M, Kerndrup G, Hasle H, Bing X, et al. Efficacy of anti-IL-1 treatment in Majeed syndrome. Ann Rheum Dis 2013 Mar;72(3):410-3.

40. Blau EB. Familial granulomatous arthritis, iritis, and rash. J Pediatr 1985 Nov;107(5):689-93.

41. Miceli-Richard C, Lesage S, Rybojad M, Prieur AM, Manouvrier-Hanu S, Hafner R, et al. CARD15 mutations in Blau syndrome. Nat Genet 2001 Sep;29(1):1920.

42. Rose CD, Wouters CH, Meiorin S, Doyle TM, Davey MP, Rosenbaum JT, et al. Pediatric granulomatous arthritis: an international registry. Arthritis Rheum 2006 Oct;54(10):3337-44.

43. Zhou Q, Yang D, Ombrello AK, Zavialov AV, Toro C, Zavialov AV, et al. Early-onset stroke and vasculopathy associated with mutations in ADA2. N Engl J Med 2014 Mar 6;370(10):911-20.

44. Navon EP, Pierce SB, Segel R, Walsh T, Barash J, Padeh $\mathrm{S}$, et al. Mutant adenosine deaminase 2 in a polyarteritis nodosa vasculopathy. N Engl J Med 2014 Mar 6;370(10):921-31.

45. Caorsi R, Penco F, Schena F, Gattorno M. Monogenic polyarteritis: the lesson of ADA2 deficiency. Pediatr Rheumatol Online J 2016;14(1):51.

46. van MJ, Zavialov A, Zhou Q. Mutant ADA2 in vasculopathies. N Engl J Med 2014 Jul 31;371(5):478.

47. Crow YJ, Manel N. Aicardi-Goutieres syndrome and the type I interferonopathies. Nat Rev Immunol 2015 Jul;15(7):429-40.

48. Volpi S, Picco P, Caorsi R, Candotti F, Gattorno M. Type I interferonopathies in pediatric rheumatology. Pediatr Rheumatol Online J 2016 Jun 4;14(1):35.

49. Belot A, Cimaz R. Monogenic forms of systemic lupus erythematosus: new insights into SLE pathogenesis. Pediatr Rheumatol Online J 2012;10(1):21.

50. Blanco P, Palucka AK, Gill M, Pascual V, Banchereau J. Induction of dendritic cell differentiation by IFNalpha in systemic lupus erythematosus. Science 2001 Nov 16;294(5546):1540-3.

51. Arima K, Kinoshita A, Mishima H, Kanazawa N, Kaneko T, Mizushima T, et al. Proteasome assembly defect due to a proteasome subunit beta type 8 (PSMB8) mutation causes the autoinflammatory disorder, NakajoNishimura syndrome. Proc Natl Acad Sci U S A 2011 Sep 6;108(36):14914-9.
52. Liu Y, Ramot Y, Torrelo A, Paller AS, Si N, Babay S, et al. Mutations in PSMB8 cause CANDLE syndrome with evidence of genetic and phenotypic heterogeneity. Arthritis Rheum 2011 Sep 27.

53. Brehm A, Liu Y, Sheikh A, Marrero B, Omoyinmi E, Zhou Q, et al. Additive loss-of-function proteasome subunit mutations in CANDLE/PRAAS patients promote type I IFN production. J Clin Invest 2015 Nov 2;125(11):4196-211.

54. Liu Y, Jesus AA, Marrero B, Yang D, Ramsey SE, Montealegre Sanchez GA, et al. Activated STING in a vascular and pulmonary syndrome. N Engl J Med 2014 Aug 7;371(6):507-18.

55. Adler Y, Charron P, Imazio M, Badano L, Baron-Esquivias G, Bogaert J, et al. 2015 ESC Guidelines for the diagnosis and management of pericardial diseases: The Task Force for the Diagnosis and Management of Pericardial Diseases of the European Society of Cardiology (ESC)Endorsed by: The European Association for Cardio-Thoracic Surgery (EACTS). Eur Heart J 2015 Nov 7;36(42):2921-64.

56. Imazio M, Brucato A, Pluymaekers N, Breda L, Calabri G, Cantarini L, et al. Recurrent pericarditis in children and adolescents: a multicentre cohort study. J Cardiovasc Med (Hagerstown ) 2016 Sep;17(9):707-12.

57. Brucato A, Brambilla G, Moreo A, et al. Long-term outcomes in difficult-to-treat patients with recurrent pericarditis. Am J Cardiol. 2006;98:267-71

58. Brucato A, Brambilla G. Recurrent idiopathic pericarditis: familial occurrence. Int J Cardiol 2005; 102:529.

59. Cremer PC, Kumar A, Kontzias A, Tan CD, Rodriguez ER, Imazio M, et al. Complicated Pericarditis: Understanding Risk Factors and Pathophysiology to Inform Imaging and Treatment. J Am Coll Cardiol 2016 Nov 29;68(21):2311-28.

60. Brucato A, Shinar Y, Brambilla G, et al. Idiopathic recurrent acute pericarditis: familial Mediterranean fever mutations and disease evolution in a large cohort of Caucasian patients. Lupus. 2005;14:670-4.

61. Cantarini L, Lucherini OM, Brucato A, Barone L, Cumetti D, Iacoponi F, et al. Clues to detect tumor necrosis factor receptor-associated periodic syndrome (TRAPS) among patients with idiopathic recurrent acute pericarditis: results of a multicentre study. Clin Res Cardiol 2012 Jul;101(7):525-31.

62. Finetti M, Insalaco A, Cantarini L, Meini A, Breda L, Alessio M, et al. Long-term efficacy of interleukin-1 receptor antagonist (anakinra) in corticosteroid-dependent and colchicine-resistant recurrent pericarditis. J Pediatr 2014 Jun;164(6):1425-31.

63. Picco P, Brisca G, Traverso F, Loy A, Gattorno M, Martini A. Successful treatment of idiopathic recurrent pericarditis in children with interleukin-1beta receptor antagonist (anakinra): An unrecognized autoinflammatory disease? Arthritis Rheum 2009 Jan;60(1):264-8.

64. Brucato A, Imazio M, Gattorno M, Lazaros G, Maestroni S, Carraro M, et al. Effect of Anakinra on Recurrent Pericarditis Among Patients With Colchicine Resistance and Corticosteroid Dependence: The AIRTRIP Randomized Clinical Trial. JAMA 2016 Nov 8;316(18):1906-12. 


\title{
Il rischio cardio-vascolare nelle IMIDs
}

\author{
Andrea Fontanella, ${ }^{1}$ Paola Gnerre, ${ }^{2}$ Roberto Nardi ${ }^{3}$ \\ ${ }^{1}$ Direttore del Dipartimento di Medicina dell'Ospedale del Buon Consiglio Fatebenefratelli, Napoli; ${ }^{2}$ Medicina Interna 2 , \\ Ospedale San Paolo, Savona; ${ }^{3}$ Medicina, Maggiore, Bologna, Italia
}

\section{Introduzione}

Sebbene siano stati fatti enormi progressi nella prevenzione e nel trattamento della malattia cardiovascolare, questa rimane la causa principale di morte nel mondo Occidentale e la seconda causa nel mondo. Negli ultimi 40 anni l'iperlipidemia è stata identificata come il maggior fattore di rischio modificabile per morte cardiovascolare ma quasi la metà di tutti gli eventi cardiovascolari insorgono in pazienti senza apparente iperlipidemia. ${ }^{1}$ La comunità scientifica si è quindi impegnata nella ricerca di nuovi e migliori predittori di rischio evidenziando una forte correlazione tra la presenza di markers infiammatori ed eventi cardiovascolari successivi.

Da quando Russel Ross postulò e dimostrò per primo l'ipotesi della risposta al danno the responseto-injury, ${ }^{2}$ ossia che la patologia aterosclerotica insorgesse da un danno alla parete dell'arteria, i successivi studi hanno da sempre evidenziato un ruolo dell'infiammazione nello sviluppo di tutti gli stati della placca aterosclerotica. ${ }^{3}$ È attualmente riconosciuto, infatti, che l'aterosclerosi sia una malattia infiammatoria cronica che interessa sia l'immunità innata che acquisita a tutt'oggi non sono noti i fattori trigger che inducano la risposta immune. ${ }^{3}$ Lo studio Feiring Heart Biopsy Study (FHBS) ha rivelato un'alta incidenza di fibrosi e infiltrato infiammatorio prevalentemente linfocitario negli strati vascolari e perivascolari dell'aorta di pazienti con malattia coronarica. Dato estremamente significativo era che gli infiltrati localizzati nella media e nell'avventizia erano più frequenti ed

Corrispondente: Paola Gnerre, Medicina Interna 2, Ospedale San Paolo, via Genova n. I, 17100 Savona, Italia.

Tel.: +39.0198404358 - Fax: +39.0198404583.

E-mail:pgnerre@yahoo.it

Articolo pubblicato secondo la Creative Commons Attribution NonCommercial 4.0 License (CC BY-NC 4.0).

(C) Copyright A. Fontanella et al., 2017

Licensee PAGEPress, Italy

QUADERNI - Italian Journal of Medicine 2017; 5(7):172-178 estesi in pazienti con malattia autoimmune reumatica rispetto ai pazienti senza. ${ }^{4}$ Questo dato concorda con il riscontro epidemiologico di un incrementato rischio di eventi aterosclerotici e malattia cardiovascolare precoce nei pazienti con malattie infiammatorie croniche come l'artrite reumatoide, il Lupus eritematoso sistemico, la spondilite anchilosante, l'artrite psoriasica, le vasculiti dei piccoli, medi e grandi vasi la gotta e le malattie infiammatorie croniche intestinali. ${ }^{5}$ Nonostante queste evidenze la ricerca scientifica non ha ancora individuato la precisa natura della relazione tra l'infiammazione locale e sistemica e la loro interazione con i tradizionali fattori di rischio cardiovascolare e il loro ruolo nell'accelerare la malattia aterosclerotica.

\section{Meccanismi fisiopatolologici}

Nella popolazione generale la patologia aterosclerotica prende il via dal danno endoteliale con la conseguenza di un'invasione della regione sub-endoteliale da parte delle cellule infiammatorie con successivo deposito di lipidi e riduzione del lume arterioso, con possibile conseguente rottura della placca, formazioni di trombi e comparsa di eventi trombo-embolici. ${ }^{6,7}$

Il più precoce evento che insorge durante l'aterogenesi consiste nell'accumulo di lipidi e particelle lipoproteiche sotto l'endotelio. Il deposito di colesterolo a bassa densità (LDL-colesterolo) nell'intima del vaso è facilitato dai proteoglicani, componenti della matrice extracellulare che legano le particelle LDL. All'interno dell'intima le particelle LDL sono attaccate dai radicali dell'ossigeno e dagli enzimi ossidizzanti che inducono modificazioni chimiche delle proteine LDL. ${ }^{8}$ Questo induce l'attivazione endoteliale e la secrezione di chemochine come il monocyte chemoattractant protein-1 (MCP-1), il regulated upon activation normal $T$ Cell Expressed Secreted (RANTES), il fractalkine e altre chemochine come il CXCL1, il CCL2, il MIF (macrophage migration inhibitory factor), il CXCL16, il CX3CL1, e i loro recettori CXCR2, CCR2, il CXCR4, il CXCR6 e il CX3CR che inducono un aumentata espressione delle molecole di adesione intercellulari, delle E-selectine e del VCAM-1. Queste proteine di adesione sono quindi responsabili del re- 
clutamento delle cellule infiammatorie tra cui i linfociti $\mathrm{T}$, le cellule dendritiche e i monociti nel sito del danno endoteliale. I monociti dell'intima sono stimolati dal Monocyte-Colony Stimulating Factor (M$\mathrm{CSF}$ ) con conseguente differenziazione dei monociti in macrofagi che esprimono una classe recettoriale, cellular Pattern-Recognition Receptors (PRRs) in grado di fagocitare le LDL ossidate. Le molecole di colesterolo contenute in queste particelle di LDL si accumulano nel citoplasma dei macrofagi e inducono la trasformazione dei macrofagi in cellule schiumose, il prototipo cellulare della lesione aterosclerotica. ${ }^{9}$ Oltre ai macrofagi partecipano alla formazione della placca ateroscleroticaaltre cellule infiammatorie come le cellule T. Tra le cellule T i linfociti T tipo Th1-CD4+ giocano un ruolo preminente in quanto, attivati da specifici antigeni, producono Interferone-g (IFN-g) responsabile dell'attivazione dei macrofagi e delle cellule endoteliali. Altri sottotipi di linfociti T reclutati sono le cellule T Natural Killer (NK), che accelerano la malattia aterosclerotica precoce e le cellule T CD8c che possono aggravare la malattia aterosclerotica. ${ }^{10}$

\section{Malattia cardiovascolare e patologie reumatologiche}

La comunità reumatologica ha da sempre evidenziato un aumentato rischio di morte prematura cardiovascolare nel paziente con artrite reumatoide. Successivamente è stato dimostrato un rischio $>82 \%$ di infarto miocardico nei pazienti affetti da LES e miosite rispetto ai controlli. ${ }^{11} \mathrm{Nel}$ complesso comunque tutti i pazienti affetti da malattie reumatiche infiammatorie hanno un incrementato rischio di malattia coronarica prematura (sotto forma di malattia anginosa, infarto miocardico acuto, by pass aorto-coronarico e angioplastica) e ictus che si associano al grado di infiammazione. ${ }^{12}$ Sebbene certe patologie reumatologiche siano prevalentemente associate ad arterite coronarica, pro- babilmente l'aterosclerosi sottende la maggior parte degli eventi cardiovascolari (Tabella 1). ${ }^{13,14}$ Questi ultimi nei pazienti con malattie reumatiche non sono comunque solo la conseguenza della malattia aterosclerotica facilitata dall'attivazione flogistica ma possono essere anche indotti da miocarditi e altre cause di scompenso cardiaco non ischemiche come gli stessi farmaci. Anche l'autoimmunità o la presenza di arterite in altre sedi possono aggravare le lesioni infiammatorie e rendere la placche più vulnerabili alla rottura e alla trombosi. ${ }^{5}$

La complessità di questo problema clinico dovrebbe, pertanto, spingere, la ricerca a sviluppare nuovi approcci terapeutici combinati per minimizzare l'infiammazione e limitare l'aterosclerosi con l'obiettivo di ridurre l'incidenza degli eventi cardiovascolari nei pazienti con malattie reumatiche.

\section{Aterosclerosi e lupus eritematoso sistemico}

L'evidenza a partire dagli anni 70' di una duplice causa di mortalità nei pazienti affetti da LES dimostrò l'importanza del rischio cardiovascolare in questa categoria di pazienti. Se infatti una mortalità precoce poteva riflettere l'attività della malattia, le cause di un secondo picco di mortalità erano principalmente correlate alle malattie cardio e cerebro vascolari. ${ }^{15} \mathrm{Ad}$ oggi i miglioramenti nell'approccio terapeutico dei pazienti affetti LES hanno sensibilmente ridotto la mortalità conseguente all'attività della malattia e pertanto la principale causa di morte nei pazienti con LES sono le malattie cardiovascolari. Il rischio di malattie aterosclerotiche incrementa per ogni anno di durata della malattia. ${ }^{16}$

I pazienti giovani affetti da LES hanno un rischio superiore al 9-50 volte di sviluppare un'IMA e hanno un'evidenza di aterosclerosi sub-clinica (placche carotidee, aumento delle calcificazioni coronariche alle immagini nucleari) maggiore del $40 \%$ rispetto alla popolazione generale. ${ }^{17}$ I classici fattori di rischio di Framingham (ipertensione, ipercolesterolemia, diabete

Tabella 1. Interessamento delle arterie coronarie e malattie reumatiche.

\begin{tabular}{ll}
\hline Aterosclerosi prematura & Arterite coronarica \\
\hline LES & LES \\
\hline Artrite reumatoide & Arterite di Takayasu \\
\hline Spondilite anchilosante & Malattia di Kawasaki \\
\hline Artrite psoriasica & Arterite a cellule giganti \\
\hline Gotta & Poliarterite nodosa \\
\hline Vasculite ANCA-associata & Poliangite granulomatosa \\
\hline Arterite di Takayasu & Sindrome di Churg-Strauss \\
\hline Arterite a cellule giganti & Artrite reumatoide \\
\hline Miopatie infiammatorie & \\
\hline
\end{tabular}


mellito, fumo, sedentarietà, età avanzata e stato postmenopausale) non possono completamente spiegare l'aumentato rischio in questa categoria di pazienti. ${ }^{18}$ Pertanto questi dati confermano come l'esposizione cronica alla disregolazione del sistema immune promuove e contribuisce allo sviluppo del danno cardiovascolare nel paziente affetto da LES.

Tra i fattori implicati nell'incremento del rischio $\mathrm{CV}$ si possono includere citochine e mediatori infiammatori come IL-6, IL-17, INF-1, MPO, IL-1a, MMP9 e molecole di adesione come VCAM, ICAM e le E-selectine. ${ }^{19}$

Il ruolo degli anticorpi antifosfolipidi (aPL) risulta a tutt'oggi controverso infatti gli eventi ischemici indotti da APL sembrano più indotti dallo stato protrombotico che da un'aumento dell'aterosclerosi. ${ }^{20}$

Tra i farmaci (Tabella 2) la ciclofosfamide sembra avere un ruolo protettivo nello sviluppo dell'aterosclerosi (i pazienti in terapia con ciclofosfamide hanno infatti un rischio più basso di aterosclerosi aortica) mentre il ruolo dello steroide è duplice. ${ }^{21}$ Da una parte i corticosteroidi riducono l'infiammazione e quindi riducono l'aterosclerosi ma dall'altro inducono effetti collaterali come l'incremento ponderale, il diabete, l'ipertensione e l'ipertrigliceridemia noti come tradizionali fattori di rischio cardiovascolari.

Gli antimalarici incrementando l'HDL colesterolo, riducendo l'insulina resistenza e inibendo l'aggregazione piastrinica potrebbero migliorare la morbidità cardiovascolare. $^{22}$

Il micofenolato inibendo la secrezione di multipli mediatori infiammatori, i linfociti $\mathrm{T}$ e i macrofagi potrebbe giocare un ruolo centrale nel ridurre l'aterogenesi ma sono necessarie ulteriori ricerche per confermare questi dati. ${ }^{12}$ Lo steso dicasi per i farmaci biologici. A tutt'oggi non ci sono particolari evidenze in merito. ${ }^{20}$

Attualmente il management delle malattie cardiovascolari nei pazienti affetti da LES prevede il man- tenimento di una pressione ideale $<130 / 80 \mathrm{mmhg}$, il raggiungimento di un livello di $\mathrm{LDL}<100 \mathrm{mg} / \mathrm{dl}$ e di un BMI $<25 \mathrm{Kg} / \mathrm{m}^{2}$. I pazienti devono infine essere incoraggiati ad utilizzare farmaci anti-malarici, a smettere di fumare e a minimizzare l'uso della terapia steroidea. $^{12}$

\section{Aterosclerosi e artrite reumatoide}

I pazienti con artrite reumatoide (AR) tendono a morire prematuramente prima dei 50 anni d'età. Le malattie cardiovascolari sono responsabili di più del $50 \%$ di queste morti premature. L'artrite reumatoide e il diabete mellito hanno un rischio di eventi CV simile con un rischio $>48 \%$ rispetto alla popolazione generale. Le morti cardiovascolari incrementano 710 anni dopo l'insorgenza dei sintomi. ${ }^{23}$ I pazienti con $\mathrm{AR}$ tendono più frequentemente a sviluppare IMA silenti e pertanto ricevono meno terapie riperfusionali e misure di prevenzione secondarie. I fattori di rischio associati con questo eccesso di mortalità includono il sesso femminile, alti valori di VES, sinovite persistente, presenza di manifestazioni extraarticolari come i noduli reumatoidi, vasculite e malattia polmonare, oltre alla presenza di una sieropositività per fattore reumatoide e anticorpi anti-citrullina. ${ }^{24}$

A dispetto dei notevoli miglioramenti nella terapia farmacologica dei pazienti con AR la mortalità per eventi $\mathrm{CV}$ non si è modificata. Ciò potrebbe anche in parte riflettere l'incremento dell'incidenza (per il miglioramento della sopravvivenza) di malattie cardiache valvolari, di scompenso cardiaco, di miocarditi e pericarditi. ${ }^{25}$

I pazienti con AR presentano una disfunzione endoteliale documentata sia dalla ridotta vasodilatazione endoteliale in risposta all'acetilcolina sia per un ridotto rilascio delle cellule muscolari liscie della parete vasale sia per il riscontro di un aumentata rigidità aortica,

Tabella 2. Farmaci anti-reumatici e rischio cardio-vascolare. ${ }^{12}$

\begin{tabular}{ll}
\hline Agenti & Effetto sugli outcome cardiovascolari \\
\hline Glucocorticoidi & Dosi prolungate effetto sfavorevole \\
\hline FANS/COX2 & Peggiorativo. Potrebbe avere un effetto protettivo nell'artrite reumatoide \\
\hline Metotrexate & Riduce il rischio in studi osservazionali \\
\hline Micofenolato & Riduce la placca ma dati minimi \\
\hline Idrossiclorochina & Rischio ridotto in LES e AR \\
\hline Anti-TNF $\alpha$ & Peggiora lo scompenso cardiaco. Potrebbe ridurre il rischio di IMA \\
\hline Anti-IL6 & Non ci sono dati \\
\hline Anti-IL1 & Non ci sono dati, in corso studi \\
\hline Deplezione B-cellulare & Non ci sono dati \\
\hline Ciclosporina & Peggiora
\end{tabular}


che potrebbe predisporre allo sviluppo di un aterosclerosi precoce. ${ }^{12}$ Più fattori comunque contribuiscono all'insorgenza di aterosclerosi precoce nel paziente con AR.

I pazienti con $\mathrm{AR}$ presentano più alta prevalenza dei tradizionali fattori di rischio per malattie $\mathrm{CV}$ rispetto alla popolazione generale se pur si ritenga che altri fattori correlati alla malattia contribuiscano all'incremento del rischio di aterosclerosi precoce e, pertanto, la stessa malattia sia un fattore di rischio indipendente per l'aterosclerosi. La disabilità indotta dalla malattia riduce l'esercizio fisico, gli elevati livelli di TNF- $\alpha$ possono predisporre all'insulino resistenza che, in aggiunta all'inattività, favorisce l'insorgenza della sindrome metabolica. I pazienti con AR presentano dislipidemia con incremento dei trigliceridi, aumentati livelli di colesterolo LDL e ridotti livelli di colesterolo HDL. ${ }^{5}$

$\mathrm{Ci}$ sono numerose evidenze a favore dell'ipotesi che l'infiammazione sistemica tipica dell'AR sia il maggior determinante dell' aterosclerosi e quindi della malattia cardiovascolare. Aumentati livelli di PCR, TNF- $\alpha$, IL-6 e IL-17 sono direttamente associati ad un incremento del rischio cardiovascolare. Il ruolo degli auto-anticorpi nella patogenesi delle complicanze CV è ancora incerta se pur la presenza del fattore reumatoide e degli anticorpi anti-citrullina è associata alla presenza di disfunzione endoteliale e di eventi $\mathrm{CV}^{2}{ }^{26}$

I dati sugli effetti dei farmaci utilizzati per il trattamento dell'AR sugli eventi cardiovascolari sono ancora estremamente limitati. Solo basse dosi di metotrexato hanno dimostrato una riduzione degli eventi e della mortalità. ${ }^{27}$ Nei pazienti con AR i corticosteroidi riducono il rischio $\mathrm{CV}$ nonostante che il loro effetto nefasto sull'insulino resistenza e sull'ipertensione arteriosa potrebbero fare ipotizzare il contrario. L'insufficiente uso di corticosteroide e la persistente attività della malattia incrementano il rischio di malattia $\mathrm{CV} .{ }^{12}$ Per quanto riguarda i biologi anti-TNF $\alpha$ e IL- 6 si potrebbe ipotizzare che il peggioramento della dislipidemia potrebbe mitigare gli effetti anti-infiammatori di questi farmaci e da qui i possibili effetti sull'aterosclerosi. ${ }^{5}$

La cura dei pazienti con AR dovrebbe prevedere pertanto una collaborazione tra reumatologi e cardiologi al fine di ottimizzare la prevenzione cardiovascolare. I pazienti dovrebbero infatti ricevere un management aggressivo per la riduzione dei fattori di rischio tradizionali con la cessazione del fumo di sigaretta, il controllo del peso corporeo e della pressione arteriosa, la prevenzione/trattamento del diabete mellito e l'aumento dell'attività fisica. ${ }^{20}$

\section{Aterosclerosi e artrite psoriasica}

L'artrite psoriasica è una malattia infiammatoria associata alla psoriasi. Mentre si sa che la psoriasi in- teressa il 2-3\% della popolazione generale l'esatta prevalenza dell'artrite psoriasica (AP) non è conosciuta se pur l'artrite è presente in circa il $30 \%$ dei casi di psoriasi. ${ }^{28}$

Studi epidemiologi hanno dimostrato una forte associazione tra malattie cardiovascolari e artrite psoriasica se pur questa correlazione sia a tutt'oggi ancora controversa. ${ }^{20}$ Pertanto la ricerca della prevalenza dei fattori di rischio tradizionale per malattie $\mathrm{CV}$ nel paziente con artrite psoriasica è stato oggetto di studio nell'ultimo ventennio.

I pazienti con AP tendono ad avere un unico pattern di dislipidemia in particolare tendono a presentare bassi livelli di colesterolo HDL e alti livelli di trigliceridi. Il grado di infiammazione inoltre correla con il grado della dislipidemia. ${ }^{29}$

I pazienti con AP hanno un BMI aumentato tendendo ad essere obesi, presentano più frequentemente segni di aterosclerosi sub-clinica. Più del $30 \%$ è iperteso. ${ }^{30}$ La prevalenza di diabete mellito è aumentata rispetto alla popolazione generale.

Alcuni studi caso-controllo hanno però evidenziato la presenza di segni di aterosclerosi sub-clinica (disfunzione endoteliale) anche in pazienti affetti da AP senza i tradizionali fattori di rischio per malattia cardiovascolare. Pertanto questi studi suggeriscono che l'artrite psoriasica sia un fattore di rischio indipendente per l'aterosclerosi.

\section{Aterosclerosi e spondilite anchilosante}

La spondilite anchilosante (SA) è una malattia infiammatoria che interessa la colonna vertebrale e le articolazioni assiali. Le principali manifestazioni extra-articolari sono l'uveite e l'aortite.

Ci sono pochi dati sulla prevalenza dell'aterosclerosi nel paziente con SA. ${ }^{31}$ Una recente meta-analisi ha dimostrato un incremento di IMA nei pazienti affetti da SA rispetto al controllo. Anche i dati sulla prevalenza dei fattori di rischio tradizionali per malattie CV nel paziente con SA sono scarsi. Una sistematica review ha evidenziato un incremento dello spessore carotideo intima-media, una più alta frequenza di sindrome metabolica, più alta frequenza di ipertensione arteriosa, più bassi livelli di trigliceridi e colesterolo HDL rispetto al controllo. ${ }^{32}$

\section{Le vasculiti}

Un aterosclerosi accellerata e una morte prematura per eventi CV sono associati a tutte le vasculiti sia di piccolo che di medio e grosso calibro. ${ }^{33}$

Tutte queste condizioni si associano ad un aumentata prevalenza dei tradizionali fattori di rischio in particolare l'ipertensione arteriosa, la dislipidemia e l'insulino-resistenza per malattie CV. 
Plurimi meccanismi fisiopatologici contribuiscono al danno vascolare in corso di vasculiti in quanto nella genesi della malattie sono implicati sia l'immunità cellulare che umorale. ${ }^{12}$

Le vasculiti ANCA associate includono la granulomatosi di Wegener e la sindrome di Churg-Strauss. Gli anticorpi citoplasmatici anti-neutrofici possono direttamente attivare i neutrofili con conseguente danno endoteliale.

Le principali vasculiti dei grandi vasi sono l'arterite a cellule giganti (ACG) e l'arterite di Takayasu (AT). Nell'AT è presente un'accelerata aterosclerosi e un rischio aumentato di mortalità prematura. I pazienti con AT hanno un'incremento della stiffness aortica, la presenza di placche aterosclerotiche precoci e un'aumentata incidenza di infarto miocardico silente. Alla base di ciò oltre al danno vascolare diretto della parete vasale sede dell'infiammazione concorrono anche l'effetto pro-aterogenico della terapia glucocorticoide e le alterazioni anatomiche della parete vascolare conseguenti allo stato pro-infiammatorio. Più del $40 \%$ dei pazienti affetti da AT dimostrano infatti anormalità del circolo coronarico. ${ }^{34}$

L'ACG invece non è associata con aterosclerosi accelerata e con un incremento della mortalità a lungo termine. L'incremento della mortalità nel breve termine sembrerebbe associato alle complicanze ischemiche dell'arterite in fase attiva e agli effetti avversi della terapia steroidea. ${ }^{35}$

\section{Aterosclerosi e gotta}

La gotta colpisce circa il 2\% di tutti gli individui. I classici studi osservazionali hanno dimostrato come la gotta e l'iperuricemia siano fattori di rischio per l'aterosclerosi, Nello studio di Framingham la gotta era associato con un incremento $>60 \%$ di malattia coronarica e di mortalità per eventi cardiovascolari ma solo nell'uomo e non nelle donne, indipendentemente dalla presenza dei tradizionali fattori di rischio o dall'uso dei diuretici. ${ }^{36}$ Numerose ulteriori meta-analisi hanno confermato un'associazione indipendente tra gotta e incremento del rischio cardiovascolare. La spiegazione fisiopatologica alla base di questa associazione potrebbe risiedere nell'attivazione da parte dei cristalli di acido urico di un complesso molecolare NLRP3 capace di generare la forma attiva della citochina proinfiammatoria IL- $1 b{ }^{37}$

La relazione della gotta con il rischio di eventi CV nella donna richiede invece ulteriori studi.

\section{Rischio cardiovascolare e malattie infiammatorie dell'intestino}

Le malattie infiammatorie croniche (IBD) che includono la colite ulcerative e la malattia di Chron sono condizioni sistemiche infiammatorie croniche che prevalentemente interessano il tratto gastro-intestinale ma comprendono anche numerose manifestazioni extraintestinali.

Numerose evidenze scientifiche hanno dimostrato l'associazione tra malattie infiammatorie intestinali (IBD) e eventi trombo-embolici venosi correlati allo stato di ipercoagulabilità presente nelle IBD..$^{38}$ Questo ha, pertanto, indotto ad implementare strategie di profilassi trombo-embolica nel management del paziente affetto da IBD.

$\mathrm{Al}$ contrario il rischio di malattia arteriosa aterotrombotica come la malattia ischemica cardiaca, gli eventi cerebrovascolari, l'ischemia mesenterica e l'aumentata mortalità per eventi $\mathrm{CV}$ nel paziente con IBD è tutt'ora problema incerto e dibattuto. ${ }^{39}$

Ma l'osservazione di un incrementato spessore intima-media dell'arteria carotide e della disfunzione endoteliale nei pazienti con IBD ha supportato l'ipotesi di un potenziale aumentato rischio di malattia vascolare indotta dall'aterosclerosi nel paziente con IBD.

Studi clinici hanno evidenziato una bassa prevalenza dei tradizionali fattori di rischio per malattia $\mathrm{CV}$ (obesità, diabete mellito e dislipidemia) nei pazienti con IBD..$^{40}$ Pertanto lo stato infiammatorio cronico delle IBD in particolare sembrerebbero implicati mediatori come la PCR, l'IL-6 e il TNF- $\alpha$ ) incrementando il rischio di aterosclerosi costituirebbe la base del possibile link biologico tra IBD e maggiore rischio cardiovascolare. ${ }^{41}$

\section{Rischio cardiovascolare e malattia celiaca}

La malattia celiaca è una malattia sistemica cronica immuno-mediata indotta dal glutine in individui geneticamente predisposti. L'enteropatia celiaca è caratterizzata da un'atrofia dei villi, da un grado variabile di iperplasia delle cripte cellulari e da un incrementato numero di linfociti intraepiteliali dell'intestino tenue prossimale. I pazienti con malattia celiaca presentano un'incrementata espressione di INF- $\alpha$ e un alto numero di linfociti T CD $4^{+}$che producono INF- $\alpha{ }^{42}$ Come già detto l'infiammazione cronica è uno dei principali meccanismi patogenetici alla base dell'aterosclerosi e quindi dell'insorgenza di eventi cardio-vascolari. Non ci sono dati certi circa l'aumento del rischio cardiovascolare nei pazienti affetti da malattia celiaca. Ma recenti pubblicazioni hanno ipotizzato come la malattia celiaca in individui giovani era il possibile link per un potenziale incrementato rischio di precoce aterosclerosi e quindi di eventi CV. Pertanto i pazienti affetti da malattia celiaca dovrebbero essere scrinati per la ricerca di altri fattori di rischio CV come l'ipertensione, la dislipidemia, l'obesità, l'iperomocisteinemia, il fumo e l'inattività fisica. ${ }^{43}$ 


\section{Ruolo del microbiota intestinale nelle patologie cardiovascolari}

Il tratto gastro-intestinale contiene diverse colonie di micro-organismi residenti principalmente nel colon. Se pur non è ancora completamente descritto si ritiene che il microbiota intestinale umano sia costituito da circa $10^{3}-10^{4} \mathrm{CFU} / \mathrm{ml}$ batteri. Tali specie appartengono principalmente ai phyla dei Firmicutes e dei Bacteroidetes entrambi derivati dai Methanobrevibacter smithii. I batteri che compongono il microbiota intestinale sono più di 1000 specie di cui il $70-90 \%$ sono anaerobi obbligati (gram positivi come Clostridium e Bifidobacterium e gram negativi come Bacteroides). ${ }^{44}$

Il microbiota intestinale interviene come barriera contro la proliferazione dei patogeni con un meccanismo noto come colonization resistance, regola la maturazione del sistema immunitario, modula la produzione di vitamine come l'acido folico, la vit. $\mathrm{K}$ e le vitamine del gruppo B) e regola la motilità intestinale fungendo quindi come organo metabolicamente attivo del corpo umano. ${ }^{45}$

I mammiferi assorbono gli zuccheri semplici ma hanno una capacità intrinseca limitata di digerire i polisaccaridi. La capacità del microbiota intestinale di degradare i polisaccaridi (come la cellulosa, xilano, amido indigerito o glicani di origine endogena come le mucine e i glicosfingolipidi) in monosaccaridi liberati e in acidi grassi a corta catena utilizzabili quindi dall'ospite gli conferisce anche la funzione di bioreattore per i carboidrati. Si ritiene pertanto che il microbiota intestinale umano si evolva con il suo ospite al fine di ottenere un recupero ottimale dell'energia dalla dieta (principalmente dai carboidrati) ${ }^{46}$ L'evidenza che il microbiota dei topi obesi presentava un più elevato rapporto Firmicutes/Bacteroidetes e il metagenoma dei topi obesi era significativamente più ricco in geni che codificavano per il trasporto e la metabolizzazione dei carboidrati non digeribili della dieta, ha suggellato l'ipotesi del ruolo del microbiota nella genesi delle patologie cardiovascolari. Il microbiota infatti è in grado di influenzare l'assorbimento dei nutrienti e l'immagazimento dell'energia. ${ }^{47} \mathrm{Un}$ successivo studio su coppie di gemelli magri e obesi ha confermato che l'obesità è correlata ad una ridotta presenza di Bacteroidetes e pertanto viene a sminuirsi il ruolo del microbiota nel controllo del metabolismo energetico e delle malattie metaboliche. ${ }^{48}$

\section{Conclusioni}

Allo stato attuale è sostanzialmente riconosciuto come l'aterosclerosi dia da considerare una malattia infiammatoria, pertanto non desta alcuna meraviglia di come, già solo per questo motivo, nel corso delle ma- lattie infiammatorie immuno-mediate vi sia un significativo incremento del rischio cardiovascolare. In questo articolo si sono volute esplicitare tutte le altre concause: fisiopatologiche, farmacologiche, fenotipiche che possono spiegare la differente incidenza, la diversità delle manifestazioni cliniche della malattia aterosclerotica nelle differenti patologie immunomediate.

Rimane comunque la domanda cruciale: qual è il link diretto tra infiammazione, inizio e progressione dell'aterosclerosi? Probabilmente, come in tutti i processi fisiopatologici, ciò che crea la differenza, a parità di noxe patogene e patofisiologiche, è il substrato, ovvero le caratteristiche di base dell'individuo ammalato. Ed in questo, in un prossimo futuro, ci potrà essere di aiuto la genetica e la Medicina di Precisione.

\section{Bibliografia}

1. Braunwald E. Shattuck Lecture - cardiovascular medicine at the turn of the millennium: triumphs, concerns, and opportunities. N Engl J Med. 1997; 337: 1360-1369

2. Ross R. The pathogenesis of atherosclerosis--an update. N Engl J Med. 1986 Feb ;314(8):488-500.

3. Willerson J.T, Ridker P. M. Inflammation as a Cardiovascular Risk Factor. Circulation; 2004; ( II) 2-9.

4. Hollan I, Meroni PL, Ahearn JM et al. Cardiovascular disease in autoimmune rheumatic diseases. Autoimmun Rev 2013;12: 1004-1015.

5. Mattar M., Jandali B., Malemud C. J. Atherosclerosis and Rheumatic Diseases. Rheumatology (Sunnyvale) 2015; 5:1

6. Sherer Y, Shoenfeld Y. Mechanisms of disease: atherosclerosis in autoimmune diseases. Nat Clin Pract Rheumatol 2006; 2: 99-106.

7. Kahlenberg JM, Kaplan MJ. The interplay of inflammation and cardiovascular disease in systemic lupus erythematosus. Arthritis Res 2011; Ther 13: 203.

8. Hallenbeck JM, Hansson GK, Becker KJ. Immunology of ischemic vascular disease: Plaque to attack. Trends Immunol 2005; 26: 550-556.

9. Cybulsky MI, Gimbrone MA Jr. Endothelial expression of a mononuclear leukocyte adhesion molecule during atherogenesis. Science 1991; 251: 788-791.

10. Robertson AK, Rudling M, Zhou X, Gorelik L, Flavell RA, et al. (2003) Disruption of TGF-beta signaling in T cells accelerates atherosclerosis. J Clin Invest 2013; 112 : 1342-1350.

11. Ungprasert $\mathrm{P}$, Charoenpong $\mathrm{P}$, Ratanasrimetha $\mathrm{P}$ et al. Risk of coronary artery disease in patients with systemic sclerosis: a systematic review and meta-analysis. Clin Rheumatol 2014;33:1099-1104.

12. Mason J.C, Libby P. Cardiovascular disease in patients with chronic inflammation: mechanisms underlying premature cardiovascular events in rheumatologic conditions. Eur Heart J. 2015 Feb 21; 36(8): 482-489.

13. Tervaert JWC. Cardiovascular disease due to accelerated atherosclerosis in systemic vasculitides. Best Prac Res Clin Rheum 2013;27:33-44.

14. KitasGD, Gabriel SE. Cardiovascular disease in rheu- 
matoid arthritis: state of the art and future perspectives. Ann Rheum Dis 2011;70:8-14.

15. Urowitz MB, Bookman AA, Koehler BE et aò. The bimodal mortality pattern of systemic lupus erythematosus. Am J Med 1976; 60:221-225.

16. Hallenbeck JM, Hansson GK, Becker KJ. Immunology of ischemic vascular disease: Plaque to attack. Trends Immunol 2005; 26: 550-556.

17. Zeller CB, Appenzeller S Cardiovascular disease in systemic lupus erythematosus: the role of traditional and lupus related risk factors. Curr Cardiol 2008 Rev 4: 116122.

18. Mehta JL, Saldeen TG, Rand K . Interactive role of infection, inflammation and traditional risk factors in atherosclerosis and coronary artery disease. J Am Coll Cardiol 1998; 31: 1217-1225.

19. Rho YH, Chung CP, Oeser A et al. Novel cardiovascular risk factors in premature coronary atherosclerosis associated with systemic lupus erythematosus. J Rheumatol 2008; 35:1789-1794.

20. Kahlenberg JM, Kaplan MJ. The interplay of inflammation and cardiovascular disease in systemic lupus erythematosus. Arthritis Res 2011Ther 13: 203.

21. Manzi S, Selzer F, Sutton-Tyrrell K et al. Prevalence and risk factors of carotid plaque in women with systemic lupus erythematosus. Arthritis Rheum 1999; 42: 51-60.

22. Taherian E, Rao A, Malemud CJ, Askari AD (2013) The biological and clinical activity of anti-malarial drugs in autoimmune disorders. Curr Rheumatol Rev 2013; 9: 45-62.

23. Cobb S, Anderson F, Bauer W. Length of life and cause of death in rheumatoid arthritis. N Engl J Med 1953;249:553-556.

24. Gabriel SE. Cardiovascular morbidity and mortality in rheumatoid arthritis. Am J Med 2008;121:S9-S14.

25. KitasGD, Gabriel SE. Cardiovascular disease in rheumatoid arthritis: state of the art and future perspectives. Ann Rheum Dis 2011;70:8-14.

26. Emerging Risk Factors Collaboration, Kaptoge S, Di Angelantonio E. C-reactive protein concentration and risk of coronary heart disease, stroke, and mortality: An individual participant meta-analysis. Lancet 2010;375: 132-140.

27. Landewe RB, van den Borne BE, Breedveld FC et al. Methotrexate effects in patients with rheumatoid arthritis with cardiovascular comorbidity. Lancet 2000; 355:1616-1617.

28. Gladman DD, Brockbank J. Psoriatic arthritis. Expert Opin Investig Drugs 2000; 9: 1511-1522.

29. Tam LS, Tomlinson B, Chu TT et al. Cardiovascular risk profile of patients with psoriatic arthritis compared to controls--the role of inflammation. Rheumatology 2008; 47:718-723.

30. Mok CC, Ko GT, Ho LY, Yu KL, Chan PT, et al. (2011) Prevalence of atherosclerotic risk factors and the meta- bolic syndrome in patients with chronic inflammatory arthritis. Arthritis Care Res 2011; 63:195-202

31. Dean LE, Jones GT, MacDonald AG et al. Global prevalence of ankylosing spondylitis. Rhermatology 2014; 53: 650-657

32. Mathieu S, Pereira, Soubrier M. Cardiovascular events in ankylosing spondylitis. An updated meta-analysis. Semin Arthritis Rheum 2014; Oct 18

33. Jennette JC, Falk RJ, Bacon PA et. Revised International Chapel Hill Consensus Conference Nomenclature of Vasculitides. Arthritis Rheum 2013;65:1-11.

34. Numano F, Okawara M, Inomata H, Kobayashi Y. Takayasu's arteritis. Lancet 2000; 356:1023-1025

35. Gonzalez-Gay MA, Blanco R, Abraira V et al. Giant cell arteritis in Lugo, Spain, is associated with low longterm mortality. J Rheumatol 1997;24: 2171-2176.

36. Abbott RD, Brand FN, Kannel WB et al. Gout and coronary heart disease: the Framingham Study. J Clin Epidemiol 1988;41:237-242.

37. Martinon F, Petrilli V, Mayor A et al. Gout-associated uric acid crystals activate the NALP3 inflammasome. Nature 2006;440:237-241.

38. Murthy SK, Nguyen GC. Venous thromboembolism in inflammatory bowel disease: an epidemiological review. Am J Gastroenterol 2011; 106: 713-718

39. Ha C, Magowan S, Accortt NA, Chen J, Stone CD. Risk of arterial thrombotic events in inflammatory bowel disease. Am J Gastroenterol 2009; 104: 1445-1451

40. Yarur AJ, Deshpande AR, Pechman DM et al. Inflammatory bowel disease is associated with an increased incidence of cardiovascular events. Am J Gastroenterol 2011; 106: 741-747

41. Andersen NN et al . IBD and risk of cardiovascular disease. World J Gastrointest Pathophysiol 2014 August $15 ; 5(3): 359-365$

42. Rueda B, Martínez A, López-Nevot MA et al. A functional variant of IFNgamma gene is associated with coeliac disease. Genes Immun 2004; 5: 517-519.

43. Mormile R. Celiac Disease and Ischemic Heart Disease: What is the Link? Clin Cell Immunol 2013; 4:6

44. Eckburg PB, Bik EM, Bernstein CN, et al. Diversity of the human intestinal microbial flora. Science 2005;308:1635-8.

45. Patrice D. Cani and Nathalie M. Delzenne. The Role of the Gut Microbiota in Energy Metabolism and Metabolic Disease. Current Pharmaceutical Design, 2009, 15, 1546-1558

46. Gerardi V, Del Zompo F., D’Aversa F. Il legame tra il microbiota intestinale e le patologie cardiovascolari $\mathrm{G}$ Ital Cardiol 2016;17(1):11-14

47. Turnbaugh P.J , Ley R.E, Mahowald M.A. An obesity associated gut microbiome with increate capacity for Energy harvest. Nature, 2006; Vol 444

48. Turnbaugh P.J, Hamady M, Yatsunenko T et al. A core gut microbiome in obese and lean twin. Nature, 2009; vol 457 


\title{
Quale ruolo degli inibitori delle PCSK9 in Medicina Interna nella prevenzione cardio-vascolare in alternativa alle terapie tradizionali?
}

\author{
Paola Gnerre, ${ }^{1}$ Paola Zuccheri, ${ }^{2}$ Mauro Campanini, ${ }^{3}$ Giuliano Pinna, ${ }^{4}$ Roberto Nardi ${ }^{5}$ \\ ${ }^{1}$ Medicina Interna 2, Ospedale San Paolo, Savona; ${ }^{2}$ Farmacista Ospedaliera, Ospedale Maggiore, AUSL di Bologna; \\ ${ }^{3}$ Dipartimento Medico, Direttore Medicina Interna 2, Azienda Ospedaliero Universitaria Maggiore della Carità, Novara; \\ ${ }^{4}$ Già Medicina Interna - Asti, Consigliere Onorario Direttivo FADOI Piemonte; ${ }^{5}$ Medicina Interna, Bologna, Italia
}

\section{Il rischio cardio-vascolare in Medicina Interna}

Da tempo FADOI si occupa di rischio cardiovascolare (CV). ${ }^{1,2}$ In due studi (FAPOI -1 del 1996 e FAPOI2 del 1999) nell'analisi di confronto delle modalità di trattamento di pazienti a rischio $\mathrm{CV}$ dimessi da reparti di Medicina Interna, rispettivamente 6450 (235 reparti) e 8133 pazienti (345 reparti) è emersa una maggiore propensione all'impiego di statine, ma con ancora evidente sotto-trattamento di alcune situazioni di rischio, specialmente dell'ipertensione arteriosa, particolarmente nel genere femminile. ${ }^{1}$ Nello studio NIMEC, ${ }^{2}$ effettuato su 902 soggetti reclutati nel rispetto dei criteri di inclusione ed esclusione [457 M, $445 \mathrm{~F}$, età media 72 anni, BMI $26,7 \mathrm{Kg} / \mathrm{m}^{2}$ (range: $26,3-27,1 \mathrm{Kg} / \mathrm{m}^{2}$ )] su 1316 pazienti totali ricoverati in reparti di Medicina Interna, la prevalenza di sindrome metabolica secondo $\mathrm{i}$ criteri ATP-III è risultata pari al 45,3\%. Considerando i criteri IDF (International Diabetes Federation), ${ }^{3}$ la prevalenza di sindrome metabolica nei reparti di Medicina Interna è risultata pari al 38,6\%. In sostanza si può ipotizzare che una quota di circa il $40-45 \%$ dei nostri pazienti ricoverati in Medicina Interna presenta un rischio cardio-vascolare elevato.

\section{Le terapie disponibili per l'ipercolesterolemia}

Le terapie ipocolesterolemizzanti attualmente disponibili includono gli inibitori della 3-idrossi-3-metilglutaril-coenzima A reduttasi (statine), i fibrati, la niacina,

Corrispondente: Paola Gnerre, Medicina Interna 2, Ospedale San Paolo, via Genova n. I, 17100 Savona, Italia.

Tel.: +39.0198404358 - Fax: +39.0198404583 .

E-mail: pgnerre@yahoo.it

Articolo pubblicato secondo la Creative Commons Attribution NonCommercial 4.0 License (CC BY-NC 4.0).

CCopyright P. Gnerre et al., 2017

Licensee PAGEPress, Italy

QUADERNI - Italian Journal of Medicine 2017; 5(7):179-187 gli inibitori selettivi dell'assorbimento del colesterolo (ezetemibe) e più recentemente gli inibitori del pro-proteina convertasi subtilisina/kexina tipo 9 (PCSK9). Il beneficio della terapia ipocolesterolemizzante dipende dal livello iniziale di rischio cardiovascolare $(\mathrm{CV})$ : più alto è il rischio, migliore risulta il beneficio nella riduzione assoluta del rischio. Tutti i pazienti dislipidemici dovrebbero essere valutati in merito al loro rischio $\mathrm{CV}$, allo scopo di definire quale livello di colesterolo LDL (LDLc) perseguire. ${ }^{4}$ La riduzione del LDL-c è un obiettivo chiave indipendentemente dall'approccio utilizzato. La riduzione della concentrazione intracellulare di colesterolo induce un'incremento del recettore LDL sulla superficie cellulare degli epatociti con incrementato uptake del LDL dal circolo ematico e pertanto induce una riduzione della concentrazione plasmatica del LDL-c e di altre lipoproteine che contengono apoB, incluse le particelle ricche di trigliceridi. ${ }^{4}$

\section{Statine, anche con aggiunta di ezetimibe}

Le statine sono tra i principali farmaci studiati nella prevenzione CV. Molteplici studi hanno dimostrato come le statine riducano del $10 \%$ la mortalità e la morbidità cardiovascolare, del $23 \%$ il rischio di eventi coronarici maggiori e del $17 \%$ il rischio di ictus indipendentemente dal sesso, dell'età e dall'etnia. $\mathrm{Al}$ dosaggio in cui riducono l'LDL-c di almeno il 50\% sembrano contribuire anche ad una regressione della malattia aterosclerotica. Il grado di riduzione del LDL$\mathrm{c}$ è dose dipendente e varia tra le differenti statine. ${ }^{5} \mathrm{Va}$ quindi calcolata la percentuale di riduzione del LDL$\mathrm{c}$ necessaria per il raggiungimento del target e successivamente va scelto il tipo di statina in grado di raggiungere quel target. Non ci sono differenze nella riduzione del rischio tra uomini e donne, pazienti più giovani e più anziani con o senza diabete mellito. Il trattamento della dislipidemia con statine è raccomandato anche in pazienti anziani con accertata malattia cardio-vascolare ad elevato rischio, nelle stesse modalità dei pazienti più giovani, pur nel contesto di una valutazione dello stato di robustezza e/o di fragilità del paziente in età avanzata. Per la presenza di comorbidità e dell'alterata farmacocinetica nei pazienti an- 
ziani, i farmaci ipocolesterolemizzanti devono essere iniziati al dosaggio più basso e titolati progressivamente (start low, go slow) per raggiungere il target lipidico desiderato. Il beneficio clinico infatti è indipendente dal tipo di statina utilizzata ma dipende dal grado di riduzione del LDL-c e pertanto il tipo di statina da utilizzare deve riflettere il nostro obiettivo terapeutico per quel dato paziente. ${ }^{6}$ Le statine riducono anche i trigliceridi e il rischio correlato di pancreatite; pertanto tutte le linee guida concordano nell'utilizzarle anche come terapia di prima scelta in pazienti con ipercolesterolemia o iperlipidemia combinata. ${ }^{4}$ Tra le complicanze più frequenti correlate all'utilizzo della terapia con statina risultano il riscontro occasionale ma generalmente reversibile dell' incremento degli enzimi epatici e nel 5-10\% dei pazienti di mialgia, se pur la rabdomiolisi sia estremamente rara. ${ }^{6}$ Il rischio di miopatia con sintomi muscolari severi può essere minimizzato evitando l'interazione delle statine con specifici farmaci. Quando i pazienti, pur presentando mialgie, non presentano la comparsa di concomitante severo incremento delle CPK può essere necessario ridurre il dosaggio della statina per alcune settimane e/o giorni con un successivo graduale incremento. Infine la terapia con statina può determinare un lieve incremento della glicemia e dell'emoglobina glicata ma i benefici correlati all'utilizzo di questi farmaci sulle malattie CV superano il rischio del lieve incremento di malattia diabetica. ${ }^{7}$

La risposta alla terapia con statina è variabile, per cui è necessario fare progressivi aggiustamenti posologici. Se la dose massima di statina tollerata non consente di raggiungere il target di LDL-c previsto si può considerare la combinazione delle statine con altri farmaci. L'uso dell'ezetimibe è raccomandato in combinazione con la statina (in monoterapia solo nei pazienti non tolleranti la statina) quando lo specifico obiettivo terapeutico non è raggiunto con la massima dose tollerata di statina. I dati indicano che la combinazione di terapia con ezetimibe comporta un beneficio aggiuntivo con una riduzione del LDL-c del $15-20 \%$ e degli eventi $\mathrm{CV}^{8}{ }^{8}$ L'utilità incrementale nella riduzione dell'LDL-c dell'aggiunta di ezetimibe alla terapia con statine nei pazienti con precedente sindrome coronarica acuta è stata confermata anche da studi recenti. ${ }^{4}$

\section{Resine a scambio ionico}

Le resine sequestranti gli acidi biliari riducono il colesterolo totale e LDL-c ma sono scarsamente tollerate e tendono ad incrementare la concentrazione plasmatica di trigliceridi. ${ }^{9}$

\section{Fibrati e acido nicotinico}

I fibrati e l'acido nicotinico sono principalmente utilizzati per la riduzione dei trigliceridi e per incre- mentare l'HDL-c mentre gli acidi grassi n-3 alla dose di 2-4 gr/die riducono i trigliceridi. Le evidenze che supportano l'uso di questi farmaci per la riduzione del rischio CV sono limitate, in contrasto alla documentata efficacia delle statine pertanto l'uso routinario nella prevenzione $\mathrm{CV}$ non è raccomandato. ${ }^{10}$

\section{L'effetto del controllo lipidico sul rischio cardiovascolare: bisogni non soddisfatti e possibili sviluppi futuri}

La prevenzione rappresenta un tema di grande attualità, da cui nessun sistema sanitario moderno può prescindere. ${ }^{5}$ La discussione sul concetto di prevenzione in campo CV è molto ampia e dura da tempo. In questo ambito la ricerca non si è mai fermata. Purtroppo ancora oggi si verificano situazioni di rischio $\mathrm{CV}$ persistente dovute allo scarso controllo del LDL-C, nonostante l'ottimizzazione della terapia. È possibile, infatti, che pur in condizioni ottimali di terapia massimale con statine anche associate ad altri farmaci, non si raggiunga il target terapeutico. Ciò riveste particolare importanza nei soggetti affetti da ipercolesterolemia familiare e nei soggetti a rischio alto e molto alto di eventi cardiovascolari in cui bisognerebbe puntare ad una riduzione del $50 \%$ di LDL-c. ${ }^{4}$ Due nuovi farmaci sono stati approvati nel 2013-2014, entrambi i quali inibiscono la produzione di LDL o il suo precursore VLDL. Il mipomersen è un farmaco in grado di inibire la sintesi di apolipoproteina B100: è un oligonucleotide antisenso (ASO), ovvero un breve frammento di DNA che contiene la sequenza nucleotidica complementare del filamento di DNA codificante (senso) o di RNA messaggero (mRNA). Il legame di mipomersen alla sequenza mRNA codificante per l'apolipoproteina B provoca la degradazione della sequenza mRNA da un enzima specifico, inibendo così la traduzione della apoB e riducendone efficacemente le concentrazioni. La lomitapide è un un inibitore della proteina che trasferisce i trigliceridi a livello dei microsomi e che si è dimostrata efficace e sicura nella gestione dell'ipercolesterolemia familiare omozigote. Oggi si stagliano ulteriori opzioni terapeutiche, nei soggetti a rischio $\mathrm{CV}$ molto elevato, basate sull'impiego degli anticorpi monoclonali anti PCSK9, su cui dovranno essere effettuate ulteriori valutazioni, alla luce delle evidenze disponibili. ${ }^{4}$ Altri farmaci proposti per l'abbassamento del colesterolo in alternativa alle statine o in caso di fallimento e/o intolleranza a tali farmaci sono i siRNA (small interfering $R N A$ - brevi RNA interferenti). ${ }^{11}$

\section{PCSK9: le basi fisiopatologiche}

Come accennato sopra, un altro target della terapia ipocolesterolemizzante è la PCSK9 (Proprotein Convertase Subtilisin/Kexin type 9), la cui azione più nota 
è relativa al suo coinvolgimento nella regolazione della colesterolemia. L'enzima viene prodotto dal fegato e, attraverso il circolo, raggiunge altri organi e tessuti. La PCSK9 agisce principalmente nel fegato, degradando i recettori per le LDL e, in alcune situazioni genetiche caratterizzate da un guadagno di funzione, è responsabile di ipercolesterolemia. Essa interagisce con il recettore LDL favorendone la precoce degradazione e impedendone il riciclo. La PCSK9 in definitiva regola il livello del colesterolo LDL, modulando il numero di recettori (LDL-r) della membrana cellulare che legano le LDL: quando il recettore lega le LDL, il complesso viene internalizzato nella cellula epatica in forma di vescicola che si fonde con gli endosomi, quindi la LDL viene degradata ed il recettore ritorna sulla superficie cellulare. Se nella formazione del complesso recettore-LDL si aggiunge la PCSK9 si ha la degradazione a livello lisosomiale anche del recettore: quindi diminuisce il numero dei recettori esposti sulla membrana della cellula epatica. La conseguenza è una minore clearance delle LDL. Inibendo l'attività della PCSK9 si riduce quindi il colesterolo-LDL circolante in quanto in pratica aumenta l'espressione dei recettori LDL. I meccanismi di inibizione della PCSK9 sono sostanzialmente due: mediante l'impiego di anticorpi che impediscono di legarsi al recettore LDL-C o con farmaci in grado di bloccare il suo RNA messaggero (Figure 1 e 2).

Sono state individuate mutazioni genetiche che determinano un aumento dell'attività della PCSK9 con conseguente grave ipercolesterolemia familiare e, al contrario, anomalie genetiche con perdita di funzione (PCSK9 LoF: loss of function), che si associano invece ad ipobeta-lipoproteinemia, ad un basso valore di LDL-c e ad una riduzione della rischio CV di circa il 40\%. ${ }^{12,13}$ I pazienti con mutazione PCSK9 GoF (gain of function) hanno viceversa ipercolesterolemia familiare con alti livelli di LDL-c, xantomi tendinei, aterosclerosi precoce con CAD e altre complicanze CV..$^{13-18}$ La PCSK9 tende ad aumentare in corso di terapia con statine contrastandone l'effetto dose-risposta: la somministrazione di una statina a dosi crescenti aumenta progressivamente il livello di PCSK9, i recettori LDL-c vengono degradati più rapidamente, la funzione recettoriale diminuisce e con essa diminuisce la rimozione delle LDL dal circolo che è il fenomeno di base dell'azione ipocolesterolemizzante delle statine. ${ }^{19}$ PCSK9 è probabilmente implicata nell'ipercolesterolemia dopo la menopausa e forse in quella secondaria all'ipotiroidismo. ${ }^{20}$

\section{Gli inibitori della PCSK9: le evidenze e i trial clinici disponibili}

Come sopra descritto, l'inibizione della PCSK9 previene la degradazione del recettore e promuove la rimozione del LDL-c dal circolo. ${ }^{21-23}$ Gli inibitori della PCSK9 (I-PCSK9) sono dunque indicati per il trattamento di pazienti con ipercolesterolemia familiare, intolleranti alle statine e ad elevato rischio cardiovascolare.

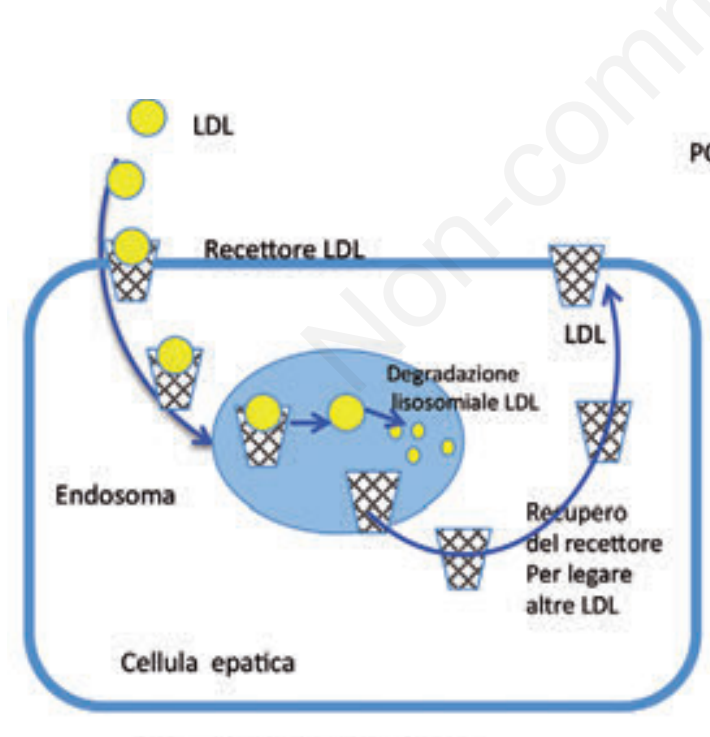

A. Recettori LDL nell'epatocita

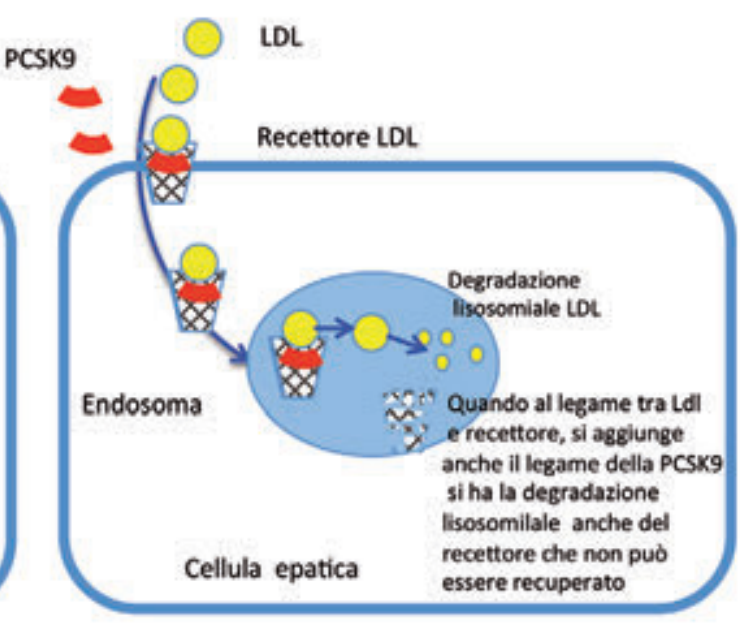

B. la PCSK9 degrada a livello lisosomiale il recettore che non diventa più disponibile

\section{L'inibizione della PCSK9 ripristina la condizione normale}

Figura 1. Attività della PCSK9. Se nella formazione del complesso recettore-LDL si aggiunge la PCSK9 si ha la degradazione a livello lisosomiale anche del recettore: quindi diminuisce il numero dei recettori esposti sulla membrana della cellula epatica. 
Tali farmaci si sono dimostrati in grado di ridurre ulteriormente i livelli di LDL-c del 50-70\% quando somministrati sia in monoterapia che insieme a statine. ${ }^{24}$ Altri dati mostrano effetti altrettanto positivi, con una diminuzione dose-dipendente del LDL-c (dal 44\% al 65\%), dell'apolipoproteina B (48\%-59\%) e della lipoproteina (a) $(27 \%-50 \%)$, in assenza di reazioni avverse, neanche nei pazienti già trattati con statine. ${ }^{25}$ L'inibizione della PCSK9 con anticorpi monoclonali, allo scopo di ridurre i livelli circolanti di LDL-c ha richiesto molti anni di ricerca. ${ }^{26}$ In base agli studi di Lagace sulle interazioni della PCSK9 circolante con i recettori LDL (LDL-r) si è sviluppato il razionale per l'introduzione di anticorpi monoclonali per inibire la PCSK $9 .{ }^{27}$ I primi due anticorpi monoclonali ( $\mathrm{mAbs}$ ), alirocumab e evolocumab, sono stati considerati in studi clinici nel 2009 e da allora sono state dimostrate riduzioni rilevanti, rapide e persistenti dei valori di LDL-c in pazienti con una vasta gamma di dislipidemie e anche in pazienti con comorbidità già in trattamento con altri farmaci. Nel 2015 sul New England Journal of Medicine sono stati pubblicati i primi dati sull'efficacia dell'alirocumab ${ }^{28}$ e dell'evolocumab $^{29}$ nella prevenzione cardiovascolare. Entrambi i farmaci sono stati conseguentemente approvati dalla $U S$ Food and Drug Administration (FDA) e dall'Agenzia Europea dei Medicinali (EMA) alla fine del 2015. Evolocumab ha ottenuto l'approvazione in Giappone nei primi mesi del $2016 .{ }^{30}$ Un terzo anticorpo monoclonale, il bococizumab, è ancora in fase III di sviluppo clinico. ${ }^{31}$ Il bococizumab è oggetto di studio nel trial SPIRE- $1,{ }^{32}$ in cui saranno arruolati 12.000 pazienti con livelli di LDL-c tra 70 e $100 \mathrm{mg} / \mathrm{dl}$ in trattamento con dosi massime di statine, con un evento CV pregresso oppure anche per la prevenzione primaria in soggetti al alto rischio: l'endpoint primario è rappresentato dall'occorrenza di morte $\mathrm{CV}$, di infarto o ictus non fatali oppure angina instabile che richieda ospedalizzazione urgente (lo studio dovrebbe essere completato nel 2017) Nel trial SPIRE-2 (www.clinicaltrials.gov: NCT01975389) è previsto lo stesso protocollo dello SPIRE-1 con la differenza che i 6300 pazienti da arruolare dovranno avere livelli di LDL-c $>100 \mathrm{mg} / \mathrm{dl}$ in trattamento con dosi massime di statine o, se intolleranti ad esse, altri farmaci ipolipemizzanti (Tabella 1). ${ }^{33-35}$

In sostanza, alirocumab e evolocumab sono a tutt'oggi approvati come terapie da aggiungere alle statine quando le statine da sole non sono sufficienti ad abbassare il colesterolo o in sostituzione delle statine stesse quando provocano effetti collaterali inaccettabili. Tuttavia gli anticorpi monoclonali hanno una relativamente breve durata d'azione, necessitando di frequenti iniezioni sottocutanee. Va evidenziato, infine, che evolocumab e alirocumab sono stati autorizzati sulla base di una misura biochimica surrogata, piuttosto che in base a risultati clinicamente rilevanti, per cui la loro efficacia clinica e la sicurezza a lungo termine rimangono incerte. ${ }^{36}$ Questa è la ragione per cui NICE ha proposto di limitare l'uso di questi farmaci costosi solamente per sottogruppi altamente selezionati. ${ }^{37,38}$

Lo studio ORION, studio multicentrico randomizzato in fase 2 , ha dimostrato risultati promettenti anche per un terzo inibitore della PCSK9, l'inclisiran che dopo una singola dose di farmaco ha evidenziato una riduzione del colesterolo LDL tra il $28-42 \%$ a 180 giorni, e dopo due dosi tra il $35-53 \%$ a 180 giorni. ${ }^{39}$

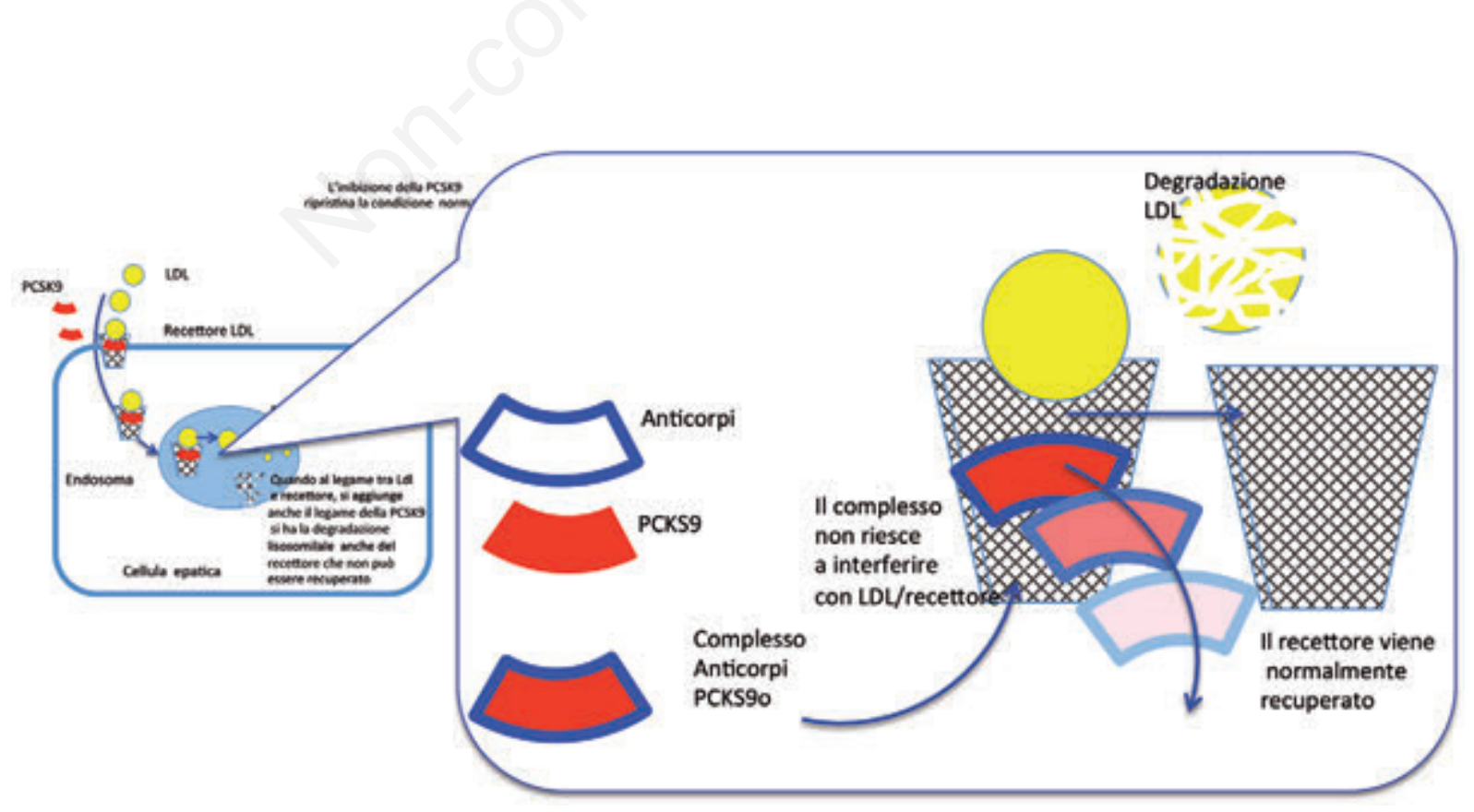

Figura 2. Gli anticorpi anti PCSK9 (alirocumab evolocumab) le impediscono di legarsi al recettore, mantenendone l'integrità e la funzionalità. 


\section{Reazioni avverse ed effetti indesiderati}

Sebbene gli studi siano stati di breve durata, non sono stati osservati eventi avversi $(\mathrm{AE}=$ adverse events) di particolare rilievo associati all' uso di Ab- anti PCSK9. Nella Tabella 2 sono riportate le più frequenti reazioni avverse (da scheda tecnica dei rispettivi farmaci considerati). Tra gli eventi avversi possibili è stato segnalato un aumentato rischio di cataratta. $^{39}$

Tabella 1. Risultati dei principali trials clinici con Alirocumab ed Evolocumab.34,35

\begin{tabular}{|c|c|c|c|c|c|}
\hline \multirow[t]{2}{*}{ Studio } & \multirow[t]{2}{*}{ Popolazione } & \multirow[t]{2}{*}{ Durata } & \multicolumn{2}{|c|}{ Riduzione LDL } & \multirow[t]{2}{*}{ P value } \\
\hline & & & Alirocumab & Trattamento di confronto & \\
\hline MONO & $\begin{array}{l}\text { Ipercolesterolemia e rischio } \\
\text { cardiovascolare moderato }\end{array}$ & 24 settimane & $47 \%$ & $16 \%$ (ezetimibe) & $<0,0001$ \\
\hline FH I & $\mathrm{HeFH}$ & 24 settimane & $49 \%$ & $9 \%$ (placebo) & $<0,0001$ \\
\hline FH II & $\mathrm{HeFH}$ & 24 settimane & $49 \%$ & $3 \%$ (placebo & $<0,0001$ \\
\hline HIGH FH & $\mathrm{HeFH}$ & 24 settimane & $46 \%$ & $7 \%$ (placebo) & $<0,0001$ \\
\hline LONG TERM & $\begin{array}{l}\text { Rischio cardiovascolare } \\
\text { alto ASCVD/HeFH }\end{array}$ & 52 settimane & $57 \%$ & +4 (placebo) & $<0,0001$ \\
\hline ALTERNATIVE & $\begin{array}{l}\text { Rischio cardiovascolare alto e } \\
\text { intolleranza ad almeno due statine }\end{array}$ & 24 settimane & $45 \%$ & $15 \%$ (ezetimibe) & $<0.0001$ \\
\hline OPTIONS I & Rischio cardiovascolare alto & 24 settimane & $44-54 \%$ & $\begin{array}{c}21-23 \% \text { (ezetimibe } 5 \% \\
\text { (doppia dose di statina } \\
21 \% \text { (cambio di statina) }\end{array}$ & $=0,01$ \\
\hline OPTIONS II & Rischio cardiovascolare alto & 24 settimane & $35-51 \%$ & $\begin{array}{c}11-14 \% \text { (ezetimibe) } \\
16 \% \text { (doppia dose di statina) }\end{array}$ & $=0,0125$ \\
\hline COMBO I & Rischio cardiovascolare alto & 24 settimane & $48 \%$ & $2 \%$ (placebo $)$ & $<0,0001$ \\
\hline COMBO II & Rischio cardiovascolare alto & 24 settimane & $51 \%$ & $21 \%$ (ezetimibe) & $<0,0001$ \\
\hline \multirow[t]{2}{*}{$\begin{array}{l}\text { ODYSSEY } \\
\text { Outcomes }\end{array}$} & Rischio cardiovascolare alto & $\begin{array}{l}24 \text { settimane } \\
78 \text { settimane }\end{array}$ & $\begin{array}{c}61 \% \\
52,4 \%\end{array}$ & $\begin{array}{l}0,8 \text { (placebo) } \\
3,6\end{array}$ & $\begin{array}{l}<0,001 \\
<0,001\end{array}$ \\
\hline & & $y_{2}$ & Evolocumab & Trattamento di confronto & \\
\hline MENDEL-2 & $\begin{array}{l}\text { Ipercolesterolemia e rischio } \\
\text { cardiovascolare basso }\end{array}$ & 12 settimane & $56-57 \%$ & $\begin{array}{l}18-19 \% \text { (ezetimibe) } \\
0,1-1 \% \text { (placebo) }\end{array}$ & $<0,01$ \\
\hline DESCARTES & Ipercolesterolemia & 52 settimane & $47-55 \%$ & $2-10 \%$ (placebo) & $<0,001$ \\
\hline LAPLACE-2 & $\begin{array}{l}\text { Ipercolesterolemia e } \\
\text { dislipidemia mista }\end{array}$ & 12 settimane & $63-75 \%$ & $19-32 \%$ (ezetimibe) & $<0,001$ \\
\hline GAUSS-2 & $\begin{array}{l}\text { Ipercolesterolemia e intolleranza } \\
\text { ad almeno due statine }\end{array}$ & 12 settimane & $55-56 \%$ & 37-39\% (ezetimibe) & $<0,001$ \\
\hline RUTHERFORD-2 & $\mathrm{HeFH}$ & 12 settimane & $56-61 \%$ & $-1 \% /+5 \%$ (ezetimibe) & $<0,001$ \\
\hline TESLA-B & HoFH & 12 settimane & $23 \%$ & $+8 \%$ (placebo $)$ & $<0,001$ \\
\hline
\end{tabular}

FOURIER 22.500 pazienti con pregressi eventi CV ed ad alto rischio residuo, con livelli di C-LDL $>70 \mathrm{mg} / \mathrm{dl}$ in terapia con statine ad alta efficacia, randomizzati al trattamento con evolocumab o placebo, valutando un endpoint composito costituito da morte cardiaca, infarto non fatale ed ospedalizzazione per angina instabile, ictus o rivascolarizzazione coronarica (www.clinicaltrials.gov: NCT01764633)

EBBINGHAUS RCT di non inferiorità, in doppio cieco, controllato con placebo, randomizzato, condotto su circa 1900 pazienti arruolati nello studio FOURIER, per la valutazione della funzione cognitiva in pazienti trattati con evolocumab. I risultati dettagliati dei trial FOURIER ed EBBINGHAUS saranno presentati i prossimi 17 e 18 marzo durante il $66^{\circ}$ congresso annuale dell'American College of Cardiology (ACC)

\begin{tabular}{|c|c|c|c|}
\hline GLAGOV & $\begin{array}{l}\text { Pazienti con coronaropatia } \\
\text { documentata con coronarografia } \\
\text { e LDL-C elevato }\end{array}$ & 78 settimane & $\begin{array}{l}\text { - Esito primario: riduzione del volume dell'ateroma } \\
\text { del }-0,95 \% \text { nel gruppo evolocumab contro } 0,05 \% \\
\text { nel gruppo placebo } \\
\text { - Pazienti con regressione della placca: } 64,3 \% \text { con } \\
\text { evolocumab rispetto al } 47,3 \% \text { con placebo }(\mathrm{P}<0,001) \\
\text { - Riduzione dei livelli di LDL-c con evolocumab: }-59,8 \%\end{array}$ \\
\hline
\end{tabular}

LDL-C=colesterolo LDL, FH=ipercolesterolemia familiare, $\mathrm{HeFH}=$ ipercolesterolemia familiare eterozigote, $\mathrm{HoFH}=$ ipercolesterolemia familiare omozigote, $\mathrm{ASCVD}=\mathrm{Atherosclerotic}$ Cardiovascular Disease, RCT = Randomized Clinical Trial; FOURIER (Further Cardiovascular OUtcomes Research with PCSK9 Inhibition in Subjects with Elevated Risk; EBBINGHAUS (Evaluating PCSK9 Binding antiBody Influence oN coGnitive HeAlth in high cardiovascUlar risk Subjects);GLAGOV (GLobal Assessment of Plaque ReGression with a PCSK9 AntibOdy as Measured by IntraVascular Ultrasound) study). 


\section{Inibitori del PCSK9 anche nei pazienti intolleranti alle statine?}

L'intolleranza alle statine è un problema relativamente comune nei pazienti. Bilanciare la sintomatologia del paziente con la sua necessità di ridurre $\mathrm{i}$ livelli di colesterolo per ridurre gli eventi cardiovascolari può essere una sfida clinica a volte difficile. In un sondaggio internazionale, l'incidenza di effetti avversi correlati alle statine variavano dal $2 \%$ in Giappone, Spagna, Italia e Svezia al $10 \%$ al $12 \%$ in Canada, nel Regno Unito, e USA..$^{40}$ In un ampio studio retrospettivo di coorte, 6579 di 11.124 pazienti che hanno interrotto una statina a causa di effetti avversi sono stati successivamente risottoposti al trattamento con il $92 \%$ di successo anche se non necessariamente con la stessa statina o dose. I risultati dello studio GAUSS-3 hanno dimostrato come nei pazienti intolleranti alle statine l'uso di evolocumab rispetto a ezetimibe ha comportato una riduzione significativamente maggiore dei livelli di colesterolo LDL dopo 24 settimane di trattamento. Ulteriori studi sono comunque necessari per valutare l'efficacia e la sicurezza a lungo termine. ${ }^{41}$

L'autore dello studio ha quindi concluso che in presenza di un paziente che riferisce sintomi da intolleranza alle statine dovremmo provare a avviare una statina a basso dosaggio con una lenta titolazione. Se l'esito è sempre negativo allora è possibile proporre le alternative disponibili. ${ }^{42}$

\section{Un limite evidente: il costo elevato di tali farmaci e la loro rimborsabilità}

In USA il costo per la terapia di un anno con evolocumab si aggira sui $\$ 14.100$, leggermente meno di quella con alirocumab. Nel Regno Unito il prezzo di listino è di 340,20 sterline per una confezione che dura 28 giorni, equivalenti a circa 6780 dollari per un anno di terapia. In Austria e Finlandia, la terapia di un anno costerà tra 7293-7825 euro. Il costo negli altri Paesi europei, tra cui il nostro, deve ancora essere determinato. In Italia esistono in commercio due specialità medicinali a base di inibitori della PCSK9: REPATHA (evolocumab) $140 \mathrm{mg}$ soluzione iniettabile sottocute, 2 penne preriempite [prezzo al pubblico 717,40€; ex-factory 434,68€] e PRALUENT (alirocumab) $75 \mathrm{mg}$ e $150 \mathrm{mg}$ soluzione iniettabile sottocute 2 penne preriempite [prezzo al pubblico $1272 €]$. La classe di rimborsabilità di Repatha è stata definita con determina pubblicata in GU n. 31 del $7 / 2 / 2017$ per i pazienti adulti affetti da ipercolesterolemia primaria (familiare eterozigote e non familiare) o da dislipidemia mista, in aggiunta alla dieta: in associazione ad una statina o ad una statina con altre terapie ipolipemizzanti in pazienti che non aggiungono livelli di LDL-c target con la dose massima tollerata di una statina, oppure in monoterapia o in associazione ad altre terapie ipolipemizzanti in pazienti intolleranti alle statine o per i quali l'uso di statine è controindicato.

Tabella 2. Reazioni avverse (da scheda tecnica).

\begin{tabular}{|c|c|c|c|}
\hline \multicolumn{4}{|c|}{ Classificazione per sistemi ed organi } \\
\hline$\sqrt{x+2}$ & & $\begin{array}{l}\text { Evolocumab } \\
\text { Classificazione secondo MedDRA }\end{array}$ & Alirocumab \\
\hline Infezioni ed infestazioni & Influenza & $\begin{array}{l}\text { Comune } \\
\text { Nasofaringite } \\
\text { Infezioni delle vie respiratorie }\end{array}$ & $\begin{array}{l}\text { Comune } \\
\text { Comune }\end{array}$ \\
\hline $\begin{array}{l}\text { Patologie respiratorie, toraciche } \\
\text { o mediastiniche }\end{array}$ & $\begin{array}{l}\text { Segni e sintomi delle alte } \\
\text { vie respiratoria* }\end{array}$ & & Comune \\
\hline Disturbi del sistema immunitario & Rash & $\begin{array}{l}\text { Comune } \\
\text { Orticaria } \\
\text { Iperesensibilità, vasculite da ipersensibilità }\end{array}$ & $\begin{array}{l}\text { Raro } \\
\text { Non comune } \\
\text { Raro }\end{array}$ \\
\hline Patologie gastrointestinali & Nausea & Comune & \\
\hline Patologie della cute e del tessuto sottocutaneo & $\begin{array}{l}\text { Prurito } \\
\text { Orticaria, eczema nummulare }\end{array}$ & & $\begin{array}{l}\text { Comune } \\
\text { Raro }\end{array}$ \\
\hline $\begin{array}{l}\text { Patologie del sistema muscoloscheletrico } \\
\text { e del tessuto connettivo }\end{array}$ & $\begin{array}{l}\text { Mal di schiena } \\
\text { Artralgie }\end{array}$ & $\begin{array}{l}\text { Comune } \\
\text { Comune }\end{array}$ & \\
\hline $\begin{array}{l}\text { Patologie sistemiche e condizioni relative } \\
\text { alla sede di somministrazione }\end{array}$ & $\begin{array}{l}\text { Reazioni al sito di } \\
\text { somministrazione }^{\circ}\end{array}$ & Comune & Comune \\
\hline
\end{tabular}

*Compresi soprattutto dolore orofaringeo, rinorrea, starnuti; ${ }^{\circ}$ compresi eritema/rossore, prurito, gonfiore, dolore indebolimento. 


\section{Ipercolesterolemia familiare omozigote}

Repatha è indicato in associazione ad altre terapie ipolipemizzanti negli adulti e negli adolescenti di almeno dodici anni di età con ipercolesterolemia familiare omozigote. L'effetto di Repatha sulla morbilità e sulla mortalità cardiovascolare non è ancora stato determinato. Repatha è in classe $A$ e quindi prescrivibile a carico del Servizio Sanitario Nazionale (SSN) solo da parte dei centri ospedalieri individuati dalle Regioni o su prescrizione dello specialista cardiologo e internista. Inoltre è obbligatoria la compilazione di un apposito Registro AIFA con scheda raccolta dati informatizzata di arruolamento che indica i pazienti eleggibili e la scheda di follow up per le successive prescrizioni. La classe di rimborsabilità di Praluent non è stata ancora negoziata, pertanto ad oggi (15 febbraio $2017 \mathrm{ndr}$ ) risulta in classe $C$, Non Negoziata (CNN) e di conseguenza non prescrivibile a carico del SSN. La prescrizione è quindi a totale carico del cittadino e può essere fatta esclusivamente con ricetta limitativa redatta da parte di centri ospedalieri individuati dalle Regioni o di specialisti cardiologi e internisti. Praluent è indicato in adulti con ipercolesterolemia primaria (familiare eterozigote o non familiare) o dislipidemia mista, in aggiunta alla dieta: in associazione con una statina o una statina con altre terapie ipolipe- mizzanti in pazienti non in grado di raggiungere gli obiettivi per il LDL-c con la dose massima tollerata di statine oppure in monoterapia o in associazione con altre terapie ipolipemizzanti in pazienti intolleranti alle statine o per i quali una statina è controindicata. L'effetto di Praluent su morbilità e mortalità cardiovascolare non è stato ancora determinato.

\section{Ulteriori strumenti farmacologici in grado di ridurre i livelli di PCSK9: le siRNAs}

Un'altra classe di molecole è in grado di diminuire i livelli di PCSK9: le siRNAs (small interfering RNA). Esse sono degli oligonucleotidi che hanno come obiettivo direttamente l'RNA [in questo caso, RNA messaggero (mRNA)] della PSCK9, distruggendolo e quindi non rendendolo disponibile per la sintesi della proteina (Figura 3). L'entusiasmo iniziale per le promesse degli inibitori del RNA da utilizzare terapeuticamente si è ridimensionato in ragione del fatto che numerosi composti non avevano dimostrato una minima efficacia clinica nei primi trials. Ma recentemente l'Inclisiran (ALN-PCSsc), una molecola sintetica che è resa long-acting dalla coniugazione con la triantennary $\mathrm{N}$-acetilgalactosamina carbohydrates

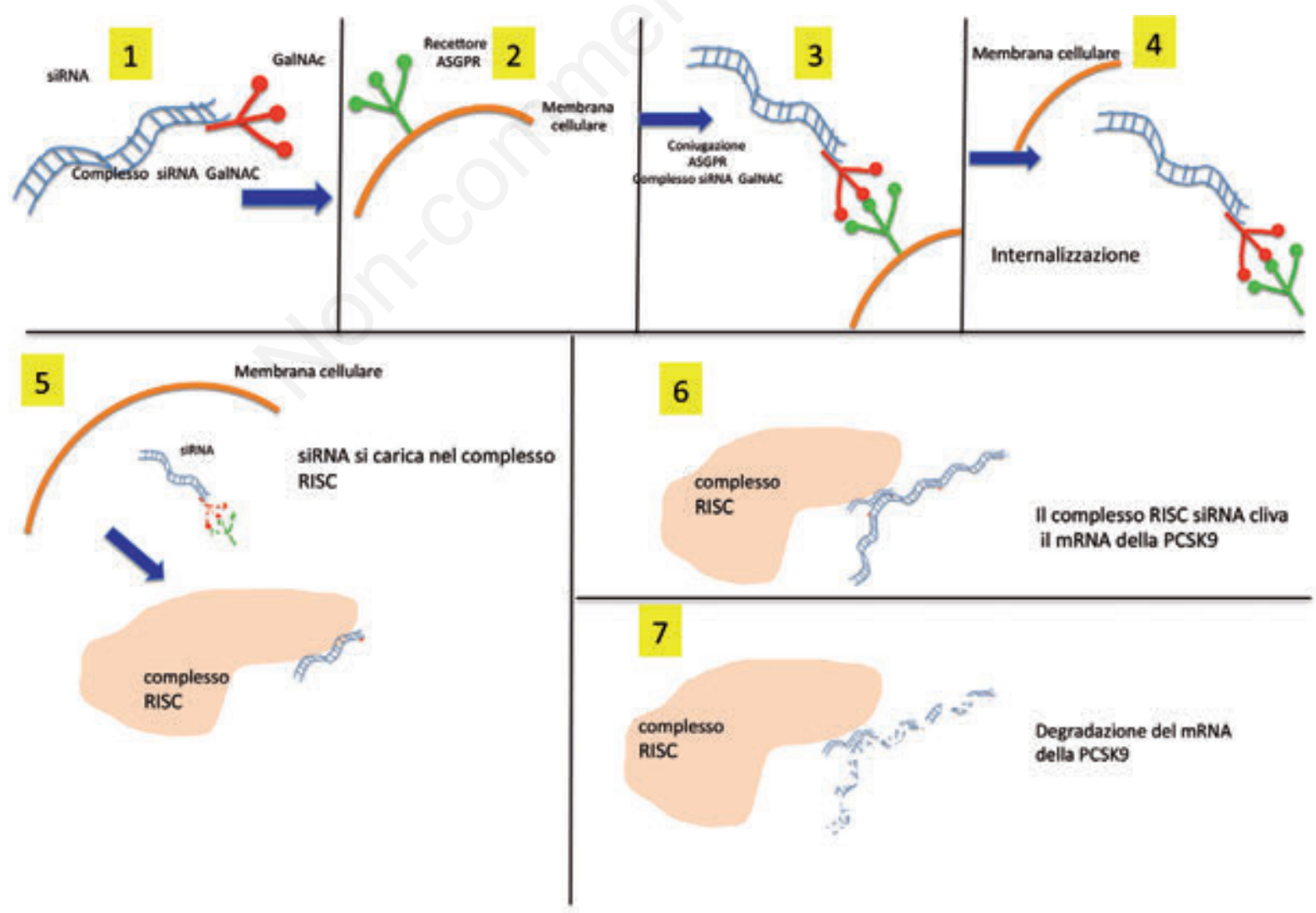

Figura 3. Modalità d'azione del siRNA. 
(GalNAc) è stato approvato per la via somministrazione sottocutanea. Questi carboidrati si legano a recettori, abbondantemente espressi nel fegato, di asialo-glicoproteine, vengono specificatamente internalizzati negli epatociti ed hanno dimostrato di avere effetti estremamente potenti e durevoli: una singola iniezione sottocutanea può abbassare l'LDL colesterolo di un paziente per sei mesi. In uno studio, Inclisiran è stato somministrato in volontari sani con un livello di colesterolo LDL di almeno $100 \mathrm{mg} / \mathrm{dL}$ in una periodica iniezione del farmaco o di placebo, con singola dose crescente o multi-dose. I parametri di valutazione comprendevano, in aggiunta ai livelli di colesterolo LDL e PCSK9, anche gli effetti collaterali e la sicurezza. I risultati ottenuti hanno rivelato come dosi di $300 \mathrm{mg}$ o più fossero in grado di ridurre I livelli di PCSK9 e di LDL-C per periodi lunghi fino a 6 mesi. Nel caso delle multi-dosi invece, tutti i dosaggi hanno dimostrato di provocare una riduzione simile del colesterolo LDL e della PCSK. ${ }^{38,39}$

Il vantaggio dunque dell'Inclisiran, anche rispetto agli anticorpi monoclonali, consiste nella lunghissima durata d'azione (un'iniezione s.c. ogni 6-12 mesi contro un'iniezione s.c. ogni 2-4 settimane con gli anticorpi monoclonali).

\section{Conclusioni}

In ogni persona, la prevenzione delle malattie cardiovascolari deve essere effettuata e adattata sulla base della quantificazione del rischio CV totale individuale. Più alto è il rischio più intenso dovrà essere il piano di azione. Il controllo lipidico basato sul raggiungimento di livelli target di LDL-c in relazione al rischio $\mathrm{CV}$ individuale è una delle azioni cardini per la prevenzione e il trattamento delle malattie cardiovascolari efficace in tutte le popolazioni, in entrambi i sessi e in qualunque classe di età. Solo nei pazienti con età superiore a 80 anni è opportuno valutare caso per caso l'avvio della terapia in considerazione della presenza di comorbidità. Dopo aver calcolato per ogni paziente il rischio CV la terapia con statine dopo la modifica degli stili di vita rappresenta il primo passo terapeutico per il raggiungimento degli obiettivi target di LDL-c. Se gli obiettivi non sono raggiunti con la dose massima di statina tollerata è indicata l'aggiunta di altri farmaci ipocolesterolemizzanti come l'ezetimibe o le resine. Attualmente abbiamo a disposizione nuovi farmaci ipocolesterolemizzanti, quali gli anticorpi monoclonali anti PCSK9 e le le siRNAs. In attesa di indicazioni operative da parte degli organi istituzionali e consapevoli del contesto economico, siamo certi che gli internisti sapranno utilizzare tali nuovi presidi con la massima appropriatezza prescrittiva secondo le indicazioni normative vigenti.

\section{Bibliografia}

1. Di Rosa S, Iori I, Vescovo G, Puddu PE, Lanti M, Menotti A, Trends in cardiovascular risk factors and their treatment among patients discharged from divisions of internal medicine. The FAPOI-1 and FADOI-2 studies, Ital Heart J 2003; 4(7): 460-7.

2. Nardi R, Blasi I, Alduino R, Arnone S, et al.for the NIMEC Investigators Group, Sindrome metabolica nei pazienti ricoverati in Medicina Interna: risultati dello studio pilota NIMEC (National Internal Medicine Equivalent/Complex C-V-@Risk), Italian Journal of Medicine 2007; 1/3: 21-31.

3. Alberti KG, Zimmet P, Shaw J; IDF Epidemiology Task Force Consensus Group. The metabolic syndrome - a new worldwide definition. Lancet 2005; 366: 1059-1062

4. ESC/EAS 2016 Guidelines for the Management of Dyslipidaemias, European Heart Journal 2016), 37: 29993058

5. Weng TC, Yang YH, Lin SJ, Tai SH. A systematic review and meta-analysis on the therapeutic equivalence of statins. J Clin Pharm Ther 2010;35:139-151

6. Mortensen MB, Afzal S, Nordestgaard BG, Falk E. The high-density lipoprotein-adjusted SCORE model worsens SCORE-based risk classification in a contemporary population of 30,824 Europeans: the Copenhagen General Population Study. Eur Heart J 2015;36:24462453

7. Piepoli MF, Hoes AW, Agewall S et al. Task Force Members. 2016 European Guidelines on cardiovascular disease prevention in clinical practice: The Sixth Joint Task Force of the European Society of Cardiology and Other Societies on Cardiovascular Disease Prevention in Clinical Practice (constituted by representatives of 10 societies and by invited experts) Developed with the special contribution of the European Association for Cardiovascular Prevention \& Rehabilitation (EACPR). Eur Heart J. 2016, 37/29: 2315-81

8. Rossebø AB, Pedersen TR, Boman K et al, Intensive lipid lowering with simvastatin and ezetimibe in aortic stenosis. N Engl J Med 2008; 359: 1343-1356

9. Ooi CP, Loke SC. Colesevelam for type 2 diabetes mellitus: an abridged Cochrane review. Diabet Med 2014;31:2-14

10. Keene D, Price C, Shun-Shin MJ, Francis DP. Effect on cardiovascular risk of high density lipoprotein targeted drug treatments niacin, fibrates, and CETP inhibitors: meta-analysis of randomised controlled trials including 117, 411 patients. BMJ 2014; 349: g4379

11. Khvorova A, Oligonucleotide Therapeutics - A New Class of Cholesterol-Lowering Drugs, N Engl J Med 2017, 376/1: 4-7

12. Turner T, Raal FJ, Stein EA, Evolving Targets of Therapy: Proprotein Convertase Subtilisin/Kexin 9 Inhibition. In: Ballantyne C, ed. Clinical Lipidology: A Companion to Braunwald's Heart Disease. 2nd ed: Elsevier; 2014: 346-357

13. Cohen JC, Boerwinkle E, Mosley TH Jr, Hobbs HH, Sequence variations in PCSK9, low LDL, and protection against coronary heart disease, N Engl J Med 2006; 354 : 1264-72 CIT

14. Abifadel M, Varret M, Rabès JP, Allard D, et al, Muta- 
tions in PCSK9 cause autosomal dominant hypercholesterolemia, Nat Genet. 2003; 34: 154-156

15. Kotowski IK, Pertsemlidis A, Luke A, Cooper RS, Vega GL, Cohen JC, Hobbs HH, A spectrum of PCSK9 alleles contributes to plasma levels of low-density lipoprotein cholesterol, Am J Hum Genet 2006; 78:410-422

16. Norata GD, Garlaschelli K, Grigore L, Raselli S, Tramontana $\mathrm{S}$, Meneghetti F, Artali R, Noto D, Cefalù $\mathrm{AB}$, Buccianti G, Averna M, Catapano AL, Effects of PCSK9 variants on common carotid artery intima media thickness and relation to ApoE alleles, Atherosclerosis 2010; 208: $177-182$

17. Tibolla G, Norata GD, Artali R, et al, Proprotein Convertase Subtilisin/Kexin Type 9 (PCSK9): From Structure-Function Relation to Therapeutic Inhibition, Nutr Metab Cardiovasc Dis 2011, 21: 835-843

18. Vogt A, The genetics of familial hypercholesterolemia and emerging therapies, The Application of Clinical Genetics 2015, 8: 27-36

19. Welder G, Zineh I, Pacanowski MA, Troutt JS, Cao G, Konrad RJ, High-dose atorvastatin causes a rapid sustained increase in human serum PCSK9 and disrupts its correlation with LDL cholesterol, J Lipid Res 2010; 51 : 2714-2721

20. Sommariva D, Primi dati sull'efficacia degli anticorpi anti PCSK9 nella prevenzione cardiovascolare, SISAUpdate, http://www.sisa.it/index.php?class=Comp\&className $=\mathrm{C}$ ontent\&op=Show\&param=cid,743,preview,0).

21. Lagace TA, Curtis DE, Garuti R, et al. Secreted PCSK9 decreases the number of LDL receptors in hepatocytes and in livers of parabiotic mice. J Clin Invest 2006; 116 : 2995-3005

22. Zhang DW, Lagace TA, Garuti R, et al, Binding of proprotein convertase subtilisin/kexin type 9 to epidermal growth factor-like repeat A of low density lipoprotein receptor decreases receptor recycling and increases degradation, J Biol Chem 2007; 282: 18602-18612

23. Benjannet S, Rhainds D, Essalmani R et al, NARC1/PCSK9 and its natural mutants: zymogen cleavage and effects on the low density lipoprotein (LDL) receptor and LDL cholesterol. J Biol Chem 2004; 279: 4886548875

24. Shimada YJ, Cannon CP, CSK9 (Proprotein convertase subtilisin/kexin type 9) inhibitors: past, present, and the future, Eur Heart J 2015, 36/36: 2415-2424

25. Bergeron N, Phan BA, Ding Y, Fong A, Krauss RM, Proprotein convertase subtilisin/kexin type 9 inhibition: a new therapeutic mechanism for reducing cardiovascular disease risk, Circulation 2015; 132/17: 1648-1666

26. Seidah NG, Awan Z, Chrétien M, Mbikay M, PCSK9: a key modulator of cardiovascular health, Circ Res. 2014, 114/6: 1022-1036

27. Lagace TA, Curtis DE, Garuti R, et al., Secreted PCSK9 decreases the number of LDL receptors in hepatocytes and in livers of parabiotic mice, J Clin Invest, 2006; 116: 2995-3005

28. Robinson JG, Farnier M, Krempf M, Bergeron J, Luc G, Averna M, Stroes ES, Langslet G, Raal FJ, El Shahawy M, Koren MJ, Lepor ME, Lorenzato C, Pordy R, Chaudhari U, Kastelein JJP, Efficacy and safety of ali- rocumab in reducing lipids and cardiovascular events $\mathrm{N}$ Engl J Med 2015; 372: 1489-1492

29. Sabatine MS, Giugliano RP, Wiviott SD, Raal FJ, Blom DJ, Robinson J, Ballantyne CM, Somaratne R, Legg J, Wasserman SM, Scott R, Koren MJ, Stein EA, Efficacy and Safety of Evolocumab in Reducing Lipids and Cardiovascular Events, N Engl J Med 2015; 372: 1500-1509

30. Stein EA, Raal FJ, Update on PCSK9 Inhibitors and New Therapies, therapies, US Endocrinology, 2016; 12/1: 18-21).

31. Ballantyne CM, Neutel J, Cropp A, et al., Results of bococizumab, a monoclonal antibody against proprotein convertase subtilisin/kexin type 9, from a randomized, placebocontrolled, dose-ranging study in statin-treated subjects with hypercholesterolemia, Am J Cardiol, 2015; 115: $1212-1221$

32. www.clinicaltrials.gov: NCT01975376

33. Perrone Filardi P, Paolillo S, Trimarco B, Controllo lipidico in pazienti ad elevato rischio cardiovascolare: focus sull'inibizione di PCSK9, Ital Cardiol 2015, 16/1: 44-51

34. Balzarotti G, Tibolla G, Catapano AL, PCSK9: present and future clinical perspectives, Giornale Italiano di Farmacoeconomia e Farmacoutilizzazione 2015, 7/3: 2843, modificato;

35. National Institute for Health and Care Excellence, Alirocumab for treating primary hypercholesterolaemia and mixed hypercholesterolaemia and mixed dyslipidaemiadyslipidaemia. Technology appraisal guidance 393, 2016. nice.org.uk/ guidance/ta393

36. Nicholls SJ, Puri R, Anderson T, et al. Effect of Evolocumab on Progression of Coronary Disease in StatinTreated Patients: The GLAGOV Randomized Clinical Trial, JAMA 2016; 316: 2373-2384

37. McGettigan P, PCSK9 inhibitors for hypercholesterolaemia. New drugs, old problems, MJ 2017;356:j188 doi: 10.1136/bmj.j188

38. American College of Cardiology. "Very low levels of bad cholesterol well-tolerated in heart disease patients." ScienceDaily, 31 January 2017; <www. sciencedaily. com/releases/2017/01/170131075628.htm

38. Khvorova A, Oligonucleotide Therapeutics - A New Class of Cholesterol-Lowering Drugs, N Engl J Med 2017; 376: 4-7

39. Fitzgerald K, White S, Borodovsky A, Bettencourt BR, Strahs A, Clausen V, Wijngaard P, Horton JD, Taubel JD, Brooks A, Fernando C, Kauffman RS, Kallend D, Vaishnaw A, Simon A, A Highly Durable RNAi Therapeutic Inhibitor of PCSK9, N Engl J Med 2017; 376: 41-51

40. Fitzgerald K, White S, Borodovsky A, Bettencourt BR, Strahs A, Clausen V, Wijngaard P, Horton JD, Taubel JD, Brooks A, Fernando C, Kauffman RS, Kallend D, Vaishnaw A, Simon A, A Highly Durable RNAi Therapeutic Inhibitor of PCSK9, N Engl J Med 2017; 376: 41-51

41. Nissen SE, Stroes E, DentAcosta RE, et al. Efficacy and tolerability of evolocumab vs ezetimibe in patients with muscle related statin intolerance. JAMA 2016; DOI:10.1001/jama.2016.3608. Abstract

42. Waters DD, Hsue PY, Bangalore S. PCSK9 inhibitors for statin intolerance? JAMA 2016. 


\title{
Trombo-embolismo venoso e malattie autoimmuni sistemiche
}

\author{
Andrea Fontanella, ${ }^{1}$ Paola Gnerre, ${ }^{2}$ Roberto Nardi ${ }^{3}$ \\ ${ }^{1}$ Dipartimento di Medicina, Ospedale del Buon Consiglio Fatebenefratelli, Napoli; ${ }^{2}$ Medicina Interna 2, Ospedale San Paolo, \\ Savona; ${ }^{3}$ Medicina Interna, Bologna, Italia
}

\section{Introduzione}

La malattia trombo-embolica (TEV) include l'embolia polmonare (EP) e la trombosi venosa profonda (TEV). La reale incidenza del TEV è sconosciuta. ${ }^{1}$ In America si stima ci siano tra i 300.000 e i 600.000 pazienti affetti per anno mentre l'incidenza europea varia tra i 104.000 e i 183.000 per anno. ${ }^{2}$ Il TEV è, quindi, una malattia abbastanza comune specie nei pazienti più anziani e l'embolia polmonare, oltre ad essere associata a una ridotta sopravvivenza, lo è anche a un rischio di mortalità superiore al 15\% nei primi tre mesi dopo la diagnosi, e ancora, se non prevenuta adeguatamente, determina un incremento dei costi sanitari. ${ }^{1}$ Il TEV è una malattia complessa multifattoriale che include nella sua genesi, un'interazione tra fattori genetici e ambientali. I fattori di rischio maggiore per TEV (Tabella 1) comprendono l'ospedalizzazione per intervento chirurgico o per malattia acuta in atto, una neoplasia in fase attiva, malattie neurologiche con paresi agli arti inferiori, $i$ traumi o le fratture, una trombosi delle vene superficiali e nella donna, la gravidanza, il puerperio, l'uso di contraccettivi orali e la terapia ormonale. ${ }^{3}$

Recenti studi epidemiologici hanno dimostrato un'associazione tra malattie autoimmuni come il LES, le malattie infiammatorie croniche intestinali, l'artrite reumatoide, ecc. (Tabella 2) e il TEV evidenziando come anche le malattie sistemiche autoimmuni possano essere un fattore di rischio per lo sviluppo di malattia trombo-embolica. ${ }^{4}$

Uno studio inglese retrospettivo ha rilevato un incremento di TEV variabile tra 1,75 e 3,7 in tutte le ma-

Corrispondente: Paola Gnerre, Medicina Interna 2, Ospedale San Paolo, via Genova n. I, 17100 Savona, Italia.

Tel.: +39.0198404358 - Fax: +39.0198404583

E-mail:pgnerre@yahoo.it

Articolo pubblicato secondo la Creative Commons Attribution NonCommercial 4.0 License (CC BY-NC 4.0).

CCopyright P. Gnerre et al., 2017

Licensee PAGEPress, Italy

QUADERNI - Italian Journal of Medicine 2017; 5(7):188-193 lattie autoimmuni. Questi dati sono stati confermati in altri studi retrospettivi condotti sia in Svezia sia in USA. ${ }^{5}$

\section{Meccanismi fisiopatologici alla base del link tra infiammazione e trombosi venosa}

Il TEV è una malattia multifattoriale causata da fattori congeniti (Tabella 3), acquisiti e ambientali. Tutti questi fattori contribuiscono allo sviluppo della triade di Virchow, classicamente caratterizzata dalla stasi ematica, dall'ipercoagulabilità e dal danno endoteliale. ${ }^{6}$ L'infiammazione è un elemento chiave di tutte le malattie autoimmuni sistemiche e di disordini immunomediati. Molti studi sono stati condotti per stabilire l'associazione tra infiammazione e ipercoagulabilità $\mathrm{o}$ tra infiammazione e danno endoteliale.

I tre principali meccanismi anticoagulanti naturali includono la via dell'inibitore del tissue factor (TFPI), la via dell'antitrombina III e della proteina C anticoagulante. ${ }^{7}$

Questi meccanismi esercitano un potente effetto anti-coagulante in condizione di benessere. Lo stato infiammatorio può shiftare questo bilancio omeostatico verso uno stato pro-coagulante con diversi meccanismi. Il tissue factor (TF) è una glicoproteina espressa sulla superficie dei monociti, delle cellule endoteliali e delle cellule muscolari lisce delle arterie. Il TF si lega al fattore VIIa attivando la cascata coagulativa a valle. Il TFPI inibisce specificatamente il complesso Fattore VIIa - TF. ${ }^{8}$ L'IL-6, un importante molecola che media molti processi infiammatori, incrementa l'espressione del TF sulla superficie dei monociti. Questo potrebbe anche essere correlato all'incremento della proteina $\mathrm{C}$ reattiva, indotto dall'attivazione dell'IL-6.

Il complesso TF-FVIIA attiva il fattore $\mathrm{X}$ che si lega al fattore Va. Il complesso Fattore Va-fattore Xa converte la protrombina a trombina. La trombina può quindi legarsi alla trombomodulina che attiva la proteina $\mathrm{C}$ che lega il recettore della proteina $\mathrm{C}$ presente sulle cellule endoteliali. La proteina $\mathrm{C}$ così attivata (APC) blocca il sistema coagulativo inattivando il fattore Va e il fattore VIIIA. ${ }^{9}$ L'infiammazione può ridurre l'espressione dei fattori anticoagulanti sulla superficie endoteliale come la trombomodulina e in- 
crementare l'espressione di fattori pro-coagulanti attraverso l'induzione di molecole di adesione leucocitaria. La trombomodulina è un proteoglicano presente sulla maggior parte delle cellule endoteliali. La trombomodulina lega la trombina e previene la cascata coagulativa. Studi in vitro hanno dimostrato come il TNF-a riduce i livelli di trombomodulina inibendo la sua trascrizione. ${ }^{10}$

Un'altra citochina infiammatoria IL-1 riduce l'attività della trombomodulina sulle cellule endoteliali.

Un altro importante meccanismo che lega l'infiammazione all'assetto coagulativo è il sistema fibrinolitico. ${ }^{11}$ Il plasminogeno è convertito in plasmina dall'attivatore tissutale del plasminogeno (t-PA) o dal- l'attivatore del plasminogeno tipo urochinasi (u-PA) entrambi regolati dall'inibitore dell'attivatore del plasminogeno (PAI-1). La plasmina degrada la fibrina nei prodotti di degradazione della fibrina. Questo processo è regolato dal b2-antiplasminogeno. La trombina attiva l'inibitore della fibrinolisi che la inibisce. ${ }^{11}$ Nei pazienti con artrite reumatoide e con spondilite anchilosante, il TNF-b riduce il PAI-1 e decrementa il rapporto PAI-1/t-PA. Pertanto il TNF-b è coinvolto nell'inibizione del sistema fibrinolitico nei pazienti affetti da malattia reumatologica. Infine lo stato infiammatorio incrementa anche i livelli di fibrinogeno associato a un rischio potenziato di trombosi venosa. Sebbene il TNF-b contribuisca alla trombosi, verosi-

Tabella 1. Fattori di rischio acquisiti per TEV. ${ }^{3}$

\begin{tabular}{lll}
\hline Fattori di rischio transitori maggiori & Fattori di rischio transitori minori & Fattori di rischio potenziali acquisiti o persistenti \\
\hline Ospedalizzazione & Contracettivi orali e terapia ormonale & Malattie vascolari del collagene \\
\hline Immobilizzazione con apparecchio gessato & Gravidanza & Scompenso cardiaco \\
\hline Chirurgia & Presenza di fattori di rischio maggiore & Cancro \\
& $1-3$ mesi prima della comparsa di TEV & \\
\hline Trauma & Viaggio aereo prolungato $(\geq 2$ ore $)$ & Farmaci \\
& & Disordini mieloproliferativi \\
& & Aborti ripetuti \\
& & Sindrome nefrosica
\end{tabular}

Tabella 2. Malattie sistemiche autoimmune associate a un incrementato rischio di TEV. ${ }^{4}$

Lupus eritematoso sistemico

Malattie infiammatorie croniche intestinali

Sindrome di Behçet

Artrite reumatoide

Malattia celiaca

Granulomatosi di Wegener

Poliartrite nodosa

Poliangite microscopica

Sindrome di Churg Strauss

Tabella 3. Fattori di rischio congenito per TEV. ${ }^{3}$

\begin{tabular}{ll}
\hline Suscettibilità genetica certa & Suscettibilità emergente \\
\hline Deficienza di antitrombina & Fattore XI \\
\hline Deficienza di cistationina $\beta$-sintetasi & Fattore von Willebrand \\
\hline Fattore V Leiden Gin506 & Glicoproteina VI \\
\hline Protrombina G20210A & Storia familiare di VTE \\
\hline Deficienza della proteina C & Kininogeno 1 \\
\hline Deficienza della proteina S & Virus dell'immunodeficienza tipo 1 che lega la proteina 1 \\
\hline Gruppo sanguigno AB0 & Catena gamma del fibrinogeno \\
\hline
\end{tabular}


milmente anche l'inibitore del TNF-b gioca un ruolo nella malattia trombo-embolica. L'inibitore del TNF$b$ può, infatti, indurre una sindrome simil lupica, stimolando la produzione di anticorpi antinucleo, anticorpi DsDNA e anticorpi anti-fosfolipidi e, quindi, favorire una trombosi venosa. ${ }^{12}$

\section{TEV e vasculite sistemica}

L'associazione tra TEV e vasculiti sistemiche è stata solo recentemente dimostrata. Uno studio francese ha evidenziato come pazienti affetti da poliartrite nodosa, granulomatosi di Wegener, poliangite microscopica e sindrome di Churg Strauss hanno presentato episodi di TEV rispettivamente nel $2,5 \%$, nell' $8 \%$, nel $7,6 \%$, e nell' $8,2 \%$ dei casi. ${ }^{13}$

Fattori associati significativamente allo sviluppo del TEV erano: l'età avanzata di esordio della malattia, il sesso maschile, un precedente episodio di TEV, l'esordio con evento ictale e deficit motorio.

Uno studio olandese ha rilevato un'incidenza annua di TEV dell' $1,8 \%$, che incrementa al $6,7 \%$ durante il periodo di attività della vasculite sistemica. ${ }^{14}$ L'incrementato rischio durante la fase di attività della malattia potrebbe suggerire il ruolo dell'infiammazione nello sviluppo del TEV, anche se bisogna comunque considerare la ridotta motilità conseguente all'evento e la concomitante insorgenza di sindrome nefrosica. I pazienti affetti da sindrome di Churg Strauss presentano una prevalenza di trombosi venosa tra il 5,8\% e il $30 \% .{ }^{15}$ In questi pazienti l'eosinofilia concorre all'insorgenza della trombosi attraverso le proteine eosinofili specifiche, come la proteina basica maggiore (MBP), la perossidasi eosinofila (EPO) e la proteina cationica eosinofila (ECP) che stimolano l'attivazione piastrinica attraverso la sovraesposizione sulla membrana del tissue factor contenuto all'interno dei granuli eosinofili. Non ci sono al momento dati in letteratura sul rischio incrementato di TEV in pazienti con arterite a cellule giganti o arterite di Takayasu. ${ }^{16}$

Da segnalare come non siano riportati indicazioni sul management del TEV in pazienti con vasculiti sistemiche nelle linee guida CHEST.

\section{TEV e malattia di Behçet}

La malattia di Behçet è una malattia sistemica infiammatoria caratterizzata da ulcere orali e genitali ricorrenti. L'eziologia di questa malattia è sconosciuta ma la vasculite può colpire arterie e vene di tutti i calibri. L'interessamento vascolare varia nei vari studi dall' $1,8 \%$ al $51 \%$ circa. ${ }^{17}$ L'interessamento venoso può manifestarsi come trombosi venosa profonda, trombosi venosa superficiale, trombosi dei seni venosi cerebrali, trombosi della vena cava, sin- drome di Budd-Chiari e trombosi delle arterie polmonari. L'interessamento venoso, a seconda delle casistiche, varia dal 4 al $38 \%{ }^{18}$ Il meccanismo patogenetico alla base della trombosi venosa non è chiaro. Fattori trombofilici, come i livelli di proteina $\mathrm{C}$, di proteina $\mathrm{S}$, l'attività dell'antitrombina III, la resistenza alla proteina $\mathrm{C}$ attivata, gli anticorpi anticardiolipina, sono stati tutti indagati ma nessuno è stato trovato correlarsi agli episodi trombotici. Il trattamento della trombosi venosa in corso di malattia di Behçet è tutt'ora controverso. Le raccomandazioni dell'European League Against Rheumatism (EULAR) per la gestione della trombosi venosa profonda acuta in pazienti affetti da malattia di Behçet consigliano l'uso di glucocorticoidi, azatioprina, ciclofosfamide e ciclosporina ma non ci sono indicazioni circa l'utilizzo della terapia anticoagulante, antiaggregante o fibrinolitica. ${ }^{19}$ L'avvio della terapia anticoagulante è controverso per il rischio di una concomitante presenza di un aneurisma dell'arteria polmonare la cui rottura potrebbe quindi essere fatale.

\section{TEV e anticorpi anti-fosfolipidi}

Gli anticorpi antifosfolipidi includono gli anticorpi anticardiolipina, il lupus anticoagulant e gli anticorpi anti b2 glicoproteina. La sindrome da anticorpi antifosfolipidi primitiva è una condizioni clinica acquisita caratterizzata clinicamente da trombosi arteriosa e venosa, da aborti ripetuti e rilievo laboratoristico di anticorpi anti-fosfolipidi (Tabella 4) ${ }^{20}$ Sebbene la presenza degli anticorpi antifosfolipidi sia un dato necessario per porre la diagnosi di sindrome da anticorpi antifosfolipidi primitiva, questi anticorpi possono essere presenti anche in altre patologie autoimmuni come il LES (33\%), le vasculiti sistemiche primitive (17\%), la porpora trombocitopenica immune $(25 \%)$, le malattie tiroidee (24\%), l'anemia emolitica autoimmune (12\%) e l'artrite reumatoide $(16 \%){ }^{4}$

\section{TEV e LES}

Il LES è una malattia acquisita autoimmune e con coinvolgimento multi-organo. La presentazione clinica è estremamente variabile ed eterogenea e la diagnosi clinica è spesso complessa (Tabella 5). ${ }^{21} \mathrm{Gli}$ eventi trombotici non sono inclusi nei criteri diagnostici se pur riportati in circa il $10-25 \%$ di tutti i pazienti con LES.22 Il rischio di trombosi è particolarmente alto durante il primo anno dopo la diagnosi. Sebbene esistano forti evidenze di associazione tra Lupus eritematoso sistemico e TEV, soprattutto nella fase attiva di malattia, il LES non è generalmente menzionato come item negli score di 
Tabella 4. Criteri per porre diagnosi di Sindrome da Anticorpi anti-fosfolipidi. ${ }^{20}$

I criteri per l'APS sono soddisfatti in presenza di almeno un criterio clinico e un criterio di laboratorio

Criteri clinici

1. Trombosi vascolare:

Almeno 1 episodio di trombosi arteriosa, venosa o microvascolare a carico di qualsiasi tessuto o organo.

La trombosi deve essere confermata da un rilievo oggettivo e convalidato (aspetto tipico a un esame d'imaging diagnostico o, per le indagini patologiche, la trombosi deve essere presente in assenza d'infiammazione vascolare sottostante).

2. Morbilità ostetrica:

a. Almeno un'occorrenza di morte fetale inspiegata prima della $10^{\mathrm{a}}$ settimana di gravidanza, con normale morfologia fetale documentata da un'ecografia o un esame macroscopico

b. Almeno un'occorrenza di parto prematuro con feto morfologicamente normale prima della $34^{\mathrm{a}}$ settimana di gravidanza, associato a grave eclampsia o pre-eclampsia o con evidenze d'insufficienza placentare

c. Almeno 3 aborti spontanei consecutivi inspiegati prima della $10^{\mathrm{a}}$ settimana di gravidanza, una volta escluse anomalie anatomiche, ormonali materne e cromosomiche materne/paterne.

Criteri di laboratorio

1. Lupus anticoagulante rilevato in almeno 2 occasioni, a 12 settimane di distanza, secondo le raccomandazioni ISTH (Human Science \& Technology Institute)

2. anticorpi anticardiolipina ( $\operatorname{IgG~e} / \mathrm{o} \operatorname{IgM})$ presenti in almeno 2 occasioni, con livelli moderati o alti ( $>40$ unità GPL o MPL o $>99^{\circ}$ percentile), misurati mediante tecnica ELISA standard.

3. anticorpi anti- $\beta$-2 GP I (IgG o IgM) con livelli superiori al $99^{\circ}$ percentile, in almeno 2 occasioni a 12 settimane di distanza, misurati mediante tecnica ELISA standard.

rischio per l'avvio della tromboprofilassi. Solo il Padua Prediction score (PPS) considera la presenza di anticorpi antifosfolipidi tra $i$ fattori di rischio trombotico, ${ }^{23}$ infatti li comprende nell'item trombofilia nota, cui vengono attribuiti 3 punti. Comunque non tutti i pazienti affetti da LES che sviluppano trombosi hanno la positività degli anticorpi anti-fosfolipidi, per cui altri fattori, come verosimilmente l'infiammazione, l'aterosclerosi precoce, una deficienza acquisita di proteina $S$, contribuiscono all'incrementato rischio di TEV in questa malattia. Data l'assenza di linee guida specifiche, il LES dovrebbe comunque essere considerata una condizione ad alto rischio trombotico anche in assenza di anticorpi antifosfolipidi, soprattutto durante la fase attiva di malattia e quindi tutti i pazienti dovrebbero essere sottoposti a tromboprofilassi, ${ }^{23} \mathrm{Se}$ ospedalizzati e con LAC positività (che vale 3 punti) la profilassi è d'obbligo.

\section{TEV e malattie infiammatorie croniche intestinali}

Numerosi studi confermano la comparsa di TEV in pazienti affetti da malattie infiammatorie croniche intestinali e quindi l'aumentato rischio trombotico in pazienti affetti da malattia infiammatoria cronica intestinale. ${ }^{24}$ L'aumentato rischio è particolarmente evidente nel primo anno di malattia e nella fase di attività della malattia stessa. Alcuni studi hanno evidenziato come in questi pazienti ci sia una down regulation della trombomodulina e del recettore endoteliale della proteina $\mathrm{C}$ che quindi favorirebbero la comparsa di eventi trombotici. ${ }^{4}$

\section{TEV e artrite reumatoide}

L'associazione tra artrite reumatoide e TEV è meno chiara rispetto a quella con il LES o con le malattie infiammatorie croniche. Studi epidemiologici non dimostrano un rischio aggiuntivo indotto dalla presenza della malattia reumatica. ${ }^{4}$

\section{Conclusioni}

I risultati della letteratura disponibili consentono di catalogare le patologie reumatiche tra le principali condizioni in grado di incrementare il rischio di TEV. In questo stesso numero dei Quaderni si pone l'accento sull'incremento del rischio cardiovascolare nei pazienti con malattie infiammatorie immuno-mediate, esaltando ancora di più il concetto che tali patologie inducono una condizione trombofilica. È d'altra parte ben noto come i pazienti con TEV idiopatico presentino un'aumentata prevalenza di lesioni aterosclerotiche asintomatiche oltre che un'aumentata incidenza di patologie ed eventi cardiovascolari rispetto ai pazienti con embolia polmonare secondaria. ${ }^{25}$ Questo suggerisce che alcuni dei fattori di rischio per l'aterosclerosi possano favorire la comparsa di patologie trombotiche venose e che la TVP possa essere la prima manifestazione clinica in pazienti ad alto rischio cardiovascolare. In realtà il rilievo conferma fondamentalmente che alla base della malattia trombotica, sia sul versante arterioso sia su quello venoso, vi sia un meccanismo fisiopatologico comune rappresentato dall'infiammazione.

La conferma di questo è stata sancita a livello internazionale dal fatto che l'unico score di rischio per TEV nel paziente ospedalizzato, riconosciuto come 
Tabella 5. Criteri diagnostici del LES. ${ }^{21}$ Per classificare un paziente come affetto da LES devono essere soddisfatti 4 criteri, di cui almeno 1 clinico e 1 laboratoristico o, in alternativa, la presenza di una nefrite lupica istologicamente provata, insieme alla positività o degli ANA o degli anti-dsDNA.

\section{Lupus cutaneo acuto, compreso}

Rash malare (escluso discoide)

Lupus bolloso

Variante di LES con necrolisi epidermica tossica

Eruzione cutanea di lupus maculo papulare

Eruzione cutanea lupus fotosensibile

in assenza di dermatomiosite

OPPURE

Lupus cutaneo subacuto (psoriasiforme non indurito e/o lesioni anulari policicliche che si risolvono senza cicatrici, sebbene occasionalmente con depigmentazione post infiammatoria delle teleangectasie)

\section{Lupus cronico cutaneo, compreso}

Rash discoide classico

- Localizzato (sopra il collo)

- Generalizzato (sopra e sotto il collo)

Lupus ipertrofico (verrucoso)

Panniculite lupica (profonda)

Lupus delle mucose

Lupus eritematoso tumido

Lupus con geloni

Lupus discoide con sovrapposizione di lichen planus

3. Ulcere orali (bocca, lingua)

OPPURE

Ulcere nasali in assenza di altre cause come vasculiti, malattia di Behçet, infezione (herpes), malattie infiammatorie intestinali, artrite reattiva e cibi acidi

4. Alopecia non cicatriziale (diffuso assottigliamento o fragilità dei capelli con capelli visibilmente spezzati)

in assenza di altre cause come alopecia areata, farmaci, sideropenia e alopecia androgena

\section{Sinovite coinvolgente 2 o più articolazioni con gonfiore o versamento}

OPPURE

Indolenzimento di 2 o più articolazioni e rigidità mattutina di almeno 30 minuti

\section{Sierosite}

Pleurite per più di un giorno

OPPURE versamento pleurico

OPPURE sfregamento pleurico

OPPURE pericardite valutata all'ECG

in assenza di altre cause come infezioni, uremia e pericardite di Dressler

\section{Renale}

Rapporto proteine urinarie/creatinina in $8-24$ ore assimilabile a $500 \mathrm{mg}$ proteine $/ 24$ ore

OPPURE residui di globuli rossi

\section{Neurologico}

Convulsioni

Psicosi

Mononeurite multipla

in assenza di altre cause come vasculite, infezioni e diabete mellito

Mielite

Neuropatia craniale o periferica

in assenza di altre cause come vasculite primaria, infezioni e diabete mellito

Stato confusionale acuto

in assenza di altre cause come tossiche/metaboliche, uremia, farmaci

\section{Anemia emolitica}

10. Leucopenia (almeno un riscontro $<4000 / \mathrm{mm}^{3}$ )

in assenza di altre cause come sindrome di Felty, farmaci e ipertensione portale

OPPURE linfopenia $<1000 / \mathrm{mm}^{3}$ almeno una volta

in assenza di altre cause come corticosteroidi, farmaci e infezioni

11. Trombocitopenia (almeno un riscontro $<100.000 / \mathrm{mm}^{3}$ )

in assenza di altre cause come farmaci, ipertensione portale e porpora trombocitopenia 
validato, e, pertanto, inserito nelle LG dell'ACCP 2012, sia il Padua Prediction Score. ${ }^{26}$ Tra gli item di tale score è giustamente posizionata la patologia reumatica, cui è attribuito il punteggio di 1 , oltre che, come già scritto in precedenza, la presenza di LAC/APA, cui è attribuito un valore di 3 .

\section{Bibliografia}

1. Osinbowale O, Ali L, Chi YW. Venous thromboembolism: a clinical review. Postgrad Med. 2010 Mar;122 (2):54-65.

2. Heit J.A. Epidemiology of venous thromboembolism. Nature Reviews Cardiology. 2015;12(8):464-474

3. Anderson F.A, Spencer F.A. Risk Factors for Venous Thromboembolism. Circulation. 2003;107

4. Zöller B, Li X, Sundquist J, Sundquist K. Autoimmune diseases and venous thromboembolism: a review of the literature. Am J Cardiovasc Dis 2012;2(3):171-183

5. Tamaki H, Khasnis A. Venous thromboembolism in sistemi autoimmune diseases: A narrative review with emphasis on primary systemic vasculitides. Vasc Med. 2015 Aug;20(4):369-76.

6. Blann AD and Lip GY. Virchow's triad revisited: the importance of soluble coagulation factors, the endothelium, and platelets. Thromb Res 2001; 101: 321-327.

7. Esmon CT. The interactions between inflammation and coagulation. Br J Haematol 2005; 131: 417-430.

8. Spronk HM, Govers-Riemslag JW and ten Cate H. The blood coagulation system as a molecular machine. Bioessays 2003; 25: 1220-1228.

9. Esmon CT. Inflammation and the activated protein $\mathrm{C}$ anticoagulant pathway. Semin Thromb Hemost 2006; 32(Supplement 1): 49-60.

10. Murray JC, Clauss M, Thurston G, et al. Tumour-derived factors which induce endothelial tissue factor and enhance the procoagulant response to TNF. Int J Radiat Biol 1991; 60: 273-277.

11. Rijken DC and Lijnen HR. New insights into the molecular mechanisms of the fibrinolytic system. J Thromb Haemost 2009; 7: 4-13.

12. Makol A, Grover M, Guggenheim C, et al. Etanercept and venous thromboembolism: a case series. J Med Case Rep 2010; 4: 12.

13. Allenbach Y, Seror R, Pagnoux C, et al. High frequency of venous thromboembolic events in Churg-Strauss syndrome, Wegener's granulomatosis and microscopic polyangiitis but not polyarteritis nodosa: a systematic retrospective study on 1130 patients. Ann Rheum Dis 2009; 68: 564-567.

14. Stassen PM, Derks RP, Kallenberg CG, et al. Venous thromboembolism in ANCA-associated vasculitis: incidence and risk factors. Rheumatology (Oxford) 2008; 47: $530-534$.

15. Lamprecht $P$, Holl-Ulrich K and Wieczorek S. Venous thromboembolism in Wegener's granulomatosis. J Rheumatol 2007; 34: 2323-2325.

16. Avina-Zubieta J, Lacaille Di, Sayre EC et al. The risk of pulmonary embolism and deep vein thrombosis in giant cell arteritis: a population-based cohort study. Arthritis and Rheumatism 2012; 64: 2568.

17. Fei Y, Li X, Lin S, et al. Major vascular involvement in Behcet's disease: a retrospective study of 796 patients. Clin Rheumatol 2013; 32: 845-852.

18. Davatchi F, Shahram F, Chams-Davatchi C, et al. Behcet's disease in Iran: analysis of 6500 cases. Int J Rheum Dis 2010;13: 367-373.

19. Hatemi G, Silman A, Bang D, et al. EULAR recommendations for the management of Behcet disease. Ann Rheum Dis 2008; 67: 1656-1662.

20. Ruiz-Irastorza G, Crowther M, Branch W et al. Antiphospholipid syndrome. Lancet 2010; 376: 1498-1509

21. Petri M, Orbai AM, Alarcón GS et al. Derivation and validation of the Systemic Lupus International Collaborating Clinics classification criteria for systemic lupus erythematosus. Arthritis Rheum. 2012;4:2677-86.

22. Palatinus A, Adams M. Thrombosis in sistemi lupus erythematosus. Semin Thromb Hemost 2009; 35: 621629.

23. Bazzan M, Vaccarino A, Marletto F. Systemic lupus erythematosus and thrombosis. Thrombosis Journal (2015) 13:16

24. Bernstein CN, Blanchard JF, Houston DS et al. The incidence of deep venous thrombosis and pulmonary embolism among patients with inflammatory bowel disease: a populationbased cohort study. Thromb Haemost 2001.

25. Prandoni P, Bilora F, Marchiori A et al.An Association betwen Atherosclerosis and Venous Thrombosis. N Engl J Med 2003; 348: 1435-41.

26. Barbar S, Noventa F, Rossetto V, Ferrari A, Brandolin $\mathrm{B}$, Perlati $\mathrm{M}$ et al. "A risk assessment model for the identification of hospitalized medical patients at risk for venous thromboembolism: the Padua Prediction Score." Thromb Haemost. 2009: 101 (5): 893-901. 


\title{
IMIID nell'anziano: cenni sul trattamento
}

\author{
Marco Masina \\ UOC Geriatria Bentivoglio, AUSL di Bologna, Italia
}

\section{Introduzione}

Le Malattie Infiammatorie Immunomediate (IMID) sono un ampio ed eterogeneo gruppo di patologie che condividono la attivazione dei processi infiammatori sostenuta da alterazioni del sistema immunitario. L'alterazione dei processi immunitari porta alla produzione di citochine infiammatorie quali IL-12, IL-6 e TNF $\alpha$ con conseguenti danni d'organo ed incremento di morbilità e mortalità. Le più note IMID sono rappresentate da patologie reumatologiche, quali la Artrite Reumatoide (RA), il Lupus Eritematoso Sistemico (LES), la Spondilite Anchilosante ( $\mathrm{SpA}$ ), la Artropatia psoriasica (APs), la Sclerosi Sistemica (SS), e l'ampio gruppo delle vasculiti. IMID sono anche le Malattie infiammatorie intestinali (IBD) quali la Malattia di Crohn, la Rettocolite Ulcerosa, o le Epatiti autoimmuni e le Colangiti sclerosanti autoimmuni. Rientrano nelle IMID patologie neurologiche come la Sclerosi Multipla, alcune polineuropatie come la Sindrome di Guillan Barrè e la Polineuropatia infiammatoria cronica demielinizzante (CIDP), la Miastenia. Hanno una patogenesi infiammatoria immunomediata anche malattie endocrinologiche come il Diabete mellito di tipo I e la Malattie di Graves. Infine si devono aggiungere moltissime malattie dermatologiche come la Psoriasi e il Pioderma gangrenoso. Recentemente l'attenzione è stata posta sul rapporto fra i processi infiammatori immunomediati e la insorgenza di tumori, sia in corso di IMID, sia in tumori primitivi come le patologie mieloproliferative croniche.

Corrispondente: Marco Masina, UOC Geriatria Bentivoglio, via Marconi 35, 40010 Bentivoglio (BO), Italia.

Tel. +39.051.6644394 - Fax: +39.051.6644491.

E-mail:marco.masina@ausl.bo.it

Articolo pubblicato secondo la Creative Commons Attribution NonCommercial 4.0 License (CC BY-NC 4.0).

CC Copyright M. Masina, 2017

Licensee PAGEPress, Italy

QUADERNI - Italian Journal of Medicine 2017; 5(7):194-199

\section{Infiammazione e invecchiamento: quali rapporti}

Crescenti evidenze correlano l'infiammazione al processo di invecchiamento (inflamm-ageing) attraverso la persistenza di uno stato di infiammazione cronica di basso grado (low-level chronic inflammation). ${ }^{1}$ Processi infiammatori acuti determinati da stimoli esterni o interni portano alcune cellule a sviluppare un fenotipo particolare, definito senescente, caratterizzato da uno stato di arresto permanente del ciclo e da una abbondante produzione di citochine proinfiammatorie come IL-6 e IL-8 e proteasi (senescence associated secretory phenotype - SASP). ${ }^{2} \mathrm{Col}$ passare degli anni le cellule con fenotipo senescente si accumulano nei tessuti con effetti sia positivi di soppressione degli oncogeni intracellulari e di arresto del danno del tessuto, che negativi di invecchiamento del tessuto e di oncogenicità sulle cellule vicine. ${ }^{3,4}$ Le cellule senescenti sono maggiormente presenti negli organi interessati da patologie croniche infiammatorie età correlate come la osteoartrite o l'aterosclerosi suggerendo uno stretto rapporto fra la presenza delle cellule senescenti, l'infiammazione, l'invecchiamento e la malattie degenerative. Molte malattie metaboliche come obesità, dislipidemia, ipertensione, insulino-resistenza e diabete di tipo 2 sono attualmente considerate malattie sistemiche caratterizzate da un stato infiammatorio persistente in risposta al danno indotto dall'eccesso di nutrienti e di introito calorico. ${ }^{5,6} \mathrm{Il}$ profilo infiammatorio senescente sembra anche esercitare una azione oncogenica sul microambiente attraverso una pressione selettiva sulla trasformazione neoplastica delle cellule dei tessuti circostanti stimolate dall'eccesso di citochine. ${ }^{78}$ Anche nei pazienti con IMID si riscontra una maggiore incidenza, spesso in età precoce, di malattie cardio-cerebrovascolari e di eventi tromboembolici venosi periferici e polmonari che sappiamo essere in rapporto con processi infiammatori e alcuni tumori.

Un ultima considerazione riguarda il microbioma intestinale nell'invecchiamento. Si tratta di un campo di studio relativamente recente che suggerisce come particolari microbiomi si correlino allo sviluppo di alcune malattie croniche degenerative o neoplasie ${ }^{9}$ mentre altri sono predittive della longevità con pattern tipici nei centenari. ${ }^{10,11}$ 
Nelle stesso tempo vi sono evidenze di un rapporto fra particolari microbiomi e le IMID anche se attualmente non è possibile identificare dei pattern di popolazione tipici di ciascuna. Nelle IBD si è però registrato uno squilibrio proinfiammatorio del microbioma intestinale simile a quello che caratterizza il microbioma dell'anziano. ${ }^{12}$ Infine va ricordato che il microbioma dialoga con le cellule intestinali, con il sistema immunitario ma anche con il sistema nervoso (microbioma-gut-brain axis) suggerendo la possibilità di una relazione anche nella insorgenza della Sclerosi Multipla. ${ }^{13}$

\section{L'epidemiologia delle IMID nell'anziano}

Gli studi epidemiologici hanno mostrato che pure in presenza di importanti differenze fra la diverse IMID, generalmente la loro insorgenza predilige soggetti giovani o adulti. Gli anziani possono tuttavia essere interessati da IMID sia per la maggiore sopravvivenza in corso di malattia che per la presenza di forme olderonset. ${ }^{14}$ Nell'ambito delle IMID reumatologiche si è recentemente osservato una tendenza verso una insorgenza più tardiva della AR. ${ }^{15}$ La Psoriasi e la Artropatia Psoriasica mostrano due picchi nell'età di insorgenza di cui uno attorno a 15-20 anni ed il secondo attorno ai $55-60 .{ }^{16,17}$ È interessante notare che anche le modalità di presentazione clinica sono differenti tanto da essere classificate in un tipo I che insorge prima dei 40 anni, ed un tipo II che compare in età successiva. Il tipo I che rappresenta il 75\% dei pazienti è più frequentemente associato a familiarità, a forme più severe ed alla presenza di HLA-Cw6. ${ }^{18}$ Le altre patologie del connettivo (LES, ecc.) sono anch'esse patologie con insorgenza prevalentemente in età giovane-adulta con picchi di later-onset attorno ai 50 anni, prima della età geriatrica vera e propria . Nella Sclerosi Sistemica il gruppo ad insorgenza $>75$ anni mostra una malattia più limitata, un incremento di ipertensione polmonare influenzata da sottostate comorbilità cardiovascolare e la sopravvivenza media appare maggiore rispetto a quella dei soggetti giovani.

Le IBD sono malattie che generalmente insorgono nei giovani, anche se vi è un picco attorno al 65-74 anni per il sovrapporsi degli effetti della aumentata sopravvivenza dei pazienti colpiti in età giovane e del recente incremento delle forme a insorgenza tardiva. ${ }^{14,19}$

Le forme older-onset sembrano meno aggressive e meno progressive con minore tendenza a stenosi o penetrazioni. ${ }^{19}$ Le IBD mostrano una distribuzione assai differente fra le diverse aree del mondo con una tendenza ad una maggiore prevalenza nelle zone di transizione economica suggerendo l'importanza degli stili alimentari oltre che di vita e delle conseguenti modificazioni del microbioma intestinale. ${ }^{12,20,21}$

Fre le IMID che interessano il fegato e le vie biliari una parte consistente è rappresentata dalle epatiti croniche autoimmuni. Nei studi disponibili circa il 20$25 \%$ dei pazienti ha una età $>65$ anni e al momento della diagnosi sono asintomatici seppure con un quadro di cirrosi già presente. L'aplotipo più frequente è HLA DR4 del quale è descritta una minore tendenza alla ripresa. ${ }^{22,23}$ Le colangiti biliari primitive interessano prevalentemente donne nella sesta decade di vita con una sopravvivenza di 9-10 anni in assenza di terapia. ${ }^{24}$ Le colangiti sclerosanti primitive interessano i maschi nella IV-V decade. ${ }^{25}$

Le IMID neurologiche come Sclerosi multipla, Miastenia, polineuropatia hanno una insorgenza in età giovane adulta. Per la Sclerosi Multipla si considera esordio tardivo quello superiore a 50 anni. ${ }^{26}$

Il paziente anziano con IMID tende a mostrare una importante comorbilità vascolare ed una maggiore incidenza di neoplasie nella cui patogenesi si intrecciano gli effetti infiammatori della IMID con quelli dell'inflamm-ageing. Nelle IMID reumatologiche e nella psoriasi la mortalità sembra dipendere dalle medesime patologie ma ad una età precoce..$^{27}$ Bloccare precocemente la produzione e gli effetti delle citochine infiammatorie potrebbe quindi avere importanti ripercussioni prognostiche non solo nei confronti della IMID ma anche delle patologie d'organo dell'età anziana.

\section{Il trattamento delle IMID nell'anziano}

\section{Le IMID reumatologiche}

Nella gestione delle IMID reumatologiche gli agenti biologici hanno consentito interventi più aggressivi in grado di bloccare la attività della malattia soprattutto nei casi di malattie con una insufficiente risposta ai convenzionali farmaci antireumatici in grado di modificare la malattia (DMARD: disease modifyng antirheumatic drugs) non biologici.

Il trattamento classico della Artrite Reumatoide si basa su di una precoce prescrizione di metotrexate (MTX) seguita dall'utilizzo, anche in associazione, di altri DMARD come idrossiclorochina, sulfasalazina, azatioprina o leflunomide. L'utilizzo di steroidi è attualmente limitato perché il loro uso prolungato presenta importanti effetti negativi sul metabolismo osseo e glicemico, sul catabolismo muscolare, sulla ipertensione, sulla integrità gastrointestinale, ecc. Gli effetti avversi sulla funzione renale o sul rischio di sanguinamento gastrointestinale suggeriscono di limitare la prescrizione di antifiammatori non steroidei (FANS) alle fasi di riacutizzazione. Gli effetti avversi dei FANS possono essere amplificati dalla concomitante assunzione di farmaci come diuretici, anticoagulanti orali, Ace-inibitori, $\beta$-bloccanti, digossina.

Nelle IMID reumatologiche in caso di inefficacia degli DMARD si inseriscono i biologici, partendo agli 
inibitori del Tumor Necrosis Factor (TNFi) sia come anticorpi monoclonali (infliximab, adalimumab) sia con inibitori dei recettori (etarercept), oppure farmaci biologici non-TNFi come il tocilizumab (TCZ), l'abatercept (ABA), o il rituximab (anticorpo monoclonale contro CD 20.

Mancano dati relativi all'efficacia, alla sicurezza $\mathrm{e}$ al rischio di reazioni avverse nelle classi di età più avanzate perchè i trial clinici registrativi hanno generalmente escluso pazienti anziani e le informazioni sono state ricavate a posteriori da registri e dai sistemi di sorveglianza di fase IV. ${ }^{28,29}$ La prima caratteristica da considerare nella prescrizione dei farmaci biologici nell'anziano è rappresentata dalle notevoli differenze individuali in termini di riserva funzionale (fragilità), comorbilità, autonomia e di rischio di complicazioni. In un recente studio retrospettivo in pazienti con AR, l'interruzione del trattamento con farmaci biologici per l'insorgenza di complicazioni nei pazienti giovani era inferiore ma negli anziani non differiva fra il gruppo di età $>65<74$ anni e quello di età $>75$ anni. ${ }^{29}$ Nonostante i pazienti più anziani mostrassero un peggiore controllo della malattia al momento della prescrizione dei biologici sia perchè presente da un tempo maggiore, sia perchè gestita con trattamento meno intensivo (con l'aumento dell'età si è registrato ad esempio una preferenza per steroidi rispetto a MTX), tutti i pazienti mostravano globalmente una buona risposta ai biologici. L'interruzione era dovuta prevalentemente alle complicanze infettive in primis quelle polmonari, poi alle interstiziopatie, alle riacutizzazioni gravi di BPCO, di pregresse TBC, o di micobatteriosi non tubercolari, alle bronchioliti croniche, alle bronchiectasie.$^{30}$ La ridotta resistenza alle infezioni e il precedente anamnestico tubercolare richiedono un attento screening prima della prescrizione dei biologici in tutte le età ed in particolare negli anziani. ${ }^{31}$ L'età non sembra essere un fattore indipendente di aumento il rischio di eventi avversi che sembra invece dipendere dalla maggiore presenza di comorbilità quali le malattie cardiovascolari, il diabete mellito, il peggioramento della funzione renale, o l'abitudine al fumo. Nel contempo l'utilizzo di alcuni DMARD come il Metotrexate, la sulfasalazina, gli steroidi oppure i biologici anti-TNF o etanercept si è accompagnato ad una riduzione della mortalità cardiovascolare a sottolineare il ruolo della infiammazione nello sviluppo della patologia vascolare. ${ }^{27}$

\section{Le IMID dermatologiche}

Il trattamento con biologici della Psoriasi/Artropatia psoriasica utilizza adalimumab, infliximab, etarercept (TNFi), ustekinumab (anticorpo monoclonale contro interleuchina 12/23), alefacept (inibitor delle T-cell). Uno studio italiano ha confermato l'efficacia e la sicurezza di adalimumab e etarnercept nel tratta- mento a lungo termine della psoriasi ed artropatia psoriasica negli anziani. ${ }^{32}$ Tuttavia il prescrittore deve tenere in attenta considerazione che l'effetto immunosoppressore degli i-TNF aumenta il rischio di tubercolosi, di granulomatosi e di tumori (soprattutto nei fumatori) ed è riportato nei fogli illustrativi dei farmaci. Va comunque ricordato che gli altri farmaci non biologici disponibili sono anch'essi gravati da altro rischio di effetti avversi in particolare negli anziani. ${ }^{33}$ La ciclosporina peggiora la funzione renale e aumenta la pressione arteriosa. Il metotrexate aumenta il rischio di fibrosi epatica, di cirrosi e di mielosoppressione e viene spesso trascurato che l'interazione con il trimetoprim può essere fatale. Il retinoide acitetina aumenta $\mathrm{i}$ trigliceridi e può produrre severe xerosi cutanee $\mathrm{e}$ mucose.

\section{Le IMID gastrointestinali}

I principi del trattamento delle IBD nell'anziano non differiscono da quelli dei giovani e sono la induzione ed il mantenimento della remissione, la prevenzione delle complicazioni indotte dalla malattia (e dal trattamento) e il miglioramento della qualità della vita. La prescrizione dei biologici varia grandemente per classi di età e nei singoli paesi ma è percentualmente inferiore rispetto ai giovani. ${ }^{14}$ Dati di efficacia e di sicurezza sono contrastanti. Da alcuni trial clinici sembra emergere una minore percentuale di risposta clinica completa nei paziente di età $>60$ anni che si mantiene anche correggendo per la maggiore durata della malattia che sappiamo essere un fattore sfavorevole. ${ }^{34}$ I dati relativi alla sicurezza confermano però un più elevato rischio di infezioni anche severe e di conseguente mortalità negli anziani. ${ }^{35}$ Nello studio dalla Mayo Clinic la azatioprina è risultata meglio tollerata dell'infliximab negli anziani con minori interruzione del trattamento che invece raddoppiava quando veniva associata ai biologici. ${ }^{36}$

Una particolare attenzione deve essere inoltre posta alla presenza di scompenso cardiaco e l'uso di anti-TNF in pazienti con classe III e IV NYHA) è controindicata. ${ }^{37}$ Con infliximab e adalimumab va posta molta attenzione anche alla trombocitemia. ${ }^{14}$

L'approccio corretto nell'anziano deve anche tenere conto della riduzione della riserva omeostatica età-correlata (fragilità) che può richiedere una ospedalizzazione precoce rispetto al giovane-adulto in presenza di severe riacutizzazioni colitiche con frequenti scariche anche notturne ed urgenza/incontinenza fecale. Gli effetti a cascata della anemia, disidratazione, alterazione elettrolitica, febbre, malassorbimento sul compenso di altri apparati possono portare a eventi catastrofici come scompenso, aritmie, angina, ipotensione cadute, frattura, dimagrimento-cachessia. Nella decisione del trattamento o meno con biologici vanno dunque considerati sia i rischi della terapia che le con- 
seguenze di un trattamento ritardato o inefficace. Un aspetto banale spesso trascurato è la presenza di incontinenza sfinteriale che può vanificare la gestione della terapia topica rettale sui cui spesso si insiste inutilmente ritardando l'inizio di una terapia efficace.

Le epatite croniche autoimmuni sono trattate con steroidi (predisone o budesonide nei casi resistenti) da soli o in associazione con azatioprina. Le percentuali di risposta nei giovani e negli anziani sono sovrapponibili ma gli anziani sembrano mostrare un minore rischio di ripresa dopo la sospensione del trattamento tranne che in presenza di cirrosi. Questo autorizza ad iniziare subito il trattamento anche nelle forme subcliniche senza astensioni per il timore di complicazioni che pure vanno attentamente monitorate. Una volta ottenuta la remissione è possibile confidare sulla minore tendenza alla ripresa della malattia. ${ }^{22}$ Risultati positivi in piccole casistiche si sono ottenuti con micofenolato mofetile, tacrolimus, ciclosporina, rituximab, infliximab, ciclofosfamide, metotrexato ma mancano dati relativi ai pazienti anziani. ${ }^{38}$ Nell'anziano è assolutamente necessario contrastare la osteopenia e l'osteoporosi per il potenziamente degli effetti della epatite autoimmune e della terapia steroidea con l'invecchiamento.

Acido ursodesossicolico UDCA è l'unico farmaco che ha indicazione nella Colangite sclerosante primitiva anche se non sembra rallentarne l'evoluzione. ${ }^{39}$ Nelle colangiti biliari primitive l'UDCA viene usato da solo o in associazione con metotrexate o glucocorticoidi (budesonide) ma mancano specifiche indicazioni per i pazienti anziani. Va ricordata l'esistenza di numerose forme di overlap con le IBD che ovviamente richiedono il trattamento specifico di entrambe.

\section{Le IMID neurologiche}

Nella Sclerosi Multipla vi è una assenza di linee guida basate evidence based per i pazienti anziani. Gli studi clinici sull'utilizzo dell'IF $\beta$ - 1 a hanno infatti escluso per lungo tempo i soggetti di età inferiore a 55 anni ${ }^{40}$ e solo recentemente il limite è stato aumentato a 65 anni anche se solo sulle forme secondariamente progressive ${ }^{41}$ Una recente analisi di un database canadese i soggetti ad esordio tardivo erano prevalentemente maschi, mostravano sintomi motori o $\mathrm{CAB}$ e mostravano un aspetto primario-progressivo all'esordio. Le progressione a livello EDSS 6 era più rapido rispetto a quelli ad esordio in età adulta ma la prescrizione di farmaci che modificano la malattia (in particolare IF $\beta$-1a) era inferiore. ${ }^{28,42}$

Nella Sclerosi Multipla terapie proposte variano a seconda della fase e della modalità di presentazione. La terapia delle fasi acute si base sul metilprednisolone ad alte dosi e/o sulla plasmaferesi. I trattamenti per modificare la progressione si basano sull'ocrelizumab per le forme primariamente progressive. Per le forme remittenti-recidivanti si considera meglio efficace una terapia antinfiammatoria iniziale aggressiva. Le opzioni disponibili consistono nelle formulazioni di interferon $\beta$, nell'ocrelizumab, nel glatiramer acetato, nel dimetil fumarato, nel fingolimod, nel teriflunomide, nel natalizumab, nell'alentuzumab, nel mitoxantrone. Di questi farmaci sono noti i potenziali effetti avversi, anche se mancano riferimenti specifici ai pazienti anziani. L'interferone è potenzialmente responsabile di danno epatico, l'ocrelizumab può aumentare l'insorgenza di cancro mammario (a tutte le età), fingolimod può determinare prolungate e pericolose bradicadie, il natalizumad può favorire lencoencefalopatia multifocale, l'alentuzumab aumenta il rischio di infezioni e di malattie autoimmuni, il mitoxantone ha significativa cardiotossicità ed aumenta il rischio di leucemie (AML) infine la ciclofosfamidesi associa a leucemie/linfomi.

\section{Conclusioni}

Nella decisione terapeutica vale il principio generale che le malattie ed i loro trattamenti sono solo un tassello del complesso mosaico del paziente. Le terapie non vanno meramente sommate ma vanno integrate in un obiettivo di salute necessariamente individuale. La regola di iniziare nell'anziano con bassi dosaggi e di titolare gradualmente le dosi fino ad ottenere la risposta clinica o rilevare effetti avversi resta basilare.

Nelle IMID del paziente anziano non è possibile basare la scelta di intraprendere una terapia con biologici su regole evidence-based. Tuttavia si tratta di porre l'individuo anziano e non la malattia al centro del ragionamento clinico, diagnostico e terapeutico. Invece che dalle singole malattie, la valutazione dell'anziano deve partire dalla persona, dal suo stato cognitivo, dalla mobilità, dalla eventuale fragilità (intesa come vulnerabilità dell'equilibrio omeostatico ai fattori esterni) per inserire successivamente le co-morbilità e la conseguente polifarmacoterapia. L'obiettivo principale deve essere il mantenimento della autonomia, della qualità della vita e della assenza di dolore. Nella scelta terapeutica il medico deve considerare la maggiore vulnerabilità agli effetti collaterali dei farmaci ma l'obiettivo deve essere quello di massimizzare i benefici e ridurre al minimo i danni. Nelle IMID molte delle terapie tradizionali sono anch'esse gravate nell'anziano da importanti effetti collaterali ma non va dimenticato che la malattia non adeguatamente trattata ha conseguenze non meno gravi degli effetti avversi dei farmaci. La personalizzazione della cura deve rappresentare un esercizio quotidiano senza overtreatment ma anche evitando un colpevole atteggiamento ageistico di astensione terapeutica.

Infine un'ultima considerazione. I farmaci per le 
IMID, sia DMARD che biologici, sono caratterizzati da effetti antinfiammatori che non solo producono effetti di controllare la malattia stessa ma sembrano anche limitare la progressione del danno infiammatorio di molti organi (principalmente del sistema vascolare) riducendo la morbilità e la mortalità cardiovascolare nei pazienti responders. Un precoce ed efficace controllo della IMID riducendo la attività infiammatoria sistemica è potenzialmente in grado di riportare la sopravvivenza del paziente con IMID a quella della popolazione non ammalata.

Una considerazione finale sulle vaccinazioni. Tutti i pazienti con IMID e in particolare se anziani e/o in corso di trattamento con DMARD o con biologici vanno considerati immunodepressi. Le indicazioni sono di non effettuare estensivamente vaccinazioni con vaccini vivi (influenza nasale, $\mathrm{BCG}$, antitifo orale, varicella, febbre gialla, morbillo, parotite e rosolia) per il rischio di malattia sistemica. Occorre poi valutare il singolo paziente e il suo stato immunitario prima di somministrare anche i vaccini attenuati come quello dell'influenza, l'anti-meningococco e l'antiHVB che potrebbero non produrre la risposta immunitaria desiderata. Il quadro vaccinale deve essere valutato prima di iniziare terapia immunosoppressive e se la vaccinazione è necessaria per ridurre il rischio di comorbilità (es. antipneumoccico in BPCO) l'inizio del trattamento con immunosoppressori va ritardato di 2-4 settimane dopo la somministrazione del vaccino in accordo con le indicazioni riportate per ciascun farmaco e/o vaccino.

\section{Bibliografia}

1. Cevenini e, Monti D, Franceschi C. Inflamm-ageing . Curr Opin Clin Nutr Metab Care 2013, 16:14 - 20 DOI:10.1097/MCO.0b013e32835ada13

2. 2) Rodier F, Campisi J. Four faces of cellular senescence. J Cell Biol 2011; 192:547 - 556

3. Di Leonardo A, Linke SP, Clarkin K, Wahl GM. DNA damage triggers a prolonged p53-dependent G1 arrest and long-term induction of Cip1 in normal human fibroblasts. GenesDev 1994; 8:2540 - 2551.

4. Freund A, Orjalo AV, Desprez PY, Campisi J. Inflammatory networks during cellular senescence: causes and consequences. Trends MolMed 2010; 16:238 - 246.

5. Das UN: metabolic syndrome $X$ : an inflammatory condition? . Curr Hypertens Rep 2004;6:66-73

6. Gregor MF Hotamisligil GkS. Inflammatory mechanisms in obesity. Ann Rev Immunol 2011; 29: 415-445

7. Korkaya H, Liu S, Wicha MS. Regulation of cancer stem cells by cytokine networks: attacking cancer's inflammatory roots. Clin Cancer Res 2011; 17:6125 6129.

8. Bonafe` M, Storci G, Franceschi C. Inflamm-aging of the stem cell niche: Breast cancer as a paradigmatic example: Breakdown of the multishell cytokine network fuels cancer in aged people. Bioessays 2011; 34:40 - 49 .
9. Candela M, Guidotti M, Fabbri A, et al. Human intestinal microbiota: crosstalk with the host and its potential role in colorectal cancer. CritRevMicrobiol 2011; 37:1 - 14

10. Biagi E, Nylund L, Candela M, et al. Through aging, and beyond: gut microbiota and inflammatory status in seniors and centenarians. PLoS One 2010; 5:e10667. Erratum in: PLoS One. 2010;5(6). doi: 10.1371/annotation/df45912f-d15c-44ab-8312-e7ec0607604d.

11. Biagi E, Candela M, Fairweather-Tait S, et al. Aging of the human metaorganism: the microbial counterpart. Age 2012; 34:247 - 267 .

12. Neish AS. Microbes in gastrointestinal health and disease. Gastroenterology 2009; 136:65 - 80.

13. Forbes JD, Van Domselaar G, Bernstein CN . The gut microbiota in Immune-Mediated Inflammatory Diseases Front. Microbiol. 7:1081. doi: 10.3389/fmicb.2016. 01081

14. El Gabalawy H, Guenthier LC, Bernstein CN . Epidemiology of Immune-Mediated Inflammatory Diseases: Incidence, Prevalence, Natural History, and Comorbidities. J Rheumatol 2010;37 Suppl 85:2-10; doi:10.3899/ jrheum.091461

15. Gabriel SE, Michaud K. Epidemiological studies in incidence, prevalence, mortality, and comorbidity of the rheumatic diseases. Arthritis Res Ther 2009;11:229.

16. Ferrandiz C, Pujol RM, Garcia-Patos V, Bordas X, Smadia JA. Psoriasis of early and later onset: a clinical and epidemiological study from Spain. J Am Acad Dermatol 2002; 46:867-73

17. Henseler T, Christphers E: Psoriasis of early and later onset : characterization of two types of psoriasis vulgaris. J Am Acad Dermatol 1985; 13:450-6

18. Enerback C, Martinsson T, Inerot A, et al. Evidence that HLA-Cw6 determines early onset of psoriasis, obtained using sequence-specific primers (PCR-SSP). Acta DermVenereol 1997;77:273-6.

19. Hugle T, Schuetz P, Daikeler T, Tyndall A, and EUSTAR members: Late- onset systemic sclerosis - a systematic survey of the EULAR scleroderma trials and research group database Rheumatology 2011;50:161165 doi:10.1093/rheumatology/keq321

20. Nimmons D, Limdi JK. Elderly patients and inflammatory bowel disease World J Gastrointest Pharmacol Ther 2016 February 6; 7(1): 51-65

21. Loftus EV. Clinical epidemiology of inflammatory bowel disease: Incidence, prevalence, and environmental influences. Gastroenterology 2004;126:1504-17.

22. Bernstein CN, Wajda A, Svenson LW, et al. The epidemiology of inflammatory bowel disease in Canada: a population-based study. Am J Gastroenterol 2006;101: 1559-68.

23. J. Chen; G. D. Eslick; M. Weltman. Systematic Review With Meta-analysis of Clinical Manifestations and Management of Autoimmune Hepatitis in the Elderly. Aliment Pharmacol Ther. 2014;39(2):117-124

24. Al-Chalabi T, Boccato S, Portmann BC, et al. Autoimmune hepatitis (AIH) in the elderly: a systematic retrospective analysis of a large group of consecutive patients with definite $\mathrm{AIH}$ followed at a tertiary referral centre. J Hepatol 2006;45:575-83.

25. Griffiths L, Dyson JK, Jones DE. The new epidemiology of primary biliary cirrhosis. Semin Liver Dis 2014; 34: 318-28. 
26. Molodecky NA, Kareemi H, Parab R, et al. Incidence of primary sclerosing cholangitis: a systematic review and meta-analysis. Hepatology 2011;53:1590-99.

27. Gabriel SE, Crowson CS, Kremers HM, et al. Survival in rheumatoid arthritis: a population-based analysis of trends over 40 years. Arthritis Rheum 2003;48:54-8.

28. Shirani A, Zhao Y, Petkau J, et al. Multiple Sclerosis in Older Aduts: the clinical profile and impact of Interferon beta treatment. Bio Med Research International Volume 2015, Article ID 451912, 11 pages http://dx.doi.org/ $10.1155 / 2015 / 451912$

29. Simard JF, Arkema E V, Sundstrom A, et al. Ten years with biologics: to whom do data on effectiveness and safety apply? Rheumatology 2011;50:204-213 doi:10.1093/rheumatology/keq326

30. Murota A, Kaneko Y, Yamaoka K, Takeuchi T. Safety of Biologic Agents in Elderly Patients with Rheumatoid Arthritis. J Rheumatol First Release September 12016 ; doi:10.3899/ jrheum.160012)

31. Duarte R, Campainha S, Cotter J, et al on behalf of Portuguese Society of Pulmonology, Portuguese Society of Gastroenterology, Portuguese Society of Dermatology and Venereology and Portuguese Society of Rheumatology. Position paper on tuberculosis screening in patients with immune mediated inflammatory diseases candidates for biological therapy. Acta Reumatol Port. 2012;37:253-259

32. Esposito M1, Giunta A, Mazzotta A, et al. Efficacy and safety of subcutaneous anti-tumor necrosis factor-alpha agents, etanercept and adalimumab, in elderly patients affected by psoriasis and psoriatic arthritis: an observational long-term study. Dermatology. 2012;225(4):3129. doi: 10.1159/000345623

33. Wong JW, Koo YM: The safety of systemic treatments that can be used for geriatric psoriasis patients: a review. Dermatology Research and Practice. 2012 article ID 367475. doi: 10.1155/2012/367475

34. Lobatón T, Ferrante M, Rutgeerts P, et al. Efficacy and safety of anti-TNF therapy in elderly patients with in- flammatory bowel disease. Aliment Pharmacol Ther 2015; 42: 441-451 [PMID: 26104047 DOI: 10.1111/apt. 13294]

35. Cottone M, Kohn A, Daperno M, et al. Advanced age is an independent risk factor for severe infections and mortality in patients given anti- tumor necrosis factor therapy for inflammatory bowel disease. Clin Gastroenterol Hepatol 2011; 9: 30-35 [PMID: 20951835 DOI: 10.1016/j.cgh.2010.09.026]

36. Colombel JF, Loftus EV, Tremaine WJ, et al. The safety profile of infliximab in patients with Crohn's disease: the Mayo clinic experience in 500 patients. Gastroenterology 2004; 126: 19-31 [PMID: 14699483 DOI: 10.1053/j.gastro.2003.10.047]

37. Singh JA, Wells GA, Christensen R, et al. Adverse effects of biologics: a network meta-analysis and Cochrane overview. Cochrane Database Syst Rev 2011; (2): CD008794 [PMID: 21328309 DOI: 10.1002/14651858. cd008794. pub2]

38. Liberal R, Grant CR, Mieli-Vergani G, Vergani D. Autoimmune hepatitis. A comprehensive review. J Autoimmun 2013;41:126-39

39. Triantos CK, Koukias NM, Nikolopoulou VN, et al. Meta-analysis: ursodeoxycholic acid for primary sclerosing cholangitis. Aliment Pharmacol Ther 2011;54: 901-10

40. "Randomised double-blind placebo-controlled study of interferon beta-1a in relapsing/remitting multiple sclerosis. PRISMS (Prevention of Relapses and Disability by Interferon beta-1a Subcutaneously in Multiple Sclerosis) Study Group," e Lancet, vol. 352, pp. 1498-1504, 1998.

41. D. H. Miller, O. A. Khan, W. A. Sheremata et al., "A controlled trial of natalizumab for relapsing multiple sclerosis," New England Journal of Medicine, vol. 348, no. 1, pp. 15-23, 2003.

42. A.Awad, O.Sutve,"Multiple sclerosis in the elderly patient," Drugs and Aging, vol. 27, no. 4, pp. 283-294, 2010 


\title{
Farmaci biosimilari e farmaci innovativi in reumatologia: quale futuro?
}

\author{
Monica Todoerti, Carlomaurizio Montecucco \\ Struttura Complessa di Reumatologia, Policlinico San Matteo, Università di Pavia, Italia
}

\section{Farmaci biosimilari}

L'avvento dei farmaci biotecnologici ha radicalmente rivoluzionato l'approccio terapeutico in differenti contesti medici, tra cui in particolare quello reumatologico, offrendo nuove valide prospettive terapeutiche nei pazienti con patologie infiammatorie articolari refrattarie al trattamento convenzionale di prima linea. Di per sé i farmaci biologici o biotecnologici sono grandi molecole complesse prodotte in microorganismi vivi, quindi purificate e solitamente modificate attraverso metodiche di tecnologia ricombinante. ${ }^{1} \mathrm{~A}$ partire dalla introduzione del primo agente biologico, l'insulina ricombinante umana approvata all'uso terapeutico nel 1982, diversi agenti sono stati via via prodotti ed introdotti nella pratica clinica quotidiana. ${ }^{2}$ Tuttavia a causa della loro complessità strutturale e delle conseguenti lunghezza e costi dei relativi processi di produzione, la loro adozione oggi è strettamente subordinata a precise indicazioni e controindicazioni definite nei vari contesti nazionali ed internazionali da linee guida e raccomandazioni ad hoc. Nel set più aggiornato delle raccomandazioni europee circa la gestione farmacologica dell'artrite reumatoide (AR), si sottolinea come attualmente nei pazienti non responsivi alla terapia immunomodulatrice convenzionale (csDMARDs quali methotrexato-MTX/equivalenti), vi siano a disposizione oggi, in particolare in presenza di fattori prognostici negativi, due differenti strategie terapeutiche: l'adozione di farmaci biologici anti-TNF e non, e di nuovi DMARD sintetici targettizzati (tsDMARDs), ov-

Corrispondente: Carlomaurizio Montecucco, Struttura Complessa di Reumatologia, Policlinico San Matteo, Università di Pavia, Italia.

Tel.: +39.0382.501878 - Fax: +39.0382.503171.

E-mail: montecucco@smatteo.pv.it

Articolo pubblicato secondo la Creative Commons Attribution NonCommercial 4.0 License (CC BY-NC 4.0).

C Copyright M. Todoerti e C. Montecucco, 2017

Licensee PAGEPress, Italy

QUADERNI - Italian Journal of Medicine 2017; 5(7):200-214 vero farmaci sintetici non biologici rivolti contro specifici bersagli terapeutici implicati nel determinismo di malattia, quali gli inibitori del pathway intracellulare JAK-STAT. ${ }^{3}$ Nel primo caso si ammette poi alternativamente l'eventualità di adozione dei farmaci biologici originatori o dei loro biosimilari, quando adeguatamente approvati secondo gli iter previsti da EMA ed AIFA. È infatti atteso che questi nuovi agenti farmacologici biosimilari, di cui è stata comprovata la sovrapponibilità del profilo di efficacia clinica ed eventi avversi insieme ad un chiaro vantaggio economico rispetto agli originator corrispondenti, possano ampliare e facilitare l'accesso a questa tipologia di farmaci ad alto costo ad un numero crescente di pazienti. ${ }^{4}$ Tutto ciò è stato reso possibile dalla progressiva decadenza dei brevetti di copertura dei farmaci biologici originatori (Tabella 1). ${ }^{5}$

\section{Nomenclatura e definizioni}

Il primo aspetto da chiarire in questo contesto riguarda proprio la terminologia e le definizioni specifiche adottate per identificare questa nuova tipologia di farmaci dalle diverse autorità regolatorie del farmaco (Tabella 2).

$\mathrm{Al}$ fine di ulteriormente chiarire il concetto di biosimilare, bisogna precisare il significato di altri termini quali quello di intended copies o non comparable biotherapeutic products, anche detti biomimics/bioquestionable/biocopies, intesi come copie di agenti biotecnologici già approvati, ma non rispondenti a precise esigenze e iter legislativi e produttivi prestabiliti dalle autorità regolatorie del farmaco (EMA/FDA/WHO) ${ }^{6}$ In altre parole gli intended copies non hanno seguito né rispettato il processo multi-step di comparabilità richiesto e regolamentato per i farmaci biosimilari: $i$ test analitici e pre-clinici potrebbero essere stati in questo caso insufficienti, i trials clinici esigui o metodologicamente inadeguati. Non vi è quindi evidenza di una loro simile efficacia e sicurezza rispetto al farmaco biologico originatore, a differenza invece di quanto accade ed è assolutamente richiesto per i farmaci biosimilari. Gli intended copies sono stati per lo più approvati e commercializzati in realtà economico-geografiche in cui 
non esistono regolamentazioni precise in merito oppure laddove esse siano meno stringenti nei confronti dei farmaci biosimilari o analoghi; attualmente vengono adottate intended copies di etanercept e rituximab in Cina, India, Colombia e Messico. Ancora differente risulta poi il concetto di bio-better, inteso come un agente biotecnologico avente lo stesso target e meccanismo d'azione dell'originator di riferimento, ma con predefinite e ricercate modificazioni strutturali e/o funzionali e/o di formulazione finalizzate ad implementarne e volontariamente migliorarne la performance clinica. Dal punto di vista strutturale, i farmaci biologici, e quindi gli stessi biosimilari o gli intended copies o i biobetter, differiscono sostanzialmente dai farmaci sintetici chimici in termini di dimensioni molecolari, complessità strutturale, processo produttivo (Tabella 3 ). In particolare i farmaci sintetici (small molecules) hanno per lo più piccole dimensioni (tra 100 e $1000 \mathrm{Da}$ ) e vengono prodotti attraverso processi di sintesi chimica che risultano per lo più nella realizzazione di composti totalmente identici tra loro; viceversa $i$ farmaci biotecnologici possiedono dimensioni molecolari maggiori, dell'ordine dei $18-150 \mathrm{kDa}$, una struttura più complessa, ed essendo realizzati attraverso sistemi viventi possono andare naturalmente incontro ad una maggiore, per quanto controllata e vigilata, intrinseca variabilità ed eterogeneità, risultando così in un insieme di varianti della stessa molecola proteica originaria. Ovviamente tale variabilità è strettamente controllata e regolamentata dalle autorità regolatorie del farmaco al fine di rimanere entro predefiniti limiti di accettabilità. In aggiunta la loro azione farmacologica dipenderà non solo dalla loro struttura primaria (sequenza aminoacidica), ma anche da quella secondaria, terziaria e eventualmente quaternaria. Pertanto il processo di realizzazione di un farmaco biotecnologico, e quindi di un biosimilare, è estremamente articolato e complesso, includendo dapprima l'identificazione e l'isolamento di una specifica sequenza genica del target molecolare di interesse, la clonazione della medesima, la veicolazione del DNA target in un sistema vivente di espressione. Successivamente la proteina di interesse così espressa deve essere raccolta dal terreno di coltura, isolata, purificata, formulata. Ciascuno di questi steps è strettamente sensibile alle condizioni di produzione, per cui diventa comprensibile come qualsiasi variazione o dif-

Tabella 1. Date di scadenza dei brevetti dei singoli agenti biologici originatori ad oggi approvati nella AR. Modificato da Goel N, et al. ${ }^{5}$

\begin{tabular}{lllll}
\hline Agente biologico & $\begin{array}{l}\text { Scadenza brevetto } \\
\text { Europeo }\end{array}$ & Status biosimilare & $\begin{array}{l}\text { Scadenza brevetto } \\
\text { USA }\end{array}$ & Status biosimilare \\
\hline Actemra/RoActemra (tocilizumab) & 2017 & 2022 & Approvato nel 2016 \\
\hline Remicade (infliximab) & 2015 & Approvato nel 2013 & 2018 & 2024 \\
\hline Cimzia (certolizumab pegol) & 2021 & & 2028 & Studi fase III \\
\hline Enbrel (etanercept) & 2015 & Approvato nel 2016 & 2016 & Studi fase III \\
\hline Humira (adalimumab) & 2018 & Studi fase III & 2018 & \\
\hline Orencia (abatacept) & 2017 & & 2016 & 2024 \\
\hline Mabthera (rituximab) & 2013 & Studi fase III & 2023 & \\
\hline Simponi (golimumab) & 2024 & & & \\
\hline Stelara (ustekinumab) & 2024 & & & \\
\hline
\end{tabular}

Tabella 2. Nomenclatura e definizioni indicate dalle diverse autorità regolatorie del farmaco per i farmaci biosimilari. Modificato da Goel N, et al. ${ }^{5}$

\begin{tabular}{llll}
\hline Stato & Agenzia regolatoria & Nomenclatura & Definizione \\
\hline Europa & EMA & Biosimilare & $\begin{array}{l}\text { Nuova versione di un farmaco biologico già autorizzato (reference product) } \\
\text { con una dimostrata similarità in caratteristiche qualitative, attività biologica, } \\
\text { sicurezza ed efficacia, basate su un esteso esercizio di comparabilità. }\end{array}$ \\
\hline USA & FDA & Biosimilare & $\begin{array}{l}\text { Prodotto biologico che risulta altamente similare al prodotto di riferimento } \\
\text { (reference product) nonostante differenze minime in componenti clinica- } \\
\text { mente inattive e che non presenta differenze clinicamente significative in } \\
\text { termini di sicurezza, purezza e potenza del prodotto. }\end{array}$ \\
\hline Worldwide & WHO & Similar Biotherapeutic & $\begin{array}{l}\text { Prodotto bioterapeutico che risulta simile in qualità, sicurezza ed efficacia } \\
\text { rispetto ad un prodotto bioterapeutico di riferimento già approvato. }\end{array}$ \\
\hline
\end{tabular}


ferenza in tali contesti possa impattare significativamente sulla qualità, purezza, caratteristiche biologiche ed attività terapeutica del prodotto finale. Data l'intima correlazione tra struttura e funzione, minime variazioni in uno o più di questi aspetti/step potrebbero comportare differenze clinicamente rilevanti nella purezza e/o efficacia e/o potenza di questi composti. Queste fondamentali differenze tra farmaci sintetici e biotecnologici giustificano pertanto come il processo di approvazione di un farmaco generico di un sintetico chimico non possa essere adottato ed adattato anche per ed alla approvazione di un biosimilare; se infatti nel primo caso è sufficiente dimostrare la bioequivalenza del farmaco generico rispetto al suo originale attraverso la comprovazione di analoghe caratteristiche farmacocinetiche e farmacodinamiche, questo non può essere valido per molecole più complesse quali quelle dei farmaci biotecnologici. In tal senso quindi i biosimilari non dovrebbero e non potrebbero essere intesi come farmaci generici, alla stregua delle piccole molecole sintetiche, ed in ogni caso non potrebbero essere considerati completamente identici al comparatore originale biotecnologico, proprio per la specificata complessità e variabilità intrinseca dei processi di produzione.

Per i biosimilari quindi le agenzie regolatorie AIFA ed EMA richiedono la realizzazione di un processo più complesso e strutturato che includa l'esecuzione ed il soddisfacimento di test preclinici di tipo analitico (finalizzati all'analisi strutturale e funzionale) e di tipo non clinico (in vitro e in vivo su modelli animali), oltre che di test clinici anche se meno estensivi rispetto a quelli condotti per il farmaco originatore (Figura 1). Lo sviluppo di un farmaco biosimilare richiede in ogni caso un processo di confronto diretto testa-a-testa con il prodotto di riferimento (esercizio di comparabilità) finalizzato ad escludere qualsiasi differenza dal punto di vista clinico che oltrepassi un pre-specificato margine di equivalenza. Nello specifico $i$ trials comparativi adoperati a questo proposito dovranno essere studi di non inferiorità o di equiva- lenza dotati di sufficiente numerosità campionaria della popolazione sensibile di riferimento e di un adeguato follow up finalizzato anche ad evidenziare eventuali eventi avversi meno frequenti. Mentre per il farmaco biotecnologico originator sono richiesti quindi numerosi studi clinici per validarne ex novo l'efficacia e la sicurezza in determinati subset di pazienti, per i farmaci biosimilari prevale la necessità di caratterizzare adeguatamente il farmaco, escludendone sostanziali differenze strutturali e funzionali rispetto all'originator. Ne consegue in ogni caso la necessità di sottoporre il biosimilare ad un processo registrativo strutturato ed articolato come previsto e richiesto dalle apposite autorità statunitensi (FDA, Food and Drug Administration), europee (EMA, European Medicines Agency) e internazionali (OMS/WHO, Organizzazione Mondiale della Sanità), oltre che ad una attenta osservazione anche dopo l'immissione in commercio (sorveglianza post-marketing). È da sottolineare come anche i farmaci biotecnologici originali possano andare incontro a modificazioni nel loro processo di produzione, più $\mathrm{o}$ meno programmate. Ovviamente anche in questo caso deve essere assicurata la stabilità del prodotto pre- $\mathrm{e}$ post-modificazioni in termini di profilo di efficacia e sicurezza. Per i farmaci biosimilari, alla stregua di quanto già accade per i farmaci biotecnologici, diviene poi obbligatoria una farmacovigilanza, ovvero l'attento monitoraggio post-marketing di eventuali eventi avversi. In particolare, risulta fondamentale la possibilità di tracciabilità di questi agenti biologici per facilitare una più precisa identificazione e caratterizzazione dell'esatto prodotto chiamato in causa.

\section{Infliximab biosimilare-efficacia clinica}

CT-P13/Infliximab-dyyb (Inflectra, Remsima) è stato il primo biosimilare approvato in Europa e USA, per le stesse indicazioni previste per il corrispondente

Tabella 3. Differenze tra farmaci biotecnologici e farmaci sintetici.

\begin{tabular}{ll}
\hline Parmaci chimici sintetici & Sintesi chimica da materiale non vivente \\
\hline & $\begin{array}{l}\text { Ottenuti tramite reazioni di chimica organica standardizzate e riproducibili grazie alle metodiche analitiche } \\
\text { attualmente disponibili }\end{array}$ \\
\hline Piccole molecole a basso peso molecolare \\
\hline Garmaci biotecnologici & Sintetizzati a partire da organismi viventi \\
\hline Ottenuti mediante tecniche di ingegneria genetica \\
\hline Molecole complesse ad alto peso molecolare \\
Generalmente immunogeni
\end{tabular}


originator infliximab/IFX (artrite reumatoide/AR, artrite psoriasica/AP, spondilite anchilosante/SA, Morbo di Crohn/MC dell'adulto e del bambino, rettocolite ulcerosa/RCU, psoriasi cutanea/PsO). Oltre alla dimostrazione della comparabilità di tipo analitico e pre-clinico rispetto all'originator, come previsto da EMA e FDA, e come ampiamente esplicitato nei paragrafi precedenti, vi sono a supporto della sua approvazione uno studio di fase III su pazienti con AR (PLANETRA) e uno studio di fase I su pazienti con
SA (PLANETAS). ${ }^{7,8}$ Successivamente sono state pubblicate anche evidenze provenienti da casistiche osservazionali, comparative e non rispetto a IFX originator, a supporto della sua efficacia e sicurezza di utilizzo in pazienti con patologie infiammatorie intestinali/IBD. Nello studio PLANETRA, studio randomizzato controllato in doppio cieco, pazienti con AR refrattari a methotrexato/MTX hanno parimenti beneficiato dell'associazione con IFX originator $v s$ biosimilare in termini di raggiungimento della risposta

A

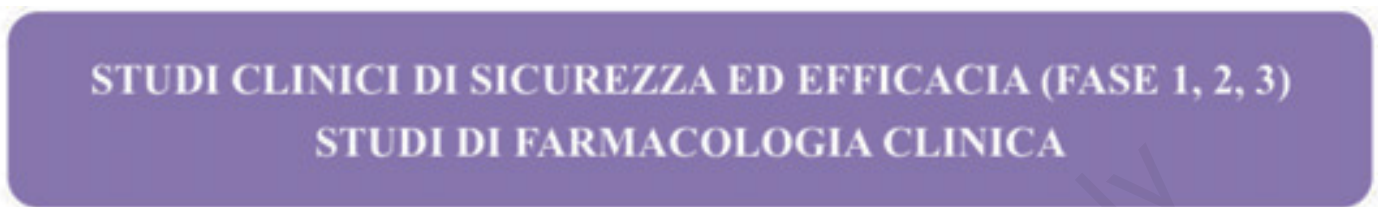

\section{STUDI NON CLINICI}

\section{STUDI ANALITICI}

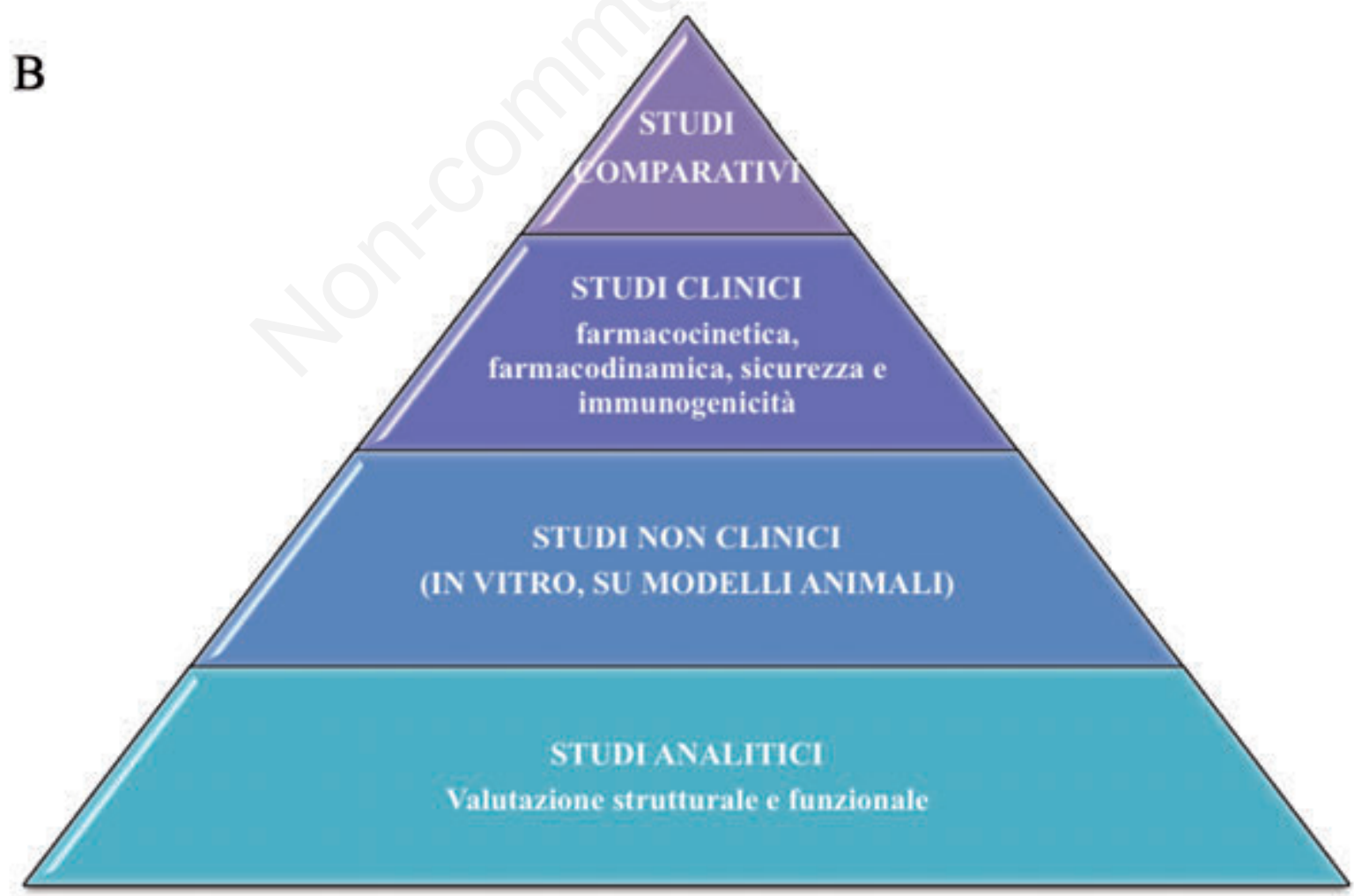

Figura 1. Schema rappresentativo del processo di sviluppo di un farmaco biotecnologico originatore (A) e di un biosimilare (B) a confronto. Modificato da Goel $N$, et al. ${ }^{5}$ 
clinica ACR20 (American College of Rheumatology Response) a 30 settimane (endpoint primario), ovvero la differenza nella risposta clinica tra i due bracci attivi è risultata entro i limiti di equivalenza predefiniti (+/$15 \%$ ) sia nella analisi per-protocol (risposta ACR20 raggiunta nel $69,7 \%$ per IFX originator $v s 73,4 \%$ per IFX biosimilare) sia nella analisi intention-to-treat $(58,6 \%$ per IFX originator $v s 61 \%$ per IFX biosimilare) ${ }^{8}$ Non si sono inoltre trovate differenze significative in termini di raggiungimento degli end-points clinici secondari allo stesso time-points (risposte ACR50 e ACR70, remissione clinica secondo ACR/EULAR). Tra questi pazienti, 455 hanno poi proseguito l'assunzione del farmaco inizialmente adottato fino alla settimana 54 con mantenimento dell'efficacia clinica in modo tendenzialmente sovrapponibile tra i due farmaci. ${ }^{9}$ Anche dal punto di vista strutturale e funzionale, non si sono osservate differenze sostanziali in termini di progressione del danno strutturale erosivo e non, con paragonabile percentuale (circa 50\%) di pazienti definibili non progressors (assenza di variazione dello score radiografico secondo Sharp rispetto al baseline). A supporto di questo dato, un ulteriore studio giapponese includente $100 \mathrm{AR}$ ha confermato che la risposta al trattamento con IFX originator $v s$ biosimilare era comparabile fino a 54 settimane di osservazione..$^{10}$ Nello studio PLANETAS invece sono stati inclusi 210 pazienti con SA attiva nonostante il trattamento con FANS e sono stati valutati come end-points primari parametri di farmacocinetica, quindi il raggiungimento di outcomes secondari di tipo clinico. A 14, 30 e 54 settimane di follow up non si sono osservate differenze sostanziali in termini di raggiungimento della risposta ASAS20, ASAS40, ASASPR (ASAS Partial Remission). Per quanto riguarda le evidenze in merito all'utilizzo di CT-P13 in pazienti con IBD, vi sono come detto vari studi osservazionali prospettici e retrospettivi comparativi e non, attestanti l'efficacia del farmaco, paragonabile a quella del comparator originale quando presente, in termini di controllo clinico, laboratoristico ed endoscopico di malattia, sia nella fase di induzione sia nella fase di mantenimento della remissione clinica. ${ }^{11}$ Attualmente è anche in corso uno studio randomizzato in doppio cieco di non inferiorità di IFX biosimilare $v s$ IFX originator in più di 200 pazienti affetti da $\mathrm{MC}$ in fase di attività (NCT02096861).

\section{Switch IFX originator $>$ biosimilare}

In entrambi gli studi PLANETRA e PLANETAS, i pazienti che hanno completato 54 settimane di trattamento (rispettivamente 302 AR e 174 SA) sono entrati in una fase di estensione in aperto di 48 settimane in cui i pazienti originariamente trattati con IFX originator sono stati shiftati a IFX biosimilare (gruppo switch), mentre quelli inizialmente riceventi CT-P13 hanno proseguito il medesimo agente biologico. Nell'estensione del PLANETRA, a 102 settimane di follow up le percentuali di raggiungimento delle risposte ACR20, ACR50 e ACR70 sono risultate rispettivamente del $71,8 \%, 51,4 \%, 26 \%$ nel gruppo switch $(\mathrm{n}=144)$ e $71,7 \%, 48,0 \%$ e $24,3 \%$ nel gruppo dei pazienti che ha mantenuto il trattamento originario (CTP13). ${ }^{12}$ Analogamente nello studio PLANETAS le risposte ASAS20 e ASAS40 sono risultate comparabili tra i due subset di pazienti nel lungo termine: a 102 settimane esse sono risultate rispettivamente pari al $76,9 \%$ e $61,5 \%$ nel gruppo switch $(\mathrm{n}=86$ pazienti) e al $80,7 \%$ e $63,9 \%$ nel gruppo che ha proseguito CTP13 ( $\mathrm{n}=88$ pazienti); le corrispondenti percentuali di ASAS-partial remission sono risultate nei due gruppi del $23,1 \%$ e $19,3 \%$ rispettivamente. ${ }^{13}$ È tuttavia importante sottolineare come, per quanto abbiano condotto a risultati positivi e incoraggianti, le estensioni a lungo termine di entrambi gli studi PLANETRA e PLANETAS non siano state disegnate o comunque finalizzate ad hoc anche in termini di potenza statistica per evidenziare una eventuale non inferiorità o equivalenza tra lo switch ed il mantenimento del farmaco originator. Dati a supporto dello switch tra originator e biosimilare sono inoltre testimoniati da report di vita reale per lo più pubblicati finora sotto forma di abstracts. Tali evidenze sono anche disponibili per pazienti affetti da IBD; nel più ampio di questi studi (PROSIT-BIO), 53 pazienti con MC e 44 pazienti con RCU, sono stati sottoposti allo shift a IFX biosimilare dopo un numero medio di 18 infusioni di IFX originator. Di questi il $90 \%$ dei pazienti a 6 mesi dallo switch ha mantenuto la risposta terapeutica, con percentuali di inefficacia primaria o perdita di risposta rispettivamente pari a $1 \%$ e $15,6 \% .{ }^{14}$ In aggiunta, recentemente sono stati presentati in occasione di congressi internazionali di gastroenterologia e di reumatologia i risultati di un ampio studio indipendente multicentrico randomizzato controllato a bracci paralleli di fase IV, sponsorizzato dal governo norvegese (studio NOR-SWITCH), avente un disegno di non inferiorità volto a valutare un eventuale peggioramento clinico nel controllo di malattia in seguito allo switch da IFX originator a biosimilare in pazienti con patologie infiammatorie articolari e non. ${ }^{15}$ Lo studio ha arruolato 481 persone, di età superiore a 18 anni, con una diagnosi di artrite reumatoide, spondiloartrite, artrite psoriasica, colite ulcerosa, morbo di Crohn e psoriasi a placche cronica. I pazienti, che avevano ricevuto IFX originator per almeno 6 mesi, sono stati randomizzati 1:1 per continuare il trattamento con il prodotto di riferimento o intercambiati a IFX biosimilare, utilizzando lo stesso regime di dosaggio. L'end-point primario è stato definito come il peggioramento della malattia durante il follow-up, sulla base 
di end-points combinati correlati alla malattia e/o consensualità tra paziente e medico circa la necessità di cambiamento nella terapia. Complessivamente si è registrato un peggioramento della malattia in 53 $(26,2 \%)$ pazienti nel braccio IFX originator ed in 61 $(29,6 \%)$ pazienti nel braccio IFX biosimilare. I pazienti sono incorsi nello stesso numero di eventi avversi, incluse le reazioni infusionali per entrambi i bracci dello studio.

\section{Infliximab biosimilare-profilo di sicurezza}

Per quanto riguarda il profilo di tolleranza e tossicità di IFX originator e biosimilare, dagli studi finora pubblicati si è osservata una sostanziale sovrapposizione nella evenienza di eventi avversi di entità prevalentemente lieve-moderata (rispettivamente negli studi PLANETRA e PLANETAS per IFX biosimilare pari al $44 \%$ e $50 \%$ vs il $45 \%$ e $52 \%$ per IFX originator), includenti prevalentemente eventi infettivi non severi, reazioni peri-infusionali, elevazione mild degli indici di epatolisi. ${ }^{7,8}$ La prevalenza di eventi avversi severi è risultata comparabile tra $i$ due gruppi sia nei pazienti con AR (7,6\% per IFX biosimilare vs 4,7\% per IFX comparator) sia nei pazienti con SA (rispettivamente pari a $3,1 \%$ e $4,1 \%$ ) nei due studi presi in esame. Anche nei pazienti affetti da IBD, il profilo di sicurezza è risultato tendenzialmente sovrapponibile: in uno studio osservazionale in aperto includente 173 pazienti con MC o RCU trattati con IFX biosimilare da almeno 30 settimane, si sono osservati eventi avversi nel $10 \%$ dei casi, per lo più di intensità non severa. ${ }^{11}$ Nella maggior parte dei casi si è trattato di reazioni infusionali, prurito e rialzo termico. Anche nelle estensioni in aperto a lungo termine degli studi PLANETAS e PLANETRA sopra presentate, non si sono osservati incrementi nella evenienza di eventi avversi farmaco relati nei pazienti sottoposti allo switch da originator a biosimilare rispetto a coloro che hanno proseguito il biosimilare: nello specifico nello studio PLANETRA questi si sono verificati nel 19\% dei pazienti del gruppo switch rispetto al $22 \%$ dei pazienti che hanno mantenuto CTP-13, mentre nello studio PLANETAS le percentuali rispettive sono state del $39 \%$ e del $22 \% .{ }^{12,13} \mathrm{Il}$ dato inerente alla sicurezza dello switch al biosimilare tra l'altro è stato confermato anche nei pazienti affetti da IBD in setting di vita reale. ${ }^{8}$ Un altro aspetto rilevante in questo contesto, è rappresentato dalla potenziale immunogenicità associata a questi farmaci, ovvero dalla possibile comparsa di anticorpi anti-farmaco (ADAs): nello specifico nello studio PLANETRA la presenza degli ADA a 54 settimane è stata riscontrata nel $41 \%$ e nel $36 \%$ dei pazienti che hanno ricevuto CT-P13 vs IFX originator, mentre nello studio PLANETAS le corrispondenti prevalenze sono risultate pari a $19,5 \%$ and 23,0
$\%$. Nelle estensioni a lungo termine degli stessi studi, lo switch dall'originator al biosimilare non ha comportato un sostanziale aumento nell'incidenza di tali ADAs rispetto al gruppo che ha mantenuto IFX biosimilare ab initio né nei pazienti con AR né nei pazienti con SA (rispettivamente 44,8\% vs 40,3\% nel PLANETRA, 27,4\% vs 23,3\% nel PLANETAS). ${ }^{9,10}$ I pazienti ADAs + rispetto ai pazienti ADAs- hanno presentato un trend di più frequenti reazioni peri-infusionali correlabili alla terapia sia nei pazienti trattati con CTP-13 sia con IFX originator in entrambe le popolazioni affette da AR e SA. Anche nei pazienti con IBD, evidenze scientifiche real-life non sembrerebbero supportare un incremento di immunogenicità nel passaggio dall'originator al biosimilare, pur esistendo dati provenienti da uno studio prospettico di coorte indicativi di una maggiore incidenza di reazioni infusionali in risposta a IFX biosimilare nei pazienti IFXexperienced rispetto a pazienti IFX-naive (27 vs 2,5\%). ${ }^{16} \mathrm{Da}$ dati provenienti dallo studio NORSWITCH, l'incidenza degli anticorpi anti-farmaco è stata rilevata in $17(7,1 \%)$ pazienti che hanno assunto IFX originator ed in $19(7,9 \%)$ pazienti che hanno assunto il biosimilare.

\section{Etanercept biosimilare}

Per quanto concerne il biosimilare di etanercept/ETA, ad oggi la bioequivalenza strutturale e funzionale del biosimilare rispetto all'originator è stata dimostrata attraverso studi analitici e pre-clinici, e la comparabilità clinica è stata inizialmente dimostrata in vari studi clinici includenti pazienti con AR e psoriasi cutanea moderata-severa. Nello specifico l'efficacia di ETA biosimilare (SB4) è stata valutata in uno studio randomizzato, in doppio cieco a bracci paralleli, di fase III in pazienti con AR attiva refrattatia a MTX, ovvero in una popolazione considerata modello rappresentativo sensibile per valutare l'effetto del biosimilare rispetto al comparator. Il trial ha incluso una prima fase comparativa di 52 settimane (596 pazienti in totale: 299 randomizzati a SB4 e 297 a ETA originator), quindi una fase addizionale in aperto di 48 settimane che ha valutato l'efficacia e la sicurezza dello switch da ETA originator al biosimilare in un sub-set di pazienti. ${ }^{17-19}$ Come per lo studio PLANETRA, l'endpoint primario prescelto è stato il raggiungimento della risposta ACR20 a 24 settimane accettando un margine di equivalenza pre-specificato pari a $\pm 15 \%$ : sia nella analisi per-protocol sia nella analisi intention-to-treat le percentuali di risposta non sono differite sostanzialmente nei due gruppi di trattamento (rispettivamente $78 \%$ per SB4 e $80 \%$ per ETA originator e $74 \%$ per SB4 e $72 \%$ per ETA originator). Anche dal punto di vista della progressione strutturale non si sono osservate differenze sostanziali 
tra i due farmaci a 52 settimane di osservazione. L'estensione dello studio ha incluso 245 pazienti che hanno completato la prima fase di 52 settimane di trattamento: 126 pazienti hanno continuato a ricevere SB4, mentre 119 sono andati incontro a switch da ETA originator a SB4 per ulteriori 48 settimane. Globalmente al termine delle 100 settimane di osservazione, si sono ottenute risposte cliniche comparabili nei due gruppi di trattamento (risposta ACR20 del $78 \%$ in SB4>SB4 e del 79\% in ETA $>$ SB4). In aggiunta, da sotto-analisi specifiche non sembrerebbe che le risposte cliniche siano state in qualche modo influenzate dalla presenza di anticorpi anti-farmaco (ADAs), anche se i dati sono più che altro limitati ai pazienti in trattamento con ETA originator. In particolare, in merito alla immunogenicità di questi due agenti, si è osservato come l'individuazione degli ADAs sia risultata significativamente inferiore in SB4 vs ETA originator $(0,7$ vs. $13,1 \%, \mathrm{p}<0,001$ a 24 settimane e 1,0 vs $13,1 \%, \mathrm{p}<0,001$ a 52 settimane), senza che questo però abbia influito sostanzialmente su aspetti di sicurezza o di efficacia clinica. ${ }^{16}$ L'EMA ha interpretato il dato alla luce di potenziali fattori confondenti che possano avere in parte influito su questo risultato (lo stesso test di elettrochemoluminescenza adottato), ritenendo come sia ancora prematuro giungere alla conclusione che il biosimilare sia meno immunogeno del reference originator. ${ }^{20} \mathrm{Al}$ termine della fase di estensione dello studio, l'incidenza globale degli ADAs è risultata del $0,8 \%$ nel gruppo $\mathrm{SB} 4 / \mathrm{SB} 4$ e del $0,9 \%$ in ETA/SB4. Per quanto riguarda i pazienti affetti da psoriasi cutanea, risultati clinici sovrapponibili tra ETA biosimilare e originator sono emersi dallo studio EGALITY. ${ }^{21}$ In questo trial pazienti con psoriasi cutanea moderata-grave refrattari a trattamenti convenzionali di primo livello hanno presentato una comparabile risposta clinica in termini di risposta PASI75 a 12 settimane tra GP2015 e ETA originator, e non hanno presentato differenze sostanziali nel lungo termine a livello del profilo di efficacia e sicurezza neanche in seguito allo switch tra i due agenti. In particolare poi la comparsa di ADAs è risultata estremamente bassa e comunque caratterizzata da anticorpi non neutralizzanti.

\section{Adalimumab biosimilare}

Per quanto riguarda adalimumab/ADA, come detto il suo brevetto scadrà in Europa nel 2018. Pertanto ad oggi diverse aziende farmaceutiche stanno sviluppando versioni biosimilari dell'originator e conducendo studi ad hoc nelle diverse indicazioni: vi sono ad oggi in corso 9 studi clinici di fase 3 includenti pazienti con AR e psoriasi cutanea che stanno appunto testando la comparabilità clinica tra la versione originator e il biosimlare. ${ }^{22}$

\section{Implicazioni nella esperienza reale dei farmaci biosimilari}

\section{Nomenclatura}

Come già indicato, al fine di agevolare la comprensione, l'utilizzo ed in particolare il processo di farmacovigilanza, soprattutto dopo l'immissione in commercio di vari farmaci biosimilari, è fondamentale una precisa e corretta distinzione rispetto agli originators, al fine di garantirne la tracciabilità soprattutto in caso di eventi avversi.

\section{Estrapolazione delle indicazioni}

Ad oggi le principali agenzie regolatorie del farmaco, hanno garantito l'estensione delle indicazioni dei farmaci biosimilari per tutte quelle condizioni già approvate per il farmaco originale, eliminando così la necessità di eseguire numerosi studi di fase 3 corrispondenti a tutte le patologie per cui il farmaco di riferimento, e quindi il biosimilare, è indicato. $\mathrm{Ne}$ consegue come pertanto ad esempio per gli anti-TNF l'adozione in ambito dermatologico o gastroenterologico si basi su questo processo e non sulla effettiva esistenza di dati di trials clinici comparativi a supporto condotti in queste specifiche popolazioni. ${ }^{23}$ Le agenzie regolatorie del farmaco ammettono pertanto l'estrapolazione della indicazione terapeutica, qualora vi sia in merito sufficiente giustificazione scientifica, considerando contestualmente eventuali differenze del meccanismo di azione del farmaco nelle diverse indicazioni, diversa farmacocinetica e farmacodinamica in differenti popolazioni di pazienti, differenti attese tossicità patologia-specifiche. ${ }^{24,25} \mathrm{In}$ particolare le agenzie regolatorie canadesi non hanno concesso l'estrapolazione automatica di IFX biosimilare alle IBD considerando le possibili differenze rispetto all'originator in termini di citotossicità cellulo-mediata anticorpo dipendente, a loro volta legate a lievi differenze strutturali nella porzione Fc dell'anticorpo. Per questo motivo in Canada IFX biosimilare è ad oggi approvato per tutte le indicazioni, eccetto MC e RCU. ${ }^{26}$

\section{Costi}

Inevitabilmente l'aspetto più saliente dei farmaci biosimilari è la loro competitività dal punto di vista farmaco-economico, aspetto che potrebbe in ultima analisi garantire un più ampio accesso a questi farmaci anche in contesti in cui vi siano maggiori restrizioni di tipo economico.

\section{Intercambiabilità}

L'argomento della sostituibilità, che caratterizza il mondo dei farmaci equivalenti, rappresenta un aspetto importante anche e soprattutto per i medicinali biosimi- 
lari (si veda: www.reumatologia.it: Società Italiana di Reumatologia - Position Paper sui Farmaci Biosimilari). In merito tuttavia è doveroso meglio esplicitare il significato dei concetti stessi di sostituibilità e intercambiabilità. Secondo la definizione dell'OMS è prodotto farmaceutico intercambiabile un prodotto che si prevede abbia lo stesso effetto clinico di un prodotto comparatore e possa essere sostituito ad esso nella pratica clinica; in definitiva l'intercambiabilità si riferisce alla pratica medica di sostituire un farmaco con un altro equivalente in un determinato contesto clinico su iniziativa o con l'accordo del medico prescrittore. Si tratta pertanto di un atto e decisione medica, o comunque di una scelta espletata in accordo e/o sotto parere del personale medico qualificato. La sostituibilità, invece, fa riferimento alla pratica di sostituire un farmaco con un altro farmaco, spesso più economico per il Servizio Sanitario o per il paziente, che abbia la stessa composizione qualitativa e quantitativa di sostanze attive, la stessa forma farmaceutica e via di somministrazione e sia bio-equivalente con il medicinale di riferimento sulla base di appropriati studi di biodisponibilità. La sostituibilità automatica (degli equivalenti) si riferisce alla pratica per cui il farmacista ha la facoltà, oppure è tenuto, conformemente a norme nazionali o locali, a dispensare un farmaco equivalente e intercambiabile, senza consultare il medico prescrittore. In merito alla sostituibilità automatica dei biosimilari, la legislazione europea ha affidato alle Autorità nazionali competenti dei differenti stati membri autonomia decisionale e legislativa in materia. L'EMA ha precisato che la decisione circa la scelta prescrittiva del medicinale specifico da impiegare, di riferimento piuttosto che biosimilare, debba essere affidata a personale sanitario qualificato. L'AIFA ha deciso di non includere i medicinali biosimilari nelle liste di trasparenza che consentono la sostituibilità automatica tra prodotti equivalenti. Di conseguenza, la scelta di trattamento con un farmaco biologico di riferimento o con un biosimilare rimane una decisione clinica affidata al medico prescrittore. L'AIFA considera, tuttavia, che i biosimilari non solo costituiscano un'opzione terapeutica a disposizione dei curanti, ma siano da preferire, per il vantaggio economico, in particolare per il trattamento dei soggetti naive (che non abbiano avuto precedenti esposizioni terapeutiche o per i quali le precedenti esposizioni in base al giudizio del clinico siano sufficientemente distanti nel tempo). In conclusione, l'AIFA raccomanda l'uso dei biosimilari solo nei pazienti che debbono iniziare un nuovo trattamento. Attualmente è in corso un aggiornamento del position paper da parte della Società Italiana di reumatologia ma, conformemente al concetto di biosimilarità espresso da EMA, viene ancora ribadito il rispetto del principio di centralità del medico prescrittore nella scelta tra biologico originatore e corrispondenti prodotti biosimilari, confermando la non automatica sostituibilità.

\section{Immunogenicità}

Come già indicato, i farmaci biotecnologici, inclusi quindi gli stessi biosimilari, possono essere intrinsecamente induttori di autoimmunità in quanto potenzialmente immunogeni, aspetto che potrebbe in qualche modo influenzare l'efficacia e la tossicità degli stessi. La loro immunogenicità può dipendere inoltre da vari aspetti quali la via di somministrazione del farmaco, eventuali co-terapie, stato immunologico del paziente. In particolare la co-adozione di methotrexato nei pazienti con $\mathrm{AR}$ può ridurre la formazione di anticorpi anti-farmaco e quindi contribuire almeno in questa indicazione a mitigare il problema della immunogenicità.

\section{Take Home Messages relativi ai farmaci biosimilari in Reumatologia}

- Lo sviluppo dei farmaci biosimilari dovrebbe garantire l'accesso a cure ad alto costo ad un più ampio numero di pazienti grazie alla disponibilità di farmaci simili all'originator e a più basso costo.

- L'approvazione e l'immissione in commercio dei farmaci biosimilari prevede il rispetto e l'attuazione di un rigoroso processo scientifico multi-step (esercizio di comparabilità), regolamentato dalle autorità del farmaco (FDA, EMA, WHO), volto a confermare un sovrapponibile profilo di efficacia e sicurezza attraverso la dimostrazione di una sostanziale somiglianza pre-clinica tra originator e biosimilare.

- La complessità di struttura e di produzione dei farmaci biotecnologici rende ragione della non completa ed assoluta identicità tra biosimilare e originator. Il farmaco biosimilare non è pertanto da intendersi alla stregua dei farmaci generici dei composti chimici.

- In Italia attualmente la scelta di adottare o meno un farmaco biologico originator o biosimilare (ab initio o come switch) risulta essere ancora dipendente dalla scelta operata dal medico prescrittore, quando non espressamente subordinata a precise indicazioni di natura farmaco-economica.

\section{Nuovi target: synthetic DMARDs}

I bDMARDs hanno indubbiamente rivoluzionato la gestione terapeutica dei pazienti con AR, tuttavia rimangono ancora nella pratica clinica odierna alcuni aspetti clinicamente irrisolti nella gestione farmacologica dei nostri pazienti. Questi farmaci possono infatti perdere nel tempo di efficacia clinica o non presentare alcun effetto benefico sin dall'esordio, possono comportare l'evenienza di eventi avversi più o meno classe specifici, o comunque generalmente 
riconducibili ad una condizione di immunodepressione iatrogena con effetti collaterali primariamente di natura infettiva, o ancora possono non essere adeguatamente adottati a causa di comorbidità rilevanti. In questo setting si può collocare una nuova categoria di farmaci sintetici, quindi small molecules, in grado di interferire elettivamente con specifici targets intracellulari cruciali nella patogenesi di malattia. È infatti via via divenuto evidente come l'inibizione di una singola molecola pro-infiammatoria (TNF- $\alpha$, IL6, IL1) non sempre conduca al completo controllo di malattia. Negli ultimi 20 anni, la progressiva conoscenza della trasduzione dei segnali intra-cellulari si è consolidata aprendo la possibilità di inibire simultaneamente l'azione di differenti citochine. Tra queste small molecules, una nuova classe di agenti farmacologici recentemente sviluppata è rappresentata dai JAK inibitori, in grado di interferire con la trasduzione dei segnali intracellulari attraverso l'inibizione delle JAK chinasi. Tali enzimi appartengono alla famiglia delle tirosin-chinasi in grado a loro volta di legarsi costitutivamente alla porzione intra-cellulare dei recettori citochinici. Quando tali recettori vengono attivati dal legame con citochine o fattori di crescita, questo comporta la iniziale auto-fosforilazione delle JAKs, quindi la successiva fosforilazione della porzione intra-cellulare dei recettori medesimi e quindi di fattori intracellulari coinvolti nella trasduzione del segnale e nella attivazione della trascrizione cellulare (STAT). Il risultato che ne consegue è l'attivazione a cascata nella trascrizione di fattori implicati nel processo immunitario innato ed adattivo, infiammatorio ed ematopoietico, globalmente implicati nella malattia. ${ }^{27}$ Di qui il razionale e le evidenze scientifiche circa la possibilità di inibire a scopo terapeutico questo specifico pathway JAK-STAT nei pazienti con AR.

\section{JAK inibitori}

La famiglia delle JAK kinasi comprende almeno 4 enzimi, JAK1, JAK2, JAK3, TyK2, variamente rap- presentati nei diversi tessuti, variamente attivati da differenti stimoli molecolari (citochine e/o fattori di crescita), variamente accoppiati a specifici recettori di membrana. A sua volta le differenti subunità delle molecole recettoriali possono variamente associarsi tra loro e più o meno selettivamente interagire con specifiche JAK chinasi. Ad esempio la catena recettoriale gammaC associa solo ed esclusivamente con JAK3 e media l'azione di varie molecole segnale, quali differenti citochine pro-infiammatorie IL2, IL4, IL7, IL15, IL 21;28 diversamente altre catene recettoriali sono in grado di legare differenti isoforme JAK: ad esempio la subunità gp 130 può legarsi con JAK1, JAK2 e possibilmente anche TYK $2 .{ }^{29}$ Una ulteriore fonte di variabilità e di specificità di azione risiede nel fatto che esistano vari membri STAT (ad oggi noti almeno 7), a loro volta in grado di essere fosforilati non solo dalle JAK kinasi, ma anche da altri enzimi intra-cellulari a livello di residui serinici. ${ }^{30}$ Nella Tabella 4 vengono schematicamente riassunte le conseguenze associate a condizioni di iper-attivazione o soppressione patologica (mutazioni loss-offunction/LOF) o iatrogena dei diversi isoenzimi JAK. ${ }^{31}$ In particolare, fattori di crescita ematopoietici (eritropoietina, trombopoietina, GM-GF) agirebbero tramite JAK2, pertanto eventuali mutazioni a suo carico risulterebbero implicate nella patogenesi di patologie ematologiche di tipo mieloproliferativo. ${ }^{32}$ Ancora mutazioni che comportino deficit funzionale di JAK1 e JAK2 non sono descritte negli uomini, in quanto tale fenotipo di immunodeficienza sarebbe incompatibile con la vita: mutazioni LOF a carico di questi due enzimi risultano embriologicamente letali in modelli murini. ${ }^{33}$ Discende inevitabilmente come questi target molecolari intracellulari possano essere potenzialmente efficaci nel trattamento di differenti patologie, tra cui quelle disimmuni ed ematologiche. Infatti il primo JAK inibitore approvato dal FDA è stato ruxolitinib, un inibitore JAK1-JAK2 che ha dimostrato efficacia clinica nella mielofibrosi. Tofacitinib invece, inibitore JAK1-JAK3 con bassa selettività per JAK2 è il primo JAK inibitore approvato per il trattamento della AR. ${ }^{34}$

Tabella 4. Alterazioni funzionali degli enzimi JAK nelle patologie umane.

\begin{tabular}{|c|c|c|c|c|}
\hline Isotipo JAF & $\begin{array}{c}\text { Aumentata } \\
\text { funzione/iperattivazione }\end{array}$ & Fenotipo knock out & Difetto funzionale & Inibizione iatrogena \\
\hline JAK1 & Leucemia, patologie neoplastiche & Morte perinatale & Linfopoiesi defettiva & Aumentato rischio infettivo \\
\hline JAK2 & $\begin{array}{c}\text { Policitemia vera, mielofibrosi idiopatica } \\
\text { trombocitemia essenziale, } \\
\text { neoplasie ematologiche }\end{array}$ & Morte intrauterina & Eritropoiesi e mielopoiesi defettive & Anemia, neutropenia \\
\hline JAK3 & Leucemie, linfomi & $\begin{array}{l}\text { Immunodeficienza } \\
\text { combinata severa }\end{array}$ & $\begin{array}{l}\text { Aumentato rischio infettivo } \\
\text { Linfopoiesi defettiva }\end{array}$ & \\
\hline TYK2 & Leucemie & $\begin{array}{l}\text { Immunodeficienza, } \\
\text { diatesi allergica }\end{array}$ & $\begin{array}{l}\text { Defettiva differenziazione Th1, } \\
\text { defettivo signalling INF-mediato }\end{array}$ & Aumentato rischio infettivo \\
\hline
\end{tabular}




\section{Tofacitinib}

Tofacitinib/TOFA è stato il primo JAK inibitore approvato in America dal FDA nel 2012 per il trattamento dell'AR attiva moderata-severa refrattaria e/o intollerante al MTX. TOFA ha dimostrato efficacia nei pazienti con AR sia in monoterapia sia in terapia di combinazione con MTX in numerosi studi clinici. In questi trials (ORAL trials) l'efficacia clinica è stata dimostrata sin dalle fasi iniziali del trattamento (1-2 settimane dall'avvio) in pazienti failure sia a farmaci tradizionali sia a farmaci biologici anti-TNF. In particolare TOFA ha dimostrato nello studio ORAL standard una simile efficacia clinica in pazienti MTX-IR rispetto ad adalimumab, con percentuali di risposta ACR2 20 a 6 mesi paragonabili tra i due farmaci attivi e significativamente maggiori rispetto al placebo $(51,5 \%$ e $52,6 \%$, rispettivamente per i due dosaggio di TOFA-per $3 \mathrm{mg}$ e $5 \mathrm{mg}$ due volte al giorno- $v s 47 \%$ con ADA vs $28.3 \%$ con placebo). ${ }^{35,36}$ In aggiunta i risultati dello studio ORAL-START hanno dimostrato come in pazienti MTX-naive TOFA abbia un effetto sostanziale anche sulla inibizione della progressione strutturale radiografica. ${ }^{37}$ Ancora nello studio ORAL scan, pazienti con AR e fattori prognostici negativi, quindi a maggior rischio di progressione strutturale (almeno 3 erosioni articolari, $o$ positività di FR e/o ACPA) e failure a pregressi DMARDs biologici o non, hanno presentato con TOFA una progressione radiografica significativamente inferiore rispetto al placebo, con una differenza statisticamente significativa solo per il confronto con TOFA 10 $\mathrm{mg} / 2$ volte al giorno. ${ }^{38}$ Globalmente ad oggi sono stati completati 6 studi clinici di fase III (ORAL start, ORAL solo, ORAL standard, ORAL sync, ORAL scan, and ORAL step), in diversi subset di pazienti (MTX-naive, MTX-IR, csDMARDs-IR, TNFi-IR), tutti dimostranti efficacia clinica di TOFA al dosaggio di 5 e $10 \mathrm{mg} \mathrm{mg}$ due volte al giorno (Tabella 5). Per quanto riguarda il profilo di sicurezza, i principali effetti avversi farmaco relati riportati nei diversi studi sono stati eventi infettivi soprattutto a carico delle vie aeree superiori (naso-faringiti, bronchiti), neutropenia, anemia, ipercolesterolemia; in generale gli eventi avversi di natura infettiva sono risultati più frequenti rispetto a quelli verificatisi nel braccio placebo; riportati inoltre eventi infettivi di natura opportunistica quali infezioni da CMV, herpes zoster disseminato, polmonite criptococcica, pneumocistosi, polmonite tubercolare.$^{39} \mathrm{Il}$ rischio infettivo è risultato principalmente correlato con l'età avanzata, la coadozione di terapia steroidea, comorbidità (diabete). Non sembra sussistere correlazione tra tali eventi avversi e la evenienza di linfopenia. Sicuramente considerando il meccanismo d'azione di questi farmaci, l'aumentata incidenza di eventi infettivi non ha rappresentato un evento inatteso e non significativamente differente rispetto a quello associato ai farmaci biologici, con eccezione della maggiore incidenza di riattivazione di herpes zoster. ${ }^{40,41}$ In parte questo specifico aumento di rischio sembrerebbe essere correlato al ruolo delle citochine JAK3-dipendenti a loro volta cruciali nello sviluppo ed attivazione delle cellule natural killer/NK, che svolgono un ruolo fondamentale nella difesa delle infezioni virali. ${ }^{42}$ Alcuni studi hanno poi riportato con TOFA una maggiore evenienza di ipercolesterolemia, ma questo non sembrerebbe comportare come dimostrato da estensioni a lungo termine di studi clinici, un

Tabella 5. Sommario dei principali studi clinici di fase III di TOFA in AR. Modificato da Curtis JR, et al. ${ }^{45}$

\begin{tabular}{|c|c|c|c|}
\hline Studio clinico & N. e subset pazienti & Intervento terapeutico & $\operatorname{ACR20\% }$ \\
\hline ORAL-start phase III & 958 MTX-naive & $\begin{array}{l}\text { MTX } \\
\text { Tofa } 5 \mathrm{mg} \text { BID } \\
\text { Tofa } 10 \mathrm{mg} \text { BID }\end{array}$ & $\begin{array}{l}42,4 \% \\
64,2 \% \\
64,2 \%\end{array}$ \\
\hline ORAL-solo phase III & 611 MTX-IR & $\begin{array}{l}\text { PBO } 26.7 \\
\text { Tofa } 5 \mathrm{mg} \text { BID } \\
\text { Tofa } 10 \mathrm{mg} \text { BID }\end{array}$ & $\begin{array}{l}26,7 \% \\
59,8 \% \\
65,7 \%\end{array}$ \\
\hline ORAL-standard phase III & 717 MTX-IR & $\begin{array}{l}\text { MTX+PBO } \\
\text { MTX+Tofa } 3 \mathrm{mg} \text { BID } \\
\text { MTX+Tofa } 5 \mathrm{mg} \text { BID } \\
\text { MTX+ADA } 40 \mathrm{mg}\end{array}$ & $\begin{array}{l}28,3 \% \\
51,5 \% \\
52,6 \% \\
47,2 \%\end{array}$ \\
\hline ORAL-sync phase III & 792 DMARDs-IR & $\begin{array}{l}\text { MTX+PBO } \\
\text { MTX+Tofa } 5 \text { mg BID } \\
\text { MTX+Tofa } 10 \text { mg BID }\end{array}$ & $\begin{array}{l}30,8 \% \\
52,1 \% \\
56,6 \%\end{array}$ \\
\hline ORAL-scan phase III & 797 MTX-IR & $\begin{array}{l}\text { MTX+PBO } \\
\text { MTX+Tofa } 5 \text { mg BID } \\
\text { MTX+Tofa } 10 \text { mg BID }\end{array}$ & NA \\
\hline ORAL-step phase III & 399 TNFi-IR & $\begin{array}{l}\text { MTX+PBO } \\
\text { MTX+Tofa } 5 \text { mg BID } \\
\text { MTX+Tofa } 10 \text { mg BID }\end{array}$ & $\begin{array}{l}24,4 \% \\
41,7 \% \\
48,1 \%\end{array}$ \\
\hline
\end{tabular}


aumento significativo di incidenza di eventi cardio-vascolari. Sembrerebbe che TOFA infatti modifichi la composizione delle HDL promuovendo un pattern antiaterogeno rispetto ad uno pro-aterogeno e promuova una attività metabolica simil-tessuto adiposo bruno a carico degli adipociti: globalmente quindi questo giustificherebbe come l'ipercolesterolemia indotta da TOFA non comporti effetti deleteri dal punto di vista cardio-vascolare. ${ }^{43,44}$ Come detto poi dal punto di vista laboratoristico, data la loro interferenza con i meccanismi mediati da fattori di crescita ematopoietici, possibili effetti avversi, generalmente di entità lieve-moderata, sono rappresentati dalle citopenie (anemia, leucopenia, neutropenia, linfopenia, trombocitopenia). Vi sono ancora inoltre aspetti discussi riguardanti una eventuale cancerogenicità del farmaco, dal momento che esso sembrerebbe inibire il signaling di IL2 e IL15, con conseguente minore differenziazione ed attivazione delle cellule NK, implicate tra l'altro nella difesa da cellule endogene atipiche e trasformate, aventi pertanto un potenziale oncogeno. Non vi sono ad oggi evidenze che TOFA possa incrementare l'insorgenza di neoplasie ma è ovviamente fondamentale una adeguata vigilanza post-marketing. ${ }^{43} \mathrm{Ad}$ oggi le autorità regolatorie hanno adottato diverse posizioni rispetto a TOFA: il farmaco è approvato da parte del FDA, in Russia, Svizzera, Giappone, Emirati Arabi, Argentina per il trattamento (5 mg per os due volte al giorno) dell'AR attiva, con inadeguata risposta a MTX, in monoterapia o in associazione con altri DMARDs convenzionali. Ad oggi invece il farmaco non è stato ancora approvato dall'EMA.

\section{Baricitinib}

Per quanto riguarda baricitinib/BARI, esso inibisce con elevata selettività in particolare JAK1 e JAK2, inibendo in questo modo a cascata il signaling intracellulare mediato da vari stimoli citochinici (IL6,
IL12, IL23, INF). L'efficacia clinica di BARI è stata ad oggi esaminata in vari studi clinici di fase II e fase III, in diversi subset di pazienti con AR (Tabella 6). In particolare risultati estremamente promettenti sono stati ottenuti nello studio RA-BEAM (JADV study): 1305 pazienti con AR attiva nonostante MTX sono stati randomizzati a ricevere come add-on therapy placebo, baricitinib $4 \mathrm{mg} / \mathrm{die}, \mathrm{ADA} 40 \mathrm{mg} / 2$ settimane. La risposta ACR20 a 12 settimane è risultata rispettivamente del $40 \%, 70 \%$ e $61 \%$, con differenza significativa per BARI vs placebo ed anche per BARI $v s$ ADA. ${ }^{46}$ In aggiunta a 24 settimane anche l'entità della progressione radiografica secondo è risultata significativamente minore rispetto al placebo. Sicuramente rilevante il risultato della migliore performance di BARI vs ADA nella quasi totalità degli end-points clinici (ACR20, ACR50, ACR70 a 12 settimane, variazione media del DAS28 dal baseline) accanto ad una simile azione di inibizione strutturale rispetto all'antiTNF (inibizione della progressione strutturale definita come $\mathrm{mTSS} \leq 0,5$ a 52 settimane riportata nel $85 \%$ dei pazienti del gruppo BARI vs $86.5 \%$ dei pazienti del gruppo ADA vs 70,4\% dei pazienti in placebo). Nei pazienti naive a qualsiasi trattamento immunomodulatore poi (assente o minima pregressa esposizione a MTX/equivalenti), l'efficacia di BARI in monoterapia (RA-BEGIN) è risultata superiore a quella del MTX sia per quanto riguarda gli end-points clinici primari (ACR20 a 24 settimane pari rispettivamente a $77 \% v s$ $62 \%, \mathrm{p}<0,01)$, sia per quanto concerne gli outcomes secondari (risposte ACR50 e ACR70, raggiungimento della LDA e remissione clinica secondo gli indici clinimetrici DAS28, CDAI e SDAI), suggerendo come BARI possa essere potenzialmente contemplato come strategia terapeutica alternativa in pazienti in cui il MTX sia controindicato. La terapia di associazione BARI+MTX non ha garantito risultati clinici ulteriori, ma è risultata associata ad una minore progressione strutturale rispetto ad i singoli farmaci adottati in mo-

Tabella 6. Sommario dei principali studi clinici di fase III di BARI in AR. Modificato da Curtis JR, et al. ${ }^{45}$

\begin{tabular}{llll}
\hline Studio clinico & N. e subset pazienti & Intervento terapeutico & ACR20\% \\
\hline RA-BEGIN (JADZ) phase III & 584 DMARD-naive & MTX & $62 \%$ \\
& & Bari 4 mg QD & $77 \%$ \\
\hline RA-BUILD (JADX) phase III & \multirow{2}{*}{684 csDMARDs-IR } & MTX+Bari 4 mg QD & $78 \%$ \\
& & PBO & $40 \%$ \\
& & Bari 2 mg QD & $66 \%$ \\
RA-BEAM (JADV) phase III & \multirow{2}{*}{ 1305 MTX-IR } & Mari 4 mg QD & $62 \%$ \\
\hline RA-BEACON (JADW) phase III & 527 TNFi-IR & MTX+Bari 4 mg QD & $40 \%$ \\
& & MTX+ADA 40 mg & $70 \%$ \\
& & PBO & $61 \%$ \\
\hline
\end{tabular}


noterapia ${ }^{47}$ Ancora, nello studio RA-BEACON, 527 pazienti con AR refrattaria ad uno o più anti-TNF sono stati randomizzati al placebo o a BARI $2 \mathrm{mg}$ o 4 $\mathrm{mg} /$ die in associazione a DMARDs convenzionali. In entrambi i gruppi attivi si osservata una risposta ACR20 a 24 settimane significativamente più elevata rispetto a quella riscontrata nel gruppo placebo (rispettivamente $49 \%$ e $55 \%$ vs $27 \%$ ). In aggiunta, i pazienti che hanno completato alcuni degli studi registrativi di BARI, tra cui RA-BUILD, RA-BEGIN e RA-BEAM sono stati inclusi in una estensione a lungo termine chiamata RA-BEYOND, volta a valutare la possibilità di riduzione posologica del farmaco una volta raggiunto e mantenuto il controllo di malattia. In questo studio i pazienti che hanno ricevuto BARI $4 \mathrm{mg} / \mathrm{die}$ per almeno 15 mesi provenienti dagli studi sopra definiti e che hanno ottenuto uno stato di bassa attività di malattia o di remissione clinica sostenuta (definizione sulla base del CDAI per almeno 2 visite consecutive a distanza di 3 mesi) sono stati randomizzati in doppio cieco a proseguire BARI $4 \mathrm{mg} / \mathrm{d}$ o ridurre la posologia del medesimo a $2 \mathrm{mg} / \mathrm{d} .{ }^{48} \mathrm{La}$ maggior parte dei pazienti ha mantenuto lo stato di controllo di malattia in entrambi i gruppi di trattamento a 12 settimane (CDAI LDA e REM 93\% e 39\% in BARI $4 \mathrm{mg}$ vs $84 \%$ e $37 \%$ in BARI $2 \mathrm{mg}$ ); tuttavia la riduzione della posologia a $2 \mathrm{mg}$ ha comportato un aumento significativo nel numero di articolazioni tumefatte e dolorabili ed un peggioramento sostanziale degli indici clinimetrici compositi DAS28-PCR, CDAI e SDAI. Per quanto riguarda il profilo di sicurezza, BARI ha presentato eventi avversi simili a quelli riportati con TOFA, pertanto attesi sulla base del loro meccanismo di azione; gli eventi infettivi si sono verificati più frequentemente con BARI rispetto a MTX, in particolare l'evenienza di infezioni opportunistiche di tipo erpetico, soprattutto nei pazienti giapponesi. Sono state inoltre riportate comunemente riduzioni dose-relate nella conta dei neutrofili, dei linfociti e dei valori emoglobinici, così come sono stati segnalati incrementi nei livelli globali di colesterolo totale, HDL, LDL e trigliceridi, senza sostanziale variazione del rapporto HDL/LDL, pertanto senza modifica significativa dell'indice aterogenico. ${ }^{49}$ Globalmente i dati di sicurezza provenienti da 9 studi su BARI in AR sono stati valutati in modo combinato in una analisi integrata. Dei 3464 pazienti inclusi complessivamente in questi trials, il $6.1 \%$ ha sviluppato eventi avversi che hanno comportato la sospensione dello studio, $3,4 \%$ ha sviluppato $\mathrm{HZ}, 3,2 \%$ infezioni severe, $0,7 \%$ ha sviluppato neoplasie (escludendo i non melanoma skin cancer), $0,5 \%$ un evento cardiaco maggiore, $0,3 \%$ decessi. Tra questi eventi avversi, solo le infezioni erpetiche sono state osservate con frequenza sostanzialmente superiore nei pazienti trattati con BARI vs placebo. ${ }^{50} \mathrm{In} \mathrm{Eu}$ ropa BARI ha ricevuto la sua prima approvazione nel
13 febbraio 2017 come monoterapia o terapia di associazione con il MTX in pazienti con AR attiva moderata-severa refrattaria o intollerante ad almeno un DMARD. Al momento inoltre vi sono diversi studi in corso circa l'applicabilità clinica di BARI nei pazienti affetti da LES, dermatite atopica, psoriasi cutanea, nefropatia diabetica, a conferma di come l'inibizione plurima di diversi meccanismi intra-cellulari possa avere rilevanti ripercussioni terapeutiche in differenti condizioni morbose.

\section{Altri JAK inibitori}

È allo studio una next-gerenation di JAK inibitori maggiormente selettiva nei confronti di uno specifico target, con l'obiettivo auspicabile di mantenere l'efficacia del trattamento limitando al contempo gli effetti indesiderati. ${ }^{31}$ Tra questi nuovi JAK inibitori, filgotinib è un potente inibitore selettivo di JAK1. Ad oggi i risultati di due studi clinici di fase IIb (DARWIN 1 e DARWIN 2) hanno riportato come in pazienti refrattari al MTX sia la monoterapia sia la terapia di combinazione (filgotinib+MTX) garantiscano in modo dose-dipendente il raggiungimento a 12 settimane della risposta ACR20 in una elevata percentuale di pazienti $(\geq 65 \%$ vs $29 \%$, $<<0,001){ }^{51,52}$ Tali risposte cliniche si sono verificate precocemente a partire dalla prima settimana di trattamento e sono state mantenute fino a 24 settimane di osservazione. In questo contesto promettente risulta anche ABT-494, un altro JAK inibitore altamente selettivo per JAK1, in grado di legare l'enzima sia a livello del sito catalitico ATP-binding site sia al di fuori di esso. Attualmente è in corso il reclutamento di pazienti uno studio comparativo versus adalimumab, ma già due studi di fase II hanno dimostrato rapide e sostanziali risposte cliniche rispetto al placebo in pazienti non responsivi a MTX e ad antiTNF (rispettivamente studi BALANCE I e BALANCE II).

\section{Take Home Messages relativi ai JAK inibitori in Reumatologia}

- I JAK inibitori rappresentano una nuova categoria di tsDMARDs per il trattamento della AR, ovvero di farmaci sintetici targettizzati rispetto a bersagli molecolari intra-cellulari, in grado a loro volta di controllare a cascata vari meccanismi infiammatori implicati nel determinismo di malattia.

- Dagli studi clinici di fase III, questi tsDMARDs hanno dimostrato la loro efficacia e relativa sicurezza in diversi subset di pazienti AR: MTX-naive, MTX-non responders, anti-TNF-non responders, indicando pertanto una valida alternativa terapeutica in differenti setting.

- Gli eventi avversi imputabili alla loro azione bio- 
Tabella 7. Lista di alcuni tra i nuovi approcci terapeutici in corso di studio per il trattamento della AR.

\begin{tabular}{|c|c|c|}
\hline Target molecolare & Agenti farmacologici in studio & Risultati attuali preliminari \\
\hline $\mathrm{TNF}$ & Vaccino Anti-TNF & $\begin{array}{l}\text { Studi di fase IIb non hanno raggiunto l'outcome } \\
\text { primario }\end{array}$ \\
\hline \multirow[t]{3}{*}{ IL6 } & $\begin{array}{l}\text { Anticorpi monoclonali diretti contro } \\
\text { IL6-receptor (IL6R): sarilumab }\end{array}$ & $\begin{array}{l}\text { Maggiore affinità per il ligando versus } \\
\text { Tocilizumab/TCZ }\end{array}$ \\
\hline & $\begin{array}{l}\text { Anticorpi monoclonali diretti contro IL6: } \\
\text { umanizzati (olokizumab, clazakizumab) } \\
\text { o umani (sirukumab, MEDI5117) }\end{array}$ & \\
\hline & $\begin{array}{l}\text { Inibitori del signaling di } \\
\text { trasduzione di IL6: FE301 }\end{array}$ & $\begin{array}{l}\text { Potenzialmente minori effetti collaterali rispetto } \\
\text { a TCZ grazie ad una azione maggiormente } \\
\text { selettiva }\end{array}$ \\
\hline \multirow[t]{4}{*}{ Pathway IL17 } & $\begin{array}{l}\text { Blocco di IL23 mediante ustekinumab } \\
\text { e guselkumab }\end{array}$ & $\begin{array}{l}\text { Ad oggi risultati non significativi in } \mathrm{AR} \\
\text { relativamente alla inibizione di questo pathway }\end{array}$ \\
\hline & $\begin{array}{l}\text { Secukinumab (anticorpo monoclonale umano } \\
\text { anti-IL17A) }\end{array}$ & \\
\hline & Ixekizumab (mAb umanizzato anti-IL17A) & \\
\hline & Brodalumab (inibitore di IL17R) & \\
\hline GM-CSF & $\begin{array}{l}\text { Mavrilimumab (mAb IgG4 umano che lega } \\
\text { in modo competitivo GM-CSF) }\end{array}$ & Risultati promettenti \\
\hline B cellule & Ofatumumab (mAb umano anti-Cd20) & Studi in corso \\
\hline IL2 a bassa dose & Alemtuzumab (antiCd52 mAb) & Studi in corso \\
\hline Targets intracellulari & $\begin{array}{l}\text { Inibitori ultraselettivi di JAK, inibitori di BTK } \\
\text { (Bruton Tyrosine kinase), ecc. }\end{array}$ & Studi in corso \\
\hline
\end{tabular}

logica necessitano di essere meglio caratterizzati nel lungo termine. Attualmente Tofacitinib è approvato da FDA e Baricitinib da EMA. Nessuno dei due è ad oggi disponibile e rimborsabile nel nostro Paese.

\section{The future?}

Nella Tabella 7 viene presentata una lista, assolutamente non esaustiva, di approcci terapeutici tentati $o$ in via di sviluppo per il trattamento della AR. Con le progressive conoscenze in ambito di genomica, proteomica e metabolomica, sarà probabilmente possibile ulteriormente caratterizzare e meglio personalizzare gli approcci terapeutici, avvicinandosi sempre più all'obiettivo ultimo di individualizzazione del trattamento in base al tipo di paziente e di espressione fenotipica di malattia. Da non dimenticare il crescente interesse attualmente attribuito anche al ruolo del microbioma orale e intestinale nell'eziopatogenesi di varie patologie reumatologiche e non, qualora l'omeostasi locale venga ad essere alterata da differenti fattori esogeni e/o in soggetti geneticamente predisposti, di- venendo così a sua volta responsabile di una aberrante attivazione della risposta immunitaria innata ed adattiva. ${ }^{53,54}$ Ulteriori studi saranno necessari per meglio chiarire e caratterizzare le condizioni di disbiosi implicate nella eziopatogenesi e nella progressione di varie affezioni morbose, inclusa la $\mathrm{AR}$, indicando pertanto un nuovo target terapeutico altamente patologiae paziente-specifico. Questo è già il futuro prossimo.

\section{Bibliografia}

1. Olech E. Biosimilars: Rationale and current regulatory landscape Seminars in Arthritis and Rheumatism 2016;45:S1-S10.

2. Johnson IS. Human insulin from recombinant DNA technology. Science 1983;219:632-7.

3. Smolen JS, Landewé, Bijlsma J, et al. EULAR recommendations for the management of rheumatoid arthritis with synthetic and biological disease-modifying antirheumatic drugs: 2016 update. Ann Rheum Dis 2017;0:1-18. doi:10.1136/annrheumdis-2016-210715.

4. Tsuruta LR, Lopes Dos Santos M, Moro AM. Biosimilars advancements: moving on to the future. Biotechnol Prog 2015;31:1139-49. 
5. Goel N, Chance K. Biosimilars in rheumatology: understanding the rigor of their development.Rheumatology 2017;56:187-197.

6. Crommelin DJ, Shah VP, Klebovich I, et al. The similarity question for biologicals and non-biological complex drugs. Eur J Pharm Sci 2015;76:107.

7. Park W, Hrycaj P, Jeka S, et al. A randomised, doubleblind, multicentre, parallel-group, prospective study comparing the pharmacokinetics, safety, and efficacy of CT-P13 and innovator infliximab in patients with ankylosing spondylitis: the PLANETAS study. Ann Rheum Dis 2013;72(10):1605-12.

8. Yoo DH, Hrycaj P, Miranda P, et al. A randomised, double-blind, parallel-group study to demonstrate equivalence in efficacy and safety of CT-P13 compared with innovator infliximab when coadministered with methotrexate in patients with active rheumatoid arthritis: the PLANETRA study. Ann Rheum Dis 2013;72(10):1613-20.

9. Yoo DH, Racewicz A, Brzezicki J, et al. A phase III randomized study to evaluate the efficacy and safety of CTP13 compared with reference infliximab in patients with active rheumatoid arthritis: 54-week results from the PLANETRA study. Arthritis Res Ther 2016;18:82.

10. Takeuchi T, Yamanaka H, Tanaka Y, et al. Evaluation of the pharmacokinetic equivalence and 54-week efficacy and safety of CT-P13 and innovator infliximab in Japanese patients with rheumatoid arthritis. Mod Rheumatol 2015;25(6):817-24.

11. Blair HA, Deeks ED. Infliximab Biosimilar (CT-P13; Infliximab-dyyb): A Review in Autoimmune Inflammatory Diseases BioDrugs 2016;30:469-480.

12. Yoo DH, Prodanovic N, Jaworski J, et al. Efficacy and safety of CT-P13 (biosimilar infliximab) in patients with rheumatoid arthritis: comparison between switching from reference infliximab to CT-P13 and continuing CTP13 in the PLANETRA extension study. Ann Rheum Dis 2017;76(2):355-363.

13. Park W, Yoo DH, Miranda P, et al. Efficacy and safety of switching from reference infliximab to CT-P13 compared with maintenance of CT-P13 in ankylosing spondylitis: 102-week data from the PLANETAS extension study. Ann Rheum Dis 2017;76(2):346-354.

14. Fiorino G, Manetti N, Variola A, et al. Prospective observational study on inflammatory bowel disease patients treated wth infliximab biosimilars: peliminary results of the PROSIT-BIO cohort. [abstract no. P544 plus poster]. J Crohns Colitis 2016;10(Suppl 1):S376-7.

15. GAFPA.NOR-SWITCH. Disponibile su: http://1yh21u3 cjptv3xjder1dco9mx5s.wpengine.netdna-cdn.com/wpcontent/uploads/2016/09/GAfPA_Norswitch_Sept.2016.pdf [accesso ottobre 2016].

16. Celltrion Inc. Inflectra (infliximab-dyyb) for injection, for intravenous use: US prescribing information. 2016. http://www.accessdata.fda.gov. Accessed 6 Sep 2016.

17. Emery P, Vencovsky J, Sylwestrzak A, et al. A phase III randomised, double-blind, parallel-group study comparing SB4 with etanercept reference product in patients with active rheumatoid arthritis despite methotrexate therapy. Ann Rheum Dis 2017;76(1):51-57.

18. Vencovsky J, Sylwestrzak A, Leszczynski P, et al. A phase III, randomized, double-blind clinical study comparing SB4, an etanercept biosimilar, with etanercept reference product (Enbrel) in patients with moderate to severe rheumatoid arthritis despite methotrexate therapy (52-week results) [abstract no. 2055 plus oral presentation]. Arthritis Rheumatol 2015;67(Suppl 10):2444-6.

19. Emery P, Vencovsky J, Sylwestrzak A, et al. Long-term safety and efficacy of SB4 (etanercept biosimilar) in patients with rheumatoid arthritis: comparison between continuing SB4 and switching from etanercept reference product to SB4 [abstract no. THU0150]. In: EULAR 2016.

20. Meacci F, Manfredi M, Infantino M, et al. Anti etanercept and anti SB4 antibodies detection: impact of the assay method. Ann Rheum Dis 2016;75(7):e39.

21. Griffiths CEM, ThacI D, Gerdes S, et al. The EGALITY study: a confirmatory, randomized, double-blind study comparing the efficacy, safety and immunogenicity of GP2015, a proposed etanercept biosimilar, vs. the originator product in patients with moderate-to-severe chronic plaque-type psoriasis. Br J Dermatol 2017;76(4): 928-938.

22. Lai Z, La Noce A. Key design considerations on comparative clinical efficacy studies for biosimilars: adalimumab as an example. RMD Open 2016;2(1):e000154.

23. Tesser JR, Furst DE, Jacobs I. Biosimilars and the extrapolation of indications for inflammatory conditions. Biologics 2017;11:5-11.

24. Food and Drug Administration. Guidance for industry. Scientific considerations in demonstrating biosimilarity to a reference product. April 2015. http://www.fda.gov/ downloads/drugs/guidancecomplianceregulatoryinformation/guidances/ucm291128.pdf (accessed 26 Mar 2015).

25. European Medicines Agency. Guideline on similar biological medicinal products containing biotechnologyderived proteins as active substance: non-clinical and clinical issues on similar biological medicinal products. December 2014. http://www.ema.europa.eu/ docs/en GB/document_library/Scientific_guideline/2015/01/W C500180219.pdf (accessed 26 Mar 2015).

26. Health Canada, Office of Regulatory Affairs, Biologics and Genetic Therapies Directorate. Inflectra. 16 June 2015. http:/www.hc-sc.gc. ca/dhp-mps/prodpharma/ sbd-smd/drug-med/sbd smd 2014 inflectra_159493eng.php\#a2 (accessed 10 Jul 2015).

27. Kuriya B, Cohen MD and Keystone E. Baricitinib in rheumatoid arthritis: evidence to-date and clinical potential.Ther Adv Musculoskel Dis 2017;9(2):37-44.

28. Hofmann SR, Ettinger R, Zhou YJ, et al. Cytokines and their role in lymphoid development, differentiation and homeostasis. Curr Opin Allergy Clin Immunol 2002; 2(6):495-506.

29. Vijayakrishnan L, Venkataramanan R, Gulati P. Treating inflammation with the Janus kinase inhibitor CP690,550. Trends Pharmacol Sci 2011;32(1):25-34.

30. Banerjee S, Biehl A, Gadina M, et al. JAK-STAT Signaling as a Target for Inflammatory and Autoimmune Diseases: Current and Future Prospects. Drugs 2017;77: 521-546.

31. Yamaoka K. Janus kinase inhibitors for rheumatoid arthritis. Current Opinion in Chemical Biology 2016;32:29-33.

32. O'Shea JJ, Schwartz DM, Villarino AV, et al. The JAKSTAT pathway: impact on human disease and therapeutic intervention. Ann Rev Med 2015;66:311-28.

33. Rodig SJ, Meraz MA, White JM, et al. Disruption of the 
Jak1 gene demonstrates obligatory and non redundant roles of the Jaks in cytokine-induced biologic responses. Cell 1998;93(3):373-83.

34. Schwartz DM, Bonelli M, Gadina M, O'Shea JJ. Type I/II cytokines, JAKs, and new strategies for treating autoimmune diseases. Nat Rev Rheumatol 2016;12:25-36.

35. van Vollenhoven RF, Fleischmann R, Cohen S, et al. Tofacitinib or adalimumab versus placebo in rheumatoid arthritis. N Engl J Med 2012;367:508-519.

36. Kremer J, Li ZG, Hall S, et al. Tofacitinib in combination with nonbiologic disease-modifying antirheumatic drugs in patients with active rheumatoid arthritis: a randomized trial. Ann Intern Med 2013;159:253-261.

37. Lee EB, Fleischmann R, Hall S, et al. Tofacitinib versus methotrexate in rheumatoid arthritis. N Engl J Med 2014;370:2377-2386.

38. van der Heijde D, Tanaka Y, Fleischmann R, et al. Tofacitinib (CP-690,550) in patients with rheumatoid arthritis receiving methotrexate: twelve-month data from a twenty-four-month phase III randomized radiographic study. Arthritis Rheum 2013;65(3):559-70.

39. He Y, Wong AY, Chan EW, et al. Efficacy and safety of tofacitinib in the treatment of rheumatoid arthritis: a systematic review and meta-analysis. BMC Musculoskelet Disord 2013;14:298.

40. Strand V, Ahadieh S, French J, et al. Systematic review and meta-analysis of serious infections with tofacitinib and biologic disease-modifying antirheumatic drug treatment in rheumatoid arthritis clinical trials. Arthritis Res Ther 2015;17:362.

41. Wollenhaupt J, Silverfield J, Lee EB, et al. Safety and efficacy of tofacitinib, an oral janus kinase inhibitor, for the treatment of rheumatoid arthritis in open-label, longterm extension studies. J Rheumatol 2014;41:837-852.

42. Strand V, Ahadieh S, French J, et al. Systematic review and meta-analysis of serious infections with tofacitinib and biologic disease-modifying antirheumatic drug treatment in rheumatoid arthritis clinical trials. Arthritis Res Ther 2015;17:362.

43. Charles-Schoeman C, Fleischmann R, Davignon J, et al. Potential mechanisms leading to the abnormal lipid profile in patients with rheumatoid arthritis versus healthy volunteers and reversal by tofacitinib. Arthritis Rheumatol 2015;67:616-625.

44. Moisan A, Lee YK, Zhang JD, et al. White-to- brown metabolic conversion of human adipocytes by JAK inhibition. Nat Cell Biol 2015;17:57-67.

45. Curtis JR, Lee EB, Kaplan IV, et al. Tofacitinib, an oral Janus kinase inhibitor: analysis of malignancies across the rheumatoid arthritis clinical development programme. Ann Rheum Dis 2016;75(5):831-41.

46. Taylor PC, Keystone EC, van der Heijde D, et al. Baricitinib versus Placebo or Adalimumab in Rheumatoid Arthritis. N Engl J Med 2017;376(7):652-662.

47. Fleischmann R, Takeuchi T, Schlichting D, et al. Methotrexate in patients with early rheumatoid arthritis who had received limited or no treatment with disease-modifying antirheumatic drugs (DMARDs): phase 3 trial results. In: ACR/ARHP Annual Meeting. San Francisco; 2015.

48. Takeuchi T, Genovese M, Xie L, et al. Baricitinib dose stepdown following disease control in patients with rheumatoid arthritis. Ann Rheum Dis 2016;75(Suppl.2): 144.

49. Nakayamada S, Kubo S, Iwata S, Tanaka Y. Recent Progress in JAK Inhibitors for the Treatment of Rheumatoid Arthritis. BioDrugs 2016;30:407-419.

50. Smolen J, Genovese M, Takeuchi T, et al. Safety profile of baricitinib in patients with active RA: an integrated analysis. Ann Rheum Dis 2016;75(Suppl 2):243-4.

51. Kavanaugh A, Kremer J, Ponce L, et al. Filgotinib (GLPG0634/GS-6034), an oral selective JAK1 inhibitor, is effective as monotherapy in patients with active rheumatoid arthritis: results from a randomised, dose-finding study (DARWIN 2). Ann Rheum Dis. 2016 Dec 19. pii: annrheumdis-2016-210105. doi: 10.1136/annrheumdis2016-210105.

52. Westhovens R, Alten R, Pavlova D, et al. Filgotinib (GLPG0634), an oral JAK1 selective inhibitor is effective in combination with methotrexate in patients with active rheumatoid arthritis: results from a phase $2 \mathrm{~B}$ dose ranging study [abstract]. Arthritis Rheumatol 2015; 67(Suppl 10).

53. Xiaohao Wu, He B, Liu J. Molecular Insight into Gut Microbiota and Rheumatoid Arthritis. Int J Mol Sci 2016;17: 431.

54. Venuturupalli S. Immune Mechanisms and Novel Targets in Rheumatoid Arthritis. Immunol Allergy Clin N Am 2017;37:301-313. 


\section{LINEE GUIDA PER GLI AUTORI}

I Quaderni dell'Italian Journal of Medicine (Quaderni ITJM), costituiscono una collana supplementare solo online annessa alla rivista Italian Journal of Medicine contenente lavori solo in lingua italiana.

I Quaderni ITJM pubblicano:

- Monografie ad hoc individuate dal Presidente FADOI, dal Consiglio Direttivo, dal Board Scientifico o dall'Editor in Chief dell'Italian Journal of Medicine, in funzione del contesto scientifico-istituzionale attuale.

- Monografie ad hoc su temi di particolare rilevanza scientifica a cura della Commissione FADOI Giovani, coordinata dalla Dr.ssa Paola Gnerre.

- Traduzioni in italiano di alcuni lavori pubblicati sui numeri standard dell'Italian Journal of Medicine, di particolare interesse per la comunità scientifica. La selezione è a cura dell'Editor-inChief, Prof. Roberto Nardi

\section{STESURA DEI LAVORI}

I lavori dovranno essere redatti in modo conforme alle linee guida sotto riportate:

- I manoscritti devono essere scritti interamente in lingua italiana, su documento di Word, con carattere Times New Roman/Arial, dimensione 12, formato $\mathrm{A} 4$, interlinea doppia e margini $2,54 \mathrm{~cm}$. Parole totali: max 4000; Sommario/Abstract: $\max 250$ parole; Bibliografia: $\min 40$ voci; Tabelle e Figure: $3 / 5$ totali (le tabelle non devono superare n. 1 pagina del documento in Word).

- La strutturazione del contenuto deve attenersi agli standard internazionali per la Rassegna (Review): i) Abstract riassuntivo dell'intero lavoro; ii) Introduzione al tema trattato; iii) Criteri e strumenti di ricerca (criteri di inclusione/esclusione, banche dati consultate, ...); iv) i successivi paragrafi devono illustrare le più recenti scoperte scientifiche nel settore; v) Conclusioni; vi) Bibliografia.

- La prima pagina deve riportare: i) titolo (in stampatello minuscolo), senza acronimi; ii) nome e cognome per esteso di ciascun autore; iii) affiliazione(i) di ciascun autore, numerate con numeri arabi; iv) eventuali ringraziamenti; v) nome e indirizzo postale completi dell'autore corrispondente, corredati da telefono, fax, e-mail; vi) da 3 a 5 parole chiave, separate da virgola. La seconda pagina può riportare: i) contributi degli autori, e.g. informazioni relative a contributi sostanziali delle persone coinvolte nello studio (http://www.icmje.org/\#author); ii) dichiarazione relativa a potenziali conflitti d'interesse; iii) ulteriori informazioni (e.g. fondi, esposizioni durante conferenze...)

In caso di utilizzo di tabelle, queste devono essere tutte numerate con numeri arabi e citate nel testo in ordine consecutivo (e.g. NON nominare le tabelle come Tabella $1 \mathrm{~A}, 1 \mathrm{~B}, \ldots$ o $1.0,1.1, \ldots$.). Le tabelle devono essere presentate in formato editabile. Ciascuna tabella deve essere corredata da una breve didascalia; in caso di abbreviazioni, riportare una nota a piè di CIASCUNA tabella che spieghi TUTTE le abbreviazioni presenti in ognuna.

- In caso di utilizzo di figure, queste devono essere inviate in formato tiff o .jpg, allegate al manoscritto in singoli files, secondo le seguenti specifiche:

i) a colori (salvate in modalità CMYK): minimo 300 dpi di risoluzione;

ii) in bianco e nero: minimo 600 dpi di risoluzione;

iii) minimo $17,5 \mathrm{~cm}$ di larghezza.

Ciascuna figura deve essere corredata da una breve didascalia.

NB: In caso di Tabelle/Figure riprese e/o modificate da altri lavori già pubblicati, sarà cura degli autori accertarsi se tali materiali siano o meno coperti da copyright e procurarsi i permessi necessari per la riproduzione. Tali permessi dovranno essere allegati alla versione definitiva del lavoro. L'ufficio editoriale si riserva la facoltà di rimuovere Tabelle/Figure coperte da copyright, se sprovviste dei necessari permessi.

- In caso di utilizzo di abbreviazioni, la prima volta che esse sono citate è necessario scrivere per esteso la definizione+abbreviazione tra parentesi tonde [e.g. risonanza magnetica $(\mathrm{RMN})]$, a seguire si dovrà riportare solo l'abbreviazione (unica eccezione: nei titoli e nelle didascalie di tabelle e figure NON si utilizzano abbreviazioni).

\section{BIBLIOGRAFIA}

Le voci bibliografiche devono essere formattate secondo lo stile Vancouver.

Nella sezione Bibliografia, le voci bibliografiche devono essere numerate consecutivamente nell'ordine in cui appaiono per la prima volta nel testo (NON in ordine alfabetico) e, nel testo, devono essere indicate con numeri arabi in apice. Voci bibliografiche riferite a comunicazioni personali o dati non pubblicati devono essere incorporate nel testo e NON inserite tra le voci numerate [e.g. (Wright 2011, dati non pubblicati) o (Wright 2011, comunicazione personale)]. Le voci bibliografiche nella sezione Bibliografia devono tassativamente essere preparate come segue:

i) più di 3 autori, citare 3 autori, et al. Se il lavoro contiene solo 4 autori, citarli tutti e 4 ;

ii) titolo del lavoro in stampatello minuscolo;

iii) nome della rivista, senza punti, abbreviato secondo gli standard internazionali; in caso di dubbi sulla corretta abbreviazione, fare riferimento ai seguenti siti:

a. ISI Journal Abbreviations Index (http://library.caltech.edu/ reference/abbreviations/);

b. Biological Journals and Abbreviations (http://home.ncifcrf. gov/research/bja/);

c. Medline List of Journal Titles (ftp://ftp.ncbi.nih.gov/pubmed/J_Medline.txt);

iv) inserire l'anno di pubblicazione subito dopo il nome della rivista, seguito da punto e virgola;

v) NON inserire giorno o mese di pubblicazione;

vi) citare solo il volume, seguito dai due punti (NON citare il fascicolo tra parentesi);

vii) abbreviare le pagine, e.g. 351-8

Per accertarsi di aver correttamente formattato le voci bibliografiche, confrontarle con le citazioni in PubMed (http://www.ncbi. nlm.nih.gov/pubmed).

Esempi (prestare attenzione anche alla punteggiatura):

Articolo standard su Rivista

Halpern SD, Ubel PA, Caplan AL. Solid-organ transplantation in HIV-infected patients. N Engl J Med 2002;347:284-7.

Proceedings

Christensen S, Oppacher F. An analysis of Koza's computational effort statistic for genetic programming. In: Foster JA, Lutton E, Miller J, Ryan C, Tettamanzi AG, eds. Genetic programming. EuroGP 2002: Proceedings of the 5th European Conference on Genetic Programming, 2002 Apr 3-5, Kinsdale, Ireland. Berlin: Springer; 2002. pp 182-91.

Articoli i cui autori sono Organizzazioni

Diabetes Prevention Program Research Group. Hypertension, insulin, and proinsulin in participants with impaired glucose tolerance. Hypertension 2002;40:679-86.

Libri

Murray PR, Rosenthal KS, Kobayashi GS, Pfaller MA. Medical microbiology. 4th ed. St. Louis, MO: Mosby; 2002. (CITAZIONE DEL LIBRO INTERO)

Meltzer PS, Kallioniemi A, Trent JM. Chromosome alterations in human solid tumors. In: Vogelstein B, Kinzler KW, eds. The genetic basis of human cancer. New York, NY: McGraw-Hill; 2002. pp 93113. (CITAZIONE DI UN CAPITOLO)

\section{MODALITÀ D'INVIO DEI LAVORI}

Monografie

Gli Autori dovranno fare riferimento all'Editor-in-Chief o alle persone da lui designate nelle lettere di invito a scrivere gli articoli programmati.

Per gli articoli inviati da giovani internisti, gli Autori dovranno fare riferimento alla Dr.ssa Paola Gnerre (e-mail: pgnerre@yahoo.it) e agli eventuali altri referenti da lei designati, nelle prime fasi di stesura dei manoscritti, revisioni e correzioni. 


\section{QUADERNI}

dell'Italian Journal

of Medicine

La Dr.ssa Gnerre raccoglierà poi le versioni definitive dei lavori di ciascuna monografia e provvederà all'invio di tutti i materiali all'ufficio editoriale.

I lavori solo nella loro versione definitiva e approvata dalla Commissione FADOI Giovani dovranno pervenire all'ufficio editoriale già pronti per l'impaginazione e immediata pubblicazione (già corredati da eventuali permessi per la riproduzione di tabelle e immagini).

\section{Traduzioni}

Previo invito dell'Editor-in-Chief, gli Autori dovranno far pervenire all'ufficio editoriale la versione tradotta in italiano, al seguente indirizzo e-mail: paola.granata@pagepress.org

Il file in formato Word dovrà essere formattato secondo gli standard editoriali della rivista ufficiale ed essere già pronto per impagina- zione e immediata pubblicazione (corredato da eventuali permessi per la riproduzione di tabelle e immagini).

Si prega di inviare le eventuali tabelle in formato editabile e le figure in alta definizione secondo gli standard sopra riportati.

\section{NOTA PER GLI AUTORI}

I lavori pubblicati sui Quaderni ITJM non verranno indicizzati, ma saranno liberamente disponibili in un'apposita sezione del sito FADOI (http://www.fadoi.org/).

Gli Autori i cui lavori siano accettati per la pubblicazione sui Quaderni ITJM e che fossero interessati a vederli pubblicati anche sulla rivista ufficiale, dovranno sottomettere attraverso il sito dell'ITJM (www.italjmed.org) la versione (già tradotta) in inglese e redatta in modo conforme alle linee guida della rivista; seguiranno poi la procedura di selezione tramite peer review e, se accettati, saranno inseriti nel piano editoriale standard.

\section{STAFF EDITORIALE}

Paola Granata, Journal Manager

paola.granata@pagepress.org

Claudia Castellano, Production Editor

Tiziano Taccini, Technical Support

\section{PUBBLICATO DA}

PAGEPress Publications

via A. Cavagna Sangiuliani 5

27100 Pavia, Italy

T. +39.0382 .464340$

F: +39.0382 .34872$

\section{agepress}

www.pagepress.org info@pagepress.org

\section{QUADERNI - ITALIAN JOURNAL OF MEDICINE}

Tutti gli articoli pubblicati sui QUADERNI - Italian Journal of Medicine sono redatti sotto la responsabilità degli Autori. La pubblicazione o la ristampa degli articoli della rivista deve essere autorizzata per iscritto dall'editore. Ai sensi dell'art. 13 del D.Lgs 196/03, i dati di tutti i lettori saranno trattati sia manualmente, sia con strumenti informatici e saranno utilizzati per l'invio di questa e di altre pubblicazioni e di materiale informativo e promozionale. Le modalità di trattamento saranno conformi a quanto previsto dall'art. 11 del D.Lgs 196/03. I dati potranno essere comunicati a soggetti con i quali PAGEPress intrattiene rapporti contrattuali necessari per l'invio delle copie della rivista. Il titolare del trattamento dei dati è PAGEPress Srl, via A. Cavagna Sangiuliani $5-27100$ Pavia, al quale il lettore si potrà rivolgere per chiedere l'aggiornamento, l'integrazione, la cancellazione e ogni altra operazione di cui all'art. 7 del D.Lgs 196/03.

Editore: PAGEPress srl, via A. Cavagna Sangiuliani 5, 27100 Pavia, Italy www.pagepress.org 
PAGEPress - Scientific Publications

Via A. Cavagna Sangiuliani, 5 - 27100 Pavia - Italy

Phone +390382 464340 - Fax +39038234872

www.pagepress.org 